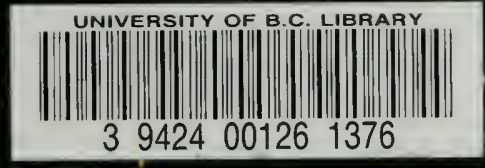

STCRAGE ITEM

P FOCESSI NG-CNE

L p 1-F 190

U.B.C. LIBRARY 


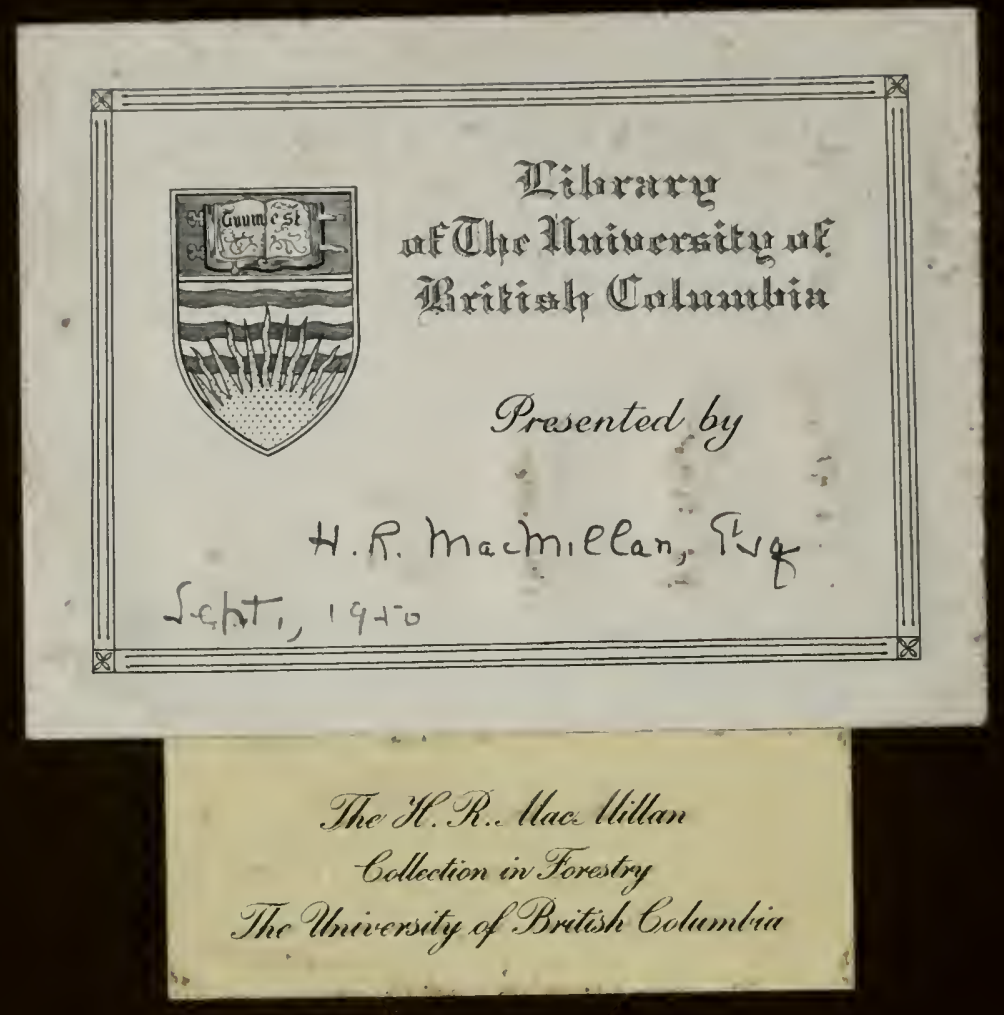





\section{Digitized by the Internet Archive in 2010 with funding from University of British Columbia Library}




\title{
DISEASES OF PLANTS
}

\section{Induced by Cryptogamic Parasites}

\author{
Introduction to the Study of \\ Pathogenic Fungi, Slime-Fungi, Bacteria, \& Algae
}

BY

DR. KARL FREIHERR VON TUBEUF

PRIVATDOZENT IN THE UNIVERSITY OF MUNICH

\section{English Edition by}

WILLIAM G. SMITH, B.Sc., Ph.D.

LECTURER ON YLANT PHYSIOLOGY

UNIVERSITY OF EDINBURGH

THREE HUIDRED AND THIRTY ILLUSTRATIONS

LONGMANS, GREEN \& CO. LONDON, NEW YORK, AND BOMBAY

I 897 



\section{AU'THOR'S PREFACE.}

In my research work, and in connection with my lectures at the University and Technical School of Munich, I have for some time felt convinced that there existed a very evident gap in the literature relating to the diseases of plants. There was need of a newer and more complete work on cryptogamic parasites and the diseases induced by them on higher plants, a work furnished with many accurate illustrations, with a survey of the newer literature, and with a general part wherein parasitism and the relations between parasite and host are discussed from a botanical standpoint. Therefore, I have undertaken to write a book intended to supply in some degree this pressing want. Here the attempt has been made for the first time to review in a general and comparative manner the biological, physiological, and anatomical relationships accompanying the phenomena of parasitism. Already De Bary has considered the varying degrees of parasitism and the phenomena of symbiosis in his celebrated Morphology and Biology of the Fungi; while Wakker has laid the foundations of our knowledge of the alterations in the anatomy of plants diseased by the agency of fungi, more especially, however, those alterations accompanying 'hypertrophy.' I venture to continue this difficult and comprehensive chapter of plant physiology, because for ten years I have devoted my time to the study of plant pathology. The book may be all the more acceptable since I have confirmed a large number of the observations and added the results of my own investigations, many of them now published for the first time.

The present time is favourable to my work. The great Sylloge Fungorum of Saccardo (with its appendices in Vols. IX. and $\mathrm{x}$.) has been recently completed; the classic investigations 
of Brefeld in the domain of mycology, and containing his classification of the fungi, are now well advanced; the Kryptogamm-Flor of liabenhorst is nearly coinpleted; and the newer literature and olsservations are now periodically reviewed in the Zeitschrift für Pflenacnliruntheiten, and other magrines. The recent publication of several investigations on the influence of parasites on the anatomy of their host-plants greatly facilitated the compilation of the general part of the work.

I have here attempted to summarize in a systematic manner the preventive anid combative agencies available against the more important diseases of economic plants. In many cases these are supported by facts given in the chapters on the natural and artificial infection of host-plants, and their disposition towards diseases produced by lower organisms.

As already indicated in the title-page, the book deals only with those diseases of plants produced by the cryptogams and other lower organisms of the vegetable lingdom. The large number of parasites which attack such lower plants as algae and lichens, although not altogether neglected, have as a rule been omitted, otherwise the book could not have been brought within the limits of a single volume. In the second or systematic part of the book, the pathological phenomena are considered along with the description of the organism producing them. Where the diseases are of economic importance, measures for prevention and extermination are also suggested. Notices of greater length are given to such parasites and diseases as have formed the subject of special investigations. We could only aim at a complete list for Germany and the neighbouring countries, yet we have included many species of interest occurring in other parts of the world, notably in America.

Though it will be possible to idlentify most of the more important parasites by the aid of this book, we do not intend it to replace the systematic works; we purpose rather to add to the descriptions given in Rabenhorst, Saccardo, and sinilar works. This book is intended above all to be, in the terms of its title-page, "an Introduction"; hence it seeks to orient in a general way, to give a summary of our knowledge, and to indicate the way to more detailed records. On this account great care has been taken in the citation of home and foreign literature, not only up to the time of finishing the manuscript 
(Easter, 1894), but also during the time of proof-reading up till the following Christmas.

Reference to the book will be rendered easier by the numerous illustrations, which are almost exclusively the work of the author, and reproduced either from drawings or from photographs of the living objects, in many cases taken in situ. I consider it more essential to illustrate the habitus of pathological objects rather than to give drawings of microscopic subjects; those one may find in other works. Some of the illustrations are copied from the excellent plates of Tulasne, Woronin, De Bary, Klebs, Reess, Colm, and Robert Hartig; while a number of woodcuts have been borrowed from the well-known Lelerbuch der Baumkrankheiten of the last named author.

The grouping of the 'Fungi imperfecti,' which have not yet been worked up for the German flora, is based on Saccardo's Sylloge; hence the arrangement into Hyclosporce, etc., which is intended for the benefit of those having access to Saccardo. Particular attention has been paid in the two Indices to the scientific names of both parasites and hosts, to popular names, and to technical expressions.

In my labours I received great assistance from the following sources: From the collection of pathological material begun by Professor Robert Hartig, and now carried on with my help in the Botanical Institute of the Royal Bavarian School of Forestry in Munich; from the facilities for research and photography afforded by the laboratories of the same institution; from the Royal Library of Munich, the Library of the University, and the private pathological library of Professor Hartig.

Living material for investigation has been kindly sent to me from many sources, particularly from the following gentlemen: Herr Lehrer Schnabl of Munich, Geh. Oberregierungsrath Prof. Kühn of Halle, Hofgärtner Kaiser of Munich, Prof. Dr. Fries of Upsala, Forstrath von Plönnies and Oberförster Lösch at Amorbach. Preserved material came from Herr Hauptlehrer Allescher of Munich, Director Dr. Goethe and Dr. Wortmann in Geisenhein, Prof. Dr. Stahl of Jena, Prof. Dr. Magnus of Berlin, Prof. Dr. Grasmann and Prof. Dr. Loew of Tokio. Dr. Bruns of Erlangen kindly photographed some specimens in the botanical museum there. Numerous botanists have greatly assisted me by sending papers, especially Dr. Dietel of Leipzig; I have also to 
thank him for valuable aid with the Uredineae. To Prof. Dr. soxhlet I am indebted for literature and the opportunity given to establish a museum of patholorical material in connection with the agricultural division of the Munich Technical School. Dr. Solla of Trieste, while working in our laboratory here, very kindly translated the earlier fascicles of the 'Funghi parasitici' of Briosi and Cavara as far as they were then published. Prof. Dr. Wolluy allowed me to carry out some researches on his experinental fields. Very opportune were the investigations of my pupils, Dr. Woernle and Dr. W. G. Smith, on the anatomical changes in plants attacked by Gymnosporangeae and Exoasceae respectively.

To all these gentlemen, and to many more who sent me material, but whom it is impossible to name individually in this place, I here express my warmest thanks.

The reproduction of my drawings and photographs has been most carefully carried out by Herr O. Consée of Munich. I am also deeply indebted to the publisher, Herr Springer, for the excellent manner in which he has done his work; this will no donbt be also appreciated by the reader.

Muxici, December, 1894.

ฯ. TUBEUE.

\section{NOTE TO THE ENGLISH EDITION.}

Sirce the publication of this work, I have received a large eontribution of original papers. Though there was no time to embody all these in the English edition, yet many of them have been used for its correction and amplification. Some were of such a kind as to necessitate the re-writing of whole sections, notably those on the genera Erroascus and Gymnosporangium. The remainder will be thoroughly revised if a second German edition be called for. I again take the opportunity of thanking all those who have sent me literature, and I shall be grateful if they will continue to do so in the future.

Muxich, December, 1895.

๙. TUBEUF. 


\section{PREFACE TO THE ENGLISH EDITION.}

MY justification for placing another translation in our libraries is that no such book as this exists in the English language, and that I could not, for some considerable time, see my way to collect so many observations on the cryptogamic parasites of higher plants, or to find so many suitable subjects for the pictorial illustration of their habits and structure, as Dr. von 'Tubeuf has given us. The work was undertaken all the more willingly, because, while working under the guidance of the author, I had seen the book take shape in his hands, and even added some items to its pages.

The aims of the book are sufficiently set forth in the author's preface, and in the preparation of an English edition these have been kept in view. The first or general part and the more important descriptions in the second part are practically translations, but a certain amount of modification was found necessary in adapting the work to the requirements of English readers. With this object many additions were made both by the author and myself. Those which I have inserted are in most cases indicated by the use of (Edit.); this has, however, been entirely omitted in the group 'Fungi imperfecti,' and nearly so in the Uredineae, on account of the number of changes found necessary. I also thought it advisable to indicate whether the different species of fungi had been recorded for Britain and North America; this has been done generally by the use of brackets,-(Britain and U.S. America.) The records for Britain are taken from the works of Plowright, Massee, and others; those of three groups,-the Uredineae, Basidionyeetes, and 'Fungi imperfecti' were, however, revised by Professor J. W. H. Trail of Aberdeen, a well-known authority. For America 
the records of economic interest are selected chiefly from Farlow and Seymour's Host-Inder, which contains the complete list.

I here take the opportunity of expressing my thanks to I'rofessor I. Bayley Balfour for valuable aid and advice; to Professor J. W. H. Trail for kindly revising important parts of the proofs; to my brother, liobert Smith, for assistance in proofreading, and to other friends who have aided me.

The diffieulties of translation are well known; in the present case they have been increased by the technical nature of the subject, and by the modification which the original has undergone. Faults there must be; for those I ask the indulgence of the reader.

W. G. SMITH.

Royal Botanic Garden,

Eninburgh, October, 1896. 


\section{BIBLIOGRAPHY.}

The following are some of the more important general works and text books. Books and papers on special subjects are given throughout the text as foot-notes:-

\section{Gexeral Works ox Fuxgi.}

Tulasse. Selecta fungorum carpologia. 1861-1865.

De Bary. Comparative Morphology and Biology of the Fungi, Mycetozoa, and Bacteria. English edition. 1887.

Zopf. "Die Pilze.” Schenk's Handbuch der Botanik. 1890.

Ludwig. Lehrbuch der niederer Kryptogamen. 1892.

Breferd. Untersuchungen aus dem Gesammtgebiete der Mycologie. 1872-1891.

Tavel. Vergleichende Morphologie der Pilze. 1892.

SACCARdo. Sylloge fungorum. 1882-1893.

Winter, Fischer, and Rehy. "Die Pilze." Rabenhorst's Kryptogamenflora.

Schroeter. “Die Pilze." Cohn's Kryptogamenflora ron Schlesien. 18851894. (Incomplete.)

Schroeter. "Die Schleimpilze und die Pilze." Engler-Prantl natiirlichen Pflanzenfamilien. 1892-1894. (Not yet complete.)

Cooke. Handbook of British Fungi. 1871.

Plowright. British Ustilagineae and Uredineae. 1889.

Farlow and Sexrour. Host-Index of the Fungi of the United States. 1888-1891.

Massee. British Fungus-Flora. 1892-1895.

\section{Works ox Diseases of Plants.}

Uxger. Die Exantheme der Pflanzen und einige mit diesen verwandte Krankheiten der Gewächse. 1833.

Wiegmaxs. Die Krankheiten und krankhaften Misbildungen der Gewächse. 1839.

Meyex. Pfianzenpathologie. 1841. 
De Bary. Untersuchungen iiber die Brandpilze und die durch sie verursachten Krankheiten der Pflanzen. 1853.

KünN. Die Krankheiten der Kulturgewïchse und ihre Verhütung. 1858.

HaLbier. Phytopathologie ; die Krankheiten der Kulturgewächse. 1868.

Hartig, R. Wichtige Krankheiten der Waldbäume. 1874.

Hartig, R. Die Zersetzungserscheinungen des Holzes. 1878.

Fraxk. Die Krankheiten der Pflanzen. I. Aufl. 1880, II. Aufl. 1894-1896.

Hartig, R. Lehrbuch der Baumkrankheiten. I. Aufl. 1882, II. Aufl. 1889.

(Editions in English, French, and Russian.)

Sмитн, Wогтн. G. Diseases of Field and Garden Crops. 1884.

Sorduer. Handbuch der Pflanzenkrankheiten. II. Aufl. 1886.

WoLF and ZopF. Krankheiten der landwirthschaftlichen Nutzpflanzen durch Schmarotzerpflanzen. 1887.

Sorauer. Die Schäden der einheimischen Kulturpflanzen durch thierische and pflanzliche Schmarotzer. 1888.

Marshall Ward. Timber and sone of its Diseases. 1889.

Kirchyer. Die Krankheiten und Beschädigungen unserer landwirthschaftlichen Kulturpflanzen. 1890.

Frank and Sorauer. Pflanzenschutz. 1892.

Prillifox. Maladies des plantes agricoles et des arbres fruitiers et forestiers causées par des parasites vegetaux. 1895 .

Zeitschrift fiir Pflanzenkrankheiten (since 1891).

The Publications of the Division of Vegetable Pathology of the Department of Agriculture, U.S. America, issued from Washington.

The Bulletins of the Agricultural Experimental Stations, issued by many of the States and Universities of the United States.

Exsiccata of Parasitic Fungi, by ( $a$ ) Briosi and Cavara, (b) Eriksson.

"Economic Fungi" of U.S. America, by Seymour and Earle; Exsiccata begun 1890, (still being issued).

Etc., etc. 


\title{
CONTENTS.
}

\author{
PART FIRST.
}

\section{CHAPTER I.}

THE PARASITIC FUNGI.

\$1. Definition of the Parasitism of Fuxgi, - - - $\quad$ - 2

\$2. Classification of Parasites axd Saprophytes, - - 3

\$3. Nodf of Life of the Parasitic Fuxgi, - - - - 7

\section{CHAPTER II.}

REACTION OF HOST TO PARASITIC ATTACK.

\$4. Effect of Parasitic Fungi ox their Host, - - - 14

\$5. Effect of Parasitic Fungi ox the Forar of the Host-Plant, 22

\$6. Effect of Parasitic Fuxgi ox Cell-Coxtents, - - 31

§ 7. Effect of Parasitic Fuxgi ox the Cell-Wall, - - 36

\$8. Effect of Parasitic Fuvgi on the Tissues of their Host, 40

CHAPTER III.

RELATION OF PARASITE TO SUBSTRATUM.

§9. Effect of the Substratum ox the Developaest of the

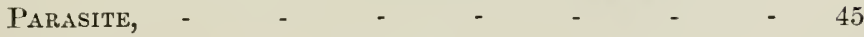


CHAPTER IV.

§ 10. NATURAL AND ARTIFICIAL INFECTION,

CHAPTER V.

§ 11. DISPOSITION OF PLANTS TO DISEASE, 58

\section{CHAPTER VI.}

§ 12. PREVENTIVE AND COMBATIVE MEASURES, -

I. Extermination and Removal of the Parasitic

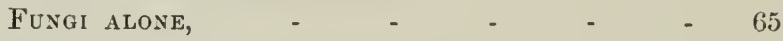

II. Removal and Destruction of Diseased Plants, - 71

III. Avoidance or Removal of Conditioxs which Favour INFECTION, - $\quad$ - $\quad$ - $\quad$ - $\quad$ - $\quad$ - 75

IV. Selection of Hardy Varieties, - $\quad$ - $\quad$ - 81

CHAPTER VII.

§ 13. ECONOMIC IMPORTANCE OF DISEASES OF PLANTS, 83

CHAPTER VIII.

SYMBIOSIS : MUTUALISM, $\quad$ - $\quad$ - $\quad$ - $\quad$ - $\quad$ - $\quad 86$

CHAPTER IX.

SYMBIOSIS : NUTRICISM, - $\quad$ - $\quad$ - $\quad$ - $\quad$ - $\quad$ - 92

Eстотrophic Mrcorhiza, $\quad$ - $\quad$ - $\quad$ - $\quad$ - $\quad$ - 93

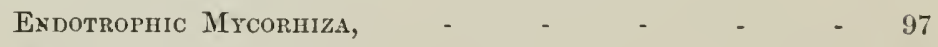

Mrcodomatia of the Alder, etc., - $\quad$ - $\quad$ - $\quad$ - 99

Mircodomatia of the Leguminosae, - $\quad$ - $\quad$ - $\quad$ - 101 


\section{PART SECOND.}

SYSTEMATIC ARRANGEMENT OF THE CRYPTOGAMIC PARASITES.

PAGE

I. THE PATHOGENIC FUNGI OF PLANTS, - _ - 104

A. Lower Fuxgi (Phycomycetes), $\quad$ - $\quad$ - $\quad$ - 106

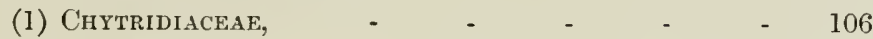

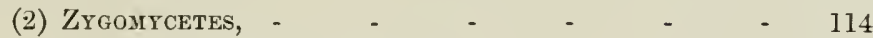

(3) Oonycetes : Peroyosporeae, - _ - - $\quad$ - 115

B. Higher Fuxgi (Mrcomycetes), -

AsCOMYCETES,

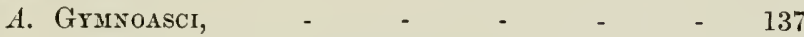

The Parasitic Exoasceae, - $\quad$ - $\quad$ - 144

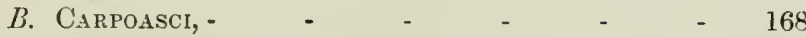

Perisporlaceae, _ - $\quad$ - $\quad$ - $\quad$ - $\quad$ - 170

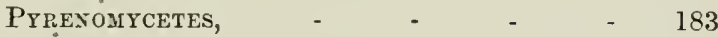

Hysteriaceae, - $\quad$ - $\quad$ - $\quad$ - 232

Discomycetes, -

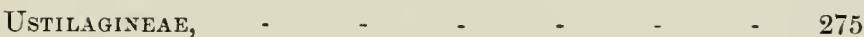

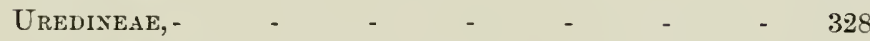

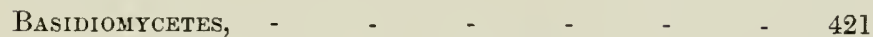

Fuxgi Imperfecti-I. SphakropsideAe, - - - 463

II. MIelanconieat, - $\quad$ - $\quad$ - 482

III. HyPIOMYCETES, - $\quad$ - $\quad$ - $\quad$ - 496

II. THE PATHOGENIC SLIME-FUNGI, - - - $\quad 522$

III. THE PATHOGENIC BACTERIA, - $\quad$ - $\quad$ - $\quad 530$

IV. THE PATHOGENIC ALGAE, $\quad$ - $\quad$ - $\quad$ - $\quad$ - 539

INDEX OF PARASITES, - $\quad$ - $\quad$ - $\quad$ - $\quad$ - $\quad$ - 556

GENERAL INDEX, - $\quad$ - $\quad$ - $\quad$ - $\quad$ - $\quad$ - $\quad$ - 580 


\section{ERRATA.}

Page 9, Fig. 1, for" "Erysipheae" read " Erysiphe."

" 35, line 11 from foot, for "tyrosin " read "trypsin."

,, 181, ,2 24, for "quercinium " read "quercinum,"

", 185, ,, 6, for "Nectrina" read "Nectria."

, 195, ", 3, for "setuloso" read "setulosa."

, 256, ", 6, for "Belionella " read "Beloniella."

, 305, ,, 11 from foot, $f_{\mathrm{Cr}}$. Tolysporium " read "Tolyposporium."

, 312, ,, 16, for "heloscladii" and "Heloscladium" respectively, read "helosciadii " and "Helosciadium."

, 337, "10, for "Onybrychis "read "Onobrychis."

, 35̃5, , 25, for "Cichoria" read "Cichorium."

", 403, ", 9, for "Cypressus" read "Cupressus."

"404, ", 5, for "Escheveria "read "Echeveria,"

"420, "3, for "Thecospora " read "Thecopsora." 


\section{PART FIRST.}

\section{CHAPTER I.}

\section{THE PARASITIC FUNGI.}

THE true Fungi, together with the Myxomycetes or Slime-fungi, and the Schizomycetes or Bacteria, constitute a group of the Cryptogams characterized by lack of chlorophyll. In consequence, the members of the group are unable to utilize light as a source of energy, and must obtain their food as organized material, complex in comparison with the simple substances required by green plants. These fungi, in short, are, in common with animals, ultimately dependent for the greater portion of their support on living or dead chlorophyllous plants. According as they obtain nutriment from dead organic remains or from living plants or animals, we distinguish them as Saprophytes and Parasites respectively. The same mode of nutrition is found in the case of most non-chlorophyllous Phanerogams, and also in a few chlorophyllous plants, both Cryptogams and Phanerogams.

When parasitic Fungi, Bacteria, and other lower organisms attack higher plants, they, as a rule, endeavour to penetrate the living organs of their host. It is only when this penetration has taken place to some extent, and the parasite has thereby come into more or less close contact with the tissues of its host, that conditions suitable to a parasitic mode of nutrition are established.

To deal with the lower forms of vegetable parasites, with their relations to their respective hosts, and with the structural alterations which they bring into existence in the latter, is our object in the present book. 


\section{§ 1. DEFINITION OF THE PARASITISM OF EUNGI.}

Parasitic Fungi are those which, stimulated by the cellcontents of another living plant, penetrate wholly or partially into its tissues, and draw their nutriment from that source.

Saprophytic Fungi are those which make no attempt to penetrate the tissues of living plants, but derive their mutriment from a dead sulsstratum.

Intermediate between these two extremes come those fungi which, in consequence of some stimulus, attempt to effect an entrance into the tissues of living plants by the secretion of some fluid or ferment, but only attain their object after first killing the part they attack (e.g. Sclerotinia sclcrotionum). A special position must also be ascribed to certain forms which inhabit the wood of trees, but have not the power to penetrate through the outer tissues; they depend on first gaining entrance through wounds into dead parts of the bark or wood, and, after living there for a time as saproplytes, extend into the living elements and cause their death.

Many parasites may be artificially cultivated so as to pass some part of their life-history on dead pabulum, and even in natural conditions many of them regularly live for a season in a saprophytic manner. On this account it appears to me more correct, in distinguishing between parasites and saprophytes, to lay less weight on the adaptation to nutrition and more on their response to the stimuli exerted by living plant-cells. The nature of this stimulus which affects parasitic hyphae has not as yet been investigated. It appears probable, however, especially from the investigations of Pfeffer and Miyoshi, ${ }^{1}$ that the influence is primarily a chemical one, and that the nutritive value of the stimulating substance is not a measure of the ensuing effect. Biisgen states that the formation of adhesive-dises by germinating spores is induced by a stimulus due to contact, whereas the production and penetration of the first haustorium is independent of contact, and is probably due to some chemical stimulus (see p. 9). Miyoshi's investigations have also proved that saprophytic fungi are capable of penetrating into living plant-organs, even

${ }^{1}$ Miyoshi. "Ueber Chemotropismus d. Pilze." Botan. Zeitung, 1894; also "Die Durchbohrung von Membranen durch Pilzfaden." Pringsheim's Jahrbuch, 1895 1895 .

Pfeffer. "Ueber Election organischer Nahrstoffe." Pringsheim's Jahrbuch, 
of boring through cell-walls, if the part be impresnated with a stimulating solution. They behave here completely as parasites. For example, hyphae of Penicillium glaucum penetrate into living cells of a leaf injected with a two per cent. solution of cane sugar, while without previous injection of the leaf they have never been observed to do so. Penicillium is also known, in certain circumstances, to become parasitic.

Many species of fungi are capable of passing the whole or a part of their life as parasites on living plants. Conspicuous in this respect are the Uredineae and Ustilagineae, many Ascomycetes, including all Exoasceae and Erysipheae; and amongst the lower fungi, most of the Chytridiaceae and all the Peronosporeae. Nor does this exhaust the list, for amongst the remaining fungi we may find isolated families, genera, and even species occurring as parasites, while forms closely related to them are saprophytic.

To classify the parasites, saprophytes, and intermediate forms, we shall adopt that arrangement proposed by Van Tieghem and De Bary.

\section{§ 2. CLASSIFICATION OF PARASITES AND SAPROPHYTES.}

1. True saprophytes are such as regularly pass through their whole life-history in a saprophytic manner. They may derive their nourishment from different kinds of pabulum, or be limited to some definite substratum. The true saprophytes do not come within the scope of this book. ${ }^{1}$

2. Hemi-saprophytes (the 'facultative parasites' of De Bary) are wont to pass through their whole development as saprophytes, but on occasion are capable of existing wholly or partially as parasites. Amongst them are included particularly such species as may be designated "occasional parasites," which commonly occur as saprophytes, and only under certain conditions become parasitic.

3. True parasites (the 'obligate parasites' of De Bary). These undergo no part of their development as saprophytes, but live in every stage of existence as parasites.

4. Hemi-parasites (the 'facultative saprophytes' of De Bary) are capable, if need be, of becoming saprophytes for a season

\footnotetext{
${ }^{1}$ Johow proposes the term Holo-saprophytes for those non-chlorophyllous Phanerogams which live exclusively saprophytic on organic debris, in contrast to those possessing chlorophyll, which he names Hemi-saprophytes.
} 
but as a rule they live throughout their whole development as parasites.

Within each of these four divisions one may introduce a number of subdivisions.

\section{Hemi-saprophytes.}

The majority of saprophytes are never parasitic, yet there are a number which become so occasionally. Thus some species of Mucor and Penicillium can penctrate into thin-skinned fruits, and this they do the more easily, the further the fruits are from the condition of full vital energy, to use De Bary's expression. ${ }^{1}$ Related to these are other fungi which, although incapable of effecting entrance into plants in active life, may yet do so as the plant, though still living, begins to wither. In such cases the parasitism is somewhat difficult to prove. In particular, the so-called 'Fungi imperfecti' contain forms of this kind.

Amongst the hemi-saprophytes we may inclucle the species of Botrytis, which are able to penetrate into unfolding parts of plants, but not into the older parts. We may specially mention Botrytis Douglasii as a form more generally known as a saprophyte, but which becomes parasitic on immature organs, and which penetrates young needles of various conifers to kill them, whereas it is unable to attack older needles. In this case the thickness of the membranes would seem to act as a protection, just as the vital energy of the plant does in the preceding cases. In Sclcrotinia sclerotiorum, Scl. ciborioides, and Scl. Fuclicliana, a saprophytic existence must, as in the example just mentioned, precede the parasitic condition; in fact De Bary holds that these forms can only become parasites after their mycelium has been saproplytically strengthened; the parasitic condition is not necessary to them, for they can go through their whole development on a dead substratum. Pythium Dc Baryanum is also to be regarded as a hemi-saprophyte which attacks and kills seedlings of many plants as a parasite, but otherwise vegetates on dead plant remains. Cladosporium herbarum, one of the commonest of saprophytes, behaves similarly, but it is of less frequent occurrence than Pythium, and in fact its parasitisin has only been suspected quite recently.

\footnotetext{
${ }^{1}$ This has been confirmed by Davaine (Compt. rend. LxiIr., 1866, pp. 277 and 344) and Brefeld (Sitzungsber. d. naturforsch. Fr. zu Berlin, 1875).
} 
As further examples of fungi, capable, as parasites, of killing living cells, but which pass through more or less of their life as saprophytes, may be taken species whose mycelium inhabits the wood of trees and shrubs. Amongst these are numerous Polyporeae, which find admission only by wounds in the wood. At first these destroy and derive nourishment from the substance of dead parts of the wood, but later they begin to attack the parenchyma of the living wood, and extending outwards kill, as they go, cambimm, bast, and rind, till they reach the exterior, and there develop sporophores. As examples we may take those species investigated by R. Hartig of Munich, e.g. Polyporus fomentarius, $P$. igniarius, $P$. Hartigii, $P$. sulphureus, Stercum hirsutum, Trametes pini. ${ }^{1}$

The heart-wood is a part of the tree generally avoided by insects, which would in very short time destroy the sap-wood with its rich starch-content, e.g. Annobiae in oak. Again, the heart-wood resists the influence of certain saprophytic fungi much longer than the sap-wood, hence it is preferred as the timber used for railway sleepers. Although in these cases we might describe the heart-wood as possessing antiseptic properties, yet this wonld scarcely be accurate, since it is just this very heart-wood which is always first attacked by the wound-parasites of trees, and gives them a hold on the tree as parasites. See also Chap. V.

Since these dangerous tree-fungi can live wholly as saprophytes in the heart-wood, and in the sap-wood partly as such, partly as parasites, they are also able to vegetate further, and to reproduce themselves on felled stems, especially when the necessary moisture is provided. Thus, for example, Agaricus adiposus, a wound-parasite of the silver fir, produces its yellow sporophores on felled stems and split wood during the whole summer in moist parts of the forest, while in a cellar or other moist chamber the development of sporophores may continue over a year. In fact, I have found that a billet of beech-wood, after being placed under a glass, and allowed to lie completely dry, on again being soaked from time to time, continued to produce a crop of toadstools annually for five years.

Some wound-parasites occur occasionally as typical saprophytes on dead wood. Thus Polyporus annosus, perhaps better

${ }^{\mathrm{I}} \mathrm{R}$. Hartig, Zersetzungserscheinungen des Holzes, 1878, and other works. 
known as T'remetes renliciperde, is an undoubter parasite of pines, spruces, and other trees, yet on timber in mines ${ }^{1}$ it grows luxuriantly, and reproduces abundantly from sporophores, which, however, differ somewhat from the typical form. Again, the rhizomorph-strands of Agaricus melleus grow under dead bark, in the earth, in mines, and in wooden water-pipes, while other forms of its mycelium are completely parasitic; thus the apices of the rhizomorphs penetrate the bark of young conifers, and, in the form of a mycelium, live parasitic on rind, bast, and cambium.

Polyporus raporarius, a true parasite on living Scots pine, is also an enemy of timber in newly-built structures, or in subterrancan spaces and cellars, so long as it can obtain the necessary moisture. Polyporus sulphureus produces sporophores on the bark of living trees, as well as on the dead stools of felled trees. Many other related forms would probably be able to live on dead timber if they were not dependent on a certain degree of moisture, and could submit to drying-up as easily as, for example, Polyporus abictinus, a true saprophyte, and one of the most common enemies of old wooden bridges.

Fungi from other groups are also known to effect an entrance into the wood of trees through wounds only, yet when once in, they spread rapidly, and at length bring about the death of their host. The spores of Cucurbitaria laburni were demonstrated by me to germinate on the laburnum, on wounds produced by hail and otherwise, and to send into the wood so exposed a mycelimm, which spread through the vessels and into the rind, killing all the tissues on its way. Similarly Nectria cinnabarina, after it has killed its host, lives thereon as a saprophyte, and develops patches of conidia and perithecia on the dead bark. Pezize Willkommii, although really a strict parasite on the living rind, yet continues to grow and to reproduce itself on the dead branches.

\section{Hemi-parasites.}

If the examples already given, i.e. Hucor, Penicillium, Botrytis, Pythizm, are typical of hemi-saprophytes, then there may arise a doubt whether the remainder, the wood-destroying Polyporene, Nectria, Cueurbitaria, and Agaricus melleus, should not be regarded

${ }^{1}$ Harz, Botan. Centralblatt, 188s, Vol. xxxvi.; Magnus, Botan. Verein d. Prov. Brandentur!!, 1 sss. 
as hemi-parasites. They must, however, be included amongst the hemi-saprophytes, because doubtless they are capable of going through their whole development as saprophytes. The hemi-parasites include, amongst others, the Ustilagineae, all of which live for a time as parasites, and cannot, even by artificial cultivation, be made to complete their life-history as saprophytes. While, however, many of the Ustilagineae are adapted to a completely parasitic life, others can, in the form of sprouting conidia, live and multiply saprophytically. The conidia of Exobasidium and Exocscus continue to bud off conidia for a considerable time in nutritive solutions, yet in nature, the spores probably produce infecting hyphae at once, and the fungus is but little suited to sustain a saprophytic mode of life. Phytophthore infestans is more easily reared as a saprophyte, and occurs in nature as such, hence it approaches somewhat towards the hemi-saprophytes.

\section{True Parasites.}

The Uredineae may be taken as the most typical of the true parasites; they constantly pass through their whole life-history on living plants, and cannot be cultivated on a dead substratum. So also the Erysipheae, although frequently their spores ouly reach maturity on a dead substratum, as do also those of Rhytisma and Polystigma. Ergot of grain and the Sclerotinice inhabiting berries, are also truly parasitic, even though their apothecia or perithecia are produced from hibernating sclerotia, and though their conidia can be saprophytically cultivated on dead pabulum.

The Peronosporeae and Protomyces are also true parasites. In many other forms the development of germ-tubes, or the sprouting of conidia, may be obtained in artificial nutritive solutions by exclusion of rival fungi and bacteria, yet it is doubtful whether this takes place in nature.

\section{§ 3. MODE OF LIFE OF 'THE PARASITIC FUNGI.}

The parasitic fungi may be divided according to the place of their occurrence and their mode of attack on the host, into two categories, which may be designated epiphytic and endophytic 
parasites. $^{1}$ The former have their vegetative mycelium spread over the surface of the host-plant, the latter penetrate into the plant and there develop their mycelium. IBotl reeeive nourishment from the cells of the host-plants, generally by means of special absorptive organs inserted into the cells of the host, the so-ealled haustoria.

We may distinguish the following groups of parasites according to the degree of their penetration into the organs of the host-plant they attack:

1. Epiphytes: (a) with haustoria which only sink into the outer membranes of the host;

(b) with haustoria penetrating into the cavity of the hostcells.

2. Endophytes: (a) with a mycelium which grows in the walls of the host-cell, and is generally nourished without the aid of haustoria ;

(b) with a mycelium which grows in the intercellular spaces only, and is nourished with or without haustoria;

(c) with a mycelium which penetrates into the host-cells and becomes an intracellular mycelium;

(d) lower fungi which live completely in a host-cell.

1. Acquisition of nutriment by the epiphytic parasitic fungi. The simplest mode of acquiring nutriment is found in yeasts (Saccharomyces apiculatus, etc.) which frequent the outside of living fruits, and live on the drops of sugary solution which diffuse therefrom. ${ }^{2}$

${ }^{1}$ Epiphytic parasites always produce their reprodnctive organs outside their host-plant. In the case of endophytic parasites, the reproductive organs of some are produced inside the host-tissne, e.\%. the zygospores and oospores of Chytridiaceae and Peronosporeae, the chlamylospores of the Ustilagineae; others form their sporocarps wholly or partially embedded, the spores and conidia only being discharged extemally; while a large number form sporocarps on the surface after the epidermis has been torn. Conidia are generally abjointed from the free surface of the host-plant.

The terms epiphytic and endophytic parasites have been chosen with regard to the development of the parasitic food-absorbing mycelium. Some authors regard epiphytism somewhat differently, and include anongst endophytes those forms which live on the surface of the host and penetrate only by haustoria. If this be accepter, epiphytism is very exceptional amongst parasites of the higher plants. Zopf ("Die Pilze") gives as examples of this condition only the following : the Laboulbeniaceae inhabiting the chitinous skeleton of certain insects, and Melanospora parasitica on filaments of species of Isaria; these have no communication between the my"celium and their host. Species of Chatocladium parasitic on fungi and alssorbing the cell-wall of the host at the point of contact, could. strictly speaking, no longer be classed as epiphytes.

${ }^{2}$ Büsgen. "Ueber einige Eigenschaften d. Keimlinge parasitischer Pilze." Botan. Zeitung, 1893. 
I can however hardly regard as parasites, fungi like these which live on an accidental outflow from plants or plant-cells, even though they regularly frequent places where an outflow is to be expected. They exert no influence on the host-plant, and they are nourished by substances which can no longer be regarded as belonging to the host. I wonld rather include them amongst non-parasitic epiphytes which, without specially adapting themselves, settle on any part of a living plant where sugary solutions suitable for their nutriment may occur. One might imagine however such epiphytes inducing a diffusion of nutritive substance from the cells of the host-epidermis to the closely adherent fungal hyphae; then we should have the simplest mode of parasitic acquisition of mutriment on the part of epiphytes. They would take up food-material from the epidermal cells in much the same manner as many intercellular hyphae do from the adjoining walls of the host-cell. ${ }^{1}$

Epiphytic parasites frequenting the surface of plant-organs generally endeavour to increase their supply of nutriment from the host-cells by formation of haustoria, which pierce the cuticle or the whole cell-wall. Biisgen has shown experimentally that the adhesive discs, often formed on the germination of a spore, owe their origin to a contact-stimulus; the formation and direction of the infecting hyphae, on the other hand, though depending on this, are much more determined by a stimulus originating from the host-cell itself. In this we have a confirmation of the accuracy of our definition of parasite and saprophyte.

The appressoria, adhesion-organs or adhesive discs just mentioned, are characteristic of many parasites. They are formed chiefly on epiphytic mycelia, but also accompany the earlier life of other fungi. In the case of epiphytes, pores are formed on definite places of such an adhesive-clisc, and from these haustoria are developed, or a hypha is given off and enters the host-plant to

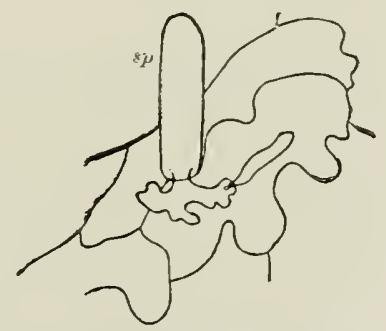

Fig. 1.- 81 , Spore of Erysipheae umbelliferarum germinating on the epidermis of a bost-plant; an adhesion-disc and haustorium have been formed. (After De Bary.) form a mycelium. The appressoria of the Erysipheae are very characteristic; in many they are broad lobed discs (Fig. 1); in

\footnotetext{
${ }^{1}$ Compare those cases of parasites on insects and fungi already given, p. $S$ (note).
} 
others, like Podosphacre eastagnei, they take the form of broadened closely-clinging hyphae with haustoria. Frank describes a swelling of the germ-tube of Fusiclaclium tremulae just before the infecting hypha pierces the cell-walls of its host. A similar phenomenon can be observed in Polystigma rubrum, in Gnomonire crythrostome, and in the germinating aecidiospores of Mclempsorre Gocppertiana. Some other examples will be mentioned in our next section.

Haustoria of the epiphytic Parasites.

The most inconspicuous haustoria are those of Herpotriehic nigre and Trichosphacria parasitica, described by R. Hartig. ${ }^{1}$

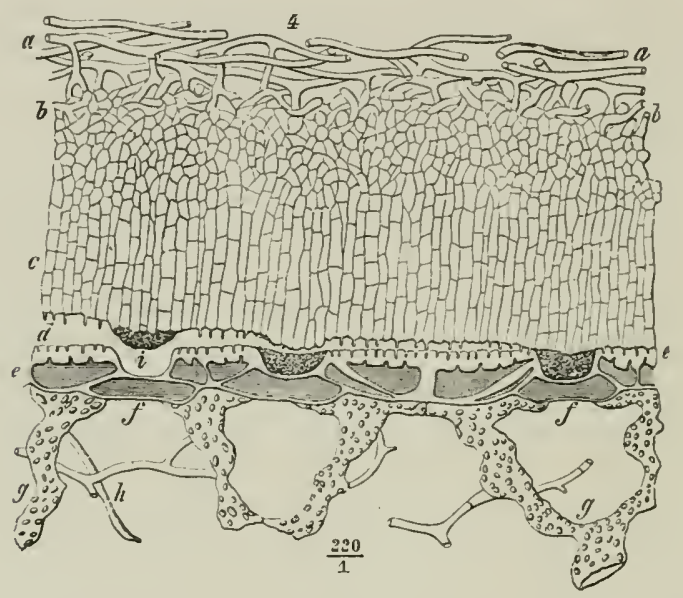

\footnotetext{
FIc. 2.-Haustoria of Trichosphecria parasitica. (Details on Fig. 58.) (After R. Hartig.)
}

They are tiny hyphal processes resting on the host-epidermis, and sunk into the outer walls of the epidermal cells, so as to pierce the cuticle but not the whole wall (Fig. 2, $d, c$; also Fig. 90). The Erysipheae are typical epiphytes, which weave a mycelium over the surface of plants they attack; the mycelium retains its hold by adhesion-discs or appressoria, and from certain parts of these a fine thread-like process is given off, which, after piercing the epidermal wall of the host, swells inside to a simple or branched sac, the haustorium. The

${ }^{1}$ Lehrbuch d. Baumkrankheiten, II. Anfl. English translation by Professor Somerville. Macmillan \& Co., 1594. 
haustoria of Podosphaere castagnei (Fig. 71) are bladder-like, those of Oidium Tucheri are lobed.

The simplest formation of haustoria consists in an outgrowth of the mycelium which depresses the cell-wall of the host without piercing it (e.g. Peronospora densa). In other cases the cell-wall, at first only depressed, becomes ultimately broken through.

Certain lower fungi live parasitic on other fungi and adhere to their hyphae by means of well-developed adhesion-discs from which haustorial structures are formed inside the hyphae of the host. Thus Piptocephalis fresenice is parasitic on hyphae of some species of Mucor, and produces from a swollen bulb-like appressorium a tuft of very fine haustoria inside the Mucor-hypha. Syneephalis proceeds even further, for the haustorial process grows and branches inside the host, becoming, in fact, an endophytic mycelium. A further advance towards endophytic parasitism is presented by the Chytridiaceae, low forms of fungi living on algae or fungi; some send haustorial structures into their host, others develop a mycelium whose attack however is directed against only one host-cell. Fischer, in his "Phycomycetes," thus describes the latter forms: "The regetative body, a resting swarmspore, consists of a spherical or ellipsoidal part which becomes a sporangium, and of a filamentous vegetative portion which spreads through the host-cell as a haustorium or mycelium and dies away after the formation of the sporangium. This primitive nycelium is unicellular, and may be unbranched or very finely branched."

2. Acquisition of nutriment by the endophytic parasitic fungi. The simplest case of the endophytic mode of life is presented by those fungi which vegetate in the epidermal membranes of their hosts, and derive their nutriment osmotically through the inner cell-walls. They live covered by the cuticle, which must have been penetrated by an infecting hypha at the time of first attack. This mode of life is exhibited by many fungi, particularly by the Exoascac; the mycelium of these vegetates under the cuticle of the host plant, and ruptures it at the time of ascus-formation. In spite of their limited distribution the species of this group so influence the development of their hosts as to induce pustule-like outgrowths, crumpling and distortion of leaves, and even "witches' brooms." In some 
of the Ficouscrue the bases of the asci penetrate deeply between the walls of the epidermal cells, so forming an intermediate stage leading to other Exousceuc aud endophytic fungi, with a mycelium growing between, or in the cells of tissues which lie deeper than the epidermis.

The mycelium of Cycluconium olcaginum grows in the epiderual cell-membranes, branching dichotomously under the cuticle and sending through it erect hyphal branches for production of eonidia. ${ }^{1}$ The germinating conidia of Sphaceloma ampelinum are said by De Bary to penetrate the euticle, and to produce a mycelium which spreads thereunder and breaks out just before formation of conidia. Mycoidece parasitica, an alga, lives under the euticle of leaves of There and Camellia.

We have next to consider fungi with a mycelium which lives and multiplies in the intercellular spaces of living plants. Like the Exocascece just mentioned, they push their way between neighbouring cells and spread through the already existing intercellular spaces. Numerous Uredineae behave in this way, and towards the period of reproduction the mycelium is capable of increasing so much that the cells of the host-tissues become isolated and even displaced. The various species of Hystcrium have an intercellular myeelium, which kills those cells with which it eomes in contact. Certain forms, e.g. Cacoma pinitorquum and Peridermium pini (Fig. 247) possess a myeelium which, while still intereellular, sends. off here and there little lateral branches into the host-cells. It is an easy step from forms like these to forms whose inycelium is no longer strictly intercellular, but derives nutriment by means of specialised haustoria.

\section{Haustoria of the endophytic Parasites.}

A large number of enclophytic parasites frequenting hosts which do not inmediately suceumb to their attack, possess "lhaustoria" or special organs for the acruisition of nutriment from the cells of the host. The haustoria are lateral outgrowths of the mycelium with a limited period of growth and a more or less constant form. They are more varied in form, but otherwise quite comparable with haustoria of the epiphytes, especially with those of the Erysipheae. One of the simplest forms of

\footnotetext{
${ }^{1}$ Figures in Funghi Parasitti, Cavara and Briosi.
} 
haustorium on an endophytic mycelium is that exhibited by the parasite Cystopus; the hyphae send off very fine filaments which penetrate the walls of a host-cell and swell up to little button-like sacs. Many Peronosporeae (P. pygmaca, P. nirea, P. viticole and Phytophthora omnivora) have haustoria of the form just described, whereas others have them thread-like and branched ( $P$. calotheca of the woodruff), or crenately lobed ( $P$. parasitica).

Amongst the species of Uredineae and Ustilagineae, haustoria are not uneommon and present many varied forms. They are, however, few in number, or confined to certain parts of the mycelium, so that they may be easily overlooked.

Haustoria in the form of long sacs of various lengths are produced by Melampsora Gocppertianse in the tissues of both cowberry and fir-needle. Gymnosporangium in juniper has occasionally very delicate button-like haustoria. Endophyllum sempervivi in the house-leek has haustorial branches which, according to Zopf, are coiled together and anastomose frequently with each other. Tuburcinic amongst the Ustilagineae possesses short branched haustoria resembling one-sided clusters, and Mclanotacnium endogenum has similar haustorial-tufts even more branched. ${ }^{1}$ Urocystis pompholygodes in Hepatica triloba has spirally coiled haustorial hyphae, while Tilletia endophylla, Sorosporium saponariae, ${ }^{2}$ and many species of Ustilago, have haustoria with the form of knotted hyphae.

Amongst the Hymenomycetes, Exobasidium vaccinii forms a mycelium which permeates the host-tissues with numerous hyphae, but the only haustoria are hyphae which here and there penetrate into a cell. No haustoria have as yet been found amongst the Basidiomycetes, ${ }^{3}$ Pyrenomycetes, or Discomycetes. The two groups last-mentioned have an intercellular or intracellular mycelium, which as a rule quickly kills all cells with which it comes in contact.

${ }^{1}$ Senckenbergische naturforsch. Ges. Abhandl. 1880. Plates I. and IV.

2Pringsheim's Jahrbuch, 1869. Plates VII., VIII.

${ }^{3}$ Sarauw has figured haustoria in mycorhiza of beech, without however determining exactly whether they belonged to a Hymenomycete. Reess also figures similar organs on mycorhiza produced by one of the Tuberaceae. 


\section{CHAP'TER II.}

\section{REACTION OF HOST TO PARASITIC ATTACK.}

TuE reaction of the host to the attacks of parasitic fungi is fairly constant for the same host and fungus. The various fungi, however, exert on the same host-plant each an influence of its own, while different host-plants behave very differently under attacks of the same fungus.

\section{§ 4. EFFECT OF PARASITIC FUNGI ON THEIR HOST. ${ }^{1}$}

\section{A. Killing of Hosi-Cells.?}

\section{Absorption of living cell-content by parasitic fungi.} The lower fungi give us examples of the simplest mode in which fungus-parasites draw nutriment from their host-cells; particularly those forms parasitic on algae or other fungi. The most primitive of all are numerous speeies which, applying themselves to a host-cell, bore through its walls and enter the cavity. There they derive nutriment at the cost of the living cell-content,- - the plasma, cell-sap, chloroplasts, starch grains, etc.,- and finally kill the cell. The host-cell does not survive the later development and reproduction of the parasite. The effect of the fungus is however limited to the

\footnotetext{
${ }^{1}$ Billroth ("iiber die Einwirkungen lebender Pflanzen und Thierzellen aufeinander,"Sammlung Medic. Schriften. Wiener klin. Wochenblatt, 1890), compares in a masterly way the effects of micro-organisms and of injuries on animal and vegetable tissnes. He employs Virchow's terms "formative stimulus" and "formative irritability" ; the former to denote the capacity of micro-organisms in producing ontgrowths of definite form or the formation of new tissues; the latter, the capacity of the tissues to react to such stimuli, and to produce outgrowths, etc. A comparison of the external phenomena of fungoid diseases in the case of animals and plants recently formed the subject of a short paper by Lewin.

2 Perniciasmus.
} 
cell attacked which is at once killed before it can enlarge or otherwise react to the influence of the intruder. Good examples of such parasites are presented by some of the Chytridiaceae - the Archimycctes of Fischer-which, as a rule, inhabit only isolated cells of their respective host-plants. This mode of nutrition is equivalent to that of the Myxomycetes and Mycetozoa, which absorb the cell-contents after completely enveloping the living cell, or after slipping inside or sending a haustorial process into it.

A second series of parasites consists of those which live on the contents of the host-cell, and give it time to react to the stimulus exerted by the intruder. The reaction generally results in a cell-enlargement or fungus-gall, which in the simpler cases includes one cell only. The gall harbours one or more parasites, which gradually use up the cell-contents. As examples we have Olpidium tumaefaciens and 0 . uredinis, ${ }^{1}$ Pscudolpidium saprolegniae, Olpidiopsis saprolegniae, Rhizomyxa hypogaca, ${ }^{2}$ etc. A specially striking case is that of Pleotrachclus fulgcns, which causes the rudiment of the sporangiophore of Pilobolus Klcinii to become hypertrophied and gall-like. ${ }^{3}$

We have as a third series those parasites which penetrate into living cells and absorb their contents, at the same time stimulating the host-cell to abnormal and increased growth, as well as some surrounding cells not directly in contact with the fungus. In this case the parasite exerts a far-reaching effect, and produces a gall composed of more than one cell. Species of Synchytrium are examples. The fungus itself penetrates into one cell only, which enlarges; but simultaneously the surrounding cells grow and multiply to form a wall or rampart enclosing the cell originally attacked. Other parasites do not absorb the host-contents as a whole, but only withdraw osmotic substances by means of delicate processes of the fungus-hyphae. These haustoria penetrate the wall of the host-cell, but the fungal protoplasm inside them remains separated from the host-protoplasm by a delicate membrane. In the case of the vine-mildew and some other Erysipheae, the cells thus preyed on turn brown and die. With other related forms (e.g. Sphacrotheca castagnei),

'See Fischer's Phycomycetes.

2 This causes a slight swelling of the root-hairs of various plants and absorbs their content.

${ }^{3}$ Zopf, Beiträge zur Physiol. u. Morphol. nied. Organismen, II. 1892. 
absorption by haustoria results in a deformation and distortion of attacked organs, which embraces even cells far distant from the point of attack, yet without death following directly to any cell.

2. Absorption of cells or tissues by parasitic fungi. The total absorption of cells or tissues by parasitic fungi constitutes a special form of cell-destruction. Cases of this lind occur particularly amongst the Ustilagineac. Thus Urocystis violec so stimulates the cells of Viole that they divide and produce a delicate tissue, rich in protoplasm; this nutritive tissue is used up when spores are formed, but without any great detriment to the host-plant. At the time of spore-formation of other Ustilagineae a great destruction of the host-tissues may, however, take place; this is especially marked in attacks of Ustilargo maydis, $U$. avence, Tilletic tritiei, on the ovaries of their respective hosts, as well as in other cases to be considered later.

3. Killing of host-cells and tissues by fungi which excrete ferments. The simplest case under this heading is presented by species of Selerotinia studied by De Bary, e.g. Sel. selerotionum. The mycelium of these, while still lying on the outer surface of the host-plant, excretes a ferment which sinks through the membranes into the cell-cavities, causing death to the protoplasm and even destruction of whole tissues.

A similar process may be assumed in the case of numerous fungi with a mycelium which grows only in the intercellular spaces, yet causes immediate death to any eell it may touch. This is the case with many leaf-spot liseases, like those due to Cercospora, Hysterium, ete. So also do the apices of rhizomorphstrands kill portions of the bast of living Conifers with which they may come in contact. The rapid death of tissue following the attack of such deadly fungi as Phytophthore is probably due not altogether to the deprivation of nutriment, but also to the effects of a poisonous excretion. This, however, has not as yet been satisfactorily ascertained.

\section{B. Killing of Orgaxs or Whole Plants.}

A large number of fungi have a mycelium which never extends beyond a very short distance round the point of first infection, and causes only local disease, frequently with no 
perceptible disturbing effect on the host. Such is the case particularly with leaf-spot diseases; the tissues of isolated spots are killed and fall out, the leaf appearing as if perforated by shot, but otherwise exhibiting no discoloration or other symptom of disease. In contrast to these there are fungi which, directly or indirectly, bring about death of their host or some part of it.

The simplest example of parasitic fungi killing their host directly is presented by one-celled or few-celled plants, which soon succumb to attack even on a single cell. Where, however, the host is a highly organized plant, its organs will resist the attack of the parasite for some time. Thus with Phytophthore fagi, the mycelium spreads rapidly through the tissues of a seedling, so that death ensues in a few days. Similarly species of Peronosporce rapidly kill leaves, branches, and fruits; likewise Cladosporium, Scptoria parasitica, and others.

Somewhat different in their action are those fungi which kill some tender part of a plant directly, and thereby indirectly further the death of other parts dependent thereon. As examples, take Pestalozic Hartigii (Fig. 301) and Phoma abictine (Fig. 293), which kill only some small portion of a young plant or branch, but thereby cause drying-up of higher or distal parts. Gibberce raccinii on stems of cowberry (Fig. 95) is another example. Similarly cankers arising from Nectria ditissima (Fig. S0), or Pezizc Willkommii. Again, Agaricus melleus and Trametes radiciperda kill roots or lower portions of the stem, and bring about the death of trees of all ages.

The case varies somewhat with certain wound-parasites like Nectria cinnabarina and Cucurbitaria laburni. There the mycelium extends so vigorously in the water-conducting organs, as to kill them and fill up the vessels, causing thereby so serious a disturbance in conduction, that branches or whole plants wither away in summer. The wood-destroying Polyporcae and Agaricini act similarly, although more slowly; they attack large branches and stems, destroying all parts of the wood, duramen as well as sap-wood, and finally the bark.

There are also cases where organs of the attacked host remain alive, but suffer on account of the hypertrophy of other parts. In this way portions of a plant may be killed although not directly the seat of the parasite. This is particularly the case where hypertrophied organs undergo increased growth and 
utilize the water which woulıl otherwise have ascended to higher parts of the branch-system (Fig. 3). It must indeed be assumed that the latter are preyed on by the hypertrophied parts and give up plastic material, which they would otherwise have utilized themselves or stored up as reserve material. On branches attacked by mistletoe and other phanerogamons parasities, it can easily be observed, particularly on broadlenved trees, that a supporting branch grows vigorously in the parts uncler the influence of the root-system of the parasite, whereas the distal parts of the same branch-system remain stunted and finally die. The mistletoe-bush thus comes to form the termination of the supporting branch. If, in consequence of this, the branch ceases to produce the leaves necessary in preparing food for it, then like every other leafless branch it dies. Such branches carrying leaves of the mistletoe alone may frequently be found on firs, pines, and broad-leaved trees; even whole tree-summits have been seen on the silver fir with every branch terminated by a mistletoe-tuft, not mnlike some huge candelabrum.

In a similar manner a witches' broom, developed from a lateral bud, exhibits thronghout an increased growth, while the branch supporting it remains thin and dies from the insertion of the broom outwards. So also in attacks of Gymnosporangium on juniper it may be observed that the parts attacked have their growth much accelerated and many of their dormant buds developed, while the distal parts of the same branch die off. In all such cases it is quite probable that, as the distal parts die back, any food material which they may contain finds its way into the hypertrophied region.

\section{(. Shortenixg of Life.}

Many fungi inhabit a plant without disturbing the develop. ment of any part or causing immediate death, yet with such effect that the vegetative period of the organ in question terminates earlier than normally.

A very striking example of this is presented by the needles of silver fir on the witches' brooms cansed by Accitium clatimum. The needles normally vegetate for several years, but when influenced by this parasite they live only a single season. So also needles of spruce attacked by Accirtium cor- 


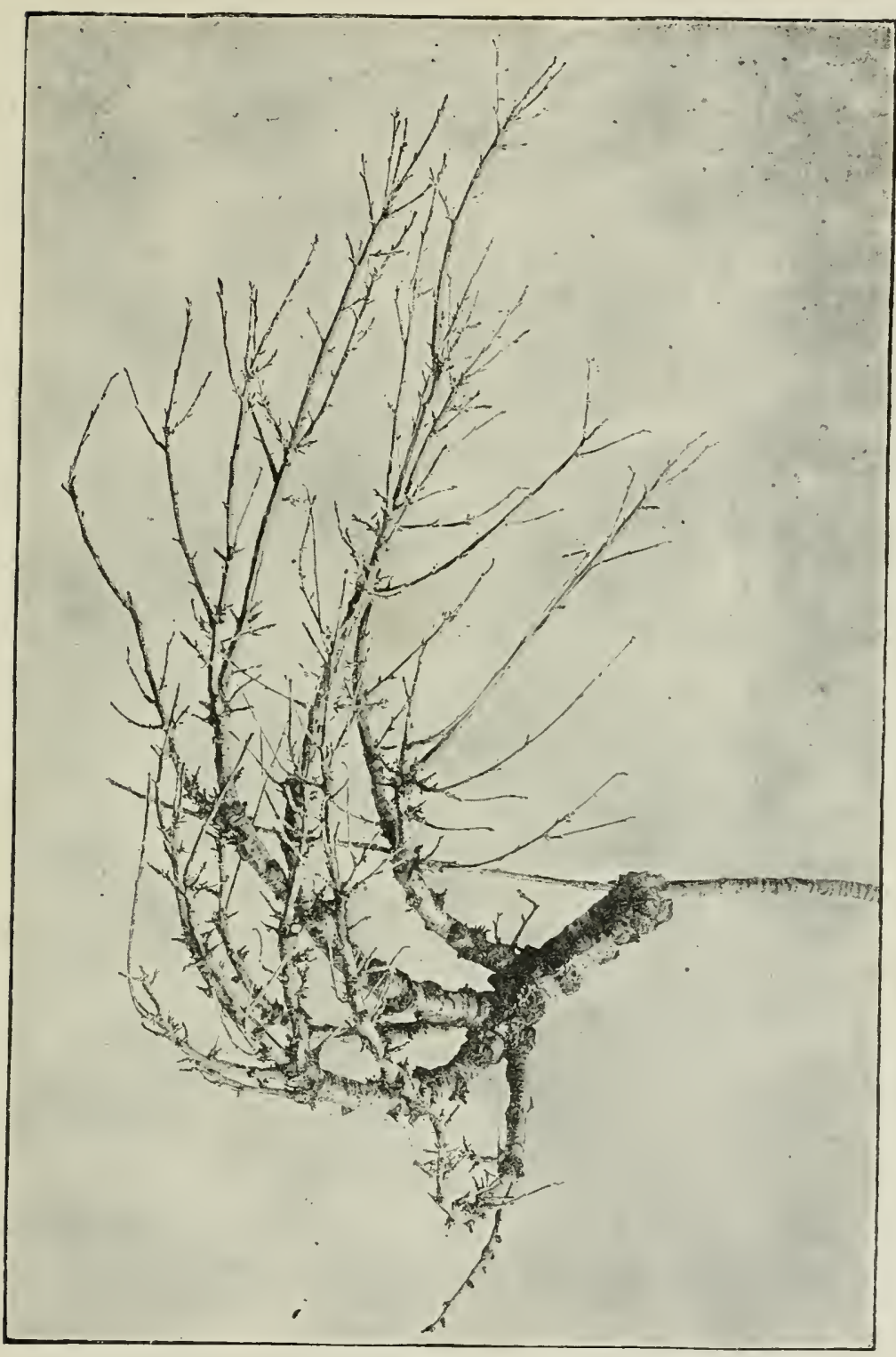

FIG. 3.-Exouscus cerasi. Witches' broom of cherry. The supporting branch is dead from its apex backwards to the seat of an infected lateral bud, which has developed into a witches' broom. On the tree the supporting branch pointed slightly more downwards than is shewn. $\frac{1}{8}$ natural sizc. (v. Tubeuf phot.) 
uscuns, which may, in addition, bring about death of the whole shoot. Needles of spruce beset by aecidia of Chrysomy.ra rhododendri are cast after reproduction of the fungus in August or September, while with Chrysomyace abretis the needles of Conifers fall in May. The latter examples differ somewhat from the former in that the mycelium lives in the witches' broom for years, and continues to send out new shoots with deformed needles, whereas in the Chrysomyxa attack the mycelium is confined to the needles and falls with them.

Examples from other groups of fungi are the witches' brooms of Alnus incana caused by Exoascus epiphyllus. The leaves of these are fully developed though somewhat modified in form; their life-period is, however, shorter than that of normal leaves, and they fall earlier. It may be observed here that this phenomenon of. premature defoliation is one recorded as a consequent of many parasites. The witches' broom twigs of the alder grow and produce buds almost normally, yet the whole broom-system dies in a few years, and long before the normal life-period of the tree.

The war of extermination by mycelium against host-plant may frequently last for a very long time. Hartig gives an example of a larch which had carried on the combat with the larch-canker (Pcsiza Willkommii) for over eighty years, because during active vegetation of the host the parasite was mable to make headway.

\section{. D. Premature Developient of Buds.}

The unfolding of buds in spring in advance of those of normal plants is also a feature of many diseased plants. This is manifest in the earlier unfolding of buds on witches' brooms of the silver fir and cherry. The alder witches' broom, already referred to, is however exceptional, in that its buds open after those of normal twigs. ${ }^{1}$

A premature Howering may also result, so that flower-buls formed in summer unfold the same autumn instead of during the following spring. Thus in a recent autumn a violet opened in a plot in the garden of Professor Hartig in Munich. The flower was found to be somewhat stunted, and its stalk beset

\footnotetext{
'Smith, "Untersuchungen d. Anat. u. Morph. der durch Exoasceen verusachten deformationen." Inaug. Diss. Muuich, 1894, p. 16.
} 
by pustules of Uroeystis violac, the mycelium of which had perennated in the stem. Kerner in his "Pflanzen-leben" 1 mentions a similar case where flowers of Primula clusiana and P. minima attacked by Uromyes primulae integrifolice unfolded prematurely in autumn.

\section{E. Preservation of the Host-Plant and of Host-Tissues.}

(Conservation.)

In contrast to those parasites which attack a plant, or parts of it, and immediately kill it or otherwise exert a direct destructive influence, we have these which live for a longer or shorter period with their host without producing such an effect. Cohabitation of this kind may last only for a short time and terminate with the first reproductive period of the fungus, or it may last for years as a perennating symbiosis, or as a perpetual one like that of lichens.

This phenomenon is particularly conspicuons amongst the Uredineae. These throughout their whole development adapt themselves to an existence with living host-cells, so that the latter die only after the reproduction of the fungus. Freqnently the mycelium lives in peremnial organs for a length of time, even for many years. The attacked parts are of course injured to a certain extent, and hypertrophy of the most varied kind, accompanied by characteristic phenomena, may take place, yet this only towards the termination of the period of development.

The Ustilagineae are in a similar manner adapted to an existence in living organs, and there produce their spores. At the time of spore-formation and liberation they are deadly enemies of their host-tissues, yet previous to this they vegetate in the living tissues with little or no apparent injurious effect. Some like Ustilago perennans, even pass the winter in the living hosttissue without killing it.

The individual species of the Hysteriaceae, Discomycetes, Pyrenomycetes, Hymenonycetes, and lower fungi differ very much in their action; many of them inhabit living tissues for a length of time withont injurious effect, while not a few, like the Exoasceae, even peremnate from year to year. The galls produced as a result of Exobasidium do not die till the fungus has reproduced itself. It is unnecessary at this place to give details

${ }^{1}$ English Edition, Natural History of Plants (Oliver), Ir., p. 525. 
of other examples, since many of these will be referred to again in other chapters, particularly when hypertrophy is under consideration.

\section{\$5. EFFECT OE PARASITIC FUNGI ON THE FORM OF THE HOST-PLANT.}

1. Arrest of growth, and Atrophy. While a large number of fungi produce more or less extensive enlargement of parts of their host, others cause arrest of organs, crippling, imporerished

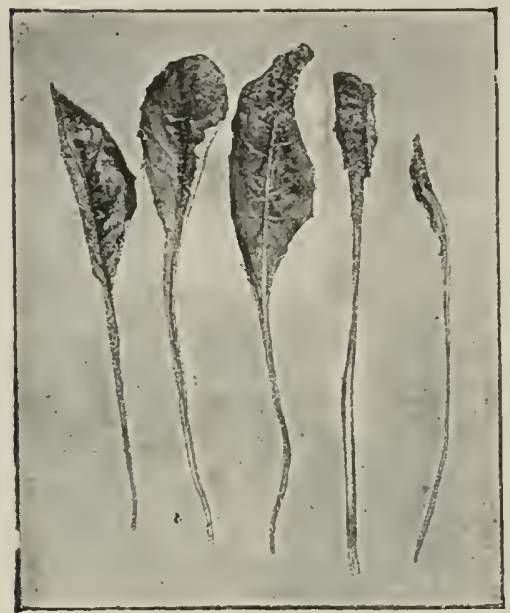

Frg.4.-Synchytrium taraxaci. Partial atroply of laminae of Taraxacum opicinale. About natural size. (v. Tubeuf phot.) nutrition, and even atrophy of an extreme kind. Incompletely developed organs of this kind may originate even where the fungus in possession produces only local hypertrophy. Interesting examples are presented by many species of Synchytrium (e.g. S. tarexacum and S. anemones). The former is endophytic in Tarcuscum, and exerts a stimulus resulting in increased growth, not limited to the single cell attacked, but extending to neighbouring cells, which, in consequence, multiply and form a ring-like swelling round it. The leaves as a whole, however, are poorly developed, so that the lamina in very extreme cases may be represented only by the midrib and narrow margin (Fig. 4); while on leaves attacked on one side, that side alone is stunted, the other is normal. Taraxacum leaves badly attacked by Puccinin are not at all deformed, whereas those of Ancmone show striking arrest of growth (Fig. 190). Leaves of Cirsium attacked by Puccinio sucteolons exhibit an arrest of the same kind, remaining less divided and of softer texture (Fig. 186).

Flowers affected by parasitic fungi present many striking malformations. Magnus ${ }^{1}$ describes such a case in Ancmone

1 Magnus, "Einfiuss v. Parasiten auf d. Ausbildung d. befallenen Pflanzentheiles." Naturu iss. Rundschau, 1891, No. 25. 
ranunculoides under the influence of Accidium punctatum. In the simpler cases the floral leaves were narrow, elongated, and greenish, stamens were formed but not carpels; in more pronounced cases, the petals were only represented as small, simple,

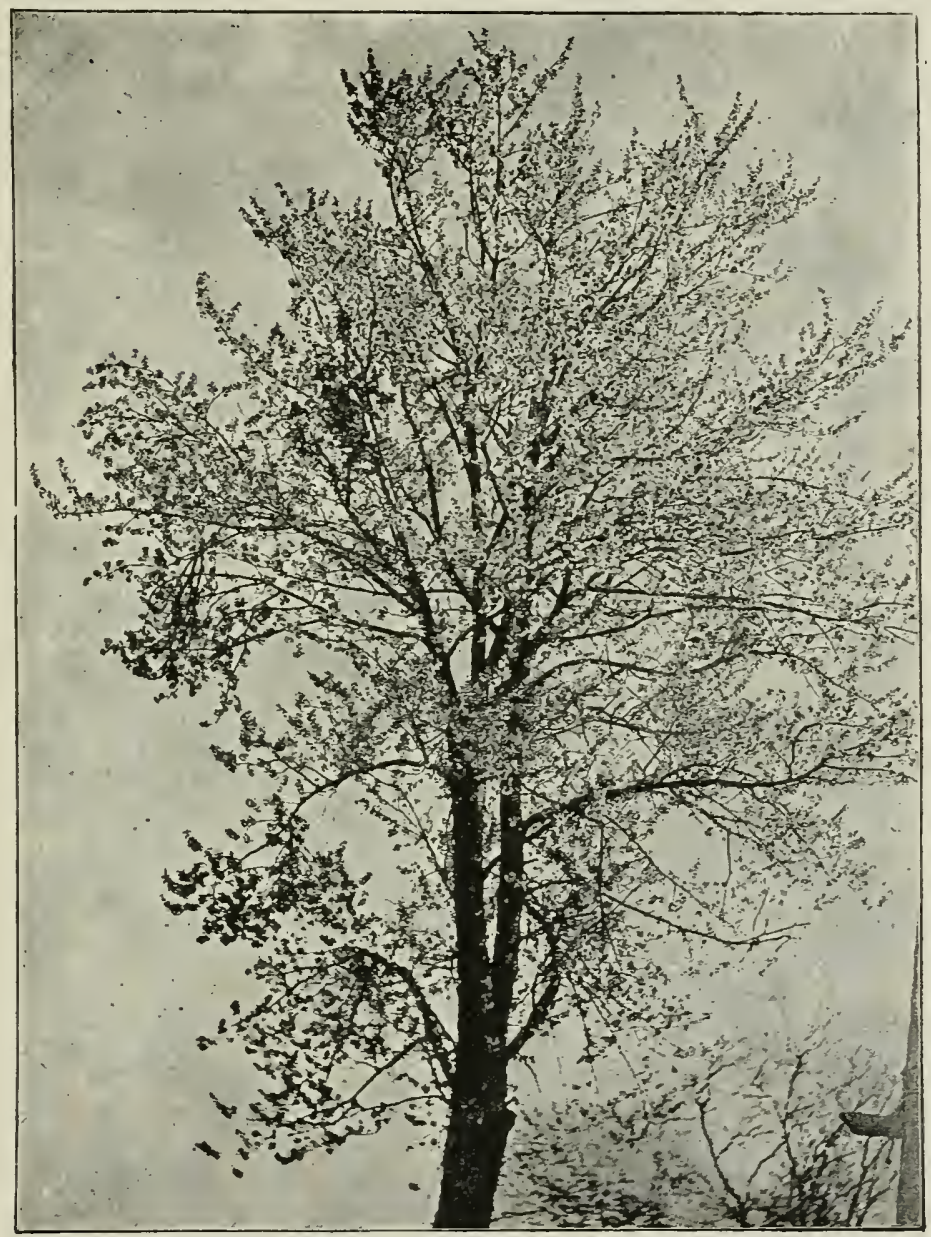

Fig. 5.-Cherry tree in blossom, with three "witches" brooms" in foliage. (v. Tubeuf phot.)

stalked, green leaves, the stamens were reduced in number and there were no carpels. One case exhibited, in place of a flower, only two leaflets terminating the flower-peduncle, one of them palmately divided. 
True atrophy is best seen in those cases where flower-formation is suppressed. This effect of parasitic fungi on their host is by no means uncommon, the fungus alone reproducing itself, while the assimilating host-plant remains sterile. This atrophy is found not only in amnual plants, but also in those where the symbiosis might be designated as perennial. The last-mentioned case is exemplified in Accidium clatinum, the witehes' broom of which never bears flowers; again, by witches' brooms of Esocescus

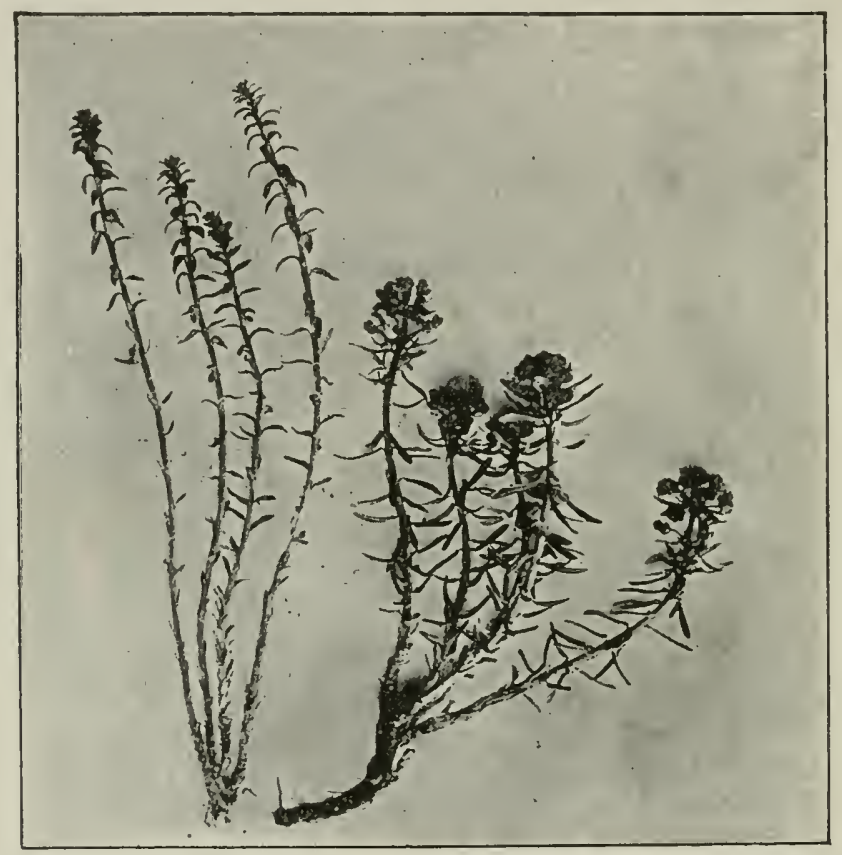

FIG. 6.-Euphorbia Cyparissias. A healthy flowering uormal plant compared with the attenuated non-flowering form inhabited by Aecidium euphorbice. (v. Tubeuf phat.)

cercesi (Fig. 5), which bears only leaves when the rest of the tree is in blossom. Another perennial symbiosis behaving thus is shown in Euphorbin Cyparissices attacked by Accidium euphorbiac; year after year the diseased shoots produce only leaves, which assist in the reproduction of the fungus (Fig. 6). Similarly with many other Uredineae.

Arrest of the seed occurs in ovaries of species of Prumus under the influence of Exocsci (Fig. 7). In flowers attacked by Cystopus 
the ovules become atrophied, whereas the rest of the flower is hypertrophied. Similarly with flowers of cowberry deformed by Exobasidium.

2. Hypertrophy.-Many parasitie fungi cause abnormal enlargement or other malformation of plants which they attack. The simplest ease of hypertrophy is seen in the enlargement of a unicellular plant as a result of an endophytic parasite, $\ell . g$. Pilobolus Kleinii with Pleotrachelus.

The same example is also the simplest possible ease of a gall caused by a plant, and distingruished by the name of "fungusgalls" or Myeocecidia, from Zoocecidia, the galls caused by animals. Larger galls oceu on leaves attacked by Synchytrium, where not only the single cell attacked

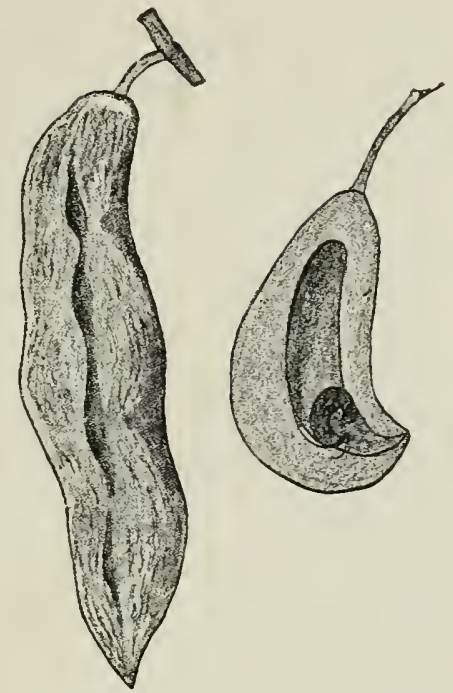

FIG, 7-Fruit of plum deformed by Exoascus pruni; the stone is shrivelled and abortive. $\frac{4}{5}$ natural size. ( $v$. Tubeuf phot.)

becomes enlarged, but also the surrounding cells; these galls, however, form but tiny points on diseased leaves. Similar small and local enlargements of the leaf-cells, accompanied frequently by cell multiplication, are caused by many other fungi, e.g. species of Exoctscus. More extensive malformation may embrace some part or even the whole leaf, so that it is more or less enlarged and beset with blister-like outgrowths, as with other Exoasceae (see Figs. 62 and 64). Other gall-forms are presented by Exobasidium on the alpine-rose (Fig. 259), where the gall is always localized to a small area of the leaf, and on the cowberry, where the gall may extend over whole leaves, and even include the shoot (Fig. 256).

Hypertrophy of the whole shoot, resulting in elongation and thickening of the twigs, is a phenomenon frequently met with in the "witches' brooms," to be referred to later. And just as entire branch-systems may become hypertrophied and elongated, so may whole plants, if the mycelium, instead of remaining localized, spreads throughout the plant. Examples of this will 
be described when we consider Euphortin with Ascidium enphorbiuc (Fig. 6), house-leek with Endophyllum, anemone with Accitium (Fig. 190), and cowberry with Culyptosporre (Fig. 202). Where plants, like the cowberry and anemone, live in communities, then these elongated individuals rise above their healthy neighbours, and the fructifying fungus las a better chance of having its spores distributed by wind. It must, however, be observed that when liypertrophy of a whole shoot or plant occurs, every part need not be enlarged to a proportionate extent; in fact some parts generally remain abnormally small, c.y. leaves in cases of rusts upon cowberry, fir, anemone, and others. On the other hand, both shoots and leaves may be abnormally enlarged, as in cases of alder with Exoascus Tosquinetii or E's: epiplyyllus. ${ }^{1}$

Hypertrophy of the roots occurs on alder, where large tubers are produced by Frankia (Fig. 21). On Leguminosae, tubercles of various sizes are caused by Rhizobium (Fig. 22). linots of Juncus develop thick-lobed outgrowths as a result of Schinsice (Fig. 179). Roots of turnip infested by Plasmodiophora have irregular swellings of all sizes (Fig. 315). Mycorhiza frequently exhibit tubercles or balls formed by the massing together of very short dichotomously branched rootlets into clumps (Fig. 18). Cycad-roots, under the influence of Rhizobium and Nostoc, also exhibit hypertrophy:?

We shall now proceed to consider hypertrophy of the reproductive organs, and at the same time to notice some other changes induced in the flower by parasitic fungi.

\section{Influence of parasitic fungi on the development of reproductive organs of host-plant.}

Disease of the flower and fruit, when not caused by fungi which kill the cell, generally causes striking floral malformation. These we may group as follows:

1. Atrophy or total suppression of flowers.

2. Arrested development of flowers.

3. Development of rudimentary organs.

4. Abnormal formation of flowers.

5. Hypertrophy of parts.

6. Transformation into selerotia.

$$
{ }^{1} \text { See also } \$ 7 . \quad \text { 'Schneider, Botanical Gazetle, 1894, p. 25.5. }
$$


The two first cases have already been considered. The arrest of the flowers of anemone, as a result of Accidium punctatum, is a further example of Case 2, and at the same time exemplifies Case 4 , in that the floral leaves become green foliage leaves, though of a very stunted kind. The petals of Cruciferae hypertrophied under the influence of Cystopus candidus often become green, and at the same time much altered in shape.

A particularly interesting case is presented by the development of the stamens of the pistillate flowers of Lychnis dioica infested by the mycelium of Ustilago violacca. These stamens normally remain rudimentary, but in the diseased abnormal Howers become fully developed like those of the staminate flowers, except that the spores of the parasite replace the pollen in the anthers. Giard ${ }^{1}$ has designated this phenomenon as "castration parasitaire," and he distinguishes three modifications amongst unisexual flowers.

(a) Stamens appear in pistillate flowers ("androgene castration parasitaire "). This occurs, as already mentioned, in pistillate Howers of Lychnis dioica frequented by Ustilago.

(b) Ovaries are developed in staminate flowers ("castration thelygen"). Examples: Carex praceox with Ustilago caricis, Buchloë dactyloides with Tilletia buchloëene, and Andropogon provincialis with Ustilago andropogonis.

(c) In flowers of either sex the sexual organs of the other appear in consequence of the influence of the parasite ("amphigene castration parasitaire"). Giard compares these cases with that of the development of the organs of the latent sex in animals, c.g. of cock's feathers on an old lien, or growth of homs on castrated or "gimmer" animals. In both cases the phenomenon is due to the same cause; in the animals the organs of the latent sex appear as the result of the normal organs becoming functionless or being destroyed by castration; in the plants through stimulation of the latent rudiments by the fungus, which does not, however, cause suppression of the organs already present. In some respects the phenomenon is comparable with what happens when the terminal shoot of a tree is lost and. some neighbouring lateral shoot turns vertically upward to replace it.

The effect of fungi on the reproductive organs of plants

${ }^{1}$ Mangin and Giard, Bulletin scient. de la France et de la Belgique, 1884. 
may also be seen amongst lower cryptogamic plants, two eases of which may be mentioned here. ${ }^{1}$ Plrotruchelus fulyens, inhabiting the mycelium of P'ilobolus Klcinii, causes the formation of galls and the suppression of sporangia, while at the same time zygospores, normally rare, occur in large numbers. Likewise a species of Synecphalis parasitic in Piloblolus rrystellinus causes suppression of sporangia and stimulates formation of zygospores.

'The transformation of floral organs may resemble that observed by De Bary, in which, as a result of attack of Peronosporce violacea on Knatida arvensis, the stamens appeared in the form of violet petals. Doubling of flowers is also caused, as in Saponaria officinulis, under the influence of Ustilago saponariae, and Compositae with Peronosporce ratii.

The Ustilagineae, perhaps, canse the greatest amount of variation on the flower, because many of them produce their spores in the floral organs of their host. Thus, in the anthers live Ustilago violacea, holostei, seabiosae, intermedia, succisae, betonicae, major, scorzoncree, capcusis, pinguicolae, Vaillantii, and Tuburcinia primulicole; the last named also occurs in ovaries and stigma. So also do many others inhabit the ovary or some other part. Many, like Ustilayo maydis, form spores throughout the plant as well as in the flower, and bring about hypertrophy and destruction of parts. Amongst these are Ustilago arenae, perennans, hordci, nuela, tritici, panici miliacei, reitiana, cruenta, sorghi, Crameri, carieis, trayopogonis, Tilletia lacris, ete.

Cystopus (Fig. 35) causes very characteristic hypertrophy of all parts of the flower, particularly an enormons outgrowth of the ovaries and floral envelopes, whereas other parts are. arrested in their growth. Wakker investigated a number of Cruciferae with flowers deformed by this parasite, and found variations in the form and anatomy of the deformations produced on the different host-species.

Exobasidium also causes well-marked hypertrophy of Howers, and even of the whole inflorescence of cowberry. Woronin ${ }^{2}$ deseribes and figures such cases (Fïg. 256). All parts of the flower may be attacked and grow to a great size, becoming

'\%opf., Beiträge zur Physiol. und Morph. niederer Oryanismen, 1592.

Zopf., "zur Kenutniss d. Infections-Krankheiten nied. Thiere u. Pflanzen." Nowa Acta d. k. Leop.Carol. D. Akad. Halle., 18s8, p. 356.

2 Naturforsch. Gesellschaft Freiburg-i.-B., 1867. 
at the same time fleshy and of a bright rose-red colour; the ovules are sterile or abnormally formed. Wakker, however, found no very marked change in the anatomical structure of such flowers.

The species of the Exoasceae also produce striking hypertrophy of flowers. Thus there are the sac-like outgrowths of the catkin-scales or ovaries of poplar caused by Taphrina Johansonii and T. rhizophore (Fig. 52), and the "pocket-plums" or "fools" due to Exoascus pruni (Figs. 49 and 51). In these lastmentioned cases, the outer layers of the ovary become thick and fleshy, sometimes remaining green, while the stone and kernel remain rudimentary. The alder, under the influence of Exoascus alni incunae, has the catkin-scales much enlarged, deprived of chlorophyll, and of a red colour (Fig. 53).

Mummification, or the transformation of the fruit into a fungal resting-body or sclerotium, is not unfrequent. In some respects this process resembles the change in ovaries brought about by Ustilagineae. Here, however, we have to do neither with hypertrophy of the fruit, nor yet with its complete destruction. The best-known sclerotimn is that of Clcoviceps purpurea (Fig. 84). It first fills up the base of the ovary, then kills it and grows out as a large horn-like sclerotium. The sclerotium of the oak (Sclcrotinia Batschiana) completely replaces the acorn, leaving only the outer covering enclosing it. Likewise, in the mummified berries of bilberry, cowberry, crowberry, cranberry, and others, one finds the normal parts almost wholly replaced by the resting-mycelium of some species of Sclcrotinic.

\section{Formation of new Organs.}

Although parasitic fungi commonly induce hypertrophy of existent organs and development of normal latent structures, they are seldom associated with formation of new organs. As such, however, we must regard the formation of adventitions buds on the fronds of Pteris quadriaurita, Retz, and Aspidium aristatum, Sw., under the influence of Taphrinn Laurcncia, and T. Cornu cervi, respectively. ${ }^{I}$ Buds or bulbils of this kind occur normally on several species of ferns; but in those just mentioned they appear only as a result of the parasite, and develop into structures reminding one of a witches' broom.

\footnotetext{
${ }^{1}$ Giesenhagen, Flora, 1592.
} 
Still more striking are certain structures resembling witches' brooms, which are produced on Thujopsis dolcubrata in Japan, under the influence of the mycelium of Cucomu leformens (Fig. 8). These consist of leatless non-chlorophyllous axes, dichotomously branched, and with each branch ending in a disc. They arise from shoots or leaves of the Thujopsis where structures of the kind would never have arisen normally, and are wholly subservient to the reproduction of the fungus, which forms its sori mder the epidermis of the terminal dises.

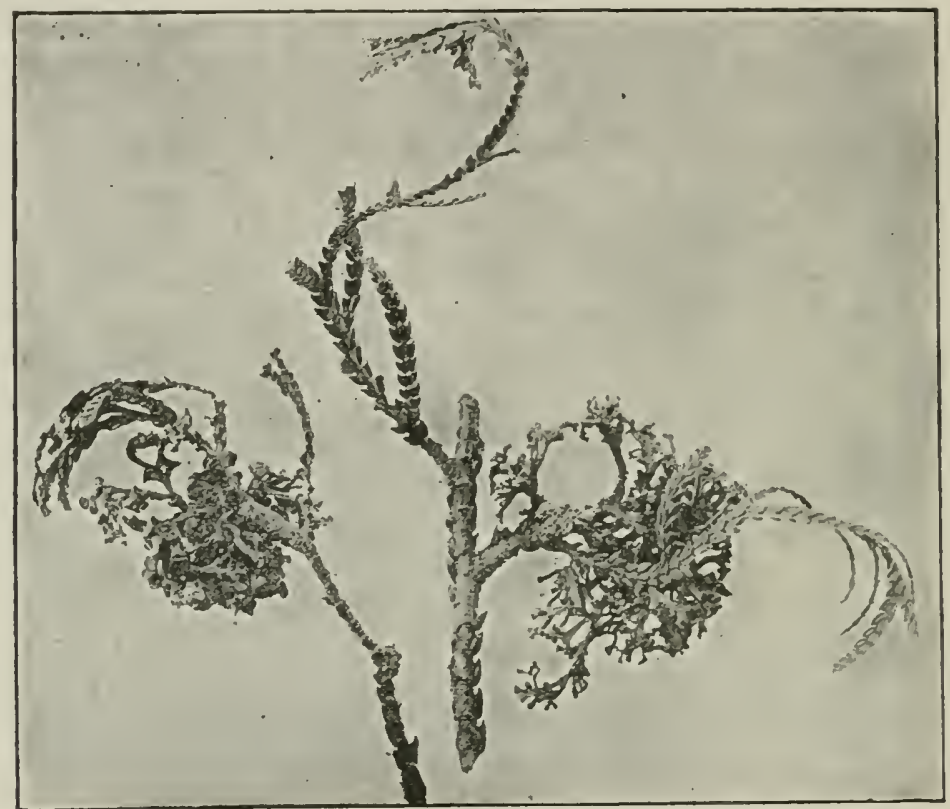

FIG. 8. Cacona deformans. The nest-like structures are much-branched, leafless shoots with each of their twigs ending in a caeoma-disc. ( $\nabla$. Tubeuf phot.)

The galls produced by Ustilrego Tireubii on Polygonum Succhalinense are particularly interesting. Here, as a result of the presence of the parasite, there are formed the so-called vegetative canker-galls, and in addition, the fruit-galls, new organs lerived from lateral outgrowths of the host-plant, and of use only in the spore-formation of the Ustilago; they contain a special capillitium-like tissue, and serve exclusively for the shelter and distribution of the fungus-spores. 
Somewhat doubtful cases are the outgrowths resembling aerial roots which arise on Laurus cunariensis attacked by Exobcsidium lauri. Geyler, their discoverer, regarded them as deformed stemshoots, but they resemble ratler the galls of the alpine-rose.

\section{\$6. EFFECT OF PARASITIC FUNGI ON CELL-CONTENTS.}

The most common and, at the same time, most apparent effect of parasitic fungi in this direction, is the stimulation to cell-division and cell-multiplication. This occurs chiefly in young tissues, or in those still in process of growth, and gives rise to numerous peculiar outgrowths and swellings, some of which have already been referred to.

The parenchyma of mature tissues may also exhibit secondary cell-division, when under the influence of a parasitic fungus. This I found to be the case in leafpetioles of Umbellifera attacked by Protomyces macrosporus (Fig. 9). The epidermis and rascular bundles are nerer disturbed, but the intervening tissues are permeated by an intercellular mycelium, which causes the cells to divide into a large number of delicate-walled chambers, all containing nuclei smaller than those of neighbouring undivided cells. The same thing is observed in plauts of Viola odorecta inhabited by Urocystis

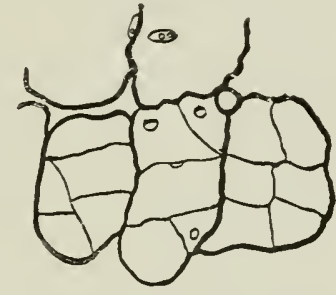

FIG. 9.-Secondars ccll-division in parenchyma of petiole of $A \in y 0$ podium as a result of Protonyces inaciosporis. The nuclei of the new cells are much smaller than those of the primary cell. (Compare Fig. 4 i.) (v. Tubeuf del.)

violac; the mature parenchymatous cells become divided up by means of delicate walls running in various directions into numerous chanbers or secondary cells, which Wakker in describing has named "nutritive tissue."1 This new tissue remains permanently in attacks of Protomyces, but with Urocystis it is almost completely used up during the formation of spores. In some diseases caused by Exoasceae, a similar secondary cell-division takes place; for example, in the subepidermal parenclyma of leaves of poplar with Taphrina aurece (Fig. 63).

An interesting observation was made by Rosen ${ }^{2}$ on the direct

\footnotetext{
1 Wakker, "Untersuchungen." Pringsheim's Jahrbuch, 1892.

${ }^{2}$ Rosen, Beiträge z. Kenntnisss d. Pflanzenzelle. Habil.-Schrift, 1592.
} 
effect of haustoria of Ureclineae on the cell-nucleus. He describes it thus: "The mycelium of I'recinia ascrina permeates letween the cells of the leaf-tissue of $A$ sarum, and sends into almost every cell of the infected part, a short, sometimes branched, hypha, which serves as a haustorium. This grows in almost every case towards the mucleus of the host-cell, and becomes firmly attaiched thereto, or completely encloses it. The nucleus, in consequence, undergoes considerable deformation, sometimes being tightly constricted by the haustorium, or the apex of the hypha penetrates deep into the nucleus, pushing the nuclear membrane before it."

Enlarcement of the cell-nucleus occurs, according to Frank, in the cells of the root-tubercles of Leguminosae caused by bacteria; likewise in the cells of endotrophic mycorhiza of orchicls. Schlicht, ${ }^{1}$ in considering the endotrophic mycorhiza of Paris quadrifolia, says, "One observes here, as in the mycorhiza of the Orchideae, that the cell-nucleus, which is very large, can exist in the cell beside the fungus-tissue. The hyphae, however, frequently penetrate into the cell-nucleus, or surround it in a close network." 2

The effect of parasitic fungi on the chlorophyll of tissues attacked by them is very varied. We may distinguish three cases, apart from those in which the parasite kills the host-cell and its chlorophyll along with it. In the first, the green parts of the plant attacked become bleached by the influence of the parasite, and ultimately lose their green colour; this we might designate "mycetogenous chlorosis." Examples are the galls of cowberry and species of rhododendron, the results of many Uredineae, such as Chrysomyua rhododendri on spruce, Accidium urticae on nettle, Gymmosporangium clarariaeforme on hawthorn, and the leaf-galls due to Exoasceae.

In the second case, there is a preservation of the chlorophyll in places infested by the fungus, in contrast to adjoining normal

\footnotetext{
${ }^{1}$ Schlicht. "Beitrïge z. Kenntniss d. Verbreitung u. Bedeutung d. My"corhizen." lnaug. Diss. 1859, p. 14.

2 Croom ("Thismin Aseroe and its Mycorhiza," Annals of Botany, June, 1895, p. 339) describes and figures a similar case. He says, "The fungus enters the cell as a single slenler hypha, which at once grows directly towards the nuclens of the host-cell." He also mentions an ohservation of Professor" MIarshall Ward, "that in Hemileic of the coffee clisease, the haustoria oftell apply themselves to the nuclei of the host's cells." (Edit.).
} 
parts, which become pale and die. This is exemplified in Cronartium asclepiadcum on the leaves of Vincetoxium, Gymnosporangium clavariaeforme on the quince, Uneinula aceris on the Norway maple, Rhytisma punctatum on Acer spicutum.

Intermediate between these two extremes are cases where the chlorophyll is retained, but in much reduced quantity. For example, organs under the influence of Exocscus alni incance or Accidium clatinum, though still green, are pale in contrast to those normally deep green; leaves attacked by Peronosporeae, c.\%. Corydatis or Anemone with Plesmopore pygnece, and Anemone with Accidium punctatum or Prccinia fusce; leaves of Cirsium containing mycelium of Puccinic succcolens; leaves of alder with Erocscus epiphyllus, and many others. This paler colouration of diseased plants is frequently an easy means of recognizing them amongst the healthy ones.

The third case is that of "mycetogenous chloranthy" or the development of green colour in organs normally of some other colour. Wakker has proved this in the petals and stamens of Bressice nigra and Sisymbrium pannonicum attacked by Cystopus and Peronospora. Likewise Magnus showed its existence in flowers of Anemone ranunculoides with Accidium punctatum.

The cell-sap, in some cases of hypertrophy, assumes on the sumny side a rose colour; thus in galls caused by Exobasidium on alpine-rose and cowberry, pear-leaves with Roestelic canccllatu and Polystigma rubrum, catkins of alder attacked by Exocrscus, and galls caused by Taphrinc carnce on the sweet birch. The epidermal galls, due to some species of Synchytrium (S. rubrocinctum, $S$. anemones, etc.), exhibit an intense carmine coloui. Yellow coloration occurs, according to Wakker, in nettle, buckthorn, and many plants when frequented by Uredineale. There may also be a yellow colour due to the yellow oily contents of the mycelium shining through the host-tissues, as in spruceneedles with Chrysomyxa abietis.

In considering the effect of parasitic fungi on the starchcontents of the host-plant, two very distinct cases may be observed. There may be, for a time, a greater accumulation of starch in the attacked parts than in the normal, or the parasite may dissolve any starch present and utilize it at once. 
Accumulation of starch is described by R. Hartigg ${ }^{1}$ in spruceneedles attacked by Lophordermium macrosporum. In the presence of the fungus-mycelium, an increased production and storage of starch takes place at a time when it is being only slowly formed in normal needles. If the needles become diseased during May, a season when they are already full of starch, this remains intact in the dead cells till October, when it begins to be used up.

Wakker observed accumulation of starch in comfrey with Accitium usperifolii, in buckthorn with Accictium rhamni, in hawthorn with Roestelia lacerata, in Sisymbrium officinale and other plants with Cystopus, in roots of Brassica inhabited by Plasmodiophora brassicae, and in hypertrophied scales of alder catkins with Exouscus. Many other examples are given throughout the literature of plant-pathology.

Particularly noteworthy is a case of starch preservation in oak-wood destroyed by Polyporus dryadeus and P. igniarius

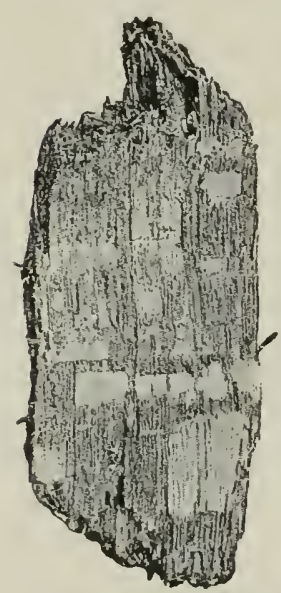

Fic. 10.-Medullary rays of oak-wood destroyed by Polyporcae. The cells are still full of undissolved starch, hence appear white. (v. Tubeuf phot) simultaneously. ${ }^{2}$ In the wood infested by either of the fungi alone the starch is dissolved, but at the boundary where the two meet it remains in the medullary rays; these, in consequence, appear snowy white, and consist almost exclusively of unchanged starch-grains, while the lignified cell-walls have been converted into cellulose or completely absorbed (Fig. 10). Loew ${ }^{3}$ remarks in regard to this: "One must assume here a variation in the kinds of diastase, and a neutralizing effect of the one on the other, in somewhat the same manner as pepsin acts on tyrosin. One is also reminded of two optical antipodes which easily unite into an optically neutral body" (c.y. sugar isomers).

The dissolution of starch by fungi has been examined in cletail by Hartig. The wood-destroying fungi dissolve the reserve starch-grains laid up in the wood-parenchyma in various ways. Assuming the view of Naegeli, that starch-grains consist of a

I Wichtige Krankheiten d. Waldbäumen, 1874.

? R. Hartig, Zersetzunyserscheinunyen, $187 \mathrm{~S}$.

${ }^{3}$ Loew, O., Lin naturliches System d. Gift-Wirkungen. Munich, 1893. 
cellulose and a granulose part, Hartig describes the process thus (Fig. 11). The mycelium of species like Polyporus igniarius gives off some ferment which dissolves the starch-grains, by corroding them from the outside inwards, so as to form holes and canals similar to those in starch-grains in process of dissolution in the cells of a sprouting potatu. In others, '.y. Thelephore perclie, the gramulose is first dissolver from without inwards, so that finally only the starch-cellulose remains, occupying a region towards the outer parts of the grain as a kind of husk,
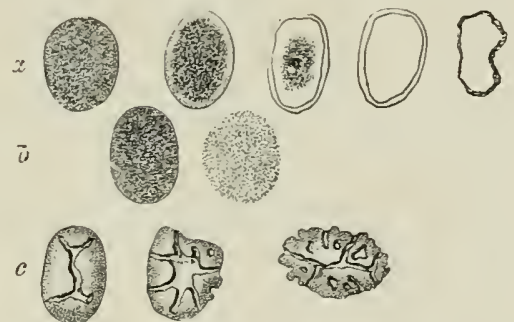

FIG. 11.-Starch grains from the oak, in process of dissolution by ferments, $t$, of Thelephore perdic; b, of Polyporus sulphureus; $c$, of Polypross ignicrius. In $a$ and $b$ the iodine-reaction is shown by shading. (After R. Hartig.) which is in time gradually used up. In Polyporus sulphureus the operation is reversed; the starch-cellulose appears to be dissolved out first, leaving a residue of gramulose. These observations were based on the assumption that the starch-grain consisted of a granulose portion which turned blue with iodine, and a starchcellulose portion which became yellow; or again, on treating the starch-rrains with dilute acids the granulose was dissolved, while the cellulose remained in the form of a skeleton. Although mole recent investigations have shown that the cellulose-skeleton results from the action of the acids, and that this view of the constitution of the starch-grain was not quite correct, yet Hartig's observations prove that the various fungusferments have each their own action on starch-grains; his results are also supported by other facts.

Other fungi besides Polyporeae utilize the starch of their host-plants, thus Phytophthora in leaves of the potato.

The formation of calcinn oxalate is influenced by action of parasites. From Wakker's synopsis of the phenomena of hypertrophy, we find that calcium oxalate normally present in crystalsacs in leaves and flowers of Rhommus Frongula, is wanting in parts deformed by Accidium rhomni; crystal-sacs are less abundant in diseased stems than in healthy; the calcium oxalate in galls of Erobesidium is not present in crystal-sacs, as in the mon-deformed organs, but as ill-defined solitary crystals of limited 
number: on the other hand, crystal-sacs, normally absent, are, under the influence of Exoascus almi incrnae, formed in hypertropliied catkin-scales of alder.

It may he here observed that calcium oxalate crystals are fomnd in the mycelimm of many fungi. De Pary ${ }^{1}$ found them very common, particularly. in the mycelium of species of botrytis, and he remarks therenn: "it may well be assumed that the oxalic acid is formed from the sugar inside the living oxygen-absurbing fungus-cell, but is immediately ejected therefrom by the carbon dioxide produced in respiration ; in other words, an oxidation-fermentation takes place in the plasma of the mycelimm. The oxalic ncid is probably separated in combination with potassium and converted into calcium oxalate, when calcium is present in the pabulun of the myelium."

\section{\$. EFEECT OF PARASITIC FUNGI ON THE CELL-WALL.}

The effect of the mycelial hyphae of parasitic fungi on the cell-wall may be either mechanical or chemical. The intracellular hyphae of fungi and the apices of the haustoria of intercellular fungi must penetrate through the cell-walls of their host, either of the epidermis, or the membranes of other cells, consisting of cellulose alone, or in some state of lignification. ${ }^{2}$

The membranes may be simply pricked, as by a fine needle, so that the opening, because of the elasticity of the cellulose, closes up again after the perforating hypha has died. This is the case with many Uredineae. In such cases the hypha is constricted in passing through the cell-wall and swells out again in the free cell-cavity. Frequently, as in the case of Pronospore donsa, the hanstorium will only cause a depression in the membrane of the cell without penetrating it.

In addition to purely mechanical perforation of the membrane, the effect of the hyphae may also be a chemical one, so that the wall is dissolved and the holes produced remain long after the hyphae which made them have disappeared. This solvent effect is probably always present in cases where perforation of lignified membranes takes place. It is a constant

${ }^{1}$ De Bary. Botan. Zeitun!, 1856.

2De Bary. Bioloyy and Morphology of the Fungi. English Fdition.

H. M. Ward. "On a lily-disease," Amnals of Botany, Isss.

Miyoshi. "Die Durchbohrung v. Memlranen durch Pilze." Pringsheim s Jahrbuch, Vol. 28, 1595 . 
accompaniment of the attacks of wood-destroying fungi on the wooly parts of trees and shrubs. Besides actual perforation of the lignified membranes of their host, the liyphae of many of the Polyporeae and Agaricini exert a solvent effect on the walls, which extends over a considerable area, and is evidently due to the excretion of some ferment. The dissolution of the walls takes place, moreover, in a way so characteristic for each species of fungus that they can be determined by it alone. Fron this it must be deduced that each wood-destroying fungus excretes a ferment peculiar to itsclf, which causes a characteristic dissolution of the host. Our present sources of information on these points are the very valuable investigations of Professor Pobert Hartig of Munich. ${ }^{1}$ Some of his results will repay our careful consicleration, but we must preface brietly some facts regarding the process of lignification and the formation of heart-wood in our forest-trees.

The elements of the wood of dicotyledonous trees and woody plants are derived from the cambium; their walls consist at first of pure cellulose, and when lignification takes place the so-called incrusting substances are laid down in the thickened cellulose wall, particularly coniferin, vanillin, wood-gum, tamnin, etc.; or as they may be collectively called, lignin. The cellulose membrane itself is coloured lilac with chlor-zinc-iodine; when lignified it no longer shows this reaction, but has others peculiar to itself, the best known being red coloration on treatment with phloroglucin and liydrochloric acid, or yellow coloration with aniline sulphate: chlor-zinc-iodine colours lignified tissues brownish-yellow. Copper-ammonium-hydrate dissolves cellulose but not wood. ${ }^{2}$ If the incrusting substances be removed from the lignified membranes by treatment with Schulze's solntion, caustic soda, or other solvent, the cellulose remains and reacts as such. In the process of conversion of alburnum into dura-

1 The most important of these works are:

Die Zersetzungserscheinungen $d$. IIolzes, $d$. Nadelhälzer $u$. d. Eiche. With 21 coloured plates. Springer, Berlin, 1578.

Der echte Hausschucamm, Merulius lachrymans, 1555.

Wichtige Krankheiten $d$. Waldbëume, 1874.

Lehrbuch d. Baumkrankheiten, I. and II. Edition, 1882 and 1859. English translation of II. Edit. by Prof. WV. Somerville.

Lehrbuch $d$. Anatomie u. Physiologie d. Pficusen, 1891.

${ }^{2}$ For further reactions see:

Zimmermann. Die botanische Wicrotechnik. 1592.

strasburger. Das botanische Praktikum, 1S57. English Edition, 1889. 
men other substances make their appearance in the lignified walls, chiefly tinctorial phlobaphenes.

The walls of the wood-elements are, howerer, not lignified to the same extent. The primary layer of the wall is, as at rule, lignified most and contains but little cellulose. In conseruence, on treatment with lignin-solvents, it becomes first dissolved while the secondary and tertiary memloranes, althongh their lignin is also partially dissolved ont, remain behind as at distinct framework of cellulose. With longer treatment destruction of the tissue proceerls till only the pure cellulose membranes of the isolated cells remain. The ferments of many fungi act in this way; for example Trametes pini, as shown in Fin. 12; at $a$ the wall is in its normal condition, showing a prinary

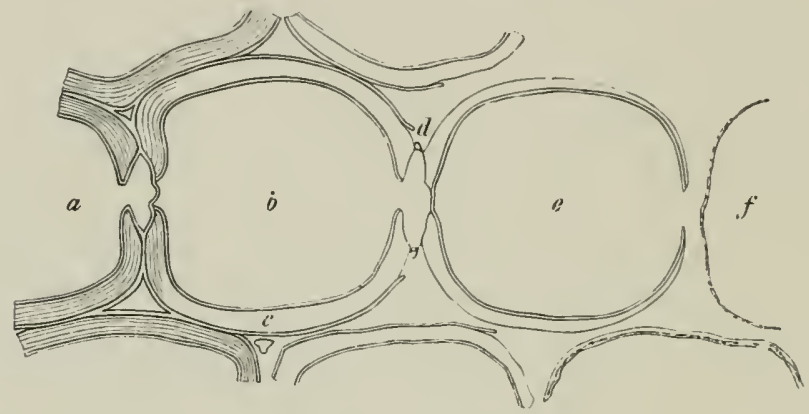

Fic. 12. - Section of tracheides of pine-wood in process of dissolution by the ferment of Trametes pini. 100. (After R. Hartig.)

wall and two striated secondary membranes; at $b$ the fungusferment has caused a splitting of the primary wall, which formerly appeared as a single layer, and the elements are separating from each other; the "filling-material" of the intercellular spaces (under $r$ ), and the ring of lime surrounding the eavity of the pit $d$, remain for a longer time; the right wall of the cell $b$ consists only of cellulose, (as indicated by the striation being no longer shown, although still present); in the cell " the primary wall has disappeared, and the secondary and tertiary membranes thin off towards $f$ in which only the ash constituents remain as fine granules, better seen in Fig. 13.

In contrast to the lignin-dissolving fungi, there are those which dissolve cellulose. When wood is treated with sulphuric 
acid the cellulose is dissolved out, and the primary wall remains almost intact, while the secondary after swelling is converted into sugar and gum. Certain fungi (e.y. Polyporus vaporarines, P. Schweinitzii and $P$. sulphureus), act in the same manner, first dissolving out and consuming the cellulose before attacking the wood-gum. When wood is destroyed by fungi of this

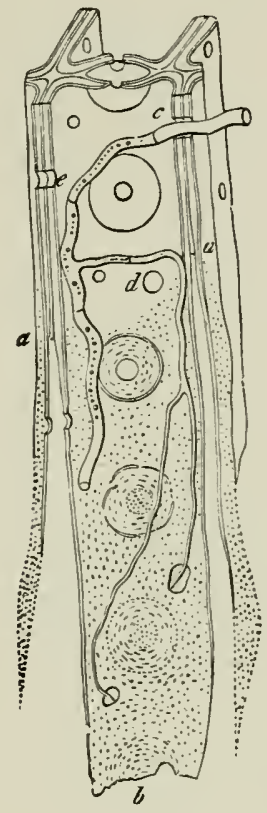

FIG. 13 .

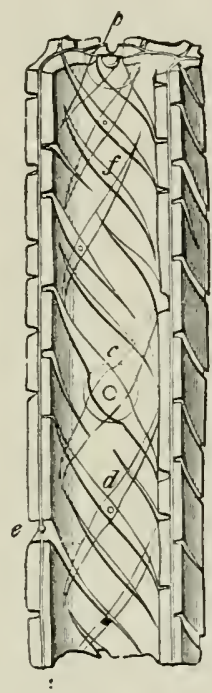

FIG, 14 .

F16. 13. - Tracheid of Pinus sylrestris destroyed by Trametes pini. The primary cell-w,Il is completely dissolved from below upwards to $a, a ; b$, secondary and tertiary layers of the walls consisting in the under portion of cellulose onls, in which granules of chalk are recognizable; $c$, fungus-hsphae boring through the walls, leaving holes $d$ and $e$. (After R. Hartig.)

F1c. 14.-Tracheid of Pinus destroyed by Polyporus Schweinitzii. The cellulose has been extracted, and the wall consists only of wood.gum. The fissures are a result of drying-11p, but they do not extend into the primary wall $a, b$. Crossing of the fissures takes place at the bordered pits $c$, and at the bore-holes $d$ and $e$; $j$, simple fissures. (After R. Hartig.)

kind, the primary wall, containing but little cellulose, is hardly affected, and the secondary membranes shrink together, so that numerous fissures are produced rumning in a spiral direction, corresponding with that of the stratification (Figs. 13 and 14.) The tertiary membrane varies in its nature; it may consist of pure cellulose or be more or less lignified, or even cuticularized. In the wood-fibres of some plants (Cytisus, Humulus, this 
layer beeomes normally loosened from the other membranes, and appears as a separate tube in the eavity of the fibre.

Variations of this kind in the structure of the wood must of course influence the action of the attacking fungus. The decay maty be a local one, as with Trametes pini, $T$. radiciperdu, Thelephore perdix, which cause destruction of isolated spots only and produce holes here and there throughout the wood. () 11 the other hand, the wood may be uniformly converted into a discoloured decayed mass. The walls may he simply piereed by little holes colresponding to the perforating hypha, or large portions of them may be more or less eompletely dissolved away, and either the cellulose or lignin remain behind as a slieleton. Hartig gives an interesting case which accompanies chry-rot (Mcrulius lacrymans); the mycelium adherent to the cell-walls dissolves out the lime granules included in the membranes by the excretion of some fluid containing carbonic (or other weak) aeid, in much the same way as roots corrode limestone.

The dissolution of starch in wood has already been considered.

In conclusion should be mentioned Hartig's observation that normal spruce wood, on treatment with ferric chloride, the reagent for tannin, gives 110 coloration, such as is given by the same wood when destroyed by dry-rot.

\section{§ 8. EFFECTS OF PARASITIC FUNGI ON THE ANATOMICAL STRUCTURE OF THEIR HOSTS.}

Effects of this kind ean only be looked for where morphological changes have resulted from the presence of parasitic fungi, particularly in the case of hypertrophied organs. Wakker was the first to colleet recorded evidence of anatomical changes due to hypertrophy; he added to these by his own investiqations, and classified the results. We shall therefore in this division depend chiefly on his publications.

Enlargement of host-cells is one of the most frequent pheno. mena accompanying attacks of parasitic fungi. It may take place with both intracellular and extracellular parasites.

A single cell hypertrophied in this way is the simplest possible form of a "fungus-gall" (see p. 25). Examples of 
simple galls of this kind are cells of Pilobulus Klcinii inhabited by Pleotrachclus fulgens, cells of turnip infested by Plasmodiophora, or of dandelion with Synchytrium.

Cell-enlargement resulting from the influence of extracellular parasites is most distinctly seen in those algal cells, which form lichens with the hyphae of certain fungi. Thus according to Stahl, the algal cells of the lichen Endocarpon pusillum become enlarged six-fold.

Cell-enlargement accompanies all hypertrophy of plant organs, whether the parasite lives purely intercellular, or has haustoria. At the same time one generally finds a disappearance of the intercellular spaces present in the normal tissues; in some special cases, however, these may become more numerous and larger. Cell-enlargement, accompanied by disappearance of normal intercellular spaces and chlorophyll, are shown by Woronin's illustrations to be very marked in the galls on cowberry, che to Exobasitium vacinii. Cell-enlargement is also frequent in cases of hypertrophy due to Exoasceae; thus in Trphrina aurce, although the mycelium is only subcuticular or penetrates but slightly into the epidermal layer, yet the cells are much enlarged and their walls are strikingly thickened (Fig. 63). Smith ${ }^{1}$ found that when leaves became thickened in consequence of attacks of certain species of Taphrina, their cells became larger and rounder, so that the large intercellular spaces of the spongy parenchyma disappeared and the characteristic appearance of that tissue was lost.

The epidermis, as has already been indicated, is influenced by fungi which live between the cuticle and cell-wall, as well as by epiphytic fungi, whose haustoria penetrate it. The epidermis is, however, more frequently destroyed by endophytes, which rupture it in forming their reproductive organs. Some of these produce their sporocarps inside the epidermal cells, and, as they enlarge, cause detachment of the outer walls of the cells from the remainder, to form for a time a covering which is ultimately ruptured as the sporocarps attain maturity. Where the fungi live under the cuticle (c\%. the Exoasceae), this alone is ruptured when the asci are formed. The repro-

IWilliam G. Smith. "Untersuchung d. Morphologie n. Anatomie d. dureh Exoasceen verursachten Deformationen." Inaug. Dissertation, Munich, 1894; also, Forstlich-naturviss. Zeilschrift, 1894. 
duetive mycelium of the following forms also grows only uncter the cuticle: lihytisma andromedec, the spermogonial nycelium of Precinia anemones, Phregmidium, and other Uredineae.

In many cases of hypertrophy the epidermal cells become enlarged in a radiul direetion, and this, as in Taphrina aurea, may be accompanied by considerable thickening of the walls. In other cases, like that produced by Synchytrium, the epidermal cells may beeome gelatinous.

- The cork beeomes abnormally inereased in many examples of hypertrophy. Thus in witehes' broom of alder due to Eroascus "piphyllu.s a phellodern is formed, while on normal twigs phellem alone is produced. Cork is found in juniper needles with Crymnosporanyium juniperinum, though never in the nornal ncedles. On the other hand, cork-formation is suppressed in twigs of hawthorn, deformed by Rocsteliu lucerata. The so-called "woundcork" is constantly associated with attacks of parasitic fungi; it separates diseased portions of rind and bast from sound, forms sheaths round bundles of selerenchyma, and permeates the medullary rays.

Collenchyma was found by Wakker to be absent in all eases of hypertrophy of parts of plunts where it is normally present; for example, in stems and petioles of cowberry attacked by Exobasidium, stems of buckthorn with Accidium rhumni, of Crataegus with Roestelia lacerete, of nettle with Accidium urticae, and of Senunzisorbia with Xenoctochess carbonarius. On stalks of Unbelliferae with pustules of Protomyees, I found, where the collenchyma region was involved, that that tissne was not developed (Fig. 46).

In all cases of hypertrophy, parenehyma plays an important part. Most abnormal outgrowths result from multiplication and enlargement of the cells of the parenchyma, the formation of mechanieal tissues being more or less suppressed. Thus the gigantic examples of hypertrophy exhibited by turnips infested by Plasmodiophore, consist almost exclusively of parenchyma. Thickening of stems or branches is generally due to increase of the rind-parenchyma, as in buekthorn under influence of Aceidium rhamni, hawthorn with Gymnosporangium clarericueforme, in most witches' brooms, and in many other cases. In 
the witehes' brooms due to Accidium flatimum, the pith appears enlarged as the result of increase of the medullary parenchyma. In diseased leaves, palisade parenchyma can frequently no longer be distinguished from spongy, and only irregular polygonal cells are formed. As examples may be given needles of fir with Accidium abietinum, and leaves with galls due to Exonsceae. Finally, there may be a marked increase of wood-parenchyma, both of medullary rays and the wool proper; this is especially well marked in Juniperus communis affected by Gymnosporangium. juniperinum, ${ }^{1}$ where in consequence of an enormons inerease of the parenchyma of rind and nuedullary rays, the tracheidal regions become separated by broad wedge-shaped rays, and at the same time they are peripherally intersected by bands of parenchymatous tissue resulting from increased development of the wood-parenchyma (Fig. 220, etc.).

The Sclerenchyma is generally suppressed where hypertrophy oceurs. Examples mentioned by Wakker are stems of cowberry with Erobasidium, of hawthorn with Gymnosporanyium, of Sanguisorbia with Xenodochus, and alder catkin-scales with Exoascus. On the other hand, sclerenchyma is developed in stems of Cirsium as a result of Puccinia suarcolens, whereas normally it is absent.

The secondary vessels of the wood frequently remain irregular, and with imperfectly absorbed partition-walls. According to Wakker, this is the case in Vaccinium with Exobasidium, Cratacgus with Rostclia, and Rhamnus with Accidium.

Suppression of interfascicular eambium. was observed by Wakker in buckthorn and nettle with their respective Accidium parasites. Prolonged activity of the same tissue he found in Sisymbrium with Cystopus.

Arrest of lignification was found by Wakker in medullary rays of Cratargus with Roestclia, and in deformed seales of alder catkins affected by Exocseus.

We have already considered increased growth in length and thickness in connection with hypertrophy. It need only be added that increased thickness of woody plants may be due to increase of the rind, the bast, the pitl, or medullary rays, and not

\footnotetext{
${ }^{1} \mathrm{P}$. Wörnle. "Anatomische Untersuchung d. dnrch Gymnosporangium-Arten hervorgerufenen Missbillungen." Inaug. Diss., Mumchen, 1894; also, For naturwis.s. Zeit.schrift, 1894.
} 
to increase in the actual wood elements. This is the case in twigs of silver fir witches' brooms, in young swellings of juniper attacked by Gymmosporanginm, and in the thickened twigs of Albiwire resulting from Uromyces Tepperiunus (Fig. 181). There may be, however, a distinctly increased growth of the woorl. Thus, with attacks of Gymnosporangim frequenting jumiper, especially $C_{r}$. sabinat, there is often a marked thickening of branches due to increase in the xylem-clements. Again, one tiucls cankers due to Accilium clatinum, accompanied by stenswellings with a diameter twice or three times that of the nomal, and in which the bark and bast form but a thin layer in proportion to the part made up by the wood. Exceptionally striking are the gigantic woody knots formed on the Japanese
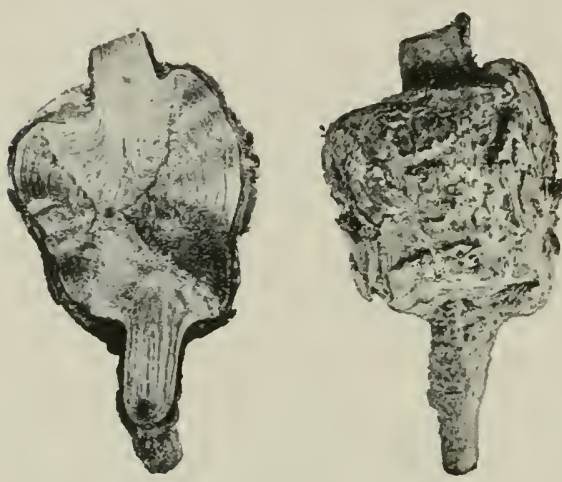

Fuci. 15.-Wood-swelling on Pinus clensifloru, attacked at this place by Periderinium gigantewm. $\frac{1}{2}$ natural size. (v. Tubeuf phot.)

(On Pinus Thunbergiistill larger examples may occur.)

Pinus densiftora, and $P$. Thunbergii affected by Peridermixm giganteum (Fig. 15).

Wakker found that mucilage canals of Rhrmmus: Frangula affected by Accidium were not so well developed as in normal twigs.

Resin-canals are often irregularly formed and abnormally multiplied in consequence of parasites. The resin-canals of the spruce were found by Hartig to be so numerous in plants attacked by Aycricus melleus that an abnormal quantity of resin is produced in the wood, and Hows from the diseased roots; hence has arisen the name "resin-glut" or "resin-flux" by which the disease has long been known. A particularly noticeable thux of resin takes place from pine-bark in presence of Peridermium pini; the mycelium grows in the medullary rays and resincanals, causing an exeretion of resin from all living parenchyma in the wood, so that both bast and wood become completely impregnated with resin, and thin sections of wood transmit a rose-coloured light. 


\section{CHAP'TER III. \\ RELATION OF PARASITE TO SUBSTRATUM.}

\section{§ 9. EFFECT OF THE SUBSTRATUM ON THE DEVELOPMENT OF THE PARASITE.}

A Numper of parasitic fungi live only on one species of host. For example Sclerotinia baccarum on Vaccinium Myptillus, Chrysomyxa abretis on Picen excelse, Triphragmium ulmariae on Spiraec ulmaria, Hysterium nerrisequium on Abies pectinata, Rhytisma andromedue on Andromeda polifolia. De Bary ${ }^{1}$ proposed for cases like this the term monoxeny, while to cases in which a parasite frequents sereral different species of host he gave the name polyxeny, or more particularly, dixeny, trixeny, etc. As examples of polyxeny may be mentioned Rhytisma sulicinum found on all species of willow, and Rhytisma accinum on the genus Acer. Other parasites attack not only different species of some genus, but also different genera; thus, Pucinia graminis occurs on varions cereals and grasses, Phytophthora onnivore on many different plants, Phyllactiniu suffulta on leaves of Corylus, Feggus, and many other trees; Claviceps purpurea on a large number of cereals and grasses, Cystopus cundidus on many Cruciferae, and Nectria cinnaberina on all kinds of broad-leaved trees.

Monoxeny and polyxeny must be carefully distinguished from the antoecism and heteroecism of the Uredineae. Many species of this group go through their whole life-history, and produce all their forms of spore on the same host, others, however, produce some forms of spore-spermatia and aecidiospores-on one host, and the remainder-uredospores and telentospores-on

\footnotetext{
${ }^{1}$ Botanische Ztitung, 1867, p. 264.
} 
another host. Such heteroecious parasites may be, however, also monoxenous; for example, Mclampsore Groppertiance has its telentosporeform only on the cowberry, its aecidium-form only on the silver fir. On the other hand, Chrysinnym rhododcndiri frequents several species of lilurlodendron, while the aecidia occur only on Pieca siselsa ; Cronutium usclepialem comes on both Gentiane and Cynanchum, the aecidial stage only on Pinus sylvestris. With Gymnosporangium clnouriacforme this conclition is reversed, the teleutospore-form occurs only on . Fniperus communis, the aecidial on various species of Craturgus and other genera.

The effect of various substrata on the development of any fungus may be most conveniently investigated: ( $(i)$ on facultative parasites and saprophytes, $(b)$ on polyxenous species of fungi, $(c)$ in cases where the fungus inhabits essentially different orgaus or tissues of the same host.

The most obvious effect of the substratum is presented during the germination of spores. The spores of most parasites germinate in water. Those of certain smut-fungi, especially in the fresh condition, will not germinate at all, or only to a very limited extent in water, whereas they will do so immediately and unanimously on being offered a nutritive solution. Tilletia, a genus of Ustilagineae, behaves, however, in quite the reverse way, it germinates only in water, and refuses to do so in nutritive solutions. Hartig found that the spores of dry-rot (Mcrulius) would neither germinate in water nor in the usual mutritive solutions, but that they did so at once on adding alkalies to the water, such as those supplied by addition of urine. Very characteristic is the behaviour of these spores, which only germinate in contact with their host-plants, like many Chytridieae ${ }^{1}$ (Synchytrium), as well as Completorir and Protomyces. ${ }^{2}$ Others again send out germ-tubes which remain small and soon die away if an immediate opportunity of penetration into a host is not presented. De Bary states this to be the case with swarm-spores of Cystopus, Peronospora nivea, Erysipheae, ete. Amongst the Uredineat, the germ-tubes are short-lived; they will penetrate into almost any

${ }^{1}$ De Bary, Morpholoyy and Biology of the Fungi, chap. vir.

"An exactly parallel case is presented by the seed of Orobancheae, which germinate ouly in contact with the roots of their host (Koch's "Orobanchen," Heidelberg, 1857). 
host, but soon die off, if it be not a suitable one. De Bary also observed a germ-tube of Peronosporce pygmaca, which frequents Anemone, making its way into Renunculus Fieuria, but soon to die. Germinating spores of C'ystopus candidus will enter the stomata on leaves of any of their host-plants, especially C'ipsella, but will only develop further if they are successful in penetrating into the cotyledons.

Variation in the substratum produces very great difference in the formation of the reproductive organs. Thus many Ustilagineae produce conidia by continuous sprouting only when cultivated in nutritive solutions, while their resting-spores are developed only from a mycelium which inhabits the reproductive organs of their host; this is the case with Ustilago earicis, $U$. enthecerum, and $U$.tritici. In others the spores are found in all parts of the Hower, and even in the inflorescence, as in Ustilayo eruente and U. tragopogonis, while in Ustileno maydis spores are also produced in leaves and stems.

The various parts of the same plant behave very differently in this respect. The Ustilagineae just considered reproduce themselves only on certain organs of their host, although the mycelium is also present in other organs. Other fungi behaving similarly are Epichloë typhinn which produces its perithecia only on the surface of the sheath of one of the leaves just below the inflorescence; Accidium clatinum develops its aecidia only on the needles of the witches' broom; Aceidium euphorbice has its aecidia only on the leaves of its host; Extocescus pruni has asci only on the fruit; Calyptospora produces teleutospores in the epidermal cells of the stem, never of the leaves; and so on in many other cases.

The formation of oogonia of Cystopes exhibits a striking variation according to the host-plant. C'ystopus cendidus on Capselle produces conidia alone, never oogonia; yet the latter are plentifully cleveloped in flowers of Brassica, being confined, however, to the flowers, while conidia are produced in all parts. Cystopu. bliti forms conidia only in the leaves, and oogonia only in the stems of Amaranthus blitum. ${ }^{1}$

The mycelium of many other fungi can only grow in certain organs, while germ-tubes from the spores are only able to penetrate into certain parts of the host. Thus, Eronseus alni ineanae

${ }^{1}$ De Bary, Morphology and Biology of the Fungi, English Edition, p. 391. 
has a myeelium only in catkin-scales; boosews pruni, however, hibernates in the twigs, and forms reproductive organs only in the walls of the ovary; Accidium strobilinum grows only on the cone-scales of spruce; Cluviceps frequents only the young ovaries of cereals and grasses; and so on, other fungi inhabit only leaf, stem, root, or Hower.

In this connection points of considerable interest are presented by the behaviour of many Uredineae hitherto little investigated. As was pointed out by De Bary, the germ-tubes produced from both uredospores and aecidiospores (in Pucriniu diunthi those from sporidia also), penetrate into the stonata of any phanerogamous plant. If, however, that should not be a host-plant of the fungus in question, then the germ-tubes die away in the stomatal air-carity. If the host suits the fungus only in a limited degree, then no hypertrophy will result, and the latter will attain only to the formation of spermogonia. Let the host, however, be the one best suited to the fungus, then hypertrophy will result and aecidia be developed. Very conclusive evidence of this interesting condition has been fumished by numerous experiments which I have carried ont with spores of Gymnosporangium. ${ }^{1}$ If one infects Cratacgus Oxyacantha with G. clavariaforme, very marked stem-hypertrophy results, even ly the time the spermogonia have made their. appearance; there is also considerable swelling of leaves and slight enlargement of cotyledons, while aecidia are produced in numbers everywhere. When the same fungus is used to infect Pyrus Aucuparia, no yellow spots or malformation of any kind results, and spermogonia, hardly visible with a lens, are formed only here and there. A similar infection on Pyrus latifolia ( ${ }^{\prime}$. Aria $\times$ torminalis) results in a crop of bally developed aecilia. If quince be infected, then without any hypertrophy whatever, little red spots bearing numerous spermogonia are formed on the leaves, but the development of the fungus ceases there; on the death of the quince leaves, the chlorophyll is retained in the immediate neighbourhood of the spermogonial spots, so that they remain for some time as green islands on the yellow leaf. R. Hartig's infections with Mclampsora tremulae also led to raried results; on Pinus there ensued a distinct disease of the cortex (Cacoma pinitorquum),

1 v. Tubeuf, Centralblatt $f$. Bacteriologic u. Parasitenkunde, 1591. 
while on Larix only little cushions appeared on the needles (Cacoma laricis).

These variations in the effect of the substratum on the development and reproduction of the parasites assist us to understand the well-known resistance of certain varieties and species against epidemic diseases, which are sweeping off their near allies. Thus, we know that some varieties of cereals suffer from attacks of rust-fungi more than others grown under like conditions. Similarly amongst the varieties of vine some are known to be more sensitive to disease than others. These points will be more fully discussed in a subsequent chapter. 


\section{CHAPTER IV.}

\section{NATURAL AND ARTIFICIAL INFECTION.}

$\$ 10$. In artificial infection we have a safe mode of distinguishing whether a fungus is parasitic or not; in other words, whether it is capable of penetrating into the organs of living plants. This method of investigation should always be resorted to in determining the cause of disease, more especially if mycelium or sporocarps of several fungi are present on the diseased material simultaneously. For it not unfrequently happens that the disease has made so much progress as to make it quite impossible to determine whether or not any fungi present on the dead remains are really the cause of disease. In many cases where one finds a mycelium in living parts, it has disappeared, and only sporocarps remain in portions already killed.

Injuries due to insects frequently accompany fungi on a diseased plant, so that it is extremely difficult to say which was the primary cause of the damage, and artificial infection must be resorted to. So also with injuries from some external source like drought, heat, cold, moisture, and mechanical causes. Fungi appear so soon after hurtful agents like these, that it becomes doubtful whether they are the cause of the death of the host, or the result of it.

Minute observations in situ of all the circumstances connected with the attack, combined with examination of numerous specimens and comparison with neighbouring plants, enable one, after some experience, to say with a fair degree of certainty, whether the disease in question is of fungoid origin or not. 
The exact proof, however, is best obtained by means of experimental infection.

With many parasites the sporocarps are normally developed saprophytically on a dead substratum, so that if parasitisin be suspected it can only be proved by infection. Thus the perithecia of Nectria cinnabarina develop only after the death of the plant-organ, which the fungus attacked when alive. The more complex reproductive organs of many fungi are developed only on dead remains of the host, while on living or dying parts one finds various forms of conidia of doubtful relationship. In many cases it has been possible, by means of artificial culture alone, or combined with artificial infection, to prove varions forms of reproductive organs to be stages in the life of the same fungus.

When a group of fungi contains both saprophytes and parasites, it is often necessary to determine whether some species is parasitic or purely saprophytic. This is particularly the case with the groups of Pyrenomycetes, Discomycetes, Hymenomycetes, several groups of the lower Fungi, the Bacteria, and Myxomycetes. It is unnecessary, however, with the Uredineae, Ustilagineae, Peronosporeae, Exoasceae, and other groups known to contain parasites exclusively.

But even in these last-mentioned groups experimental infection is necessary for obtaining information on other points. The reproductive organs of Uredineae cannot be reared in artificial solutions, so that their cultivation must be carried out on the living host-plant. In this way alone can we ascertain the relationship of uredospores, teleutospores, and aecidial-forms, where any doubt occurs as to their belonging to the same species. Infection becomes particularly valuable when one has to investigate heteroecions Uredineae, whose various forms of reproductive organs inhabit several host-plants. Thus it was by means of infection that De Bary discovered the connection of Accidium berberidis on the barberry, and Puceinia graminis on cereals; likewise Hartig, the relationship of Mclampsorc Goeppertiance on cowberry with Aceidium columnare on needles of silver fir. There still remain many aecidia, telentospores, and uredospores, whose related forms have not yet been found.

Infections are also necessary to deternine the species of a fungus. It has been found, for example, that Gymnosporangium 
confusum and $G$. sabinne may, in their aecidial stage, be distinguished as two species inhabiting distinct hosts-Crataegus and Pyrus respeetively - whereas, in their telentospore stage on juniper, they scarcely vary. In infection we have an important aid in determining the host-plants of the varions forms of heteroecions fungi, and in this way it has been found that the same fungus behaves differently according to the host-plant on which it is present. Thus, in the genus Gymnosporangium, I have found that a certain species had well-developed aecidia on one plant, poorly developed ones on another, while on a third only spermogonia appeared. Similarly, in that case alrearly mentioned, Hartig found the Melampsore of the aspen to produce on the pine a disease of the cortex, accompanied by marked deformation, while on the larch the symptoms were mere inconspicuous aecidia on the needles.

Amungst the Ustilagineae, experimental infection is necessary to determine whether the natural infection of host-plants results from germinating spores (chlamydospores), or from germinating conidia (sporidia). Kuihn was able by this means to demonstrate exactly that the spores of Ustilagineae produced germ-tubes capable of direct infection. Brefeld succeeded in observing the penetration of germinating sporidia into a host-plant. In this way he proved, amongst other facts, that maize may be attacked by Ustilago maydis on any young part; also, that the mycelium remained local. Oats, on the other hand, could only be infected by Ustilago avenae at the neck of the young seedling, and the mycelium extended through the plant till it reached the inflorescence, where the spores are formed.

In the case of the Exoasceae, two points were cleared by the aid of artificial infection - the penetration of spores into leaves of host-plants, and the production of witches' brooms. Sadebeck, ${ }^{1}$ by means of infections of Exoascus cpiphyllus on Alnus incana, has produced witches' brooms artificially, thus proving that these malformations really originated from the mycelium of Exoascus.

It is by infection-experiments that one determines into which part of a host the germ-tubes penetrate, whether into leaf, flower, fruit, stem, or root, and also whether it passes through the epidermis, or between two adjacent epidermal cells, or through

\footnotetext{
${ }^{1}$ Kritische. Untersuchungen über d. durch Taphrina herrorgebrachten Baumkrankheiten, 1890.
} 
the stomata. Also, whether the germ-tube formed from a germinating spore penetrates direct, or if, as shown by De Bary for Sclerotinia, a mycelium vigorous enough to penetrate must first be developed saprophytically.

In this comection De Bary ${ }^{1}$ states that the germ-tubes from all aecidiospores and uredospores only penetrate by stomata, and thence extend through the intercellular spaces. Entry through the stomata has also been observed on the germ-tubes from sporidia of Leptopuccinia dianthi, and from spores of Entyloma. On the other hand, germ-tubes from the spores of teleutospores, from spores of Peronosporeae, Ustilagineae, Sclerotinia, Polystigna, Protomyces, and Synchytrium effeet an entrance through the onter cell-walls into the epidernal cells or stomatal gnard-cells. De Bary also deseribes the peeuliar behaviour of zoospores of Cystopus and Peronospora umbelliferarum, which, if they come to rest near a stoma, germinate, and the germ-tube enters therein, whereas one developed in water soon dies. Certain fungi penetrate sometimes through the niembrane, sometimes by a stoma, e.g.Phytophthora infestans, Peronospora parasitica, Exobasidium vaccinii.

In the case of Phytophthora omnivora, Hartig found that the germ-tubes from the zoospores crept along the surface of the leaf till they reached a place where two epidermal cells adjoined; there they entered, and only rarely grow into the epidermal cells. The gernu-tubes of Protomyces macrosporus and Tuburcinia trientalis enter their hosts in the same way.

From experiments, one is able to determine the conditions favourable, or otherwise, to infection by parasitic fungi; to ascertain the influence of temperature, air-moisture, water-conteut of the host, hairiness of the leaves, and the effect of resin or other excretions as protections to wounds. For example, it was in this way that Hartig found Salix pulchre (mruinosa $\times$ daphnoides) to be a hybrid which, on account of its hairy leaves, is more resistant to Mclampsora than Salix pruinosa. ${ }^{2}$ Much investigation remains yet to be clone in this direction to ascertain what varieties or species of cultivated plants are likely to be least liable to attack by epidenic diseases. ${ }^{3}$

The methods used in carrying out artificial infection are based on the observation of cases of natural infection. Most frequently infection is performed by means of spores, less often with mycelium.

The spores of lower forms of fungi are generally distributed by means of water, especially in dew or rain. Zoospores are

1 Morphology and Biology of the Fungi, English Edition, pp. 361-362.

"Hartig, Diseases of Trees, English Edition, 1894, p. 171.

3See Chapter v. on "Disposition." 
completely adapted for distribution in water. Amongst the higher fungi, spore-distribution almost always takes place by means of wind. Insects as agents are rare, although one does occasionally find special adaptations intended to secure their visits. The spores of many fungi are forcibly ejected from the sporocarps, asci, or sporangia; some of the many arrangements which ensure this will be given in the special part of this book, others will be found in the works of Zopf, ${ }^{1}$ and De Bary. ${ }^{2}$ Ludwig, in his text-book, ${ }^{3}$ points out that the spores of many Ustilagineae frequenting entomophilous flowers, are provided with ridges and spines, which are probably an adaptation to their transportation by insects; smooth-coated spores are more common on leaves, stems, and organs other than the flower, and are evidently distributed by the agency of wind.

The mode of distribution and infection is quite apparent in many fungi. Thus in the oat-smut (Ustilago arence), the diseased ears in a field rise above the sound, so that the light dusty spores are shaken out in clonds by the slightest wind; they hibernate on the earth or on straw, and germinate in spring to infect the oat-seedlings at the base of the stem. Equally simple is the distribution of spores and conidia from one plant to another by wind during summer. Good examples of this mode are the conidia of the Erysipheae, and the aecidiospores and uredospores of the Uredineae. Thus, the yellow spores of Chrysomyra rhododcndri, when the aecidia are present in very large numbers on the needles of spruce, may cause the phenomenon known as "sulphur-rain." It is well known that this is generally due to the yellow pollen of conifers caught and carried to the ground in showers of rain, but R. Hartig describes a case observed by him near Achen-see (Tyrol), where objects were covered by a yellow dust, consisting exclusively of spores of Chrysomyea. Spores of this kind are capable of transport to very great distances, so that heteroecious species can still keep up their connection even though by no means near each other.

Aecidiospores of all kinds are distributed more by wind than by insects. In rare cases, however, the aecidia have a sweet floral

${ }^{1}$ Zopf, Die Pilse, 1s90, p. 349.

'De Bary, Morpholo!ny and Biology of the Fungi, English Edition, 1S57.

${ }^{3}$ Lehrbuch d. niederen Kryplogamen, e.g. p. 370. 
odour, e.g. Aec. odoratum in America. The wind we must also regard as the distributor of uredospores and of the sporidia of germinating teleutospores. The Uredineae have typical spores for distribution by wind with the exception of the so-called spermogonia. These structures are produced by most Uredineae, generally on the upper surface of the leaf and before the aecidia; they are brightly coloured, and give out spermatia in a sticky gelatinous slime, frequently with a clistinct odour. Thus they seem to be admirably adapted to transport by insects, and are in fact visited by them. Their distribution, however, has little importance, since they are, as far as known, incapable of germination. They are regarded by many as degenerate forms, either of male sexual organs, or of pycnidia. Some of the spermatia have been made to germinate in artificial culture, but of their incapacity to germinate in natural surroundings there can be no doubt. I am not aware of any one who has succeeded in bringing about infection with these spermatia, but I have tried it often with no result.

It is much more difficult to ascertain how fungi, which hibernate on the earth, find their way in spring to their respective host-plants, in some cases even to the crown of very large trees. Amongst such forms one frequently finds an arrangement by which the spores are forcibly ejaculated. Thus Rihytisma acerinum, which reaches maturity only in spring after hibernating on dead sycamore leaves, and Sclerotinia betulce, which does so on fallen fruits of birch, both have their spores forcibly ejaculated and carried off by wind. Klebahn states that the ejaculation takes place in dry weather, and that the spores of Rhytisma are prevented from drying up by a gelatinous covering. In a similar manner the hibernating spores of Erysipheae on fallen leaves must be carried up again by wind; so also those of Polystigma, which ripen on the ground and then infect young leaves of plum and cherry trees.

Infection by means of the mycelium generally occurs where the mycelium lives in the earth. Thus, the hyphae of Trametes reclieiperda grow rapidly from one root to another, causing a centrifugal spreading of the fungus, so that forests attacked by it have the trees killed off in patches. Mycelial infection is still more effective in fungi like Agarieus melleus which assume the form of rhizomorphs. Infection by means of the mycelium may 
also oecur amongst species of fungi living above ground. Thus the mycelium of Botrytis spreads from plant to plant, and on seedlings in hot-beds, may form felted masses. Similarly the mycelia of Erysipheae, of Trichosphueria, and of Herpotrichia make their way from one part of a plant to a neighbouring part in contact.

Artificial infection may be carried out by means of spores or by mycelium. In the case of swarm-spores, the operation can only be conducted in a clamp chamber and on wellmoistened leaves. Thus, young plants of beech must be well sprayed, then infected with conidia of Phytophthora omnizora, and placed under a bell-jar to prevent drying up. In this and many other similar cases one finds that while the spores require moisture to ensure germination, yet the germ-tubes easily leave the water-drops and penetrate into the leaves; in other words, the living leaf exerts a greater influence on them than the water, the chemotropic stimulus is stronger than the hydrotropic.

The spores of the lower fungi are best isolated by the airl of a lens or microscope, then washed on to the place to be infected. In the case of Ustilagineae and Uredineae the same method is used, except that dry powdery forms of spore are simply dusted on to the host-plant to be infected. When spores of Ustilagineae are being used the addition of excrement of some sort is frequently of advantage, since it promotes better germination and the formation of conidia capable of infection after it is exhausted. One must also pay attention to the fact that some smut-spores can only infect the base of the stem or parts in process of elongation, while others can only attack parts of the flowers. The teleutospores of the Uredineae must first be germinated in order to obtain the sporidia with which infection is carried out; this generally takes place in water. Thus with species of Gymnosporangium it will be found best to mix the whole gelatinous mass of teleutospores with a little water in a shallow glass dish, and to ascertain, by microscopic investigation after a few hours, whether any sporidia have been produced. If this be the case, the gelatinous mass is thoroughly broken up, more water added, and the yellowish water sprinkled over the host-plant. Care must, however, be taken that the larger portions of the teleutospore-mass are not left on the leaves, otherwise death of the latter will occur at these places without infection taking place. For a similar reason it is not 
advisable to lay portions of diseased leaves directly on healthy ones, it is much better to place them near each other in a moist chamber, hanging the former over the latter.

When infection is carried on ont-of-doors, it is best to obtain a small plant which can be accommodated under a bell-jar. If this be unattainable, it is often possible to bend one of the lower branches down to the ground or other support, so that it can be covered with a bell-jar. Again, a branch or portion of it may be first sprinkled, then bound loosely up in a parchment-paper. When carrying on infection it is of importance to avoid very hot and dry or cold days; moist, warm and cloudy days, or close still nights, will be found best. In the case of diseases of the rind, it is generally necessary to wound the periderm by a few fine knife-cuts, then to place thereon a few drops of water with infecting spores suspended in it.

Artificial infection by means of mycelium is generally attained by placing a diseased portion containing living mycelium in contact with the healthy, so that the mycelium can grow from the one to the other. Thus, with bark-diseases, a small portion of diseased rind is cut out and fitted into a corresponding incision in the rind of the plant to be infected, the oculation or graft being then protected against drying up by gutta-percha, tree-wax, or parchment. The ingrafted portion need not fit very accurately if well bound up, because the mycelium will grow well in the moist chamber so formed. The most vigorous mycelium is generally found on the boundary between healthy and diseased parts, so that portions from this region should be selected for infection.

If the fungus under investigation frequents the wood, it is, as a rule, a wound-parasite, so that for its infection the wood must be laid bare, and a diseased portion applied to it. If a branch is to be infected (e.g. with Nectria, or Cucurbitaria), then it should be cut over a bud, the exposed end split, and a fine wedge of diseased wood inserted, the whole being bound up. It is also possible to graft a diseased branch on to a healthy. In the case of stems, a portion of the healthy one should be removed, a diseased piece inserted, and the wound closed over with graftingwax or clay. Pressler's growth-borer may in such cases be used with good results to obtain a cylinder of diseased wood, and to make a suitable receptacle for it in the sound plant. 


\section{CHAPTER V.}

\section{DISPOSITION OF PLANTS TO DISEASE.}

$\S 11$. We must here distinguish between an internal or inherent disposition dependent on the constitution of the living protoplasm of the host-cells, and an external or accidental disposition arising from anatomical peculiarities or from the conditions of environment.

The condition of inherent disposition has as yet been little investigated. In many cases it must be allowed that resting cells are more disposed to disease than those in full activity of life. Thus De Bary, ${ }^{1}$ basing his conclusions on the observations of Davaine and Brefeld, points ont that various species of $M$ Hecr, Penicillium, and allied forms penetrate into ripe juicy fruits, and remarks: "Observation of the fruits shows that the fungi develop more easily, the nearer the vital powers of the plants attacked are to their lower limit, and at this point the conditions of saprophytic vegetation make their appearance." 2 Davaine also found that the regetative organs of several succulent plants show the same phenomena as the fruits. As further examples may be mentioned that fungi can frequently penetrate withering plant-organs while they could not infect the fresh living tissue. Hartig observed on Pezisc Willkommii that the mycelium of this bark-parasite advanced and killed the tissues only while the hostcells were in a condition of vegetative rest, not during their active period.

1 Morphology and Biology of the Fungi, English Edition, p. 380.

2 Wehmer (Beitrü!fe z. Kennt. einheimischer Pilze, Jena, 1595), has contributed new facts to this subject, which are referrerl to later. 
Hartig ${ }^{1}$ also found that Agaricus melleus, in penetrating into stools of oak, only killed those cells which, as it were, rested, whereas the cells of parts in communication with stool-shoots are not attacked. Likewise, Schwarz states that the mycelium of Cenangium abietis only extends through pine-shoots at a time when there is little vegetative activity.

Accidental disposition depends largely on the nature of the epidermis enclosing plant-organs. The stems of many plants are protected from intruding fungi from the time the epidermis is replaced by a corky layer, still better after a bark is formed. Hence young shoots are in a condition of greater disposition than older ones. There are, however, various grades of disposition to be observed, even when a simple epidermis forms the only covering, as is the case with most leaves, flowers, and many fruits. The newly-formed epidermis is, as a rule, most disposed while its walls are still delicate and uncuticularized, hence many organs are exposed to attacks of fungi only in their youngest condition. It is easy to infect and kill young leaves, and shoots of conifers with Botrytis Douglasii, whereas older needles will remain quite unharmed. Similarly with Chrysomyxa rhododendri on spruce-needles, Calyptospora Goeppertiana on silver fir, and others. Flowers are also more easily infected in the young stage, e.g. cones of spruce by Accidium strobilinum.

During early youth plants are insufficiently protected from great cold and dronght, and also from infection by parasitic fungi. This may be becanse the young non-cuticularized walls offer less resistance to the germ-tubes and haustoria, or because they are more permeable to any ferment excreted by the fungus. Organs developed late in the regetative season resemble those in the spring-condition in that they have not as yet matured, and are but poorly protected against extremes of temperature, or attacks of parasites.

The condition of disposition may be easily promoted for purposes of artificial infection, by cultivating the host-plants in a moist chamber, or under a bell-jar. The same condition may easily arise in glass houses or hot-beds, hence one has, by means of constant ventilation, to guard against it.

Many diseases of seedlings (e.g. Phytophthorc omnivora, and Pythium) are only to be feared so long as the stems of

${ }^{1}$ Forstl.naturuis.s. Zeitschrift, 1894. 
their hosts are unprotected by cork-formation. l'lant-organs rich in water are in a condition which disposes them to attack, much nore than irier parts. The younger parts of any plant are more lisposed than older parts. Thus in a spruce-hedge with young shouts appearing at different times, only those shoots will be liable to attack, which are young at the time of the scattering of the spores of Chrysomyia abiotis, or other spruce-fungus. De Bary was of opinion that plants of C'apsella were disposed to attacks of C'ystopus cunclidus, only as long as they retained their cotyledons, because only those spores germinating on the cotyledons form a inycelium which ultimately finds its way through the plant, whereas plants which had already lost their cotyledons at the time of infection were in no danger. Many of the Ustilagineae attack cereals only when these have just emerged from the soil, infecting the young stems on the first sheath-leaf, whereas older and more advanced individuals are exempt. While all plants with a delicate epidermis or corky layer are liable to disease, yet some are more so than others. This is exemplified by the different, powers of resistance to disease, or insect attacks exhibited by nearly allied forms of our cultivated plants, c.\%. vines; a difference probably due to some variation in their outer membranes, such as is further demonstrated by thick-skinned potatoes being more resistant to disease than thin-skinned.

Disposition is often due to external circumstances. These, however, act rather in presenting favourable opportunities for infection by germinating spores, than by directly disposing the plant to disease. Thus prolonged wetting of a leaf from rain favours germination of spores, and at the same time by softening the leaf, facilitates penetration of the germ-tubes. Stahl ${ }^{1}$ has pointed out that leaves on which water remains for any length of time, present greater opportunity for growth of saprophytic epiphytes or for infection by parasites, than leaves with a smooth surface or of a shape which facilitates ready escape of water from their surface. It is also well known that larehes in damp situations suffer more from Pesize Willkommii than those in drier places, the fungus-spores maturing and germinating only in moist air. Similarly, moist weather or damp

1 “Regenfall u. Blattgestalt," Ann. du Jardin botan. de Buitenzorg, xı., 1593, p. 1204 . 
situations favour reproduction of mildew and other diseases; under such conditions a rapid inerease of potato-disease during July is easily observable and may be safely foretold.

The extension of Herpotrichic is greatly facilitated by snow, which weighs down young plants or branches of spruce and pins them to the soil, where the fungus develops on its host under the snow-covering. On this account elevated situations and hole-planting render the spruce liable to disease.

Many plants which, as a rule, suffer from fungus-diseases will be found to remain exempt in open or dry situations, ${ }^{2}$ during a dry period. The tops of trees are not attacked by many fungi which frequent the lower parts of the crown. This is particularly the case with epiphytic lichens and certain fungi, which require a high degree of air-moisture. Trichosphaeric parasitica, always very abundant in damp silver fir regenerations, is almost absent from free-standing trees, or from the higher parts of the crown in closed forest. It is, in fact, a parasite well adapted for extension in the crowded masses natural to the early growth of the fir, and the host is, during its youth, disposed to disease from this particular parasite. A fungus on the beech behaves similarly, oceurring in Bavaria only in the very damp parts of close high forest and in Alpine gorges. Other fungi have better means of protection against drought, for example, Hysterium macrosporium has its spores enclosed in gelatinous envelopes and may be found on the highest point of the spruce, although, on the whole, its distribution is most favoured by moisture. Fungi which frequent algae, or are distributed by means of zoospores, depend absolutely on moisture; hence they frequent hosts growing on banks of streams, places liable to flooding, or low-lying moist meadows, whereas the same host-species remains completely exempt from their attacks in a dry locality.

A plant may be said to be in a condition of abnormal disposition to disease when deprived of its natural protection. Thus wounds of any kind render a plant disposed to infection from wound-parasites, which are unable to harm uninjured parts. After severe hail-storms an outbreak of Nectria ditissima is not unfrequent amongst regenerated beech, or even in the canopy of older forest. I have also observed an extensive outbreak of Cucurbitaria laburni on laburnum near Munich, obviously due 
to hail. Juicy fruits whose epidermis las become l,roken, soon rot unless a protecting layer of wound-cork is rapidly formed. Wounds in the wood present an entrance-gate to numerous Polyporeae, otherwise unable to pentrate. In the case of wounds to the wood of spruce or young branches of pine, a protecting crust is frequently formed by the rapid excretion of resin from the injured surface. ${ }^{1}$

The disposition of a host-plant depends then on some inherent condition of the protoplasm or on some accidental circumstance. The latter may be anatomical and due, for example, to thickness or other property of the cuticle, or to a hair-covering; it may be morphological, from some defect, say on the part of the leaf in not allowing easy escape of water. The disposition may be periodic (e.g. in youth or at flowering), or it may be permanent. It may be generic, or confined to some particular variety or species, or it may be individual. It may be normal or abnormal.

The practical lesson of this chapter has been that we should cultivate our plants so as to avoid the conditions which dispose them to disease, and that we should rear and cultivate these kinds least liable to injury from disease. The consideration of these points forms the subject of our next chapter.

${ }^{1}$ Resin is in itself not antiseptic, and in the fluid contition inside plants affords no barrier to fungus-hyphae of Peridermium pini and Tectria cucurbitula; the hardened crust on a wounded surface serves, however, to keep off spores from the plant tissues, and prevents the penetration of germ-tubes. 


\section{CHAPTER VI.}

\section{PREVENTIVE AND COMBATIVE MEASURES.}

$\$ 12$. Measures are known for the prevention and cure of many fungoid diseases of plants of agricultural, sylvicultural or horticultural interest. These have been deduced from the biology of the parasite and its relation to its host, and have been used practically with more or less success. In a large number of cases, however, little advice can be given, because as yet the cause of many diseases is obscure, while for others suitable reagents for cure have not been found. Many of the methods known are impracticable from the cost entailed in carrying them ont. Others, directed against some widespread disease, fail from lack of organized co-operation, the efforts of a few individual cultivators here and there making but little headway against the disease, so long as the patches of crop under treatment are subject to fresh invasion from untreated places. It is desirable on this account that the combating of diseases of our cultivated plants should be conducted under some kind of state supervision.

The first step towards combating the more destructive diseases of plants is the spread of knowledge concerning them, and the remedies available against them. In Bavaria and other German states this is done for the diseases of sylvicultural importance by regular courses of instruction in plant-pathology in the forestry schools. In the same way it would also be advisable to give similar instruction in agricultural schools, and also to make it a subject for examination. Another important step consists in the establishment of experimental stations where investigations in 
plant-pathology may be carried out, while at the same time the cultivator conld have advice with regard to the nature of any disease and its treatment. Another system for the supply of information is to be found in collections of specimens of plantdiseases arranged for easy reference in places accessible to the public.

State supervision over crops under cultivation is also desirable with a view to collect and distribute information concerning prevalent crop-diseases. The same agency could also arrange and, if need be, enforce a general and simultaneous treatment of widespread epidemics, where proved methods were known and advisable. Such regulations for supervising and combating a plant-disease are already universally applied against the I'hylloxera. Similarly in Germany and other countries official notice is annually given for extermination of mistletoe (Viscum album) on fruit-trees, and in Prussia the combating of Gnomonice erythrostome is carried out by order of the police authorities. The tar-ringing of trees as a preventive against attacks of pine moth (Gastropacha pini), is regularly enforced everywhere in forest-countries, and with the best result. In a sinilar manner, in most countries, this and other forest pests are supervised by the penal code, and combated with success.

By arrangements of this kind it is possible to keep certain diseases completely in check. Thus, as a result of regular inspection and the timely use of tar-rings, a dangerous outbreak of pine moth is well-nigh impossible. Again, the universal sterilization of the seed-corn of cereals before sowing has done much to exterminate smut-diseases. In the case of the Dodder-disease, much can be done for its prevention by the careful purification of clover seed.

We shall consider the methods for combating parasitic fungi under the following heads:

I. Methods for extermination and removal of the parasitic fungi alone.

(1) Killing of fungi attached to seed through sterilization by means of hot water or copper steep-mixtures.

(2) Combating leaf-frequenting fungi by dusting or spraying with mixtures containing sulphux or copper.

(3) Excision and extermination of the sporophores of Polyporeae and Agaricini on orchard or garden trees. 
(4) Removal and destruction of dead parts of plants carrying sporocarps or other hibernating stages of any fungus.

II. Methods for combating fungi by removal of diseased plants or plant-organs.

(1) Removal of the parts of a host-plant harbouring fungi.

(2) Removal of the whole or part of a complementary host of a heteroecious fungus, for the purpose of saving the other host or hosts.

III. The avoidance or removal of conditions which favour infection.

(1) Preventive measures against wound infection; antiseptic and aseptic wound-treatment.

(2) Avoidance of localities favourable to disease.

(3) Avoidance of the niassing together of plants of the same species and like age; rotation of crops on the same cultivated area.

(4) Avoidance of neighbourhood of those plants which are hosts of the same heteroecious fungus.

IV. Selection and cultivation of varieties and species of cultivated plants least liable to the attacks of parasites.

\section{Extermination and removal of the parasitic fungi alone.}

(1) That the seed be clean and free from the spores of parasitic fungi, is a most essential condition. The purity of seed is investigated in seed-control stations, ${ }^{1}$ where special attention is paid to purity of seeds (e.g. clover, from its liability to contain seeds of the parasitic Dodder), and to their freedom from spores of smut or other fungi.

As a preventive against smut, especially those forms due to species of Ustilagineae, sterilization of the seed is adopted, ${ }^{2}$ This is chiefly carried out by the use of "steeps," which kill the smut-spores adherent to the seed. The composition of the steep-liquid, and the duration of immersion are the points to be attended to, and for these various recipes are extant. Recently

'State-aided stations of this kind are fairly numerous in Germany, France, and other continental countries, also in America. It is thus somewhat remark. able that in Britain this important work receives no state recognition, but is left in the hands of more or less experienced analysts, or others. (Edit.)

2Swingle, W. F. "Grain-smuts and their prevention." Yearbook of U.S. Dept. of Agriculture, 1894. A very useful summary. (Edit.) 
it has been pointed out that the different speeies of Ustilugo have different powers of resistance, and must be treated accordingly. It has been found from experience that when trustworthy and tested steeps are in general nse in any neighbourhood, the diseases of erops caused by Lstilagineae gradually disappear. This is due to the fact that the smut-fungi frequent principally the cultivated cereals, while they are comparatively rare on the wild grasses from which, as in the case of "rusts," they might make their way to the cultivated forms.

\section{Sterilization by Copper Sulphate.}

The "steep " which is in most general use is that first recommended by Kühn ${ }^{1}$ in 1858 . It consists of a $\frac{1}{2}$ per cent solution of copper sulphate prepared as follows: $1 \mathrm{lb}$. crushed commercial sulphate of copper (blue vitriol or bluestone) is dissolved in hot water and added to 22 gallons of water. The seed is poured into the "steep" and allowed to stand covered with the liquid for a night (twelve to sixteen hours). The seed is then taken out and allowed to drip. An improvement on this method consists in running off the copper sulphate liquor and adding milk of lime (prepared by soaking $1 \mathrm{lb}$. good lime in 4 gallons of water), after stirring for about five minutes, again run off the liquor and allow the grain to drip.

If sown by hand the seed may be used in a few hours, if by machine it must dry for twenty-four hours.

\section{Sterilization by Hot Water.}

Jensen's method for treatment of seed-grain by. hot water, consists in placing the seed for a certain time in water at a temperature which does not injure the grain, but is sufficient to kill any adherent smut-spores. This takes place in five minutes in water at $132^{\circ} \mathrm{F} .\left(55^{\circ} \mathrm{C}\right.$.), but the germinating power of the grain will not be injured though it remains a quarter of an hour. The immersion is carried out by placing the seed in a vessel easily permeable by water; a bushel basket lined with coarse canvas serves very well. A convenient quantity of seed

${ }^{1}$ Julius Kühn, Die Krankheiten d. Kulturgewëchse, 1858, p. S6. Numerous articles on this subject have from time to time appeared in the agricultural Journals and Bulletins. 
to handle in such a basket would be a full half-bushel. The hot water is best contained in two large boilers, the first at a moderate temperature, serving to wet the grain somewhat and to prevent cooling of the water of the second boiler, which must be maintained between $130^{\circ} \mathrm{F}$. to $134^{\circ} \mathrm{F}$. A lower temperature will not ensure death of all spores, a higher will injure the grain. The grain is immersed a few minutes in the first boiler, then placed in the second for fiftecn minutes, being meanwhile frequently shaken to ensure complete sterilization. Next the basket and its contents are cooled in cold water and the grain spread out to dry. ${ }^{1}$

The important point in the application of these methods is their general and simultaneous use throughout a whole district.

For smut-diseases the removal of diseased plants is at the same time a preventive and a combative measure. This is not difficult where the plant is large or the disease conspicuous, as with the maize-smut; the diseased plants can then be removed and burnt before the smut-spores are shed. If the smut is not very prevalent it is possible to keep it in check by removal of diseased specimens on such crops as maize, barley, wheat, and oats. This treatment can also be applied to some garden-smuts like that on violets.

Brefeld recommends as a preventive measure the aroidance of the use of fresh farmyard manure. Smut-spores from infected hay or straw, which finds its way to the manure heap, germinate there and multiply yeast-like giving rise to conidia, which, on exhaustion of nutrition, give rise to germ-tubes capable of infecting seedling plants. The spores are capable of germination even after being eaten with the fodder and passing through the digestive canal of animals. In this connection Professor Wollny carried out the following experiment at my instigation: three fields situated at some distance from each other were sown with maize, which I had mixed with living spores of Ustilago maydis collected the previous autumn. One field was left ummanured, the second received old farmyard manure, the third fresh. All plants in the first plot grew up healthy, two of the second were diseased, and eleven of the third. The summer being a dry one the number of diseased

In the literature issued from the United States Experimental Stations other "steeps" are given, with results. (Edit.) 
plunts was sualler than usual. The immunity from smut with old manure is probably explicable on the assumption that in it the kind of nutriment suitable for the smut-conidia is exhausterl, so that any spores, which may sprout, die off.

It must, however, be here observed that the spores of some species of smut-fungi (c.y. I'illotiu, the stinking brand of wheat) do not germinate directly in manure, but do so in water easily. The spores of most smuts are adapted to a long winter rest.

(2) Other diseases are fought and prevented from spreading by the direct extermination of the fungus or its reproductive organs while in full activity on the growing host-plant. For this purpose Fungicides are used, either as powders or solutions applied to diseased plants. These reagents are employed with most success against epiphytic fungi, where the mycelium is fully exposed on the surface of the host.

The Erysipheae are generally treated in this manner, especially the powdery mildew of the vine (Oilium Tuckeri or Uncinulu spiralis). This vine-parasite is combated by dusting from time to time with dry powdered sulphur or flowers of sulphur. The sulphur may be simply shaken from a tin with perforated licl, or it may be blown on by a sprayer provided with a bellows, or dusted on by a sulphur-brush, consisting of a hollow handle filled with sulphur which distributes the powder through fine perforations in its end to a tassel of fine bristles. In a similar manner may be treated the powdery mildews of hop, rose, peach, apricot, apples, ete., caused by Erysipheae.

Fungicides are also used against fungi with endophytic mycelia. The Peronosporeae cause injury to quite a large number of eultivated plants, and many methods of treatment have been employed against them. The mycelium lives inside the host-plant, especially in its leaves, and only the conidiophores make their appearance externally. Dusting with sulphur or spraying with preparations of copper has on this account little effect on the mycelium, but will kill the conidiophores, while any conidia or oospores, which may alight on the leaves, will be prevented from germinating. The most general forms of fungicides are various preparations of copper, of which the following are some of the more important: ${ }^{1}$

\footnotetext{
${ }^{1}$ Consillerable liberty has been taken here with the original. The anthor's account has been extended with the assistance of the Joumal of Mycology and
} 
Bordeaux Mixture or Bouillie-Borlelaise, a 2 to 4 per cent. solution of copper sulphate and lime. It is prepared by dissolving 6 lbs. of copper sulphate in warm water, and placing this mixture in a barrel capable of holding about 44 gallons; in another vessel slake $4 \mathrm{lbs}$. of fresh-burnt lime, and make it up to a creamy whitewash with water; strain the lime through coarse eanvas into the barrel of eopper sulphate solution, fill up with water, stir thoroughly, and the mixture is ready for use. This mixture may be used either more concentrated, or somewhat diluted.

Ammoniacal Solution of Copper Carbonate. This may be prepared directly by dissolving $5 \mathrm{oz}$. of eopper carbonate in enough water to form a thick paste; dissolve this paste in three pints of strong aqua ammonia (or as much as may be necessary to effect complete solution) then dilute to 45 gallons. If copper carbonate cannot be obtained, make it by mixing ( $a$ ) 3 lbs. of copper sulphate in 2 gallous of hot water, (b) $3 \frac{1}{2}$ lbs. washing soda in 1 gallon hot water; $\operatorname{mix}(a)$ and $(b)$, add water up to 10 gallons, stir up, and allow to settle; pour off the elear liquid, fill up again with water and allow to settle; on again pouring off the clear water a greenish sediment of copper carbonate remains. This dissolved in as much aqua ammonia as necessary, may be lept till required when it is to be diluted at the rate of 1 pint to 2 gallons of water.

Eau Celeste. Dissolve 2 lbs. of copper sulphate in about 8 gallons of water; when completely dissolved add 3 pints of strong aqua ammonia and dilute to 45 gallons. This may be used in a modified form.

Fungicides like these are used ehiefly against attacks of vine mildew (Peronosporce viticola), potato disense (Phytophthora infestans) and Peronosporeae generally; also for numerous other leaf-diseases caused by various fungi. What the results of any given experiment may be, is as yet diffieult to say till more is known of the effects of the reagents, the strength of the mixture to be used, the kind of plant and its stage of development, and other factors dependent on climate. The efficacy of a fungicide lies less in its effects on the fungi actually present

other American literature, not the least important being "Bordeaux Mixture as a Fungicide," by D. C. Fairchild ; U.S. Amer. Bulletin, No. 6, 1894. In this connection reference may also be made to F. (G. Lodemann's account of the "Spraying of Plants" (Macuillan, 1S96). (Edit.) 
and causing disense, than on its eapacity to kill spores which light on the leaf', or to prevent their development to a dangerous extent. On this account crops liable to attack should be dusted or sprayed in marly spring, and at intervals thereafter as long as there is any risk of disease. Used in this way, fungicides soon repay themselves in increased yield of healthy prodnce; on the one hand, they hinder the development of the fungus, on the other hand, they act like antiseptic wound-treatment in preventing infection. What jart the copper compounds play is as yet not completely established; liumm ${ }^{1}$ considers that. they are not actually absorbed by the plant, but only give rise to some electrical effect.

The advantage to be gained from the use of fungicides may be greatly incrensed if all cliseased plants or portions of them he removed before the remedy is applied. Precautions must also be taken against reappearance of the disease. In the case of infected forcing boxes, frames, or glass-houses, disinfection by some of the above fungicides is certainly advisable. Leaves on other plant-remains containing resting-spores of the fungus should be burnt, and soil containing diseased material should be watered with a fungicidal solution which will kill the fungus while it does no harm to the leaves or roots of plants. Finally i rotation of crops of as long a duration as possible will do much to keep epidemic fungoid diseases in check.

(3) Frequently the ravages of a parasite can be considerably reduced, although not completely stopped, by destroying its reproductive organs. Methods of this kind are particularly useful in the case of the Polyporeae which inhabit the wood of many fruit-trees. The excision of the sporophores must be carried ont nnce or twice a ycar, hecause the mycelium remains alive insicle the stems and continually gives off new sporophores on the surface. The diseased tree lives on and produces fruit for many years, maybe till the wood of its stem becomes so much decayed that death ensues. Fungi of this family are even more destructive on those trees which are cultivated not for their fruit alonc but also for timber, c.g. olive, sweet chestnut, and hazel.

(4) By the removal and destruction of rlead plants or portions of plants containing reproductive or hibernating organs of para-

${ }^{1}$ C. Rumm, Berichte d. deutsch. botan. Ges. 1593. 
sites, much may be done to shorten the existence of a disease, and to prevent its reappearance in the following spring.

Fungi which reach maturity on fallen leaves are easily combated in this way. Hartig gives a striking example of the success of this measure. In the English Garclen, a large park in Mumich, the leaves are carefully removed at frequent intervals as they fall, and utilized as stable-bedding; here Phytisma acerinum, the black spot of the sycamore leaf, is hardly known, whereas in the park at Nymplenburg, and in other places round Munich, where the leaves are allowed to remain lying, the leaf-spot is very common. Rhytisma salicinum can be treated in the same way in osier-nurseries. In plum orchards Polystigma rubrum may be held completely in check by removal of fallen leaves. So also the numerous mildews (Erysipheae) of our cultivated plants. Cherry leaves killed by Gnomonic crythrostome remain hanging on the trees, but the disease has almost disappeared since the practice of removing and destroying these was introduced in gardens, like those of the Altenland, once completely devastated by this parasite.

The progress of the disease caused by Nectria cinnabarina is reduced if the branches which die during the summer be at once removed and burnt before the red fructifying patches appear. It would also be advisable to burn in the autumm other dry brushwood, since it frequently contains Nectric and other wound-fungi, and if left over winter only serves as a nursery and source of infection for all neighbouring trees. In a similar way should be treated branches infected with sporocarps of Cucurbitaria laburni and such-like fungi.

Immediate removal, burning, or burying of young trees attacked by Phytophthore omnivore is of advantage in preventing the distribution of the fungus by conidia and swarm-spores during summer, its hibernation in dead tissues, and its continued distribution in the following spring. The hibernating oospores of many other lower fungi may be similarly got rid of by destruction of the plant-remains inhabited by them.

\section{Removal and destruction of diseased plants or portions of these.}

(1) The removal of symbiotic organs comes here particularly into notice. Amongst these are the "witches' brooms" which 
live for years on their lost deriving nutriment from them; they also are detrimental to fruit trees because they bear neither flower or fruit, and on some timber trees they so deform the stems as to considerably reduce their value. The witches' brooms of the cherry or the plum grow into large infertile bushes of striking appearance, so that they may be easily detected and removed in antumn or spring; those on hornbeam, birch, and alder are of less practical importance, but should be cut off wherever accessible.

Great damage is caused by the witches' broom (Accilium clatinum) of the silver fir in producing canker spots which may in some cases attain gigantic dimensions and thereby much reduce the value of the timber, or maybe render it quite valueless. The cankered spots are, in addition, frequently attacked by wound-parasites, whereby the stem is weakened and breaks over at the canker, causing breaches in high forest, which cannot be refilled. The witches' brooms should therefore, as far as accessible, be cut off while still young, and all cankered trees should be removed at the first thinning.

The removal of twigs of plum bearing the so-called "pocketplums" or "fools" is also to be recommended, because the mycelium of the fungi cansing these hibernates in them. Rose-twigs affected by rose-mildew (Sphaerothece pannosa) should also be cut away as soon as possible, before many plants have fallen victims. Portions thus removed are both worthless and dangerous, hence should be destroyed. So also all trees rotted by fungi should be removed from their healthy neighbours, and, if possible, burnt or buried, or otherwise rendered harmless.

This forms a convenient place to consider generally the wood-destroying wound-parasites of our timber-producing plants.

The wood-destroying wound-parasites belong chiefly to the families of the Polyporeae and Agaricini, and each possesses a mode of life and method of destroying its host, so similar to that of its relatives, that it is quite impossible to consider them separately in a practical way. They are enemies of our fruit orchards, our parks, and our forests, and the means to be employed against them varies in the hands of the fruit-grower, the gardener, or the forester.

Every fruit-tree, whether grown in a garden, an orchard, or 
on a roadside as in some countries, is an object of such value that, if need be, costly methods can be employed on its behalf. Its branches must be kept free of all intruders like the mistletoe, witches' brooms, mosses and lichens, and above all, from the sporophores which indicate the presence of a wooddestroying fungus. This is all the more easy because the trees are frequently closely examined for pruning, for crop, or for insect attacks. The sporophores of fungi on stems and branches should, as already indicated, be early and carefully cut out, the wound scraped and tarred over. ${ }^{1}$ In this way the fungus will be deprived of its sporophores and the safety of other trees ensured, although it must be remembered that the mycelium still continues to destroy the wood and probably to produce new sporophores. If the sporophores appear on weak branches, these would best be completely cut off and the cut end tarred over. Trees although diseased and requiring annually to have sporophores cut ont should still be spared, as they often continue to live and yield heavily for years. Amongst the sporophores which appear frequently on fruit-trees are those of Polyporus igniarius, $P$. fulvus, $P$. hispidus, $P$. sulphureus, $P$. squamosus, $P$. spumeus, Hydnum Schicdermayri, and others to be more closely considered in the special part of this work.

Particular attention of this kind is of course more difficult for the park-gardener, because his trees are higher and stand closer together. The trees are, however, of less value individually than fruit-trees. It is advisable, as far as possible, to keep the trees clean, to tar all wounds and to remove poorly developed branches and stems.

To the forester in high forest all this is, however, a matter of difficulty. The trees are high, the forest large, and the individual trees of a value which does not allow of costly labour being expended on them. Tet there is one forest operation in which a plantation may at small cost be easily cleared of diseased stems. This is the repeated process of thinning, during which all diseased and backward trees should be fellerl. In forests of high value with high-priced timber and near towns or centres of industry, this cleaning out is, of ccurse, easy, but in remote forests with a small working staff,

\footnotetext{
1 The sporophores cannot be remover too young; the wounds produced should be treated with tar; see Section III., p. $7 \%$.
} 
deficient modes of conveyance, and a small demand for the thinned-out material, this may appear impracticable. I shall give one example how the number of "fungus-sponges" (as the sporophores are called) decrease with enclosure and introduction of proper forest-management. ${ }^{1}$ Bischoffsrent is a forest in Bavaria, near the Bohemian frontier, consisting of mixed spruce and fir up to four hundred years, and beech up to two hundred. Forty years ago the sporophores of Polyporus fomenturius, the tinder-fungus, were so numerous and large that for their collection for manufacture of caps, gloves, tinder, etc., a sun of one hundred gulden ( $£ S 10$ s. 0d.) was paid annually as rental. Ten years ago the same brought in a revenue of twelve shillings; to-day it is free. In course of time the disensed stems have been gradually felled and less wood has been allowed to remain lying in the forest to decay; as a result the wood-destroying fungi have now but little foothold. A mixed damp virgin forest is especially favourable for the life and distribution of fungi of this kind. ${ }^{2}$ All fallen wood remains lying, while injuries from storm afford easy spots for infection. In Bischoffsrent eighteen per cent. of the felled heary wood was at one time useless and rotten.

(2) It is often possible to avert diseases of valuable cultivated plants caused by heteroecious fungi, by keeping the supplementary host at a distance, or, if the disease has already broken out, to remove it altogether, with the view of keeping the more useful host free from the dreaded disease.

The best example of this is presented by the heteroecions rust-fungus Crymnosporangium sabina. One host frequents Juniperts sabina (savin), the other damages pear-trees, causing, in the case of a severe attack, considerable loss. It would thus be easy to exterminate pear-rust by removing the not very decorative savin-bush. Particnlarly in nurseries, it would be well to aroid placing pear-trees near the savin, an arrangement very suitable for cultivating the Gymnosporangium.

As another example we may take Mclampsorc tremular frequenting the aspen, the supplementary host of (a) Cutoma pinitorquum (the pine twister), and (b) Cacoma laricis (larch

${ }^{1} v$. Tubeuf, "Mittheilung iib. einige Feinde d. Waldes." Alleg. For:st.-u. Jagdzeitung, 1SS7.

${ }^{2}$ v. Tubenf, "Vegetationsbilder, aus d. boehmischen Urwalde." Oesterreich, For:xtzeitung, 1890, p. 108 ; with six figures. 
needle-rust). The exclusion of the aspen from the neighbourhood of pine plantations is advisable as a means of limiting the pine-disease, and is now being recommended in forestry.

Still another example is Puccinia graminis the rust of whent and its Accidium on the barberry. This is, in all probability, able to reproduce itself by means of uredospores on wild grasses, and to retain its position without the barberry, yet the latter doubtless tends to distribute the disease, and its removal minimises the risks of attack.

An investigation of the heteroecious rust-fungi will easily furnish many examples of the same lind, and lead to the conclusion that Euphorbia cyporissias, for example, should be exterminated near fields of peas or other Leguminosae because of Uromyces pisi, and U. striutus.

\section{Avoidance or removal of conditions which favour infection.}

Various examples of this have already been given when the conditions disposing plants to disease were under consideration in our last chapter.

(1) The most important measures of this class are those directed against infection through wounds. This may be attained by avoiding any unnecessary wounding of woody plants, and the immediate treatment of any wounds rendered necessary in pruning or other operations.

When the stems of roody planits are injured, the first step' towards healing the wound proceeds from the tree itself. Conifers containing resin have in it a very ready agent immediately available: the resin escapes from its ducts and soon hardens into a crust on exposure to air. In the case of nonresinous conifers and of broad-leaved trees, the first steps towards healing are less obvious, but it has been found that a healing tissue immediately begins to form on wounded surfaces. ${ }^{1}$ It consists of a parenchyma, the formation of which is induced apparently by atmospheric air penetrating into the wood, and

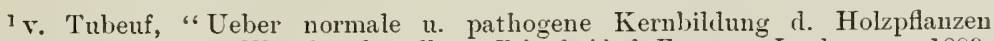
u. d. Behandlung v. Wunden dersellen, Zeitschrift f. Forst.-u. Jagd.-resen, 1859. Contains Bibliography of allied papers.

R. Hartig, Diseases of Trees, English Fdition, 1894.

Gaunersdorfer, Sitzungsber. d. k. Akad. d. Wissenschaft, Vienna, 1881.

Boehm, "Ueber die Function d. veget. Gefasse," Botan. Zeitung, 1879. 
its object probahly is to restore the same condition of gaseous pressure inside the tree as existed previous to the injury. A number of wooly plants, for example, Robinice and Quercus, which normally form tyloses in their heart-wood or sap-wood, do the same on wounded surfaces, and thereby stop up all the cut ressels. ${ }^{1}$

The formation of tyloses is due to sac-like ingrowth into the vessels from adjoining parenchyma, and can only take place where rapid growth of the elosing membrane of pits or the thin portions of the wall of annular or spiral vessels occurs. Tylosesformation takes place in normal heart-wood, and also in the sap-wood of many kinds of trees, except in the very youngest water-conducting year-rings. It also occurs in leaf-scars at the the time of normal defoliation. ${ }^{2}$ Species of trees in which tyloses are not normally produced in the heart-wood, but in which the vessels of that region become filled with resinous secretions, use these substances as healing agents in the case of leaf-fall or wounds to the wood. For these reasons it is quite correct to designate these preliminary steps towards woundclosure as a pathogenic formation of duramen, and the tissue derived from the process as wound-duramen. Similarly a corky tissue-wound-cork-may be formed in consequence of wounds to the bark or as an accompaniment of certain diseases. I have repeatedly observed that the normal duramen is preyed on for nutriment by many wound-parasites, and also that this wound-duramen is not sufficient to keep out germinating spores of the wound-parasites. It cannot therefore be designated a protective wood, nor are the artificial methods of closing wounds so superfluous as some would have us believe. ${ }^{3}$

Frank says: "The use of all such artificial means of healing wounds is thus only necessary in serious cases, in which, in consequence of delay in the healing-process, decay would be inevitable without some septate agent. Smaller wounds, and particularly cut surfaces of twigs or thinner branches, are, by the natural fornation of protective wood accompanying every wound of the wood, sufficiently protected for the few years the

${ }^{1}$ Molisch, "Zur Kemntniss d. Thyllen," Akarl. d. Wissenschaft, Vienna, 1888; Wieler, Biolog. Centralblatt, 1893.

2 Staby, "Ueber Verschlıss d. Blattuarben nach Abfall d. Blätter," Flora, 1856.

${ }^{3}$ Praël, Pringsheim's Jahrbuch, $18 s s$.

Temme, Landevirthschaftl. Jahrbuch, 1885.

Frank, Die Krunkheiten d. Pfanzen, 1894, p. 153. 
wound must remain open till completion of occlusion." If we followed this view, then numerous wounds would be left freely open as entrances for wound-parasites, and serious loss would result. It is just the numerous smaller wounds (e.g. those produced by hail), which are the principal places of infection for species of Nectria, Cucurbitaria, Hymenomycetes, etc., in fact, they form very convenient places whence a tree may be easily infected artificially.

The following points in regard to treatment of branches may be conveniently summarized here. Trees in closed plantations are naturally stripped of their branches by these dying in consequence of deficient illumination; they then break off, and the short stumps are soon occluded or grown over. During this process there is always a risk of infection by fungi, and "snag-pruning" 1 is employed to shorten the period of occlusion as much as possible. This at the same time prevents the inclusion of long branch-stumps in the timber, and reduces the number of knots in sawn boards. Such dead snags or stumps. are deficient in nutritive materials and very dry, so that they are less suited for the entrance of wound-fungi than wounds on the living branch.

The usual process of forest-pruning is necessary to produce clean boles, to increase the illumination for undergrowth, or to utilize the brauches so removed. In the operation, all branches should be cut off' close to the shaft, no suags should be left, nor must injury be inflicted on neighbouring bark. The operation is best carried out in autumn or winter when the bark is most adherent to the wood, occlusion then begins with the renewal of regetative activity in spring and is well advanced by the time the greatest dispersal of fungus-spores takes place. Infection by fungi will, however, be rendered quite impossible if wounds are immediately painted over with tar, or, in the case of smaller wounds on garden stock, with tree-wax; these reagents, if applied in winter, will easily penetrate into the wood, and even replace the formation of protective wound-wood. Hartig says on this subject: ${ }^{2}$ "tarring produces satisfactory results only when pruning has been done in late autumn or in winter, because it is only then that the tar is absorbed by the surface of the wound. It would appear that the absorption of tar is due partly to the diminished amount of water in the

\footnotetext{
1 Trockenästung. 2 Hartig, Diseases of Trees. English Edit. p. 258-59.
} 
wood during antumn, and partly to the consequent negative pressure of air in the tree. When pruning is undertaken in spring or summer the tar altogether fails to enter the wood, and the thin superficial layer does not prevent the cut surface from drying later and forming fissures into which water and fungi may enter." From what has been said it follows that dicotyleclonous trees may be best pruned in the months of October, November, and December-perhaps also in January and February, - and that a good coat of coal-tar should be at once applied to the wounds.

Conifers should also be pruned in autumn and winter, for although the wounds resulting from removal of small branches with no heart-wood are soon protected by an excretion of resin, yet thicker branches with heart-wood, which secretes 110 resin, unst be tarred over. Similar precautions are advisable to protect the stools of trees felled in order to produce coppice.

Wounds are produced on fruit-trees by removal of branches, by pruning and grafting, and again during the fruit-liarvest. Hail and wind are frequent sources of wounding. Gnawing of the bark by animals, such as mice and other rodents, may also occur.

Red deer, by peeling off the bark, are a somrce of great damage in the forest. In this way spruce plantations may be so peeled, and in consequence so subject to red-rot that they have to be prematurely felled. The trees which suffer most are those like spruce, silver fir, Weymouth pine, and Douglas fir, which remain for a considerable time smooth-barked, whereas species with a rough bark are comparatively safe; the latter can also cover up any wounded surface by means of an excretion of resin. Conifers suffer most from peeling, but the broadleaved trees are not quite exempt. At certain seasons the deer rub the fur off the young antlers or knock off the old; for this purpose they generally choose younger plants, which, in consequence of the injury, frequently dry up. Injury by deer is more serious in summer than in winter, because with the increased temperature and moisture the spores are able to convey infection quickly and easily.

Injuries similar to peeling by deer are produced in gathering resin, and in the process of "testing" the timber of conifers. Both practices are, however, prohibited in well-managed forestry, and occur only as misdemeanours. Resin-collecting of whatever 
kind, whether from spruce, larch, pine or the silver fir, necessitates removal of the bark, and probably cutting into the wood itself. The exuded resin and naked wood dry up in course of time and crack, thereby allowing the entrance of fungus-spores, which germinate in the fissures of the wood and lead to its destruction.

The forests of spruce and fir in Bararia furnish valuable wood suitable for the manufacture of violins and other musical instruments. Till recently the practice was first to split a testpiece from the standing tree to ascertain the clearage of the stem. If the test did not split true, the tree was left standing and wounded; such stems naturally were soon attacked by fungi (Polyporeae and Agaricini) and succumbed to some storm.

The beech is frequently injured in a somewhat similar manner by the woodmen, who hew ont large pieces of the stem to obtain material for wedges from the very tough occlusion-tissue which is afterwards formed. Stems so damaged soon fall a prey to Polyporus fomentarius. Wounds to the wood are also frequently produced during the felling of neighbouring trees, or as a result of storms, or by the action of woodpeckers, ants, and other enemies. In short, wounds are so common that the necessity of practical remedial measures for closing them as entrances for destructive parasites, must be at once evident.

(2) Localities should be avoided which are known to predispose certain plants to disease. Just as one avoids cultivating tender plants in cold situations, or planting our less hardy trees in places known to be liable to frost, so ought we to avoid the cultivation of plants in localities which will render them more than usually liable to infection by fungi. Thus the formation of spruce-nurseries at considerable elevations has had to be abandoned, because it was observed that they were there liable to complete destruction by Herpotrichic nigra. For similar reasons the hole-planting of spruce in elevated situations must be avoided. In moist localities nurseries of Donglas fir and other trees are in danger of attack from Botrytis; while close glass-houses and hot-beds are breeding-places for many parasites which would at once die away with good ventilation.

(3) The neighbourhood of plants which are supplemental hosts of the same heteroecious fungus should also be avoided. (See also p. 74.) 
(4) The massing of numbers of the same species of plant together is dangerous, because it presents a favourable opportunity for the rapid spread of epidemic diseases. On this account the smaller fields of small holdings tend to prevent any epiclemic from assuming serious proportions. Still better is a system where, as in Northern Italy, a few rows of vines alternate with narrow strips of Indian corn with gourds or melons on the ground below, and strips of grass or millet intervene here and there.

Wherever similar plants must be cultivated in close neighbourhood over extensive areas, as in vine cultivation, any epidemic, which may obtain a hold, soon produces disastrous effects. Our cultivated forest plants, when occupying extensive areas, are particularly open to attacks of certain fungus-diseases. Thus Pines from Hysterium pinastri, Cacoma pinitorqum, and Peridermium pini; pole-forests of pure spruce from Hystcrium macrosporum, all plantations of conifers from Trametes radiciperda and Agaricus mellous, the latter especially if preceded by beech forest, the stools and dead roots of which offer the Agaricus an opportunity for easy and abundant development.

The prevention of many epidemic diseases is one of the advantages claimed by Gayer ${ }^{1}$ in favour of natural regeneration and mixed plantations. On exposed areas the prevailing strong winds facilitate distribution of many fungus-spores, while, at the same time, they introduce the supplemental hosts of of heteroecious fungi (c.g. aspen, ragwort, cowberry, etc.), which would be excluded from a closed permanent mixed forest naturally regenerated. Of course, we do not maintain that, under these conditions, diseases are entirely absent, because it is just on naturally-sown beech seedlings in closed forests that Phytophthora finds a habitat. Similarly Trichosphaeria on silver fir, and other parasites, are in closed forest provided with that degree of atmospheric moisture which favours them. In fact, several parasitic fungi exhibit adaptations to such conditions. Diseases, speaking broadly, are less dangerous in mixed forest; they never attain the same distribution, and they are more easily restricted where trees of different dispositions are grown together. Thus, the forests of Bavaria consist, in the lower elevations, of mixed beech, silver fir, and spruce; higher up ${ }^{1}$ Gayer, Der Waldbau. 
the beech is omitted, and in the more elevated parts spruce alone is planted. The fir alone is attacked by Phoma abietina Accidium clatinum, Lophorlcrmium nervisequium, Trichosphaciu purasitica; the spruce, on the other hand, has to itself Lophodermium macrosporum, Chrysomyxa abietis, Herpotrichia nigra, while both are subject in youth to Pestalosia Hartigir, and later to several wood-destroying fungi.

The storing together of crops like apples, potatoes, onions, turnips, etc., should be carefully carried out. They should be handled as little as possible, and decaying individuals should be sought ont, and destroyed when possible, to save the remainder.

\section{Selection of hardy varieties.}

An important methor for the protection of plants from disease, both from the preventive and remedial side, consists in the selection and cultivation of varieties and species of plants able to resist the attacks of parasitic fungi.

It has already been mentioned that different varieties and species show different powers of resistance agninst enemies. As a further example, we have numerous Anerican grape-vines which are not attacked by downy mildew (Plasmopara viticola), that dangerous enemy of the Emropean vine of cultivation (Vitis rinifera). Some American vines (ry. Titis ripuria) are proof against the phylloxera, the root-louse which attacks the roots of European vines and devastates the vineyards of the wine-producing comtries; while, on the other hand, other American vines are no nore resistant than the European. In fact, it was the importation of those vines into Europe for experimental cultivation which brought us both phylloxera and the downy mildew. The cultivation of such disease-proof species would ensure us immunity from the phylloxera, if it were not that the wine from these vines has neither the quality nor the flavour possessed by the European. On this accomnt the grafting of European vines on American stocks has been introduced, whereby the roots remain mattacked by the phylloxera, and the grapes are of the approved standard. Very good results have also been obtained from experiments in lyybridization of American and Emropean vines with the object of obtaining roots from the American parent, and grapes from 
the European. The long and patient experiments of Millarlet ${ }^{1}$ are the most conspicuous anongst many which, by means of grafting and hybridization, have ained at obtaining disease-proof vines. Millardet, out of numerous hybrids raised by him, has sncceeded at last in oltaining vines with roots proof against phylloxera, leaves resistant to attacks of downy mildew, and grapes which impart the esteemed flavour to the various old and well-known European wines. From these nany ruined vineyards of southern France have been alrearly re-stocked, and promise well.

The results obtained from Eriksson's investigations on cerealrusts are also worthy of notice. ${ }^{2}$ This investigator, after carrying on cultivations for a number of years, has found that there are varieties of wheat able to resist the more frequent forms of rust, and in no way endangered by them. By a similar methoul of investigation, varieties suitable for cultivation in the rustinfested districts of Australia have also been obtained.

1 Millarlet, "Notes sur les vignes americaines." Ser. 111. Mém de la sor. des sciences de Bordeatx, 1891 ; Joum. d'ayriculture pratique, 1892; Compt. rend., 1894 ; Zeitschrift $f$. Pflanzenkranklkeiten, 1894, p. 47, and 1595,1$) 116$.

Esser, "Die Bekampfung parasit. Pflanzenkrankheiten," Samml. wissensch. Vortrïge; by Virchow u. Wattenbach, IS92. With Bibliography.

"Eriksson. Zeitschrift f. Pfansenkrankhtiten, 1s95, p. so. 


\section{CHAP'TER VII.}

\section{ECONOMIC IMPORTANCE OF DISEASES OF PLANTS.}

$\$ 13$. The economic importance of any plant-disease dejends on its distribution, its intensity, and the value of the plants attacked. Of most consequence ire those epidemic diseases of fungoid origin, which cause rapid death of their host, and spread with great rapidity over wide areas. Such, through repeated attacks, may render the cultivation of certain plants impossible in a locality. Almost equal damage may result from those parasites, which, although they do not kill their host, yet destroy or prevent the development of that part for which we grow the plant. Amongst these are species which inhabit Howers or fruits, the wood-destroying fungi of forest-trees, and forms inimical to the foliage, roots, or tubers of plants of economic value.

As examples of parasitic fungi which bring about rajud death of their host, are the originators of many diseases of young plants. Phytophthore omnivore may during a few days of damp weather completely kill out not only healthy beds of seedling beech or conifers in the nursery, but even the young plants by which a forest is being naturally regenerated. P'estaloz:in Hartigii, a few years ago in the beech-forests in some districts of Bavaria, exterminated three-fomths of the natmally-sown plants from one to four years old. Heipotrichia nigra is capable of completely destroying the young spruce plantations, so important for the afforestration of bare slopes in mountainous districts, and it may attack with such violence nurseries established at great cost and labour that they have to be 
abimdoned. Whole gatrens of roses have Jeen devastaterl by Promospmer sporise, and nurseries of conifers have been rxterminated by Mystrimm pinustri, or Ayariars mellows.

Anomgst the fungi, which attack the orwans of older plants and canse serious losses to cullivators, are the following : the well-known potato diserse caused by Phytophthore infesterns; the vin" diseases arising from Uncinula spivalis, Plasmmpum viticoln, and Dematophor" necutrix; many cliseases of conifers and other trees. As destroyers of the fruit alone nua le mentioned the smut-fungi of the cereal crops.

Other cases of injurions diseases, of more or less practical import, will be describer in the special part of this book; at present we shall only select a few estimates of the loss resulting from them.

In the forest of Bischoff'sreut in Bavaria-a magnificent one, containing spruce, fir, and beech-eighteen per cent. of the feller timber consisted of roor rendered useless by decay; while tifty years ago the utilizing of the so-called fungus-sponges of Polyporus fommtarius in the same forest for manufacturing purposes and for tinder, was let for a small sum (see p. 74).

Higher figures are, however, reached when we calculate the injuries on vines or cereal crops. Pierce, ${ }^{1}$ in 189.2 , furnished estinates putting the loss resulting from the Anaheim vinelisease in California at ten millon dollars. The area of infecter land was about 25,000 acres, in great part with an original value of 300 to 500 dollars per acre, int so depreciated in the course of five years that it became worth not more than 75 to 200 dollars.

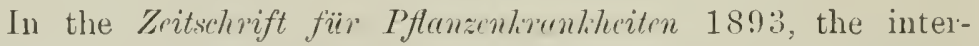
national phytopathological commission gave, from estimates mates furnished by the Prussian statistics-bureau, a review of the losses in Prussia from grain-rust. Anongst other estimates we find that in 1891 the whent harvest of Prussia reached a total of $10,574,168$ doppelcentner, ${ }^{2}$ which at 2 ? marks per d.c. $=£ 11,459,690$ sterling. Of this $3,316,059$ d.c. or $£ 3,593,758$ was depreciated by rust. The rye harvest was $30,505,068$ d.c. at 22 marks, of which $8,208,913$ d.c. or $\mathfrak{Q} 8,896,364$ was depreciated by rust. Oats reached

${ }^{1}$ The California Vine-Disease. U.S. Dept. of Agriculture, Bull. 2, 189:2, p. 1.5.

"Doppelcentner $=100$ kilogramme. 
$32,165,473$ d.c. at 16 marks, of which $10,325,124$ d.c.

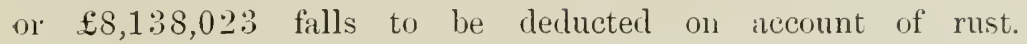
Thus on the crops wheat, rye, and oats, the loss reached the sum of $\mathfrak{E} 20,628,1 \pm 7$ sterling, or almost a third of the total value of the crops. The year 1891 was a very unfavourable one, but even taking the estimate at the half of the above sum we have a yearly loss by rust amounting to $\mathfrak{E} 10,000,000$ sterling.

In Australia the loss in the wheat harvest of 1890-91, on accomut of rust, has been estimated at $£ 2,500,000$ sterling.

Consideration of the loss of sums of money like these, which might be consillerably reduced if energetic and universal measures were employed against fungoid plant-diseases, will serve to emphasize the importance of remedial measures. It must also be borne in mind that the use of diseased folder, especially hay, srass or grain, infested by rust or sinut-fungi, is productive of serious results to the varions animals of the farm; while the use of meal or flour contaminated with smuts, stinking-smuts, or ergot is dangerous for mankind.

'Frïhner, Lehrbuch i. Toxikolonie f. Thierïrzte, 1890. 


\title{
CHAPTER VIII.
}

\author{
SYMBIOSIS.
}

\section{\$14. MTTTALISM.}

Mutualisn, or Symbiosis in the stricter sense, ${ }^{1}$ has been distinguished as a special case of parasitism. This condition nceurs when a parasite and its host mutually work for the lenefit of une another, each contributing to the other's nomrishment. The lichens furnish the most conspicuous example. Here fungus-hyphae unite with algal cells, the algae furnishing the fungi with assinilated organic nutriment, the fungi proviling water and dissolved salts for the algae.

While it is by no means uneommon to find two organisuns taking a mutual advantage of each other, yet mutualism in its strictest sense is a rare phenomenon. For it generally happens, and is indeed to be expected, that one or both symbiotic organisms modify in some degree their mode of life to suit the alterel conditions necessary for their untual support. Thus amongst the lichens, as a result of the union of fungus and alga, a living organism originates, which in form, necessities, and mode of life is quite nu, and differs completely from either of its components. In the lichen-community, the fungus alone reproduces itself; yet the alga occurs as a free organism in nature, while the fungus can only be reared in artificial culture. This combination might perhaps be compared with that of oxygen and hydrogen to form water, also to a certain extent with the mion of the sexual cells to protuce a new

${ }^{1}$ The term Symbiosis was applied by De Bary, (who introducerl it), by Frank and others, to denote those cases where a cohabitation or partnership was observerl to take place between two different organisms. (Frank, Lehrbuch il. Botanik, 1892). "Mntualism" was first userl by Tan Benerlen. 
individual. These, and other examples, will serve to illustrate how we have in the lichen an organism with peculiarities of structure and of life, widely differing from those of either an alga or a fungus. This unification of two living beings into an individual whole, I have designated "Individuation." 1

In the case of the lichen-symbiosis, the chlorophyllous part consists of minute algal cells, completely enclosed in a tissue of fungus-hyphae, and the lichen lives as a perfectly isolated and independent plant. The case is, however, different where the fungus enters into parasitic relationship, with the green cells of a large plant. Union may then take place, so that the fungus lives on, or inside its host, and removed from contact with any other substratum. The fungus is, however, not in a position to convey any nourishment to its host, and in fact is absolutely dependent on it for the organic substance and water necessury for growth. Where, howerer, the relationship is such that the parasitic fungus is still in contact with some other substratum, then it may be assumed that, in spite of its parasitism, it takes np nutriment from this sonrce, and shares it with its host. This, as lias already been pointed ont, is the state of things in the lichens, where the fungus completely envelojes the small isolated algae, and nust, as a condition of the growth of the lichen, remain in direct contact with the substratum; the fungus is believed to take from the substratum water and inorganic food-material with which it supplies the algae, while it receives in returu plastic organic substance to be used in its own growth. Of course cases do occur amongst the lichens, where, in moist places, the alga is not dependent on the fungus, or, on the other hand, where the fungus can itself take up organic substance from its substratum.

Another example of the case is the union of fungi with non-chlorophyllous plants which inhabit humus (e.g. Mnnotropa). Here the fungus takes up organic nourishment from the substratum and supplies it to the higher plant, which, in consequence of its lack of chlorophyll, is directly dependent on the plastic organized substance from the soil, supplied through the agency of the fungus. The latter, however, receives nothing in return; it requires nothing, since its substratum offers it the nost favourable conditions for nutrition. This form of

\footnotetext{
${ }^{1}$ Individualismus.
} 
symbiosis, in which the fungus becomes the nurse or feeder, I distinguish as Vufrirism. Between the rase just citen and that in which the fungus is a pronounced root-parasite on grem plants, there exists every possible intermediale stage.

liefore mutricism is consilered in detail it womkl be well to (xemplify brictly from the ranks of plant-parasites, that phenomenon of individuation so sharply defined in the lichens. A large number of parasitic fungi cause local cell-enlargement and rell-increase, with the frequent result that :u attacked plantmoan becomes very much enlarger and its form much changerl. ()ne speaks in such cises of hypertrophy and hypertrophied olgans. It is quite evident that in eases of hypertrophy the attacked part must be better nourished, otherwise it could nevor sustain the great increase in number and size of its cells. The hypertrophied organ is, in fact, indebted to the surrounding healthy parts for its additional nomrishment; in other worls, the place of lemand draws to itself the materials it requires. 'lhis is all the more necessary when the region of increased growth is deficient in, or altogether devoid of, ehlorophyll, and thus quite dependent on the assimilating green parts. This is frequently the case, as in the seales of alder catkins attacked by Exouses alni incunur, in the needles of silver fir deformed by Acridium clutinum, or in the yellow needles on spruce resulting from Accilimm coruscans. So also must the woorly swellings of branches attacked by Accidium clatinum, Gymmusporenyium subinue, and other fungi, be produced at the cost of neighbouring parts of the host. The hypertrophied organs behave, in fact, like these plant-organs-Howers, roots, etc.which are normally deficient in chlorophyll, and to which plastic material must be supplied.

In other cases the part of a plant attacked by fungi behares like a specialized organ, and, in combination with the fungus, attains to a certain degree of independence. The so-called "witches' brooms" funish an interesting example. It is a wellknown fact that the direction of growth of the main axis of plants is negatively geotropie, whereas that of the lateral branches is mly a modified form of this condition. If the terminal bud of a tree ( $: \%$. a spruce or fir) be removed, then one or more lateral branches, or even buils of those branches, will exhibit an increased negative geotropism. This is very markerl in 
the case of the so-called "storm-firs" of the mountains, on which are rlevelopecl not a single apex, as in the normal fir, but many, each of which grows up like a little independent tree on the branches of the old stem. A similar result follows where a portion of a lateral branch is planted as a "cutting," one bud grows directly upwards, the others form lateral branches. The stimulating effect which the removal of the terminal shoot produces on lateral branches is thus one which extends to a considerable distance. A stimulus of a somewhat similar nature appears to be exerted on buds attacked by certain fungi, so

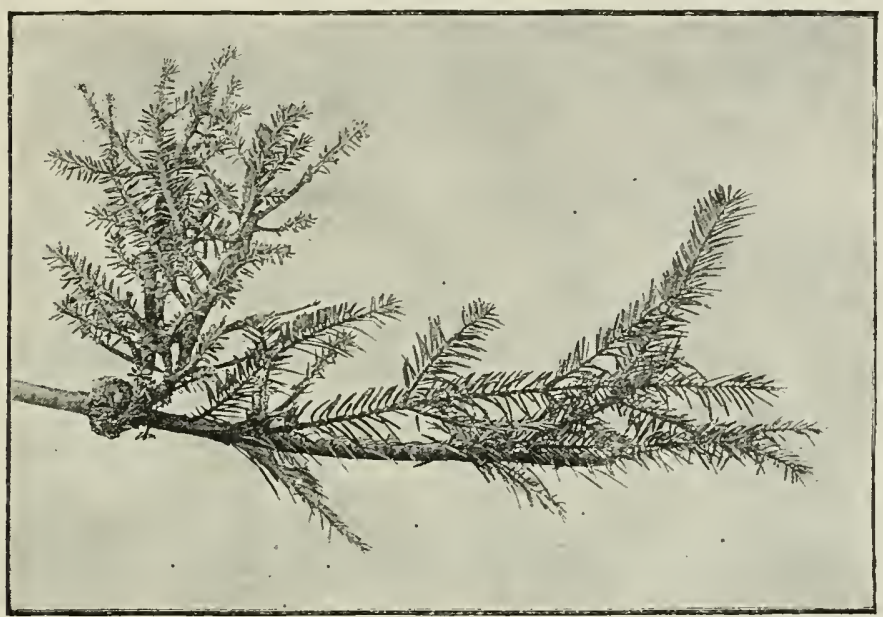
Fic, 16.--Witches' broom of Silver Fir, caused by focidium elatinum.
(v. Tubenf phot.)

that the shoot producel from such a bud no longer retains its normal direction of growth, but becomes negatively geotropic like an independent plant. This marked negative geotropism is characteristic of all witches' brooms (Fig. 16), and shows clearly that they are no longer controllerl by the same laws of growth as the normal lateral branches. They have in addition other peculiarities not exhibited by normal plants. Thus the witches' broom of the silver fir caused by mycelium of Accilium clatinum is not evergreen, but bears needles which fall each autumm. Moreover, no witches' broom bears flowers or fruit; for example, that on the cherry (Fig. 5) produces exchusively leaf-buds. which unfold simultaneously with the 
opening of the flower-huds of mattacked twigs, the nommal foliage coming later.

We have here an expression of the existence of a closer symbiotic relationship between the fungus and its host-luranch, than between that host-branch and its main branch. It also shows that the host-hranch is completely at the service of the fungus, although the latter is dependent on the former for its support. The host-branch is, at the same time, under the necessity of conclueting itself in the partnership in the way nost suitable to the development of the fungus. ${ }^{2}$ Thus the asci of the Fxoalsceae are produced on the leaves of the witches' broom, and ripen as the nommal leaves unfold, so that the spores are in a position suitable for successful infection of the young normal lenves.

From these facts it can be dednced, that parts of plants attackerl by fungi exhibit that kind of symliosis with the fungus which we call indiviluation, the joint community hehaving more or less as a parasite on the stem or branches of the hostplant. This is clearly the case where the attacked parts oxhibit increased growth, and at the same time a diminished production of chlorophyll resulting from degeneration of chloroplasts. Such parts of plants are quite as individualized as the lichens, with the single distinction that they remain in communication with the parent plant and draw nourishment from it.

There are, however, other cases where the chloroplasts are apparently increased, where at least they attain a lengthened duration of life. This is evident in certain instances first pointed out by Cornu, mentioned by De Bary, and on which I have made extended observations. Maples may be found in autumu on whose discoloured, withered leaves large green spots are still present. On Norway maple I have olsserved these spots, very conspicuous on almost every leaf, and especially on those of the lower crown. The green parts were beset with the white epiphytic mycelium and perithecia of Uncinula accris. Cornu describes similar appearances acconpanying another Erysiphe, certain Uredineae, and Cladosporimm. andriticum. I have seen the same phenomenon regularly on the mountain maple on leaves carrying black spots of Rhytismu

\footnotetext{
1 Plant-galls caused by animals also exhibit ataptations serviceable only for the gall-oceupant.
} 
munctetum (Fig. 129). As other examples may be mentioned quince leaves, which I infected with Gymnosporangium clarariceforme, and leaves of Cynanchum Tinctorimum infested with Cronartium aselepiadeum. In all these cases, nutritive substances seem to be still transmitted to attacked parts after death of the rest of the leaf. The attacked spots show also an independent behaviour in that they do not turn yellow before the fall of the leaf, but continue to work at the service of the parasite. One can even believe that these green islands, so long as inorganic substance and water are supplied to them, live with the fungus like lichens, especially those lichens whose algae obtain water and inorganic material direct, not through the fungal-hyphae. 


\title{
CHAP'TER IX.
}

\author{
SYMBIOSIS.
}

\section{\$15. NUTRICISM.}

Fol the greater number of the faets used in our discussion of this peculiar phenomenon, we are inclebted to Frank, who laid the basis of our knowledge in regarl to it. We have chosen the expression Nutricism for reasons already stated $(\S 14)$, and would only add that its scope is variable in different cases, and reaches its most comprehensive application in connection with Frank's views on the so-ealled myeorhiza. We shall hest explain the phenomenon by describing individual examples.

In a number of cases the symbiosis between fungi and higher plants does not result in the fungrus being supplied with organic nutriment by its host, but rather that the fungus is in no way indeloted to the host-plant for nutriment, and may even, is in the lichens, convey solutions of inorganie materials to it, thus assisting in its nutrition. There are two cases distinguishable in this connection. In the first, the fungus lives in humus and in close external contact with the roots of its host, obtaining food for itself, and at the same time supplying its host with organic mitriment. In the other case, the fungus develops inside the root-cells of its host, and is probably nourished from that source, till on dying it gives up certain albuninoid substances, which are absorbed and utilized by the host-plant. The parts of the roots which shelter the fungi, Frank has named "fungus-traps," the plants themselves being "fungus-rligesting plants."

The organs resulting from the symbiosis of root and fungus 
have been named mycorhiza ${ }^{1}$ or fungus-roots. Where, however, new structures (swellings, etc.) are produced on the roots, as a result of symbiosis with fungi or bacteria, the name mycodomatia or fungus-chambers has been applied.

One division of nycorhiza consists of those which live in humus, and act as intermediaries in supplying their hosts with nutritive material. In this case the fungus covers the hostroot like an onter covering, forces itself between the cells of the outer layers, and produces hanstorial branches in the interior of the host-cells. These Frank designates as ectotrophic mycorhiza. The remaining mycorhiza do not form such an external sheath, but live inside the fungus-traps, and produce tangled coils of hyphae in the root-cells of the host. These Frank distinguishes as endotrophic mycorhiza.

\section{Ectotrophic Mycorhiza.}

(1) On non-chlorophyllous plants living on humus

Kaminski ${ }^{2}$ was the first to observe that Monotropa hypopitys, a non-chlorophyllous plant living rooted in forest-mould, possessed a compact root system devoid of root-hairs, but covered with the hyphae of a fungus. At the same time, he expressed the belief that a symbiotic relationship existed between the fungus and the roots of Monotropt , whereby the former supplied nutriment to the latter. The fungus clothes the growing point, and extends backwards to that part of the root which has ceased to elongate: there the mycelium penetrates ${ }^{3}$ inwards between the root-cells, and remains intercellular. The mycorhiza of Monotrope thus showed complete agreement with those known earlier on the roots of C'upuliferne, ${ }^{4}$ and since proved by Frank to have a very general distribution. Johow ${ }^{5}$ has pointed out that an exterial mantle of fungi also exists round the root-apices of Hypopitys hifpophaeger, a holosaprophytic plant devoid of chlorophyll.

\footnotetext{
INarallw, Rodsymliose of Mycomhizer saerlig hos Shortraeme, 1S93. With Bibliography.

${ }^{2}$ Kaminski, Mém. de la sac. des sciences natur. de Cherhoury, T. 24, 1S52.

${ }^{3}$ Frank, Berichte d. deutsch botan. Ges., 1855.

* Miiller, Studier over Skoxjord som Bidrag til Skovdrykningens Theori, 18 is.

"Johow, "Die chlorophyllfreien Humuspflanzen," Pringsheim's Jalubuch, 1 ss9.
} 


\section{(2) On chlorophyllous plants.}

Frank has extender Kaminski's theory to include the myeorhizil of trees and other green plants. This assumption is fomnded on his observations of the common occurrence of mycorhiza on the Cupuliferae, and many other plants. He says that all trees are probably capable, moler certiin conditions, of entering into symbiosis with mycorhiza-fungi, and that in this way the tree is supplied not only with the necessiry water ancl mineral food-constituents from the soil, but also with organic material derived direetly from humus and decaying plant-remains. The tree is thus enabled, through the nycorhiza, to directly utilize organic vegetable remains. Frank supported this theory by imatomical investigation of the mycoriza of numerous plants and later by physiological experiments. The latter consist in the comparative cultivation of seedling forest-trees in a sterilized humus-soil, and also in a non-sterilized soil containing the mycorhiza-fungi. These experiments showed, in the ease of beech, that those trees in sterilized soil with normal roots and root-hairs without mycorhiza, were poorly developed, and died after several years, while the others with mycorhiza sgrew vigorously.

Frank also pointed out that myeorhiza are developed only in soils containing humus, and in the humus layer. He assumes that the fungus conveys to the tree-roots not only carbon compounds, but also, since the nycorhiza-cells contain no nitric acid, nitrogen in organic compounds.

The mycorhiza-caps suppress the formation of root-hairs, but I have freyuently seen hairs on neighbouring roots or on parts of the same root behind the fungus-cap (Figs. 17 and 18 ). In soil free from humus, root-hairs are always present and carry on their work nomally. Schlicht ${ }^{1}$ found that pines growing in poor sandy soil without humus had no nnycorhiza, but only normal ront-hairs. lieess found that pines near Erlangen had quite as many rootlets without mycorhiza as with. It would thus appear that while every tree possesses a number of roots with fungus on them, yet the complete transformation of the whole root-system to mycorhiza is by no means so general as

\footnotetext{
${ }^{1}$ Schlicht, Inang. Dissertation, Berlin, 15s9, p. 9.

Frank, Ber. d. deutsch. botan. Ges., 1592, p. 553.

Reess, Ber. d. deutsch. botan. Ges., 1855, p. 295.
} 


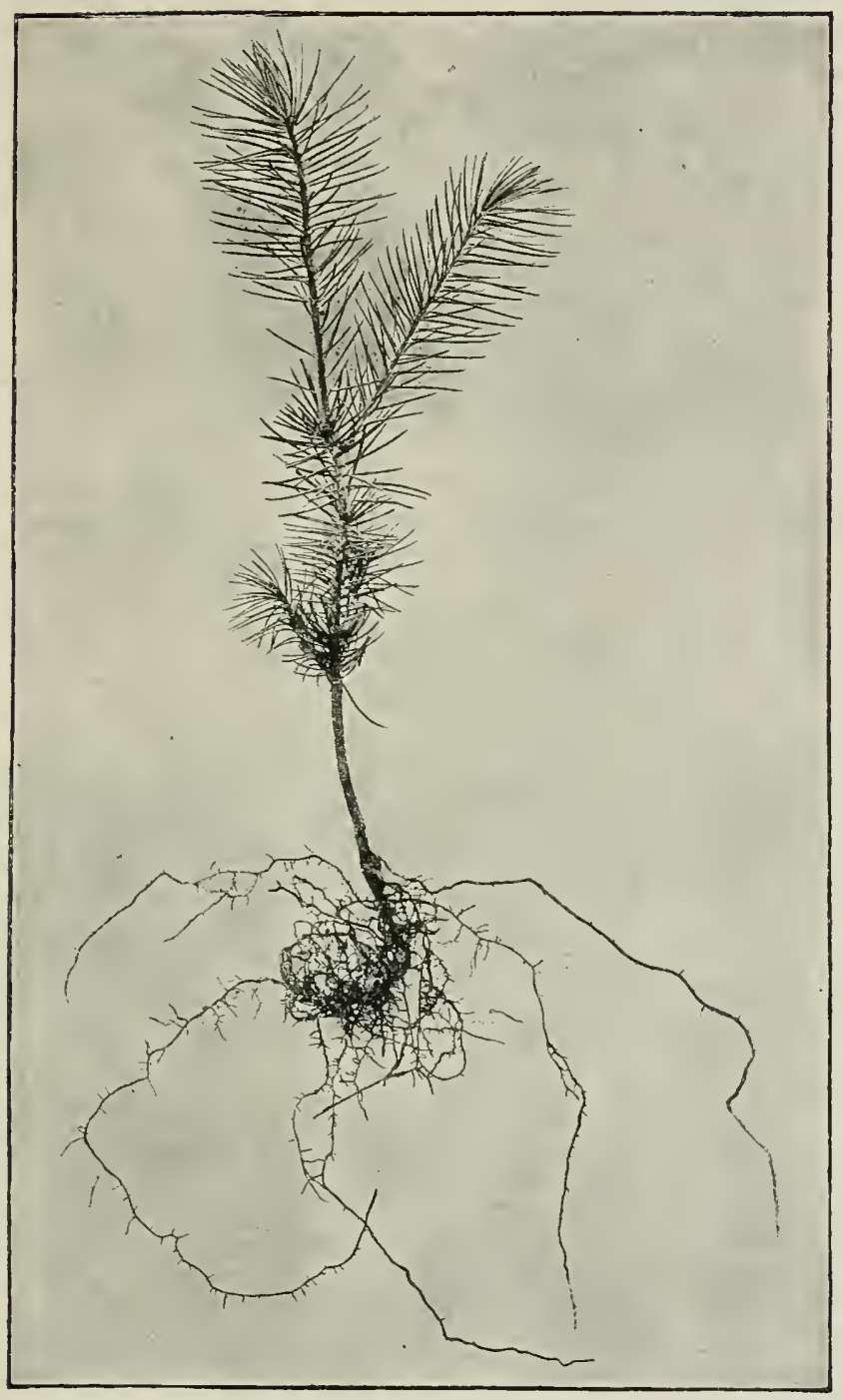

FIG. 17.-Spruce seedling in third year, grown in clay-loam. Typical coral-like mycorhiza are absent. The strong root to the right shows, on its newer parts and on all lateral roots, only root-hairs aud no fungus. The remaining roots are not modified in any way-some are covered with loose fungal caps, others have both fungal caps and root-hairs, while others are quite free from fungi. (v. Tubeuf phot.) 
in Monofripu. The root-system of a tree has not only to secure momrishment, lut also the rigidity and stability of the tree. This latter can only be attained ly a wirle distribution of roots in the firm sulssil free from humus, where normal roots with root-hairs will be formerl. The nursing function of the mycorhiza seems thus to be less important than in the case of Monotrom.
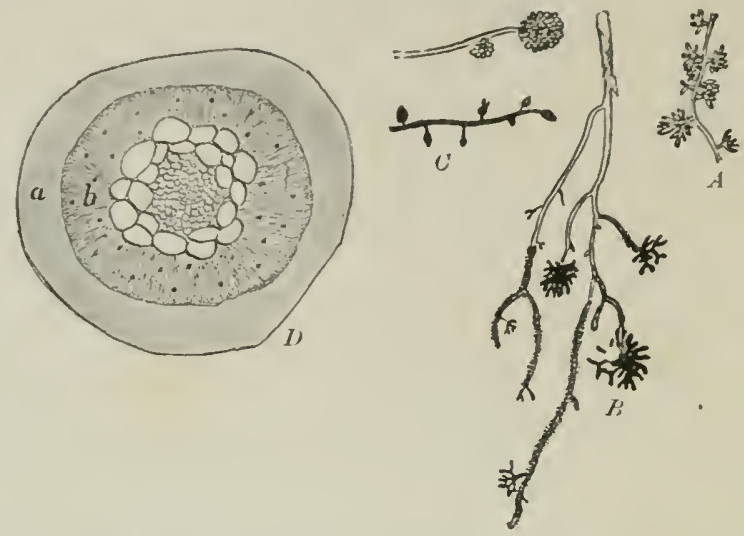

Fig. 15.-Mycortize of Pinus Cembre. A, Typical mycorhiza. B, Ruot showing clusters of uycorhiza as well as portions elad with fine root-hairs. $C$, Rontlet exhibiting button-like thickenings extermally deroid of a fungoid mantle. but internally completely destroyed by mreelium. D. Seetion through a thiekened brunch of a myeorhiza-eluster: a, fungoid mantle; l, fungoid tissue between the eells of the root, rendering them unreeognizable except by their lirge nuclei; the inner parts contiin no fungi. ( $\mathrm{x}$. Tubeuf del.)

My newest investigations on this subject ${ }^{2}$ show that, amongst the gymnospermous forest-trees, the Abietineat alone have roots externally clothed with a fungus; the remaining groups have all endophytic mycorhiza. The Abietineae have frequently only a fine mantle of fungus on their rootlets, and do not produce the tufts of short, branched roots so characteristic of mycorhiza in general. Frank does not seem to be altogether correct in his view that the Abietineae are almost or quite incapable of multiplication by slips, because they would then require to exist for a time without nycorhiza. Probably there is some other reason for this, because the Salicaceae (r.\%. Poplars), which have typical coral-branched mycorhiza, are almost exclusively multiplied by slips.

${ }^{1}$ Hoveler, ("iib. die Verwerthung d. Hunns bei d. Eirnihrung d. chlorophyllfubrenden Pflanzen." Inang. Diss., Berlin, $1592 \%$, states that roots are able to utilize the soil-constituents without aid of fungi.

"'Tubenf, Forst.-naturuis., Zeitschrift, 1896. 
After the mycorhiza have functioned as such for some time, the fungoid sheath, as well as the hyphae contained in the cortex of the root outside the endodermis, are thrown off by internal cork-formation. This is, however, not always the case, for the fungus may penetrate further and develop injurious parasitic characteristics; this is so with Polysaccum ${ }^{1}$ and Elophomyces. ${ }^{2}$

\section{Endotrophic Mycorhiza.}

\section{(1) On non-chlorophyllous plants living in humus.}

Certain Orchicleae-Neottiu Nidus uris, Epiporyon Gimelini, Groolyerr repens, etc., as well as some Gentianeae, ${ }^{3}$ possess roots developed as endotrophic mycorhiza. In Coralliurtizu the fungus frequents the short coral-like rhizomes. The fungus in these cases penetrates into the cells of the root-cortex, and there forms a ball or coil of hyphae; it neither covers the roots externally nor inhabits the epidermal cells, so that the production of root-hairs goes on quite normally. From the circumstance that the hyphal coils become emptied and only the remains of walls are left in the still living root-cells, Frank concludes that the fungus after being nourished for a time by the root-cells is ultimately deprived of its contents by them. On this account he calls these roots "fungus-traps," and the plants possessing them "fungus-rligesting plants." It must be remarked, however, that the fungus grows onwards from older parts of the roots to younger, so that here, as in many other cases, the contents of the hyphae may pass from the older into the younger hyphae. Frank himself suggests ${ }^{4}$ the possibility that the roots take up nutriment without aid from the enclosed fingus, and also that the latter receives its food parasitically from the former. What advantage the roots may receive from reabsorption of food, which they have previously supplied to the fungus, has not been closely investigated, nor has the question whether the roots are in at position to nourish the plants equally well without fungi.

The root-fungi of Orchideae have long been known, and Pfeffer ${ }^{5}$

${ }^{1}$ Bruns, "Beitrag z. Kenntniss 1. Gattung Polysaccum," Florce, 1594.

?Reess, "Untersuch. iiber 1. Hirschtriffel," Bibliog. Botan. 1857.

"Pringsheim's Jahrluch, xvi. and xx.

${ }^{4}$ Frank, Lehrbuch d. Botanik p. 267. ${ }^{5}$ Landuirth. Jahrbuch, 187.. 
suggested that the reduced formation of hairs on their roots was due to the fungus-hyphlate hehaving physiologically as root-hairs.

Johow, in opposition to Frank, states that the non-chlorophyllous Wullschlerigchin, a relative of Ncuttin, shows no trace of

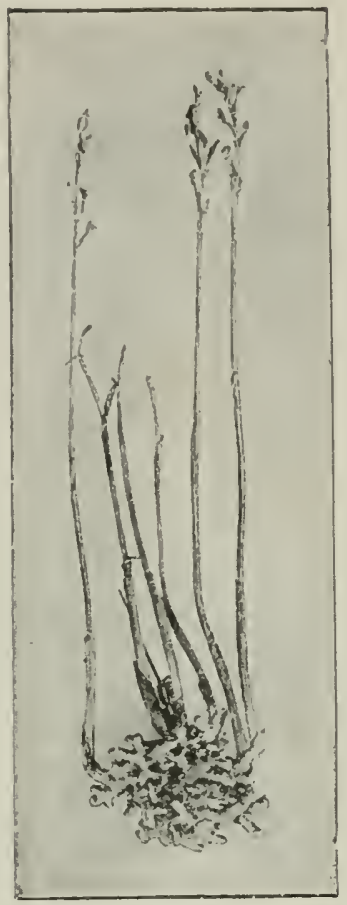

Fro. 19.--Corallionkize in nete $\mathrm{Br}$. (v. Tubeuf phot.)

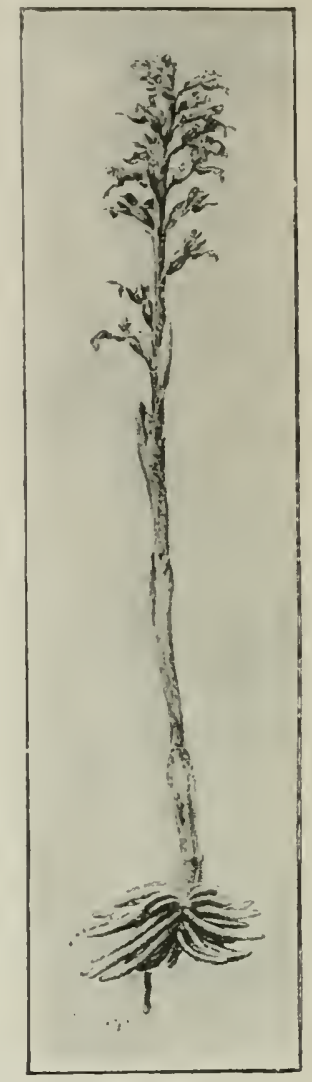
Fro. 20.- Niottia Nidus avis Rich.
(v. Tubenf jhot.)

fungal hyphae about its rots, and yet derives nourishment direct from humus. The same author found among ronts of the Burmanniacrae, some free from fungi, and some with the rind, and even the epidernis full of mycelium.

\section{(2) On chlorophyllous plants living amongst humus.}

According to the investigations of Frank, all our Ericaceae, Epacrideae, and Finpetracene, living in the humus of moor, heath, 
or wood, possess endotrophic mycorhiza. These appear as fine, elongated rootlets whose epidermal cells never develop as roothairs, but become filled with coils of fungoid hyphae.

Schlicht mentions a large number of herbaceous plants out of the most widely separated genera of Angiosperms, the finer roots of which he found regularly developed as mycorhiza. These, however, possess in addition normal root-hairs, which without doubt function as such. The endotrophic coils of fungi are sitnated in the imner cells of the cortex surrounding the conductive tissues, and Sclilicht regards them as important in transmitting to the conducting tissues substances taken up by the root-hairs. Since, however, the fungus inhabits living cortical cells, it is quite possible that these transmit the food-materials direct without the aid of the fungus.

Schlicht found endotrophic mycorhiza on Leguminosae, while Frank found them on the alder, both being distinct from the well-known tubercles of these plants.

Kiihn ${ }^{1}$ and Goebel $^{2}$ found endophytic root-fungi on Marattiaceae, Ophioglosseae, and Lycopodium; Kïln also found spores which resembled those of Schin:ia.

Endotrophic mycorhiza are also present in saprophytic green orchids, as well as in hemi-saprophytic orchids without green colour; and Meineke ${ }^{3}$ found hyphae passing through the little cells of the endodermis of the aerial roots of orchids into the mucilage-masses of the rind-parenchyma. Schimper found fungi present on the adherent side of the roots of epiphytic orchids.

\section{Mycodomatia of Myricaceae, Elaeagnaceae, and the Alder. ${ }^{4}$}

The above-mentioned plants possess a well-developed and normal root-system, and also characteristic lateral outgrowths,

${ }^{1}$ Kühn, "Untersuchungen iib. d. Anat. d. Marattiaceen," Flora, $18 s 9$.

2 Goebel, Botan. Zeitung, 1S5\%.

${ }^{3}$ Meineke, "Beitr. z. Anat. d. Luftwurzeln d. Orchideen," Flora, 1894.

+ Bibliography-Woronin, Mém. de l'acad. des sci. de St. Pétersburg, 1860. Brunchorst, Ber. d. dentsch. botan. Ges., $188 j$.

Brunchorst, Unters. aus d. botan. Inst. Tübingen, 1556.

Möller, Ber. d. deutsch. botan. Ges., 1585 and 1590. Frank, Ber. d. deutsch. botan. Ges., 1S5\% and 1559.

Atkinson, "The genus Frankia in U.S. America," Torrey Club Bulletin, 159:2, p. 1il, with plate. 
which may increase to very large tubers, with surfaces resembling a bunch of grapes (Fig. 21). In the large cells of the middle layers of the primary root-cortex of these growths, coils of very fine fungus-threads are sheltered; these extend year after year into the younger parts of the enlinging tubercles, and gradually disappear in the older parts. What may be the significance of these structures for plants possessing

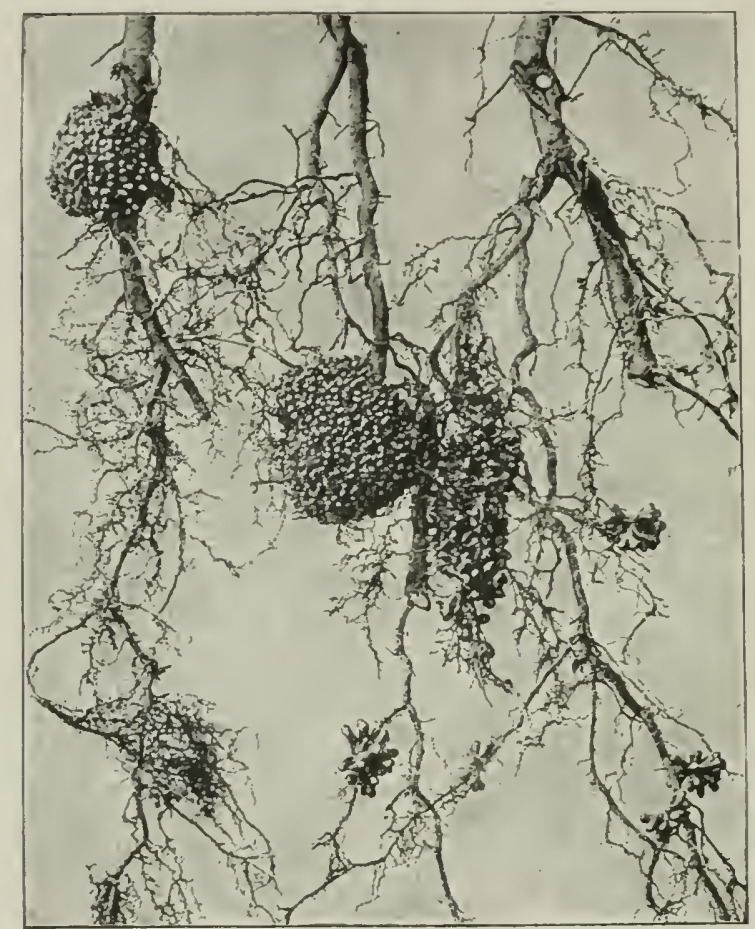

FIr; 21.-Finentia alni. Root-tubercles on the Alder. (v. Tubeuf phot.)

chlorophyll and furnished with normal roots is as yet unknown. I'lants which have grown well for year's in water-cultures do not show them. On account of the cork-covering with which these tubercles are furnished, it would seem that they are not adapted for taking nourishment out of the soil.

Woronin described them first on the alder, Warming on Elaeagnaceae, while Möller proved their fungal origin.

The species of fungi which produce these tubercles have been 
provisionally distinguished as Frankia alni (Wor.) on alder, and Frankia Brunchorstii (Möll.) on Myrica Gale.

Hiltner, ${ }^{1}$ after a series of experiments, states that first-year alders without tubercles do not thrive in soil free from nitrogen, nor do they take up nitrogen from the atmosphere; when, however, provided with root-tubercles they assimilate nitrogen. The tubercles also functionate in water, and soil rich in nitrogen has the affect of slightly increasing the assimilation of that element. The tubercle-fungus is at first parasitic on the alder, and is only of use to the plant after the tubercles have fully developed.

\section{Mycodomatia of the Leguminosae.}

All Leguminosae growing in their native soils exhibit the so-called tubercles. These are accessory formations of the primary root-rind and are furnished with vascular bundles connected with the rootbundles; they consist of a cortex of normal cells surrounding an inner large-celled parenchyma with turbid cell-contents consisting of numbers of bacteria, (Bacterium radicola, Beyerink, or Rhizobium leguminosarum, Frank.) ${ }^{2}$

Frank describes minutely the formation of these tubercles. ${ }^{3}$ The short rod-shaped microlse forces its way into a root-hair or epidermal cell, multiplies there, and is conducted to the inner cortical cells by plasma-threads continuous through the cell-walls. A rapid division of the inner cortical cells is set up, till a tubercle is formed, which may still further increase by continued cell-division from a meristem at its apex. The bacteria multiply simul-

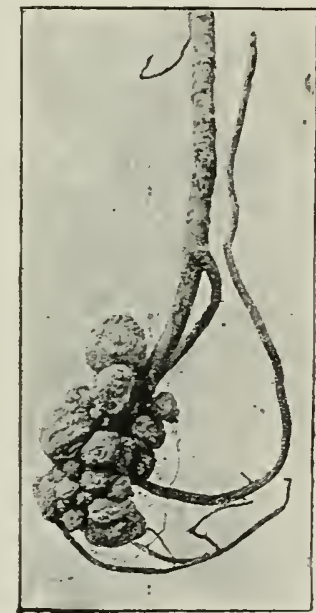

FIG. 22.-Rhizobium legeminosarum. Root-tubercles ou Genisla tincloria. (v. Tubeuf phot.) taneously, and are transferred into the new cells where a great change comes over most of them; they enlarge very

${ }^{1}$ Hiltner, "Ueber d. Bedeutung d. Wurzelknöllchen v. Alnus glutinosa," Nobbe's Landuirtschaft. Versuchs-stationen, 1895.

${ }^{2}$ Woronin, Mém. de l'acad. des sci. de St. Pétersburg, $18 s 6$.

${ }^{3}$ Lehrbuch d. Bolanik, p. 2 II. 
much and become club-shaped or dichotomously branched hodies withont power of division, which may be designated "bacteroids." 1 Brunchorst found the contents of the bacteroids

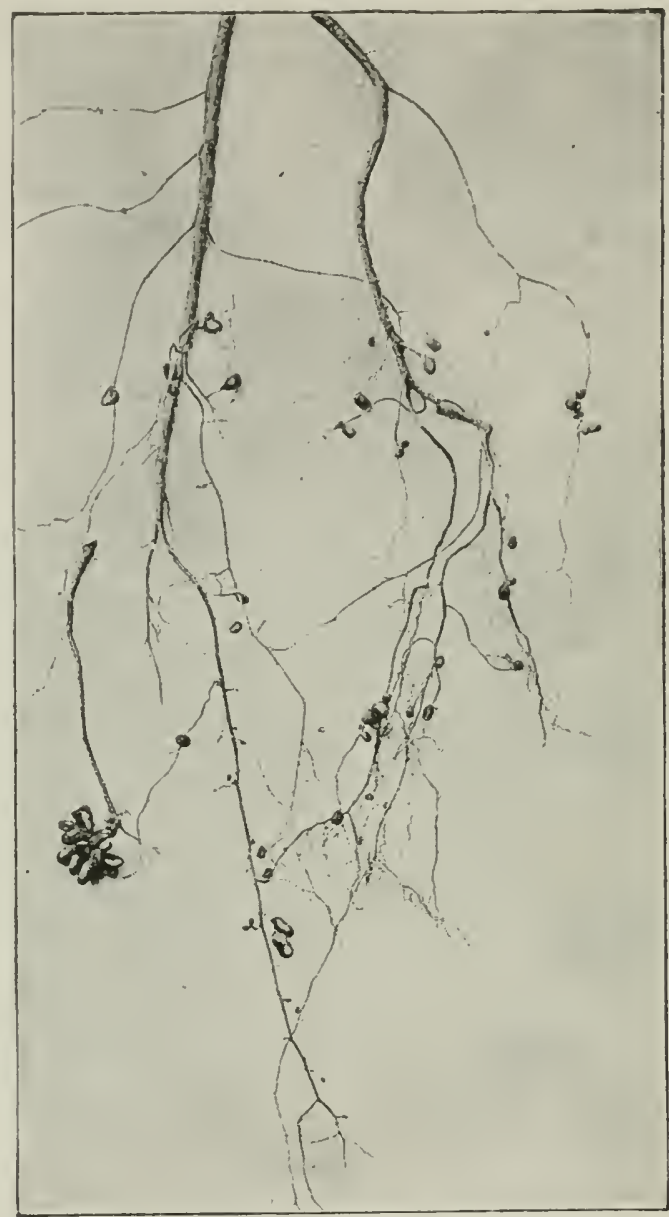

Fug, 23,-Rhizobium leguminosarum. Root-tubercles on Robinia Pseudacacia (v. Tubeuf phot.)

to disappear at the time of the fruit-formation of the hostplant. A small number of microbe-bodies still remain, according to Frank's observations, capable of division, and these, after

${ }^{1}$ According to Moller, they unlergo fatty degeneration. 
decay and break-up of the tubercles, reach the soil ready to bring about new infections.

The great importance of the tubercles of Leguminosae is that the plants bearing them are capable of taking up free nitrogen from the atmosphere and utilizing it, while without the tubercles they conld not do so. ${ }^{1}$ If Leguminosae be grown in soil rich in nitrogenous food-substances, the tubercles are not so well developed.

According to Schneider," the host-plant under the influence of the Rhizobium produces cellulose tubes, which hecome filled with the fungus. According to lieyerink, ${ }^{3}$ these tubes consist of bacterial slime secreted by the Rhisubium. The epidermal tissue of the tubercles consists of a loose layer of cork with many intercellular spaces; this arrangement is stated by Frank ${ }^{4}$ to facilitate the usual transpiration. ${ }^{5}$

${ }^{1}$ Hellriegel n. Wilfarth, Berichte d. deutsch. hotan. Ges., 1s59; also Zeitschrift f. a. Rübenzucker-Industrie, 1 sss.

2 Ber. d. deutsch. Wotan. Ges., 1894, p. 11.

"Centralbl. $f$. Bacterologie u. Parasitenkunde, 1894.

${ }^{+}$Ber. d. rleutsch. botan. Ges., 1592.

s'shneicler (Bulletin of the Torrey Chul, 1S92), gives a short account of American Rhizobia, and refers to the chief works on this subject. (Wlit.) 


\section{PAR'T SECOND.}

\section{SYSTEMATIC ARRANGEMENT OF THE CRYPTOGAMIC PARASITES.}

\section{THE PATHOGENIC FCNGI OE PLANTS.}

TuE vegetative boly of the Fungi is a thalloid structure known as a mycelium, and composed of one or more hyphae. The hyphae are cells included in a firm wall of fungus-cellulose of varying composition; they grow apically, and hence are always filamentons in shape. In the simpler cases, the myceliun is a non-septate tube unbranched or branched; in the more complex forms, it consists of a system of hyphae divided into cells by cross-septa. By the mion and anastomosing of numerous hyphae, a tissue may be formed not unlike the parenchyma of higher plants, hence receiving the name pseudo-parenchyma. From this tissue may arise distinct structures of many linds, such as the sporophores of the Polyporeae, or strands of tissue like the well-known rhizomorphs of Agaricus melleus, or masses of resting-mycelium like the sclerotia of Clariceps. It is also not uncommon to find a differentiation in the structure of the vegetative inyeelium in the form of lateral ontgrowths of the hyphae, leveloped as organs for the collection of nutriment-the haustoria, - or as organs of attachment-appressoria.

lieproduction may take place sexually by the union of two cells or nuclei, the product of which is a spore or zygote capable of germination; or asexually by means of endogenous spores or swarn-spores, or by the abjunction of conidia of different kinds. Sexual reproduction is common anongst the lower fungi, but in the higher forms, if existent at all, it is very 
obscure and is replaced by numerous and complex modes of asexual multiplication.

The lower forms of fungi, in the structure of the thallus, node of reproduction, and adaptation to an aquatic life, exhibit distinct relationship with the Algae, particularly with the Siphonece.

Since the fungi do not possess chlorophyll, their nutrition is carried out by the absorption of organized material in a saprophytic or parasitic manner. Parasitic fungi are the cause of numerous and dangerous diseases of plants, whereas they only rarely bring about a diseased condition of the animal body. Bacteria on the other hand, which cause so many animal diseuses, seldom affect plants injuriously. While many parasites are strictly limited to a parasitic mode of life, a large number naturally spend a part of their lives as saprophytes, and others may be made to do so artificially on nutritive substrata under suitable conditions. The latter method forms in fact a valuable aid for completing our imperfect knowledge of the life-histories of parasitic forms. In addition to the well-marked parasitic fungi, there are many saprophytic forms which become parasitic for a relatively short time or under special conditions of enviromment.

The Fungi are divisible into two large groups, the lower fungi (Phycomycetes) and higher fungi (Mycomycetes).

The systems instituted by rarious investigators differ not a little from each other. Three of the principal are:

DE BARY.

(1) Phycomycetes

(2) Ustilagineae

(3) Ascomycetes

(4) Uredineae

(5) Basidionycetes
ZopF.

(1) Phyconycetes

(2) Mycomycetes

(a) Basidionycetes

(b) Credineate

(c) Ustilagineae

(d) Ascomycetes

Brefeld.

(1) Phyconycetes

(2) Higher Fungi

(a) Mesomycetes

Hemiasci-Hemibasidii

(b) Mycomycetes

Ascomycetes-Basidio-

mycetes

We shall in the present work consider the Fungi in the following order :

Lower Fungi or Phycomycetes:

Chytridiaceae, Zygomycetes, Oomycetes.

Higher Fungi or Mycomycetes:

Ascomycetes.

Ustilagineae, Uredineae, Basidiomycetes. 
1. Lower Fusal (Phycumyetes).

The lower fung possess, at least in their earlier stages, single-celled mycelia, which may in the higher families beconte branched. They reproduce sexually by oospores or zyogospores, asexually by coniclia. The Phycomycetes are dividerl into: Chytrillieerem, Zyygomyetes, anel Oomyertes.

\section{(1) ('HYTRIDIAC'EAE.}

The fungi of this family are chiefly parasites on aquatic plints, or on land-plants inhabiting noist places. The mycelium is one-celled, very rudimentary, or altogether absent. Asexual reproduction takes place by the formation of zoosporangia which usually produce uniciliate swarm-spores. Sexual reproluction is rare, and is effected by fructification of one cell ly a fertilization-tube from another; the resulting bodies are zoosporangia which on germination set free swarn-spores. Hibernation is effected by resting-spores produced from sporangia in which the formation of swarm-spores is suppressed, and which become clothed in a thick nuembrane. Some of the species cause interesting deformations on the organs of plants.

The Chytridiacene include the families of Olpidiacece, Synchytriacae, Cladochytriacene, Rhisidiaccae, Hypochytriacear, and Oochytriacce. Of these, only the first three contain species parasitic on higher plants. They occur epidemic only in moist situations, and rarely cause great damage to cultivated plants.

\section{OLPIDIACEAE.}

The whole vegetative body becomes a single zoosporangium or a resting-spore. Sexual reproduction is very rare.

\section{Olpidium.}

The vegetative body consists of a maked mass of protoplasm, the product of a single spore. This becomes later enveloped in a thin wall of cellulose, and forms a zoosporangium with a long neck through which the cell-contents are ejected as uniciliate swarm-spores. The cellulose membrane may become thicker and a resting-spore (sporangium) result, which in course of time germinates and gives off swarm-spores.

${ }^{1}$ Bibliography-A. Fischer in Rabenhorst's Kryptogamen Flora, 1592. Schroeter in Engler-Prantl Pflañenfamilien, 159:. 
Olpidium brassicae, (Wor.) $)^{1}$ (=Chytridium brassicae, Wor.) Cabbage-seedlings die if this fungus finds its way into the tissue at the neck of the root. The spherical sporangia are formed at this place, and their long necks project out of the cells enabling the uniciliate swarm-spores to escape. Resting-spores with a warty thickened membrane occur in the cells of the epidermis.

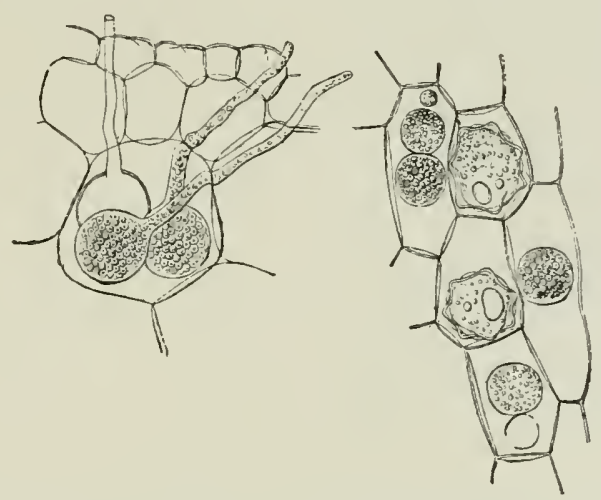

FIG. 24.-Chytrilium biressicae, Wor. Cell containing three sporangia, two of which are discharging zoospores; one sporangium is already empty. Resting. spores inside the cells of a cabbage-plant. (After. Woronin.)

The disease is favoured by moistnre, and restricted by dry surroundings. Ground subject to attack should be planted with crops other than cabbage.

Olpidium trifolii, Schroet. (= Synchytrium trifolii, Pass.) Proluces deformation of the leaves and petioles of Trifolium repens. The fungus lives in the epidermal cells.

Olpidium lemnae, Fisch., in epidermal cells of Lemnu.

Olpidium simulans, De Bary and Wor., in Taracteum officinale.

A number of other species inhabit algae, spores, fungusmycelium, pollen-grains, and egrgs of Rotatoria.

The genera Recssia, Pscudolpidium, Olpitliopsis, Plcotrcchclus, Ectrogella, Plcolpidium are parasitic only on lower plants, especially on algae.

\section{SYNCHYTRIACEAE.}

The whole mycelium divides up into a number of sporangia, which remain together as a sorus. The winter resting-spores

1 Woronin, Pringsheim's Jahrbuch f. wiss, Botanik, 1878 (Fig. 31). 
originate from the whole nycelium or parts thereof, and are isolated or united into a sorus.

\section{Synchytrium and Pycnochytrium. ${ }^{1}$}

Here, as in Olpidium, the mycelial hyphae are wanting, and the vegetative body eseapes from the spore as a naked mass of plasma, which is later enclosed in a membrane. This vegetative body may also develop into a sorus of thin-walled sporangia: these separate in water, and each ejects from a pore numerous swarm-spores with a single long cilium. In the event of restingspores being formed, the nembrane of the regetative body becomes thickened into a brown exospore. The resting-spores on germination liberate their contents as a single mass, or as several zoospores. In the former case the single mass divides at once into zoospores, or into a sorus of sporangia, which ultimatcly give off zoospores.

These fungi are found in the interior of cells, especially of the epidermis. The one eell inhabited by the fungus grows out as a simple papilla, or several neighbouring cells are also modified, and grow out along with the original one to form a gall-like swelling. The species of Synchytrium generally inhabit the epidermal cells of land plants, yet disease caused by them is commoner in moist than in dry situations. They cause so slight deformation and damage to enltivated plants that they are of little practical importance.

The Pycnochytrium of De Bary is regarded by Fischer as a sub-genus, by Schroeter as a genus.

\section{Synchytrium.}

The sori of zoosporangia are formed by direct division of the mature sporophore, and are enclosed in the colourless membrane of the mother-cell.

Synchytrium taraxaci, De Bary and Wor. (U. S. America).2 This produces, especially on Taraicucum, warty galls composed of a diseasecl epidermal eell, enlarged and surrounded by a wall of

\footnotetext{
${ }^{1}$ Schroeter: Coln's Beitrïge z. Biol. d. Pflanzen I., 1875, and in Engler.Pruntl Pfanzenfamilien, 1892.

De Bary and Woronin, Bericht. d. natforsch. Ges. zu Freiburg, 1863.

" We propose to inclicate in this way species recorded in Seymour and Farlow's "Host-index" for North America; British species by (Britain). (Edit.)
} 
less swollen neighbouring epidermal cells. The sporangia contain reddish-yellow drops of oil, so that the swellings appear yeliow. The organs attacked are much distorted and more or less stumted.

The same fungus occurs on other Compositae, and is probably identical with $S$. sanyuineum of Schroeter, which produces dark red, crusty swellings on Cirsium polustre and Crepis biennis.

Along with S. terrasci one often finds Olpillium simuluns.

S. fulgens, Schroeter (U. S. America), produces reddishyellow swellings on the leaves of Oenothere biennis and 0 . muricute; when resting-spores appear they form brown crusts.

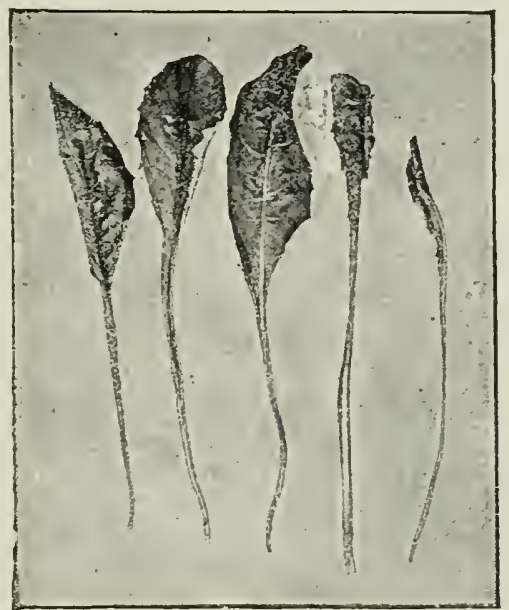

FIG. 25.-Synchytriun tarexuci. Leaves of Taraxacum omincinale so deformed by the fungus that the laminae are all more or less undeveloped. (v. Tubeuf phot.)

The sori of zoosporangia are

detached from the host-plant as single sporangia, which become scattered over the leaves.

S. trifolii, Pass. (=Olpiclium trifolii, Schroeter), is as yet little known.

Other American species are:-

S. papillatum, Farl., on Gercuium.

S. decipiens, Farl., on Amphiearpaee.

S. vaccinii, Thomas, ${ }^{1}$. on Vaceinium, Geuttheriu, Kalmiu, Rhododcndion, etc.

\section{Pycnochytrium.}

The sori of zoosporangia are not produced directly from the mature sporophore, but the contents of the sporophore pass ont by a fine opening and form a thin-walled vesicle, the protoplasm of which breaks up into sporangia.

Sichroeter divides the genus into two sub-genera.

(A) Mesochytrium. The discharge of the original sporophore

${ }^{1}$ Halsted, "Cranberry gall-fungus"; N. Jersey Agric. Coll. Bullet. 64, Dec. 1859. With figures. 
and the formation of zoosporangia take place in the cells of the living host-plant. In addition, spores are formed which have a resting period.

(b) Only one kind of spore is formed; it has a resting period, and only proceerls to produce sori of zoosporangia after decay of the host-plant.

(11) Chrysochytrium: protoplasm eontains a yellow oil.

(b) Leucorhytrimm: protoplasu eolomrless.

Eiteh of these divisions is sub-divided into forms with simple vesicles, and those with eompound.

\section{Mesochytrium.}

Synchytrium (Pycnochytrium) succisae, De Bary and Wor. ${ }^{1}$ This parasite forms warty swellings and yellow spots, generally
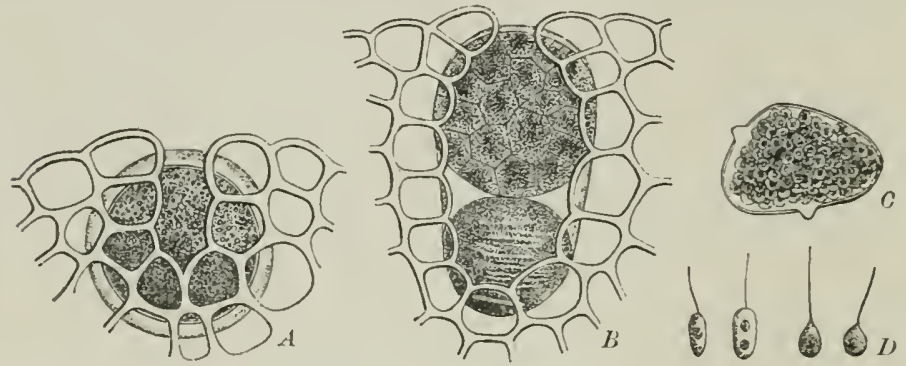

Fig. 26.-Sinschytrium succisce. A, A mature sporocarp inside its host-cell. $B$, lu the upper nart of the cell a sorus of swarm-sporangit after escaning from its covering, which lies below it. $C$, Isolited swarm-sporangium. $D$, Swarmspores. (After vichroeter.)

on the radical leaves and base of stem of Scctbiosa succisc. Infection is lorought about in damp situations by means of swarm-spores. These have a single cilium, and bore their way into the host-cell. After entrance, they produce a plasma-mass, which becomes enclosed in a delicate membrane. The cell so formed sprouts at its uppermost pole, and gives rise to a new spherieal cell, into which the older discharges itself. In the second cell numerous small sporangia are formed, so that it represents a sporangial sorus; beside it is always found the empty membrane of the first cell. The sorus breaks up later into single sporangia, which on opening, set free their contents

${ }^{1}$ Schroeter, "PHanzenparasiten aus l. Gattung Synchytrium." Cohn'x Beitr. :. Biolog. d. Pftansen, 1575. 
as zoospores swarming by means of a cilium. In addition, resting-spores are developed singly or in groups.

The first effect on the host-cell of the entrance of a swarnspore is that it becomes distinctly larger. At the same time neighbouring cells are so stimulated that they multiply and form a prominent ring-shaped swelling. The sporangia discharge their zoospores on the host-plant itself, and these pass into other cells of the swelling; here they form resting-spores and the host-cells die. Schroeter states that the resting-spores may be found from August onwards.

S. stellariae, Fuck. On Stellaria metic and S. nemomem. The reddish-yeliow hemispherical swellings are produced on leaves, stems, Hower-stalks, and sepals, either isolated or as a crust. The resting-spores generally form brown crusts. The host-leaves may be somewhat crumpled, but beyond this undergo little deformation. ${ }^{1}$

\section{Chrysochytrium.}

(1) Forming simple resicles:

Synchytrium myosotidis, Kiihn (U.S. America). The epidermal cells whẹ attacked swell up to form club-shaped processes, while the cells with no fungus remain unaltered. The normal hairs of the host-plant are fewer on diseased than on healthy parts. This parasite attacks Boragineae, c.y. Myosotis stricta, Lithospermum arense.

S. cupulatum, Thomas, produces red eruptions on Potcntilla crogenter and Dryers octopetale; diseased cells of the host-plant contain red sap.

S. punctum, Sorokin. On Plentengo lenecoleter and $P$. mertia.

S. laetum, Schroet. On Geigea.

(2) Forming compound vesicles:

S. aureum, Schroet. Attacks many herbaceous plants as well as leaves of many shrubs and trees. Frequent on Iysimachice Summularia, Fraguria, etc. The cells attacked are swollen and enclosed in a patch of enlarged neighbouring cells.

S. pilificum, Thomas. On Potentilla Tormentille. The vesicles are hemispherical, and bear on their summits a tuft of abnormally elongated hairs. Thomas ${ }^{2}$ found this species

${ }^{1}$ Clendenin (Botanical Gazette, 1894, p. 296) describes and figures a Synchytrium on Stellaria media in America (Edit.).

2 Ber. d. rlutsch. botan. Ges., 1853, p. 496. 
on stems, flower-stalks, rarlieal and cauline leaves, and floral envelopes.

\section{Leucochytrium.}

(1) Forming simple vesicles:

S. punctatum, Schroet. On Grugce prectensis.

S. rubrocinctum, Magnus, forms little rerl eruptions on Scuifirerge yirenulutu, the cell-sap of the host-plant becoming reel.

S. alpinum, Thomas. On Vivla tiflore.

S. anomalum, Schroet. (U. S. America). On Ailorre Moschethllina, less conmon on Renunculus Ficrria, Isopyirum thrictroides and Riumir Acrtose. The size and shape of the swellings, as well as of the spores, are very variable.

(2) Forming compound vesicles:

S. anemones, De Bary and Wor. (U. S. America). On Anrmone nemorose, A. ranunculiniles and Thatictimm purpure-

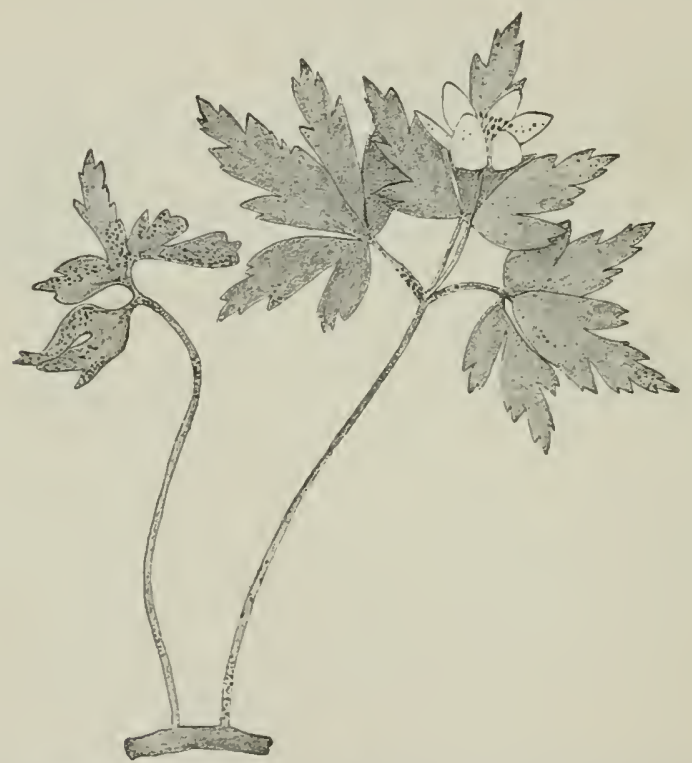

F1G. 27.-Synchytrien cinenones. The sporocarps form black points on luitus, petioles and perianth of the Anemone; the laminie are also stunted and distorted. (v. Tubeuf del.)

scchs, attacking stems, leaves, or tlowers, and forming eruptions whose cells contain a red sap. In very bad cases, erumpling and swelling of attacked organs occur. 
S. globosum, Schroet. Where the attack is severe, this causes pearly swellings or incrustations; it frequents plants like Viole, Gelium, Achillea, Sonchus, Nysotis.

S. mercurialis, Fuck., is very common on Mcreuricelis perennis though seldom injurions to it. One severe case is thus described by Schroeter: "In spring the stem of the plant was covered by a thick uneven glassy crust, which in course of time became raised into wing-like processes running clown the stem and coated on both sides with white granules of the immature parasite; the leaves were completely rolled together, crumpled, and covered with glistening prominences as with fine silver sand. The plant in this condition developed poorly, scarcely flowered, and soon died, so that by the end of September few diseased examples could be found."

\section{CLADOCHYTRIACEAE.}

The regetative body is frequently a branched mycelium. It lives intercellular as a saprophyte, or intracellular as a parasite, and forms intercalary or terminal swellings, in which zoosporangia or resting-spores are produced, then it disappears. Sexual reproduction does not occur. The parasite lives in and forms swellings on aquatic plants, or land plants in moist situations. The genera Urophlyctis and Physoderma contain species parasitic on higher plants; together with the saprophytic Cladosporengium, these are regarded by Fischer as sub-genera of Cladochytrium, and as such they are also here regarded.

Urophlyctis has both zoosporangia and resting-spores, Physoderma has only resting spores, Cledosporangium only zoosporangia.

\section{Urophlyctis.}

The delicate mycelium is unbranched, or only slightly branched, and lives endophytic, boring through the walls of the host-plant. At the place where a hypha enters a hostplant it forms a swelling or collecting cell (sammelzell), which generally becomes differentiated into a larger cell rich in contents, and an outer smaller one with few contents, but with fine terminal bristles. From the collecting cells new hyphae originate and produce other collecting cells in neighbouring host-cells. The zoosporangia are situated outside the host-cells, 
but send a hyphal process inside, which branches into a tuft of rhizoils. liesting-spores may be found, several in each cell.

Cladochytrium (Urophlyctis) pulposum, (Wallr.), causes on leaves, stems, and Howers of Chenoportium and Atriples glassy swellings, in the undermost cells of which are situated the zoosporangia. The resting-spores have brown shining walls and lie inside the cells. The zoospores are miciliate.

Cl. (Ur.) butomi, Biisgen. On leaves of Butomus umbellatus. Black spores are produced containing resting-spores. The collecting cells have tufts of hair.

\section{Physoderma.}

Zoosporangia are absent. liesting-spores formed, several in each host-cell.

Cladochytrium (Phy.) menyanthis, De Bary (U. S. America). (On leaves and petioles of Menyonthes trifoliate this forms vesicles containing resting-spores. The collecting cells have terminal hair-tufts. Diseased leaves are generally smaller than healthy.

Cl. (Phys.) flammulae, Biisgen, forms little swellings on leaves of Ranunculus Flummulu.

Cl. (Phys.) Kriegerianum, Magnus, causes transparent swellings on Carrum Carrei.

Cl. (Phys.) iridis, De Bary, on Iris pscudacorus.

Fischer mentions other species on Scirpus; Alisma, Ranunculus, Potcntilla anserina, Silans pratensis, Sinm latifolinm, Phalaris, Glyceria, Symphytum, Nentha, Rumex, Allium, etc.

Prunet ${ }^{1}$ describes Cladochytrium viticolum as the cause of the much-discussed Brunisure of vine; also $\mathbf{C l}$. mori as a new disease of the inulberry. ${ }^{2}$

The same authority ${ }^{3}$ designates as Pyroctonum sphaericum, a parasite ou wheat, which has becone very abundant in Southern France.

\section{(2) ZYGOMYCETES.}

Unicellular fungi. Sexual reproduction does not take place by the fertilization of an ovum in an oogonium by an antheridium,

\footnotetext{
${ }^{1}$ Prunet, Compt. rend., 1894.

${ }^{2}$ Prunet, Compt. rend., cxx., 1895, p. 222.

${ }^{3}$ Prunet, Compt. rend., 1894, Iı, p. 108.
} 
but by conjugation or union of two cells of the mycelium separated off from the ends of two hyphae by transverse walls. As a result of conjugation, a zygospore is produced, which is a resting-spore and corresponds to the oospore of the Oomycetes. The zygospore puts forth a germ-tube, which becomes a mycelium bearing sporangia on sporangiophores. From each sporangium, spores, never swarm-spores, are set free, germinate, and produce a mycelium. Sporangia similar in form to the zygospores may be asexually produced on the mycelium. The unicellular and much-branched nycelium grows into its substratum, and is nourished as a rule saprophytically. The Entomophthorecte cause important insect-diseases on Muscidae, Cabbage Butterflies, and caterpillars of Trachea piniperda (the Pine Beauty).

Another common group of the Zygomycetes, the Mucorini, penetrate into bruised places in living fruits, and produce decay (see p. 1S0). Some other Zygonycetes are parasitic on fungi (Conidiobolus), some on animals.

\section{(3) OOMYCETES.}

These fungi possess a one-celled and much-branched mycelium. In their vegetative structure they most nearly resemble algae like Vaucheria. Reproduction is brought about, asexually by means of swarm-spores formed in sporangia (conidia also occur); sexually by oospores derived from oogonia and antheridia.

There are three families of Oomycetes: Sapiolegniacece, Monoblepharidece and Peronosporece. Two of these groups contain parasitic forms: Saprolegnincene (e.f. Achyle prolifere, dangerous to Fish and Crustaceans); and Peronosporece.

\section{PERONOSPOREAE.}

The greater number of the Peronosporeae live as parasites in the tissues of higher plants, and obtain nourishment generally by means of haustoria. The mycelium, in earlier life at least, has no dividing septa, and generally grows in the intercellular spaces of the lost-plant, and sends haustoria into the cells. Reproduction is effected asexually by formation of swarm-spores in sporangia, and sexually by means of oospores. The latter are produced from the fertilization of an ovum in an oogonium by an antheridium whose contents pass through a fertilization-tube penetrating the 
cogonimu wall." No formation of spermatozoids occurs, as is the case in Voucherio and other groups of algae showing close relationship to these fungi. In certain cases the formation of swarm-spores in sporangia does not take place, but conidia are produced, which germinate directly into a myeelium.

l'reventive measures against the whole group consist in destruction (by burying or liurning) of diseased and dead parts of host-plants which contain the hibernating oospores; by change of (rop on infected fields; and by treatment with copper reagents (see Cliap. VI.).

To the I'eronosporeac belong the senera Pythium, I'lytople-

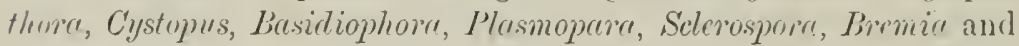
I'ronosporre.

\section{Pythium.}

The mycelium possesses no haustoria, and grows both between the host-cells and inside them. Cross-septa are not present at first, but later these may be found at irregular intervals. P'ythium lives as a parasite in living plants, or as a saprophyte on a dead smbstratum. The conidia are of various forms, and either germinate directly into hyphal filaments, or discharge their contents into a bladler where zoospores are developed and liberated as free-swimming spores with two lateral cilia. The oogonia contain only one ormm-cell, which is fertilized by means of an antheridial tube applied to the oogonium. The thickwalled oogonia on germination produce hyphae or discharge zoospores.

Pythium de Baryanum, Hesse ${ }^{2}$ (Britain and U. S. America). This parasite is injurious to the seedlings of various plants in gardens and fields. Some of its commoner hosts are maize, clover, mangel, millet, and many species of the Cruciferae; it has also been found on the prothalli of Equisetum and Lycopodium." It may also attack living or dead leaves and tubers of potato.

The sporangia have a lateral beak-like outgrowth, into which the plasma passes and divides into biciliate zoospores. The

${ }^{1}$ In many speeies the fertilization-tube remains closed e.g. Plasmojara riticola.

"Hesse, Pythinm de Baryanum, Halle, 1574. Atkinson (C'omell Eniv. Arric. Expt. Stat., Bull. 94, 1895), describes and figures this and otlier fungi eansing "I Mamping-off." (Edit.)

"Sadelseck, Naturforsch. - Versammluny., 1576. 
sporangia, however, may first pass through a resting period. Sexual reproduction consists in the impregnation of an egg-cell by means of a fertilization-tube from an antheridium. The oospores are formed singly in each oogonium, and are liberated only after decay of the oogoniurn walls and the tissues of the host-plant containing them. After a resting period they produce a germ-tube, which penetrates into the host-plant and becomes a delicate branched colourless intercellular mycelium. Hibernation is accomplished both by these oospores and by restingconidia, which remain amongst the decaying plant-debris on the ground.

Humphrey has observed sickness and death of cucumber seedlings as a result of $P y$. de Buryanum. Wittmack found a species (Py. Sadebechianum) very destructive on peas and lupines ${ }^{1}$ in various localities; it has been observed frequently since.

Py. gracile is parasitic on algae.

Py. dictyospermum, Rac. occurs in Spirogyru.

Py. cystosiphon is found on species of Lemna.

Py. intermedium frequents prothalli of vascular cryptogams.

\section{Phytophthora.}

The mycelium is at first non-septate though much branched. It grows both between and through the host-cells, and in some species, (c.\%. Ph. omnivor( $)$, has small haustoria.

The conidiophores branch and produce a large number of conidia or sporangia in succession. The first coniclia are terminal, but are displaced towards one side and thrown off by further growth of the conidiophore to produce other conidia.

The sporangia distribute their contents as swarming cells with two lateral cilia; the conidia produce a hypha direetly. The eyg-cells are developed one in each oogonium, and are fertilized by an antheridium. The spherical oospores germinate in spring by means of a germ-tube.

Phytophthora omnivora, De Bary ${ }^{2}$ (syn. Ph. fagi, R. Hartig.) This is a destructive enemy to the seedlings of conifers, and even more deadly amongst naturally-sown beech-seedlings. Death of the beech is preceded by brown-spotting of stems, cotyledons and

${ }^{1}$ Verein z. Bef. d. Moorkultur, 1891.

"R. Hartig, Zeitschrift f. Forst u. Jagd-wesen 1875; also, Untersurhungen aus 1. forstbotan. Inst. Wiüchens, 1850. 
first leaflets. 'The disease is spread during smmmer by conidia, or swarming cells produeed from sporangia. The passarge through

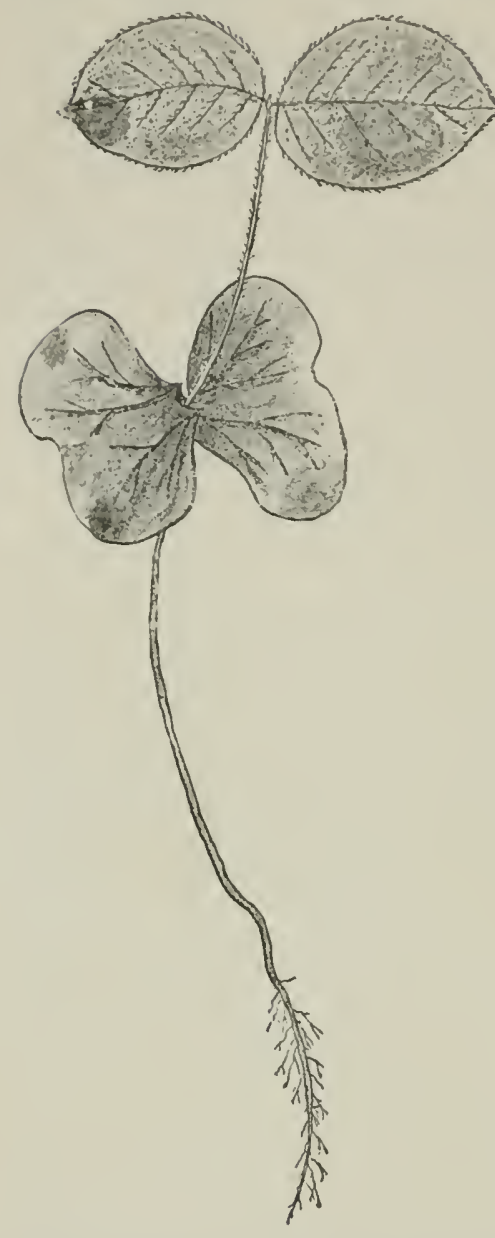

Fitt. Es. - Phylophliora omnivora. Cotyledons and primary leaves in early stage of attack the disense forms brown spots where patehes of mpeclium are developed. $\frac{4}{\delta}$ natural size. (s. Tubeuf del.)

The fungus often appears in such force that seed-beds of beech or conifers are demuded of every plant within a few days, and in the forest beechseedlings may, during damp weather, be completely exterminated nver great areas. oospores, resulting from fertilization of an ovum in the oogonimu by a fertilization-tube from an antheridium. The intercellular mycelium is at first nonseptate, later septate, and forms small hanstoria. Seedlings of other plants, besides those alrearly mentioned, and also suceulents (c.g. Simperuivum and Cuctus) nua be attacked and killed by this sime fungus.

This epidemic cammot well be combated except by methorls applicable only in the nursery. The most effective method is to plant no young seedlings in plots which have already been diseased, but to reserve such plots for older plants to which the fungus is not dangerous. If the disease be not very greneral, attacked plants may be removed singly and destroyed. Since moist air is very faromable to distribution of the disease, all nettings or trellises should be removed from seed-beds threatened by attack. In dry airy localities there is less danger to seedlings than in moist.

winter is effected by means of 
Another parasite of conifer seedlings-Fusoma parasiticumwhich somewhat resembles Phytophthora, is figured and described amongst the "Fungi imperfecti."

Phytophthora infestans, De Bary. ${ }^{1}$ This parasite was first observed in Europe in 1845, and has since then becone

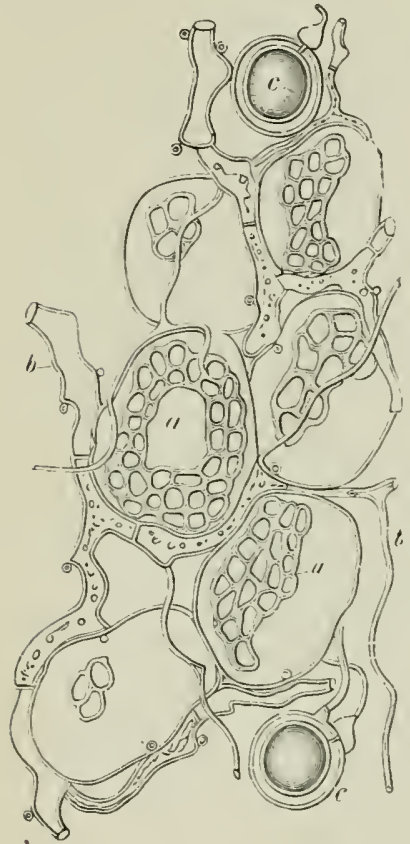

Fig. 29.

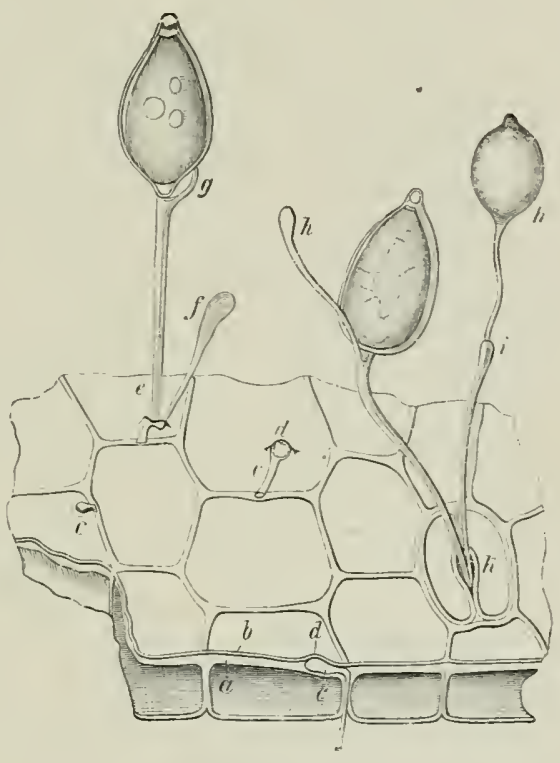

FiG. 30.

FIG. 29.-Cellular tissue from diseased cotyledon of Beech. The starch-grains have been absurbed from the cell-protoplasm which has shrunk awar from the cell-wall $a ; b, b$, intercellular fungal hyphae with very tiny haustoria; $c, c$, fertilized oogonia, each containing a single oospore. (After R. Hartig.)

Fig. 30.-Phytophthora omnirora on the epidermis of a Beech-cotyledon. a Outer wall of epidermal cell; $b$, cuticle; $c$, hyphae growing between cell-wall and cuticle, causing the slight protuberance $d ; e$, spot where a bypha bas emerged through the cuticle and dereloped as a sporangiophore $f$; after the first sporangium has reached maturity a second begins to form, $g$ and $h$, whereby the first is displaced; $k$, a stonit from which sporangiophores have developed. (After R. Hartig.)

only too well known. It attacks leaves, shoots, ancl tubers of potato and other Solanaceae, c.g. the tomato (S. Lycopersicum). The potato leaves become discoloured, brown-spotted, and crumpled, especially in damp weather. The sporangiophores (gonidiophores of De Bary) issue from the stomata in

${ }^{1}$ De Bary, Journal of Botany, 1876, and Joumal of the Royal Agric. Society, 1876. 
tufts, and form a white border round the brown parts of the leaf; they are monopodially branched and produce terminal sporangia (gonidia), which are easily detached. The sporangia

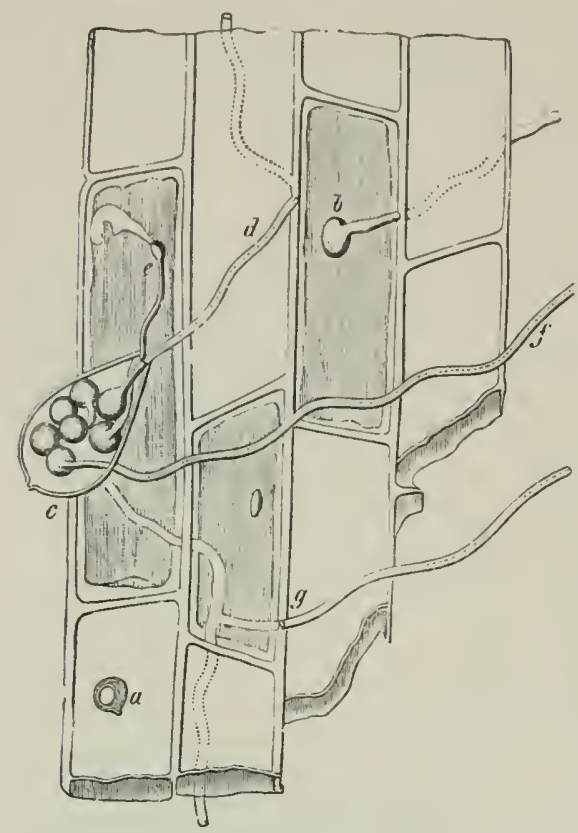

Fit: 31.-Surface of a Beech-seedliug with swarmspores $a, b$; the germ-tubes from these ponetrate between adjicent epidermal cells ; $c$, sporangium with zoospores already germinating inside it, $l, f ; c, a$ germ-tube which has penetrated directly into an epidermal cell; $g$, germ-tube which, after growing for a time inside a cell, has again made its way out. (After R. Hartig.)

( 1 ) the potato-blight or wet-rot which, according to Boehm, is the result of closing up of the lenticels, with a consequent stoppage of respiration; (b) bacteriosis, which will be considered amongst the bacterial diseases of plants.

Lagerheim $^{3}$ has pointed out that Solanum muricatum unch cultivated in Ecuador on account of its edible fruit, has been for many years subject to attack from Phytophthora infestams; the fruits sicken and rot off before ripening. The

1 This is a well-known point of controversy, for an interesting discussion of which we would refer to "Disea.ses of crops," Worth. G. Smith, 18S4. (Edit.)

"Boehm, Sitzungsber. 1. Zool.-botan. Ges., Vienna, 1592.

"Rivista Ecuatoriana, 1591. on germination either produce a varying number of zoospores, or germinate a mycelium capable of producing new conidia. The potato-disease is distinguished from Phytophthora omnivora in the absence of sexual reproduction by oospores.' It is grenerally assumed that the mycelium hibernates in potato-tubers, from which the fungus recommences to spread in spring. Boehm, ${ }^{2}$ however, contests this, and holds the hibernation of the fungus to be quite unknown, and that from the tubers of a diseased plant, either a healthy plant or none at all results.

The Phytophthore potatodisense is quite distinct from 

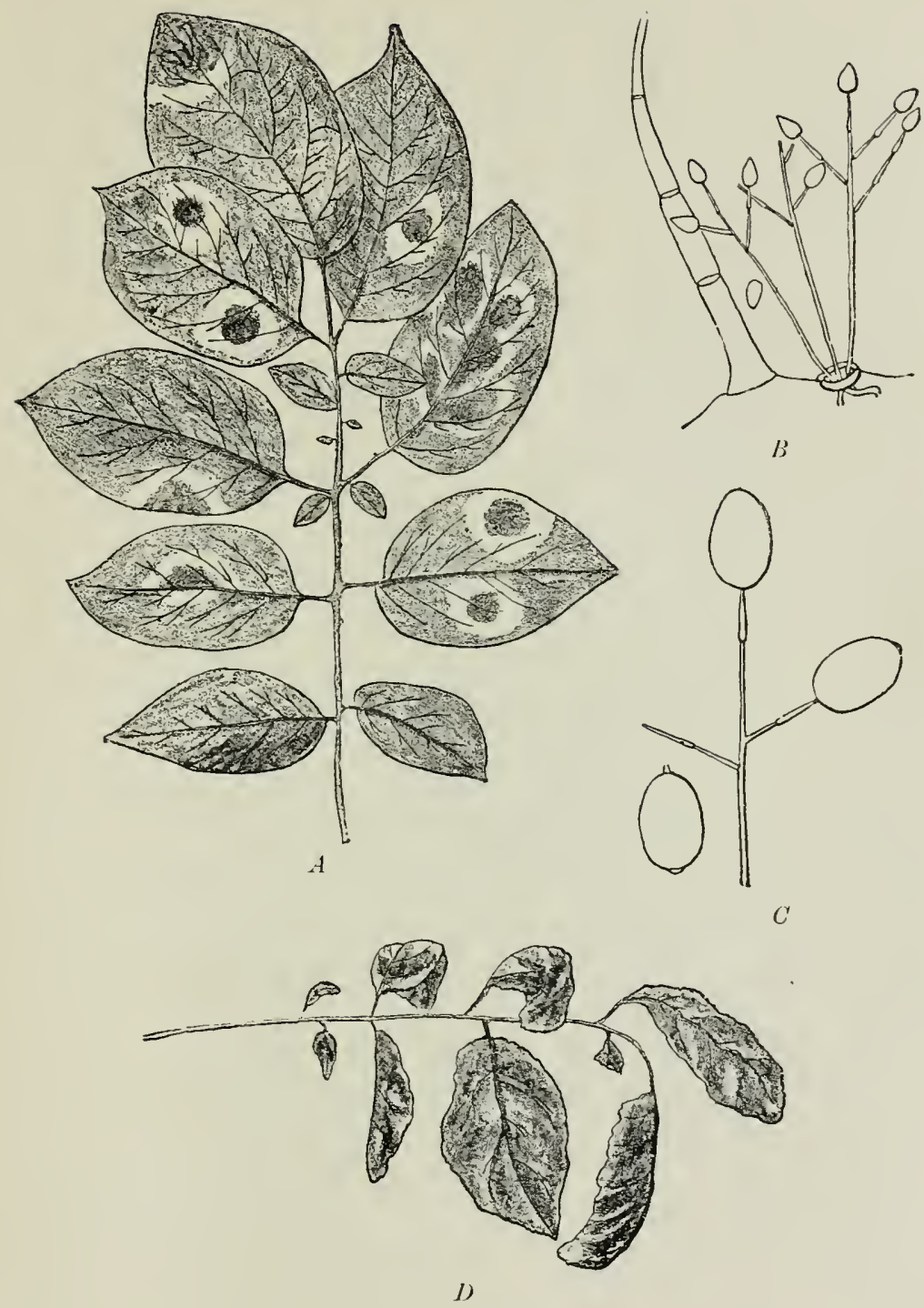

F1G, 32.-Phytophthoru incestuns. The Potato disease. 4 , Potato leaf with brown spots and white patehes of fungi on the lower side. $B$, Groups of eonidiuthores emerging from a stoma close beside a hair of the protato leaf. $C$, Conidiojhores and conidia, much enlarged. $D$, Leaf of potato nuch shrivelled up and brown, as in the later stages of the disease. ( $r$, Tubeuf del.) 
same author also quotes the disease on Shlonum curipense at Quito, and on Petunia hybricile at Lpsala.

The potato clisease is above all an associate of moist weather. In such eireumstances, the conidia are produced very rapidly and the zoospores readily distribute themselves in the moist soil. There is thus greater risk to the potato crops on wet soils.

For wintering, potatoes as healthy as possible should be chosen. This is particularly the ease if the tubers are required as seed; for the fungus-mycelium spreads from the tuber into the shoot. Whole tubers are less liable to infection than those cut or hroken. Some varieties (e.g. thick-skinned) are less ensily infected than others; such should be selected and bred.

As a preventive neasure the leaves may be sprayed with Bordeanx mixture, or with a copper earbonate mixture. ${ }^{1}$ By these means conidia and zoospores which alight on the plant. are killed and their germination prevented. The leaves themselves remain uninjured if the copper compound be used dilute enough. These compounds may even be beneficial to the growth of the host-plant, as was found by Rumm² for the vine, and Frank and Krüger ${ }^{3}$ for the potato.

Frank and Kriger found on using a two per cent. eopper sulphate and lime mixture, in which the copper is known to be the potent constituent, that the potato leaves were stronger, their chlorophyll-contents greater, their power of assimilation ancl transpiration was increased, the life of the leaf was lengthened, and the yield and starch-contents of the tubers were increased. They regard the effect of the copper on the leaf as the result of a chemotaxic stimulus.

Jensen recommends disinfection of seed-potatoes by heating at $40^{\circ} \mathrm{C}$. for four hours.

Ph. phaseoli, Thaxter, lives in young bean-pods and causes them to shrivel up. The fungus is as yet incompletely known, having only been observed in America where Thaxter ${ }^{4}$ reports great destruction of Lima bean (Phassolus lunatus) near New Haven.

\footnotetext{
1 See also s 1:2. Detailed experiments of this kind are frequently descrilyed in the magazines relating to agricnlture. (Erlit.)

${ }^{2}$ Ber. d. deutsch. botan. Ges., 1895, p. 189.

${ }^{3}$ Ber. d. deutsch. botan. Ges., 1594, 1. 9.

'Thaxter, Botanical Gazette, 1859.
} 


\section{Cystopus (Albugo).}

The mycelium is branched and grows between the cells of living plants, obtaining its nourishment by means of haustoria. The conidial cushions rupture the epidermis of the lost. The conidia or sporangia are smooth-coated, and are produced acropetally in chains on short stalks from which they fall off separately when ripe. The sporangia germinate and discharge

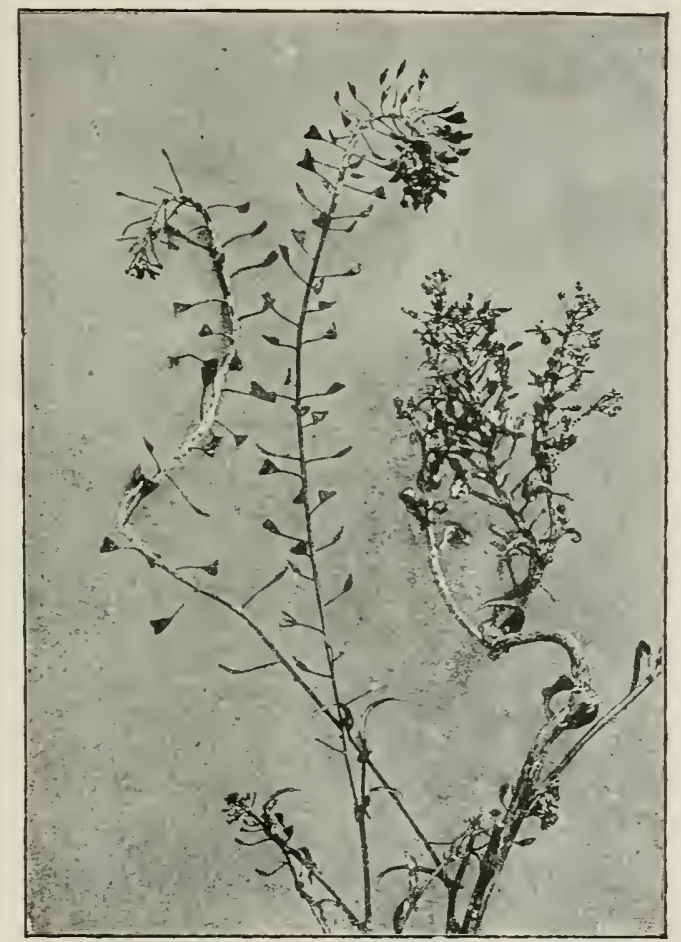

FIG. 33-Cystopus candidus on plants of capsella 7nuse pastoris. The fungus has caused distortion and thickening; the white porcellanous conidial cuslions shew up distinctly on the dark background. (v. Tuheuf phot.)

swarming spores with two unequal lateral cilia. The egg-cells, produced singly in each oogonium, are fertilized by an antheridium. The thick-walled oospores remain enclosed in the intercellular spaces of the host-tissue, and on germinating in spring discharge swarming spores.

Cystopus candidus (Pers.) Lev. White Rust. This fungus 
is very frequent on wild and cultivated Cruciferae throughout the whole world, and causes ileformation of shoot, leaf, and flower.

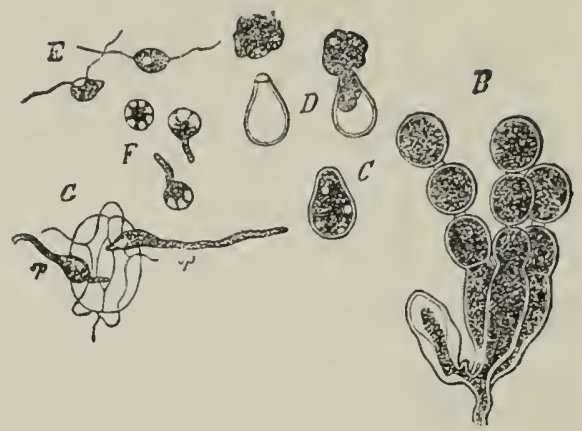

Fig. 34.-Cystopus candidits. $B$, Conidiophores isolated from the eushion; the eonidia or sporingia are united by intermediate cells. $C$, Sporangia breaking up to form swarm-spores. $D$, Swarm-spores escaping. $E$, Swarm-spores in motile condition. F', Swarm-spores come to rest and germinating. G, Two gernn-tubes entering a stoma of Lepidium sutioum; the stomia is slown from the inside, so that the spores from which the germ-tube; arise are on the outer surfaee and unseen. (After De Bary.)

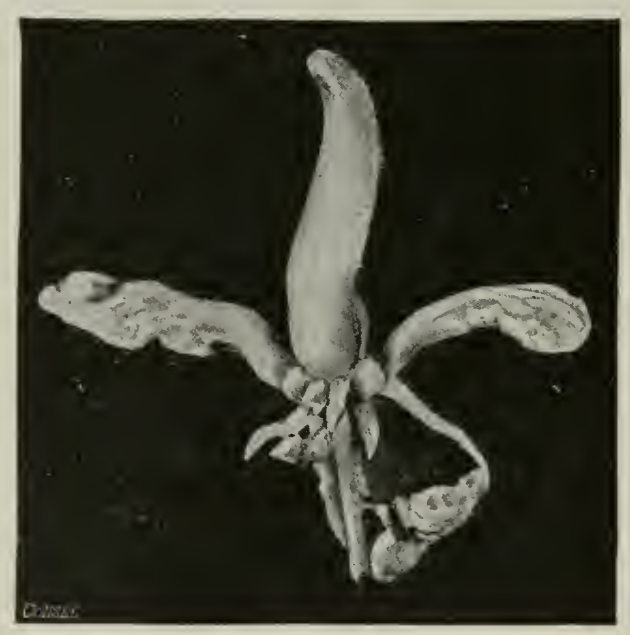

Fis. 35. - Flower of Radish (Raphanus sativus) bypertrophied by Cystopus crumlities. The mnch.enlarged ovary stands out in the centre. The autlicrs are leaf-like; the petals are much enlarged and bang downwards; the sepals are somewhat enlarged. (Speeimen from Botanieal Musenm of Erlangen, and photographed by Dr. Brins.)

The conidial cushions form thick white stripes with a porcellaneous appearance, by which they are easily distinguished from the cushions of Peronosporce parasitica often present on the same plant. 
Besides conidia, spherical oospores may also be present; these are generally produced on the stems of the host-plant, but also on Hower-stalks and ovary-walls.

The spherical conidia arise in simple chains on short conidiophores, and are loosely connected by tiny intermediate cells. The conidial cushions rupture the epidermis and the ripe conidia fall off to produce biciliate swarming cells (Fig. 34). These give rise to germ-tubes which enter the stomata of seedlings and

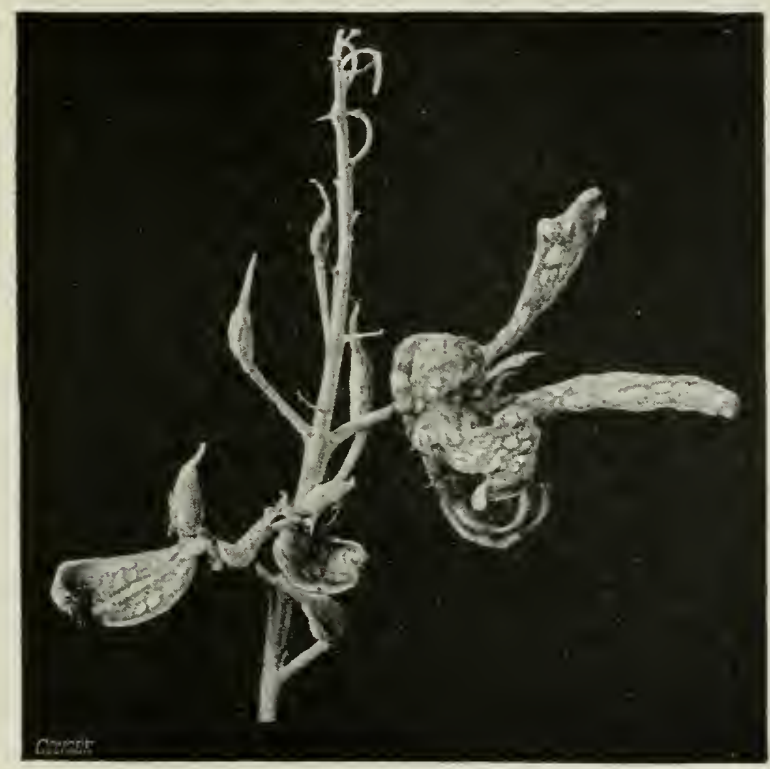

FIG. 36.-Flower of Radish hypertrophied by Cystopus condidus. The white swollen conidial cushions occupy the enlarged petals, sepals aud ovaries. (Dr. Bruns' phot.)

develop to intercellular mycelia, fine short lateral twigs of which pierce the wall of the host-cells and become little spherical haustoria.

The oogonia arise as thick-walled spherical swellings on the mycelium. The antheridium, after applying itself to the oogonium, widens and projects a fine fertilization-tube through the wall to the egg-cell. After fertilization is effected, the egg-cell is enclosed in a firm uneven membrane, and hibernates inside the oogonium. In spring the plasma of the oospore forms numerous biciliate 
swarm-spores which escape from the enclosing coats and germinate

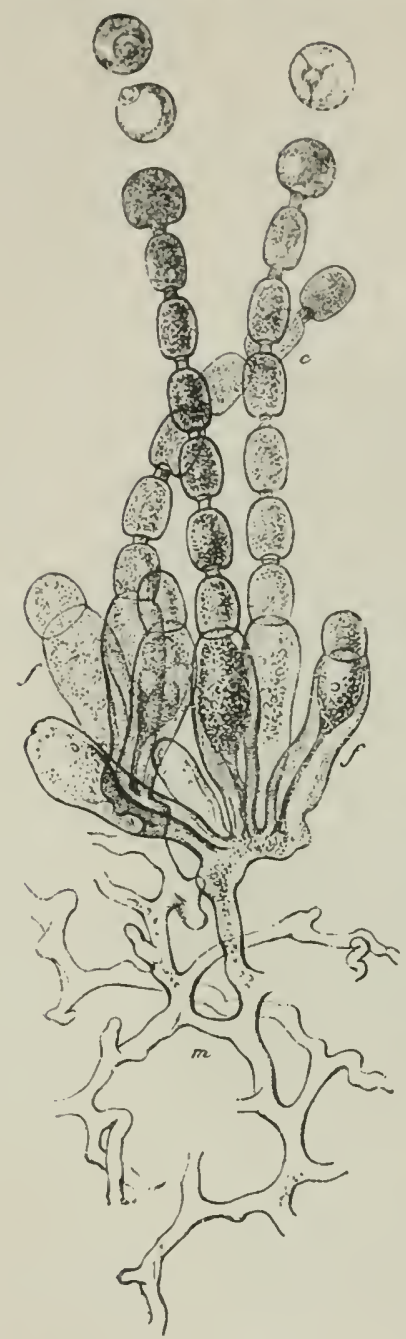

FIG. 37 .-Cystopues portulacue, D. C. $m$, mycelium ; $f$, basidia ; $c$, spores with intermediate cells. (After Tulisue.) (1) seedling plints.

De Bary ${ }^{1}$ fouml serm-tubes of C'ystopus entering all the stomata of Leprelizme setirem and of C'cpssclle, lut they only ileveloped further if the part attacked were the cotyledons.

Magnns ${ }^{2}$ observed an infection of Fiepluanus Rerphanistrum in which the unopened buds were infeeted by swarmspores. Oogonia may be found in the Howers of this same plant, whereas conidia alone only are present in C'epsellee.

White rust is most commonly observed on Cupsellu, eausing slight local swelling or marked liypertrophy. It is also found to injure radish (Rirphunus sativus), horse radish (Cochleceric armoracin), eress (Lepillium sutivum), species of cabbage and turnip (Bircssiere Nepus, B. nigra, B. Riepa, B. olerecece), wall-Hower (Cheirunthus. Cheiri), water cress (Nesturtium amphibium, ete.), caper-plant (Crppuris spinosis), and other wild and cultirated plants belonging to, or closely allied to the Cruciferae.

Wakker ${ }^{3}$ investigated the changes brought about on a number of Crnciferae by Cystopus. Some plants showed little or no deformation or anatomical alteration, others showed much. While the anatomical changes in the various species examined ingreed in general, yet some showed a predominant or exclusive formation of conidia, others of nospores. The changes

1 Morpholoyy and Biology of the Fungi. English Edition.

"Abhand. 1. lootan. V'ereins d. Proe. Bramdenbury, xxxv.

${ }^{3}$ Pringsheim's Jahrbuch, 1592. 
observed on Crapselle may be summarized here: the fungus attacks all parts above ground, and causes enlargement of parenchymatous cells; it forms only conidia; formation of chlorophyll is increased; the formation of interfascicular cambium is diminished or altogether suppressed ; the intrafascicular cambium retains its activity longer; accessory vascular bundles make their appearance; no differentiation of tissue takes place

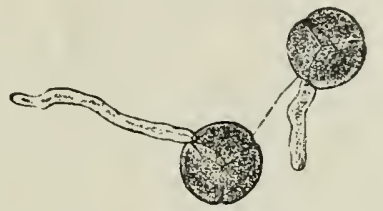

FIG, 3S.-Germinating spores of Cystopus portulecce. (After'T'ulasne.) in the ovary wall, the secondary vessels remain incomplete, and the embryo dries up.

C. portulacae, D. C. On Portulaca oleracen and P. sativa (U. S. America).

C. tragopogonis, Pers. ${ }^{1}$ (C. spinulosus) (Britain and U. S. America). On Compositae, e.g. Chamomilla, Achilleu, Cirsium, Scorzoneru, etc. The markings on the spore-coat take the form of a double net-work.

C. convolvulacearum, Otth. (C. ipomoeae-panduranue, Farl.). On Coniolvulacene. (Halsted ${ }^{2}$ gives this as one of the causes of rot in sweet potato in America.)

C. bliti (Biv.-Bern.). On species of Amarantaceae (U.S. America).

C. lepigoni, de Bary. On Spergularia (Britain).

\section{Basidiophora.}

The non-septate mycelium inhabits intercellular spaces of living plants, and is nourished by small haustoria. The conidiophores issue in tufts from the stomata, and have a characteristic for'm; they are unbranched with club-shaped ends, from which arise several sterigma-like conidiophores with almost spherical conidia. The conidia or sporangia are produced in large numbers, and on germination discharge numerous zoospores with two lateral cilia. The oospores are formed singly in the oogonia, and appear as yellowish-brown bodies in the interior of the plant.

Basidiophora entospora, Roze and Cornu. On Erigeron canaelense, Aster, Solirlago, etc. (Britain and U. S. America).

\section{Plasmopara.}

The mycelinm is richly branched and grows intercellnlar, nourished by little button-shaped haustoria. The conidiophores

${ }^{1}$ Magnus, Ber. d. deutsch. botan. Ges., 1893.

${ }^{2}$ Zeitschrift f. Pflanzenkrankheiten, 1895, p. 338. 
arise in tufts from the stonata; they are branched in various ways, and from each branchlet a single conidium is abjointed. The contents of the conidia emerge as swarming cells with two lateral eilia, or as vesicles which emit a germ-tube. The egg-cells occur singly in each oogonium, and are fertilized by an antheridiun. The oospores remain long enclosed in the thick-walled oogonimm.

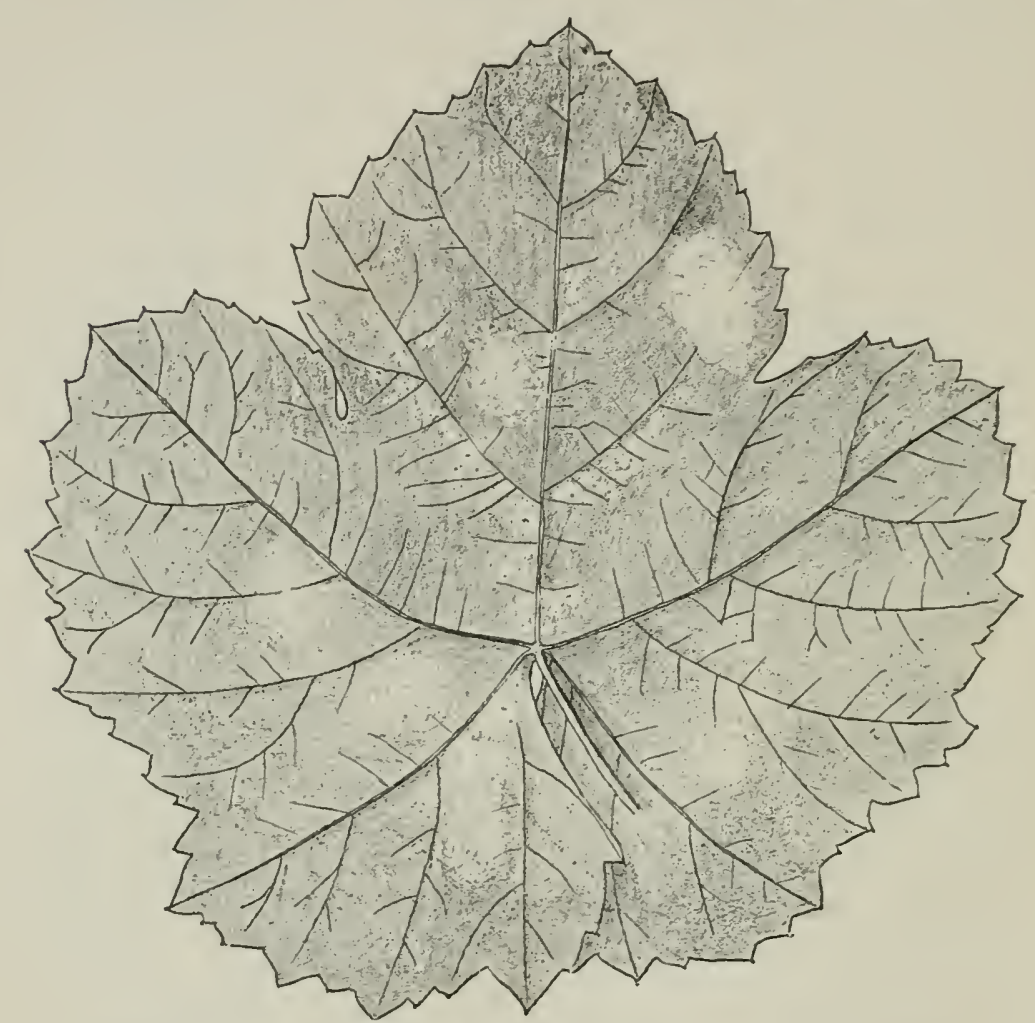

Fis. 39.-Plarmopara viticola. Vine leaf with white spots on the under surfice, from which tufts of conidioplores emerge. ( $v$. Tubeuf del.)

Plasmopara nivea (Unger). (Britain and U. S. America). Inflicts great injury on various wild and cultivated Umbelliferae, eg. earrot (Datucus Carota), parsley (P'etroselinum setivum), chervil (Anthriscus Cerefolium).

Plasmopara viticola, Berk. ${ }^{1} \quad$ The Downy or False Mildew of

${ }^{1}$ Bibliography. De Bary, Annal. d. sci. nat., 1863. Viala, Die Pilze d. Weinstockes; with good bibliography. Prillieux, Annal. de. l'instit. nat. agronomigne, 1881. Cornu, Le Péronospora des Tignes, Paris, 18s2. Sajo, 
the Vine. This parasite was introduced into Europe from America. ${ }^{1} \quad$ It makes its appearance in early summer as white patches on the under surfaces of leaves, sometimes also on stalks and fruit. In the course of the summer the leaves show brown spots and dry up.

The white patches consist of tufts of branched conidiophores, from which ovoid conidia are abjointed. These on germina-

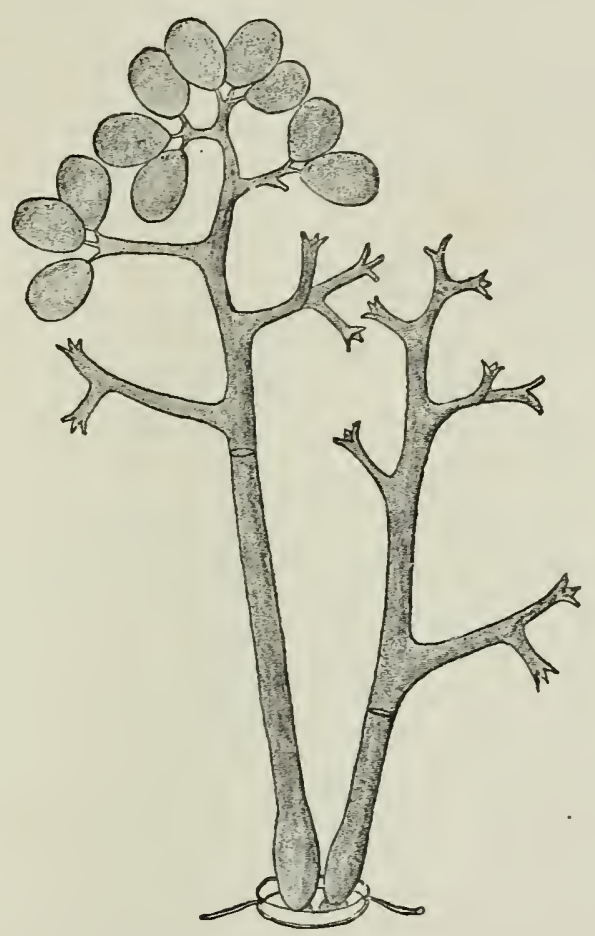

Fig. 40.-Plasmopara viticola. Conidiophores, much enlarged. (v. Tubeuf del.)

tion in rain-drops discharge six to eight swarming cells from which germ-tubes grow into the epidermis of the host-plant; thus the disease spreads rapidly during moist weather and a

Peronospora viticola, 1S90. Magnus, Witmack's Gartenzeit, 18s3. Scribner, Report of U.S. Dept. of Agriculture for 1S56, pp. 96-105; this contains an excellent account of this mildew. Articles on this subject dealing with remedial neasures are frequently published in the U.S. Amer. Department reports and bulletins, in the bulletins from experimental stations, and in the horticultural journals.

${ }^{1}$ Seymour and Farlow give it as occuring on every American species of Vitis. 
wet season is very favourable to it. The mycelium is nonseptate and spreads through the intercellular spaces of the host, nourished by button-like hanstoria sunk into the host-cells. The antheridium comes into contact with the oogonium by a fertilization tube, which, however, remains closed. The oospores hibernate in leaves and fruit.

Prevention. ${ }^{1}$ Ammoniacal copper carbonate solution, eau celeste, or Bordeaux mixture, prepared as described on p. 69 , may be used. The first-named solution seems least liable to injure the foliage; the others must, on this account, be used with care. The first application is made about the time the

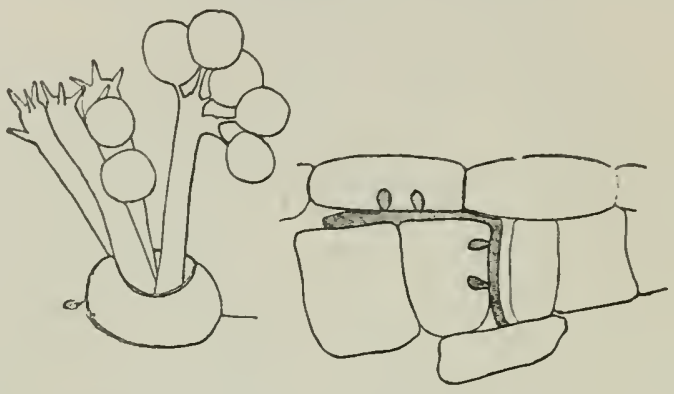

FIG. 41.-Plasmopara pygmaea on Aneinone nemorosa. Conidiophores emerging from a stoma. Intercellular mycelium with haustoria. (v. Tubeuf del.)

berries are well formed, and the sprayings are repeated every twelve to fifteen days, or oftener if there are heavy rains, till the grapes begin to eolour. It must, however, be remembered that sprayings of this kind do not reach the mycelium inside the leaf, but only act superficially, lilling any developing conidiophores or conidia which may alight on the leaf. These fungicides are, at the same time, remedies for powdery mildew (Uncinula).

"Sulphuring" as a remedy for this and the powdery mildew has been recommended by continental writers. ${ }^{2}$ The burning of all diseased vine-leaves is strongly recommended. Attention also should be given to the cultivation of disease-proof varieties. ${ }^{3}$

P1. pygmaea (Unger). On Ranunculaceae (Britain and U.S. America).

Pl. pusilla (De Bary). On Geraniums.

\footnotetext{
'Galloway, "Fungous diseases of the grape and their treatment," U.S. Dept. of Ayric., Farmers' Bulletin, No. 4, 1851.

2Oesterr. Weinbaukongress, 1891. Reported in Oest. landwirth. Wochenblatt, $x ., 1881$.

${ }^{3}$ Millardet (see Chap. vi.)
} 
Pl. viburni, Peck. On Viburnum (U.S. America).

Pl. densa (Rabh.). On Scrophularineae (Britain).

Pl. ribicola (Schroet.). On Riles rubrum (U.S. America).

P1. epilobii (Rabh.). On Epilobium palustie, and E. parvifolium.

Pl. obducens (Schroet.). On cotyledons of Impatiens (U.S. America).

Pl. geranii (Peck.). On Geraniums in America.

Pl. Halstedii, Berl. and de Toni. On Silplium, Rudbeckia, Helianthus, and many other American Compositae.

\section{Sclerospora.}

Mycelium intercellular in living plant-tissues, and deriving nourishment by means of haustoria. The conidiophores are thick, short, and divide at their apices into short broad branches, from each of which a single conidium is abjointed. The conidia in germinating discharge swarming cells. One oospore is formed in each oogonium.

Sclerospora graminicola (Sacc.) lives in several species of Setaria (U.S. America).

\section{Bremia.}

Mycelium intercellular in higher plants, and nourished by little button-like haustoria. The conidiophores are branched, and at their apical ends become swollen in a characteristic manner, so as to resemble a hand held cuplike with the fingers projecting separately upwards, like the tentacles of Hydra. The conidia are abjointed singly from the tentacle-like processes, and germinate, emitting a germ-tube through a definite thin spot in their coat. Oospores originate singly in oogonia.

Bremia lactucae, Reg. (Peronospora ganglioniformis

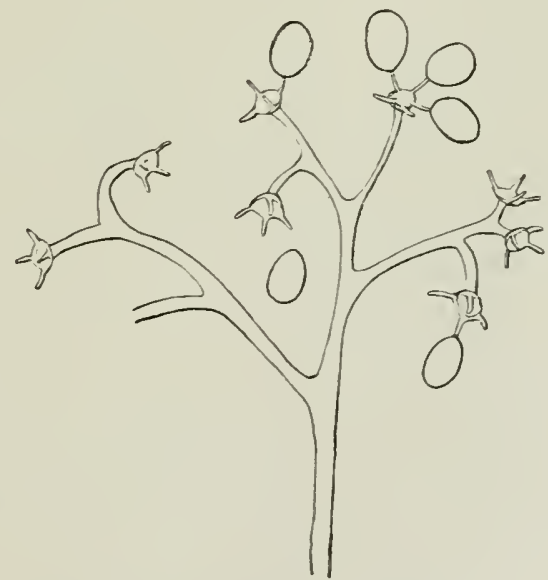

FIG. 42.-Biemia lactuca. (v. Tubejf del.) Berk. $\left.{ }^{1}\right)$ (Britain and U.S. America). The richly-branched conidiophores appear singly on attacked parts of plants. This fungus

${ }^{3}$ Cornu, Compit. rend., 1578. 
may canse considerable damage to the lettuce (Lartura sutiva), this being especially the case in lrance. The parasite is inost dangerons in forcing-honses during winter or early spring, and spreads rapidly, favoured by the daunp atmosphere. The young diseased plants are stunted, and take on a pale colour. Early removal and destruction of diseased plants is to be recommenderl; also abandomnent for lettuce-cultivation of infecter houses or frames.

In addition to lettuce, this fungus attacks a number of Compositae, e.g. Cincraria, Sonchus, etc.

\section{Peronospora.}

The mycelium is intercellular in living plants. The haustoria may be simple, button-shaped, or threat-like, or may branch insicle the host-cell. The long and much-branched conidiophores produce conidia singly at the ends of their branches. The conidia produce a germ-tube. The oospores are brown-coated and are formed singly in the oogonia; they germinate in spring.

Peronospora Schachtii, Fuck. ${ }^{1}$ is injurious to the inner leares of sugar beet and mangold (Bete vulguris), while young seedlings are killed by it. The mycelium hibernates in the roots; as yet oospores have not been found.

P. effusa (Grev.) This causes injury to spinach (Spinaciu) olerece $)$ and other Chenopodiacene (Britain and U.S. America).

P. Schleideni, Ung. Kills the leaves of cultivated and wild species of onion (Allium) (Britain and U.S. America).

P. dipsaci, Tul. Injures stems and leaves of Dipscecus syleester and D. Fullonum.

P knautiae, Fuck., of Knautia and Scerliose, is probably identical with last.

P. viciae (Berk.) (Britain and U.S. America). A dangerous species to many Papilionaceae (especially peas, beans, tares, lentils, etc.), often causing great damage to ficld crops. In recent years the new fodder-plant Lrithymus sylcestris has been frequently attacked. ${ }^{2}$

P. trifoliorum, De Bary ${ }^{3}$ (Britain and U.S. America). I)istingnished from the preceding form by its irregularly marked

${ }^{1}$ Kiilnn, Bolan. Zeilung, 1873.

¿Zeilschrift f. Pflanzenkrankikeiten, I., p. ․o.j and 283.

${ }^{3}$ Smith, Discases of Crops, Lonton, lists. 
oospore-coat (oospores of $P$. vicice have a coat with a regular network). It occurs on stems, leaves, and petioles of clovers, lucerne and other Papilionaceae, often with disastrous effect.

P. sparsa, Berk. (Britain and U.S. America). This parasite on the rose was first observed in England. It injures indoor roses, causing a fall of the leaf, preceded by the appearance of lilac-coloured spots which, on the underside of the leaf, are closely beset with a white coating of conidiophores. ${ }^{1}$

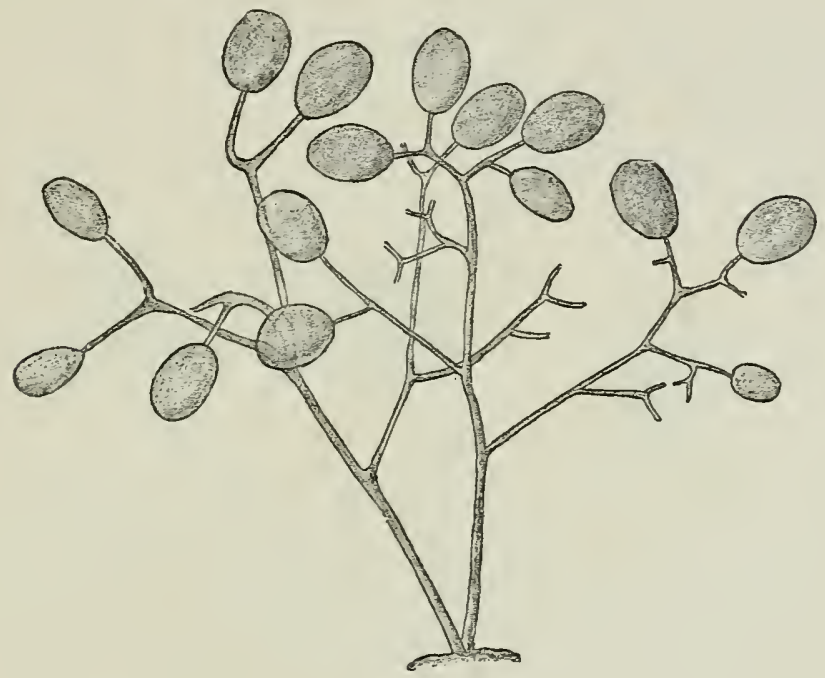

Fig. 13.-Peronnspore viciec. Conidiophores and conidial. (v. Tubenf del.)

P. arborescens (Berk.). On leaves and shoots of wild and cultivated poppies; especially injurious to seedlings of garden species.

P. parasitica (Pers.) (Britain and U.S. America). This produces greater or less deformation of attacked stems of many wild and cultirated Cruciferae. Amongst cultivated plants the most liable to injury are the varieties of turnips and cabbage, radish, rape, cress, wallflower, also the mignonette. It is generally found along with Cystopus eandidus on shepherd's purse (Capsella).

P. cytisi, Rostr., ${ }^{2}$ attacks seedlings of laburnum in I) lenmark, causing death in a few days. The leaves become brown spotted,

${ }^{1}$ Zeitschrift $f$. P.-krank., II., p. 3S6, (description of attack in Silesia.)

2 Rostrup, Zeitschrift f. Pfanzenkrankhtiten, 1892.

Magnus, Hedurigia, 1592. 
and branched conidiophores with light-lirown conidia arise from their underside. Numerous onspores may be found in the leaves. Kirchner ${ }^{1}$ observed the disease on leaves of four-year-old plants, yet without injurious effects.

The following are other British or American species:

Peronospora ficariae, Tul. On Ranunculus, Mynsurus, etc.

P. corydalis, De By. On Coryctulis and Dicentre.

P. violae, De By. On Viola tricolor.

P. arenariae vir. nacrospora, Farl. On sitene.

P. alsinearum, Casp. On Cerastium.

P. claytoniae, Farl. On Claytonia.

P. lini, Schroet. On Linum.

P. potentillae, De By. On Rosaceae e.g. Geum, Fragaria, and I'otentille.

P. Arthuri, Farl. On Oenothera.
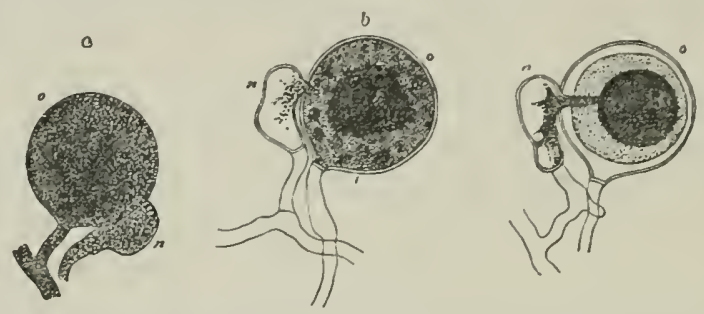

Fig. 44.-Peronospora alsinecrerm. Sexual organs. a, Young condition; $b$, formation of ovum and fertilization-tube; $c$, after fertilization, (periplism somewhat contracted by preparation, and the fertilization-tube unusually thiek); $n$, antheridium; $o$, oogonium. $\times 350$. (After l)e Barg.)

P. leptosperma, De By. On Compositae e.\%. Artemisia.

P. candida, Fuck. On Androsace and other Primulaceae.

P. cynoglossi, Burrill. On Cynoglossum.

P. myosotidis, De By. On Myosotis and Echinospermum.

P. sordida, Berk. On Nicotiana and Scrophularia.

P. hyoscyami, I). By. On Tobacco in America and Australia (Gard. Chron. Ix.).

P. linariae, Fekl. On Linciric.

P. grisea, Uning. On V'eronicu.

P. lophanti, Farl. Ou Lophantlets.

P. alta, Fckl. On I'lantago.

P. (Plasmopara) cubensis is reported ${ }^{2}$ as causing an extensive and destructive disense of cucumbers (Cucumis aud Cucurbitu).

P. (Plasmopara) australis, Speg. On Eclinocystis lobata and Sicyos angulatus in America.

${ }^{1}$ Kirchner, Zeitschrift $f$. P'flanzenkrankheiten, 1592.

${ }^{2}$ Humphrey, lieport of the Mass. Agric. Exper. Stat., 1890-92.

Massee, Grardener's Chronicle, Vol. xrir., p. 656, 1595. 
P. oxybaphi, Ell. and Kell. On various Nyctaginaceae.

P. polygoni, Thiim. On Polygonum.

P. euphorbiae, Fuck. On Euphorbia.

P. urticae (Lib.). On Urticaceae.

P. elliptica causes death of lilies. ${ }^{1}$

\section{B. Higher Fungi (Mrconycetes).}

The higher fungi are distinguished from the lower in possessing a mycelium, which, from the first, is divided by means of crosssepta. The mycelium of the lower fungi, though often much branched, remains unicellular till cross-septa arise on formation of reproductive organs or in the older stages of the fungus. ${ }^{2}$ In higher fungi, septation begins with the first appearance of mycelium and extends acropetally, growth in length proceeding from the terminal cell. Sexual organs are without doubt present in the lower fungi, but amongst the higher forms, Brefeld believes that the sexual act no longer exists. On the other hand, eertain organs, found especially in the lichens, have been regarded as sexual.

Dangeard regards the union of cell-nuclei as a sexual act, and assumes its existence in the asci and basidia of higher fungi. His more recent investigations on the nuclei of fungi, combined with those of Pairault and Raciborski, have laid the way to a new systematic arrangement. ${ }^{3}$ Just as amongst the lower fungi the cell produced by a sexual act contains a nuclens derived from the fusion of two nuclei of distinct origin, so amongst the higher fungi one also finds cell-nuclei derived from copulation. The investigations of Dangeard, Rosen, Wager, Pairault, and Raciborski, lead to the conclusion that: ${ }^{*}$ "a stage may be found amongst higher, as well as lower fungi, in which two cell-nuclei of one cell copulate. The cells known as oospores of the Oomycetcs, zygospores of the Archimyectes and Zygomycetes, chlamydospores of the Ustilagineae, and telentospores of the

${ }^{\mathrm{T}}$ Snith, Discase of Lilies, 1888.

${ }^{2}$ Zopf. Die Pilze, 1890 ; and Beitrüge z. Physiol. u. morphol. niederer Organismen, Heft 11., 1893.

${ }^{3}$ Dangeard. "Recherches sur la reprod. sexuell d. champignons" Le Botaniste, 1893. Pairault and Raciborski. "Snr les noyanx des Uredinees" Jour. de Botanique, 1895.

${ }^{4}$ Raciborski. Flora (ergänzungsband), 1895, p. 439. Compare also: Strasburger. "Ueber periodische Reduktion d. Chromosomenzahl im Entwickelungsgang d. Organismen," Biol. Centralblatt, 1894, p. 862. Wager. "Nuclear division in the Hymenomycetes," Anmals of Botany, 1S93, p. 490. 
Uredincae, we designate anongst the Ascomyectes, as asci, and amongst the Protomyertes and Busirtionyeetes as basidiat. This cell, a homologne of the primary embryo-cell of the Areheyoniatae and Embryonatue, indicates a turning-point in the development, the beginning of a new generation. It either becomes a restingspore, as in I'hycomycetes, Ustilugincue, Uredinere (exclusive of Colcosporium and Chrysomyxa), or divides at once to form free enclospores as in the Ascomycetes, and exospores in the Protomyectes and Basidiomycetes. From these facts the distinction between basidiospores and conidia, asci and sporangia, teleutospores and chlamydospores, has been for the first time distinctly proved."

\section{ASCOMYCETES.}

The Ascomycetes show relationship to the higher fungi in the possession of a septate mycelium. Their spores are produced in cylindrical sacs called asci, whence the name Ascomycetes is given to the group.

The primary nucleus of each ascus results from the copulation of two nuclei of distinct origin and with no relationship to each other. From the division of this nucleus and its daughternuclei, there are produced a number of free endospores varying accorling to the species. These may remain unicellular or, by means of septa, become many-celled bodies from each of whose individual cells germ-tubes may develop. It is advisable to give the name spore to each cell-group which develops from one nucleus. ${ }^{1}$

Ascospores are never zoospores, but are always quiescent and possess a cell-membrane. They are generally forcibly expelled from the asci. The asci originate either directly from the mycelium, as in the Saccharonycetes and some Exoasceae, ${ }^{2}$ or a part of the mycelium becomes differentiated into an ascogenous layer. The ascogrenous layer may include only a few cells, as in the lower forms, or it may be a complex tissue. In the higher forms the aggregations of asci are enclosed in coverings, but the ascogenous layer takes no part in the formation of the enclosures nor of the accessory organs known as paraphyses and periphyses.

\footnotetext{
${ }^{1}$ De Bary held that each individual cell capable of germination is a spore, the single multi-cellular spores he designated sporidesmia.

"Hansen, Centralbl. f. Bacteriologie und Parasitenkunde, 1 S93.

Sadebeck, Die parasitischen Exoasceen, 1593.
} 
This ascogenous layer has been named the ascogonium, and it was at one time generally believed that it arose from a female cell, the homologue of the oospore of lower fungi; a hypha which applied itself to the ascogonium was regarded as a male or antheridial organ, and called a pollinodium. In other cases, a thread-like hypha, which proceeded from the ascogonium, was called a trichogyne; it was believed to be fertilized by means of certain very small cells (spermatia) produced in special structures, the spermogonia. These spermatia, though known for a long time, have only recently been made to germinate, and that only in nutritive solutions. The significance of the pollinodium as a male organ is not necessarily wrong, though it may be a functionless structure, such as we already know antheridia of many of the Phycomycetes to be. So also we may still consider the spermatia as sexual bodies, even though they germinate like spores, for their never-failing production before aecidia would seem to suggest some relationship. In the following pages we will speak of these little spores, sometimes as spermatia, sometimes as conidia.

Reproduction of Ascomycetes may also take place by conidia. and chlamydospores, capable of germination to form mycelia.

Amongst the Ascomycetes one finds the higher stages of development accompanied by an almost complete enclosure of the aggregations of asci. The asci of the Saccharomycetes originate at any spot whatever between the mycelial threads; in Gymnoascus one finds a loose web of mycelium forming a covering to the asci ; in higher forms an enclosure (sporocarp) of definite shape is developed. On this account, the forms which do not produce sporocarps are classed together as Gymnoasci, the sporocarpous forms as Carpoasci. Amongst the latter, the sporocarp of the higher forms possesses a definite opening from which the spores are emitted after liberation from the asci ; certain lower forms (Perisporiaceae) have indeed sporocarps, but these possess no opening, and it is only after they have ruptured or decayed that the spores are set free.

\section{A. Grunoasci.}

\section{(Ascomycetes without Sporocarps.)}

The asci are produced over the whole mycelium, or from a special ascogenous part of it, and are never enclosed in a sporocarp. 
The genera placed in the Gymnoasci are: Dipodascus, Eremascus, Ascoülen, Protomycrs, Taphrina, Erroetscus, Margnusiclla, Sacclaromyces, Monospora, Enulomyces, I'oulocupsa, Eremothecium, Oleina, Barycllinir, Ascodesmus, Gymnoascus, Ctenomyces.

Protomyecs, Taphlina, Exoaseus, Mugnusiclla, are true parasites of higher plants: Endomyecs, Ascoidca, and Succharomycrs occur in the flux diseases of trees; the others are saprophytes, or prarasites on fungi (Podocapsc $)$.

\section{Protomyces. 1}

The genus Protonyces possesses a septate mycelium, and in this shows relationship with the higher fungi. It is also distinguished by the formation of sporangia (asci), which are produced in an intercalary manner like the chlamydospores of the Ustilagineae. Conidia are also developed, which sprout yeast-like and conjugate like those of many Ustilagineae. Thus Protomyces stands in one direction between the sporangiferous lower fungi and the Ascomycetes, and in another between the Ascomycetes and the non-sporangiferous Ustilagineae. Brefeld allocates them with the Ascoidea and Theleboleae to his intermediate group the Hemiasci. De Bary (Comparatirc Morphology of the Fungi) agrees with Fisch in placing them between the Chytridiaceae and Ustilagineae, but in his "Bcitrïgcn" considers them as the simplest forms of Ascomycetes.

In any case they do not show very close relationship with any group.

Protomyces macrosporus, Ung. (Britain). This parasite lives by means of an intercellular septate myeelinm in leaves and stems of Unbelliferae, especially Acyopodium Podagraria, Chacrophyllum hirsutum, Heraclcum Sphondylium, etc. It also causes injury to cultivated carrots.

The disease shows itself externally as pustule-like swellings on the organs attacked. These are caused, as shown in the figures, by a mycelium which pierces the epidermis, and, after

1 De Bary, Unlersuchungen ub. d. Brandpitze $u$. $l$. durch sie vemersachten Krankhriten d. P'lanzen. Berlin, 1853.

De Bary u. Woronin, Beitrüge z. Morph. u. Physiol. d. Pilze, I. Bd., 1564.

Fisch, Beiträge z. Kenntniss d. Chytridiaceen, $18 \$ 4$, p. 41.

Brcfeld, llejepitze, p. 176.

B. Meyer, "Untersuchmingen ub. die Entwickelung einig. parasit. Pilze bei saproplyt. Ernährung." Inaugural Dissertation, ls\$s. 
distributing itself through the intercellular spaces, stimulates the parenchyma-cells of the host to growth and cell-division. The
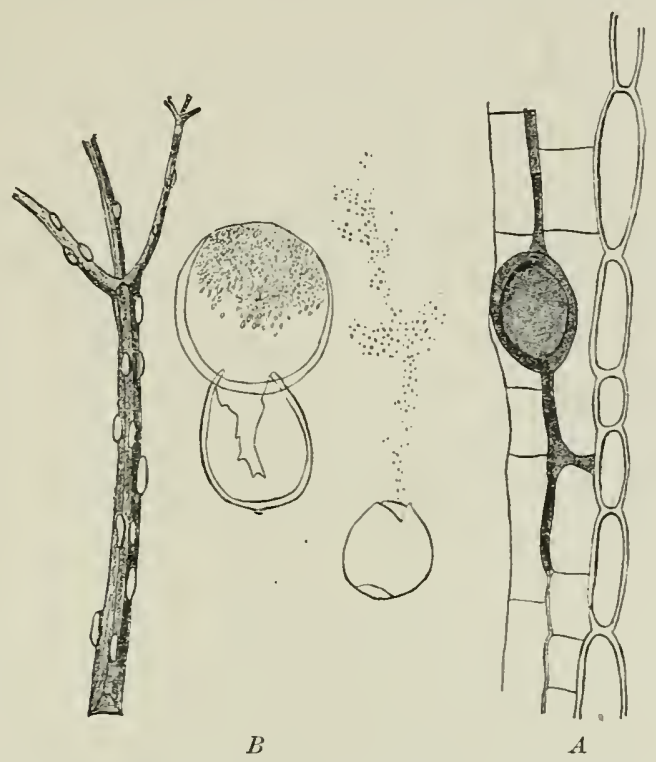

F1G. 45.-Protomyces nucrosporus on leaf-stalk of Aenopodium Podagraric. $A$, Mycelium and sporangium in the tissue under the epidermis. $B$, Sporangia in stages of develupment. (. . Tubeuf del.)

latter is a secondary process and consists (see Fig. 9) in the formation of exceedingly delicate membranes inside the original

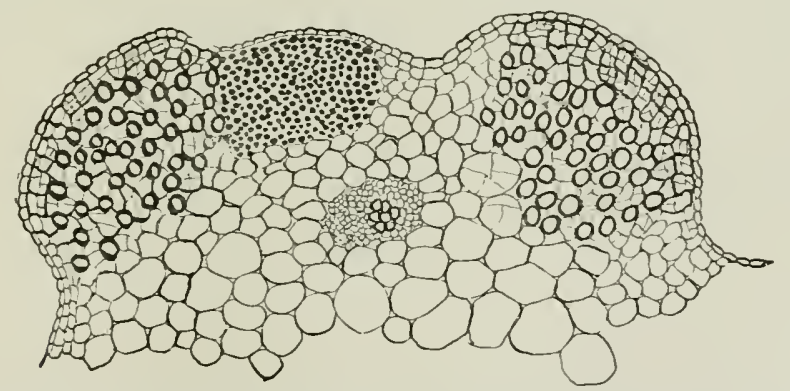

FiG. 46.-Protomyces nucrosporus. Section of petiole of Aeropodium with two swellings containing spores. Secondary cell-walls have been formed, and a collenchyma region lies betwcen the two swellings. (v. Tubeuf del.)

cells of the parenchyma, so that they become divided into younger cells rich in protoplasm and each showing a distinct 
cell-nucleus. This tissue so formed may be compared to the nutritive tissue formed secondarily from parenchyma as a result of other fungoid diseases, e.g. in violas attacked by Urocystis violuc. If the formation of sporangia ensues in parts which would normally become collenehyma, the tissnes there remain thin-walled.

The sporangia of I'rotomyecs, according to De Bary," begin to develop as soon as the young leaves and shoots of the hostplants emerge above the ground in spring. The sporangia first

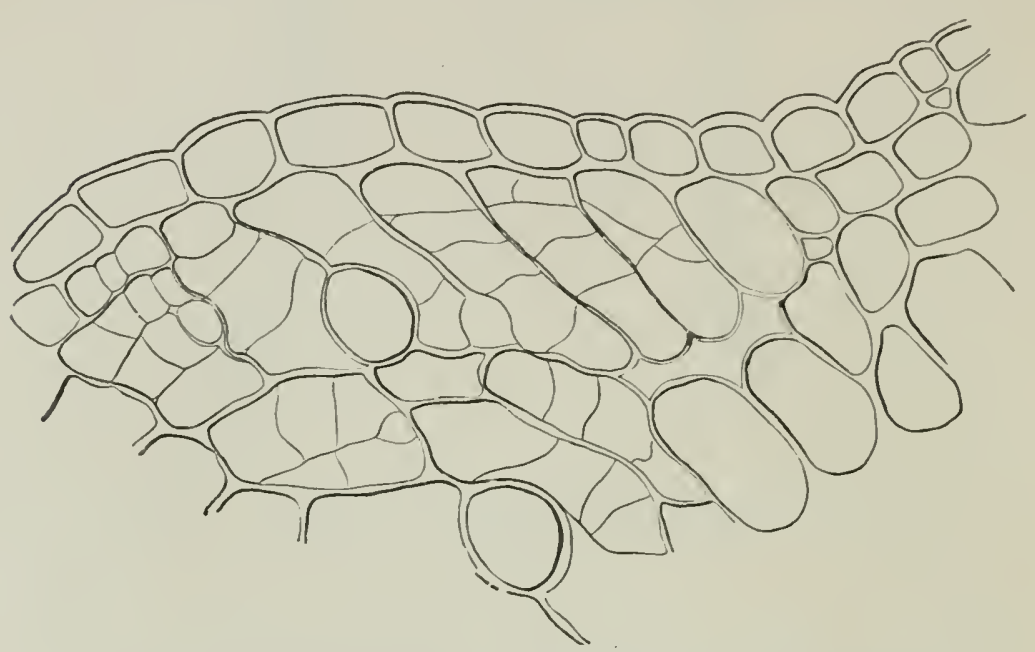

Fic. 47.-Protoniyces macrosporus. Section through swollen leaf-stalk of Aegoporliumz. Towards the right end the cells are normal, elsewhere they are, under the influcnce of the mycelium, muel enlarged and secondarily divided; two roundish sporangia lie in this tissue. ( $\nabla$. Tubcuf del.)

appear as series of swellings on the hyphae and are easily detected in deformed plants as large thick-walled bodies lying in the intercellular spaces. They are liberated on decay of the host-plant, and in spring the contents swell up so as to rupture the thick outer wall, and the endosporium emerges as a vesicle or sporangium into which the protoplasmic contents pass to form numerous rod-shaped spores. The spores are ultimately expelled with considerable force, and, after conjugating in couples, they send forth a germ-tube which penetrates again into the tissues of the host-plant.

${ }^{1}$ De Bary, Beitrü̈ge z. Morph. u. Physiol. d. Pilze, also Botan. Zeitung, 18 s. 
In nutritive solutions germination cloes not take place in this way, but is replaced by a yeast-like sprouting of the sporangial spores without disjunction of the sprout-cells. ${ }^{1}$

According to Meyer, these sprout-cells produce elongated hypha-like cells with which, however, he did not succeed in infecting a new host-plant. He also found that spore-conjugation takes place better in water than in nutritive solutions.

Pr. fuscus, Pk., occurs on Anemone in America.

Pr. pachydermus, Thüm., occurs on Compositae esp. Taraxacum.

Pr. radicicolus, Zopf. ${ }^{2}$ A form similar to $P$. macrosporus, but furnished with coiled haustoria. It lives intercellular in roots and kills the cells, without, however, causing external hypertrophy. Zopf found it in roots of Stiftice Chrysenthe and Achillere clypeolete in the botanic garden of Halle, but the plants were not killed, because their roots were not all attacked. ${ }^{3}$

\section{Endomyces.}

The asci contain four spores which do not produce coniclia. The sterile hyphae give rise to chlamydospores and an oidial form of spore.

Endomyces dccipiens lives as a parasite on sporophores of Agaricus melleus.

According to Ludwig, species of Endomyces have much to do with the slime-flux of trees, which contain in addition other forms of Gymmoasci, e.\%. Succharomyces Lucluigii, Ascoidcc rubescens, etc. We shall here devote some space to the general consideration of the slime-flux of living stems. This phenomenon remained uninvestigated until Ludwig took it up and directed attention to it. He found several species of considerable systematic interest, the pathological effects of which, however, require further investigation.

${ }^{1}$ Brefeld, Schimmelpilse, Heft Ix., 1891.

${ }^{2}$ Zopf, Zur Kenntniss d. Infectionskrankh. niederer Thiere u. Pfanzen, 1 Sss.

${ }^{3}$ Saccardo, who ranks the Protomycetes along with the Chytridiaceae, includes a large number of species. Magnus places Protomyces (?) filicinns, Niessl. (Verhund. des internat. botan. Kongress in Genoa, 1592) in the neighbourhood of the Phycomycetes; it, howerer, possesses a septate mycelinm and stylospores which are enclosed in a coat so that they recall spores of the Uredineae, hence Magnns namerl it Uredinopsis filicina on Phegopteris vulgaris. This species must not be confused with the species of Uredo occurring on Phegopteris Diyopteris, Cystopteris frayilis, and Scolopendrium officinale. 
The Slime- or Mucilage-flux of Trees.

This is a very common phenomenon in our avenues, parks, and forests. It ean be observed during the period of vegetation on several species of trees, particularly on spots wounded by removal of branches, by frost rupture, or by some other cause. The wound may, however, be so grown over or oceluded that at first sight the slime appears to flow from the uninjured bark. These slime-fluxes are very common on deack branchsnags and in places affected with sun-stroke or frost-wounds; while I have frequently found them on dead tree-stools and on wooden water-pipes where the water trickled from some fissure. It is thus probable that they are always produced on the site of some wound, although Ludwig, without giving any details, says that there may be no previous injury. I have never observed any case where a tree with a slime-outflow became sickly and died, and the cases of death recorded by Ludwig are probably due to some other cause. Ludwig, however, says decidedly that the white slime-flux on oak, as well as the brown flux of apple, horse-chestnut, and others, are really parasitic phenomena. I must say, however, that I have carefully examined the occluding tissues on frostcracks showing slime-flux, and found them quite healthy.

\section{The white slime-flux of the oak. ${ }^{2}$}

According to Lndwig, the white slime-flux of the oak and other species of trees takes place during moist weather, and from June to September. It flows from branch-scars, former frost-ruptures, and other wounded places; also from apparently uninjured bark. Ludwig believes that such wounds are infected by the agency of insects, particularly hornets; that the disease spreads through the bark and breaks out in various places. On such spots the edges of the wound are alternately occluded and killed again, so that a flux-wound may come in course of time to resemble a "canker-spot." Large areas of the bark die off, and the death of the wood frequently follows.

${ }^{1}$ Ludwig : (1) "Ueber Alkoholgihlhrung u. Schleimfluss lebender Baimme u. deren Urheber." Ber. d. deutsch botan. Ges., 1856. (2) "Ueber profuse Gimmose d. Eichen u. weiter. Nitth. iil). Alkoholgihurung u. Schleimfluss lebender Baume." Centrbl. f. Bakt. u. Parasitenkunde, 1S90. (3) Lehrbuch, 1892. (4) Forst.-naturwiss. Zeitschr., August, 1894. 
The slime-flux is the product of an alcoholic fermentation and has at first a distinct odour of beer. The fermentation produces a transparent foam in which are found Endonyces Magnusii (Ludw.) and a yeast, Sctechuromyces Luclwigii (Hansen); this latter, Ludwig regards as a stage of the Endomyces. Later a gelatinous slime is developed in the foam from the presence of Leuconostoc Lagerhcimii (Ludw.) Since this latter plant does not appear in the early stages of the disease, it cannot be the cause, and Ludwig says that the alcoholic fermentation due to the Endomyces always appears first; this conclusion requires confirmation.

\section{The milky outflow of trees. ${ }^{1}$}

Towards the end of winter and in spring a white foamy slime flows from freshly cut birches or hornbeams. According to Ludwig, this is due to Endomyees vernalis (Ludw.)

\section{Red slime-flux. ${ }^{1}$}

Ludwig found on the cut twigs of hornbeam, a red fungus which he called Rhodomyees dendroporthes. This may occur alone or along with the white flux, which it colours red.

\section{Brown slime-flux. ${ }^{2}$}

This is found on apple-trees, elms, birch, horse-chestnut, poplar, oak, etc., from spring till winter. The slime, Ludwig says, is developed in the wood, and breaks through, causing the bark to decay. The wood is destroyed and smells of butyric acid. The slime contains micrococci (Micrococcus dendroporthes, Ludw.) and a form of Toruld (T. monïlioides).

In Thuringia, many avenue-trees (c.g. chestnuts, apples, and birch), are reported to have been killed from this canse. That the disease was really the result of a Bacterium, and that death was due to this slime-fiux, has yet to be proved, as Ludwig himself states.

\section{Black slime-flux.}

Ludwig considers briefly some forms he found in a black slime-flux observed by him on beeches.

${ }^{1}$ Ludwig, Lehrbuch der nied. Kryptogamen, 1592.

'Ludwig, Centralbl. f. Bakt. u. Parasitenkunde, 1 sss. 


\section{Chocolate-brown slime-flux. ${ }^{1}$}

A slime-flux of this colour appears on the stumps, of felled beeches; it contains numerous forms of Oirlium, and later Ascobolus Constantini (Ioll) is developed in large quantity. ${ }^{2}$

\section{THE PARASITIC EXOASCEAE. ${ }^{3}$}

In this family are included the genera Exouseus, Magnusicllu, and Taphrina. The asci of most of the known species are produced from a mycelium which lives under the cuticle of the host-leaf, in a few (c.g. Magnusiclla flur, ), the mycelial hyphae are developed between the cells of the epidermis, while in others (c.y. M. potentillac), the mycelium permeates the whole leaf-tissue and the asci arise from hyphue situated muder the epidermis. T. Laurencic and a few others have an intracellular mycelium, and produce asci inside the epidermal cells. A number of species are known to possess a perennating mycelium, in the remainder the hyphae are wholly used up in the formation of asci.

The ascospores produce conidia before leaving the asci, which are therefore frequently found filled with minute conidia instead of the usual ascospores. In mutritive solutions the conidia sprout yeast-like; on a host-plant, they give rise to a hypha which penetrates the cuticle.

${ }^{1}$ Ludwig, "Ein neuer Pilzfluss d. Waldbäume," Forst.-natuririss. Zeitschrift, 1893 , and 1894 .

2 Krüger has found varions micro-organisms, including a fungus (Prototheca) and several algae, in the slime-flux of broad-leaved trees. (Zopf, Beitr. z. Physiol. थ. Morph. nied. Organismen, 1894.)

${ }^{3}$ Sarlebeck : (1) Untersuch. üb. die Pilygattung Eroascus, 1Ss4. (2) Kritische Untersuch, ïb. die durch Tuphriua-Arien herrovebrachten Baumkrankheiten, 1890. (3) Die parasitischen Exoasceen, 1893. (4) "Einige neue Beobachtungen ". kritische Bemerkmogen ib. die. Exoasceae," Ber. d. deutsch. botan. Ges., 1895.

Johanson: (1) Studier ofver siampläiget Taphrina, 1SST. (2) Om sitampslïgtet Taphrina och dithörande Siensila arter, 1SS5̃.]

Rostrup, Taphrinaceae Daniae, 1890.

De Bary, Beitriuge z. Morph. u. Physiol. d. Pilze, 1864-1870.

Giesenhagen, "Die Entwickelungsreihen der" parasitischen Exoasceen." Flora, Eryänzungsiand, 1895. With numerous tigures from nicroscopic sections.

Atkinson, "Leaf-curl and plum-pockets." A contribution to the knowlcelge of the prunicoluns Exoasceae of the United States. Comell Unir. Ayric. Exp. Station, Bu'letin 73, 1S94. With numerous illustrations.

Patterson, "A study of N. America parasitic Exoasccae." Bulletiu of the Lab, nat. hist., Unit. of Iove, 1895.

Surth. "Untersuch. der Morph. n. Anatomie der durch Exoasceen vernirsachten Deformationen." Forst.-naturuiss. Zeilschrift, Mnnich, 1S94 ; Italian, translation liy lierlese, livirista di Paloloyia, 1895. 
The presence of a perennating mycelium is the cause of many so-called "witches' brooms" on woorly plants. In fact, the majority of the structures known by that name are caused by species of Exouscus, though these of barberry, silver fir, acacia, and buckthorn, are due to Uredineae, and others are ascribed to mites (Phytoptus).

"Witches' Brooms" (Hexenbesen) are bushy growths, which remind one at first sight of stranger-plants growing, like mistletoe, on the branches of wher plants. They generally originate from a bul which has been infected during the previous summer, either directly or through its subtending leaf. This bud produces a twic capable of abnormally increased growth, most of its sleeping buds are developed into branches, and the whole system shows marked negative geotropism. (See Fig. :3). The spores of the fungus are produced on the leaves of the broom.

The characteristic features of a witches' broom are: that, without regard to the direction of the branch on which it is borne, it is negatively geotropic in a marked degree, and endeavours to develop like a terminal leader shoot; that the point of infection is distinctly conspicuous as the starting point of the broom. Sadebeck regards any twig-hypertrophy as a witches' broom, even that of Exoascus Tosquinctii where there is no basal swelling and the twigs exhibit only very slight negative geotropism.

The forms of witches' brooms are very varied. Amongst the best known are the hanging broom-like masses developed from buds of the leader shoots (e.g. on cherry trees). As a result of the rich growth of twigs and their premature death, many of these brooms become tangled nest-like structures. The twigs in some are much elongated, in others shortened, in every case, however, they are abnormally numerous. As a rule the original leader shoot, on which some lateral bud has developed into a witches' broom, shrivels up and dies, its contents being, as it were, absorbed by the hypertrophied branches. Other general features have already been discussed in Part 1 . of this book.

Smith $^{1}$ found that the form of the witches' broom is not determined exclusively by the fungus. The perennating mycelium indeed gives the first impetus towards its formation,

$$
{ }^{1} \text { Smith, loc. cit. }
$$


but it is completed by the weight of the broom itself, the excessive development of sleeping buds, and the premature death of twigs. Snith also investigated the anatomical changes occuring in witches' broons due to Exooscent. From his resumé we select the following: "In a witehes' broom the increased thickness of the twigs and branches is due to a proportionally greater inerease in the bark than in the woorl, the hyporlerm, especially, having its cells more numerous and larger, while their normal arrangement in longitudinal rows is lost. The cork-cells are enlarged and retain their plasmacontent longer. The phelloderm is better developed. In the sclerenchyma-ring, the primary bundles of bast-fibres are smaller and further apart from each other, or they may be quite absent; the bast-fibres are shorter and have thinner walls; selerenchymatous cells are more nmmerous, larger, and have thinner walls. The phloem is increased ehiefly through enlargement and inerease in number of its medullary rays; phloem crystal-deposits tend to be multiplied. In the wood, the parts most enlarged are the pith and medullary rays; tracheae are more numerous, but their component elements are shorter; the wood-fibres have thinner walls, wider lumina, and are often chambered; the normal course of the long elements is much disturbed by the greatly enlarged medullary rays.

Sadebeck has recently divided the parasitic Exocscere into these genera: ( $($ ) Magnusivlla, with asei isolated on the ends of mycelial threads which lie between the epidermal cells; in the other genera the asci arise from a subenticular hymeniun; (b) Tuphrinu, without a perennating mycelium; (c) Exocescus, with a perennating mycelium: (l) Taphrinopsis may be taken as another genus. Ascomyces he does not reekon with the Erouscere.

Brefeld divides the family into Erouscus, with eight spores in the ascus, and Taphrina, with four-spored asci. Sadebeck shows, however, that eight is the normal number of spores in all the species, and that rariation therefrom is frequent, four or more spores or numerous conidia being formed.

Schroeter separates the genus Maynusiella, as Sadelseck has done, then livides the remainder into Eronscus with eight-spored asci at time of maturity, while those with many-spored asci are placed muder Tapleria (the older name given to Taphina) 
According to Sadebeck, the Erousccue may be divided as follows :

\section{Exoascus.}

The mycelium perennates in the tissues of twig or bud. The subcuticular mycelium is developed from the perennating one, and becomes completely divided up, without any differentiation, into ascogenous pieces. The species are all parasites and produce. hypertrophy of leaves, flowers, and shoots.

A. The mycelium perennates in the inner tissues of the shoot. Thence, in the next vegetative period, it sends branches into the leaves in process of development, at first into the inner tissues, but later subcuticular for the formation of reproductive parts of the fungus.

(1) Asci developed in the carpels, which in consequence become hypertrophied; asci with a stalk-cell: E. prmmi Fuck. E. Rostrupicunus Sad. E. communis Sad. E. Farlowii Sad. E. rhizipes Atk. E. longipes Atk. E. confusus Atk. E. cecidomophilus Atk.

(2) Asci developed only in the foliage leaves.

(a) Asci with stalk-cell: $E$. insititice Sad. $E$. cercesi (Fuck.). E. nanus (Joh.). E. deformans (Berk.) $E$. accipicns Atk. E. acerinus Eliass.

(b) Asci without stalk-cell: E. purpurasecns (Ell. and Ever.). $\quad E$. cosculi (Ell. and Ever.).

(3) Asci developed on leaves and fruits.

(a) Asci with stalk-cell: E. mirabilis Atk.

B. The mycelium perennates in the buds of host-plants and issues thence in the next regetative period to develop in young leaves, subcuticular only.

(1) Asci only on the foliage leaves.

(a) Asci with a stalk-cell: E. crataegi (Fuck.). E. minor Sad. E. Tosquinetii (West.) E. epiphyllus Sad. E. turgidus Sad. E. betulinus (Postr.). E. alpinus (Joh.).

(b) Asci without a stalk-cell : E. carpini Rostr. E.bcetcriospermus (Joh.). E. Kruchii Vuill.

(2) Asci on carpels; without stalk-cell: $E$. alni incanae Kühu. $E$. Johonsonii Sad. E. rhizophorus (Joh.).

(3) Mycelium grows intercellularly. E. connu cervi Giesh. 


\section{Taphrina.}

The whole mycelium is subcuticular and differentiated into one portion, which remains sterile, and into an ascogrenous part. l'erenuation of the mycelium does not occur. The species produce spots or hypertrophy on leaves or carpels.

A. The fertile hyphae are completely used up in the formation of the asci.

(1) Asei with a stalk-cell: T. bullutu (Berk. and Br.). T. ostryae Mass. 'T. Sculcbeckii Joh. T. uneeu (Pers.) (may also occur without a stalk-cell).

(2) Asci without a stalk-cell: T. filicina liostr. T. polysporr (Sorok.). T. errnea Joh. T. coerulesens (Mont. and Desm.). T. virginier Seym. and Sad. T. cxtense (Peck.).

B. The fertile hyphae are not completely used up; asci with a stalk-cell : T. betular (Fuck.). T. ulmi (Fuck.). T. coltis Sarl.

\section{Taphrinopsis.}

Mycelium and hymenimu developed only inside the epidermal cells. T. Lanrencie Giesh.

\section{Magnusiella.}

The mycelium inhabits the inner tissues of living plants and is always parasitic. Asei are formed at the extremities of branches of the mycelium, either between the epidermal cells or between cells of the imner tissues. The asci contain more than four spores, which generally produce conidia inside the ascus. The species generally cause leaf-spots, more rarely they appear on stems.

(a) Asci without a stalk-cell: M. potentillae (Farl.). M. lutesecns (liostr.). M. flava (Farl.). M. githaginis (Rostr.). M. umbelliferarum (Rostr:).

(b) Asci with a stalk-cell: M. frescirulate Lag. et Sad.

Giesenhagen (loc. cit.) comes to the conclusion that the species of the parasitic Exoasceae have developed from a common ancestor simultaneously with the species of the ligher plants inluabited by them, and that the development of host and parasite 
has progressed side by side. He shows that Exoasceae, living on related hosts, agree so closely in their ascogenous forms, that it is evident they are generically related species. On this ground he sets up a genus containing many species, and names it Tuphrina. According to the host-plants, this gems is divided into four stems, and from it twenty-five species are separated off as the genus Marnusiclla. Giesenhagen's systematic division, gives a synopsis of the host-plants and their distribution as follows:

I. Genus. Taphrina: asci club-shaperl to cylindrical.

A. Filices-stem, on Ferns: asci slender, club-shaped; tapering to both ends, rounded apex, greatest breadth in the upper quarter of the ascus.

T. cornu cervi (Giesh.) on Aspidium rristetum in East Indies and Polynesia.

T. filicina (Rostr.) on Aspidium spinulosum in Scandinavia and Balkan-peninsula.

T. Laureneia (Giesl..) on Pteris quadriaurite in Ceylon.

T. fasciculatre (Lag. et Sad.) on Nephrortium in South America.

T. lutescens (Rostr.) on Aspidium Thelypteris in Denmark.

B. Betula-stem on Juliflorce: asci plump, cylindrical, with rounded apex or even a slight depression there.

(1) On Ulmaceue: T. ulmi (Johan.) on Ulmus montene and $U$. compestris in Central Europe and North America.

T. celtis (Sad.) on Celtis australis in North Italy and Switzerland.

(2) On Betrelaccre.

(a) On Betuld:

T. alpina (Johan.) on B. nene in Scandinavia.

T. nene (Johan.) on B. nene in Scandinavia.

T. betulee (Johan.) on B. verrucose, B. pubescens, and B. twhestanice in Central Europe.

T. betulina (Rostr.) on B. pubeseens, and B. odorcete in Germany, Denmark, and Scandinavid.

T. carnea (Johan.) on B. odorata, B. pubescens, B. nana, B. intermedia in Scandinavia, Tyrol, and Silesia.

T. baeteriospermum (Johan.) on B. nana in Scandinavia and Greenland. 
T. flaze (Farl.) on B. populifere and B. prepyrecece in North America.

T. turgide (Sad.) on 13. verruense in Germany and Tyrol.

(b) On Alnus:

T. epiphylla (Sad.) on A. incenre in Europe.

T. Sedcbectii (Johan.) on A. glutinose in Europe.

$T$. Robinsoniana (Giesh.) on $A$. inerena in U.S. Anerica.

T. Tosquinetii (Magn.) on $A$. glutinose in Europe.

$T$. alni incance (Magn.) on $A$. inerence in Europe.

( $T$. alni glutinosac (Tubeuf) on $A$. glutinosı in Italy, Sweden, and Demmark.)

(c) On C'upuliferae:

$T$. ostryae (Mass.) on Ostryu earpinifolire in Tyrol and Italy.

T. virginica (Sey. et Sad.) on Ostrya virginica in North America.

T. corpini (Rostr.) on C'arpinus Brtulus in Europe.

T. australis (Atk.) on Carpinus cmericana in North America.

T. Kruchii (Vuill.) on Quercus Ilex in Italy and France.

T. eocrulescens (Tul.) on Quereus sessiliftora, Q. pelunculcte, Q. pubescens, Q. alba, ete., in Europe and America.

(1) On Salieaceac:

T. aurea (Fries.) on Populus nigia, P. pyramidalis and $P$. moniliferce in Europe and North America.

T. Johrensonii (Sad.) on Populus tremula, $P$. tremuloides, and $P$. grendidentate in Europe and North America.

T. rhizophore (Johan.) on Populus alba in Europe.

c. Prunus-stem on Rosacece: asci slender and club shaped.

(

T. eretergi (Sad.) on Crectergus Oryeanthe in Europe.

T. bullata (Tul.) on Pyrus communis and Cydonia japoniea in Europe.

(b) On Pruneac:

T. deformans (Tul.) on Persica vulyaris and Amyydalus communis in Europe and North America.

T. minor (Sad.) on Prunus Chamaceerasus near Hamburg and Munich. 
T. insititice (Johan.) on Prunus Insititic and P. domestica, in Europe, and $P$. pennsylvaniea in North America.

T. Aecipicns (Atk.) on Prunus americune in North America.

T: cercasi (Sad.) on Prunus Cerasus and P. Chamaceerasus, in Europe, and $P$. arivem in North America

T. pruni (Tul.) on Prunus domestiea. and P. Padus in Europe and North America.

T. mirabilis (Atk.) on Prunus angustifolia, P. hortulena and $P$. americana in North America.

T. Farlowii (Sad.) on Primus serotina in North America.

T. confuse (Atk.) on Prunus virginiana in North America.

T Rostrupianu (Sad.) on Prunus spinose in Europe.

T. communis (Sad.) on Prunus maritima, P. pumila, P. americana and $P$. nigia in North America.

T. longipes (Atk.) on Prunus americanu in North America.

T. rhizipes (Atk.) on Prunus triftora in North America.

(c) On Potentillece:

T. potentillae (Johan.) on P. sylecetris, P. eunudensis, and $P$. yeoïles in Europe and North America.

D. Aesculus-stem on Eucyeliere: asci plump, cylindrical, with flit or rounded apex.

(a) On Sepindaceu:

T. resculi (Ell. et Ever.) on Aesculus californiea in California.

(b) On Anacarticuesce:

T. purpurescens (Robins.) on Rhus copalline in North America.

(e) On Acerinece:

7. acerieolu (Mass.) on A. ecempestre and A. Pseudoplatanus in Italy.

T. acerina (Eliass.) on A. platenoides in Sweden.

T. polyspora (Johan.) on A. tartarieum in Europe.

II. Genus. Magnusiella: asci ovoid or spheroidal.

M. githaginis (Sad.) on Agrostemma Githago in Denmark.

11. umbelliferctrum (Sad.) on Herceleum Sphondylium, Peucedunum polustre, and P. Oreoselinum in Europe. 
The frrouscene may be groupen, according to the symptoms of the clisease produced, as follows; for this purpose we shall class all the species as one genus, 'Eroassus' (or T'aphlirina):

I. Species which eause deformation of the orary or other part of the fruit.

E. pruni (Fuck.) on Prunus Ammestire, I'. Patus, I'. Mirginimine.

E. Rostrupirmus (Sart.) on I'rumus spinosu.

E. communis (Sad.) on Prunus pumilla, I. maritima, $P$. nigre, $I^{\prime}$. enncricreute.

E. Farlowii (Sad.) (E. verius, Atk.) on Prunus serotinu, causing also deformation of twigs.

E. lonuipes (Atk.) on Prumus americone.

E. confusus (Atk.) on Pirnues virginienu.

E. rhizipes (Atk.) on Prunus triftere.

E. cceidomoplitus (Atk.) on insect-galls on the fruits of Prunus virginiana.

E. mirabilis (Atk.) on Prunus angustifolia, l'. hortulunu, I'. americana.

[Also species on Prnums subcordete, P. Clicerse, and $I$. tennsylounire.]

E. alni incenure (Kiihn) (E. amentorum, Sirl.) on Aluus incence.

E. alni glutinosac (Tubenf) on Aluns glutinoss.

E. Rotinsonimus (Giesh.) on Alnus incoun.

E. Fohensomii (Sad.) on Populus tremule, I'. tromuloitl's, I'. grandidentata.

E. rhizophorus (Johan.) on Populus wllur.

II. Species which (1) produce witches' broous, or (2) at least cause deformation of shoots; asci produced on the leaves.

(1) E. epiphyllus (Sad.) (E. borcelis, Johan.) on Alnus incana (uniform grey coating of asci on both sides of leaf.)

E. turyidus (Sad.) on Bitule remrueosa (coating of asci on under surface accompanied by slight crumpling of leaf).

E. betulinus (Rostr.) on Betule pubescens and B. odorata (coating of asci on under surface). 
E. alpinus (Johan.) on Betula nana (coating on under surface).

E. carpini (Rostr.) on Carpinus Betulus (coating on under side, and crumpling of leaf).

E. cerasi (Fuck.) on Prunus Cerasus and P. arium (coating, chiefly on under sicle, and crumpling of leaf).

E. insititice (Sarl.) on Prunus Insititio, P. domesticu, P. pennsylianicu, ( $P$ '. spinosa ?); (coating on under side, and crumpling of leaf).

E. acerinus (Eliass. ${ }^{1}$ ) on Aeer platenoides; (asci on both surfaces).

E. uesculi (Ell. et Ever.) on Acsculus californiea; (coating on both sides).

E. Kruchii (Vuill.) on Querens Ilex.

E. comu cervi (Giesh.) on Aspridium aristatum.

E. Laurencia (Giesh.) on Pteris quadrianrita (with deformation of leaves).

(2) E. nanus (Johan.) on Betulu name (white coating on upper side).

E. bacteriospermess (Johan.) on Betule nena (coating on both sides).

E. decipiens (Atk.) on Prumes americame (coating on both sides).

E. purpurecens (Ell. et Ever.) on Rhus copullina (crumpling and red-colouration).

E. Tosquinetii (West.) on Alnus glutinose and A. glut. $\times$ incana (large blisters and elongation of shoots).

E. muni (Fuck.) on Prunus domesticr (blistering and crumpling).

E. minor (Sacl.) on Prunus Chomacerasus.

E. deformans Berk. on Persica vulyaris and Amygdalus communis (blistering and crumpling).

E. cratargi (Fuck.) on Cratargus Oxyacantha (spots and blisters on the leaves).

E. mirabilis (Atk.) on Prunus angustifolia, P. hortulana, $P$. americana (on twigs, leaves, and fruits).

E. celtis (Sad.) on Coltis austrulis (brown spots).

E. githaginis (Rostr.) on Agrostemma Githago.

${ }^{1}$ Siensika l'et.-Aliad. Handl. 20, 1895. 
III. Species which prodnce (1) pustule-like outgrowths, (2) leaf-spot, or (3) smooth coatings of asci.

E. aurcus (Pers.) on Populus nigra (incl. myramilalis) and $P$. monilifere.

E. polysporus (Sor.) on Acer turturicum and A. Pseudoplatumus.

E. bullutus (Berk. et $\mathrm{Br}^{2}$.) on P'ymes communis and Cydonice japonice.

E. carncus (.Johan.) on Bctula nrena, B. odorata, and $B$. intcrmerliu.

E. corrulescens (Desm. et Mont.) on Qucreus pubescens, Q. sessiliftore, Q. Cerris, Q. lanrifoliu, Q. rubre, Q. tinetoria, Q. aquatica.

E. Sudcbeclii (Johan.) on Alnus glutinose.

E. ulmi (Fuck.) on Ulmus campestris, $U$. montena, and $U$. americana (spots and blisters!:

E. virginicus (Sey. et Sad.) on Ostrya virginica.

E. australis (Atk.) on Carpinus amcricanus.

E. filicinus (Rostr.) on Aspidium spinulosum.

E. potentillae (Farl.) on Potentilla geoïles, P. canarlcnsis, I. sylvestris.

E. githaginis (Rostr.) on Agrostcmma Githago.

E. lutescens (Rostr.) on Polystichum Thelypteris.

E. umbelliferamu (Rostr.) on Heracleum S,hondylinm, Pcucedunum pulustre and P. Orcosclinum.

E. ostryae (Mass.) on Ostryu carpinifolia (brown spots).

E. betulue. (Fuck.) on Betula verrucosa, B. mebescens, B. turkestanicre (whitish spots).

E. flavus (Farl.) on Betula populifolia, B. prepryracca.

E. recricolus (Mass.) on Acer cermpestie and A. Pscutoplatanus.

E. fusciculatus (Lag. et Sad.) on Nephrodium (whitish spots).

The following are some of the more important species of Exoasceae :

Exoascus pruni Fuck. (Pocket-plums). This attacks the ovaries of Prunus tomestica (plum), P. Padus (bird cherry), and $P$. virginiana, causing the mesocarp to grow rapidly, whereby the fruits increase in size and become much changed in form, 
while the stone, including the embryo, remains stunted. (Fig. 49.) The "pocket-plums" (fools or bladder-plums) dry up, and remain hanging on the tree till autumn. De Bary found on the plum a withering of calyx and stamens resulting from the development of the hymenium of this Ecoascus; on the bird cherry, according to Magnus and Wakker, enlargement of the stamens occurs. Sometimes a considerable thickening and twisting of the young shoots takes place, and their leaves curl up.

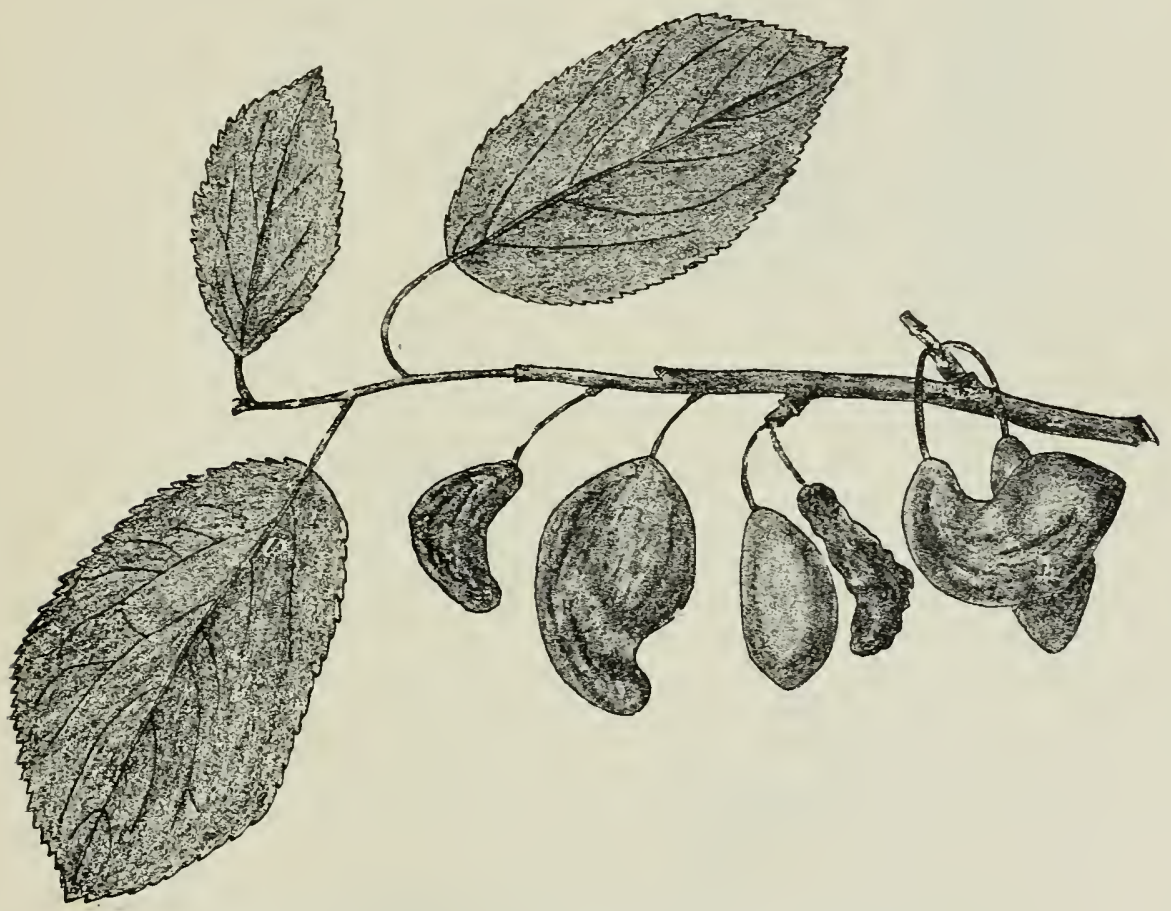

Fig. 4S.-Exoascus pruni. Twig of Plum, with four deformed fruits; one normal plum is partially hidden, the other is in the middle. $\frac{t}{5}$ natural size. (₹. Tubeuf del.)

The mycelium hibernates in the soft bast of the twigs, and proceeds thence in spring into young shoots and ovaries. According to De Pary, the infected ovaries double their size in two days, and are full grown in eight days. The asci form a close layer under the cuticle of the ovary, and finally rupture it. 

Exoascus communis Sad. This produces pocket-plums on Prunus americanu, P. pumile, and P. maritima in America.

Similar "pockets" also occur on Prunus subcordata, P. Chicasa, and P. pennsylvanica, in America, as a result of some Exocscus.

Exoascus Farlowii Sad. produces similar leformation of carpels and floral envelopes on Prunus serotina in North America.

Exoascus Johansonii Sad. produces carpelenlargement on the female catkins of Populus tiemela, P. tremuloides and P. grendidentate; the contents of the asci are yellow. (Fig. 52.) The anatomy of the deformed ovaries has just been described by Sadebeck. ${ }^{1}$

Exoascus rhizophorus Johan. causes similar enlargement of the female catkins of Populus alber.

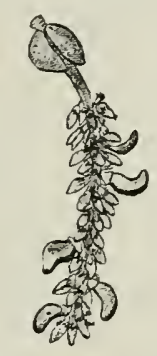

Fir. 52.-Esoascus Johansonii Sad. on Populustremulc. (v. Tubeuf del.)

Exoascus alni-incanae Kiihn (Ex. cmentorum Sad.) This species is readily distinguished by the absence of a stalk-cell on the ascus. It causes increased growth and enlargement of the seed-scales of alder catkins, the fruit itself being seldom attacked. The fleshy bladder-like outgrowths at first appear as little red processes; later, the asci are developed on the outer surface as a whitish coating. On many of these red processes may still be recognized the trifid apex of the normal scale, (this is really formed from five smaller scales fused into a single large one with a trifid apex). A number of these red outgrowths are generally present on each infected catkin, yet the alders continue to Hower vigorously every year.

Wakker, ${ }^{2}$ in investigating the anatomy of the deformed scales, found the following alterations:- the scales are increased to many times their original size and contain two cavities; all parenchymatous cells become regular and iso-diametric; lignification of the elements of the wood is more or less interfered with, and fewer wood-fibres are produced; there is an accumulation of transitory starch.

Exoascus alni-glutinosae Tubeuf. This is a new species distinguished by v. Tubeuf in 1895. It occurs in the Sudetic mountains, Italy, Denmark, and Sweden, on Alnus glutinosa. Its habit is similar to that of $E x$. alni-incanac, but the asci 
contain only conidia, whereas those on Alnus-incenu are said by Sadebeck to contain only ascospores, unless on very rare occasions. In the lower and higher Alps, although loth species of alder are not infrequently found together, yet the Wrorscus is found only on Alnus incana, and no species occurs on $A$. glutinose.

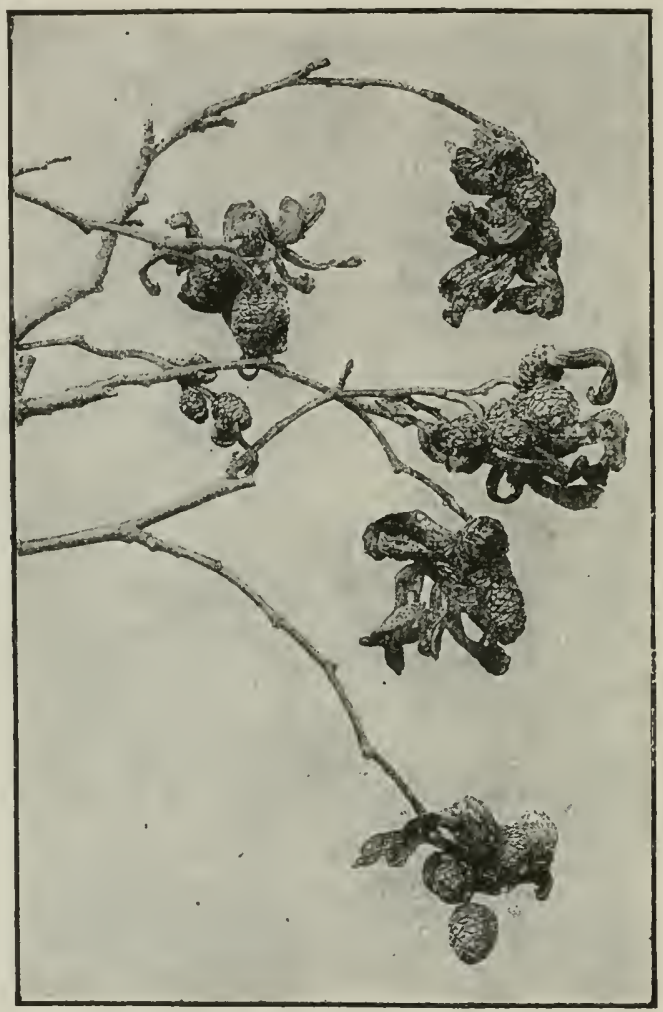

Fig. 53.-Ecoascus almi-incance in eatkins of Alnus incana. Mans of the scilcs ure developed as elongated red soft tongue-like structures, on which the asei are produeed as a whitish conting. (v. Tubeuf phot.)

Exoascus epiphyllus Sad. (Er. borculis Joh. ${ }^{1}$ ) The witches'broom fungus of the white alder (Alnus incanu.)

The anthor ${ }^{2}$ was the first to describe and figure this form of disease in 1884; and Sadebeck recently succeeded in pro-

${ }^{1}$ K. Sven. Vet. Akad. 1855 and 1S87. Tubeuf, Botan. Centralbl., 1890.

2 Tubeuf, Beitrüge z. Kenntniss d. Baumkrankhtilen, 1858. 
ducing the brooms by artificial infection of alder. The disease is common and epidemic, and a single tree may carry as many as a hundred brooms.

The witches' brooms are composed of many thickenel twigs, beset with an abnormal number of lenticels, and the point of infection shows a distinct swelling, from which the broom tends to turn directly upwards. The leaves are somewhat modified, they are larger and thicker than the normal, they unfold later and wither earlier, while their stipules remain attached for some time. The brooms of alder only survive a few years, and by their decay cause the deatl of large branches, and frequently of the whole tree.

The asci, which are sunk in a depression of their stalk-cell, form a white coating on both surfaces of the leaves. The mycelium hibernates in the buds.

Exoascus turgidus Sad. causes the formation of witches' brooms on Bctula verrucose. The leaves formed on the brooms are somewhat crumpled, and the asci are produced on their lower surface.

Exoascus betulinus Rostr. produces witches'

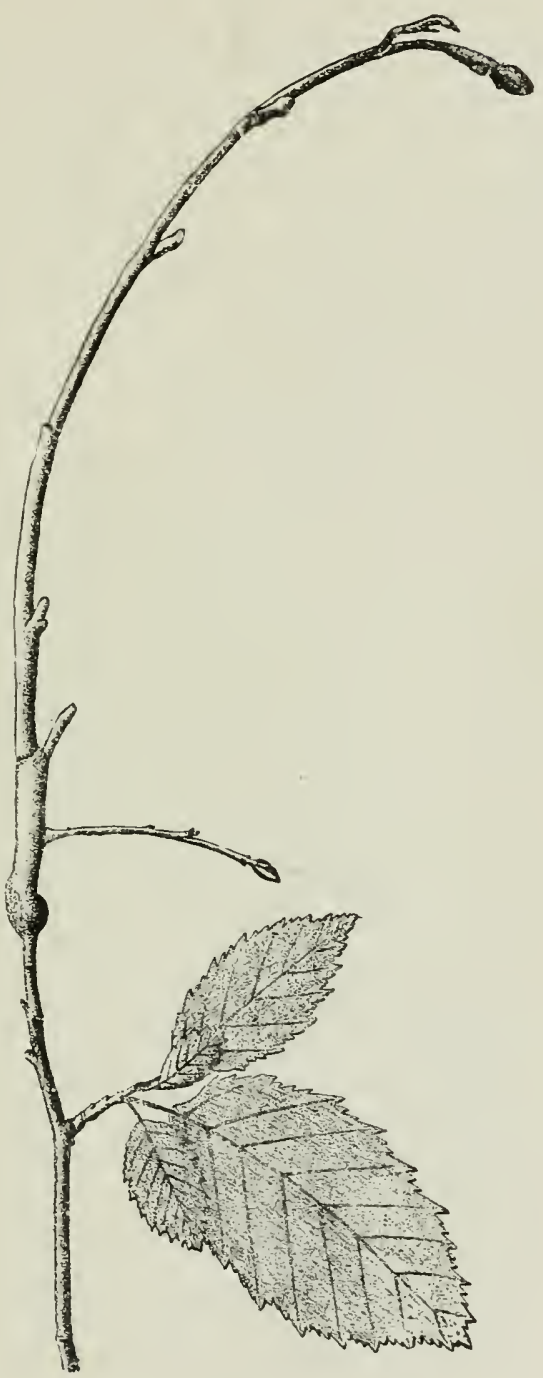

FIG. 54.-Exoascus epiphyllus. Witches' broom in first year, showing swelling at the point of infection. The leaves are already shed in autumn, while the normal still remain $\frac{4}{5}$ natural size. After v. Tubeuf.) brooms on Bctula pubescens and B. odoratu. 
* Witches' brooms on birch are very common in Scotland. They appear as tangled masses of twigs, which at first sight give the impression of some bird's nest. I have frequently examined the leaves borne on these brooms, and have never failed to find the asci of an E'rouscus. Sadebéck gives in his monograph the two above-named species as found on birches bearing witches' brooms. Mites (e.g. Phytoptus) have also been given as the cause of these malformations. On close examination of brooms which undonbtedly bore Exouscus, I found that a broom results from a prolific development of small twigs on one or a few knotty swollen parts of a branch. Each central

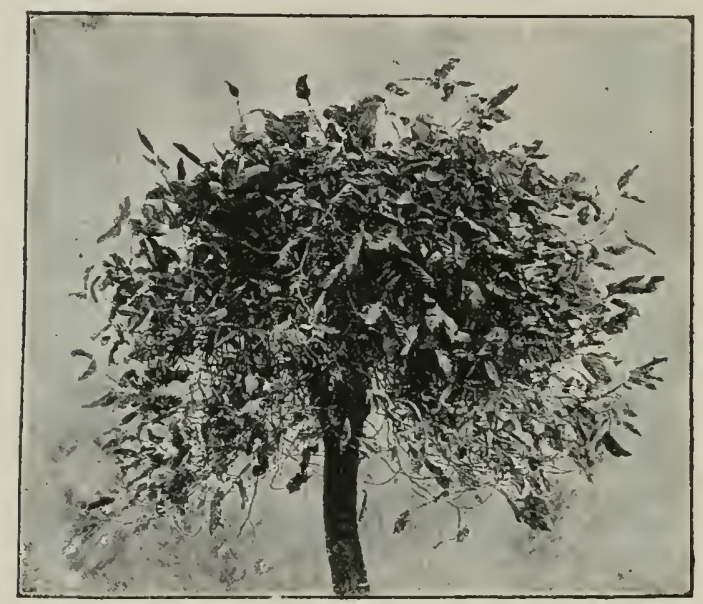

Fig. 55. - Witches' Broom of the Hornbeam. Exouseus carpini on Carjinus Betulus. The bush measures about 1 metre across, and arises laterally from a braneh, the upper normal part of whieh has been removed. (v. Tubeuf plot.)

knot we may regard as the position of the bud which was first infected, and from which the broom system took its origin. As one result of the attack of the fungus, the greater number of the buds in the axils of the scales of the infected hud have grown out as twigs, but not into well-developed ones. In consequence, nearly every twig has been killed back by the winter, but not completely, so that from each twigbase has sprung a new crop of stunted immature twigs like the first, and equally liable to be killed in the following winter. Thus has arisen that tangled mass of dead or sickly birch twigs which we call a witches' broom. [Edit.] 
Exoascus alpinus Johan. and Ex. nanus Johan. Both occur on Betule nane, and induce formation of hypertrophied twigs.

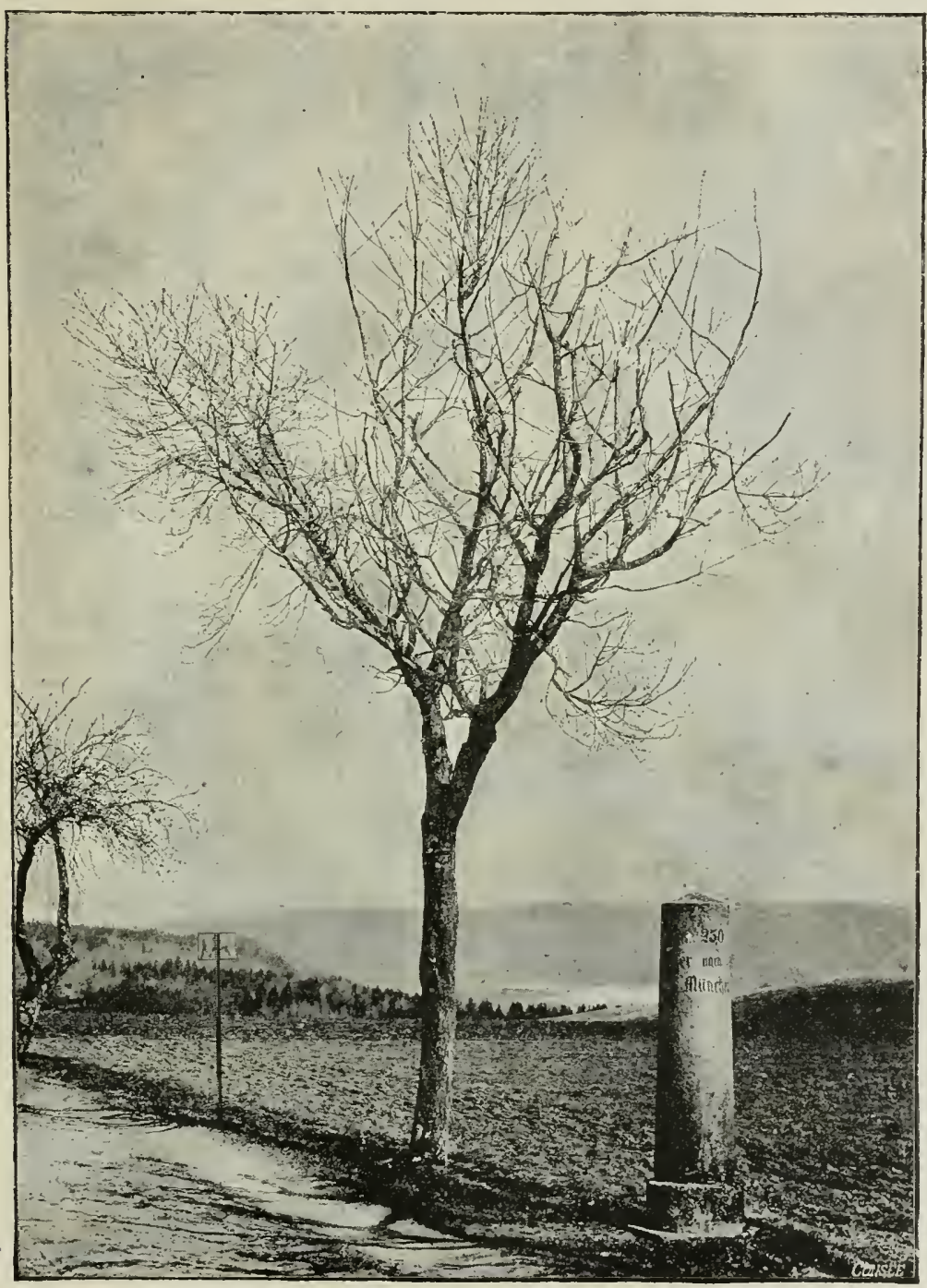

FIf. 56-Witches' Broom of the Cherm. Exoascus cerasi on Prunus Cerasus. The whole left side forms a large broom. A smaller example occupies the summit of the crown, while another hangs downwards to the right. In winter condition. (v. Tubeuf phot.)

The mycelium of $E$ : nanus hibernates in twigs, and penetrates 
into the inner tissnes of newly-formed twigs and leaves. The inycelium of Eu alpinus passes the winter in the buds, spreading thence in spring into young twigs and leaves.

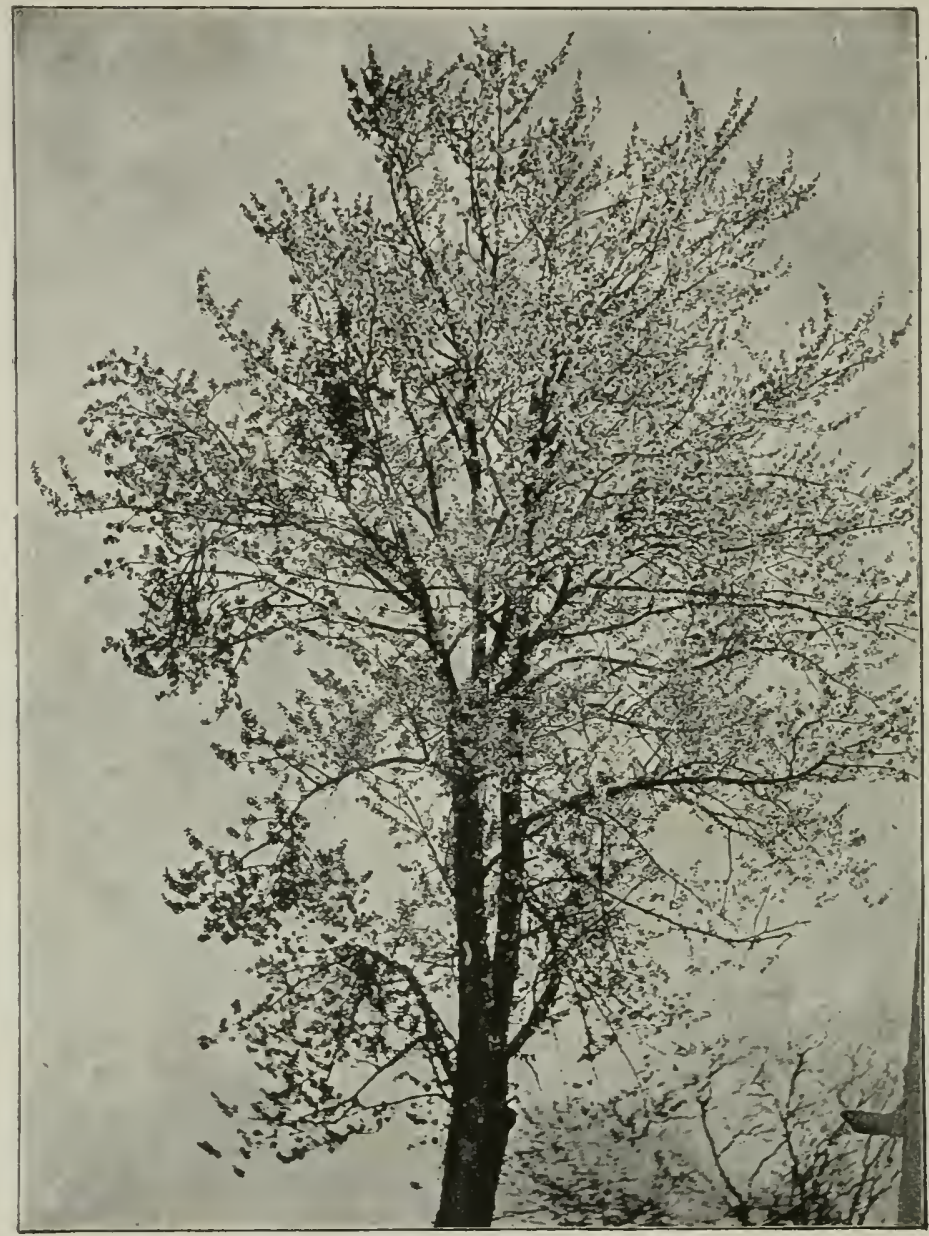

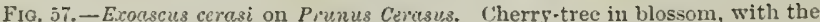
exception of four witches' brooms. The tree is as jet leafless except the brooms, which are in full foliage and show up rark. (

Exoascus carpini Postr. is common on Carpinus Betulus (hornbeam) (Fig. 55). The brooms produced are bushy and densely leafed; the twigs are thickened and much branched; the leaves 
are somewhat curled up, and the asci appear on their lower surface. ${ }^{1}$

Exoascus cerasi Fuck. occurs very commonly on cherry trees (Prunus Cercusus and P. uvium) both in Europe and America." It produces witches' brooms, which may be large, upwardly directed, bush-like, and very conspicuous structures, with numerous thickened and elongated twigs (Fig. 3); or they may be small, hanging bunches of twigs with upturned free encls. The leaves are somewhat wavy, slightly crumpled, and reddish; on their lower epidermis they bear asci, and fall off prematurely.

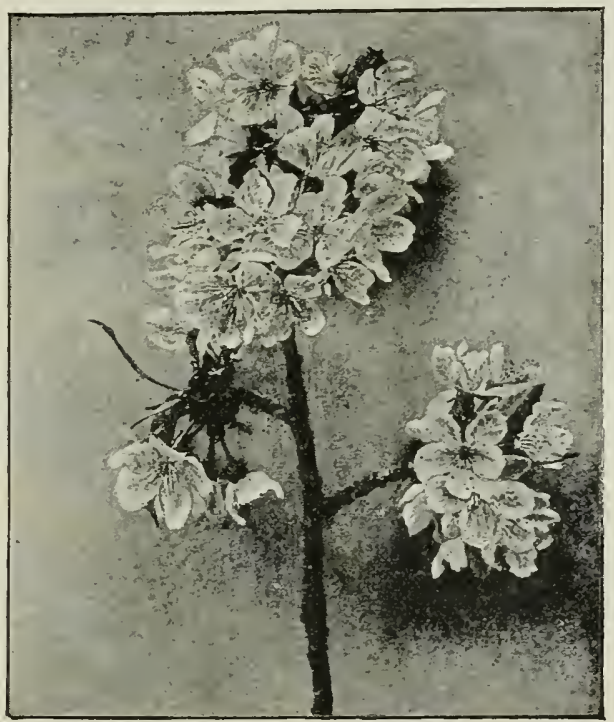

FIG. 58.-Normal twig of Cherry from a tree in blossom, as in Fig. 57. (v. Tubeuf phot.)

The brooms are visible at a considerable distance in the winter (Fig. 56), while they are even more conspicuous during the Howering season (Fig. 57). At the latter time, before the leaf-buds open, the cherry trees are normally covered with white blossom, while the brooms bear leaves only, and rarely blossom. Hence they produce little or no fruit. Each tree

1 Wehmer (Bot. Zeitung 1S96) discusses the formation of these witches' brooms. (Edit.)

"E. Rathay, "Uber die Hexenbesen d. Kirschbäumen."-Sitzungsber. d. $K . K$. Akad. :u Wien, 1 SSl. 
may bear several brooms, and every tree in it fruit-gardent may be attacked, so that this disease has assmed considerable economic importance. As a preventive neasure, the removal of all brooms at the time of pruning the trees is strongly

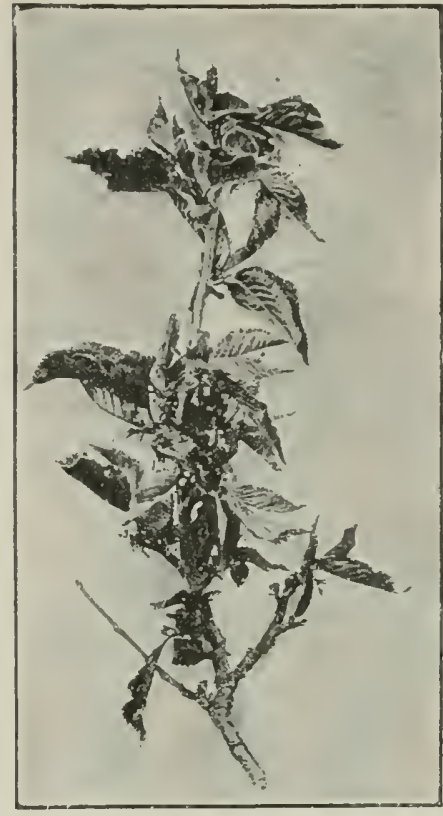

F1c, 50.-Twig from witches' broom in foliage, as in Fig. 57. Photographed at same time as Fig. 58 for comprarison. (v. Tubeuf phot.)

\section{recommended.}

[According to Shirai (Tulitis botrinical mayazine, 1895 ) witches' brooms are produced in Japur on Prunws posendo-cerasus, by a distinct species, Ei. psenducrecusus.]

Exoascus minor Sad. This species induces hypertroply of shoots of Prenus Chamucerusues and $P$. Cerasus, lut camnot be said to cause formation of witches' brooms. The mycelium hibernates in the buds, and spreads only underneath the cuticle, while that of Eu corrsi lives in the tissue of the twigs and leaves. It is characteristic of this species that only leares here and there on a twig mily be attacked, while their neighbours remain quite healthy; both Howers and fruit may also be borne. Diseased leaves appear much crumpled, and Sadeleck states they have an odour of emmarin: they turn brown prematurely and fall off:

Exoascus insititiae sad. is fomnd on Prumus domesticn and $P$. Insititia in Europe, and P. pennsyltanica in North Anerica. It canses formation of witehes' brooms smaller than those on the cherry tree, yet probably more common in the fruit garden. They bear no fruit, and are a source of considerable loss. The mycelimm hibernates, like that of Er: rercesi, in the lark of twigs, and spreads in spring into the buds.

The leaves of the host bear asci on the lower epidermis; they are always more or less curled up, and full off early. To prune off all brooms is the best preventive measure. 
Exoascus deformans (Perk.) causes the "curl disease" of the peach (Prisicu vulgeris), and may inflict great injury. The

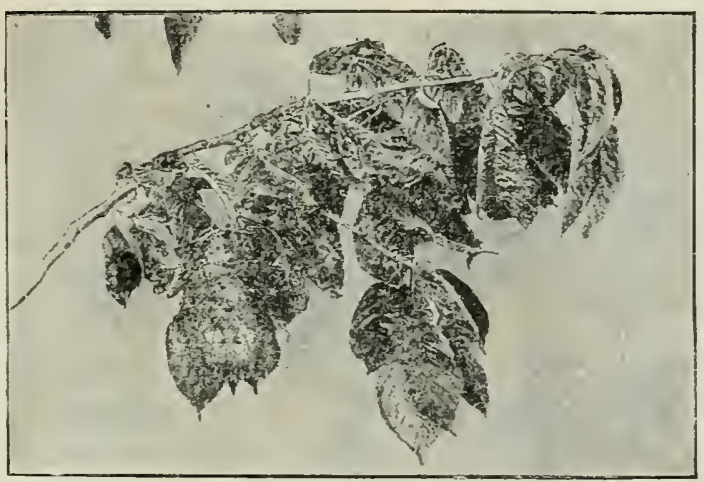

F1r. 10.-Ernoscus minor. Curl disease of Cherry.

mycelium hibernates in luark, pith, and medullary rays of twigs, so that it reappears each year. An Errouscus, which occurs
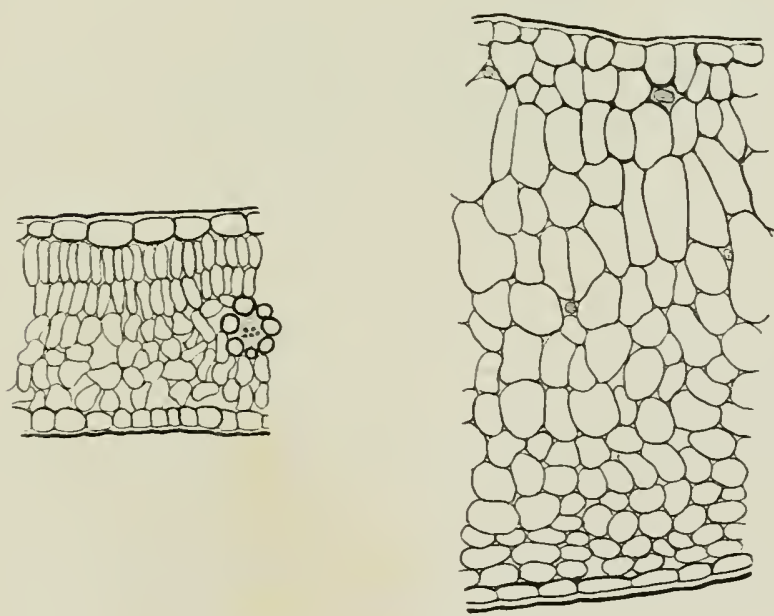

B

FIci, b1.--Exoascus deformens. Comparison of normal section of leaf of Prunus Persice with a hypertrophied one, B; in the latter the myeelial hyphae have been slightly shaded. The sections are from different parts of the same leaf, and are drawn with the same magnifieation. (After W. G. Smith.)

on the almond (Amyylalus communis), resembles Ex. deformans so closely that they are now regarded as the same species. 
This is supported by Smith's investigations, in which an anatomical comparison of disensed twigs of peach and almond showed no difference in the pathological effects.

Exoascus crataegi Fuck. occurs on Ciruturyns Oryunenthu, and canses red swellings on the leaves and flowers, accompanied by hypertrophy of shoots in which the myceliun perenuates.

Exoascus Tosquinetii (West.). The deformation caused by this species is frequent on the hlack alder (Aluus glutinusa). The thickened, elongated, wrinkled twigs render attacked parts very conspicuous in contrast to the normally developed parts of

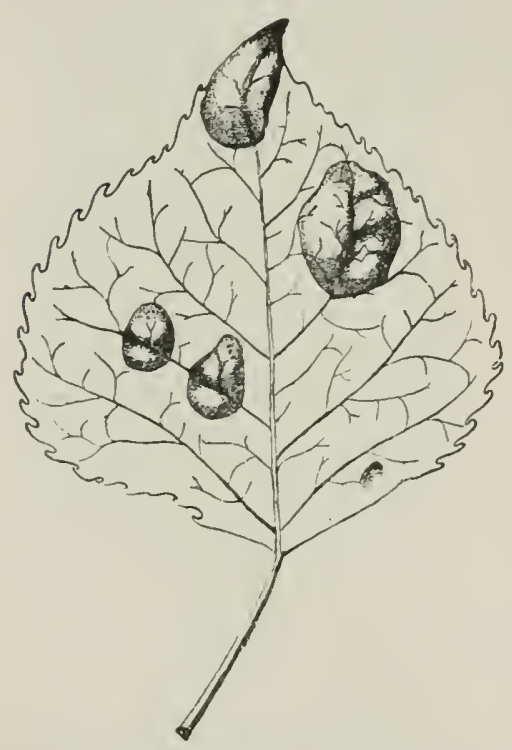

FIr: 6is.-Exoascus aureus. Leaf of Populus nigra, showing the pustule-like swellings. ( $\mathrm{r}$. Tubeuf del.) the tree. The leaves may he wholly attacked and nuch enlarged, or they may only be hypertrophied at places so as to form pustule-like swellings. The epidermal and mesophyll-cells of disensed leaves become greatly enlarged.

Exoascus aureus (l'ers.). The leares of the lilack poplar (Popnelus nigrou) attacked by this parasite exhibit pustules (Fig. 62). The asci are formed as a golden coating on the concave sice of the pustules, which is, in most cases, the under side of the leaf, rarely the upper. The cells forming the pustules have thicker walls and a somewhat different shape from the normal epidermal cells, and they are not unfrequently sub-divided by walls of secondary origin (Fig. 63).

According to Smith, the cells of the palisade parenchyma have also thickened walls, as well as being elongated and occasionally chambered; the cells of the spongy parenchyma are enlarged and have thicker walls; so also are the cells of the collenchyma of the leaf venation. 
Exoascus coerulescens (Mont. et Jesm.) produces similar blisters on oak leaves.

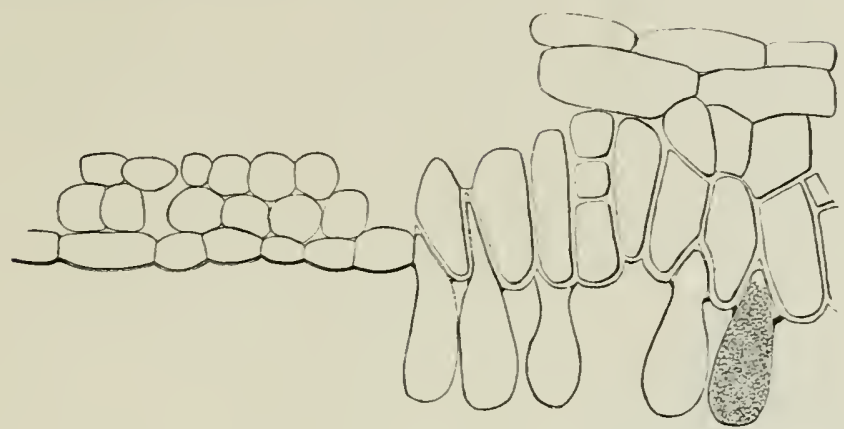

FI1. 63.-Evocscus auiex!s. Leaf scction from the margin of a swelling, showing normal and hypertrophicd tissue. The cells of the swelling are abnormally elongated with thickened walls, and some show secondary cell-division. The bases of the asci are wedged in between the cells; one ascus is shown with conidia. (v. Tubeuf del.)

Exoascus carneus Johan. occurs on leaves of Brtulu orlorectu, B. nana, and B. intermedia. The pustular outgrowths rise above

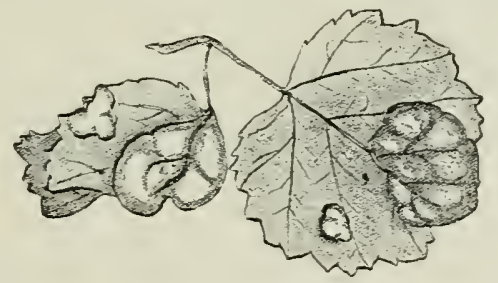

Fig. 61-Esoascus cameus an Betula odorata. (r. Tubeuf del.)

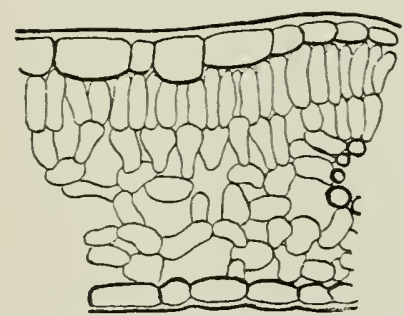

Fig. 65.-Section of normal leaf of Betula odorata. (After W. G. Smith.)

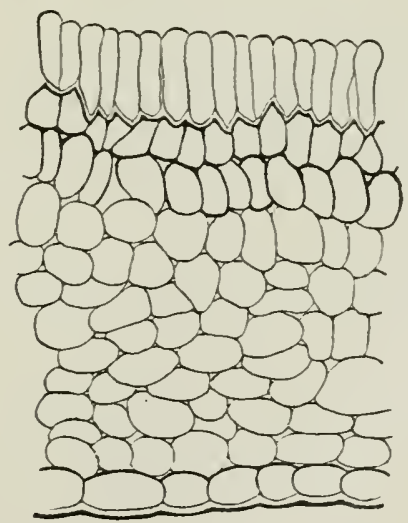

FIG. 66.-Section of leaf hspertrophied by attack of Exouscus cameus; the asci of the attack of Exocscus carneus; the asci of the
fungus coat the upper epidermis. Drawn with the same magnification as Fig. 65, for comparison. (After W. G. Smith.) 
the upper surface of the leaf (Fig. 64), and the upper epiclermis alone bears the asci. In the pustules, the leaf may be two to four tines as thick as healthy parts. The wreatly increased thickness is due for the most part to enlargement of the cells of the mesophyll, while at the same time their normal arrangenent is completely lost (Figs. 65, 66). The elements of the fibrovascular bundles are enlarged; the cells of the upper epillermis are more numerous, contain a reddish sap, and their walls are thickened. All chlorophyll is destroyed in the pustules.

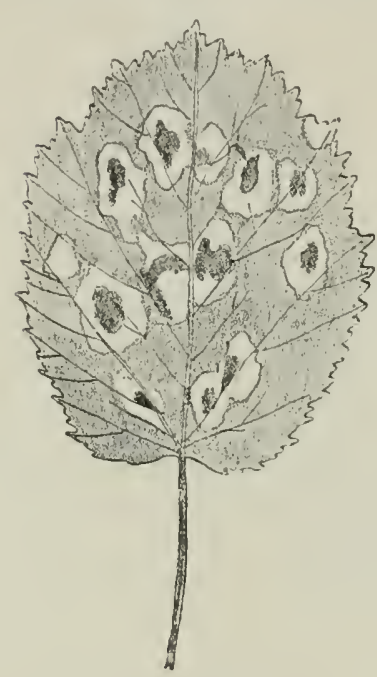

F'IG. bit.- Eirocescus polyspoinzs on Acer turtaricum from sweden. The attacked leaf shows pale spots with brown centres. The former result from the Taphrina, and are eovered by a white coating of asci ; the brown spots are produeed by other fungi which grow on the spots already killed.

Ex. polysporus (Sor.) causes swollen spots on leaves of Acr tartaricum.

Ex. bullatus (Fuck.) causes similar spots on leaves of pear (P'yrus communis) and quince (Cydonire juponicete.

Ex. Sadebeckii (Johan.) causes simple spots on leaves of Almus ylutinose.

Many other species, named in our list and in Sadebeck's papers, will be fornd described in detail in one or other of the papers already cited.

\section{b. Carpoasci.}

\section{(Ascomycetes with Sporocurps.)}

The asci of the Carpoasei are not formed directly on the mycelimm, but from a special part of it, which becomes more or less enclosed in another non-ascogenous portion. From these two portions of the mycelium a sporocarp is formed, in which we can distinguish three distinct constituents: (a) the envelope containing $(b)$ the paraphyses and $(c)$ the asci. Amongst the Gymnoasci the envelope, if present, is nerer more than a loose hyphal tissue, but in the Carpoasei both paraphyses and envelope are present, the latter with characteristics distinctive of each species. The sporocarps of the lower Carpoasci are completely closed structures containing only one or a few asei; those of the higher forms, however, 
contain many asci, and the envelope is pierced by a definite aperture.

Brefeld endeavours to explain the ascocarp of the Erysipheae from the sporangial structures of the Zygosporeae (Rhizopus and Mortierellu); De Bary ${ }^{1}$ and Zopf, " on the other hand, see in it an oosporanginm, like that of the Oosporeae. Under this latter view the envelope of the Carpoasci is morphologically homologous to the antheridia of the Saprolegnieae and Peronosporeae. In the latter group the antheridiun generally takes the form of an open fertilization-tube, in the Saprolegnieate it remains closed, and is physiologically no longer an antheridimn. Zopf found in one of the Saprolegnieae (Dictyuchus carpophorus), an envelope resembling that of the Erysipheae, and on this gromd he, along with De Bary, links the Erysipheae to Oomycetes like Achyla through forms like Podosphaera.

The reproductive cells or ascospores result from direct nuclear division inside the asci. They are generally simple and unicellular, but it is not uncommon to find that, by the formation of cross and longitudinal walls, each spore forms a cell aggregation (sporidesm of De Bary), with each cell capable of germination on its own account. The number of cells in each aggregation, as well as the size and shape of each cell, are in many cases constant, and form points for the determination of species. Appendages to the spores are characteristic of many species.

The Carpoasci possess, in addition to ascospores, other means of reproduction. Thus, thick-walled chlamydospores occur either in the mycelium as resting-spores (Hypomyces), or as spores (oidia) resulting from a breaking-up of hyphae. Many kinds of conidia may also be produced, some from the germinating ascospores, some abjointed from a branch of the mycelium or from some form of special conidiophore. These latter may be produced isolated, or massed togrether in hollows of the stroma, or in closed structures resembling ascocarps, and called pycnidia. The various forms of reproductive organs presented by each species will be more closely considered as we proceed.

The Carpoasci are arranged, according to the structure of the ascocarps, mnder the following divisions:- the Perisporiaceae, Pyrenomycetes, Hysteriaceae, Discomycetes, and Hel-

${ }^{1}$ De Bary. Beitrïge z. morph. u. Physiol. «. Pilse.

${ }^{2}$ Zopf. Beitrüge z. Physiol u. morph. neider Organismen. Heft :3, 1893. 
vellaceae. All these groups include forms parasitic on plants, except the last, which is saprophytic.

crymnouseus and Ctenomyers are forms intermediate to the (iymnoasci and Carpoasei; they have the asei enclosed in a sliny envelope of mycelial tissue. We place them along with the former group, although Brefeld puts them in the latter.

\section{PERISPORIACEAE.}

The Perisporiaceae are distinguished by having an ascocarp or perithecium which never opens, so that the asci are only exposed by decay of the envelope. It includes three families, the Erysipheae, Perisporieae, and Tuberaceae.

\section{ERYSIPHEAE.}

The nembers of this family all live as parasites on the outer surface of plant-organs, and have a much-branched, white, septate mycelium, which derives nourishment from the interior of the epirlermal cells of the host by means of haustoria of various forms.

The Erysipheae or Mildews appear as white spots and coatings, on which the ascocarps or perithecia appear later as black points. On microscopic examination, the perithecia will be found to contain one or many asci, while externally they are beset with thread-like appendages of a definite form and definitely arranged, so that they are of great nse in determining the various species.

The fungus passes through the winter by means of the ascospores. These do not ripen till spring, when, liberated by decay of the ascocarp, they are carrierl to plants, where they germinate, especially on the leaves, and form a mycelinm. In ardition, the fungus is propagated throughout the summer by means of conidia prodnced on special conidiophores in acropetal series or chains, of which the distal terminal conidium (acrospore) is the oldest and largest. The ripe conidia fall off and produce a mycelium which is at once fixed in place by the formation of haustoria.

Prevention. "Sulphuring" is the method chiefly used for combating mildew. This consists in dusting powdered sulphur (flowers of sulphur) over the plant threatened with attack. 
The operation is done by hand or by special implement. One of the best known of these is the "Sulphur Puff." This eonsists of a brush with a hollow stem to contain flowers of sulphur, the end of the stem being perforated to allow the sulphur to escape on to the plant. Sulphuring must be earried out during dry weather to prevent the powder being washed away. It has also to be frequently repeated, so that young growing shoots, flowers, fruits, leaves, and all parts liable to attack, may be kept well dusted. Sulphur prevents germination of eonidia on the leaves; it also kills the myceliun, while the plant itself remains uninjured.

Besides sulphuring, various copper solutions give very good results, while at the same time they act as a preventive against the false mildews (Plasmopare, Pcronospora, ete.).

\section{Sphaerotheca.}

Peritheeia spherical with thread-like appendages; they contain one spherical ascus with eight colourless oval ascospores.

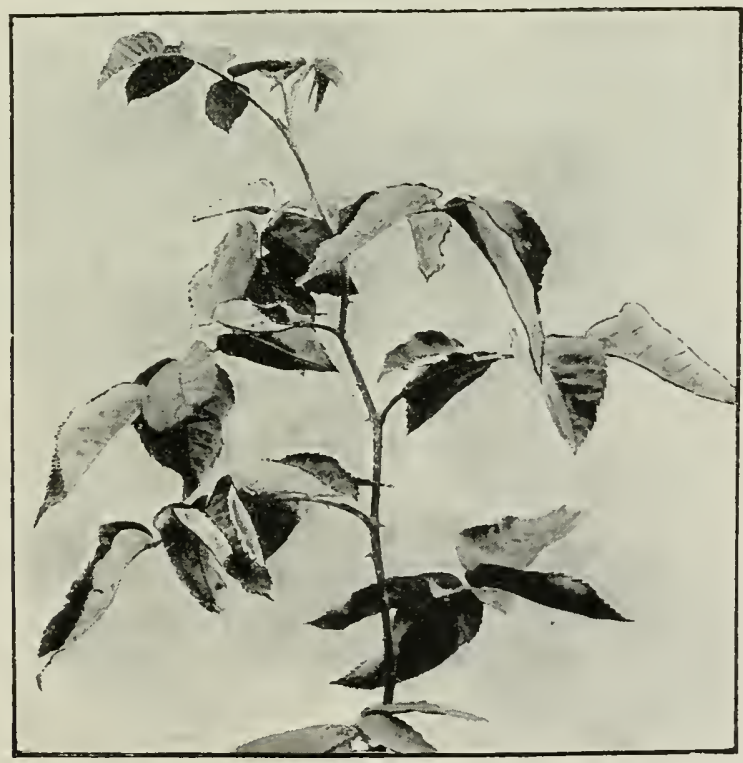

Fra. 68.-Rose-mileve. Sphaerothece penmoso. The fungus forms a white mealy coating on the leaf, especially on the lower side; the leares are alsu more or less curled up. (v. Tubeuf phot.) 
Sphaerotheca pannosa Wallr. (Britiu and U.S. Aneriea). The liose-milkew. The mycelinm forms a thin white coating on the leaves, and is nourished by lobed hanstoria inserted into the epidermal cells. Young leaves or buds when attacked become more or less deformed, their function is interfered with, and death may result. In this way great damage is done in rose-grardens. This parasite also attacks young leaves and fruits of peach and apricot.

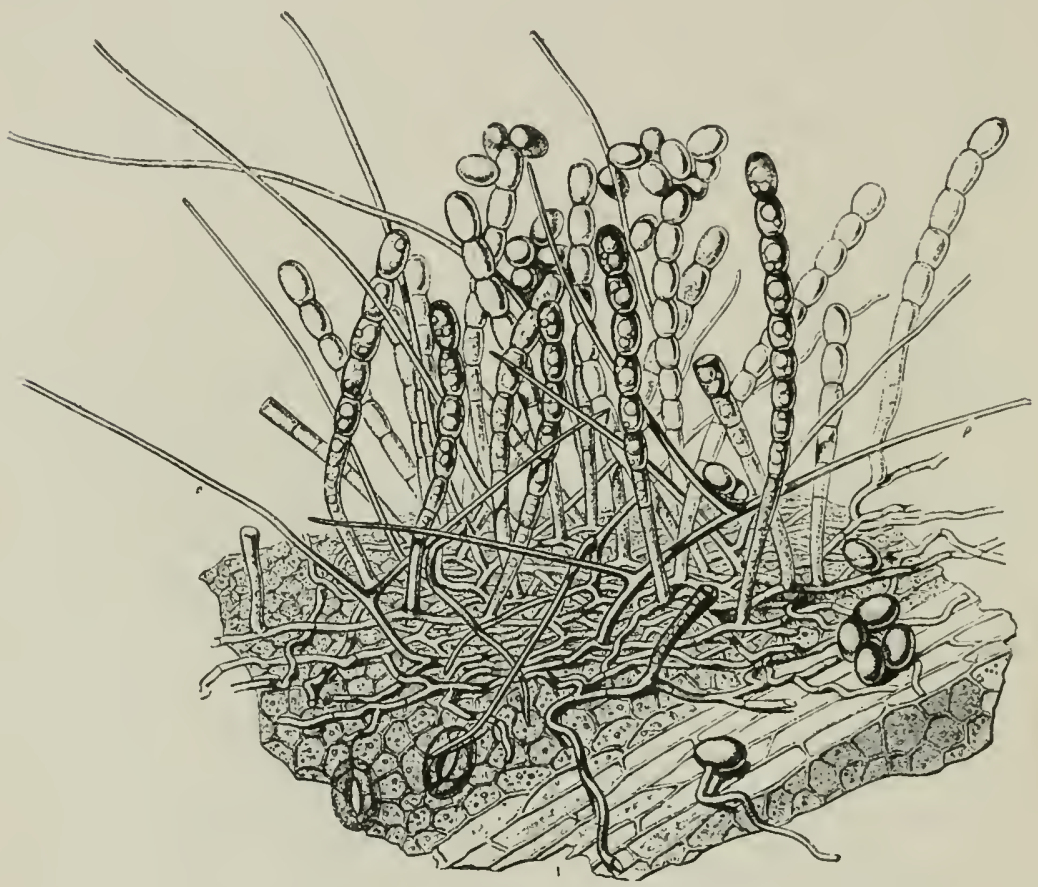

Fia. 69.- Spharothece pennose on Peach. The mycelium and conidiophores arc shown on the epidermis of a leaf. (After 'lulasne.)

liose-mildew is propagated during summer by ovoid, unicellular coniclia abjointed in acropetal series from erect conidiophores. The perithecia have short simple appendages, and contain elliptical spores.

The disease may be combated by "sulphuring"; according to liitzema-Bos, spraying with Bordeanx mixture has also shown good results. 
Sphaerotheca (Podosphaera) castagnei Ler. (Britain and U.S. America). The Hop-mildew. The mycelium is found on all parts of hop-plants, cansing considerable clamage, especially when it attacks the young inflorescences. The perithecia liave recumbent, brown, simple appendages. This species appears chiefly on various Compositae, Rosaceae (esp. Spiract Ulmarir), Cucurbitaceae, Geraniaceae, etc. Soraner reports it as very injurious to apple-trees.

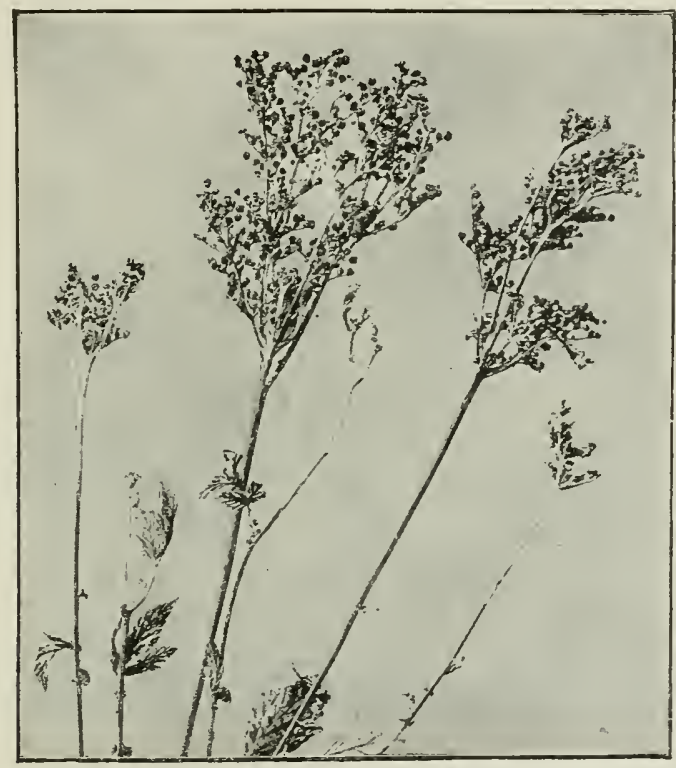

Fig. To.-Sphaerotheca castagiei on Spiraea Ulmaria. The white mycelial coating covers every part of the inflorescences. Two specimens are much less deformed than the others. (₹. Tubeuf phot.)

Oidium farinosum Cooke. Attacks young leaves and calyx of apple: it is easily distinguished from the oidium-condition of the preceding species. ${ }^{1}$

Sph. mors-uvae B. et C. The Gooseberry-mildew. Is specially injurious to Ribes Uta crispe and other species of Ribes in America. Spraying with a solution of potassium sulphide $\left(\frac{1}{2} \mathrm{oz}\right.$. in 1 gallon water) at intervals of twenty days is recommenderl. ${ }^{2}$

${ }^{1}$ Sorauer, Hedwigia, 1889.

${ }^{2}$ Halsted (U.S. Department of Agriculture, Report for 1887) describes this disease (Edit.). 
Sph. epilobii Lk. oceurs on Ejpilobium (U.S. America).

Sph. Niesslii Thiim. on Sorbus (I'yruss) Arire.

Sph. pruinosa C. et Pk. on likus in Anerica.

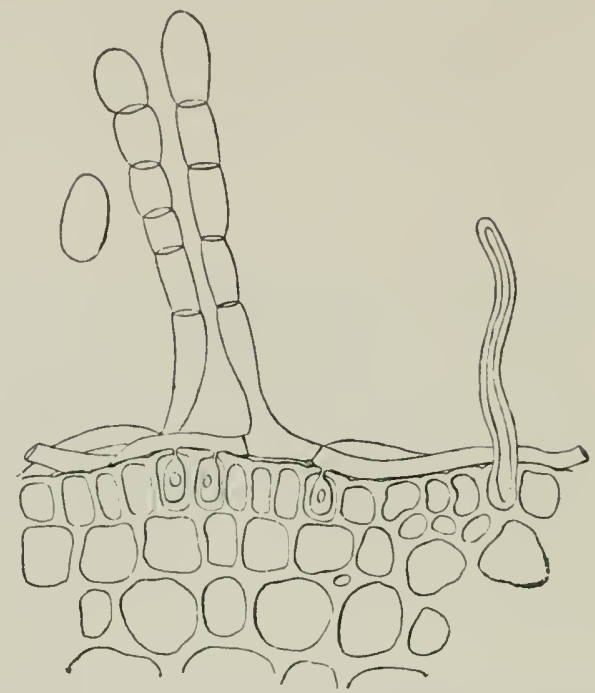

FIG. 71.-Sphacrolhece custagine. Epiphytic mycelium on epirlermis of Spiraec Ulmaric. Three haustoria are cmbcdded in epidermal cells. Two conidiophores are shown, from one of which a conidium has become detached. A hair of Spiraea is shown at one side. (v. Tubeuf del.)

\section{Podosphaera.}

This genus is distinguished from Sphaciothece by its upright perithecial appendages, which branch dichotomously towards their extremities.

Podosphaera oxyacanthae 1). C. Apple powdery mildew, also occurring on pear (Pyrus), hawthorn (Cratacgus), mountain ash (Pymus Aucuparia), and medlar (Mespilus). In America this disease is very injurious to apple-cultivation. ${ }^{2}$ It attacks chiefly young seedling plants, stunting their growth and causing them to lose their leaves.

P. tridactyla Wallr. This causes injury to leaves of various species of Prunus (cherry, plum, and sloe) ${ }^{3}$ (Britain and U.S. America).

Account by X. B. Waite (U.S. Department of Ayriculture, Report for 1S58); notes on treatment in Fairchild's experiments (Journal of Afycology, viI. p. 256), and elsewhere (Edit.).

${ }^{3}$ Halsted Zeitschrift f. Pflanzenkrankheiten, 1895, p. 335) gives as additional hosts: Apple, Crataegus Oxyacantha, Amelanchier canculensis and Spiraea (Edit.). 
P. myrtillina Schub. on leaves of Vaccinium Myrtillus (bilberry), V. uliginosum, and Empetrum nigrum (crowberry), (U.S. America).

\section{Erysiphe.}

The perithecia contain several asci, each with two to eight oval hyaline spores. The appendages are like these of Splucerothece, simple and thread-like.

Erysiphe graminis D. C. Mould or mildew of grass and wheat. Grass and cereals, especially wheat, often suffer serions damage from this parasite. The mycelium appears on the leaves as white or brownish spots, generally on the upper surface. Colourless conidia (Oidlium monilioides, Lk.) are produced acropetally in chains. The somewhat rare perithecia have brown appendages, and contain eight to sixteen asci, with four to eight spores each; the spores mature in spring as the dead leaves lie on the ground. This mildew has inflicted great loss both in Europe and America. Dusting the threatened crop with "flowers of sulphur" will probably check the first stages of an attack, but care in destroying infected crops is by far the most effective preventive.

Erysiphe martii Lev. This frequents various Leguminosae (clover, beans, vetches, peas, lupines, etc.), Cruciferae, and other plants (Britain and U.S. America).

Er. umbelliferarum De Bary. Occurs on various Umbelliferae (Britain).

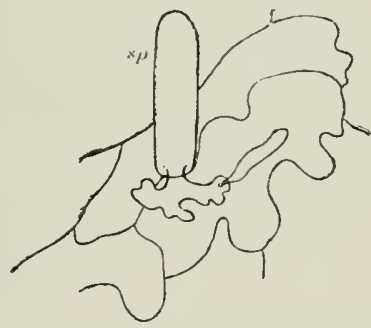

FIG. 72.-Erysiphe wimblliterarum. Germination of a conidium $(s p)$ on Anthriscus sylvestris, An attachment-disc lias been formed, and a germ-tube has penetrated the epidermis to become the first haustorium. (After De Bary.)

Er. communis Wallr. on tobacco, also on various Ranunculaceae, Papilionaceae, etc. (Britain and U.S, America).

Er. tortilis Wallr. on Cornus sanguince (Britain and U.S. Anerica).

Er. galeopsidis D. C. on Labiatae (Britain and U.S. America).

Er. cichoriacearum D. C. on Compositae, Boragineae, and also causing considerable damage to cncumbers (Britain and U.S. America). 


\section{Microsphaera.}

The perithecia contain sereral asei with two to eight spores, and the appendages have dichotomously brancherl ends like those of P'inlusplucer".

Microsphaera astragali I). C. Occurs on Astrargulus glyciyphyllos and A. virgntus (Initain and U's. America).

M. berberidis D. C. on Parberry (Britain).

M. Ionicerae D. C: on species of Lonicert.

M. grossulariae Wallr. on Gooseberry (Britain and L.S. America).

M. lycii Lascl. on Lycium, and Desmodium (Britain and U.S. America).

M. evonymi D. ( $\%$ on Evonymus europaeus (Britain).

M. alni D. C. on Alnus glutinosa, Betula cerrucosa, and D. pubescess. lihemnus cuthartice, Viburnum Opulus, and I. Lantuna, etc. (Britain and U.S. America).

M. densissima (Schwein.). This species forms orlicular patches on the leaves of (puercus tinctoria, etc., in North Anerica.

M. Guarinonii Bi. et Cav. on Cystisus Lubumem.

Also several other American species.

\section{Uncinula.}

The perithecia contain several asci with two to eight spores. The appendages have involute ends, and are simple or dichotomously branched.

Uncinula spiralis B. and C. ${ }^{2}$ (U. S. Ameriea and Britain). The Vine Mildew. This disease was first observed in England in 1845 , and since then has spread over the whole of Europe. The conidial stage has caused widespread injury, but the perithecia remained quite unknown till 1892 , when they were observed on vines in France ly Coudere, and in 1893 in large numbers by Viala. In America, a similar disease is also well known; it. perithecia have been long reeognized and named Uncinuln spiralis. The identity of the American and European mildew was first suggested by Viala in 1887 , and may now be assumed. The perithecia ${ }^{3}$ when mature are brown, spherical, and beset with

${ }^{1}$ Atkinson, Bulletin of Torrey Botanical Club, Dee. 1894.

"In consequence of recent investigations, this species has been transferrer from the genus Erysiphe, and revised with the author's consent. (EDIT.).

Viala, Compt. rend. cxix, 1894, p. 411. Prillieux, Bull. de la Soc. mycol. de France, 1S93.

${ }^{3}$ B. T. (ialloway (Botanical ('azette, 1595, p. 486), gives a recent account of the development of this Uncinala. (EDrT.). 
appendages having hooked tips. Within the perithecia are found the ovoid asci containing the spores; there are from four to ten asci in each perithecium, and four to eight spores in each ascus.

The conidial stage was formerly known as Oidium Tucheri. The coniclia are abjointed as oval colourless bodies from simple septate conidiophores, to the number of two or three in each chain. They germinate at once, and as they are formed in large numbers, especially in moist weather, the disease spreads rapidly. The mycelium is non-septate, or almost so, and attaches itself to the epidermal cells of vine-leaves and young grapes, by lobed attachment-discs, from which simple sac-like haustoria make their way

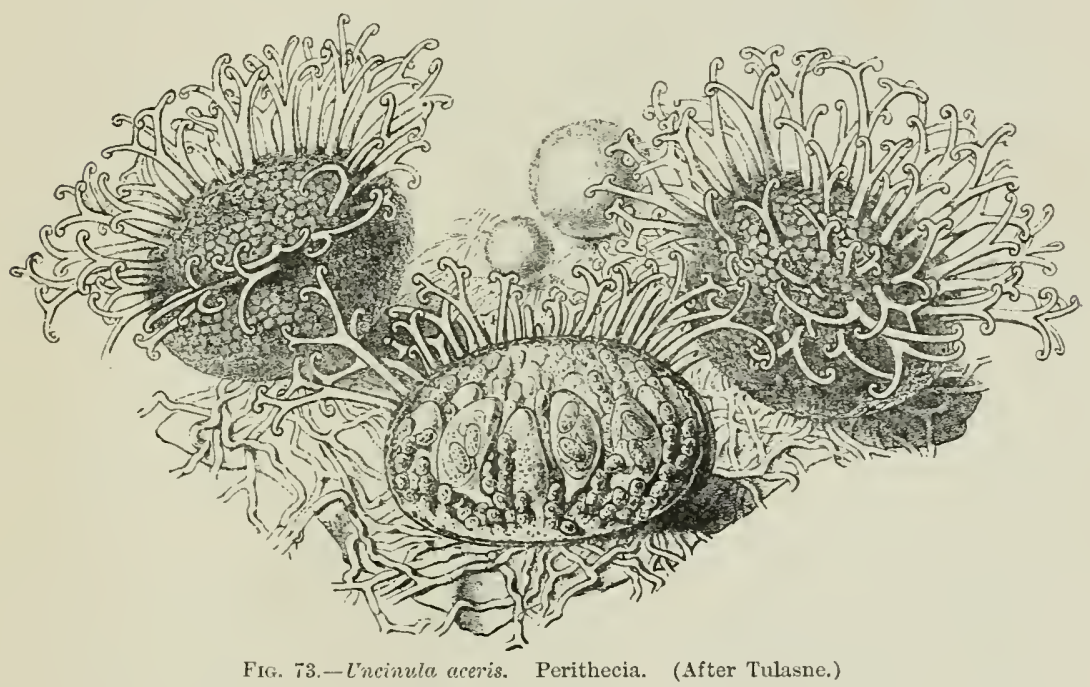

into the cells. The mycelium forms white spots, but after it time causes the death of cells near it, so that brown withered spots appear. The leaves generally wither, the grapes, however, continue to grow at the places not attacked, till rupture of the coat ensues, then they shrivel up or fall a prey to mould-fungi. Sulphur is the preventive generally used (See p. 170).

Uncinula aceris D. C. (Britain). This appears as white spots on the leaves of species of Acer, native and cultivated. When attacked by this mildew, young unfolding leaves are stunted in growth, while older leaves in autumn still retain their chloro- 
phyll in diseased spots, so that when dead and yellow, they are still spotted with green. The conidia are oval, so also the spores of which six to eight are found in each ascus.

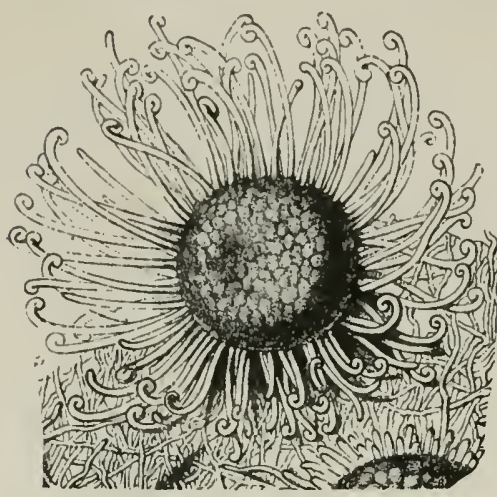

F1r. 74.-Uncinula selicis. Perithecium. (After Tulasne.)

U. Tulasnei Fuck. produces a white coating over the whole leaf-surface of $A c r$ plutenoides. The conidia are spherical.

U. circinata C. et Peck. is found on species of Acer in America.

U. salicis I). C. (Britain and U.S. America). This species occurs on leaves of the willow, and produces white spots or thick coatings on one or both surfaces. It is also found on leaves of poplar and birch.

U. prunastri 1. C. on Prunus spinosa (Britain).

U. Bivonae Lev. on Ulmus montana (U.S. America). Also other American species.

\section{Phyllactinia.}

The spherical perithecia are flattened at the poles, and enclose several asci containing two or three oval sulphur-yellow spores. The appendages are sharp-pointerl hairs with swollen bases.

Phyllactinia suffulta Rebent. ( $P \%$. grettetu Wallr.) produces white spots or coatings on the leaves of many trees, e.y. beech, hormbeam, ash, birch, hazel, oak, etc. (Britain and U.S. America).

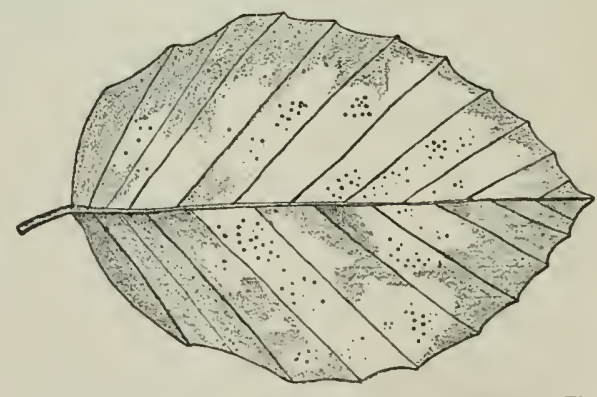

FIG. 75.--Phyllactinia suঠ̆ulta on Fagus sylvatica. The leaf is vartially covered by it white mycelium, on which the peritheeia aplear as blick points. (v. Tubeuf del.)

\section{PERISPORIEAE.}

The Perisporieac include the following genera Thiclavia, Dimerosporium, Marnnesiu, Cephalotheen, Zopfiella, Anixia, Eurotium, 
Aspergillus, Penicillium, Zoptiu, Perisporium, Lasivbotrys, Apiosporinem, Capnodium, Asterina, Microthyrium.

To this sub-division of the Perisporiaceae belong some common forms of monld-fungi which are generally only saprophytic,
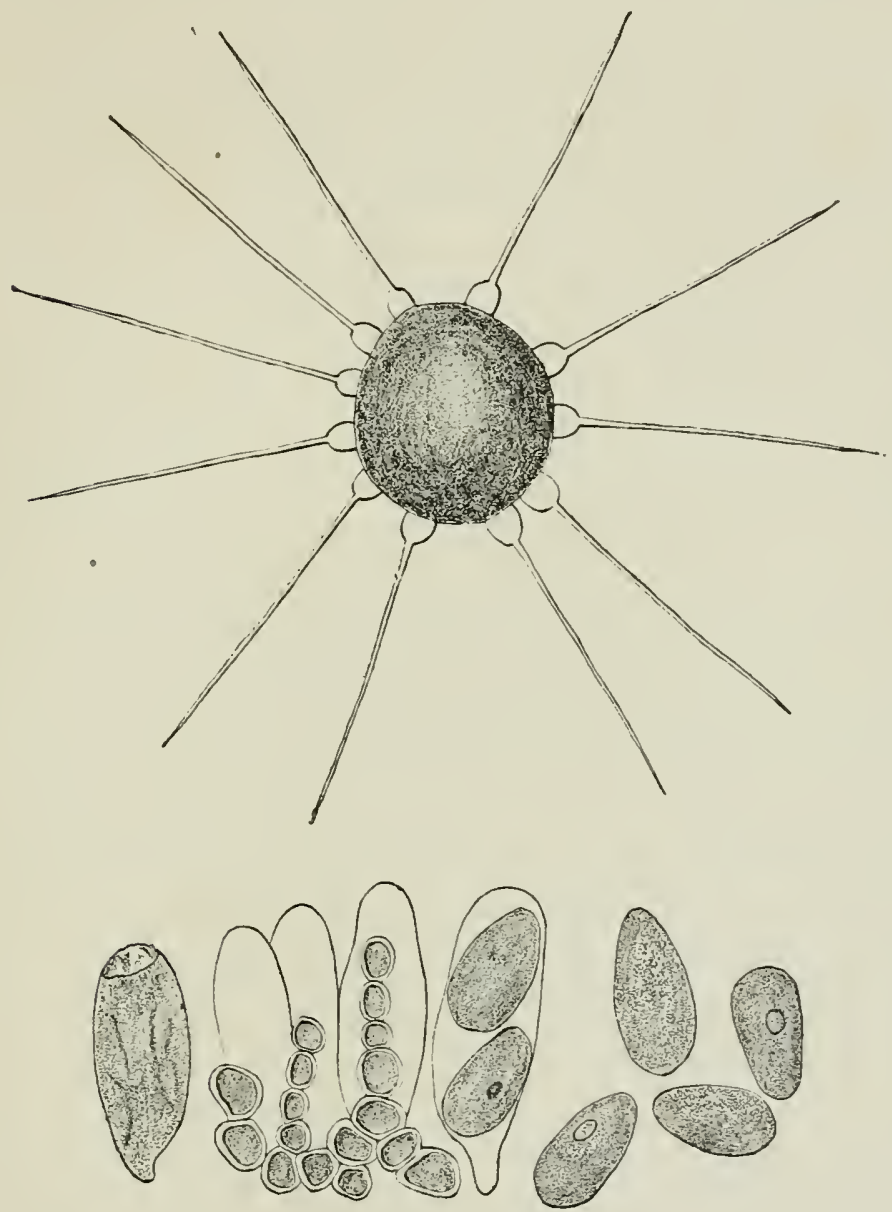

FIt. 76.-Phyllactinia sujulta from Beech. Perithecium, with characteristic appendages. Contents of the perithecium: asci, spores, and chains of cells resembling paraphyses. (v. Tubeuf del.)

but occasionally find their way into fruit with broken epidermis. They are thus found carrying on secondary decay and rot, where other diseases have begun the attack. 
In this group are included certain species of fungi which are able of themselves to induce rot in ripe fruit. Davaine ${ }^{l}$ was the first to direct attention to these, and recently they have heen made the subject of very searching investigations by Wehmer. ${ }^{2}$ According to this author, only a limited number of species of fungi accompany this kind of rot and give rise to it primarily. As a rule they effect an entrance by some wound, possibly also through lenticels or other apertures. Some forms prefer certain species of host-fruit, in some cases even certain varieties.

Wehmer gives the following symopsis:

\begin{tabular}{|c|c|c|c|}
\hline Fruit. & CAUNE OF RIPE-ROT. & FRLit. & CALSE OF RIPE-ROT. \\
\hline $\begin{array}{l}\text { Apple, } \\
\text { Pear, } \\
\text { Medlar, }\end{array}$ & $-\left\{\begin{array}{l}\text { Penicillium glaumum. } \\
\text { Mucor piriformis. } \\
\text { (Mucor stolonifer. })\end{array}\right.$ & $\begin{array}{l}\text { Orange, } \\
\text { Citron, } \\
\text { Mandarin, }\end{array}$ & $\begin{array}{l}\text { Penicillium italinm, } \\
\text { Penicillixmolicasmm. }\end{array}$ \\
\hline Plum,- & $\begin{array}{l}-\left\{\begin{array}{l}\text { Penicillium glaucum. } \\
\text { Botrytis cinerea. }\end{array}\right. \\
-\left\{\begin{array}{l}\text { Mucor racemosus. } \\
\text { Penicillium qlaucum. }\end{array}\right.\end{array}$ & $\begin{array}{l}\text { Cherry, - } \\
\text { Wahnut, - }\end{array}$ & $\begin{array}{l}\text { - Penicillium glancmm. } \\
\left\{\begin{array}{l}\text { Botrytis cinerea. } \\
\text { Penicillium glaucum. }\end{array}\right.\end{array}$ \\
\hline
\end{tabular}

He then arranges then according to their occurrence, beginning witl the most frequent:

Penicillium glaucum Link. : on stone-fruits, pome-fruits, grapes, walnuts, especially common on apples.

Penicillium italicum Wehmer: on southern fruits, e.\%. citron, orange, mandarin.

Mncor piriformis Fisch.: on pome-fruits, particularly on pears.

Botrytis cincrea Pers.: on grapes and walnuts.

The following are less common species:

Penicillium olivaceum Wehmer: on sonthem fiuits.

Mucor racemosus Fres.: on plums.

Mucor stolonifer Ehrenb.: on apples.

Ripe fruit should be so treated as to renove risk of infection as much as possible. This is lone by storing the fruits in airy, clry places, and in loose contact with each other. A damp atmosphere promotes infection and facilitates the progress of rot. All decaying fruit should be separated at once, and valuable fruits are best isolated by wrapping singly in tissue paper before transportation.

\footnotetext{
'Davaine, "Recherches sur la pourriture des fruits et des vegetaux virants," Compt. rend., Lxul., 1866.

${ }^{2}$ Wehmer, Beiträge z. Kenntniss einheimischer Pilze, Jena (Fischer), 1595.
} 
Species of fungi included in this group are the cause of those black, sooty coatings found on leaves frequented by green Hy $\left(A_{p}\right.$ his $)$ and other leaf-insects. These are purely epiphytic and saprophytic forms which derive nourishment from the "honey-dew" excreted by the insects. ${ }^{1}$ They multiply very rapidly, and soon form dark coatings on the upper side of leaves and twigs. Little clamage need be feared, since the leaves retain their green colour, and the coating is not enough to stop access of light. Anongst them are species of Capnutium, Metiolu, and Apiosporium, as well as the conidial forms Fimergo, Toruln, Antennaria.

The modes of reproduction of these forms are exceedingly varied. According to Zopf ${ }^{2}$ they form: (1) ascocarps; (2) manycelled large conirlia; (3) micellular, very small conidia; (4) isolatẹd and clustered conidiophores; (5) gemmae; (6) buds in a yeast-like manner; while every fragment of a mycelium can produce a new growth. Any of the species may frequent many various plants, and can pass easily from one host to another. Some of the better-known forms are:

Capnodium salicinum Mont. (Britain). This occurs on species of willow, poplar, hop, and many other plants.

If it appears early and abumlant on hop it may cause considerable damage. (Fumayo rayuns is a conidial form).

C. quercinium Pers. on oak. (U.S. Anerica.)

C. taxi Sace, et Roum. on Tarms.

C. foedum Sace. (spermogonium form = Chartophoma foedu). On the leaves of oleander. (U.S. America.)

The genus Apiosporium forms similar sooty coatings.

A. pinophilum Fuck. This covers with a black coating whrle twigs and leaves of silver fir; the needles however retain their green colour completely. (Antemuria and Tomula are forms of this.)

\section{A. rhododendri Fuck.; A. ulmi Fuck.; and other species.}

The conidial form Pellicularia which produces grey coatings on the coffeeplant is considered among the Hyphomycetes.

Species of Meliola also procluce sooty coatings.

M. citri Sace. and M. Penzigi Sace. oceur on Citrus in

${ }^{1}$ Busgen, Der Honiytlaur. Bioloyische Studien an Pflanzen. Jena (Fischer).

"Zopf, "Die Conidienfrichte v. Fumago." Tore arta, Bu. 40. Also: Zopf, Die Pilse; Tulasne, select. fung., InI. 
Southern burope and Anerica. Sooty mould of the orange is also aseribed to Capnortium riti i Perk. et Desm. ${ }^{1}$

M. camelliae Catt. on Cumellire jepmoneu. Aceording to Briosi and Cavara, this causes drying up of the leaves.

Stemphylium eriroctonum Br. et Bary, the "sonty-rlew" of indorr heaths is considered amongst the Hyphonycetes.

\section{Lasiobotrys.}

L. lonicerae Kunze. ${ }^{2}$ The peritheeia form black masses on green leaves of species of Lonicer. If these be removed the epiclermis remains minjured, except for a slight eavity with a lighter green colour than the neighbouring surfice.

\section{Thielavia.}

Perithecia spherical and without an aperture. The asei contain eight brown unicellular sjores. Paraplyses absent. Coniclia and chlamydospores are formed.

Thielavia basicola Zol,f. ${ }^{3}$ This is the only species of the Perisporieae which causes a really serious plant-disease. It is allied to the Erysipheise, and prodnces three kinds of reproductive organs on the underground parts of plants of Lupine: (1) Cylindrical, delicate, hyaline ehlamydospores, produced in pistol-shaped branches of the mycelium. (2) Thick-walled, brown-coated, resting eonidia arrangerl several in a row, like spores of a Phragmirlium. (3) P'eritheeia, or little, spherieal, permanently elosed, brown structures with oroid asci containing: eight lirownish lemon-shaped spores.

A white coating of the liyaline coniclia is first formed, then i brown coating of the dark eonidia, and finally peritheeia. The myeelimm bores throngh the eell-walls and fills first the cells of the cortex, later those of the deeper parenchyma of the host-root. The disease of the root soon eauses a stunting of the shoots and leaves, finally death of the plant. The roots attacked are at first brown, then they rot and become detacherl.

1W. G. Farlow, Bull. Bussey Institute, I. 1876, p. 404; Swingle and Webluer; "Diseases of citrous fruits," U.S. Dept. A gric. Bull. 8. 1896.

"Jaczewski includes Lasiobotry: with the Cucurbitariaceae.

'Zopf, "Ueher die Wurzell,riune d. Lupinen." Zeitschrift f. P'fausenkvonkheiten, I. 1). 72 . 
The fungus has been observed on Lupinus anyustifolius, L. albus, L. thermis, Trigonella cocrulca, Onobrychis Crista galli, Pismm sativum, Senecio clegans, and Cyclamen.

Thielaviopsis ethaceticus Went. ${ }^{2}$ has been given as the cause of a sugar-cane disease in Java.

The Tuberaceae form a third sub-division of the Perisporiaceae. The group includes the Tubereae and the Elaphomycetes. It contains no forms injurious to plants.

In investigating Elaphomyces granulatus and E. variegatus, Reess ${ }^{3}$ found that it not only formed mycorhiza, but was also parasitic on the roots of Pinus and destroyed them.

\section{PYRENONIYCETES.}

The ascocarp or perithecium of the Pyrenomycetes is a closed structure provided with an opening by which the ascospores are discharged. The ascocarp of the Perisporiaceae, as has already been pointed out, has no such opening. The inner wall of the perithecium is clothed with $(a)$ the asci, $(b)$ delicate fungal filaments. Of the latter, those in the depth of the perithecium are known as paraphyses, and among them the asci originate; others around the sides and opening of the perithecium are the periphyses, which grow inwarts so as to close both pore and canal. Perithecia may occur isolated or massed together, and are frequently sunk in a special cushion of fungoid tissue, the stromata.

The Pyrenomycetes may also produce chlamydospores and various forms of pycnoconidia and free conidia; these also are frequently developerl on special stromata. According to Brefeld's researches, the structures so well known as spermogonia with their contained spermatia are only pyenidia containing conidia, which have in many cases been artificially caused to germinate.

The Pyrenomycetes include a large number of forms parasitic on all parts of living plants, most of then are capable of existing for some part of their lives as saprophytes, and as

\footnotetext{
${ }^{1}$ This fungus is described as cansing a root-rot of riola odorata in U.S. America (Connect. Agric. Exper. Stat. Peport for 1891). (Edit.)

${ }^{2}$ Went, Archief roor de Jara-Suikerindustrie. 1893.

${ }^{3}$ Reess and Fisch., "Untersuch. üb. Bau u. Lebensgeschichte d. Hirschtrüffel." Bibliolleca botan. Heft 7. 1887. With Illns.
} 
a rule they reach maturity only on the dead remains of host plants. Many of them are enemies of woody plants, and the mycelium of some can live in the elements of the wood itself, hence they constitute a dangerous group of wound parasites.

The Pyrenomycetes may be sub-divided thus:

1. The Hypocreaceae having soft coloured perithecia often placed several togrether on a stroma.

2. The Sphaeriaceae with firm dark-coloured perithecia frequently embedded in a stroma.

:3. The Dothideaceae with perithecia so embedded in a stroma that they have no distinct wall of their own.

All three divisions include forms parasitic on plants.

\section{(1) HYPOCREACEAE.}

The Hypocreaceae consists of a single family bearing the same name. Of the seventeen genera contained therein only six contain plant parasites, viz.:-Gibberella, Caloncetria, Ncetria (including Nectriclla), Polystigma, Elichloë, Cluvicrps. The remainder are saprophytic only, and do not come within the scope of the present work: they are-Melanospora, Selinia, Eleutheromyecs, Hypomyces, Sphacrostilbe, Letcudraca, Hypocrea, I'lconectria, Barya, Oomyces, and Cordyeeps.

\section{Gibberella.}

The perithecia have a transparent blue or violet colour, and form tufts on the stromata. A stroma is not present in all the species. The spores are light-coloured, and spindle-shaped or oblong.

G. moricola C'es et de Not. Passerini gives this as the cause of a disease of young twigs of mulberry.

G. pulicaris (Fr.) is very frequently found on trees. (Britain).

\section{Calonectria.}

The perithecia are yellow or red, and occur isolated or several together. The asci contain spores composed of three or more cells, rarely of one cell.

C. pychroa Desm. causes death to young leaves of planes (esp. P. occidentulis); it also multiplies by means of conidia (F'usurium platani). 


\section{Nectria.}

Perithecia yellow or red in colour, and generally produced in close tufts on stromata of the same colour. The asci contain eight bicellular spores and few or no paraphyses. Conidia of various kinds and shapes are also produced.

Nectrina cinnabarina Fr. ${ }^{1}$ (Britain and T.S. America). The bright-red, button-shaped conidial cushions of this fungus may

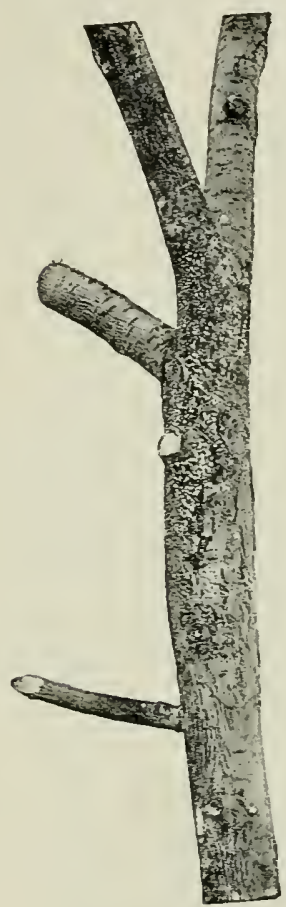

FIG, 77.- Nectric cismebcrine, with perithecia on the dead bark of a still-living stem of Elm. Infection has eridently begun at the wound of a cut branch near the middle, and extended ontwards. ( $v$ Tubenf phot.)

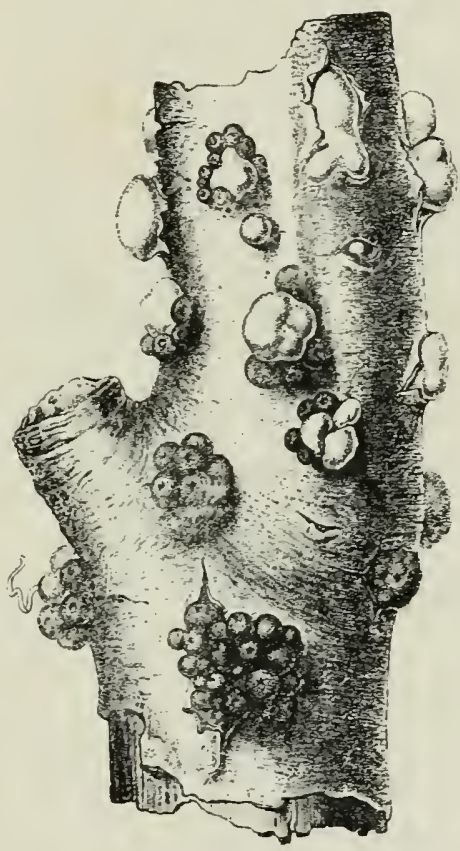

Fur is - Nectio civaluerina. Portion of brinch (magnified). Light-coloured cusliuns of conidiophores with conidia are breaking out towards the upper end, and colonies of hard red perithecia towards the lower end. (After Tulasne.)

be found almost at any time on the dead branches of many deciduous trees, c.g., Acsculus, Acer, Tilire. Morus, Ulmus, etc.; also on Lonicera, Sambucus, Robinia, and Pyrus, in America. ${ }^{2}$

1 Tulasne, Select fung., 1865.

${ }^{2}$ Behrens (Zeitsrh. $f$. Pfanzenkrankiheiten (1895) ascribes to Nectria the very common tuberous swellings on the twigs of Abies balsamea; these, however, may arise without the agency of the fungus. 
The dark-red masses of thick-coated, warty perithecia appear in autumn and winter on the dead branches only; the asci contain eight bicellular hyaline spores which germinate directly to form a mycelimm. Infection of a new host-plant is effected by the mycelium, which enters by open wounds into living branches; it is quite mable to penetrate the living bark and is dependent on wounds. The mycelium spreads

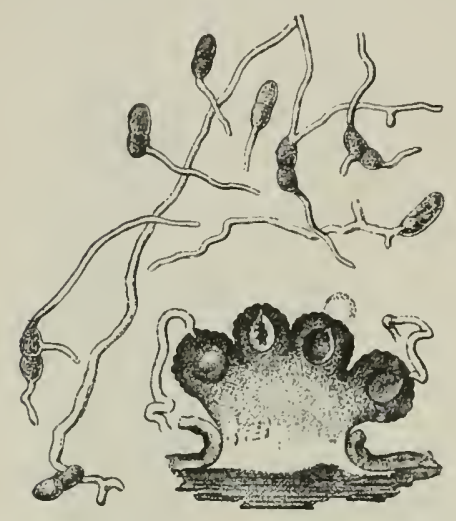

Fic. 79.-Nectria cinnabarina. Enlarged section of perithecial colony. Germinating ascospores. (After Tulasne.) rapidly through the tissues of the host, especially through the ressels of the wood; the cambium and rind are not attacked directly, but are killed in consequence of the destruction of the wood. ${ }^{1}$ The regions attacked in the wood appear as greenish stripes, and withering of leaves, followed by death of branch after branch, results in consequence of the growth of mycelium in the water-conducting elements of the wood.

For protection against this and all other parasites, which find entrance by wounds, it is recommended to prune or diess trees only when necessary, and to paint all wounds with tar or tree-wax. This Nictric is one of the commonest parasites of our parks and fruit gardens, hence all branches already attacked should be removed and burned, likewise all blown timber which might serve as a nursery for production of spores or conidia.

Nectria ditissima Tul. (Britain and U.S. America). This is a common parasite and a frequent canse of the canker of beech, apple, and other trees. ${ }^{2}$ The inycelium lives chiefly in the bark, causing it to die and form cracks. Under ordinary conditions all cracks and fissures are occluded or

${ }^{1}$ Mayr in Hartig's Untersuchungen a. d. forst-lotan. Institut an München, IIt. Berlin, 1882. Brick, Arbeiten d. hotan. Inseums, Hanburg, 1892.

Wehmer (Zeitsch. f. PHansenkrankheiten, 1894 and 1895), opposes Ilayr's conclusions and holds that Nertia can penetrate intact, living bark.

"Goethe, "Ueber Krebs d. Apfelläume." Rhein. Blatt f. Olst., Wein, n. Gartenlani, 1879. R. Hartig, Untersuch. aus d. forst-botan. Institut. zu Minchen, I. 
grown over in course of time by the activity of neighbouring living tissues, but the rapid development of the mycelium of this Nectria prevents any such healing, and brings about death of more bark. As a result the so-called "cankers" are

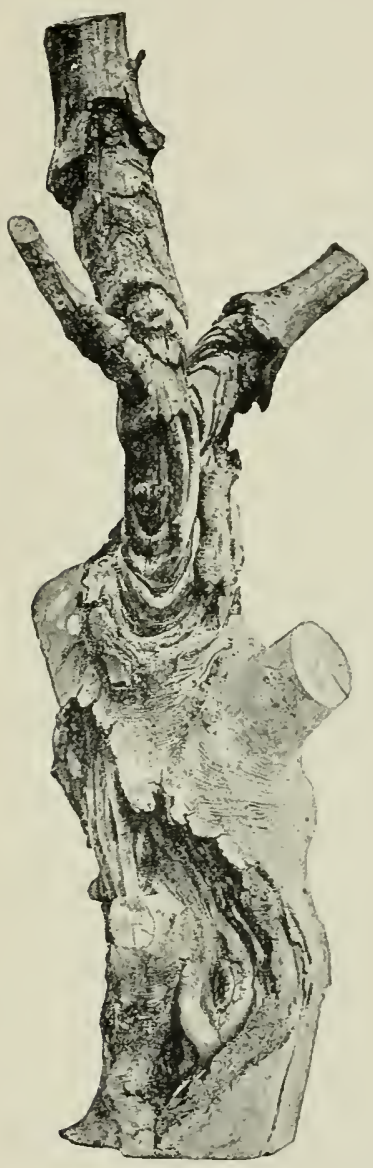

Fig. S0.-Nectrie ditissine. Canker on a stem of Beecl. ( $v$. Tubeuf phat.)

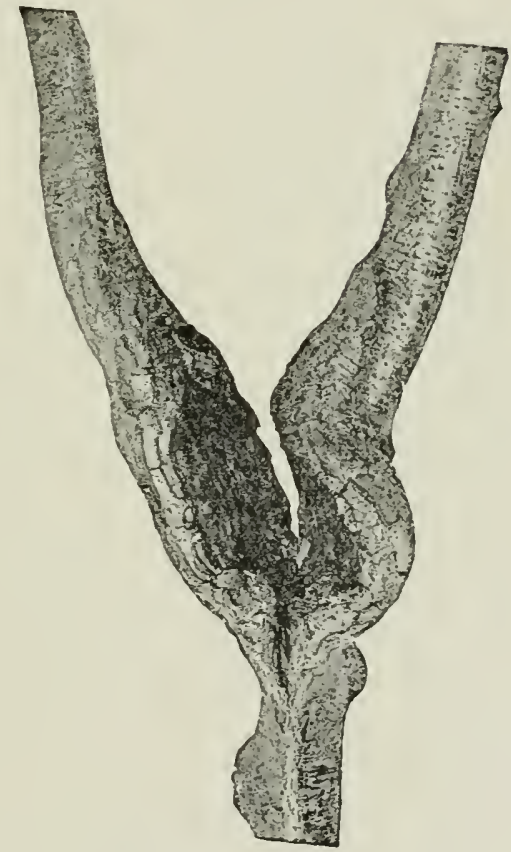

Fig, S1.-Nectria ditissimo. Canker on Hazel. The place of infection, a partially broken branch-fork.

prorluced. The mycelium at first gives off tiny unicellular conidia on the bark, then later white cushions bearing fine conidiophores, from which are abjointed multicellular conidia, shaped like a sickle. Infection is brought about by the germination of spores or conidia on wounded parts of the 
bark, ${ }^{1}$ and even on young unfolding leaves. The red lemonshaped perithecia break through the bark as compact patches. They are distinguished from the perithecia of $N$. cimneburinu hy their smooth exterior and their smaller asci and ascospores.

Combative measures to be used are plentiful dressing of wounded places with tar, and the burning of all infected material.

Nectria cucurbitula Fr. ${ }^{2}$ (Britain and U.S. Anerica). This parasite on conifers generally, is particularly injurious to spruce (Piccu). It enters the host by wounds, such as those caused by the caterpillars of the spruce moth (Grapholitha pactolana), or by hail. The mycelium lives chiefly in the bark and bast; luring the active growth of these tissues further extension of the mycelium is almost completely hindered by the formation of a secondary cork, but in the resting periods of these tissnes of the host, new hyphae are rapidly produced. Reproduction is brought about by little unicellular, and larger multicellular sickle-shaped conidia produced on conidiophores. The mycelium frequently proceeds as soon as formed to give off the smaller variety of conidia. The dark-red perithecia are produced later on the same stromata as the conidia. The asci contain eight bicellular spores; the paraphyses are very delicate and slightly brancherl.

The fungus sometimes occurs epidemic in spruce plantations, and may be the canse of many deaths. According to Magnus, the larch and cembran pine may also be attacked. As a prerentive measure all dead parts should be cut out and burned.

Nectria Rousseliana Tul. lives in and kills leaves of the box (Burus).

Nectria pandani Tul. ${ }^{3}$ is said to be the cause of a clisease on Pandanus, also ascribed to Melanconium pandani. The Penchuns disease has been reported from the Botanic Gardens

1 loung forests in districts subject to hailstorm, (e./. on the lower Alps of Bavaria), may become completely infested with Nectria through hail-wounds. (EDIT.)

${ }^{2}$ R. Hartig, Untersuch. auts d. forst-botan., Institut. I., $185 s$.

3Schroeter ("Ueber die Stammfaule d. Pandaneae," Cohu's Beiti. :. Biol. d. I'lanzrn. Bd. I., 1S95) suggests that this Melanronium is a conidial form of Vertria. During the investigation of a case of a Pandanus killed in the Palm House at Edinburgh Botanic (rarden, J. H. Burrage found both forms present aul agreeing in order of levelopment with Schroeter's observations. (Edit.) 
of Breslau, Berlin, Paris, Kew, Glasnevin (Dublin), and Edinburgh.

Nectria ipomoeae Hals. ${ }^{1}$ Stem-rot of egg-plant and sweet potato. In America this attacks young growing plants, and causes stem-rot. The Fusarium-stage developes as a white mouldy coating on the withered stem, and is followed later by flesh-coloured clusters of perithecia.

\section{Polystigma.}

On the leaves of species of Prunus, one finds bright-coloured spots, these are the stromata of this family, and in them are embedded pycuidia containing hookshaped conidia. Perithecia embedded in a similar manner are developed after the fall of the leaves, they contain asci with eight unicellular elliptical spores, which are expelled on reaching maturity in spring.

Polystigma rubrum (Pers.) (Pritain and U.S. America). This appears as red circular spots on the leaves of plum and sloe. Micropjenidia are developed in summer on the under-surface of the leaf and give rise to curved conidia. The perithecia begin their development in summer, but only reach maturity in the following spring, after the leaves have fallen from the tree and lain on the ground over winter. The asci are clubshaped, long-stalked, and contain eight spores, which are set free in succession from April to June. Germination ensues on young leaves, and in six weeks

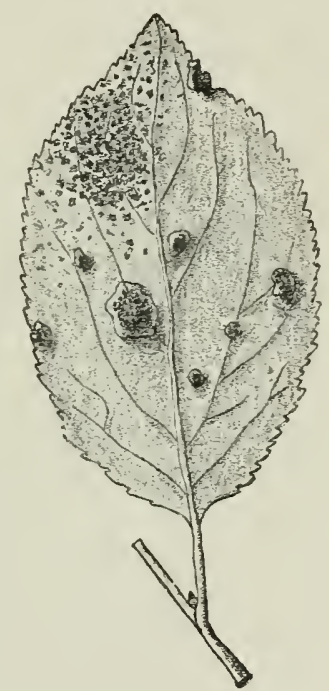

FIG. 82, - Polystigna rubrui on a leaf of Plum. The large projecting red spots contain perithecia and spermogoria. Dark brown patches of Puccinia prani arealso shown on the upper part of the leaf. ( $\nabla$. Tubeuf del.) pycnidia reappear. A variety, "Amygdali Desm.," is found on the leaves of the almond (Amygdalus communis).

Frank and Fisch found in connection with $P$. mibrum, certain hyphae which they designate as trichogynes, while they regard the small form of conidia as spermatia which

${ }^{1}$ Description and illustrations in N. Jersey Agric. Exper. Station Report, 1 S91. 
fertilise the trichogyne and cause it to develop as an ascogonium.

P. ochraceum (Wahlenb.) (P. fulcum 1). C.) causes yellowishrerl spots on leaves of Prunus Pulus.

P. obscurum Juel. proiluces thickened leaf-spots on Astrayglus alpinus and $A$. oroboinles; on the under side these are whitish, on the upper side they show the spermogonia as red points.

The dlamage causerl by Polystigmu is easily kept in check by burning infectel leaves in autumn.

\section{Epichloë.}

The stromata form on the stems of grasses yellowish mouldlike coatings in which the flask-shaped perithecia are embedded.

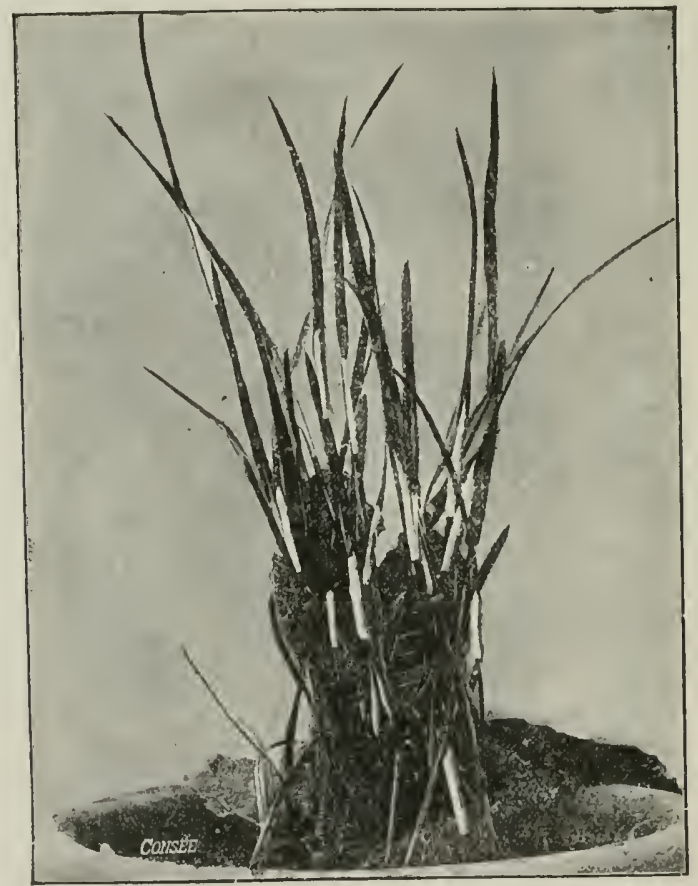

Fig. S3.-Epichloë typhina, forming numerous white cushions, which completely encirclc the grass-stems. (v. Tubeuf pliot.)

The asci are cylindrical, and contain eight thread-like unicellular 
spores. The formation of perithecia is preceded on the same stroma by that of conidia. ${ }^{1}$

Epichloë typhina Tul. (Britain and U.S. America). This may be found on many grasses as a mouldy coating which surrounds the haulms and causes withering of the parts above it. The fungus not unfrequently attacks such fodder-grasses as Ductylis, Pou, and Phleum moctense, causing severe loss where these crops are much grown. On the white stromata conidiophores are produced, and from them small, ovate, unicellular conidia are abjointed. These are followed later by perithecia embedded in the same stromata. The asci, of a somewhat yellowish colour, are long with button-shaped apices and contain eight threadlike spores.

Ep. Warburgiana, Magn." is an interesting species found on alrowroot (Maventa) in the Philippines.

\section{Claviceps.}

The sclerotia are black horn-like bodies, and on them the stromata are dleveloped as stalked structures, with spherical heads, in which the flask-shaped perithecia are embedded. The asci contain eight thread-like spores.

Claviceps purpurea (Fries ${ }^{3}$ ) (Britain and U.S. America). This fungus becomes most apparent, when in the stage of the well-known "Ergot" grains, bluish-black curved sclerotial bodies in which the mycelium perennates over winter. Ergot is found in the ears of our cereals, especially in rye, also in other cultivated and wild Cramineae. The sclerotia fall into the ground direct, or are sown out with the seed, and in spring or early summer produce a large number of stromata, each consisting of a violet stalklet carrying a reddish-yellow head. The ovoid perithecia are completely buried in the head of the stroma, and contain the asci, each with eight thread-like ascospores. The spores, after ejaculation, germinate on flowers of Gramineae, and the septate mycelium developes in the onter

${ }^{1}$ Atkinson, G. F. (Torrey Club Bulletin, 1894, p. 222), proposes a revision of the species of Epichloë and other species of $\mathrm{N}$. American graminocolous Hypocreaceae. (Edit.)

¿ Iagnus, Internat. Bot. Congress, 1892.

"Tulasne, Annal. el. sci. natur. 3 sér. xx. Kuhn, Mittheilungen d. landwirth. Institut. Halle, 1863. 
coats of the ovary, till gradually lut completely it fills up the whole cavity. Outside the ovary the mycelium forms an

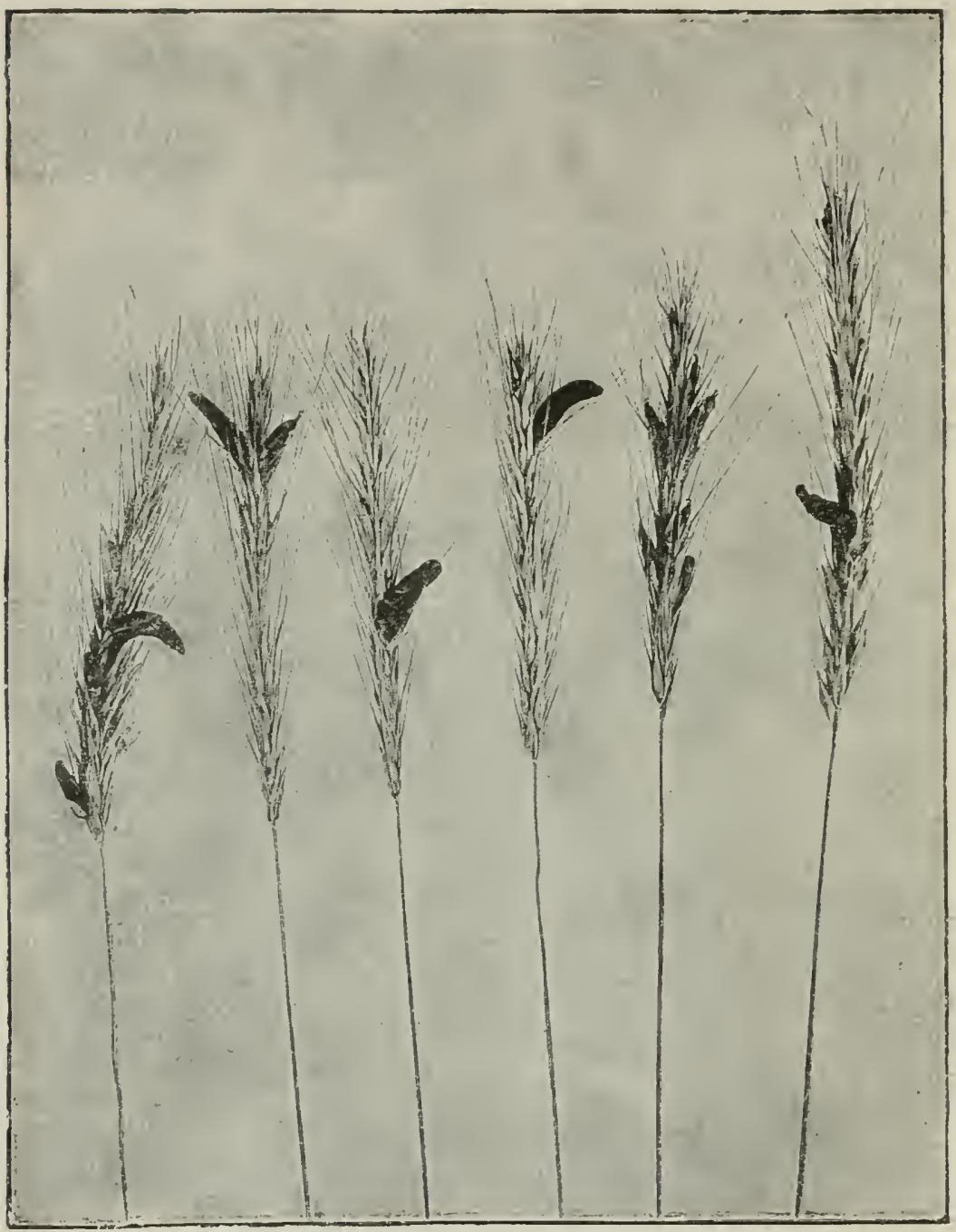

FIG. S4.-Clariceps purpuree. Ergot. Sclerotia or Ergot-grains in ears of Rye. (v. Tubeuf phot.)

irregular wrinkled white stroma or sphacelia, from the hollows and folds of which little ovoid conidia are abjointed from short 
conidiophores. A very sweet fluid, the so-called "honey-dew," is separated from the sphacelia; this attracts insects, which carry the conidia to other flowers. Since the conidia are capable of immediate germination, and give rise to a mycelium which penetrates through the outer coat of the ovary, the disease can be quickly disseminated during the flowering season of the grasses. After the formation of conidia has ceased, the sclerotia become firmer, with a dark wrinkled cortical layer and an internal firm-walled pseudoparenchymatous

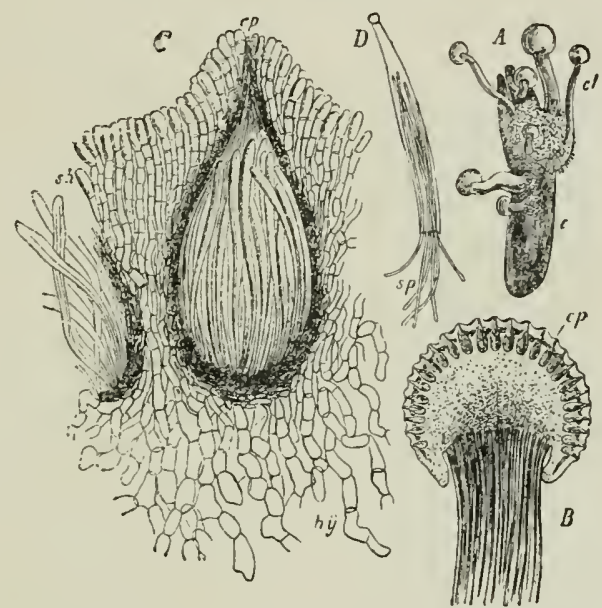

Fig. 85,-Claviceps purpurea. A, Sclerotium with seven stromata $(c l)$. $B$, median longitudinal section through the upper part of a stroma, the flask-shaped perithecia $(c p)$ are embedded in the head. $C$, Perithecium in longitudinal section (highly magnified)- $h y$, hyphal tissue; $s h$, cortical tissue of the stroma; $c_{p}$, orifice of the perithecium. $D$, Isolated ascus ruptured, so that the thread-like ascospores $(s p)$ have begun to escape. (After Tulasne, from Sach's Lehrhuch.)

hyphal tissue. In this condition they are introluced along with grain into bread, which when eaten acts as a powerful poison, producing very serious results (Ergotism). The sclerotia are also used medicinally, and are collected for this purpose (Sccule cornutum).

Kobert (Fröhner, Lehrbuch der Toxikologie für Thieriïtze, 1890) states that Ergot contains three poisonons agents:

(1) Cornutin, an alkaloid which produces that particular effect of ercot in causing contraction of the uterus.

(2) Sphacelic acid, a non-nitrogenous, resinons, non-crystallizable substance, insoluble in water and dilute acids, but soluble in alcohol, and 
forming, with alkalies, salts soluble in water. This is the real canse of ergot prisoning and gives rise to gaugrene. In large doses it produces cranp similar to strychnine, and tetanus of the nterus.

(3) Eryotic acid, a nitrogenons, easily decomposed glycoside, which has no effect on the uterus. It is more a narentic which diminishes reflex excitability and finally stops it.

Kobert experimented ehiefly with cattle and fowls. He fouml that an acute course of the poisoning can be distinguished from a eluronic; also a gangrenous ergotism from a spasmodic. The symptoms of the disease are:

(1) Gastro-enteric, an excessive salivation accompanied with redness, blistering, inflammation, wasting and gangrenization of the nouth-epithelium; similar changes also occur on the epithelimm of the gut, produciug romiting, colic, and diarthoea.

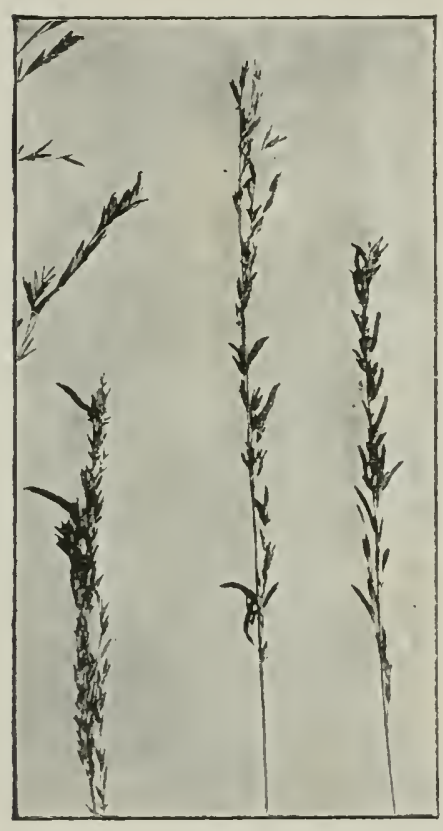

Fig: St.-Siclerotia of Claviceps microcephale on Molinie cocivles. (v. Tubeuf phot.)
(2) Gangrenization and mummification of extremities, consisting of a drying-up, a dying-off, and a detachment of extremities, such as nails, ears, tail, wings, claws, toes, and point of tolugne.

(3) Spasmodic contraction of the uterus and consequent abortion.

(4) Nervous phenomena such as insensibility, blindness, paralysis. etc. The presence of ergot may be detected both microscopically and spectroscopically.

The fungus may be combated by careful separation and destruction of sclerotia, and by the use of clean seed. ${ }^{1}$

Claviceps microcephala (Wallr.) (Britain). This is founcl on Ploceymites, Molinia, Mardus, etc. It has smaller sclerotia, which, according to Hartwich,? contain three times as much Ergotin as those of $\mathrm{Cl}$. murpmer.

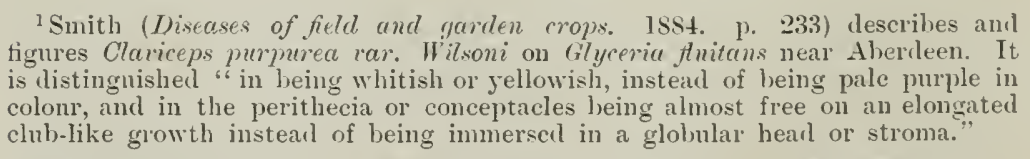

"Hartwich, "Sclérote dı Molinia coerulea." Bullet. de la Sor. Mycolog. de France. 1595 . 
Cl. nigricans (Tul.) on Helcocheris and Scirpus, with sclerotia of a dark violet colour (Britain).

C1. setuloso (Quel.) on Poa. Stromata straw-yellow in colour.

Cl. pusilla Ces. on Andropogon Ischaemum.

(2) SPHAERIACEAE.

The group of the sphaeriaceae includes eighteen families, but only the following contain parasites of interest to us.

Families: Trichosphaericae, Melanomeas, Amphisphacricae, Cucuritariecue, Sphaerelloideac, Pleosporece, Gnomonieae, Talseae, Diatrypeac, and Mclanconideae.

\section{TRICHOSPHAERIEAE}

(including Coleron and Herpotrichia).

\section{Coleroa.}

The perithecia have thin walls with radiating bristles, and sit superficially on the substratum. The asci have thickened apices, and contain eight two-celled, faintly coloured spores.

Coleroa chaetomium Kunze, occurs on living leaves of Rubus eacsius and $R$. Idacus. In addition to perithecia, it forms conidia known as Erosporium rubi Nees.

C. alchemillae Grev. (Britain and U.S. America). On leaves of Alchemille vulyaris.

C. andromedae Rehm. On leaves of Andromeda polifolia.

C. potentillae Fries (Britain and U.S. America). Leaves of Potentilla anserina. It forms perithecia which are situated on the leaf-ribs: also conidia (Marsonia potentillac).

C. subtilis Fuck. On leaves of Potentilla cinerea.

C. circinans Fries. On leaves of Gerctnium rotundifolium and G. molle.

C. petasitidis Fuck. On leaves of Pctasites officinalis.

\section{Trichosphaeria.}

Perithecia small, spherical or ovoid, and more or less hairy. Paraphyses distinct. Spores with one, two, or four cells.

We give this geuns a wider scope than Winter, and include species with one, two, and four-celled spores of hyaline or light colour, and whose 
other characters conincide; this seens to be all the more justifiable since one finds on the same species asci with spores made up of one, two, or four ceells.

Trichosphaeria parasitica Hartig. ${ }^{1}$ (Britain and U.S. America.) Everywhere in young naturally regenerated woods of silver fir, espeeially in diamp places or where the plants are crowded, one finds partially browned needles hanging loosely from the twigs, held only hy a fine white nucelium (Fig. 87). In addition to this, one finds in spring young twigs completely enveloped in myeelium, with all their

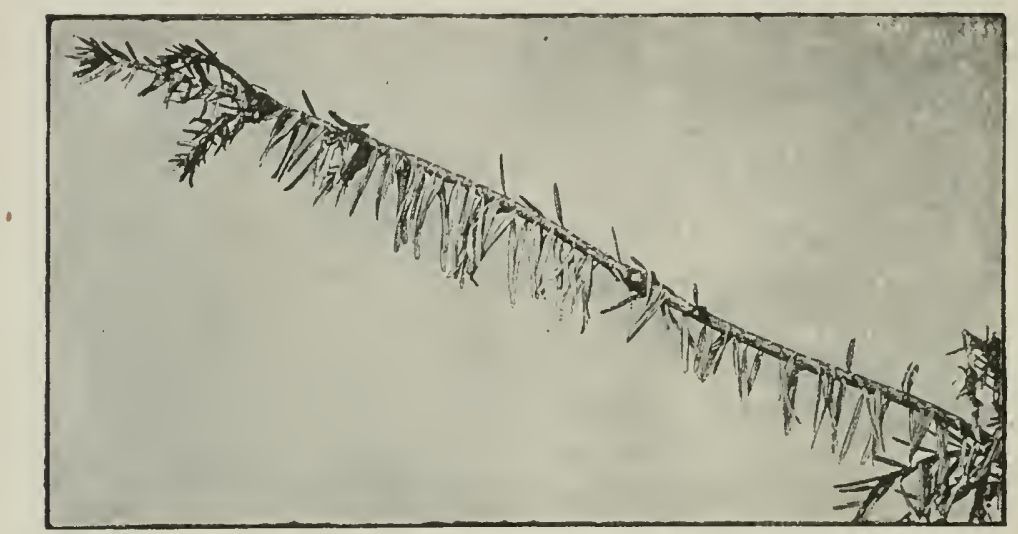

Fig. 87.-Trichosphaerice parasitica on Silver Fir. The withered and dead needles hang loosely downwards, attached to the twig only by a white mycelium. (v. Tujeuf phot.)

needles killed, so that the twig itself soon dies. The white mycelium grows especially on the under side of the shoot, and on the lower epidermis of the horizontal needles. A pseudoparenchyma, consisting of layers of mycelium, is there laid down, the lowest layer of hyphae sending short coneshaped haustoria into the walls of the epidermal cells (Fig. SS). Inside the needles, occupying the intercellular spaces, there are numerous branches of septate hyphae, which kill the cells of the leaf. The peritheeia occur here and there on the mycelial coating ontside the leaf; they are spherical and blackish, with radiating hairs. They contain paraphyses and

${ }^{1}$ R. Hartig, "Ein neuer Parasit d. Weisstanne." Alleg. Forst.-u. JaydZeilumy, Jan., 1854. 
asci, the latter with eight four-celled light-grey spores, which germinate directly and distribute the fungus over new hostplants.

I found this same fungus on Tsugu canadensis ${ }^{1}$ at BadenBaden, and on spruces in several parts of the Bavarian forests. ${ }^{2}$ It, however, rarely attacks spruces, although they often occur in the same forest with firs. One of the cases of infection referred to above was caused by the diseased branch of a fir lying in contact with a twig of the spruce, so that the mycelium grew from the one to the other; the spruce needles were killed, and woven on to the twig by hyphae.

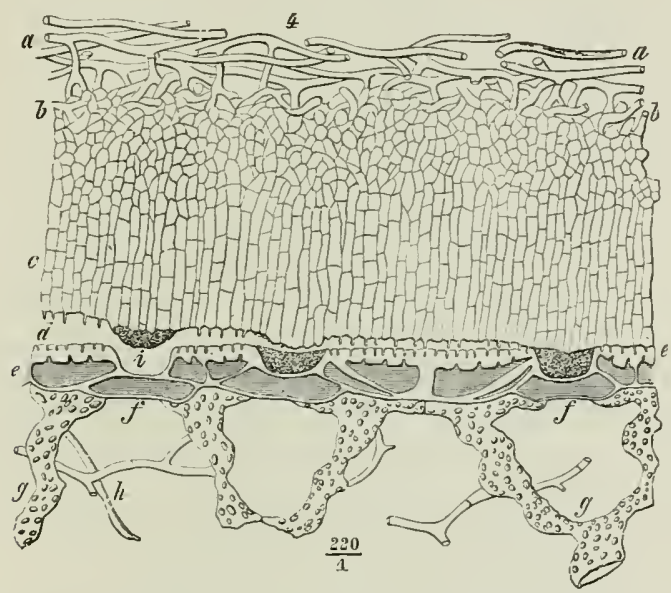

FIG. S8.-Trichospharia parasitica. Mycelial cushion on lower side of Fir needle. $a$, Filamentous mycelium, which, at $b$, sends downwards numerous branches to produce a cusbion of parallel hyphae, $c$. Where the mycelium rests on the epidermis, rod-like hanstoria are sunk into the outer wall of the epidermal cells, e $e ; d$ shows the mycelial cushion slightly detached from the epidermis, so that the haustoria have becn withdrawn. $f^{\prime} f$, Epidermal cells filled with bruwn contents. y g, Chlorophyllous mesophyll, which becomes brown after the mycelium has penetrated to it. $i$, Onter conrt of a stoma filled by a mycelium with no hanstoria, but adhering to the waxy granules of the stomatal aperture. (After R. Hartig.)

In woods of young silver fir naturally regenerated, this fungus causes great damage by killing numerous twigs. It occurs everywhere in young fir forests, c.y. the Alps, Bavarian forests, the Black Forest, etc. On dry airy situations, on free-standing trees, and on the highest branches of a tree, it is rarely present.

\footnotetext{
${ }^{1}$ v. Tubeuf, Beiträge z. Kenntn. d. Banmkrankheiten, Berlin (Springer), 1888.

2v. Tubeuf, "Trichosphaeria parasitica der Fichte." Botan. Centralblatt, XLI., 1890.
} 
Its injurious effects can be minimized hy removal of attacked branches.

Trichosphaeria sacchari Massee, is regarded as a dangerons wonnd parasite of cane-sugar in the Antilles; it seems to obtain entrance chiefly by the eanals left hy a caterpillar. ${ }^{1}$

\section{Herpotrichia.}

The smooth dark perithecia bear long brown hairs, which do not stand erect and stiff, but are more or less prostrate.

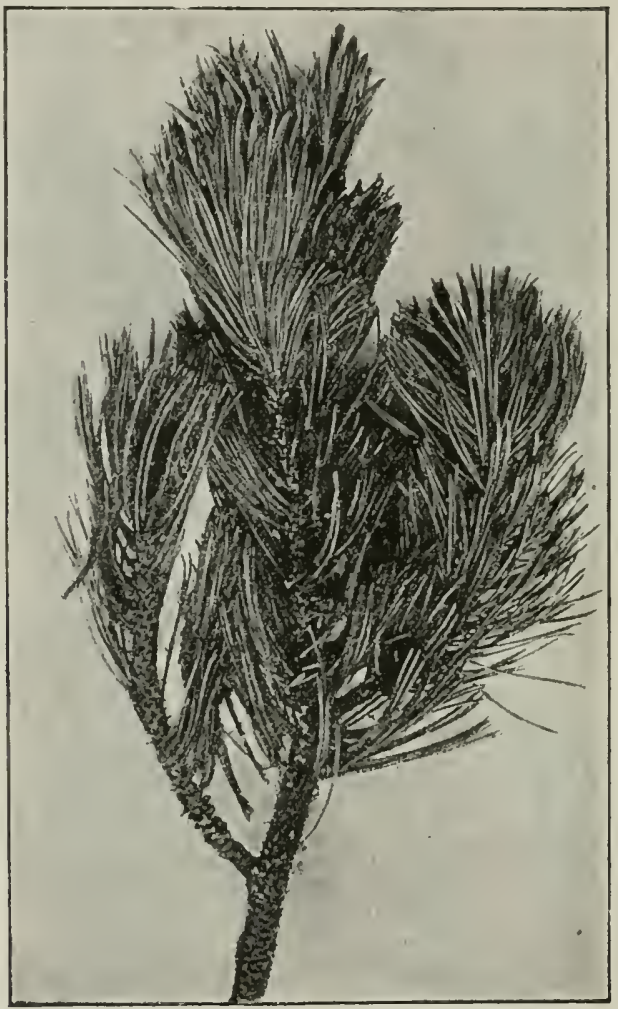

Fis. S9.-Herpotichia nigra on a branch of Pinus montana. The ends of the twigs, with most of the younger needles, are still green; the others are dead and felted together by hyphae into a black mass. (v. Tubeuf phot.)

The asci contain eight spores, at first generally two-celled, later becoming four-celled.

${ }^{1}$ Massee G., Amucels of Botany, 1893, p. 515. 1894.

Barber, "Experimental Cultivation in St. Kitto," Leeward Islands Garette, 
Herpotrichia nigra Hartig. ${ }^{1}$ This parasite is distinguished by its grey mycelium, which covers and completely envelops twigs and young plants. On the dwarf mountain pine it is not uncommon to find branches bearing patches of blackened needles closely bound together by gossamer threads, the other parts remaining still green and forming a background against which the blackened masses show up prominently (Fig. 89). Young spruce plants under a metre in height and the lower branches of taller trees are frequently completely enveloped in mycelium, and, where they have been pressed down to the ground by weight of snow, the twigs may be woven round and fastened to the earth by a felt of mycelium.

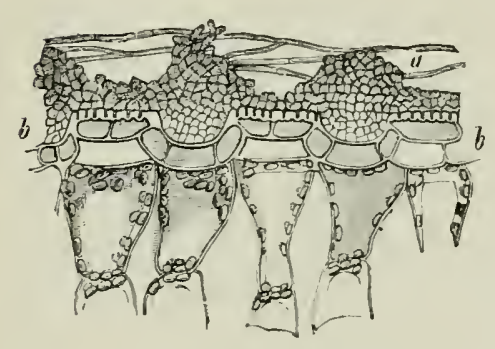

FIG, 90.-Herpotrichia nigia, a, hyphae weaving a granular mycelium on the surface of the needle and forming tuber-like bodies over the stomata; rod-like haustoria are sumk into the outer walls of the epidermal cells. (After R. Hartig).

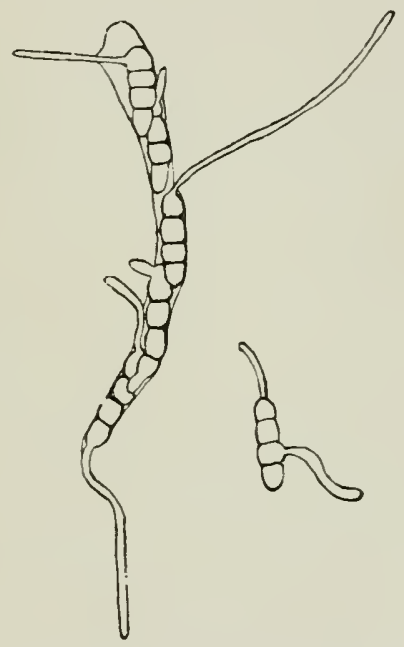

FIQ. 91.-Herpotrichic nigre. Ascus with germinating spores. (v. Tubeuf del.)

I have frequently observed the fungus on Juniperus communis, especially in Bavarian forest-land, and on Juniperus nana in the Alps. Professor Peter found it on the latter host in Sweden.

The spherical dark-coloured perithecia are covered with prostrate hairs, and contain asci with eight four-celled spores. The spores germinate directly to hyphae. The mycelium closely

${ }^{1}$ R. Hartig, "Herpotrichia nigra." Alleg. Forst.-u. Jargd-Zeitun!, 1sss.

v. Tubeuf, "Mittheilnng iib. einige Feinde d. Waldes." Alleg. Forst.-u. Jagel-Zeitung, 1887. 
envelops the needles and sends out haustoria similar to T'richosphareice purasitice (Fig. 90).

Hevpotrichue is, in highl-lying situations, a very dangerous enemy of young spruces, and nurseries in such places have frequently to be abandoned owing to the death of all the plants. Serions damage also frequently results in young plantations where snow lies long and keeps the young trees pressed down towards the earth. Then the fungus, even under the snow-covering, weaves round and fixes the shoots so firmly together, that only the healthy ones are able to free themselves again and to resume their growth in spring.

As preventive measures, nurseries should not be established in high situations, nor in valleys where there is a large snowfall; while in localities liable to attack, the planting of young trees in basins or cups (hole-planting) should be aroided. The loss from crushing-down by snow may be lessened by laying trunks and branches of felled trees amongst the young plants, and by going over them in spring, raising up all prostrated plants.

\section{MELANOMEAE.}

\section{Rosellinia.}

The perithecia generally occur in numbers together; they are black, and smooth or studded with bristles. The asci contain eight oval, spindle-shaped, dark-coloured, one-celled spores. Filanentous paraphyses are always present.

Rosellinia quercina Hartig. ${ }^{1}$ The oak-root fungus. This fungus lives in the roots of oak seedlings one to three years old, and catuses the leaves and shoots to become pale and to dry up. It spreads only during damp weather, especially in June, July, and August. In wet years it may cause very serious damage, especially in seed-beds. The mycelium penetrates into the living cells of the root-cortex, extending even to the pith. At first the mycelium is hyaline, but later it darkens, and the hyphae become twisted together into spun thread-like strands-the rhizoctonic. These structures apply themselves to roots of neighbouring plants, and soon enclose them in a weft of hyphae; by this means the disease is

${ }^{1}$ R. Hartig, Untersuch. aus. d. forstbotan. Institut zu München, Berlin, $18 s 8$. 
propagated through the soil from plant to plant. There is a resting-stage in the form of chambered sclerotia, black tuberlike bodies which have their origin in the cortical parenchyma of the roots and break out through the cortex. Reproduction is effected throughout the summer by means of conidia, produced from a mycelium which vegetates on the surface of the soil; this mycelium bears conidiophores with whorled branches, from which the conidia are abjointed.

The perithecia are spherical structures composed of hyphae with walls which swell up in a gelatinous manner. At first the inside of the perithecium is a gelatinous mass containing the paraphyses and the rudinent of the ascogonium. As the asci are developed, they push their way into the gelatinous mass amongst the paraphyses. Each ascus is a long clubshaped tube, the apex of which is thickened and stains blue with iodine, showing at the same time a canal piercing it. The ascospores are canoe-shaped with sharp ends, and when mature have a dark brown colour. The spores germinate in spring; in water-cultures germ-tubes are emitted twenty-four hours after sowing. The spores open by a longitudinal slit, and a germ-tube emerging from each end branches into a mycelium which soon takes on the form of a rhizoctonia-strand. Infection takes place through the tender non-cuticularized apices of roots.

The fungus may be combated if diseased portions of seedbeds are isolated by means of trenches clug round them. If boards soaked in carbolic acid or coal-tar are placed upright in the trenches, greater certainty will be secured that the disease does not spread.

Several species of Rhizoctonia, probably related to the above, may now be briefly considered.

Rhizoctonia violacea Tul.' (U.S. America). Root-fungus of lucerne and clover. The presence of this disease is shown in summer by the plants withering, and finally dying. The mycelium lives inside the roots, and covers them externally with violet coatings on which the sclerotia appear as black tubers.

On plants with sclerotia, Fuckel found pycnidia and perithecia of Leptosphaeria (Trematosphaeria or Byssothecium) circinans; whether the various forms were related could not, however, be determined.

${ }^{1}$ Rostrup, Undersuegelser anyacende Srampeslaegten Phizoctonia, 1586.

Tulasne, fingi hyporgaei, Pl. IX. and XX., 1851. 
The disense spreads throngh fields in a centrifugal direction from a starting-point. Besides the alove plants, it is also said by Kiiln to attack carrots, sugar-beet and mangolds, femnel and potatoes; and Tulasne gives asparagus and red clover as hosts. Prunet ${ }^{1}$ believes that the fungus remains three years in the soil, and recommends that diseased fields should not be cropped with lucerne or clover for several years. He also advises the isolation of infected land by surrounding it with a deep trench in which sulphur is strewn, then covered over with soil. The enclosed plot should next be deeply trenched between .June and August, and all plant-remains removed and burnt.

Rh. crocorum D. C. ${ }^{2}$ The Saffron destroyer. This parasite attacks and kills corms of the saffron (Crocus sativus). The mycelium finds entrance by the stomata of healthy corms, and covers them externally with a web of violet-coloured inycelium.

Rh. solani Kuhn. occurs as black sclerotia on the skin of potato-tubers.

Rh. batatas Fr. occurs in Ainerica on sweet potato.

Rh. allii Grev. occurs on tubers of shalot (Allium ascalonicum) and onion ( $A$. sativum).

$\mathrm{Rh}$. betae Kühn is said to attack beet-root in America. ${ }^{3}$

We may also consicler at this place:

Dematophora necatrix Hartig. ${ }^{4}$ The vine-root fungus. This parasite causes a very destructive disease of the vine, and is often confused with attacks of the Phylloxera-insect. It occurs in the United States, and is common throughout France, Switzerland, Italy, and South-west Germany, being known under a variety of names. ${ }^{5}$ Occasionally it has been known to attack the roots of fruit trees and other plants cultivated in vineyards.

${ }^{1}$ Prunet, "Sur le Rhizoctone de la Luzerne." Compt. rend., Paris, 1893.

Fr. Wagner, "Das Torkommen des Wurzeltüters d. Luzerne." Zeitsch. d. Landwirth. Terein in Bayern, 1894.

"Prillieux, "Sur la maladie des Safrans." Compt. renl., xrıv, and xcr.

Tulasne, Fungi hypogaei, Pl. VIII., 1851.

${ }^{3}$ Iowa Agric. Exper. Station, Bulletin 15, 1891 ; with illustrations.

${ }^{+}$R. Hartig, Untersuchungen aus al. forstbotan. Institut zu München, 1II., 1853.

5 Wurzelpilz, Weinstockfaule, Pourridié de la Vigne, Pourriture, Blanc des Racines, Blanquet, Champignon blanc, Aubernage, Mal nero, Morbe bianco, etc. (Hartig's Lehrlurh). 


$$
H_{1}
$$


Dematophora forms fine rhizoctonia-strands which grow through the soil from root to root. The mycelium kills the fibrous rootlets, and spreads from these into older roots to form rhizomorph-strands, which, however, have a structure quite distinct from those of Agaricus mellers. The rhizomorphstrands may pass out of the root into the soil, there to form a filamentous mycelium, or, remaining in the root-cortex, may produce rows of black tuberous sclerotia which on maturity break out to the exterior. On the sclerotia, or other parts of the nyycelium, bristle-like conidiophores may be developed as branched panicles from which ovoid colourless conidia are abjointed.

This enemy of the vine is rapidly assuming great importance. Thus, for instance, in Baden, ${ }^{1}$ there is no Phylloxera, but whole tracts of vine land are infested with Demutoploore.

According to Viala, ${ }^{2}$ Dcmatophore forms perithecia, which, however, only develop after artificial culture for several years on decayed plants. If this be so, the fungus should be classified between the Tuberaceae and the Elaphomycetes. Berlese, ${ }^{3}$ howerer, contests this view, and regards it as nearly related to Rosellinia.

Hartig ${ }^{4}$ suggests impregnation of the vine poles with creosote as a means of combating this disease.

\section{Strickeria.}

Strickeria Kochii Korb. develops its perithecia on the cortex of living Robinic I'seudacaciu; its parasitism is howerer not yet fully established.

\section{CUCURBITARIEAE.}

\section{Gibbera.}

The black perithecia, beset with stiff bristles, are developed in large groups on a dark pseudoparenchymatous stroma.

Gibbera vaccinii Sow. (Britain). In damp situations amongst moist patches of Hypnum and other mosses, one often finds the cowberry (Vaccinium Vitis-Idaca) with its leaves and

${ }^{1}$ Beinling, Das Aujtreten $v$. Rebenkrankheiten in Baden, 1891.

${ }^{2}$ Viala, . Monorraphie du Pourridié d. Vignes, 1891.

${ }^{3}$ Berlese, Rivista di patoloyia vegetale, I.

${ }^{4}$ R. Hartig, Lehrbuch d. Baumkrankheiten, English edition, 1894, p. 8\%. 
twigs brown and dead (Fig. 95). If more closely examined, the twigs will be found to bear patches of coal-black,

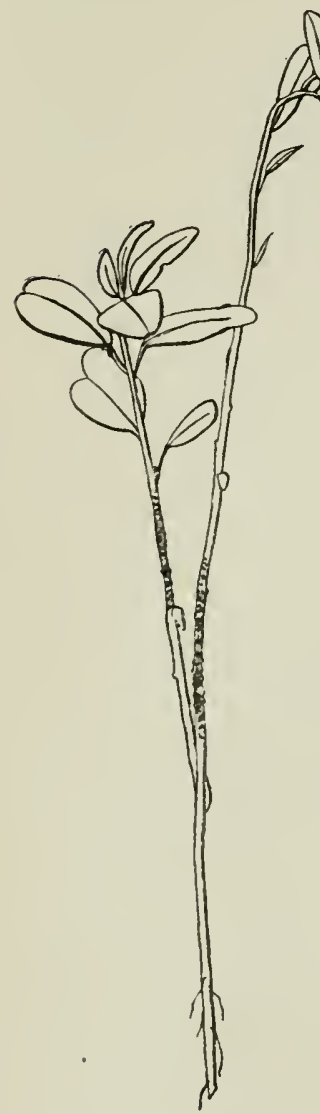

FIG. 95.-Gibbera vaccinii on Cowberry. The perithecia form black patches on the living leafy branch, as well as the dead brown one. (v. Tubeuf del.)

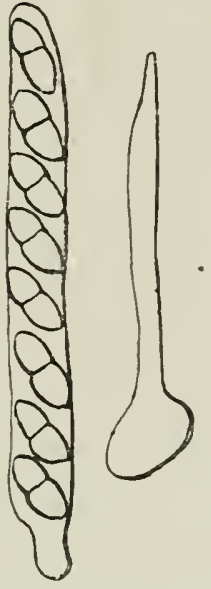

FIG. 96.-Gibberce vaccinii. Isolated ascus with eight spores; isolated hair from the outside of a perithecium. (v. Tubeuf del.)

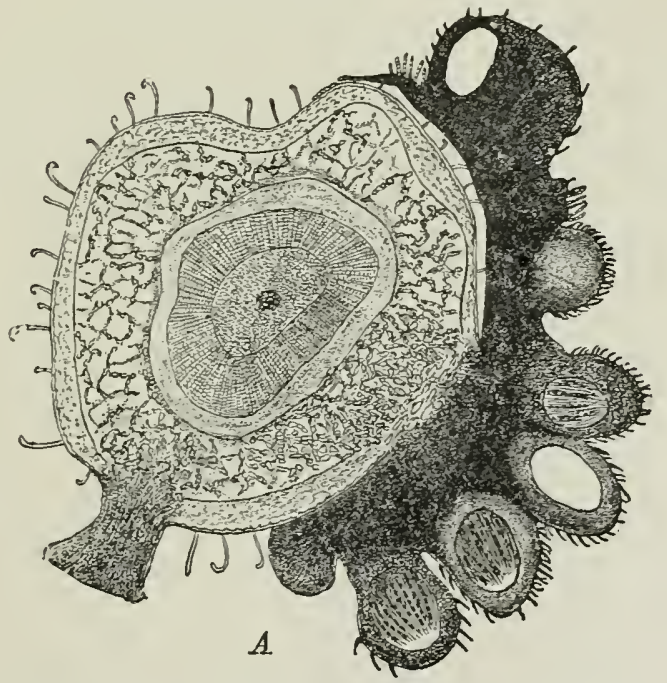

FIs, 97-Gilbera raccinii. Cross-section of Cowherry showing a patch of perithecia in section; the hairy perithecia contain paraphyses and asci with spores; a mrcelium permeates the cortical tissue of the host. Short hooked hairs cover the epidermis of the stem. (v. Tubeuf del.)

spherical perithecia, which are coated by short, acute, unicellular, black hairs (Fig. 97). The perithecia contain paraphyses and 
asei, the latter with eight or fewer bicellular dark-colsured spores. The mycelium is dark-coloured, very vigorous, and furnished with many lateral bladiler-like outgrowths; it permeates the whole cortical tissue as far in as the wood, and under the epilermis forms a brown pseudoparenehymatous stroma, which extends over the cortex, and gives rise to numerous perithecia. The living cells of the cortex turn brown in presence of the fungus-mycelium, and collapse, causing the whole shoot above the place of attack to wither and die.

\section{Cucurbitaria.}

The dark perithecia and pyenidia break through the epidermis in large numbers. The asci contain six to eight brown spores, divided by cross-septa.

Cucurbitaria laburni I'ers. ${ }^{1}$ (Britain). The spores of this fungus germinate on wounded parts of laburnum (Cytisus Luburnum), and, as the branches of attacked plants soon die off, considerable damage to nursery stock may result. The mycelium spreads through the wood, particularly the ressels, in spite of the early stoppage of these by a yellow wood-gum. Diseased parts of the wood of living branches appear as dark strips; reproductive organs are prodnced in the bark, and there the plant attempts to isolate the diseased parts by continued cork formation.

If diseased, but still living spots on stems be examined, they will be found to include many yellow and black pustulelike swellings, some buried in the bark under a periderm eight to ten cells in thickness, others in process of breaking through or altogether exposed. Many of the pustules will attract attention from the presence of red, twisted, elongated tendrils on then. On the lower parts of dead branches the same appearances will be found, but, in addition, the perider'm will generally be ruptured, and the openings so produced filled with spherical dark grey or black fructifications. These are variable in form, and amongst them can be distinguished some which are very large, round, smooth-coated, and light-coloured, with a round pore; oțhers, which appear more warty, and have a depressed opening; while still others, generally smaller, have

${ }^{1}$ v. Tubeuf, "Cucurbitaria laburni." Botan. Centralblatt, xxi., 1586. 
an acnte beaked pore. Where the bark has been lost, a good lens may distinguish the spherical or ovoid dark-coloured perithecia. On the finer twigs the whole bark is often perforated by numerous tiny pycnidia, hardly distinguishable with the naked eye.

If these various forms of fructification be submitted to microscopic examination, sections through the yellow pustules will show them to have that colour, because the transparent periderm has become loosened from the rest of the bark; moderneath the corky layers will be found a red stroma of pseudoparenchymatous hyphal tissue. This stroma by its growth canses a gradual rupture and loosening of the corky and other layers of the periderm; wherever this takes place, conidiophores are developed, and give off mumbers of tiny, hyaline, ovoid or cylindrical conidia. The stroma itself is somewhat spongy, and encloses numerous cavities which also become lined with conidiophores. At a later period the tissue enclosing these cavities may become dark coloured, so that structures similar to pycnidia are formed. In such cavities the red colour disappears, and the hyphae, conidiophores, and conidia appear transparent. The real pyenidia appear later, and consist of a peridium of coarse pseudoparenchyma containing conidia similar to those just described (Fig. 99, A). From the openings of these pycnidia the conidia emerge as red tendrils, rising as much as one centimetre above the pore. Adjoining these forms of sporophore just described will be found others: undeveloped perithecia with young asci; darkbrown pycnidia with brownish-grey, multiseptate, compound conidia; or similar pyenidia

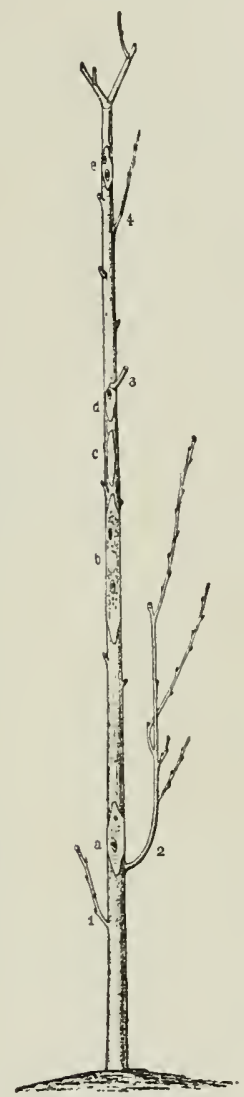

FIG. 95.-Cucurbitaria laburiti. Plant of Laburuum(diagrammatic); the branches $1,2,4$ are still living, and were in full foliage during the preceding summer; $a, b$, $c, d, e$, places where the rind is dead and the cork-layer ruptured; at $a$ and $b$ the perithecia are already developed, and the mycelium has extended into the wood. (After $\nabla$. Tubeuf.) with unicellular spherical, brownish-grey conidia.

Where the disease has made further progress, the pustules 
will be found changing from yellow to black on account of the peridem and dead stroma becoming darker. On dead branches the large cushions of fructifications will be found to inchde: (a) perithecia with a warty exterior and pores set in a depression; (b) large pycnidia, standing out from the cushions, with brown smooth coats, and full of compound multiseptate coniclia (Fig. 99, B; see below No. 3, " ); (c) other smaller pycnidia containing the same conidia, but whose pore is situated on a sharp prominence $($ No. $3, b)$. All or any of the three forms may be present.

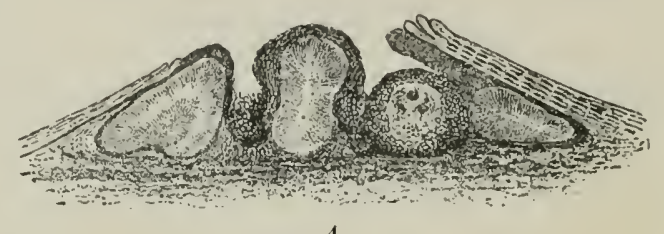

$A$

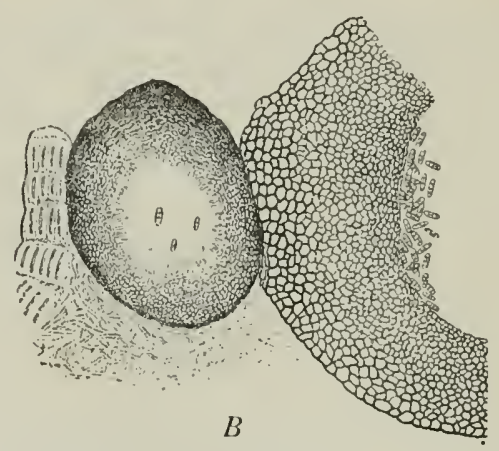

FIf. 99.-Cucurbitaria laburni. A, Stroma with prenidia containing minutc unicellular conidia. $B$, One of the large smooth pycnidia, (After v. Tubeuf.)

The mature perithecia have a peridium consisting of a loose pseudoparenchyma with a rough warty exterior and a pore set in a distinct depression (Fig. 100.) The paraphyses are long, strong threads, often branched, and between them arise the long cylindrical asci with rounded ends. The normal number of ascospores is eight in each ascus, but fewer is no exception.

In addition to the forms already described, pycnidia of still another sort occur (No. 1, c). They are spherical, with a dark-coloured coarse peridium, and are smaller than the stromapycnidia. These pycnidia contain no conidiophores, but give off 
unicellular conidia, at first white, later grey. It is these pycnidia which cause the fine perforations of the periderm of twigs.

Yet another form of pycnidia, previously known as Diplodia cytisi (Awd.), (No. 4). This, like the last, breaks through the corky layers of the bark. It has a peridium composed of loose psendoparenchyma and, without the intervention of conicliophores, produces two-celled conidia of a dark greyish-brown
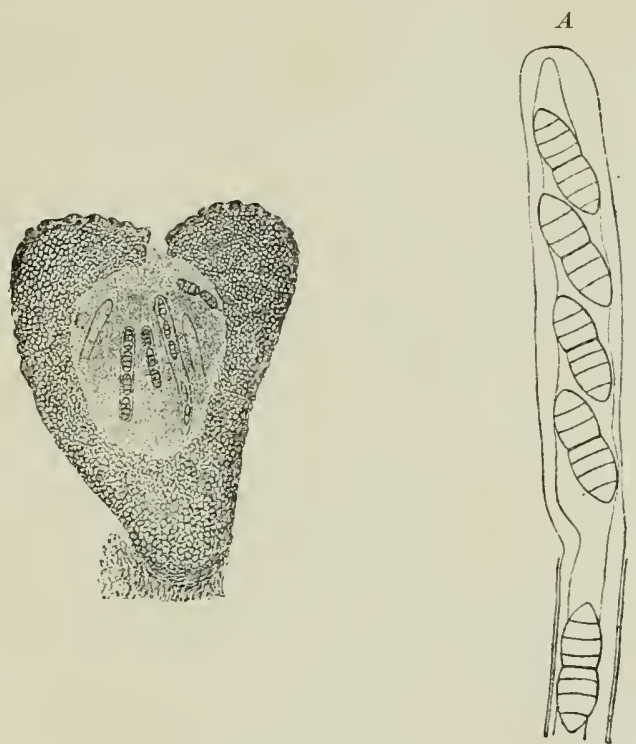

FIG. 100.-Cucurbitaria laburni. Perithecium isolated. A, Ejaculating ascuwith the inner membrane as yet unruptured, but emerging beyond the outer ruptured coat. (After v. Tubeuf.)

colour. This form, however, I failed to find in the conrse of my investigation, although I looked through much material.

Tabulating these various forms of fructification we have:

\section{A. Prosidia.}

1. White transparent, small, unicellular conidia on long conidiophores:

(a) Free on the stroma.

(b) Enclosed in cavities in the stroma:

(a) In cavities as yet not resembling pyenidia.

(B) In cavities with firm dark-coloured periphery.

(c) Enclosed in dark-colonred free pycnidia, with a peridium of coarse pseudoparenchyma.

จ. Brown, unicellular, round conidia, in little brown pycnidia (Fig. 99, $a$ ). 
3. Brown, multiseptate conirlia :

(ii) In brown, very large, smootli-coated pycnidia (Fig. 99, b).

(b) In darker and smaller pronilia with pointed aperture.

4. Brown, licellular eonidia, in little dink pyenidia (Diplodir cytisi).

\section{Perituecia.}

5. Brown, multiseptate ascospores, in perithecia generally of rark colour, and with depressed pore (Fig. 10(0).

Cucurbitaria sorbi Karsten. This fungns appears to produce disease in a manner similar to C. laturni. It was described by me in $1886^{1}$ from specimens collected in the Bavarian forest-land from young P'yrus Aucuparin. They were ensily listingnished in August by their withered twigs, both lark and wood being killed in tracts by the nnyceliun. In another locality I found well-developed perithecia, also on $P$. Aumparin.

Cucurbitaria pityophila Fries. occurs on the living branches of various conifers, r.g. I'inus Cembru.

\section{SPHAERELLOIDEAE.}

\section{Stigmatea.}

The naked perithecia are superficially seated on the sul,stratum. The ascospores, eight in each ascus, are clear and twocelled. The species are parasites.

Stigmatea robertiani Fr. (Britain and U.S. America). Occurs on living leaves of Gronium Robritionum.

St. ranunculi Fries. On living leaves of Renumenlus repens (Britain and U.S. America).

St. mespili Sor. (U.S. America). This species appears in spring as reddish-brown spots on the leaves of wild pear-trees. At these places the epidermis becomes ruptured, and cushions are formed from which brown. conidia are given off from short conidiophores. This stage was formerly known as Morthicre mespili. The conidia are at first olovoid, but later seem to consist of four separate cells arranged in a cross, and each furnished with a transparent bristle. Ench conidium produces a germ-tube which penetrates the epidermis, and in a month

II have since foumd from Saccarlo that this fungus was described by Karsten (.Yycol. Fenn., II. "ad ramos dejectos sorti anupariue in Fennia mericl. et media"); it was, however, unknown for Germany to that author. (Auth.) 
new conidial cushions may appear. The mycelium itself is brown. From winter to spring, brown perithecia containing eight-spored asci may be found on the same leaves formerly occupied by the conidia. The colourless spores consist of two unequal cells; they germinate in May, before or after ejaculation from the asci, and bring about new infections.

St. polygonorum Fr. occurs on leares of Polygonum. (Britain and U.S. America).

St. andromedae Piehm. On living leaves of Andromerla polifoliu.

St. alni Fuck. On living leares of Alnus glutinosu.

St. juniperi Desm. On living needles of Juniperus communis.

\section{Ascospora.}

The mycelium forms brown crusts under the host-epidermis, and there the perithecia develop. The asci are small and contain unicellular hyaline spores. The perithecia contain no paraphyses.

Ascospora Beyerinckii Tuill. The conidial form of this fungus (Conyneum Beycrinclii) produces a form of the "gumflux" of cherry trees. The mycelium lives in leaves of cherry, peach, plum, apricot, almond, which in consequence become spotted, and die off along with the young fruit. Mature perithecia may be found in spring. The fungus lives to a certain extent as a saprophyte.

\section{Sphacrella.}

The delicate perithecia are embedied in the tissues of the host-plant; they contain asci with two-celled colourless spores, but no paraphyses are present.

Sphaerella laricina Hartig. ${ }^{2}$ The needle-cast fungus of Larch. This fungus is the cause of a dangerous larch-disease found everywhere, except in mountainous localities over 1200 metres. The symptoms of disease consist in the needles becoming brown-spotted and falling prematurely in summer. Cushions of conidia are formed in June on the brown spots; these enlarge, and from their surface rod-shaped, four-celled conidia are

${ }^{2}$ Vuillemin, Titres et traraux scientifiques, 1590.

22. Hartig, Forstlich-naturmiss. Zeitwchrijt, 1595, p. 445.

Through the kindness of Prof. Hartig we have been enablerl to add an account of this important new disease, with the accompanying figures. (Auth. and Edit.) 
abjointed (Fig. 10:3); in the interior of the spots are producer tiny conidia (Lrptostrome lavioinm), incapable of germination.

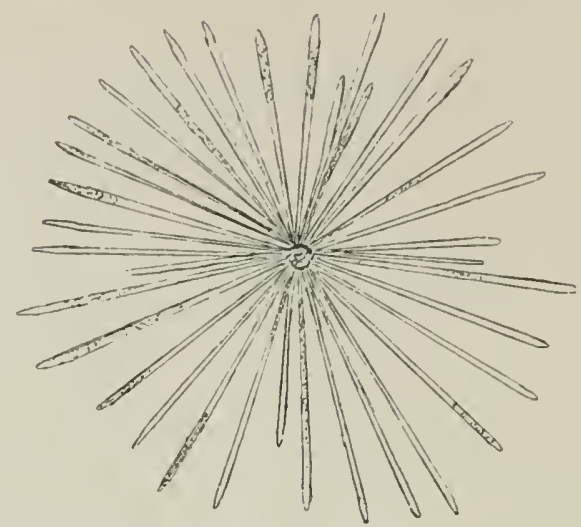

FiG, 101.-Tuft of larch needles, the greater number of which are more or less attacked by sphaerella lericina. (After R. Hartig.)

The rod-shaped conidia infect particularly the lower needles of the crown, and three weeks thereafter new conidial cushions

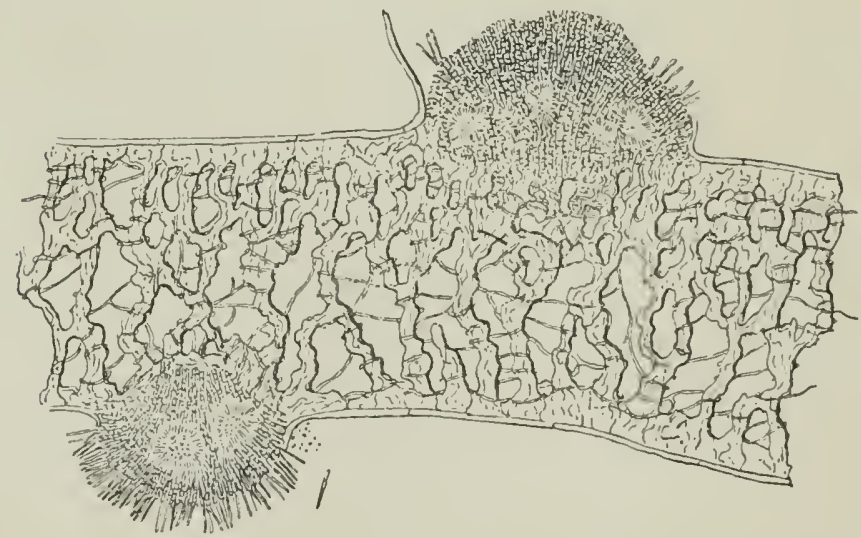

Fra, 102.-Sphuerelle, laricina. Section through a diseased spot on a larel needle. The interior of the leaf is permeated with the intercellular mycclium. Two conidial cushious are shown; fron these uumerous long rod-shaped conidia are given off externally (those of the upper cushion have nearly all been carried off by rain), while cavities inside the eushions are filled with micro-conidia. $\times 100$. (After R. Ilartig.)

appear. Their distribution and germination are faeilitated by wet weather. The perithecia (Fig. 104) are matured towards 
spring in the fallen needles, which lie on the ground over winter. The ascospores are mature and capable of infection at the beginning of June. In forests of pure larch, or in mixture with spruce, the ascospores are easily distributed by wind. In larch, underplanted with beech, the spores are kept down towards the ground by the canopy of beech foliage, so that, during the summer, they cannot be carried up to the larch crown.

Hartig gives the following interesting facts on its distribution.

"As already remarked, the perithecia de- Fis. 103.--a, Rod-slaped velop in spring on the fallen larch needles, detachment from the and in low-lying localities the spores reach from the interior of the maturity at the beginning of June. New R. Hartig.) conidial cushions are not found on the larch in our neighbourhood before July. The parasite has thus four months at its disposal

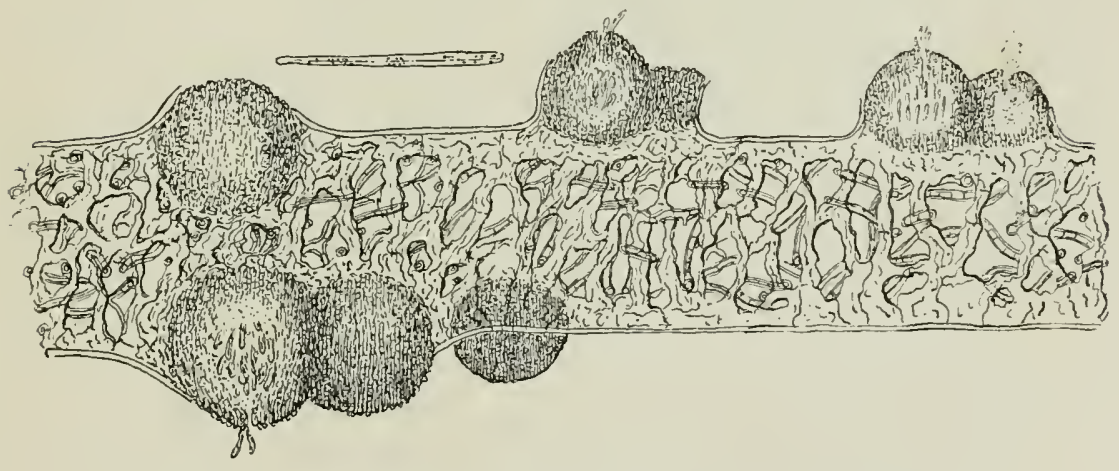

FIG. 104. - Sphaerella laricina. Section through a diseased larch needle in June after it lias lain on the ground from the previous year. The mycelium is thick, thick-walled, and of a light-brown colour. The perithecit contain asci and ascospores. To the extreme right is a pycnidium containing little oblong conidia, alongside a perithecium. $\times \frac{100}{1}$. (After R. Hartig.)

for distribution by means of conidia. As, however, we ascend into the mountains, the snow lies longer, so that the perithecia cannot begin to form so early, the ascospores are correspondingly late in reaching maturity, and the season during which the parasite may spread is still further shortened by the earlier commencement of winter. At an elevation of 1500 metres, 
active vegetation begins about two and a half months later than in the plains, i.r. at the beginning of .June. The season of mature spores of Splucerelle is thus relayed till about the

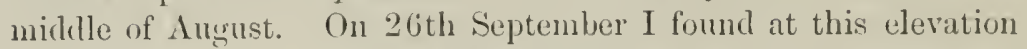
only a few spots on the larch needles, and

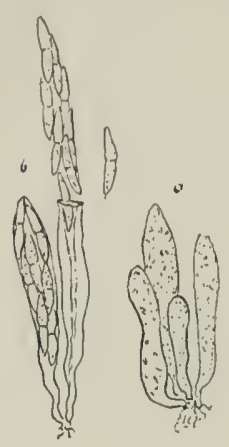

F19. 105.-Enlarged usci. a, lmmature asci without paraphyses, as on $A$ juril 30. $b$, Hature asci, from one of $b$, Mature asci, from one of
whieh the spores are eseay. ing, as on Jume $1 . x \pm 1$ is. (After R. Hartig.) on these liarlly any conidial cushions. liy 28 th September this larch plantation was alieady under snow."

"It will thus be seen, that while at a high elevation the larch ean flourish with a regetative period extending only to three and a quarter or four months, the Splucerlln lias not the time necessary for its development, so that the larch, though much handicapped, remains healthy. Similarly with the larch in Siberia, it grows there, as in the momntains, very slowly, yet this parasite can no longer reach it."

Sphaerella fragariae Tul. Strawberry leaf-blight. ${ }^{1}$ In summer free conidia (Ramulnrice Tulasnci Sace.) and pycnidia are produced, while the perithecia ripen in spring.

[This destructive disease of the strawberry has been recorded from all parts of the United States. It first appears on the upper surface as small reddish spots, which rapidly enlarge, the centres withering and browning. The growth of the plants and the crop-yield is serionsly impaired.] (Edit.)

Sph. gossypina Atks. ${ }^{2}$ [Cotton leaf-blight is a disease on leaves of the cotton plant caused hy the Corcosporce-stage of this fungus. Small reddish spots appear on the leaf, enlarge, and become dry whitish spots with a red margin. The conidia are elongated and prodneed in long chains. The asci contain eight elliptical spores, which are slightly constrieted at the septum when mature, one cell being usually somewhat smaller than the other. This disease frequently accompanies that one known as "yellow leaf-blight," or mosaic disease.] (Edit.)

${ }^{1}$ Trelease, Winconsin Exper. Station, 1585.

Scribner, F. L., Report U.S.' Dept. of Africulture, 1Ss\%. Plate. Other papers by Arthur, Dudley, and Garman.

${ }^{2}$ Atkinson, Bullctin Torrey Botan. Club, Vol. xrir., 1891. 
Sph. mori Fuck. causes a similar disease on leaves of mulberry (U.S. America).

Sph. taxi Cke. On the yew. ${ }^{1}$

Sph. longissima Fuck. On living leaves of Bromus asper.

Sph. depazeaeformis (Auersw). On living leaves of (rialis acetosella anid Ox. corniculata.

Sph. brassicicola (Duby.). On withering leaves of Brassicue. (Britain and U.S. America.

Sph. laureolae (Desm.). On living leaves of Daphne laureola.

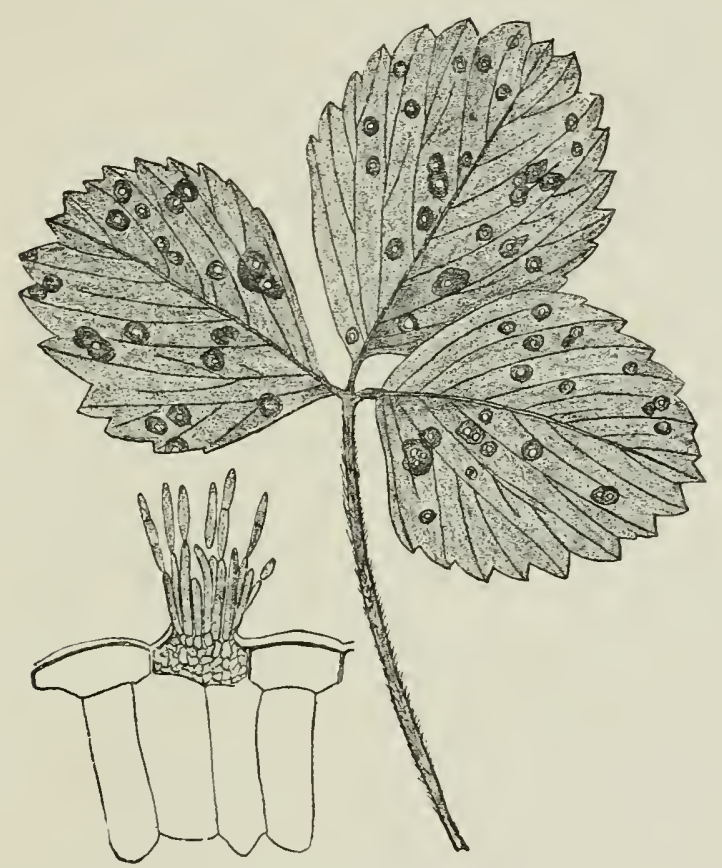

FiG. 106. - Spluerella fragarice on leaf of Strawberry. The section through a spot shows formation of conidia. (v. Tubeuf del.)

Sph. hedericola (Desm.). On living leaves of ivy. (Britain).

Allescher ${ }^{2}$ describes other fungi on iry.

Sph. Gibelliana (Pass.). On living leaves of Citrus limonum and $C$. medicu.

Sph. polypodii (Rabh.). On living fronds of Polypodium vulgare, Aspidium Filix-mas, Asplenium Trichomanes, Pteris aquilina.

Sph. vitis Fuck. On withering vine-leaves.

'Worth. G. Smith, Gardener's Chronicle, xxr., ISS4.

2 Allescher, "Blattfleckenkrankheit d. Ephues," Zeitsch.f. Pfl.-krankheiten, 1595. 
Sph. sentina (Fr.) (U.S. America). In spring of 1891 this caused at (reisenheim ${ }^{1}$ a severe spot-lisease $m$ the leaves of certain varietiss of peall.

Other related species ocenr on pear.

There are numerons other sprecies of Sphaerellu. Saccardo gives 279 species, many of which are probably more or less prejudicial to plants in orchart or garden. None, however, are recorded as very injurions.

\section{Laestadia. $^{2}$}

This genus is similar to Spharefla, but has one-celled conidia; it is distinguished from Physalosporr by the absence of paraphyses.

L. maculiformis (Bon.) on living leaves of various trees.

L. (Physalospora) Bidwellii (Ellis) ${ }^{3}$ (Britain and U.S. America). The Black-rot of the Tine. This parasite attacks all young organs and shoots of the vine. On the leaves the symptoms are spots with dark sharply-defined margins, on which the pycnidia appear later as minute black pustules. The leaves lie, but do not fall off, as with Sphucelonne ampelinum. The berries show disease when only the size of peas, and finally fall off singly or in clusters. The grapes are not dusty with a mealy powder, nor do they burst as in attacks of Oidium Tuckeri. Two kinds of pycnidia occur: one sometimes described as spermogonia, has very small rod-like conidia, borne on threadlike conidiophores; these conidia have not as yet been seen to germinate. The other pycnidial form (Phoma uricola of Berk. and Curt.) contains forked filamentous conidiophores, from which one-celled ovoid conidia (stylospores) are produced and soon germinate by emission of a septate hypha. The latter form of conidia is produced after the spermogonia, and may be

'Geisenheim Jalirbuch, 1592.

2 Accorling to the laws of priority this genus must, as shown by Magnus (Oesterreich. lotan. Zeit., 1594, p. 201), be called Carlia. Bon.

${ }^{3}$ Bibliography : Cavara, Intorno al dissecamento dei grappoli della vite, ISss.

Thumen, "Die Black-1'ot Krankheit d. Weintranben." Alleg. Weinzeitun!, Vienna, 1891.

Galloway and Scribner, Reports for 1588-59, U.S. Dept. of Agriculture.

Viala and Ravaz, Less Progrès agric. et rifirole. Montpelier, lsss-S9.

Rathay (1), Der Black-rot, 1S91. With 19 figures (2). Bericht uib. eine narh Frankreich z. Erforschung l. Black-rot Krankheit Reise, IS91. With 7 figures (3). Der White-rot in die Weinlaube, 1592.

Viala. Die Krankheiten $d$. Weinstockes.

Linhart u. Mezey, Die Krankheiteu d. Weinstockes, 1895 (Hungarian).

U.S. Dept. of Agriculture. Numerous references in reports and bulletins, where details of treatment experiments will be found. 
found right on into autumn, even thronghont the winter. Hibernating sclerotia are also produced, the cells of which grow out directly into septate conicliophores with oval conidia. Perithecia, externally resembling pycnidia, are formed in May and 'June on the fallen berries of the preceding year. The asci have gelatinous walls, which swell and burst so as to ejaculate their spores. Tiala and Ravaz successfully infected living grapes by means of the larger coniclia, and also by the germinating ascospores.

The disease is one of the most drearled in America. It has been found also in Europe, having been observed in France since 1885 , though not as yet in Germany, Switzerland, Italy, or Spain. Moist situations are favourable to it. As with other diseases of the vine, the various varieties have different powers of resistance, and a judicious selection of varieties may prove a good preventive neasure. According to Tiala, the black-rot is found in the United States on both wild and cultivated vines, but never on the fruit of Vitis mpestris, $V$. Berlancicri, $V$. cincrea, $V$. Liuscemii, $V$. Monticola, and $V$. eandicuns, and very rarely on their leaves. The "vine-stoclis" themselves suffer little or nothing from the disease. Rathay says that Vitis riparia, $V$. mpestris, and $V$. Solonis, so important as grafting-stocks, are seldom affected; the green shoots of other species, however, may be attacked and the disease be transmitted through the grait-slip.

For combating the disease. Galloway, Prillienx, and l'Ecluse recommend Bordeaux mixture. ${ }^{1}$

Laestadia buxi (Desm.). The perithecia of this species are found as tiny points on yellow spots on the lower surface of green leaves of box. This fungus, regarded by Desmazieres as saprophytic, is said by Briosi and Cavara to be parasitic.

\section{PLEOSPOREAE.}

\section{Physalospora.}

The perithecia are formed under the epidermis, but are otherwise devoid of covering; they contain asci and paraphyses; the spores are one-celled, and oroid or elliptical.

${ }^{1}$ For details see Rathay (loc. cit.), the American bulletins, etc. 
Physalospora laburni (Bonord.) occursun living twigs of rytisess Lalumrnum.

Ph. fallaciosa siace. On withering leares of Alotris and Musa in Berlin Botanic Garden.

\section{Didymosphaeria.}

I'erithecia sinilar to Physalospmir, but with two-celled spores.

Didymosphaeria genistae Fuck. occurs on Genista pitost.

D. epidermidis (Fries). On living bunchess of Berberis, ,ionluens, Salin, and Euculyptus. (Britain and C.S. America).

D. albescens Niessl. On living branches of Lomicers Iylostemm anul Myriouria yermanicu.

D. dryadis (Spegazz). On living leaves of Droys octopetuln. (C... Anerica).

D. populina Tuill. Prillieux and Vuillemin' resgari this as a parasite, and the cause of a peculiar dying-off of Populns pmomidulis throughont Ciemany; Rostrup, un the other hand, ascribes this to Dothion spleceriodes Er. Prillieux regarts Yupicladirm tremulae as a conidial form of I hitymosphaeria ; Vuillemin, however, belieres it to be saprophlytic.

\section{Venturia.}

The perithecia are embedded in the stroma, and have stiff bristles roumd the pore; they contain both paraphyses and eight-spored asci. The spores are two-celled, with or without colour.

Venturia geranii Fr, occur's on the living leares of Geranium pusillum. G. molle, etc.

V. rumicis (Desin.). On withering leaves of Rimer: (Britain).

V. maculaeformis (Desm.). On living leares of Epilobinin.

V. vermiculariaeformis Fuck. On witherel leaves of Euonymus europraeus and Lonireru Iylosteum.

V. Straussii sacc. et Romm. This I lave fomml as a parasite on Evice carner in Tyrol. It is also said to canse a clisease on Ericaceae in France.

The various coniclial forms at present placed amongst the "Fungi imperfecti" as Fusiclutium are probably related to Venturio.

Fusicladium dendriticum Wallr. on apple, and $\mathbf{F}$. pirinum Lib. on pear, are at present the subject of an investigntion at the hands of Aderhold, ${ }^{2}$ who has, on account of their perithecia,

${ }^{1}$ Bullet. de la sor. mycol. de France, 1892; Compt. rent., 1859 : Rerue myrol., 1892.

${ }^{2}$ Adlerhold, "Die Perithecienform $v$. Fus. dendriticum" Vorlaufig Mlittheilung, Ber. d. deutsch. looten. (ites, 1894, p. 33s. 
placed them in the genus Tenturu. His investigations are, however, not quite complete.

The scab or black spot of apple and pear is a very familian disease in America and elsewhere. It attacks leaves, young shoots, and fruits. Dirty greenish spots appear first, then enlarging, they run together, and darken in colour till almost black. If the attack occur on young foliage, it may be dwarfed and killed; the newly-formed fruit will in such cases be attacked, shrivel up, and fall. If the attack be deferred till the foliage and fruit are well advanced, then spotting results and the fruit remains hard, perhaps cracks. The conidia are oval, micellular, and yellowish-brown; they are produced from short conidiophores

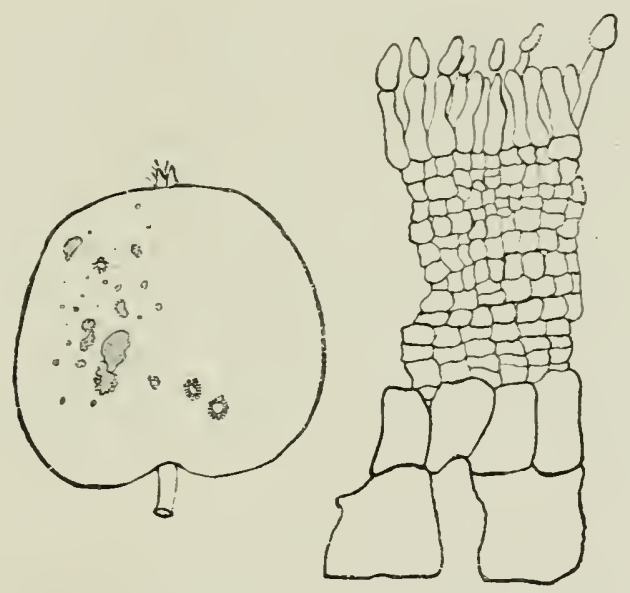

Fig, 10- - Ferturide (Fusicladium) dendriticum forming bromn spots on an apple; those still in the earlier stages hare a radiate margin and bear conidia. The enlarged section shows two rows of large-celled parenchyma of the apple, corered by a stroma of pseudoparenehrma bearing conidiophores and conidia. (v. Tubeuf del.)

with warty prominences which grow on spots of leaf or fruit (Fig. 107). The perithecia (as yet lescribed) are distinguished by black bristles surrounding the pore, and occur on fallen leaves. The asci contain eight greenish ovoid spores with two or three cells.

In addition to the injury to leaves and destruction of young fruit, the disfiguration of the apples is a cause of considerable monetary loss. Dilute Bordeaux or copper sulphate mixture applied before the opening of buds, and once or twice after 
"setting" of the fruit, is recommended. No fungicide should, however, be applied towarls the ripening season. ${ }^{1}$

\section{Gibellina.}

The spherical perithecia are embedded in the stroma, their necks projecting. The asci contain eight brownish spores, oblong or spindle-shaped, and bicellular.

Gibellina cerealis Iass. This parasite of wheat has hitherto been fairly common in Italy; recently it has appeared with disastrous effect in Iungary. According to Cavara, it produces on the uncler part of the stems, grey plate-like coatings with a brown margin; these may remain as spots, or enlarge till they form a ring round the stem. The perithecia are little black points arranged in rows, and embedded under the epidermis, except the black projecting necks. The asci have thin walls and break up inside the perithecia; they contain eight spores arranged in two rows. The spores are spindle-shaped and bicellular, but their germination has not as yet been observel. The mycelium is found in all the host-tissnes, besides forming a stroma-like sheath round the stem. The plants attacked become brown and limp in early summer, and no fruit is produced. ${ }^{2}$

Cavara recommends early removal aud burning of affected stems, and the cultivation of crops other than cereals on the infected ground.

\section{Leptosphaeria.}

Perithecia black, rarely with bristles; at first they are embedded in the host, withont a stroma. The spores oceur four to eight in each ascus; they are spindle-shaped and generally multicellular by means of cross-walls only. Thread-like paraphyses are always present.

Leptosphaeria herpotrichoides de Not. This species, generally regarded as a saprophyte, was found by Frank $^{3}$ as a parasite on rye. The stalks attacked break over at a node or

\footnotetext{
${ }^{1}$ Further details of treatment-experiments are giren in Gall and Scribner's "Report on Experiments for 1859," U... Amer. Dept. of Afgriculture Bulletin II. ; also in the Bulletins of rarious Experimental stations. The above account has been considerably extended by aid from the American literature. (Edit.)

"Cavara (Zeitschrift $f$. Pftansenkrankheiten, III., 1593, p. 16) gives a detailed account of this fungus with illnstrations.

${ }^{3}$ Frank, Zeitschrift f. Pflansenkrankiheiten, 1895.
} 
just over the root, thus resembling the symptoms accompanying an attack of Hessian Fly.

L. tritici Pass. is said ly Frank to be destructive to wheat in Germanr. (See also Cladosporium).

L. subtecta Wint. In Tyrol the perithecia of this species accompany disease of the leaves of Erica carned. Simultaneonsly Hypoderma eiveae Tub. and Sphaeria ericina Tub. were found, the former appearing to cause the disease (see p. 234).

L. anceps Sacc. On living branches of Ribes nigrum.

L. vitigena (Schnlzer). On living tendrils of the vine.

L. circinans Sacc. (see Rhizoctoniu p. 201).

L stictoides Sace. on Liviodendron tulipifere is an American species.

\section{Pleospora.}

The black perithecia are not developed on a stroma, and are at first concealed in the host-tissues only. They contain paraphyses and eight-spored asci. The spores are multiseptate, and generally coloured.

Pleospora hyacinthi Sor." produces black coatings on the bulb-scales of hyacinth. The mycelium inside the tissues is colourless, but outside is dark red, and its presence causes disease of healthy parts. Certain perithecia which appear on the bulbscales in autumu may perhaps belong to this fungus.

P. tropaeoli Hals, is given as a disease of Tropaeolnm in U.S. America. ${ }^{3}$

P. hesperidearum Catt. The conidial form (Sporidesmimm hesp.) appears as a black coating on the orange.

P. ulmi Fr. (ver. minor) Allescher, causes a leaf-spot on young elm-seedlings, and the leares drop off prematurely.

P. napi Fuck. is the canse of rape-smnt. Leaf-spots carrying coniclial cushions (Sporidesmium eritiosum Kuihn) appear on the rape and other allied root-crops.

Other "black smut-diseases" have been ascribed to Polydesmus (Sporidesmium) exitiosum (rur Danci) on carrot; Helminthosporium gramineum Rablh. causing withering of rye and barler leares; and Sporidesmium putrefaciens Fuck. which attacks and kills the roung lieart-leares of beetroot.

${ }^{1}$ v. Tubenf, Botan. Centralblatt, xxi., 1885.

2.Soraner, Handbuch d. Pflanzenkrankheiten, I1. Aufl., p. 340; and Untersnch. ïb. elie Ringelkrankheit $u$. d. Russthar $d$. Hyacinthen. Leipzig, $187 \mathrm{s.}$

${ }^{3}$ N. Jersey Agric. Exper. Stat. Report, 13, 1592. 


\section{Dilophia.}

The genus is parasitic aml cause swellings. The perithecia remain permanently embedderl in the tissnes of the host-plant. The asei contain eight transparent, thread-like, finely-pointed, multicellular spores.

Dilophia graminis sace. (Britain). This causes defornity of the leaves and inflorescences of will grasses; also of rye in France, and wheat in England and switzerland. Fuckel assumes a relationship, between this species aud Dilophospore gruminis 1) esm., but this we regard as iloubtful.

\section{Ophiobolus.}

I'erithecia seattered and alnost spherical; they eontain paraphyses and eight-spored asci. The spores are hyaline or yellowish, thread-like, and unicellular or septate. The fungus is minute and inhabits stems and haulus.

Ophiobolus graminis Sace. was indicated by Prillieux, Jelacroix, and schribaux as the cause of a cereal disease in France. The cereals attacked broke over very easily near the ground; they continued to develop, but produced ears of a poor quality, and often quite withered. The disease was designated "maladie du pied des céréales," and described in Jour. d'Agric. princtique, 1892; also under the name "la maladie du pied du blé" in Trecture del latbor. de pathol. végétule inst. agronom., 1890. The perithecia have a enrved lateral beak; the asei contain eight long, spindle-shaped, multiseptate spores.

Frank also records this disease as injurious to wheat in Germany in 1894.

\section{GNOMONIEAE.}

\section{Gnomonia.}

Perithecia without a stroma, and generally remaining embediled in the host-tissues, with only a beaked opening projecting; they contain $n$ paralhyses. The asei have a thickened apex with in fine central pore. The hyaline spores consist of from one to four cells.

Gnomonia erythrostoma Auersw. ${ }^{1}$ This is the cause of an

${ }^{1}$ Frank, Ber. d. dentwch. Lotan. Ces., 1886 and 1SST; also Zeitschrift $f$ : Pfanzenkraukheiten, 1891. 
epidemic disease of the cherry (Prunus arium and P. Cercusus), observed for several years past in North Germany and elsewhere. The fungus attacks the leaves, and there the mycelimm grows. The leaves wither prematurely, but remain all winter hanging from the tree by a reldish-brown mycelium. Pycnidia and perithecia are produced in the leaves, the latter reaching maturity in spring, when the two-celled ascospores are ejaculated. The pycnidia contain short conidiophores bearing hook-shaped conidia. The fruit is also attacked, and ripens mequally, so that the cherries are listorted: then they crack and rot.

Frank has succeeded in carrying out artificial infection. This takes place in . Inne, and immediately on germination the germhypha produces an attachment-disc on the host-epidermis, whence a hyphal filament penetrates the epidermal wall, grows through the cell, and reaches an intercellular space. A thick septate mycelinm is formed and spreads, especially amongst the spongy parenchyma. There is no stroma, and the perithecia hibernate on ijy leaves.

Frank recommends the plucking and burning of dead leaves hanging on the trees. This must of course be lone througlont the whole district attacked. In one part of Prussia (Altenlancle) this precaution was taken twice each winter for two years, with the result that the disease, which had long completely ruined the cherry crop, disappeared, and the harvest increased to its former amolint.

Gnomonia quercus-ilicis Berl. ${ }^{1}$ causes brown spots on leaves of Quereus Ilex.

\section{VALSEAE.}

\section{Mamiania.}

Perithecia produced in a black stroma, from which their long necks project. The asci have a thickened apex, and contain eight oral hyaline spores with one or two cells.

Mamiania (Gnomoniella) fimbriata Pers. (Britain and L.S. America). The stromata of this appear in summer as little black cushions on the leaves of the hormbeam (Curpinus). The perithecia are developed in these spots, and their long black beaks projecting distinctly above the surface of the leaf cause

\footnotetext{
${ }^{1}$ Berlese, Rivista di Patologia regetale, I.
} 
rupture of the epidernis. Nimnerons leates may be disensed and each carry many cushions, yet Vuillemin, who describer the clisease, ${ }^{1}$ does not believe the host-plant is affected to any serious degree.

M. (Gnom.) coryli Batsch. (Britain and U.S. Anerica). The black stromata are found in withered spots on the leares of hazel (Corylus); as a rule, each stroma carries only one perithecium with a long beak similar to that of M. fimbriatu.
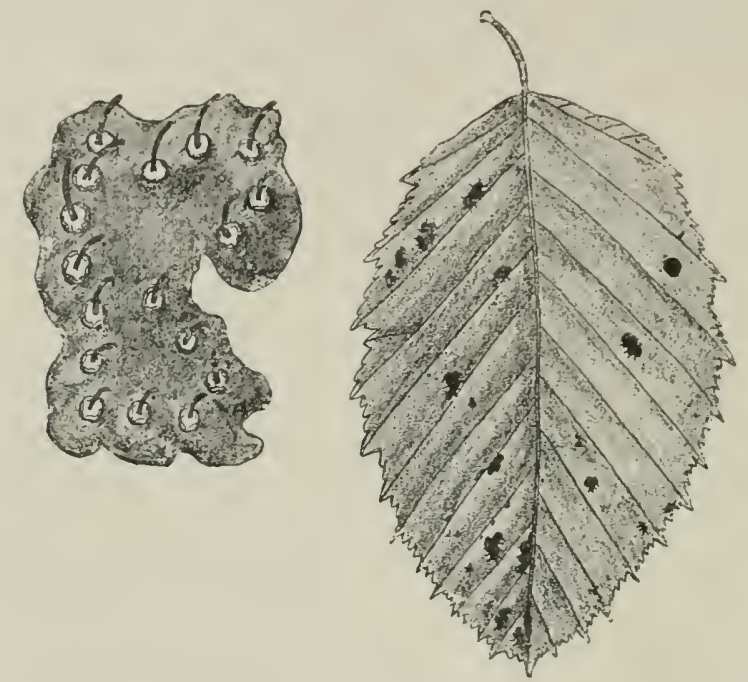

Fia. 10., - Mamiana fimbrata on Carpinus Bitul's. Leaf of Hornbeam seen on lower surfuce. Stroma (eularged), with the long black necks of the peritheci: projecting from the ruptured leaf-epidermis. (s. Tubeuf del.)

\section{Valsa.}

A stroma is generally present, but is of very variable appearance; embedded in it are the perithecia, with only their beaklike months projecting. The spores are hyaline or light-brown, unicellular, and generally bent. No paraphyses are present.

Valsa oxystoma Rehm. ${ }^{2}$ This causes disease and death of branches of Alnus viridis in the Alps. The symptoms are withering and drying np of single branches on an otherwise green bush. This disense causes severe loss in the Tyrol,

1 Titres et traraux scientifiques, 1890.

${ }^{2}$ ๖. Tubeuf. "Zwei Feinde d. Alpenerle," Forstlich-nahuruiss. Zeitschritt, 1 s92. 
where leaves of the alder are dried in summer for use as winter-fodder for goats.

In the branches attacked, a mycelium is developed in the vessels of the wood, whereby the supply of water is stopped and the bark dries up. Black lens-shaped stromata arise under the epidermis of the twig and rupture it. The perithecia are produced under the stromata in the bark, and communicate
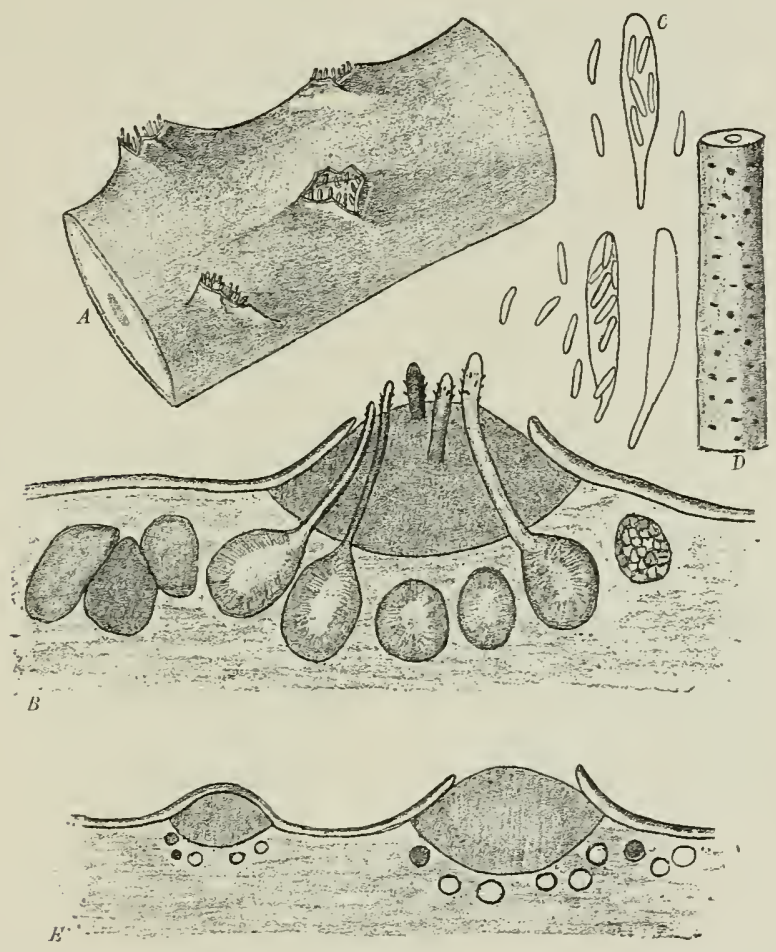

Fig. 109. - Valsa oxystoma on Alnus viridis. A, Portion of branch with stroma of Valsa breaking through the periderm at four places. B, Enlarged section through a stroma from $A$. $C$, Asci and ascospores, isolated from a perithecium. $D$, Portion of younger branch with periderm ruptured by stromata, in which, however, the perithecia are not yet dereloped. $E$, Enlarged section through a stroma of $D$. (After $\nabla$. Tubeuf.)

with the exterior by means of long projecting necks. The asci contain eight unicellular spores of a slightly bent, rodlike shape. Maturity is reached on the dry dead twigs. Externally this disease is identical in appearance with one I ascertained to be due to a beetle (Cryptorhynchus lapathi), 
the larva of which bores cimals in the wood of alders, birches, and willows, causing them to die.

Most of the other species of $V_{1}$ lsa cause only leaf-spot, or occur on dead leaves.

\section{Anthostoma.}

The perithecia are embedded in the substratum or stroma, and have generally long necks. The asci contain eight brown or black, oval, unicellular spores. Paraphyses are always absent.

Anthostoma xylostei (l'ers.) occurs on living and dead branches of Lonicere Iylosteum. (Britain).

Anthostomella pisana Pass. lives on leaves of Chamerops humilis and kills them.

\section{DIATRYPEAE.}

\section{Calosphaeria.}

No stroma is formed, the perithecia arising singly or in groups in the bark under the periderm; they have often long beaks. The asci are club-shaped, and frequently long-stalked; they contain eight or more spores, which are little, unicellular, and somewhat curved.

Calosphaeria princeps Tul. occurs on living branches of cherry and plum. (Britain and U.S. America).

Quaternaria Personii Tul. has black perithecia and, according to Willkomm, causes death of twigs of beech. (Britain and America).

\section{MELANCONIDEAE.}

\section{Aglaospora.}

The perithecia are beaked and embedded in the stroma. The spores are furnished with appendages.

Aglaospora taleola Tul. ${ }^{1}$ (Diaporthe talcola Fries. and probably nearly related to those Mclanconi with appendages on their spores, e.g. Mel. thelebola, previously known as Aglaospora thel. Tul.). (Britain and U.S. America). This fungus causes a disease of twigs and young stems of oak which have not

${ }^{1}$ R. Hartig, "Eine krebsartige Rindenkrankheit d. Eiche," Forstlich-naturwiss Zeitsclirift, 1593. 


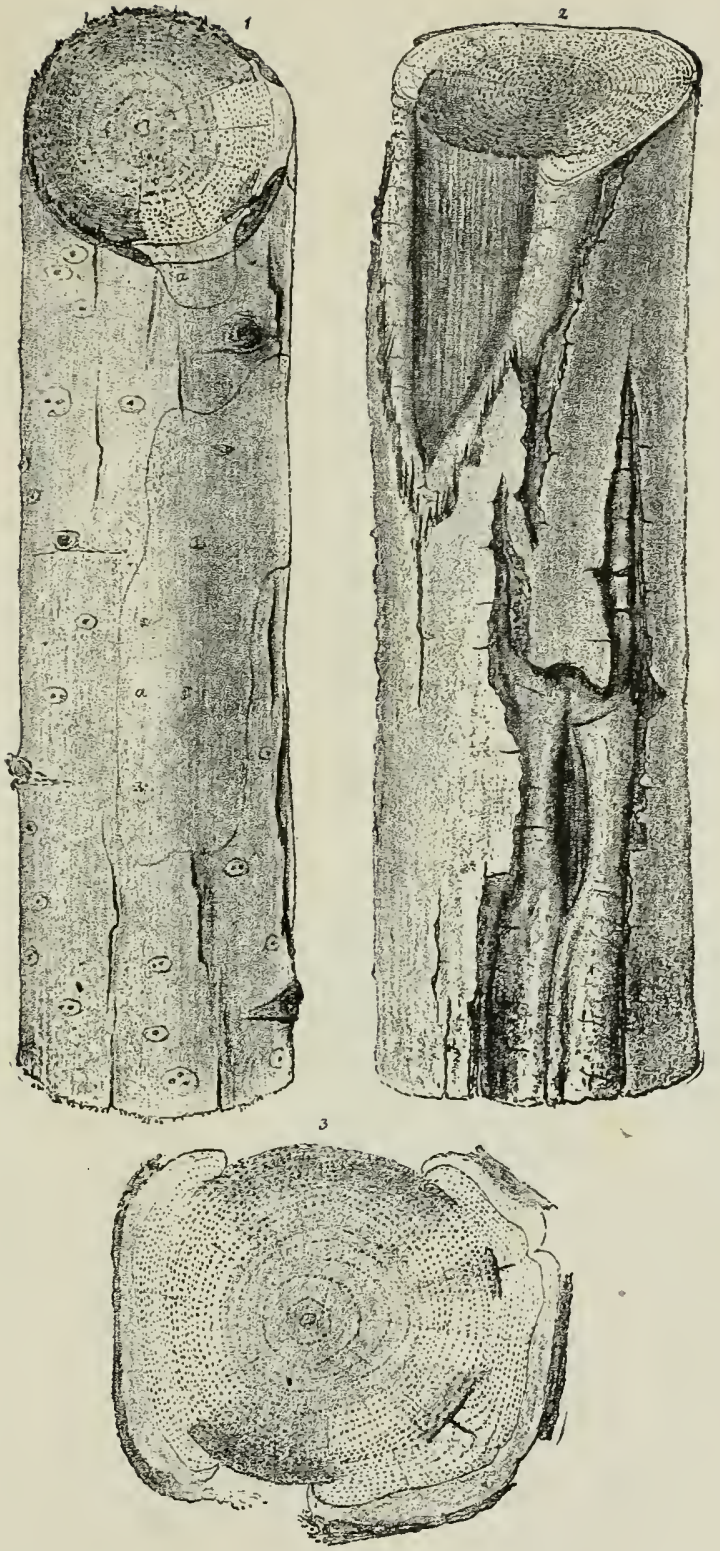

FiG. 110.-Fxamples of Oak-stem attacked by Aglaospora taleole. 1, Portion diseased for two years; $a$, the portion still healthy $\left(\times \frac{1}{1}\right)$. 2, Portion diseased for four years $\left(x \frac{1}{2}\right)$. 3, Section with spots diseased for four, seven, and ten years respectively $\left(\times \frac{1}{1}\right)$. (After R. Hartig.) 
as yet formed a bark. l'ortions of the rind become brown, dry up, and peel off; this on stronger twigs may be followed by a more or less complete occlusion of the wounded part. The browning also extends into the underlying wood. The myeclium is found both in rind and wood, where it probably obtains entrance through small wounds in the bark. In the second year after infection, a circular stroma is formed in the bark under the periderm. Siekle-shaped conidia are

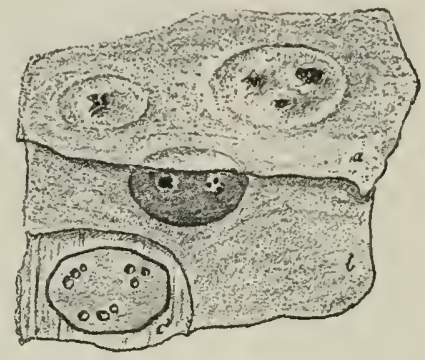

Fig. 111.-Aglaspora taleola. Portion of cortex with embedded stromata. $a$. Corky layer; $b$, after removal of corky layer; $c$, section of stroma. $\left(\times \frac{4}{1}.\right)$ (After Hartig.)

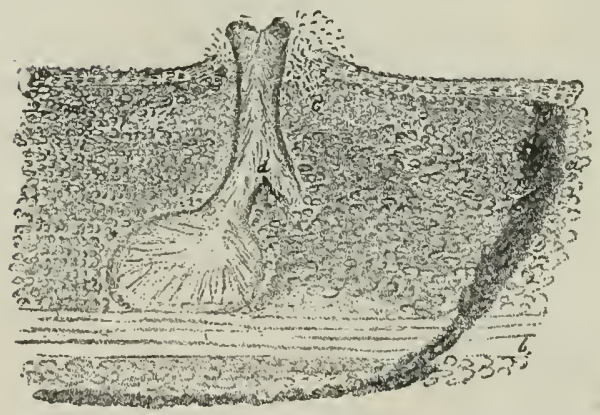

Fig. 112.-Section of stinma of Aglaspora. a, Boundary of stroma formed of dark brown fungus-mycelium; $b$, sclerenchyma-strand of the cortex; $c$, conidial cuslion ; d, union of necks of two perithecia. (After Hartig.)

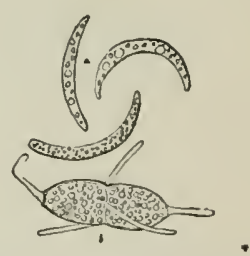

F1G. 113.- $a$, Conidia ; $b$, ascospore of Agluosporce taleola $\left(\times \frac{360}{1}\right)$. (After Hartig.)

superficially abjointed from the stromata; while embedded in it are groups of perithecia with necks which join together into one or a few common channels opening externally. The asei contain eight spores, which are two-celled and bear five thread-like appendages, one on each end, and three round the median septum (Fig. 113). 
Ag. profusa Fr. (Britain and U.S. America). This occurs along with, and probably is some form of Dothiorelle rolinice. Prillienx and Delacroix ${ }^{1}$ blame it for killing young twigs of Robinic pseudacacia in France.

\section{Fenestella.}

The stroma is similar to Eu-Vulsu, and contains several long-necked perithecia. The spores, eight in each ascus, are coloured and multiseptate, as in Cucurbitaria.

Fenestella platani Tav., to this is probably related Glocosporium nervisequium (Fuck.), the cause of a disease on the leaves of Platcmus, and described under Glocosporium.

\section{(3) DOTHIDEACEAE.}

\section{Phyllachora.}

The perithecia are small and produced in a black stroma buried in the tissue. The asci contain eight hyaline, oval, and unicellular spores.

Phyllachora graminis (Pers.). (U.S. America). This species causes elongated black swellings on grasses and sedges (Lusulc and $C(u r e x)$. The black perithecia occur massed together, and embedded in the leaves. The asci contain eight hyaline unicellular spores.

Ph. trifolii (Pers.), with conidial form known as Polythrincium trifolii Kunz. (Britain and U.S. America). The mycelium causes the formation of roundish dark spots on the green leaves of clover frequented by it, and death ultimately follows. On the spots, especially those on the lower epidemis of the leaf, the conidiophores make their appearance as brown septate structures, constricted at intervals so as to become rosary-like; they bear terminal, brown, two-celled conidia, the upper cell of which is somewhat spherical, and larger than the lower.

Ph. cynodontis (Sacc.). On living leaves of Cynodon Dactylon.

Ph. podagrariae (Roth.). On living leaves of Aegopodium Podagraria (Britain).

Some other species are found on withering leaves.

${ }^{1}$ Bulletin soc. mycol. de France, 1890. 
Diachora onobrychidis (D. C.$)^{1}$ This fungus is common on sainfoin (Onobrychis satiru) and Lathyrus tuberosus, causing black spots on both surfaces of the leaf. During sumnner pycnidia arise on the spots, and from them are produced spindleshaped conidia (spematia) with tail-like appendages. Later there arise spherical perithecia containing asci arranged in tufts on the walls. The asci contain eight oval, hyaline, unicellular spores.

\section{Dothidella.}

The perithecia are black and embedded in the stroma, similarly to Plypllachora. The pale-coloured spores are, however, two-cellerl.

Dothidella betulina (Fries.). (Britain and U.S. America.) The black stromata form spots on the upper surface of birch leaves. In these the perithecia arise, and reach maturity in spring. The asci contain eight elliptical greenish spores, eonsisting of two unequal cells with rounded-off ends.

D. ulmi (Duv.). (Britain and U.S. America.) A species similar to the preceding, and causing round blistered spots of a grey colour on the upper surface of elm leaves. Pycnidia (Piggotic restroirtca) are formed in summer, perithecia in the following spring.

\section{Dothidea.}

The stromata have the form of black projecting cushions, in which numerous perithecia are embedded. The asci contain eight greyish or brown spores, consisting of two eells with a constriction between them.

Dothidea virgultorum (Fries.) attacks living branches and stems of birch, and develops further on the dead parts. The stromata originate in the wood, then brealing through the bark, make their appearance extermally as large black cushions. Whole stems may be covered by these cushions.

D. sphaeroidea (Cke.) occurs on living needles of juniper.

\section{Plowrightia.}

The stromata are black, aud run together in masses. The asei are eight-spored; the ascospores ovoid or oblong, hyaline or light yellow, and two-celled.

\section{${ }^{1} \mathrm{~J}$. Miuller, Pringsheim's Jahrbuch, $1 \$ 93$.}


Plowrightia morbosa (Sch.) (Britain and U.S. America). Black-knot of the plum tree. ${ }^{1}$ In America this is a very
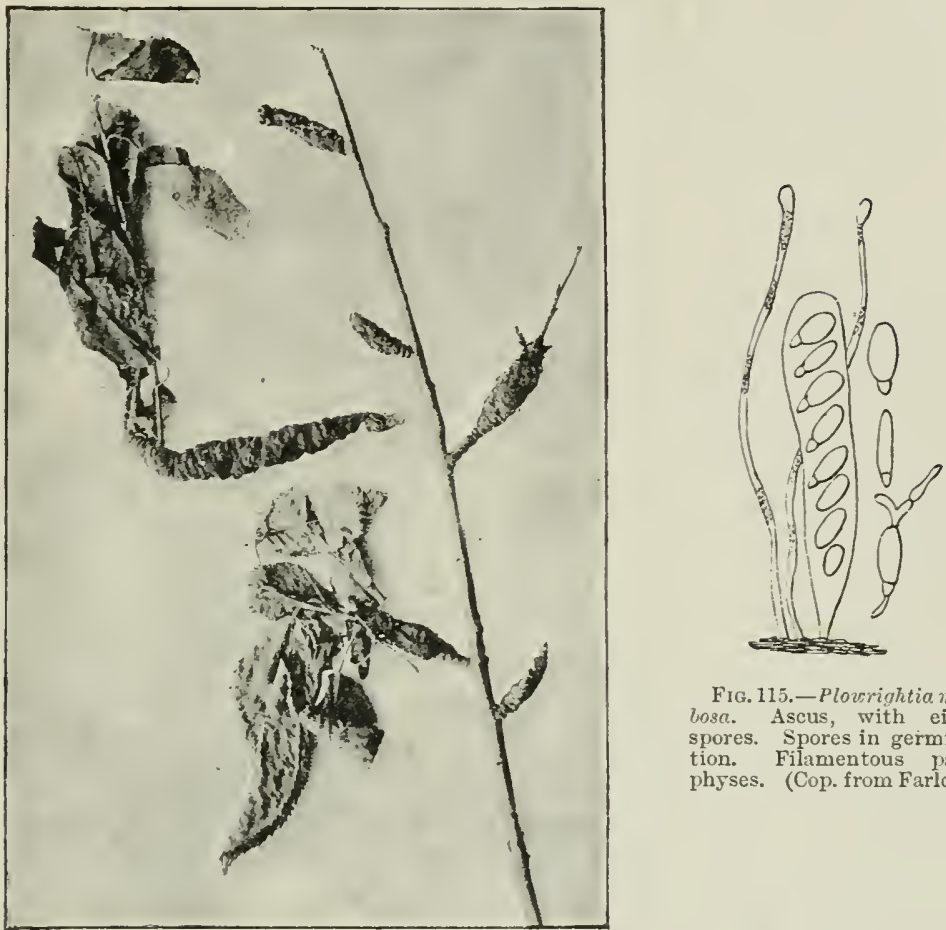

Fig. 115.-Plowrightia morlosa. Ascus, with eight spores. Spores in germination. Filamentous para. physes. (Cop. from Farlow.)

F1G. 114.-Plowrightia norbosa. (v. Tubeuf phot.)

injurious and widely distributed disease of various species of Prunus, especially plum and cherry. The living brauches and twigs become coated with a crust of warty excrescences, and at the same time are more or less thickened and deformed. A mycelium permeates the tissues of those swollen twigs, and forms black crusty stromata in which the perithecia are emberded. The perithecia contain simple paraphyses and eightspored asci. The spores consist of a larger and a much smaller cell. (P'ycno-conidia are produced frequently in artificial culture,

${ }^{1}$ Farlow, Bulletin Bussey Institution, Part v., 1876.

Humphrey, Annual Report of Wass. Exper. Station, 1890.

Lodeman (Cornell Unix. Exper. Station, Bulletin No. 81, 1S94) gives general account of Black-knot and a Bibliography. 
but are rarely found in natural conditions; as yet infection with these has had no result.)

[Remedial treatment must be promptly applied. Trees liable to attack should be frequently examined, so that any young knots may be early removed. If the clisease is of long standing, the only remedy left is to remove all knotted branches and burn them immediately.] (Edit.)

\section{HYSTERIACEAE.}

The ascocarps of the Hysteriaceae, like those of the Discomycetes, are known as apothecia. They are distinguished from those of the Pyrenomycetes and Perisporiaceac in that the ascocarp, although formed in or under the epidermis of attacked plant-organs, is not a closed structure or flask opening by a pore only; it is, indeed, at first completely closed, but later it, as well as the epidermis covering it, splits open and freely exposes the whole hymenium. So long as the apothecium is closed, it is filled with paraphyses, between which the developing asci gradually wedge themselves. The spores are generally thread-like, with a gelatinous membrane. The mycelium lives intercellular, and is often parasitic in living plants. The apothecia, however, only reach maturity on parts which have been killed. In addition to apothecia, little pycnidia (spermogonia) are formed, containing small unicellular conidia. The Hysteriaceae include the Hysterineae, Hypodermicae, Dichaenaccue, and Acrospermaceac.

\section{HYSTERINEAE.}

\section{Hysterographium.}

Apothecia black, highly vaulted, and dehiscing by a linear fissure. The asci are club-shaped and thick-walled; they contain eight multicellular spores, which are at first transparent, but later dark-coloured. The branched paraphyses of the upper part form a coloured epithecium. ${ }^{1}$

Hysterographium fraxini (Pers.) (Britain). This occurs on various Oleacene and some other species of woody plants.

${ }^{1}$ The excipulum of De Bary. 
Rostrup ${ }^{1}$ regards it as a parasite on Fracinus. Twigs of the ash attacked show flat collapsed plates of bark, on which are developed pycnidia containing one-celled conidia, and, later, the apothecia. On young twigs the diseased part often extends round the whole circumference, and causes the death of the upper living part. As yet I have only found this fungns as a saprophyte.

\section{HYPODERMIEAE.}

\section{Hypoderma.}

The apothecia are oblong, and at first closed by a thin black cover, which opens by a long fissure. The asci are sessile in

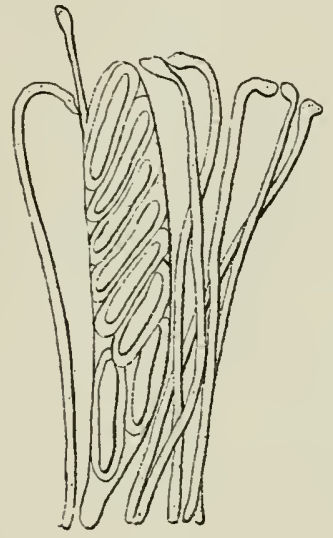

FIG. 11ti.-Hypolema strobicala on Pinas Strobus. Ascus contajning eight ascospores with gelatinous coats; paraphyses with clivate ends. (After v. Tubeuf.)
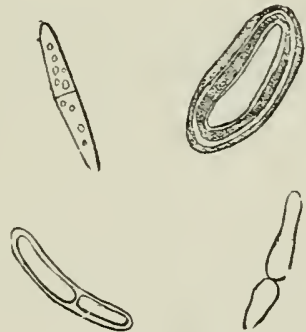

FiG. 117.-Hypoderma strobicola. Isolated ascospores: with and without a gelatinous coat, and one- or two-celled. (After $\nabla$. Tubeuf.)

some species, but have a delicate stalk in others. The spores, eight in each ascus, are never long and thread-like, but always much shorter than the asci, and two-celled when mature. The paraphyses have button-shaped or hooked ends.

Hypoderma strobicola 2 (Rostr.). Needle-blight of the Wey-

${ }^{1}$ Rostrup, Fortsatte Undersoegelser or. Snyltescampes Angreb paa Skov. traeerne, 1983.

2Rostrup, Fortsatte Undersoegelser, 1883.

r. Tubeuf, Beit. z. Kenntniss d. Baumkronkheiten, 1588; also Botan. Centralblatt, XLI, 1890.

Note: When I decided to place Lophodermium brachysporum under the genus Hypoderma, there already existed a Hypoderma brachysporum Speg. (iss;). For the future 1 shall therefore call Loph. brachysporum Rostr. as Hypoderma strobicala. 
mouth pine. According to the observations of Lostrup, in Demmark, and myself in varions localities of Germany, this is a dangerous parasite on Pimus Strobus.

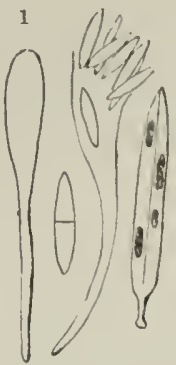

F1G. 118.--Leaf of Erice carnea witl apothecia of Hypoderma ericae on the lower surface. 1, An cutire and a dehiseing aseus ; in two-eelled ascospore. (v. Tubeuf del.)

It kills the needles and young shoots, and may devastate whole tracts of forest. The diseased needles become brown in summer, and fall off during next winter. On then are produced apothecia containing club-shaped asci and paraphyses with buttonshaped ends. The eight spores of each ascus are at first unicellular, later apparently bicellular, and enclosed in a very mucilaginous coat. The asei have an average length of $120 \mu$, the spores $20 \mu$, and when swollen 28 to $30 \mu$.

H. pinicola Brumch. ${ }^{1}$ forms linear apothecia on neelles of Pinus sylrestris.

H. ericae Tubeuf." In Tyrol and Northern Italy, this fungus canses a disease on Ericr carnco. It is common and epidemic, cansing death of the leaves.

\section{Hypodermella.}

Similar to Hypoderma, except that the spores are pear-shaped and unicellular; they oceur four in each aseus, and are shorter than it.

Hypodermella sulcigena (Link) $)^{3}$ las four long, club-shaped, unicellular spores. Rostrup regards it as parasitic on Pinus montence and $P$. syliestris, its mycelimm being found in living green needles, and cansing their leath.

Hyp. laricis Tubeuf." This is a new fungus of the larehneedle found by Tubeuf on the Sonnenwendstein (Bavaria) in September, 1894. It was present in large quantity on larches on the "pper part of the mountain, and was in every way so decidedly parasitic in character, that there is little doubt as to its being an epidemic disease. The full-grown needles on many of the foliar spurs had died off and turned brown. The

${ }^{1}$ Brunchorst, Wogle norslie shorsygrlomme in Beryens Wus.. 1892.

¿v. Tubeuf, Botan. Centrallutul, Xxi., ISS5. aut LXi., IS95.

${ }^{3}$ Rostrup, Fortsutte Undersopgelser, 1883. 
apothecia were present on the upper surface of the needles as isolated black spots or united into lines; they dehisce by an elongated fissure. The asci are cylindrical with rounded apices, and measure about $110 \mu$ in length; they are almost sessile. Each contained four hyaline, micellular, club-shaped spores

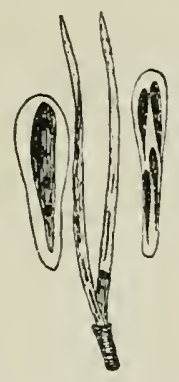

Fic. 119.-Huporlermella sulciatna. The apothecia form black lines on the needles. Ascus containing four spores (enlarged). Single spore with a gelatinous covering (still further enlarged). (Cop. from Rostrup.)

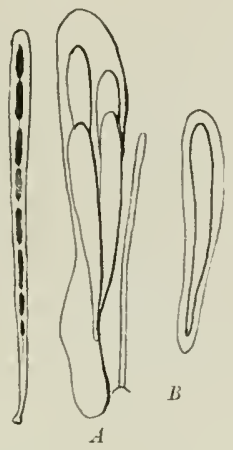

Fic. 120.-Hypodemella laricis. Larchneedle with apothecia on the under side. $A$, Paraphyse, and an ascus containing four spores. $B$, Isolated (enlarged) ascospore in its gelatiuous coat. (v. Tubeuf del.)

$(66 \mu \times 16 \mu)$ with a gelatinous nembrane. The paraphyses are simple hyaline filaments, shorter than the asci.

\section{Lophodermium.}

The oblong apothecia are embedded in the host-tissues under a thin black cover, which breaks by a long fissure. The clubshaped asci contain thread-like unicelüular spores, with a mucilaginous membrane. The paraphyses are sometimes septate and furnished with hooked or button-shaped ends. The spores reach maturity on killed portions of plants, and are forcibly ejaculated. The formation of pycnidia (spermogonia) precedes that of apothecia. Many nembers of this genus are destructive enemies of plants.

Lophodermium pinastri (Schrad.). ${ }^{1}$ Pine-blight or needlecast. (Britain and U.S. America.) This disease of the Scots pine (Pinus sylrestris) is very injurious to young plants, especially those in nurseries.

${ }^{1}$ Hartig, Divenses of Trees, Eng. edit., 1894.

Prantl, Flora, 18 17 ; also, Forstuiss. Centralblatt, 1880. 
"Casting" or premature withering and till of needles is not unconmon in nurseries of pine. Amongst some of the causes which lead to this are: frost, drought in winter on frozen ground free from snow, lronght in summer on dry soil, overcrowding of plants in the nursery, and, finally, a "casting" due to fungi.

The symptoms in the case of the present fungus are spotting and withering of the needles, due to the presence of a mycelium insicle then. In early autumn, or later if the weather be dry, the pycnidia (spermogronia) make their appearance as little black prominences containing tiny unicellular conidia. The Hat black apothecia are leveloped later, on first-year seedlings during the first autumn, or on older plants during the second autumn, but generally they do not appear till the third year; they reach maturity on needles still attached, more frequently, however, on fallen ones. Dehiscence consists in the rupture of their delicate black covering, through pressure of the swelling asci and spores in damp weather. The asci are club-shaped and contain eight threarl-like one-celled spores, more or less twisted round one another. The septate paraphyses have a slightly bent point.

Diseased seedlings die olf, generally without loss of their leaves. Two-year-old and older plants are always weakened by the loss of needles, and in severe cases are killed. On such, the "casting" or sudden fall of all infected spurs and needles takes place in spring. The mycelium often makes its way from the needles into the tissues of the shoot, and then death of the whole plant soon follows. Disease of the needles of old trees may also occur without intlicting much damage on the trees themselves; they will, however, act as centres for infection of younger plants, particularly those in seed-beds and nurseries in the vicinity.

Confirmatory experiments on infection of pines by this Lophodcrmium were first carried out by Prantl, later by Tursky and Hartig.

The disease appears with such virulence and frequency, that the whole of the young pine-growth of a locality may be destroyed. It is thus a most dangerous disease, and at the same time one difficult to combat. Districts which have

${ }^{2}$ Holzner gives a summary of numerous theories on leaf-cast, (Freising, 1877). 
suffered by it should, where other soil conditions permit, be planted with Weymouth pine (Pinus Strobus) and the Douglas fir (Pseudotsuga Douglasii), which are, as yet, exempt from attacks of this parasite. Infection would seem to be brought about chiefly by westerly winds (in Germany), which carry diseased leaves or fungus-spores from infected places. Large areas run greater risks than small patches or young trees naturally sown out. Seed-beds of Scots fir should not be placed under the drip of older trees of the same kind, particularly if this fungus is known to exist there. Shelter-belts of other trees often afford much protection from this disease. $^{1}$

Lophodermium macrosporum Hartig ${ }^{2}$ (Hysterium). (U.S. America). Scab or rust of the spruce. This disease exhibits itself in various ways. Frequently the needles of the preceding year turn brown in spring, and perithecia are produced in

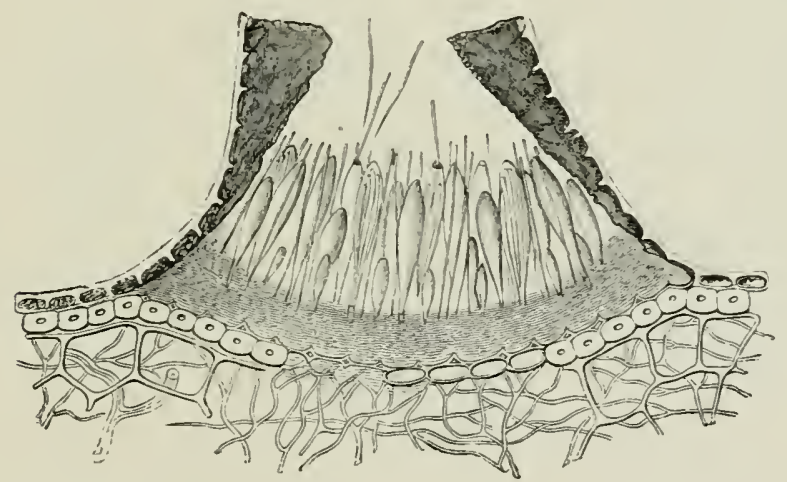

FiG. 122.-Lophodernivm macrosporvm. Section through a mature debiscing apothecium. (After R. Hartig.)

summer, reaching maturity on two-year-old needles. Again, the needles of the two-year-old shoots become brown in autumn, and perithecia appear on them in the following summer,

\footnotetext{
'Preventive measures are discussed in greater detail in Prof. Somerville's translation of Hartig's Diseases of Trees, p. 115.

${ }^{2}$ R. Hartig, Wichtige Krankleiten d. Waldböume, 1574.
} 
ripening in the spring of the fourth year. Or, again, a "casting" of brown one-ycar-old neculles nuly take place in antumm.

The disease is found everywhere, but in some parts (e.\%. in the forests of Saxony ${ }^{\mathbf{1}}$ ), it is exceedingly common and very dangerous. The apothecia are developed as long, shining, black swellings on the two under surfaces of the quadrangular needles (Fig. 121). The club-shaperl asci emit

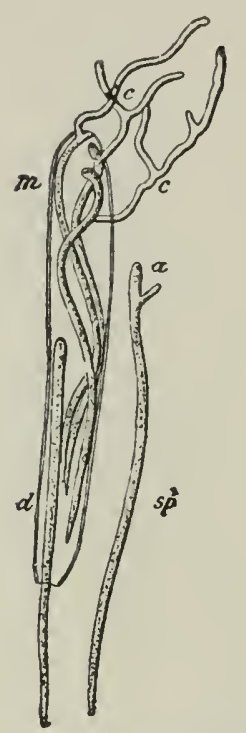

Fic. 123. - Lophoutemium macrosporum on Spruce. Germinated ascosjores ; some have germinated inside the ascus. (After R. Hartig.) thread-like spores with gelatinous coats. The ascospores produce a strong germ-tube, which grows inside the needles to an intercellular mycelium without haustoria. Browning and shrinkage of the cells of attacked needles soon follow. The mycelium also penetrates into the cells of the epidermis, and develops there a coil of hyphae, which, under a black membranous cover, forms an apothecium containing paraphyses and club-shaped asci (Fig. 122). When ripe, the apothecia rupture the overlying epidermis. Little black pycuidia (spermogonia) may also occur on diseased needles. ${ }^{2}$ On needles which have been prematurely cast, only little spherical apothecial knobs will be foumd.

According to Hartig, the effects of this fungus on the cells of attacked needles is very interesting. If the disease of the needles appears in autumn, the cells, which at this time are roid of starch, become brown and die. If the disease attacks in May, when the neelles are rich in starch, their death ensues soon, but the starch only disappears gradually from October onwards, as it is used up by the fungus-hyphae. If the disease appears in spring, when starch-storage is just beginning, the cells already attacked become quite full of starch, whereas the other cells of the same needle remain empty.

${ }^{1}$ Nobbe, Ber. l. sächsisches Forstereins Versammlung zu Schandan, 1891.

'Another ascomycetous fungus-Natria piniperda Rehm-occurs alone or together with this species; Pehm regards it as parasitic (Hedwigia, 1892, p. 302). 
Lophodermium nervisequium (D. C.) ${ }^{1} \quad$ (U.S. America). This very common fungus attacks both old and young silver firs. The needles die after becoming brown, and remain for a long

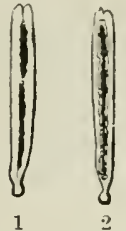

FIG. 124.-Lophoclermium nevvisequium on Abits pectinata (Silver Fir). 1, Under surface of needle with apothecia. 2 Upper surface with pJcnidia.

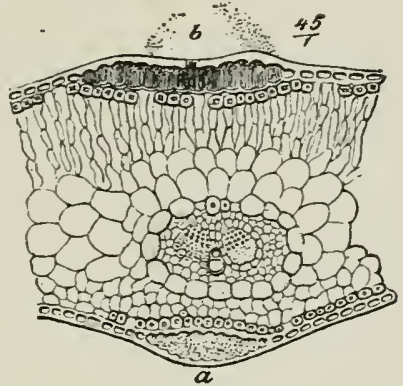

FIG. 125.-Lophodermium nerisequium. Section of a needle of Silver Fir, b, Pycnidium an upper surface shedding conidia. $a$, Apothecium on the lower surface. (After R. Hartig.)

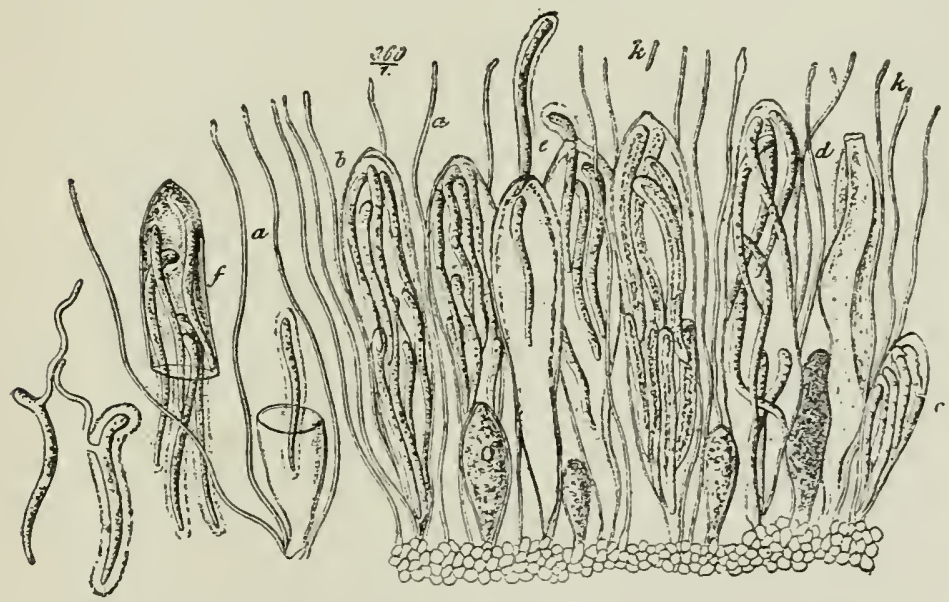

Fig. 126.-Lophodeminim nerrisequizm on Silver Fir. Portion of a ripe apothecium. $\quad a$, Filameutous paraphyses; rod-like cells (conidia?), $k$, abjointed from the apex of the paraphyses; the asci contain eight spores about half as long as the ascus itself, four occupying the upper half, four the lower; $c$, a ruditaeutary ascus; some mature spores possess a gelatínous coat, others do not; spores escape by an apical opening, $e$, or by rupture of the ascus, $f$; two germinating spores are also shown, one with a gelatinous coat, the other without. (After R. Hartig.)

time hanging on the twigs. The disease varies in its development on the mountains and lowlands, according to climatic conditions.

${ }^{1}$ R. Hartig, Wichtige Krankheiten, 1874. 
The mycelium lives intercellular, and produces the same effects on the cells of the fir-needles as those of Loph. macrosporum on the spruce. The mycelial hyphae penetrate into the epidermal cells and form a cushion, which bursts the epidermis and gives rise to numerous straight conidiophores, with very small, oval, unicellular conidia. The apothecia are developed while the needles are on the tree or after they have fallen; they form shining black stripes on the middle nerve of the lower surface of the needle (Fig. 124). The thread-like spores have a mucilaginous coat, and are ejaculated from club-shaperl asci (Fig. 126). Pycnidia (spermogonia) are often produced before the apothecia as long wavy bands on the middle nerve of the upper surface of the needle (Fig. 125).

L. juniperinum (Fries.) (Britain and U.S. America). A common species on dead needles of Juniper communis, also on needles on the branch: I have, however, never seen it in such mass as to believe it to be a dangerons parasite.

L. gilvum Rostrup ${ }^{1}$ attacks and kills living needles of the Austrian black pine.

L. laricinum Iuby. The pycnidia and apothecia of this fungus are common on dead needles of larch, but parasitism has not been proved.

L. abietis Rostr. A species found by Rostrup on needles of spruce, causing yellow spots and then large black points (Fig. $121,2)$.

\section{DISCOM YCETES.}

The Discomycetes have an apothecium of varying shape, but always more saucer-like than spherical. The ascocarp, at first a closed structure, opens sooner or later and exposes the hymenium. The apothecium is composed of two distinct portions of mycelium. The essential part, often called the hymenial layer, consists of hyphae which give rise to the asci. The remaining portion of the ascocarp forms a support or envelope for the hymenium; it consists of a pseudoparenchyma, and may be differentiated into a sub-hymenial layer or hypotheciun with its hyphae interworen with those of the hymenium, and a lateral portion or excipulum usually more or less cup-shaped.

${ }^{1}$ Rostrup, Fortsatte Undersoegflser, 1583. 
The paraphyses are developed from the inycelium of the envelope and occupy the interior of the ascocarp, while the asci arise later from the ascogenous hyphae and force their way in. The formation of asci and paraphyses may go on for a long time. Periphyses are not produced.

The Discomycetes include five divisions, the Phacidiacene, Stietideae, Tryblidieae, Dermateaceac, and Pezizene. Many of the species included in these are parasitic on cryptogamic plants to form lichens, the majority are saprophytes, and only a few isolated groups are true parasites on higher plants. The latter belong to the Phucidicuecue, Dermatececue, and Pezizeae.

\section{(1) PHACIDIACEAE}

The apothecia are black and thick-walled, at first emhedded in their substratum, but later breaking through it. The ascogenous layer is spread out on a delicate flat hypothecium. The black apothecia of the species of Phacidium are frequent on leaves and needles. Rehm divides the group into two fanilies: the Euphacidieae and the Pseudophacidicae.

\section{EUPHACIDIEAE.}

The apothecia are embedded in the tissues of the host; the superincumbent layers of the substratum forming over them a blackish membranous plate, which is ruptured into lobes and exposes the black apothecial disc.

\section{Phacidium.}

The apothecia are fused with the superincumbent layers of the host-plant, and the black cover so formed is split into several lobes. The club-shaped asci contain eight colourless, unicellular, ovoid or spindle-shaped spores. The paraphyses are filamentous. The pore of the ascus is coloured blue by iodine.

Phacidium repandum Fr. (Britain). Occurs on living leaves and stems of Asperula odorata, Galium mollugo, and other Rubiaceae. The pyenidial form is probably Phyllachora punetiformis Fr. 


\section{Schizothyrium.}

The roundish or olulong apothecia dehisce by lobes. The elubshaped asci contain oblong, hyaline, two-celled spores.

Sch. ptarmicae Desm. (Britain). This occurs as a parusite on living green leaves and stems of Achilleu Ptarmicu. The apothecia form little black points, which on rupturing break

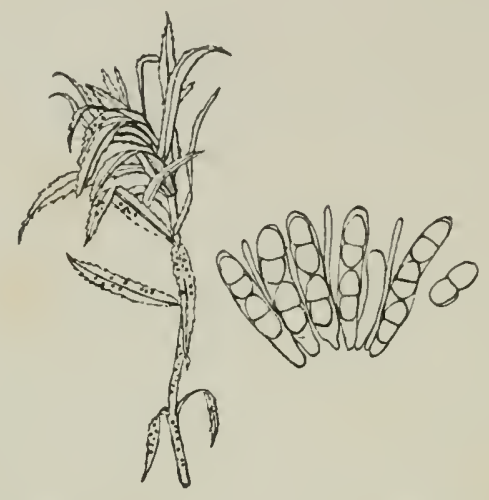

Fic. 12\%.-Schizothyrium ptamicae on Achillec Ptarnica. (v. Tubeuf del.)

up the epidernis into lobes. The thick asci contain two to four large two-celled spores. Paraphyses are present. A pycnidial form is known as Leptothyrium ptarmicae (Sacc.).

\section{Rhytisma.}

The fungi of this genus live in the tissues of living plants and form sclerotial cushions as isolated black spots. In these places the pyenidia are developed, and are followed by apothecia after the death of the leaves. The apothecia open by a fissure, and contain threal-like paraphyses and club-shaped asci with eight needle-shaped spores, which are septate when mature.

Rhytisma acerinum (Pers.) (Britain and U.S. America). Towards the close of summer, the large black spots caused by this fungus on leaves of various species of Acer (sycamore and maple) are by no means uncommon. Pycnidia (Jelasmin acerinum Lév.), containing little unicellular conidia, are first produced under the cuticle, while the epidermis and underlying cells become filled with mycelium till a black sclerotium 
is completed. In the following spring, the sclerotium-spots on the fallen leaves have become thicker and superficially wrinkled. At this stage the apothecia are produced, and dehisce by fine elongated fissures; they contain club-shaped asci and thread-like paraphyses with hooked ends. The threadlike ascospores are ejaculated with considerable force, and reach

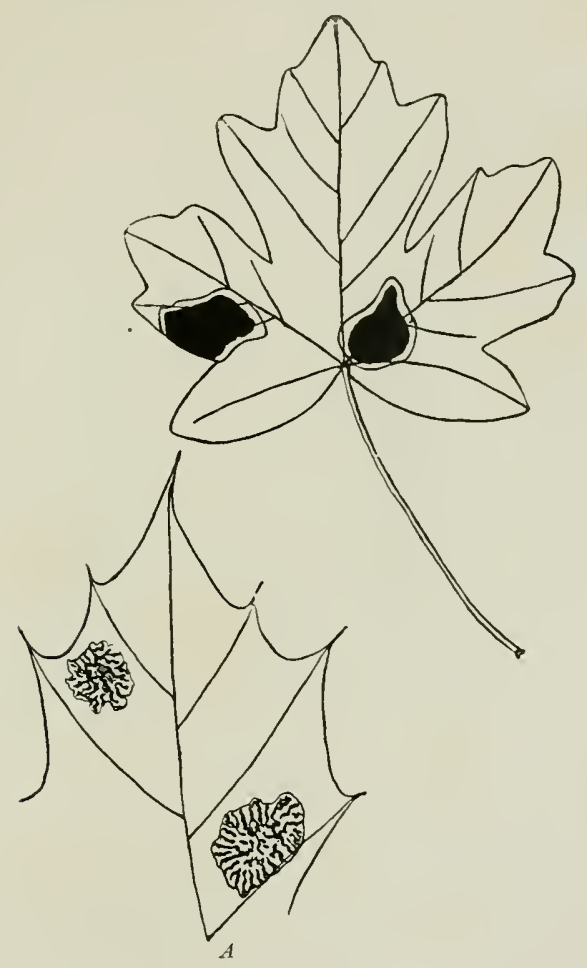

FIG, 12S, - Rhytisma acerinum. Two apothecial cushions on leaf of Acer ccmpestre in first summer. $A$, Leaf-apex of $A c e r$ platanoides with the mature apothecial cushions as seen in the second summer, with their characteristic wavy marking. (v. Tubeuf del.)

maturity in May or June. According to Klebahn, ${ }^{1}$ the spores have a mucilaginous membrane, but this does not throw much light on the problem of how they reach the leaves of trees; wind, however, would seem to be the agent for distribution. In three weeks after infection, leaves show yellow spots; in eight weeks the pycnidia appear.

${ }^{1}$ Botan. Centralblatt, LviII., 1594, p. 321. 
The disease is best combated by prompt removal of fallen leaves in autumn; where this rule is followed Rhytismu is seldon found (see p. 71).

Rhytisma punctatum (Pers.) (Britain and U.S. America). Whereas the spots of the Rihytisma just considered are large, those of this species seldom exceed a few millimetres. They are

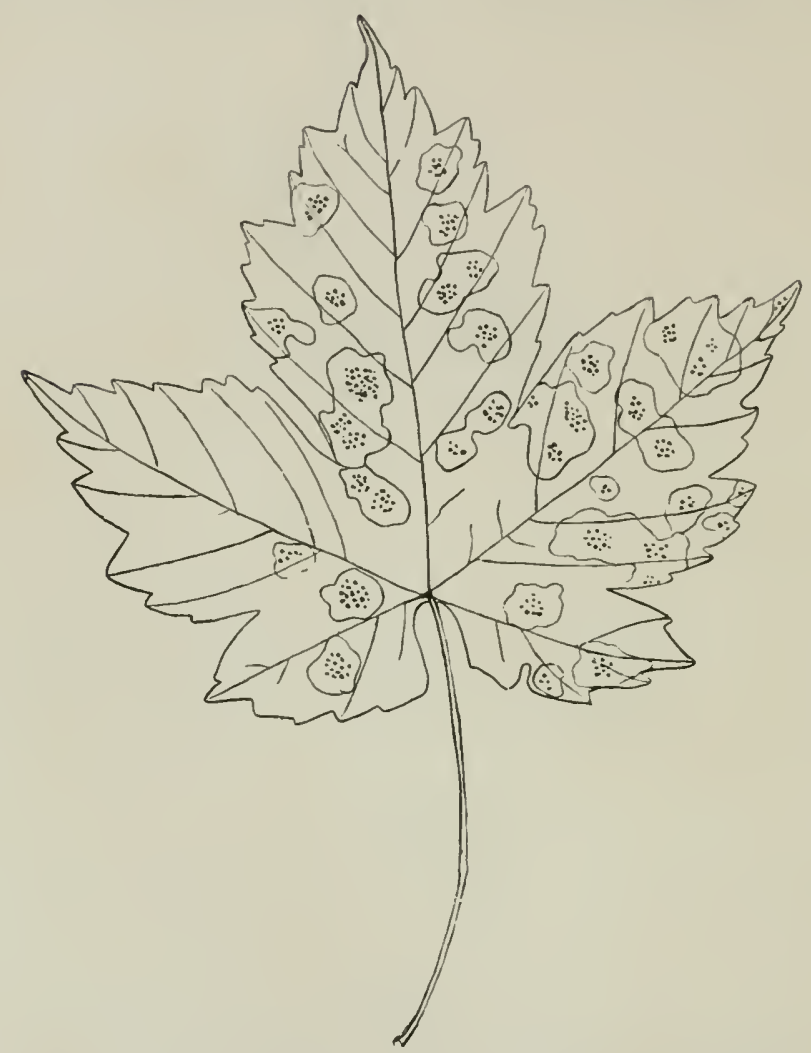

FIG. 129 - Rhytisma punctatum. Leaf of Acer Pseudoplatenus with apothecia ; the leaf is yellow, but the spots enclosing the apothecia are still green. ( $\nabla$. Tubeuf del.)

black in colour, angular, and scattered over the whole leafsurface. After the leaf has turned yellow, portions of it surrounding spots of this Rhytisma retain their green colour, so that we have black spots on green islands in the yellow leaf.

The sclerotia dehisce by valves. The apothecia contain threadlike paraphyses and asci. The asci are club-shaped and contain 
eight needle-shaped unicellular spores; pycnidia (spermogonia) with little unicellular conidia are also formed.

The fungus attacks leaves of sycamore (Accr Pseudoplatanus), the black spots making their appearance in September. The apothecia ripen on the ground during the following summer.

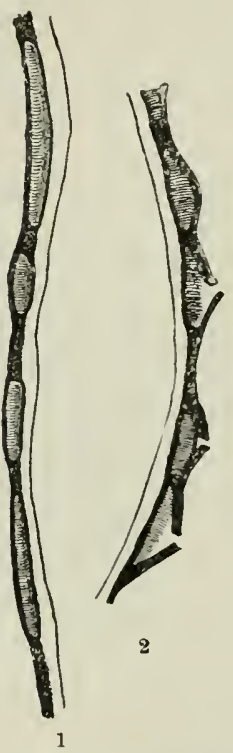

FIG. 130.-Sections of Maple leaves showing the upper epidermis ruptured by 1 , Rhytisma acerinum; 2, Rhytisma punctatum.

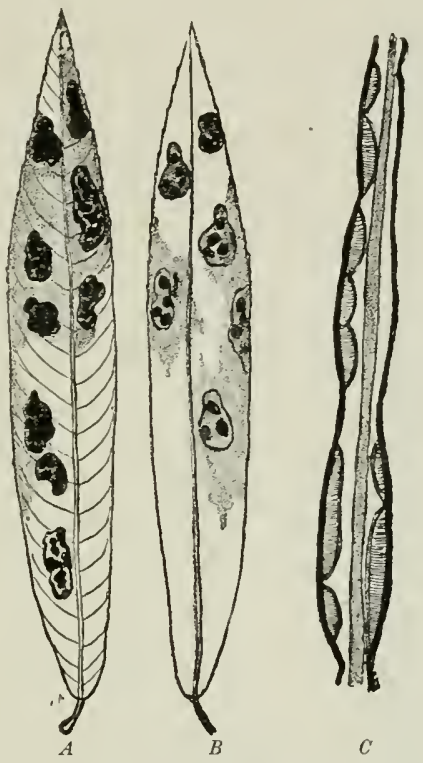

Fıg. 131.-Khytisma symmetricum IIüll. Two leaves of Salix purpurea with stromata. $A$, The upper side. $B$, The lower side. $C$, Longitudinal seetion through the same leaf, showing numerous apothecia on the upper side, fewer on the lower; the shaded middle part represents leaf-tissue, the remainder is the light fungal stroma in which the darker apothecia are embedded. (v. Tubeuf del.)

Rh. salicinum Pers. (Britain and U.S. America). Thickened black wrinkled spots appear frequently on living leaves of various species of willow, e.g. Salix Caprea, S. cinerea, etc., also on some alpine willows, c.g. S. reticulate. These contain apothecia of this fungus, which reach their full maturity during the second summer.

${ }^{1}$ Dyscomycopsis rhytismoides Abiill. Black spots similar to those of Rhytisma appear on the leaves of sycamore. The black crusts are here only subcuticular and enclose a transparent tissue from which large spherical spores are produced. The systematic position of this fungus is unknown. 
Rh. symmetricum J. Miiller ( $R h$, autumnule Schroeter) $)^{2}$ is a form occurring on Sulir merpurec and recently separated as a listinct species. This willow, one of the best for cultivation, may often be seen with its leaves covered with blick spots, and the disease may spread over every tree in a nursery.

The apothecia are found on the upper surface of the leaf, on black, shining, and much wrinkled eushions. In addition, black apothecial cushions are developed on the under surface of the leaf, which is not the case with any other species of lihytisma. According to Schroeter, the spores ripen in autumn on still living leaves.

(This species may be synonymons with Rh, austrule Dur. et Mont. on Salix purpurea in Algeria.)

A species which canses little thick cushions on Salix Caprea has been called Rhytisma umbonatum Hoppe.

Rh. andromedae Pers. occurs on leaves of Andiomedu polifolia. (Britain and U.S. America).

$\mathrm{Rh}$. empetri Fries. on leaves of Empetrum nigrum. (Britain).

$\mathrm{Rh}$. juncicolum Rehm on Juncus Hostii.

Rh. urticae Fr. on stems of Urtica dioica. (Britain and U.S. America).

Rh. bistortae D. C. on Polyyonum viviparum in France, Greenland, and America.

\section{PSEUDOPHACIDIEAE.}

The apothecia are at first embedded in their substratum, under the superincumbent layers of the host-tissue, and form blistered patches; on rupture, this cover forms a rim round the apothecial cushion; the excipula of the apothecia themselves are membranous, generally black, and dehisce by lobes or fissures on the apex.

\section{Cryptomyces.}

The apothecia break out from the substratum as black crusts. The asci contain eight oval, unicellular, colourless spores. The paraphyses are thread-like and septate.

Cryptomyces maximus Fries. ${ }^{2}$ (Britain and United States). This fungus lives parasitic on twigs of various speeies of willow.

'J. Mïller, "Zur Keuntniss 1. Runzelschorfs," Pringsheim's Jahrbuch, 1 s93. Schroeter, Flora $\because$ Schlesien, 1894.

Both appear to be idlentical with Rh. amphigenum Wallr. (Flor. Crypt. II. 412).

2 Tulasne, Selert. fungorum Carpologia, III. 
especially Salix incana, but also on S. purpurea. When the black apothecial cushions break out through the bark, the twigs of the host-plant are frequently still green and leaf-clad.

The apothecia originate in the lower bark and so loosen the epidermal layers as to cause the appearance of yellow spots. Black centres appear in the spots, due to the formation of a

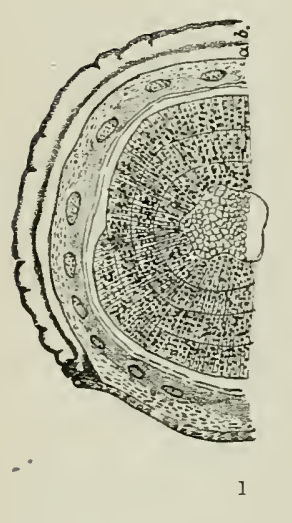

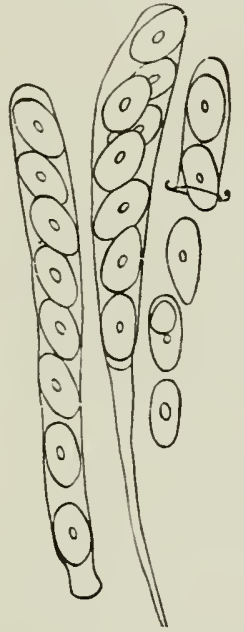

2

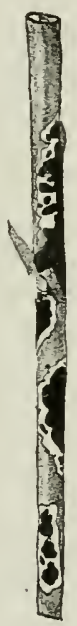

3

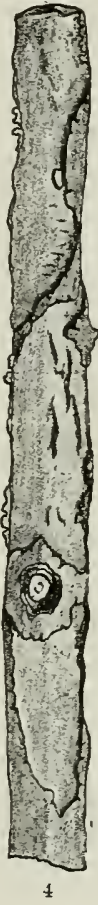

Fig. 132.-Cryptomyces maximus. 1, Cross-section of a twig of Salis incana, with stroma $a b$; the mycelium occupies the rind and bast into the cambium, so that a wood-ring for the current year has been only partially developed; the shaded part between $a$ and $b$ is an aerating tissue, formed of loose hyphae, which, with $a$, forms the stroma proper; $b$, the ascogenous laser. (Lcus-magnification.) 2 , Asei, showing a dry ascus; one to which water has been added, so that it is elongating; one ruptured and ejaculating spores. 3, Yomng stromata in spring, still covered by the epidermis of the Salix. 4 , Willow twig after detachment of the patches of ciyptomyces in autumn. (v. Tubeuf del.)

black apothecial cover underneatl the epidermis. On rupture of the epidermis, black apothecial cushions emerge and cover large areas of the living twigs. Rain causes the apothecia to become gelatinous, and to swell considerably; on drying the cushions roll up and fall off, leaving scars in the bark (Figs. 132, 4). 
A longitudinal section through a cushion exhibits a thick hypothecium, consisting of a close psendoparenchyma of hyaline fungal cells, which permeate every tissue of the bark and cause death of the canbium; above this comes a looser layer with many air-spaces, and over this the layer from which the asci and paraphyses arise.

The asci contain eight oval unicellular spores with distinct cell-nuclei. When a section is placed in water, a very evident swelling takes place, and the asci elongate to twice their original length. I liave not observed ejaculation of spores, but rupture of the asci occurs in water-preparations and the spores are set free in large numbers. The spores probably germinate and infect young shoots, the inycelium hibernating there.

The effects of this fungus are death of diseased twigs of willow above the spot where a sporogenous eushion is formed.

This species is also said to frequent Cormus in America.

Cryptomyces pteridis (Rebent.) occurs on fronds of Pteris: aquilina, but whether a parasite or not is as yet uninvestigated. The asci ripen after the fronds have passed through the winter. To this belongs the conidial form F'usidium pteridis Rabh.

\section{Clithris.}

The apothecia, at first spherical, become oblong, and break through the superincumbent layers by a lobed fissure. The apothecial dise is oblong and flat. The club-shaped asei contain eight hyaline spindle-shaped or thread-like spores, with one or more cells. The paraphyses are thread-like. The majority of this group are saprophytes.

Clithris (Colpoma) quercina (Pers.) (Britain). According to Schroeter, this causes disease and death of living branches of oak. The oblong apothecial discs are greyish-white, and covered at first by a brownish-grey wall which, later, becomes ruptured. The ascospores are simple. Cylindrical pycnidia, with somewhat bent conidia, are also produced.

Cl. juniperi (Karst.) occurs on living twigs of juniper. Nothing is known of its parasitism.

${ }^{1}$ Schroeter, Pilze Schlesiens, IS93. 


\section{Dothiora.}

The spherical apothecia are embedded in the substratum, which they rupture into lobes, while they themselves dehisce by irregular fissures. The club-shaped asci contain eight colourless or yellow, club-shaped or spindle-shaped, multicellular spores. Paraphyses are never present.

Dothiora sphaeroides (Pers.) is regarded by liostrup as the cause of a disease of the Lombardy poplar (Populus pyremidalis), in which the branches, particularly those of the upper part of the tree, die one after another till all are gone. The spores are club-shaped and constricted at the middle; each half is divided by four or five cross-septa, and each cell so formed is again subdivided by a longitudinal septum.

Vuillemin ascribes the same disease to Didlymosphureriu populina Vuill. (see p. 218).

According to Rehm, Do. spltacroides also oceurs on Populus tremula, and is distinguishable from Do. mutila (Fr.) on both Populus italiea and P. tremula.

\section{Heterosphaeria.}

The spherical apothecia are at first embedded, but later emerge through the covering layers and dehisce, their apices breaking up into teeth-like lobes: they are dark-brown or black in colour. The asci are club-shaped and contain eight spores, which are colourless, oblong or club-shaperl, and consist of one, two, or four cells. Iodine colours the pores of the asci blue. The paraphyses are colourless and thread-like.

Heterosphaeria Patella (Tode). (Britain and U.S. America.) The asci contain eight bicellular spores. The paraphyses are thread-like and septate, some being forked or branched; they bear scalpel-shaped conidia.

The mature apothecia are found chiefly on the stems of various Umbelliferue, e.g. Daucus Carota, Anethum grareolens, Petroselinum sativum, Pastinaca, etc. A variety alpestris occurs amongst the mountains on Herceleum Sphondylium, also on Gentiana lutea, Veratrum viride, etc. liehm and others believe that the fungus attacks living green parts of plants, and reaches maturity in the following year on the killed organs. 


\section{Scleroderris.}

A black stroma is formed in the lark of twigs attacked by this fungus, and thence the apothecia break out in great numbers, at first as closed spheres, later as stalked open cups with finely lobed rims. The asci are cylindrical or club-
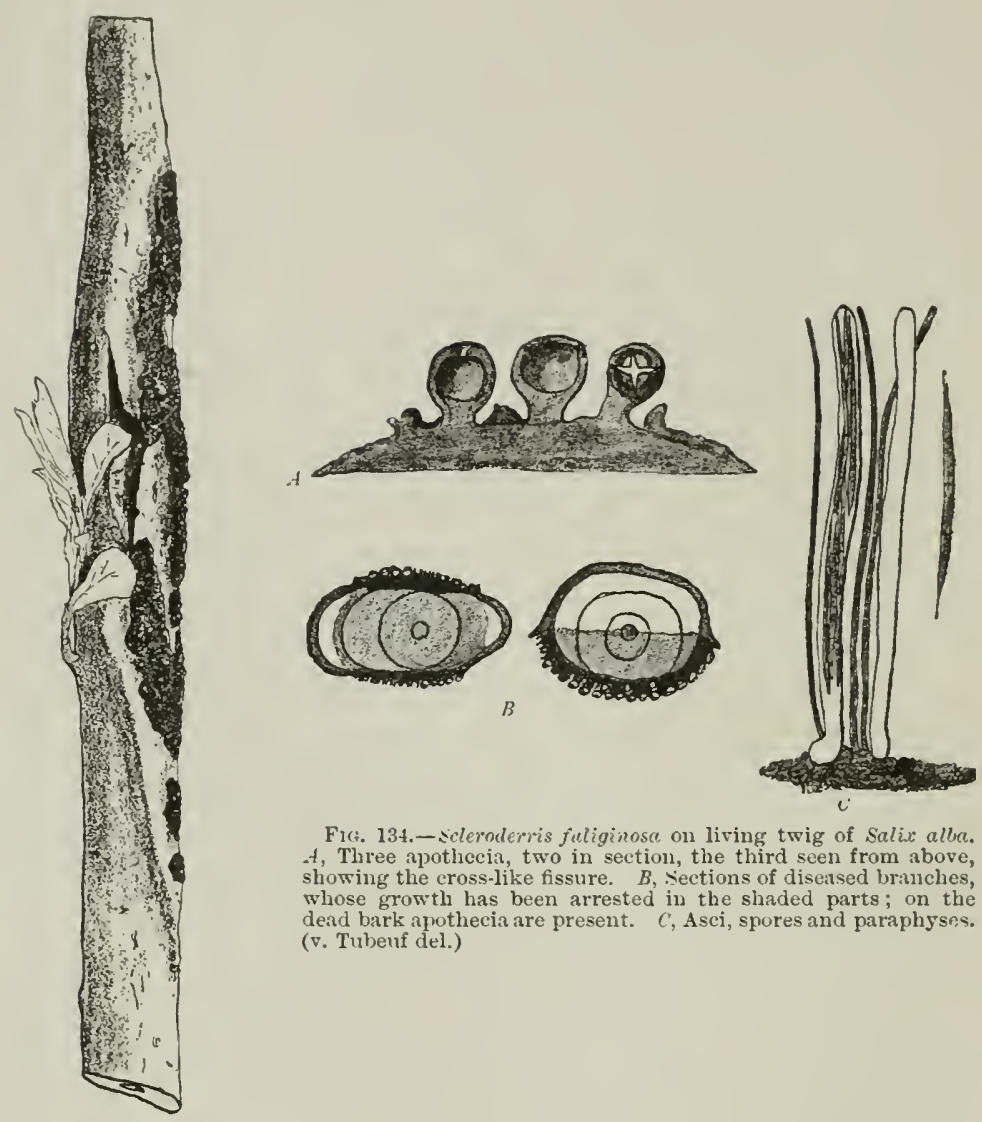

FIG. 134.-scleroderris fuliginose on living twig of Salix alba. 4 Three apothecia, two in section, the third seen from above, showing the cross-like fissure. $B$, Sections of disensed branches, whose growtl has been arrested in the shaded parts; on the dead bark apothecia are present. $C$, Asci, spores and paraphyses. (v. Tubeuf del.)

Fuc. 133.--Scleroclerris fuliainose on living twig of Salix Caprece. (v. Tubeuf del.)

shaped, and contain eight colourless spores which are clubshaped, needle-shaped, or thread-like, and divided by septa into four to eight cells. The pores of the asci are coloured blue by iodine. The paraphyses are thread-like. 
Scleroderris fuliginosa (Fries). (Britain and U.S. America.) This was considered to be a saprophyte till my attention was directed to its injurious nature. It accurs on living branches of Salix C'aprea, S. triandra, S. albe, etc., and brings about their death. The black crusts, on which the apothecia develop, appear both on weakly twigs and strong branches. The mycelium makes its way through the tissues to the cambium, which it kills, cansing this and neighbouring parts to become brown. Adjacent parts, as yet unattacked, continue at first to grow in thickness, but they ton are gradually killed. As a result, the twigs attacked grow irregularly according to the extent and number of diseased places (Fig. 134); and when all or most of the lower tissues of a twig are killed, the higher parts die off with their leares. Wherever the fungus appears, many trees are generally attacked.

Sc. aggregata (Lasch.) develops on the living stems of Rhinanthaceae and matures on the dead.

Sc. ribesia (Pers.) is a common species on twigs of red and black currant, but whether parasitic or not is mknown.

\section{(2) DERMATEACEAE.}

The apothecia are developed at first either under the substratum or altogether superficially. The ascogenous layer extends over a thick hypothecium.

The Dermateaceae contain the Cenangiece, Dermatrae, Patellariacece, and Bulgariaceue.

\section{CENANGIEAE.}

Apothecia at first embedded, then exposed. They are sessile, clavate or cone-shaped, and broaden out to dises on opening.

\section{Cenangium.}

Apothecia globose; on dehiscence at first cup-shaped, but afterwards flatter and more saucer-shaped, with entire margins; they may occur singly or massed together. The club-shaped asci contain eight colourless, oblong, unicellular spores, and filamentous paraphyses with thickened apices.

Cenangium abietis (Pers.). (Britain and U.S. Americn.) This fungus is usually a saprophyte, but Thïmen suggests it as an 
occasional parasite. Schwarz ${ }^{1}$ has recently described it as attacking pines, weakened by an imporerished water supply to the twigs and by other unfarouralule conditions. It appearerl for at time as an epidemic in the pine forests of Germany, but very soon disappeared again.

The symptoms of disease were, withering of twigs in spring from the apex downwards into the region several years old. The epidemic harl been previonsly noticed in the spring of 1892 , and was described by Hartig, who, along with Kienitz, regarded it as a result of the long dry preceding winter. The disease has never been observed on pines uncler five years old, and serious injury only results when the fungus is accompanierl by damage done by insects. The apothecia containing the asci are generally produced only on dend twigs and needles.

Sichwarz regarls as a conidial form of this species, brunchorstiu destruens Erikss., which will be described in greater detail amongst the "Fungi imperfecti." In addition to Brunchorstic, other pycnidia with unicellular conidia occur.

\section{DERMATEAE.}

The apothecia, at first spherical and embedded in their host, break out in clumps; they are generally short and thick-stalked, and open to form a roundish sancer-shaped disc with an unbroken rim. The hypothecium is thick and often colomred.

\section{Dermatella.}

A stroma is developed under the bark of the attacked parts of the host, and in it originate dark brown apothecin with short thick stalks. The lork is ruptured and the apothecia emerge as flat, expanded, saucer-shaped dises with a complete rim. The asci are club-shaped and thick-walled. The spores, at first unicellular, later multicellular, are large and colourless or brownish. The paraphyses are septate and generally forked: they often form a coloured epithecium.

Dermatella prunastri (Pers.) (Britain and U.S. America). According to Ludwig, this lives as a parasite on the living bark of plums, apricot, sloe, and other species of Prunus.

1Schwarz, Die Erkrankun! d. Kiejem durch Cenangium abietis, Jena, 1595. 
Apothecia and pycnidia (Sphacronema spurium Fr.) are both developed. The ascospores are one-celled and hyaline.

[Wagner ${ }^{1}$ adds the following species found by him in Saxony as more or less marked parasites: (Edit.)

Dermatea (Pezicula) cinnamomea (Pers.) on (nuercus. It attacks the rind in places injured by deer, and canses injury to the trees.

D. (Pez.) carpinea (Pejs.) kills many young hormbeans; it probably obtains entrance through wounds.

D. (Pez.) acerina Karst. is a doubtful parasite on Acer Pseudoplatanus.]

\section{BULGARIACEAE.}

Bulgaria polymorpha Wett. (B. inquinans Fr.) (Britain and U.S. America). A dangerons enemy of the oak, ${ }^{2}$ cansing death. Researches into its parasitism are still wanting. The sporocarps develop on dead bark, especially of beech.

(3) PEZIZEAE.

The apothecia are never embedcled, but appear as saucer- or cup-like structures on the substratum; they are fleshy or waxy, and often of bright colour. The hypothecium is very strongly developed.

The families included in this group are: Nollisiece, Heloticae, Eupezizece, and Ascobolece. Of these, all except the last contain parasitic forms. The Mollisicce and Heloticue contain also a number of lichen-fungi not considered of sufficient practical value to be inchuded here. The Ascoboleac live as saprophytes on animal droppings.

\section{MOLLISIEAE.}

The apothecia generally sit free throughout their whole existence on a close, firm substratum of hyphal tissue, or they may be sunk in the host and break out later; they are at first closed and spherical (rarely tapering downwards), but afterwards open and expose a cup-like, saucer-shaped, or flat dise of asei. The disc is waxy and soft; externally it is brownish and generally smooth; exceptionally it may be downy or beset with short hairs or bristles. The sporocarps are brown and com-

${ }^{1}$ Zeitsch. f. Pflanenkrankheiten, 1896, p. 76.

${ }^{2}$ Ludwig, Centralblatt $f$. Bacteriologie u. Parasitenkunde; also, Lehrbuch $d$. niederer Kryptogamen. 
posed of pseudoparenchyma, which, towards the mitrons, beeomes more elongated and prosenchymatous. Hypothecium generally poorly ileveloperl.

\section{Mollisia.}

The sessile brownish apothecia on opening generally exhibit a that, sancer-shaped, transparent stratum of asei. The spores are unicellular, lyyaline, and spindle-shaped or club-like. The paraphyses are liyaline or coloured, sometimes forkerl.

Mollisia Morthieri (Sacc.). The apothecia are developed on yellow spots of the lower epidermis of living leaves of Rubus Schlcicheri and $R$. finticosus. The young apothecia are reddishbrown and spherical; when open they form yellowish-brown lises with very delicate margins. The asci contain eight spores, arranged in two rows. The spores are unicellular, cluibshaped, and colourless. The paraphyses are colourless or brownish, with slightly bent points.

\section{Niptera.}

Apothecia as in Mollisin. The spores, however, on completing their development are two-celled.

Niptera hypogaea (Bres.). ${ }^{1}$ Found by Bresadola in Southern Tyrol, underground on the roots of Adenostyles albifrons. The apothecia are massed together on brown hyphae in blackened parts of the host-roots. The ascogenous dise is greyish-brown or whitish, with fine fibrous margins. The asci are spindleshaped, and contain eight spindle-shaped colourless spores, which are at first one-celled, later two-celled. The septate colourless paraphyses are forked.

\section{Pseudopeziza.}

The nembers of this genus live as parasites in the leaftissue of higher plants and produce dead brown spots, in which the ascocarps are afterwards developed. The apothecia have delicate walls, and, after rupturing the epidermis, emerge as delicately-coloured saucer-like hymenial discs. The clubshaped asci contain eight spores, arranged in two rows. The

${ }^{1}$ Bresarlola, Fungi trident, A. Lxxr., Fig. 1. 
spores are ovoid or elliptical, colourless, and unicellular. The colourless paraphyses have thickened apices, rarely forked.

Pseudopeziza (Phacidium) trifolii (Bernh.). Leaf-spot disease of the clover. This disease appears on the leaves of various species of clover in Europe and America; its attacks may attain considerable sererity, and inflict great injury to crops. The leaves become spotted, and finally die off. The apothecia occupy brownish-yellow dises on the surface of the leaf, and hence are not unlike pustules of a Puccinia. The asci are club-shaped, and contain eight ovoid, unicellular, colourless spores. The paraphyses have broadened apices, rarely forked. A conidial form (Sphaeronema phacitioides Desm.) is generally allocated to this species.

Ps. trifolii (var: medicaginis) (Lib.) is found on species of Medicago (Britain and U.S. America).

Ps. bistortae (Lib.). This occurs on the lower epidermis of living leaves of Polygonum Bistorta, and P. viciparum, cansing dark-brown swollen spots where the apothecia are developed. Juel ${ }^{1}$ has transferred this species to the Phacidiaceae, and namerl it Pseudorhytismo bistortue (D. C.).

Ps. alismatis (Phill. et Trail) causes spots on leaves of Alisma Plantrago (Britain).

\section{Fabraea.}

This genus is distinguished from Pseudope:iza by the spores, which, though at first unicellular, become two or four-celled. The species are parasitic in the leaf-tissue of higher plants.

Fabraea astrantiae (Ces.). The mycelium lives in the leafparenchyma of Astiantia major and A. camiolica, causing dead spots. A form occurs on Senicula europaea.

F. ranunculi (Fries.) (Britain). The apothecia of this are very common on brown spots on the leaves of various species of Ranunculus.

F. cerastiorum (Wallr.) frequents leaves of Cerastium (Britain).

F. Rousseauana (Sacc. et Bomm.) occurs on leaves of Caltha pulustris. (A British species if synonymous with Pseudopeziza calthae Mass.).

\section{Beloniella.}

The gregarious apothecia are at first embedded, but break out later. Externally the apothecial dises are rough, dark brown,

${ }^{1}$ Nykol. Beitr. I'etensk.-Akad., 1894. 
and striped, the margin being fibrous. The asci contain four to eight spores. The spores are generally ovoid or spindleshaped, at first unicellular, but dividerl later into two to four cells by means of cross walls. The colourless paraphyses have thickened club-like apices.

Belionella Dehnii (Kabl..). ${ }^{1}$ This parasite covers stems and leaves of Potentilla nuregica, and is distinguished by its sharp, spindle-shaped, bicellular spores.

\section{HELOTIEAE.}

The apothecia are generally quite superficial; less commonly they are at first embedded, and emerge later; or they may levelop from a sclerotiun. In form they are spherical, cupshaped, or top-shaped, and a stalk of some kind is generally present. On opening, they form a cup or flat plate, on which the hymenium lies exposed; the cup is soft or waxy, and enclosed in a delicate wall, which is externally either smooth or hairy. The sporocarps consist of a pseudoprosenchyma (after Rehm).

\section{Sclerotinia.}

The sclerotia ${ }^{2}$ give rise to smooth-stalked ascocarps with the form of beakers, funnels, or saucers. The stalks often produce rhizoids. The asci eontain eight unieellular hyaline spores, elliptical or spindle-shaped, and of equal or unequal sizes. The paraphyses are thread-like. In several families conidia are formed before the sclerotia. Some forms are heteroecions. Most of the species are parasitic on plants.

\section{The Sclerotium diseases of the Vaccinieae. ${ }^{3}$}

These are a well-known group of sclerotium diseases, and amongst them the following have been named as species.

Sclerotinia vaccinii Wor. (Scl. Urnula Weinm.). The sclerotium disease of the cowberry. The young shoots and

${ }^{1}$ Figures in Hedrigia, 1581.

"Literature: De Bary, "Uebereinige Sclerotien ". Sclerotienkrankheiten," Botan. Zeitung, 1S56; also Morphology and Biolony of the Fungi, English edition.

Brefeld, Schimmelpilze, Heft. Ir. n. x., and Botun. Zeitung, 1876.

Saccardo, Sylloge, Vol. vin.

${ }^{3}$ Woronin, Mém. de l'academ. impér. d. sci. d. St. Petersburg, vir. Ser., t. 36, 18sS (with ten plates); also Berichte d. deutsch. botan. Ges., 189t. 
leaves of Vaccinium Vitis-Idaed exhibit in spring a mouldlike coating, consisting of chains of lemon-shaped conidia.

Woronin thus describes it: "In the outer layers of the cortex, amongst the dying elements, a pseudoparenchymatous cushion is formed, from which simple or dichotomously branched hyphae grow out through the overlying cuticle. The individual members of the chains of conidia are separated from one another by a spindle-shaped piece of cellulose-' the disjunctor."

The disjunctor spoken of here is a spindle-shaped cellulose body found between the single conidia; it easily breaks across and so facilitates the breaking up of the chains of conidia

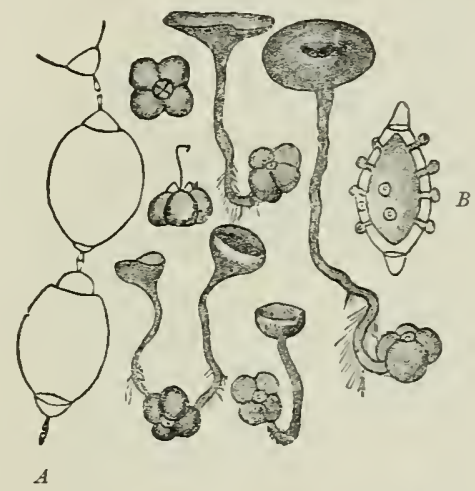

Fut. 135.-Sclerotinia raccinii on Vaccinium Vitis-Idaea. Mummified Cowberries iu fresh condition and in the following Ilas, after development of Peziza-cups. $A$, Chain of conidia united by disjunctors. $B$, Germinating conidium after treatment with iodine; the plasma has shrunk, but remains connected with the sporidia in process of abjunction. (After Woronin.)

(Fig. 135). It has its origin as follows: The conidia at first lie closely end to end, enclosed in a delicate primary membrane; the partition-membranes split into two lamellae, each of which takes part in the formation of a cellulose body which gradually becomes spindle-shaped. In the course of its growth this cellulose body - the disjunctor-ruptures the primary enclosing membrane, and, being released, becomes more elongated, so that the conidia are pushed away from each other and fall apart.

The conidia have a strong characteristic odour of almonds, attractive to insects, which carry off the conidia and dust them on the stigmata of other Vaccinium flowers. Wind is also, in all probability, an agent in the distribution of the consdia. The 
conidia germinate and give off" long septate hyphae which, following the course of the pollen-tuhe, reach the ovary, and soon fill all four loculi with a white myeelium. The growth of this mycelium proceeds from the central axis towards the walls, and forms a hollow sphere open above and below. The diseased berries cannot be distinguished till ripe; then, whereas the normal are red, the diseased are yellowish-brown to chestnutcolourecl, and soon slrink up, leaving only the outline of the sclerotiun.

The dead or mummified berries fall prematurely, and lie over winter on the earth. In April or May, the sclerotia give rise

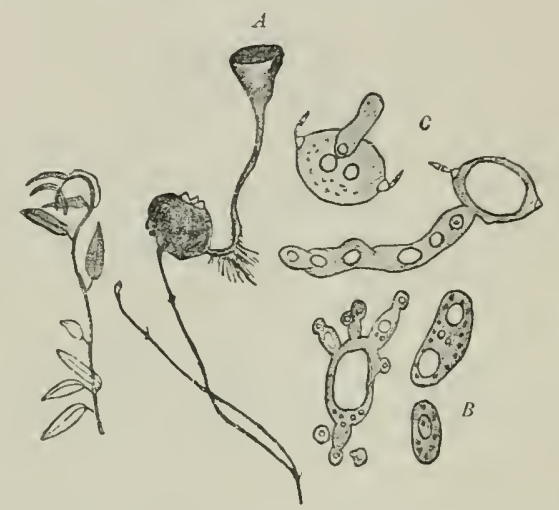

FIt. 13it,-Sclerotinia oxycocei on Vaccinirm oxycoccus. Toung shoot of Cranberry with mature conidial cushion and diseased upper leaves. $A, p_{e s i z a-c u p}$ developed from a sclerotial fruit: numerous rlizoids procecd from the base of the stalk. $B$, Ascospores in stages of germination. C. Conidia in gemination, with remains of disjunctors still attached. (After Woronin.)

to several primordia or horn-like stalks, on the extremity of which an apothecium is afterwards formed. Phizoids are produced at the base of the stalk and attaching themselves to the ground act as supports and organs of nutrition. The apothecia contain both asci and paraphyses; the latter are septate, dichotomously branched filaments, with club-shaped ends, and coated with a brown resinous substance. The asci have a canal at one end through which are ejaculated eight spores of almost equal size. These produce sporidia in water: in mutritive solutions, however, they form a septate mycelium with conidia. The ascospores bring about infection by means of one or two germ-tubes which penetrate the outer membranes of young 
cowberry shoots, the stomata being always avoided. In less than three weeks conidia are prodnced.

The mode in which the germ-tubes attack the host-plant is very remarkable. Woronin says: "The germ-tubes developed from the ascospores grow inwards towards the vascular bundles of the host-plant and enter them; then they contimue to develop, but now in the opposite direction from the interior of the plant towards the periphery. Here a peculiar phenomenon is exhibited, the fungus exerts its injurious effects on the surrounding tissues of the host-plant, then, having killed these, it utilizes

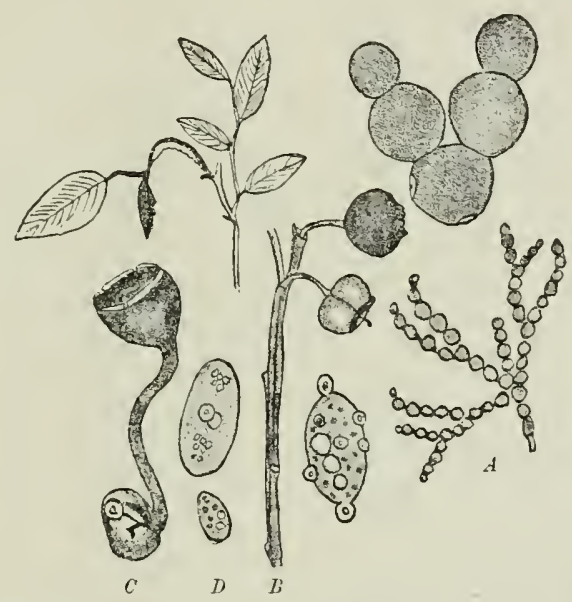

FIG. 137.-Sclerotinia baccarum on Vaccinium Myrtillus. Young shoot of Bilberry with deformed branch bearing white conidial patches on its lower side; also a withered leaf. A, Conidial chains, and a portion enlarged. $B$, shoot with an upper healthy ripe berry and a lower mummified one. C, Pezizu-cup developed from a sclerotium. $D$, Ascospores; the smaller incapable of germination, another germiliating and giving off sporidia. (After Woronin.)

them as food-material." "Finally, the germ-tubes penetrate between the elements of the outer rind already killed, and there develop to a stroma-like mshion of large-celled pseudoparenchyma from which the chains of conidia emerge through the ruptured cuticle."

(Saccardo also mentions Scl. oreophila Sace. on leaves of Traccinium Yitis-Idaca.)

Sclerotinia oxycocci Wor. The sclerotium disease of the true cranberry (Vaccinizm Oxycoccus). The spores of this species are smaller than those of the preceding; each ascus contains four 
larger and four smaller spores, the latter appearing to be rudimentary and incapable of germination.

Scl. baccarum Schroet. ${ }^{1}$ (Britain). ${ }^{2}$ The sclerotium disease of the bilberry (Vucc. Myrtillus). This varies from the other species in having round conidia incapable of germinating in water, in having more robust apothecial beakers, and in lacking rhizoids. The spores are similar in number and arrangement to the preceding species.

Scl. megalospora Wor. The sclerotium disease of the crowberry (Empetrum nigrum). This species is distinguished by the

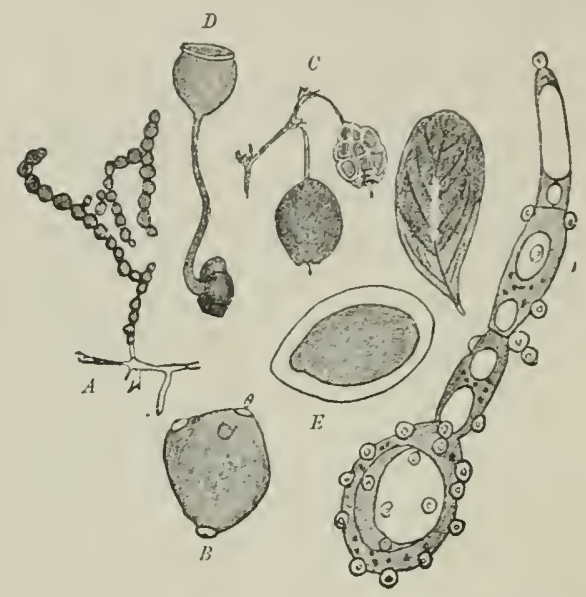

Fif. 138.-Sclerotinia megulosport on Vuccinium uliqunosum. Partially withered leaf with a white conidial cushion on the inid rib. $A$, Conidial chains produced on a mycelium, resulting from an artificial eulture of ascospores in plum.solution. $B$. Isolated conidium with remains of disjunetors still attached. $C$, Twig with upper mummified berry. $E$, Aseospores; one in its gelatinous envelope, the other giving off a germ-tube and sporidia. (After Woronin.)

form of its conidia, and the manner of their germination; in the form of the sclerotium, and the absence of primordia; in the absence of rhizoids; and, particularly, in having large ascospores almost similar to each other.

The "white berries" of the Vacciniaceae are distinct from the mummified berries caused by Sclerotinia. ${ }^{3}$

Scl. aucupariae Ludw. The mummified fruits of Pyrus Aucuparia, resulting from this fungus, were first observed by

I'schroeter, Herlueigia, 1579; Woronin (loc. cit.).

"Sclerotia of this species have been found in Scotland by Professor Traill.

${ }^{3}$ Magmus and Ascherson, Berichte 1 . deutsch. botan. Ges., ISS9; also Zool.. botan. Gies., Vienna, 1591. 
Woronin ${ }^{1}$ in Finland, and later by Ludwig in the Erz mountains. The ascocarp developed from the sclerotia has no rhizoids. The ascospores infect leaves, and there the conidia are produced.

Scl. padi Wor. Causes mumnification of the fruits of Prunus Padus. Woronin regards Monilia Linhartiana Sace. as belonging to this Sclcrotinia.

Woronin also consiclers the conidial form Monitia cinerea as related to the mummified fruits of cherry.

Ovularia nelans on Mespitus is probably also a form of some Sclerotinia.

A Sclerotinia occurring on Cotoneaster nigra produces mummification of the fruit, and forms conidia on the surface.

Monilia fructigenc of the apple, pear, quince, plum, peach, etc., is in all likelihood a form of some Sclerotinia, although the ascus-form is still unknown (see also "Fungi inperfecti").

Scl. betulae Wor. (L.S. America). This sclerotium of the birch-fruit was discovered by and briefly described by Woronin in 1888. Nawaschin ${ }^{2}$ has recently re-investigated it, and named it the "birch-catkin disease." It is found on the green catkins in June. The fruits containing sclerotia are obcordate in shape, instead of the normal elliptical form with both ends acute; the wings are similar to those of healthy seeds. The sclerotium is composed of a very hard white pseudoparenchyma, which passes in the form of a horse-shoe round one side of the apex of the fruit (Fig. 139). The outer layer is black and rery firm. Sclerotia placed on moist, sand produced ascocarps at the beginning of May. Development in the open also takes place about this time. In the birch forests near St. Petersburg this disease is common, and birch-catkins containing sclerotia may be found abundantly amongst fallen leaves about the month of May. From each sclerotium there are produced one or two ascocarps, with rhizoids and stalks of a length varying with the depth of dead leaves on the ground. The apothecia are at first funnel-shaped, but later became saucer-shaped and $1-4 \mathrm{~mm}$. broad, with a golden or fleshy colour. The asci contain eight spores which are forcibly ejaculated, and if a handful of damp birch leaf-mould is thrown up into the air

1 Woronin, Berichte d. deutsch. botan. Ges., 1891; also Mém. de l'acad. imp. d. sci. de St. Petershurg, 1595. With five plates.

¿ Nawaschin, Sclerotinia betulae, Wor. Russian brochure with four coloured plates, 1893. 
a clond of spores so ejected may easily be seen. Infection takes place on the birch flowers. It is possible to promote germination in water and on moistened leaves, but the germtubes soon die.

This disease, on account of the small size of the birch fruit and the tiny sclerotia, remained for a long time quite unobserved, yet it secms to be common everywhere; in Russia it has been found frequently, also in Germany, North America, and Japan. It possesses considerable economic importance, since diseased seeds are no longer capable of germination.
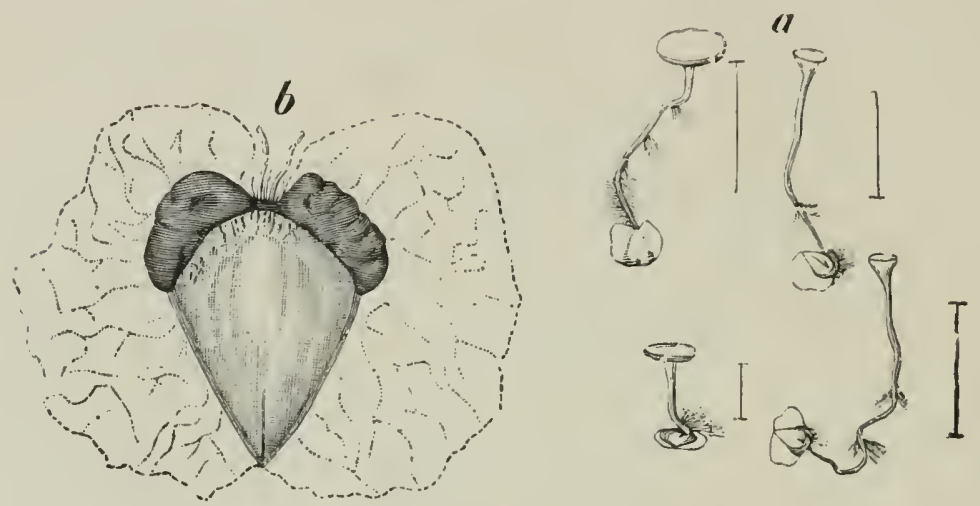

FIG. 139.-Sclcrotinic betulae. "t, Bircli fruits with sclerotia, which have germinated and formed cup-like apothecial discs; rhizoids have developed on the stalks. $b$, Birch fruit, somewhat enlarged, with semilunar sclerotia. (After Nawaschin.)

Hormomyia betulac Wtz. often oceurs along with the above. It canses the production of thick spherical fruits with little or no wing. Sclcrotinice culusta Karst. has also been found on birch leaves in Finland.

Scl. alni Naw. Woronin found this first on catkins of Alnus incenu. Nawaschin has more recently investigated it. ${ }^{1}$

Scl. rhododendri Fischer: ${ }^{2}$ This was first discovered by Fischer in 1891 in fruits of the Alpine-rose (Rhododendron ferrugineum and $R$. hirsutum) in Switzerland. It has since been observed in various parts of Switzerland and the Tyrol.

1Nawaschin, Berichle d. deutsch. botan. Ges., 1S94; Maul, Hedwigia, 1894, p. 213. With two plates.

2 E. Fischer, Nalurforsch. Ges. Bern, 1891 ; also Berirhte r. schueiz. botan. Ges., 1894. With figures. 
Fischer succeeded in obtaining stalked ascocarps from selerotia of one and two years old. They resembled most closely those of Scl. vaccinii, their stalk being provided with numerous rhizoids. The asci contain eight similar spores which germinate directly on ejaculation. They develop a mycelium and, later, chains of chlamydospores which separate by means of disjunctors. The little conidia found by Woronin on Vaccinium are never producerl. The paraphyses are crenerally unbranched and correspond in length to the asci.

The mummified fruits are easiest found after the healthy capsules have dehiscerl, then the diseased ones remain closed. In winter the healthy capsules remain attached to the plant, the diseased fall off. Seeds of diseased capsules are completely overgrown by hyphae.

Wahrlich ${ }^{1}$ found selerotia in capsules of Rhoul. duhuricum. from Siberia. They gave off a selerotial ascocarp with a stalk devoid of rhizoids. The mummified fruits resemble closely those of Scl. rhododendri.

Scl. heteroica Wor. et Naw.=Scl. ledi Naw. ${ }^{2}$ oceurs on Ledum palustre in Russia and Finland. It is very similar to Scl. rhododendri, but is distinguished by the paraphyses being swollen and frequently forked at the end. In nutritive gelatine a copions mycelium is developed, and produces chains of ripe conidia with tiny disjunctors. Woronin found that these conidia are produced only on Vaccinium uliginosum, never on Ladum; but the conidia so formed can successfully infect the ovary of Lodum. We have here the first known case of heteroecism outside the Uredineae.

Scl. sclerotiorum Lib. ${ }^{3}$ (Britain and U.S. America). The sclerotia of this fungus are found in many various plants. They fall to the ground with the dead plants, hibernate under snow, and on the arrival of warmer weather in spring give rise to several stalked apothecia. The ascospores are ejaculated from the asci, germinate, and produce a parasitic mycelium, described thus by De Bary: "The ripe spores of $P c \approx i z a$. sclcrotiorum produce germ-tubes on any moist substratum.

${ }^{1}$ Berichte d. deuts.h. botan. Ges., 189:.

${ }^{2}$ Nawaschin, Berichte d. deutsch. botan. Ges., 1894, p. 117.

${ }^{3}$ Brefeld, Schimmelpilze, IV. and x.; De Bary, Morphology and Biology of the Fungi; and Botan. Zeitung, 1886. 
These develop to strong mycelial threads if they reach any source of nutriment, such as disorganized borlies and particularly dearl plants. On any other substratum the germ-tubes never pass heyond a rudimentary stage. The germ-tules developerl in water eannot make their way into living plants. If, however, grown in suitable nutriment, the nycelial threads are smaller and capable of penetrating as parasites into suitable hosts. This they are able to do because they give off a fluid which enters into and kills living plants. The dead parts of the plants serve as nutriment to the fungus, which makes its way into the tissues and causes death of cells in direct contact or inlmediate neighbourhood. The deadly fluid separated by the fungus contains, as an essential constitnent, an enzyme soluble in acid solutions and capable of dissolving the cell-walls; also a number of imperfectly known organic and inorganic acids and salts, amongst which oxalates can certainly be proverl. The mycelium generally penetrates parts covered only by cuticle or a thin periderm. It does so by hyphal branches which grow into the air till they reach some suitable host; then, stimulated by the pressure, they give off characteristic organs of attachment, which secrete a cell-killing fluid and cause disorganization of the place attacked; they derive nourishment from the products, and give off branches which penetrate into the plant."

Conidia capable of germination are never produced, though rarely tiny spermatia or conidia ineapable of germination are abjointed from the mycelium.

A Botrytis-stage is certainly never present in the life of this species.

Scl. sclerotionum is one of the worst enemies of cultivated plants. De Bary observed total or partial death resulting from it to the following plants: Phascolus velgeris, Petunia nyctayiniflora and P. violeceec, Solenum tuberosum, Zinnie elegens, Helienthus tubcrosus, and Dutucus Carote. It has also been found on species of Bressiea, Beta, Ciehorium, Dehlia, Topinambur, etc., and on seedlings of munerous other dicotyledons. It is thus evident that many and varied plants, lelonging to widely removed families, may serve as hosts; on the other hand the fungus avoids certain plants, and is known to injure species in one locality, which it avoids in another.

De Bary regards a destructive canker on hemp in Russia 
(Pcsiza Kaufmaniana Tichom. $)^{1}$ as related to, or identical with Scl. sclerotionum. Behrens, however, is inclined to ascribe it to Scl. Fuckeliona, which has occasionally a Botrytis-stage. This hemp disease has also been found in Alsace. ${ }^{2}$

Humphrey ${ }^{3}$ regards this species as the cause of a disease of indoor cucumbers; he ascribes a Botrytis-stage to it.

Scl. sclerotionum is best known by the conical funnel-shaped depression in the hymenial disc, not present in other species.

Sclerotinia trifoliorum Eriks ${ }^{4}$ (U.S. America). ${ }^{5}$ Clover is not attacked by the Sclerotinic last considered, but falls an easy prey to this species, which again derives but scanty nourishment from such food as fresh carrots. Scl. trifolion is observed wild only on species of clover, and is there fairly common; many other plants, however, have been artificially infected by it. Host-plants are attacked through their green foliage, which very soon becomes brown and shrivels up. If the atmosphere be sufficiently moist, the mycelium emerges on the exterior and spreads to neighbouring organs or plants. Sclerotia are not often formed superficially as with Scl. sclerotionum, because the mycelium lives principally inside the plant tissues. This mycelium resembles that of Sel. sclerotion in its peculiar property, that successful infection only follows if the fungus has lived for a time saprophytically: on this account direct infection by spores is harmless. In the secretion of an enzyme and of oxalic acid, and in the manner in which it destroys the tissnes of its host-plant, this species behaves like Scl. sclerotionm just described. It is distinguished by its larger ascospores, and the absence of a central funnelshaped depression in the hymenium. Spores germinated in water produce numerous bodies (so-called spermatia) which distinguish the species from Scl. Fuekelianc where this does not take place. Rostrup ${ }^{6}$ found in Denmark that Meciicago lupulina suffered

${ }^{1}$ Tichomiroff, Bull. soc. nat. de Mloscou, 1868.

2 Behrens, "Ueber das Auftreten d. Hanfkrebses im Elsass." Zeitschrift f. Pfanzenkrankheiten, 1891, p. 208; "Trockene u. nasse Fänle d. Tabaks," inlem, 1893, p. 82.

${ }^{3}$ Humphrey, Agric. exper. station Mas., 1892, pp. 212-224.

${ }^{4}$ Kühn, "Die Sklerotienkrankheiten d. Klees." Heduigia, 1870.

Rehm., Entrickelungsgesth. eines d. Klee zerstörenden Pilzes.

${ }^{5}$ Massee (Bvitish Fungn-s-flora, rv., 1895). "There is no eridence of this species having occurred in Britain."

${ }^{6}$ Rostrup, Tidsskrift for Landokonomie, 1890. 
most from this fungus; red clover was less affected, though the disease often had its origin in that species; while white clorer was least often attacked. He recommends keeping ont Medicayo from clover mixtures, and the addition of a large proportion of grass-seeds. Fields badly affected should be kept ont of clover-cultivation for several years. English and French white elovers he found to be very sensitive, but distribution of the fungns did not take place by means of seed.

Scl. tuberosa (Hedw.) (Britain and U.S. America). This on the rhizomes of Aurmone nemorose causes formation of sclerotia larger than tilbert-nuts. The ascospores on germination produce groups of tlask-shaped processes from which are given off chains of spherical conidia incapable of germination. Certain pycnidia which appear on the anemone-plants or on the sclerotia belong to a parasite (Pycnis sclerotivora Brefeld).

Scl. bulborum Wakk. ${ }^{1}$ (Britain). Wakker observed this form on hyacinth, onion, etc. It is very similar to Scl. trifoliorum, but the hyacinth-fungus will not infect elover, and vice verse. The leaves attacked become rotten and the plants clie.?

Eriksson describes, from Wermland (Sweden), a destructive appearance of bulb-rot due to sclerotia, which he attributed to Scl. Fucheliana De Bary.

Scl. candolleana Lev. on oak-leaves.

$$
\text { Appendix. }
$$

\section{Sclerotia of Unknown Affinity.}

Scl. oryzae Catt. Lice plants (Oryzin sutive) are often attacked by this Sclerotium, and a disease called "Brusone" produeed. The sclerotia are found during June in the sheaths and stems. The symptoms are blackening at the base of plants and withering of upper parts.

Scl. rhizoides Anersw. occurs on living plants of Phalaris urundinacen, and Calamagrostis; also on dead leaves of Dactylis glomerate.

Scl. rhinanthi Magn. ${ }^{3}$ forms selerotia on the roots and root-

'Wakker, Allyem. Vereenig. voor Bloembollencultur, 1883-84; also Botan. Centrallilatt, xix., 1887.

2 (4. Massee (Gardener's Chronicle, Vol. xvi., 1894) gives description and figures.

${ }^{3}$ Terhand. d. botan. Fer. d. Proe. Brandenburg, xxxv. 1894. 
neck of living Rhinanthus minor: these bodies begin their development in the cambium and bark, which they kill; afterwards the wood itself may be attacked.

\section{Sclerotinia with Botrytis-conidia. ${ }^{1}$}

Scl. Fuckeliana De Bary. This Sclerotinice is distinguished from all preceding ones by its passing through a Botrytisconiclia stage (Botrytis cinerce). If conidia are sown out on plum-juice gelatine, there appear within fourteen to twenty-one days round groups of sclerotia, which soon give rise to conidia. From such artificiallyreared sclerotia I have never succeeded in gretting the Pezizc-fruit, so easily cultivated from sclerotia gathered in the open-air $(c . g$. from vine leaves). ${ }^{2}$ Thus the actual proof that Sel. Fucliclicence and Botrytis cinerece are stages in the life of the same fungus is not reached by this experiment. ${ }^{3}$ The two forms

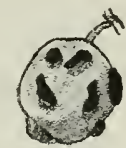

FIG. 140.- Sclerotinic Fuclieliana. Ripe-rot of the Grape. Berry with sclerotia. (v. Tubeuf del.) are, however, very frequently met together.

The sclerotia of Scl. Fuckcliana are produced in the mesophyll of the leaves, also in the parenchyma and epidermis of the host-plants, but never in the wood. Pezizo-fruits with flat apothecia are produced from them. Sclerotia are found in vine leaves and over-ripe grapes (Fig. 140), especially of the Riesling, Orleans, and Sylvaner varieties. ${ }^{4}$ Other plants and fruits may also be attacked. Diseased parts become brown from the effects of the parasitic mycelium, and die off. The inycelium can only live parasitic after it has been strengthened by a previous saprophytic existence. Ascospores are thus unable to effect direct infection. The Botrytis-conidia seem, however, capable of directly infecting a host-plant, at least I have always succeeded in infecting Conifers successfully with the conidial form Butrytis Douglasii.

'See also Botrytis amongst the "Fungi imperfecti."

${ }^{2}$ Brefeld, Heft Iv., p. 1:29, and x., p. 315; Tubeuf, Beitrüge z. Kenntniss d. Baumkranklheiten, 18 SS.

${ }^{3}$ Zopf. (Die Pilze, p. 742) states that Pezi:a-fruits may be reared from these sclerotia after they have rested a year.

"Muller-Thurgan, "Die Edelfäule d. Trauben." Landwirth. Juhrbuch, 1888 (Ref. in Botan. Centralblatt, xxxv., 18s8, p. 94). 
Epidemies of great magnitude have been ascribed to attacks by the Botrytis-forns of this Sclemtinir. Thus on lilies in England, ${ }^{1}$ on yellow gentian, ${ }^{2}$ on male flowers of Conifers, and on the twigs of Conifers and other plants. This is especially the ease in houses under glass, where the fungus, favoured by the moist atmosphere, lives as a saprophyte on dead plant-remains, and multiplies till it becomes strong enough to act as a parasite. It is, however, quite possible that conillial forms of other sclerotia (r.g. Scl. sclerotionum) may be confounded with this species.

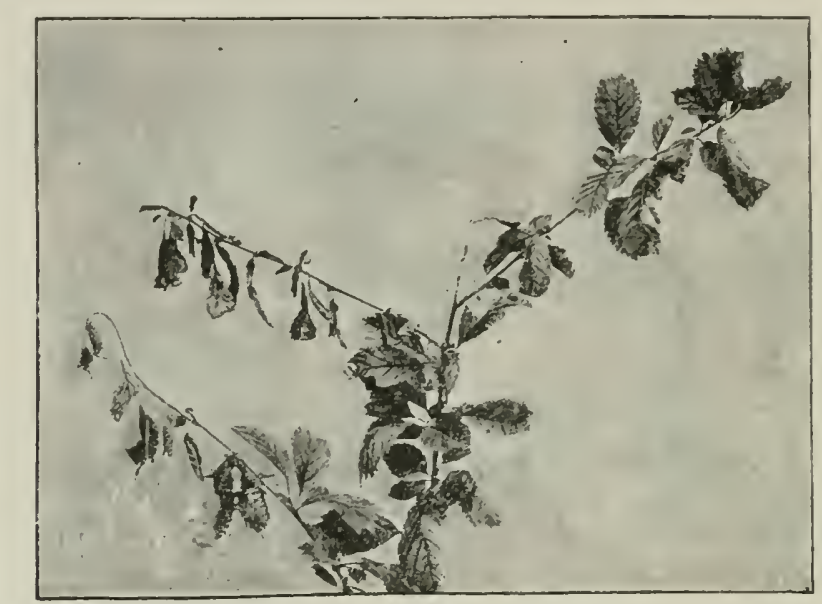

Fig. 141.-Botrytis cinerea (Scl. Fuckeliana). Branch of Prunus triloba with two diseased shoots, withered and dead. ( $\nabla$. Tubeuf phot.)

The presence of Botrytis and allied forms on the vine is the canse of a disease of great economic importance, because severe loss may be incurred through rotting of the grapes and the injurions after-effects on the "most."

A decay of the potato-plant is said to be caused by sclerotia formed inside the stems, and also by a botrytis. ${ }^{3}$ Smith $^{4}$ has figured similar sclerotia, which he aseribes to Peviza postume Berk. and Wil.

'H. M. Ward, Annals of Botany, $18 s 8$.

${ }^{2}$ Kissling, Hedluigia, 1859.

${ }^{3}$ Ritzema-Bos., Zeitsch. f: Pflanzenkrankiheiten, 1s94; O. Kirchner, Wrurtemburg. Wochenblatt $f$. Landwirth., 1893.

${ }^{4}$ Worthington G. Smith, Diseases of Field and Garden Crops. London, 1584. 
Sclerotia, along with Botrytis-conidia, have been found frequently on diseased geraniums.

During the summer of 1894 a withering of twigs of Prunus trilobe occurred in several gardens at Munich (Fig. 141). A mycelium was found in the bark, leaf-petioles, and young ovaries, while Botrytis-conidia were developed on the dead parts. With these I successfully infected young needles and twigs of spruce. Sclerotia were also formed on plumgelatine in fourteen days. The parasite in this case had killed old twigs of Prunus, and also infected twigs of Conifers.

Botrytis Douglasii is a parasite which I studied some time ago on account of its presence along with a disease on the Donglas fir (Pseudotsuga Douglasii). ${ }^{1}$ I have since had reason to believe that it is allied to some form of sclerotim like that just considered, and my view is supported by Behrens. ${ }^{2}$ The disease as seen in various parts of Germany is characterized by withering, curling-up, and death of young shoots towards the summits of young seedlings, and on the lower twigs of older trees up to about five feet above the ground. In autumn, black sclerotia about the size of pin heads, break through the epidermis under the old budscales, at the base of dead shoots,

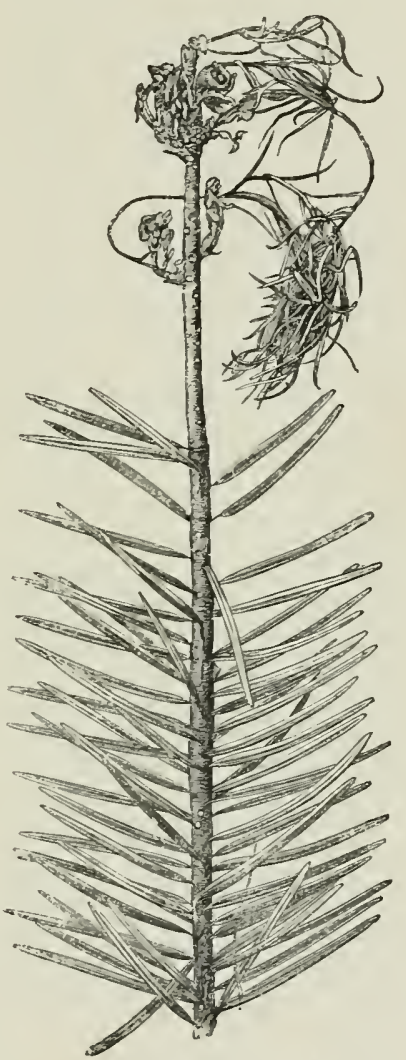

Fici. 142.-Botrytis Douglesii on the Douglas Fir. The young shoots and apex of last year's shoot are dead. (After Tubeuf.) and on the needles. In adclition to these, smaller masses of tangled hyphae are also formed. When sclerotia are placed in a moist chamber, tufts of erect conidiophores arise, and branch, forming numerous whorls of conidiophores, from which

\footnotetext{
${ }^{1}$ v. Tubeuf, Beiträge z. Kenntniss d. Baumkrankheiten, Berlin, 1888.

${ }^{2}$ Behrens, Zeitsch. f. Pfanzenkrankkeiten, 1895.
} 
oral hyaline conidiat are abjointed. These germinate at once in water, and infect young developing shoots or needles of Donglas fir, silver fir, spruce, and larch. Death of these ensues in a few days, and finally the whole plant is killed. On the dead needles a copions development of Butrytis takes place, and the conidia being easily detached, spread the disease in damp, localities. The mycelium and conidiophores are very sensitive to drought. The sclerotia serve to carry the fungus over winter, and may be found in autumn and winter.

I have found Juniperis communis with its young shoots dead, and sclerotia similar to the above on the needles.

Whether Sclerotini" Ferneri Wettst. found on neerlles of Alies pectinat, is parasitic or not, I do not know.

Scl. galanthi Ludw. ${ }^{1}$ Ludwig observed this disease on snowdrops. In place of the flower a shapeless mass was produced, completely covered with conidiophores of Botrytis. The sclerotia develop inside the tuber.

Scl. pseudotuberosa (Rehm). (Scl. Batschiana Zopf or Ciborice pseudotuberosa Rehm) (Britain). The cotyledons of acorns are sometimes found replaced by a firm sclerotium, from which a peziza-fruit (Ciboria) is produced. Nothing is known in regard to mode of infection or the parasitism of this species.

\section{EU.PEZIZEAE.}

The apothecia, at first closed, open out to form saucershaped or cup-like dises, with a margin. The dises have usually a thick hypothecium: they are fleshy or waxy in texture, and are often brightly coloured.

\section{Dasyscypha.}

The waxy or membranous ascocarps are sessile or shortly stalked, and beset on the outer surface and margin with hairs of various colours. The asci dehisce by a round apical opening. The spores are ellipsoidal or spindle-shaped, unicellular, and hyaline. The paraphyses are thread-like. Most of the forms are saprophytic on dead plants; the following species alone is known to be parasitic.

\footnotetext{
${ }^{1}$ Ludwig, Lehrbuch d. niederen Kryptoyamen.
} 
Dasyscypha (Peziza) Willkommii, Hartig.' The Larch Canker (Britain and U.S. America). Everywhere in the mountains, the home of the larch, one finds, on young branches and old stems, depressed cankér-spots, on which the sporocarps of Dasyscyphu Willkommii are developed. Young twigs, when attacked, are already conspicuous in .July and August by their pale and withered needles, and on them small canker-spots will be found; these rapidly enlarge so that on older stems they may reach very great dimensions. Hartig easily succeeded in producing canker-spots on healthy trees by artificial infection.

If canker-spots are examined soon after the death of the bark, the stromata will be found as yellowish-white pustules. Conidia are produced either on the free surface or in the internal carities of a stroma; they are tiny unicellular hyaline bodies, produced from little conidiophores. Hartig never succeeded in getting these spores to germinate. If the atmosphere be moist enough the apothecia make their appearance later on the same places; they are externally yellow, and internally orangecoloured. The apothecial disc carries long thread-like paraphyses and cylindrical asci

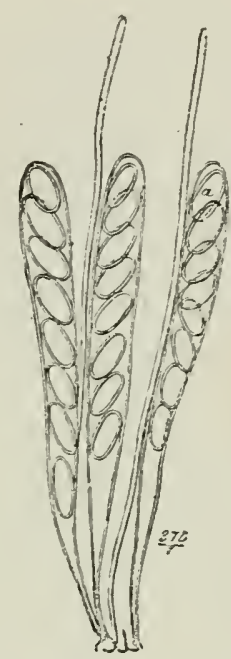

FIG. 143. - Dasyscyphe Willhomit. Three asci and two paraphsses isolated from an apothecium. (After R. Hartig.) with rounded apices (Fig. 143). The ascospores are oval, unicellular; and hyaline. They germinate and give off one or two germ-tubes which are unable to penetrate the periderm of a host-plant, and only find entrance through wounded places. Wounds are very common on larch as the result of hail, or injury to twigs by snow or ice, or destruction of needles by insects. For example, the Larch-moth (Colcophorn laricella) is well known to cause less damage on the mountains than in the lower regions, and in the same degree Dusyscypha is least injurious to mountain forests.

The mycelium is septate and much branched; it spreads chiefly through the soft bast, especially in the siere-tubes and

${ }^{1}$ R. Ha1tig, Untersuch. aus d. forstbotan. Institut München, I., 18s0. M. Willkomm, Mikros. Feinde des Waldes, II., 1869. 
intercellular spaces, but it may also penetrate the wood as far as the pith. The fungus only sprearls during autumn and winter, never during smmmer, the veretative period of the larch. The attacked tissues of the bark turn brown and shrivel up, causing the depressed canker-spots. Healthy parts continue their growth normally, and are frequently cut off from diseased areas by formation of layers of secondary cork; this isolation is, however, rarely effective, since fresh invasions of mycelium from the wood into the bast take place annually, and thereby the canker-spots keep cnlarging for an indefinite time.

The fungus develops reproductive organs only in damp marshy sitnations. On this account spore-formation is less frequent on inountainous slopes than in moist valleys and ravines. The larch, on its first introluction into the low-lying parts of Germany, Denmark, and England, was much cultivated as a pure forest in close damp localities, and with great success; but now this parasite has followed its lost from the mountains and causes ever increasing damage.

As preventive measures may be recommended: larches in low-lying districts should be grown in open, airy situations, and never massed together nor placed in the neighbourhood of diseased larches.

\section{Lachnella.}

The reproductive organs are similar to Dasyscypha, but the apothecia are firmer and generally have no stalk; the spores as a rule become two-celled at maturity.

Lachnella pini Brunch. ${ }^{1}$ occurs in Norway on twigs of Pinus syliestris, as a parasite which quiekly kills young plants and twigs. It is rare on old plants. The apothecia resemble those of $D$. ITilliommii, but are larger, externally brown, and covered with brown hairs and scales. The clise is reddish-yellow with a whitish margin. The asci measure about $100 \mu$ by $9 \mu$, and contain colourless unicellular spores about $20 \mu$ long.

\section{Rhizina. ${ }^{2}$}

This genus contains the single species Rhizina undulata

${ }^{1}$ Brunchorst, Nogle narske skor:sygrlomme, Bergens Mus., 1592.

"Rhizina has a position somewhere between the Perizcae ind the Helvelleae. Saccarlo places the genus under Pezizece, while Schroeter makes for it the special group of Rhizinarei, included under his Helvellinei. 
Fr. (Rh. inflata, schaeff.). Root fungus, or Ping-disease. ${ }^{1}$ This fungus is found as a saprophyte on the earth, especially where forest fires have occurred; also as a parasite on indigenous and exotic conifers. As such it has been observed in nurseries in various parts of Germany, and in woods of Pinus Pincster in France. The fungus itself is known in Britain, though not as a parasite.

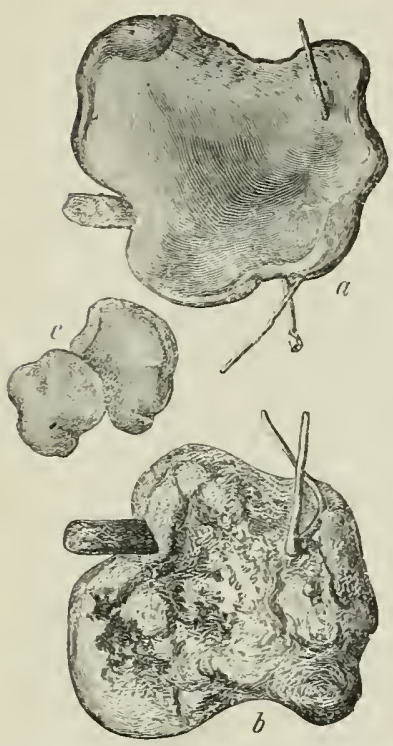

FIG. 14t. - Spoiophores of Rhizina umululata. , Upper surface; $\ell$, lower surface; $c$, small sporophores. (After Hartig.)

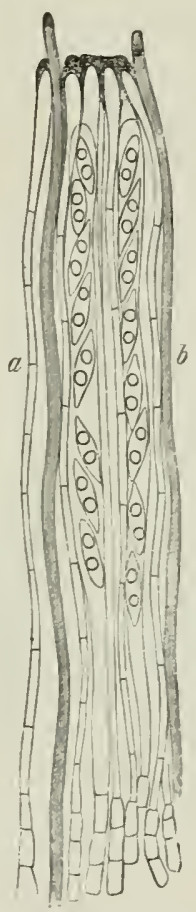

Frg. 145.-Section of hymenium. a, Para. phrses; $l$, secreting-tubes; $c$, asei, each with eight spores. (After Hartig.)

The disease extends from a centre and attacks one plant after another, causing them to lose their neelles and die. The sporophores are large ( $\frac{2}{3}$ to 2 inches), chestnut-brown, flattened or undulating structures, which sit directly on the mycelium, without a stalk. On the upper surface is the ascogenous layer which, when moist, is peculiarly sticky and

${ }^{1}$ R. Hartig. Forstl-natumwissen. Zeitschrift., 1892, p. 591; Prillieux, Compt. rend. de la Soc. des Agric., 1880. 
glutinous; it consists of small eight-spored asci over which project scptate paraphyses, and also non-septate paraphyse-like structures which discharge a brown secretion. The ascospores are unicellular, hyaline, and canoe-shaped: on germination they give off a germ-tube which immediately develops into a septate mycelium. The mycelium is found in the intercellular spaces of the rind-parenchyma, but in the bast it grows both inside the cells and hetween them, so that the sieve-tubes are often completely

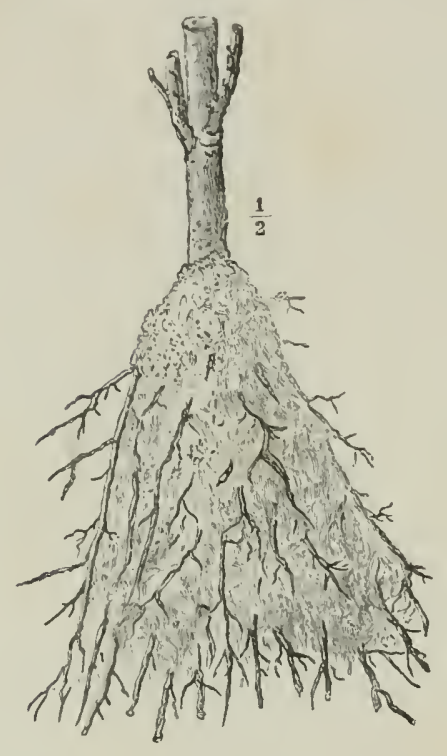

Fig, 146,-Rorit-system of a Silver Fir orergrown and killed by the mycelium of Rhizine andulata. (After Hartig.)

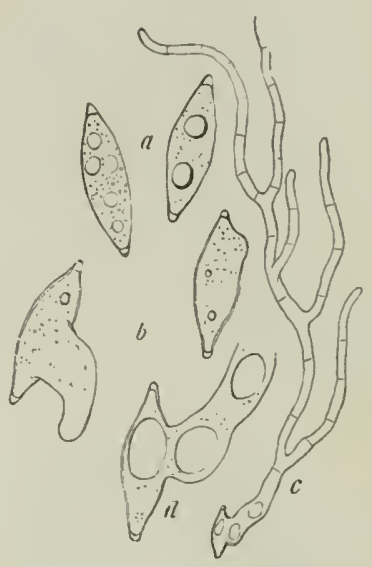

FIG, 147.-Ascospores of Rhizind. u, As taken from the ascus; $b, 24$ hours after sowing; $c, 45$ hours after sowing: $d$, the spore of $c$ enlarged. (After llartig.)

filled up. Masses of fungoid pseudoparenchyma are frequently formed between the dearl and diseased tissnes. Strands of the nature of filizoctonic emerge from the diseased roots, many of them carrying thread-like processes, at the extremity of which an oil-drop is secreted and escapes on rupture of the apex.

Accorling to Hartig, very tiny conidia are abjointed from the mycelium.

De la Boulage ${ }^{1}$ and Prillieux have both come to the conclusion that "la maladie dn rond" of Pinus syluestris and P. maritima is the same disease as the "ring-disease" cansed by Rhizinr.

${ }^{1}$ Bull. de la soc. des Agric. de France, 1880. 
Appendir.

\section{The Helvellaceae.}

This family is well known, some as poisonous, others as edible fungi (morel, etc.), and a few are suspected of being parasites. The ascogenous layer occupies the upper surface of the sporophores, which grow on the earth and assume many various forms. As a rule they are erect and flesshy, and more or less lobed, wrinkled, or folled.

\section{LSTILAGINEAE.}

The Ustilagineae or Smut-fungi are distinguished by their dark-coloured or black chlamydospores, which, on germination, produce some form of promycelium capable of giving rise to an indefinite number of conidia or sporidia. ${ }^{1}$ The chlamydospores themselves are produced in large numbers from a mycelium, and serve as resting-spores to carry the fungus through the winter, being often, in fact, the only part which persists. An endogenous formation of spores in sporangia as in the lower fungi, or in asci as in the Ascomycetes, does not oceur in the Ustilagineae, Uredineae, or Basidionycetes.

The resting-spores of the Ustilagineae contain only one nucleus, the result of copnlation of two nuclei; their formation thus marks the end of one generation, and their germination the beginning of a new. In the case of the Uredineae, Basidiomycetes, and Ascomycetes, the beginning of the new generation is indicated by the germination of the teleutospore, the formation of basidiospores on the basidium, and the germination of the ascospore respectively.

All the Ustilagineae are parasitic on higher plants, the mycelium growing intercellularly and nourished by means of haustoria sunk into the host-cells. The mycelium itself causes neither disease nor deformation of plants, and it is only when

\footnotetext{
${ }^{1}$ Brefeld regards the promycelium of the Ustilagineae not, like De Bary, as a mycelial structure, but as a conidiophore or basidial structure. In accordance with this view he has founded his intermediate group, the Hemibasidii corresponding to the Ustilagineae. Brefehl then subclivides this group into $(a)$ Ustilagineae (Ustilago, Sphacelotheca, Schizonella. Tolyposporium), which as a rule have a septate promycelium ; and (b) Tilletieae (Tilletia, Entyloma, ILelanotaenium, Schroeteria, Thecaphora, Sorosporium), with non-septate pronycelia. (Schimmelpilze, Heft v., 1883, and Heft xi., 1895.)
} 
the resting-spores are ileveloperl that ileformation ocems. These spores arise by intercaliry growth in the mycelium, which is generally completely used up in their formation; they are produced in large numbers, and scattered after decay of the tissues enclosing them.

As a result of the germination of the resting-spores, there is produced either a mycelium capable of immediate infection, or a promycelium from which coniclia ${ }^{1}$ are abjointed. In the latter case, conidia are generally formed in succession, and continue to be given off from the promycelium for a considerable time. They either give out a germ-tube capable of infecting a new host, or give rise to further conidia. The latter process is most frequently observed in artificial nutritive solutions, where the coniclia continue to sprout in a yeast-like manner till nourishment is exhausted, when they rerminate and form mycelial filaments. In the host-plant, chlamydospores alone are developed, conidia exceptionally (T'ulurcinia and Entyloma).

The Ustilagineate are very dangerous and injurious enemies of cultivated plants, especially to the various cereal crops. The species are fairly easy to identify, because each is, as a rule, confined to one or a few species of host. The smut-fungi are best combated by sterilizing the seed of suspected cereals in a copler sulphate solution or in lot water shortly before sowing out; (see General Part, chap. vi.) In this way any atherent smut-spores are killed, and where this preventive measure is regularly carried out, disease is less common and its effects considerably minimized.

The Ustilagineae include the following genera: Ustilago, Sphacelothece, Schizondla, Tolyposporium, Tilletia, Entyloma, Mchunotacnium, Urocystis, Tuburcinia, Deossansia, Schroetcria, Thecaphora, Sorosporium, Graphiola, Schinziu, Tubcreularia.

\section{Ustilago.}

The vegetative mycelium makes its way through the tissues of the host-plant without causing any deformation. The spores are developed in certain parts of the host, and form a muchbranched, compact, sporogenous mycelium, with membranes

1 'Conidia' = the sporidia of De Bary. 
which at first swell up in a gelatinous manner. Spores are formed inside the ultimate ranifications of the mycelium, and as they reach maturity, the membrane loses its gelatinous character, the cells break up, and the spores are set free; they are dispersed as a dry dusty powler after rupture of the tissues

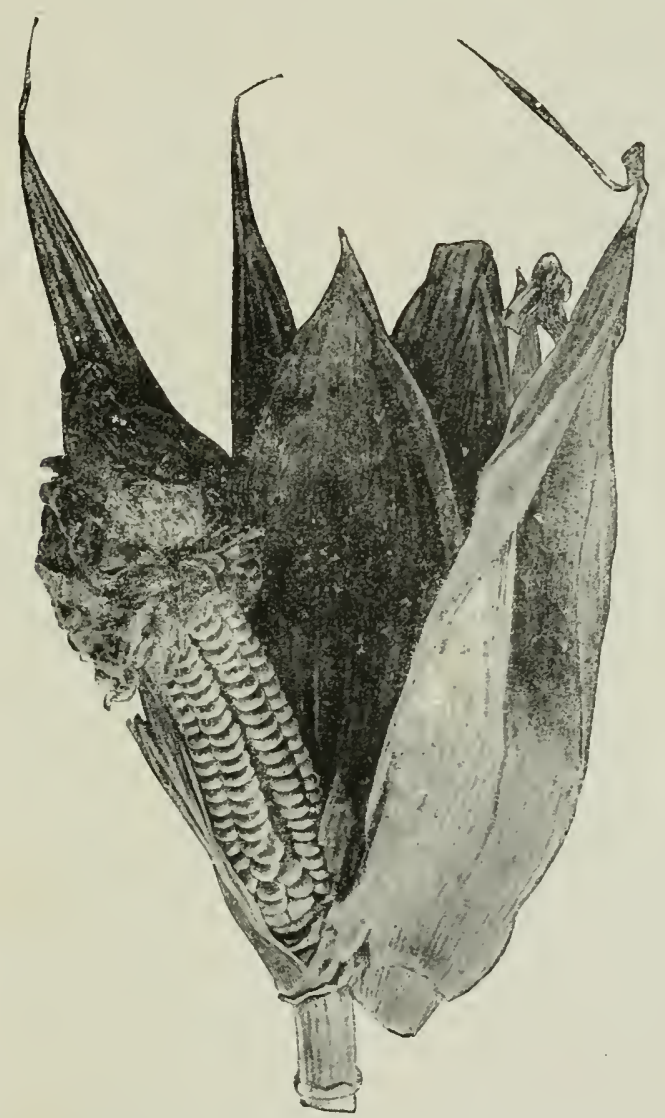

Fia. 148.-Ustilago maydis. The head has been exposed to view by dissecting away the enclosing leaves; it is beset towards the apex by smut-boils. (v. Tubeuf phot.)

of the host enclosing them. The spores germinate, giving rise to a promycelium (basidium), which becones divided up by means of cross-septa into several cells, from each of which conidia are laterally abjointed. These conidia spront yeastlike, and give off new conidia, or they produce a mycelium; 
the former is the case when nutrition is abunlant, as when under artificial cultivation, the latter under less favourable nutrition; in very unsuitable conditions, the constituent cells

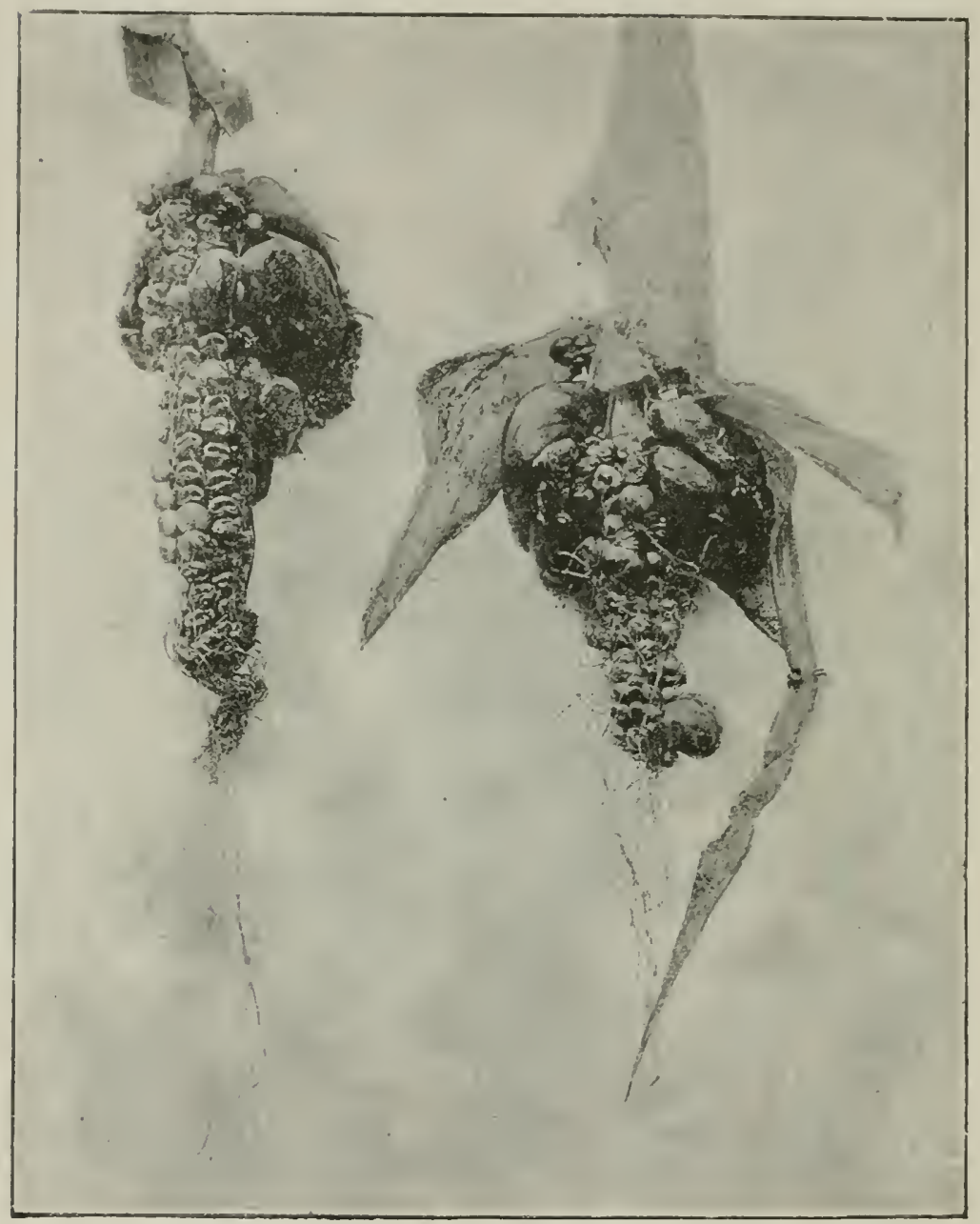

FIG. 149.-Ustilago maydis. Disensed Maize-heads after removal of enclosing leares. The heads are beset witl smut-boils of all sizes, some ruptured, others still umbroken. (v. Tubeuf phot.)

of the promycelium may each develop directly into hyphae capable of infecting a new host. 
Ustilago maydis (D.C..) ${ }^{1}$ (Britain and U.S. America). ${ }^{2}$ This smut of Zea Mais produces large and conspicuous deformations on leaves, leaf-sheaths, stems, roots, and all parts of the male and female flowers. These are whitish, gall-like swellings and blisters, containing a mass of gelatinous mycelium, from which spores are prorluced. The swellings may attain to the size of a fist, or even larger. The spores appear at first as dark olive-green masses seen through the lightergreen outer tissues of the hostplant. When mature the spore masses cause rupture of the enclosing host-tissues, and escape as a dusty powder. The spores are dark-brown in colour, irregularly spherical in shape, covered with delicate spines, and measure $9-12 \mu$ in diameter. They remain capable of germination for miny years.

On being sown from the hostplant directly into water, very few spores germinate at once, yet if sown in the following spring they readily do so. In a nutritive solution (e.g. plum-juice gelatine) an abundant germination may be obtained at any time. A delicate hyaline lypha is given out first, and after becoming divided up by several cross-septa, it proceeds to abjoint conidia from various places. The conidia spront in the gelatine

${ }^{1}$ American Literature: U.S. Dept. of Ayriculture Report, 1ss9, p. 380, with ilescription and recommentations as to treatment. Also Ohio fgric. Exper. Stat. Bulletin, Tol. II., p. 271, 1590.

2 The principal authorities for the occurrence of the Ustilagineae in Britain and the United States are Plowight (British Ustilayineae, 1Ss9), and Farlow and Seymour (Host-index of Fungi of U.S. America, 1591). (Eilit.) 
in a yeast-like manner, but on exhaustion of the nutritive materials, the primary conidia, and even the constituent cells of the pronycelimm, give off germ-tubes. Conidia are nerer found on the maize-plant itself, but Brefeld's investigations have demoustrated their production on dung-enltures, so that conidia may passibly be produced on manure-heaps or manured soil, and young plants be infected by them. Brefeld has, by means of germinating coniclia, suceessfully infected maize-

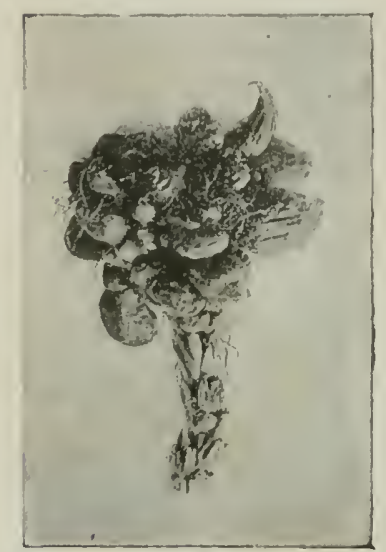

Fig, 151,-Ustilagr, momelis. Maize-heal completely malformed into smut-boils, which have not yet ruptured. (v. Tubeuf phot.)

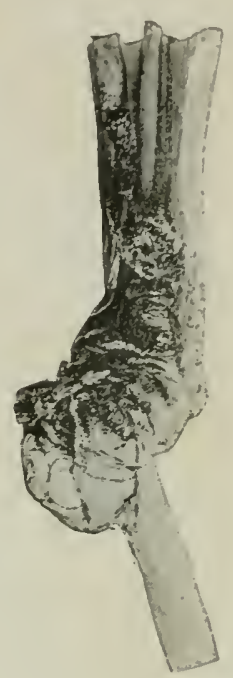

Fir, 152.-Ustilego mandis, Smut-boils ind stem and leaf of a Maize-plant. (v. Tubeuf phot.)

seedlings as well as growing points and other young parts of older plants.

Infection may take place on any immature part of the host. The mycelium does not grow through the whole plant, but only inhabits a part in the vicinity of the place infecterl. The heads are most frequently attacked, with the result that the grain fails to reach maturity, or is destroyed during the formation of fungus-spores.

Owing to the danger of infection, grain mixed with smutspores should never be used for sowing; nor ean such be safely used for feeding eattle on account of its injurious effects on them. 
Knowles, ${ }^{1}$ Cugini, ${ }^{2}$ and Wakker ${ }^{3}$ have investigated the anatomical changes produced by this fungus. The latter investigator found that the xylem-elements with unlignified walls remain incompletely dereloped, and hare a peculiarly twisted course; that normal sieve-tubes are absent; that the cells of parenchyma undergo secondary division, and give rise to a new tissue provided with little fibrovascular bundles, and rich in starch-contents, in other words, a nutritive tissue to be used up in the spore-formation of the smut.

The disease may be found wherever maize is cultivated, and often causes a very serious diminution in the harvest. It may be combated by early removal and destruction of the smut-galls. As a preventive measure, the treatment of seed-corn with copper sulphate solution ${ }^{4}$ is recommended. The avoidance of fresh manure is also advisable, since conidia capable of germination may be lodged in it.

The following are the results of an experiment carried out at my instigation by Professor Wollny in his experimental plots at Munich. Three plots were selected distant from each other about 70 metres. On 2nd May, 1893, these were marked out in rows 40 centimetres apart, in which maize was sown at intervals of $50 \mathrm{~cm}$. The grain was previously mixed with smut-spores obtained from the Tyrol in autumn, 1892. Plot No. 1 was left without manure, No. 2 was treated with old, No. 3 with fresh cow-manure. Maize had never been grown in the vicinity, so that no infection could result from external sources. The results were:

\begin{tabular}{|c|c|c|c|c|}
\hline \multirow[b]{3}{*}{ Plot No. 1, unmanured, } & \multirow{2}{*}{\multicolumn{2}{|c|}{ Number of Plants. }} & \multicolumn{2}{|c|}{ Smutted. } \\
\hline & & & Absol. & Per cent. \\
\hline & - & 148 & 0 & 0 \\
\hline 2, old cow-manure, - & - & 124 & 2 & $1 \cdot 6$ \\
\hline 3 , new cow-manure, & ,- & 132 & 11 & $7 \cdot 6$ \\
\hline
\end{tabular}

Ustilago Schweinitzii Tul. from Carolina U.S.A. is probably identical with Ust. maydis.

Ust. Fischeri Pass. ${ }^{5}$ This smut, observed in upper Italy,

${ }^{1}$ Knowles, E. J., Amer. Journal of Mycology, Vol. Iv., 1889.

"Cugini, "Il carbone del grano tureo," Boll. dell. stat. Agrar. di Modena, 1891.

${ }^{3}$ Wakker, Pringsheim's Jahrbuch, Bd. 24, 1892.

"See "General Part," chap. vi., and also "Vergleichende Untersuchungen üb. Flugbrandarten." P. Herzberg in Zopf"s Beitrügen, 1895.

${ }^{5}$ Passerini, Just's botan. Jahrbuch, 1859, p. 123. 
attacks the axis of the mitize-hearls. Its spores are spherical with slightly gramular conts, and measure only $4-6 \mu$ in diameter. It causes damage through shrivelling up of the grain.

Ust. Reiliana Kühn. This smut frequents Sorglum haleprnse and S. vulyore (Durra or Indian millet); also maize in rarious pirts of Europe and America, ${ }^{1}$ as well as in Egypt and India. It is called "Hamari" in the Arabic language.

Kiihn" thus describes it: "This species causes the eurs of lourra to become large smut-galls of roundish or ovoid shape, with a height of $60-95 \mathrm{~m} . \mathrm{m}$. and a cliameter of $40-60 \mathrm{~m} . \mathrm{m}$. It first the smut is enclosed in a whitish skin, which is ruptured into shreds to allow the escape of the black spore-puwiler. After the smut-spores are shed, there remains a stiff sheleton consisting of the fibrovascular bundles of the aborted ear."

The spores are distinguished from those of Ust. mayrlis by their greater size $(9-15 \mu)$, and their almost smooth membrane with very small spines. According to Brefeld, the spores are capable of germination in nutritive solutions after eight rears. In the fresh condition they germinate in water to a linited extent, producing multicellular promycelia which give off coniclia. In nutritive solutions they germinate and produce thick promycelia with three or four cells, from which multitudes of coniclia $(5-12 \mu$ long and $3-5 \mu$ broad) are abjointed. The conidia fall off and sprout till the nutritive substratum is exhausterl, when they give rise to thread-Iike conidia which do not coalesce. If kept dry the conidia easily retain their vitality for months.

Kühn distinguishes further Sorosporium Ehrenbergii Kiihn on Sorgherin irreverim.

Ust. cruenta Kiihn. ${ }^{3}$ Another parasite on the ears of Sorylum. It is described by Kiihn as follows: "On the spikelets little reddish-brown protuberances of roundish or oblong shape are formed and enclose molerately-sized masses of clark-red smut-powder. If the pustules are very numerous they coalesce with each other, and the branches of the ear become more or less shortened, thickened, and twisted. There

${ }^{1}$ Norton, "Ustilago Reiliana," Botanical Gazelte, 1895, p. 462.

"Kühn, "Die Brandformen cler Sorghum-arten," Nittheil $d$. l'er. $f$. Evillumit ou Halle, $187 \%$.

${ }^{3}$ Kuihn (loc. cit.) and Hamburger Garten-Zeitung, Bd. 28.

Brefeld, Heft r., p. 91. 
the pustules are fewer in number the parts of the ear retain their normal position, but all the floral organs contained in the glumes are wholly or partially converterl into irregular greyish smut-masses. Isolated pustules may occur under the inflorescence, on the next internode of the haulm."

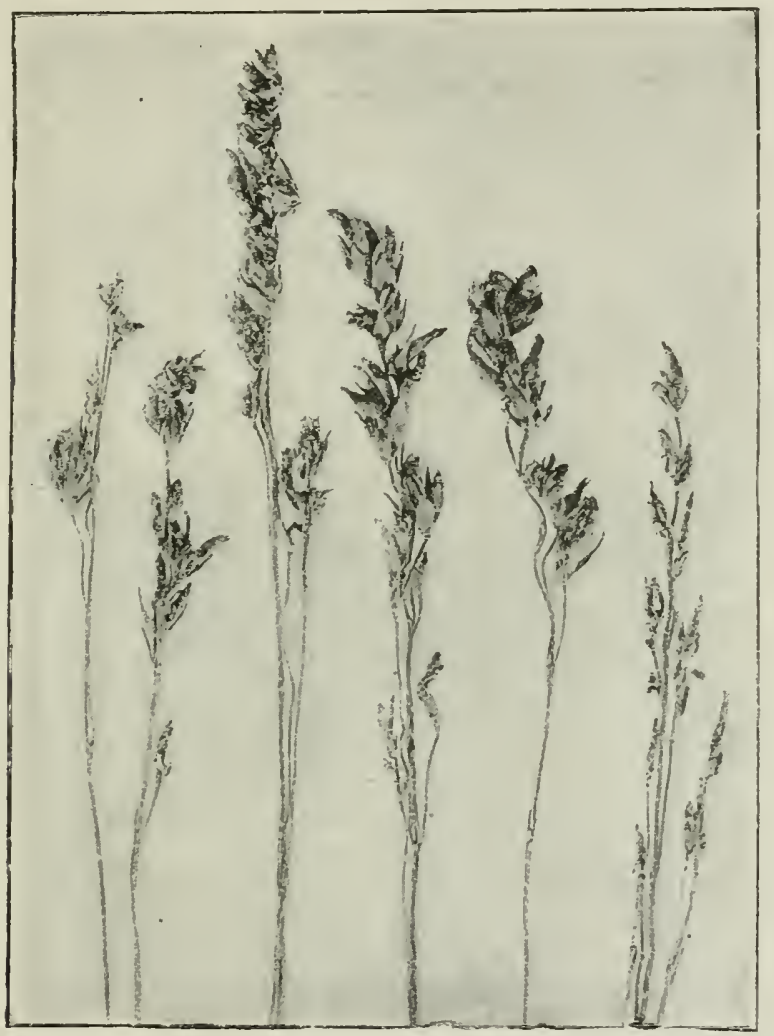

FIG, 153.-Ustilago cruenta. Smut of Dumra or Sorghum The head has been divided up and the isolated branches photographed. The ovaries are transformed to loug crooked sacs, and pustule-like outgrow ths are also present on stalklets and stalks. (v. Tubeuf phot. from material supplied by Prof, 1)r. Jul. Kïhn.)

The spores are yellow to brown in colour, smooth-walled, and of very variable shape, $5-12 \mu$ long and $5-9 \mu$ broad. As a rule, germination in water results in the formation of a germtube composed of four or five cells, which elongate to long mycelial threads or, exceptionally, produce a single conidium. As a result of germination in nutritive solutions, a lively 
formation of coniclia ensues; the conidia multiply in at yeastlike mamner, and only grow out as hyphae on exhanstion of nntritive material. Infection takes place on seedling-plants.

Kuilun cultivated this species on Sorghum succhorotum and S. valgurr, and suggests that a common disease of Durra in South Africa may be cansed by this parasite.

Ust. sorghi (Link.) (Ust. Tuelesnei Kiihn) (U.S. America). This is another widely distributed parasite of Sorghum vulgarr and $S$. succharatum. Its extemal appearance is described by Kiihn somewhat as follows: "Diseased plants attain to almost their normal size, and the flower-head is developed as far as the glumes. The ovary, however, is completely metamorphosed into a sac filled with spores, its onter wall forming a delicate

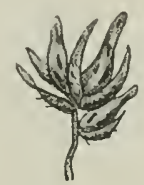

Fis. $154-U$ stilayo cruenta. Spikelet enlarged from a head of Sorghum. The ovaries are transformed into long flaskshaned saes, from slits of which the spores are emerging as a black powder. 芩natural size. (v. Tubeuf del.)

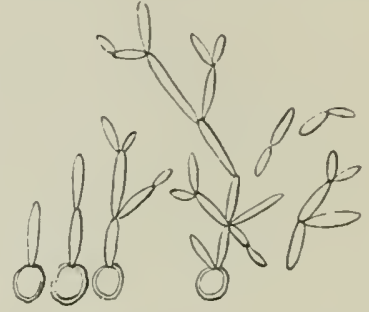

FIG. 155.-Ustilago crenta. Gernin. ating and sprouting conidia from a cultivation in plum-gelatine. (v. Tubeuf del.)

whitish coat, which is easily torn, and, when the spores have escaped, a columella will be found to occupy the centre of the smut-mass. The stamens may also become filled with spores, and be externally more or less irrecognizable. As a rule, all the Howers of a head are smutty; if any escape, they remain more or less rudimentary."

The spores, according to Brefeld, germinate only in nutritive solutions. They produce a four-celled promycelium, on which few conidia are formed.

Ust. sacchari Rabh. Dust-brand of cane sugar. This fungus injures the stems and heads of Saccharum officinale, S. eylindricum, and S. Erienthi in Italy, Africa, and Java.

Ust. sacchari-ciliaris Bref. occurs on Sacharum cilirere near Calcutta.

Ust. avenae (Pers.). The smut or brand of the oat occurs 
very frequently on Avena sativa, also on Avence orientalis, A. fatuc, and A. strigose in Europe and North America. So common is it that one seldom sees a field of oats free from the black smutted ears (Fig. 156).

All parts of the flower are attacked, the ovary, stamens, glumes, and even the awns. The grains become filled with the black spore-powler, which shows through the transparent

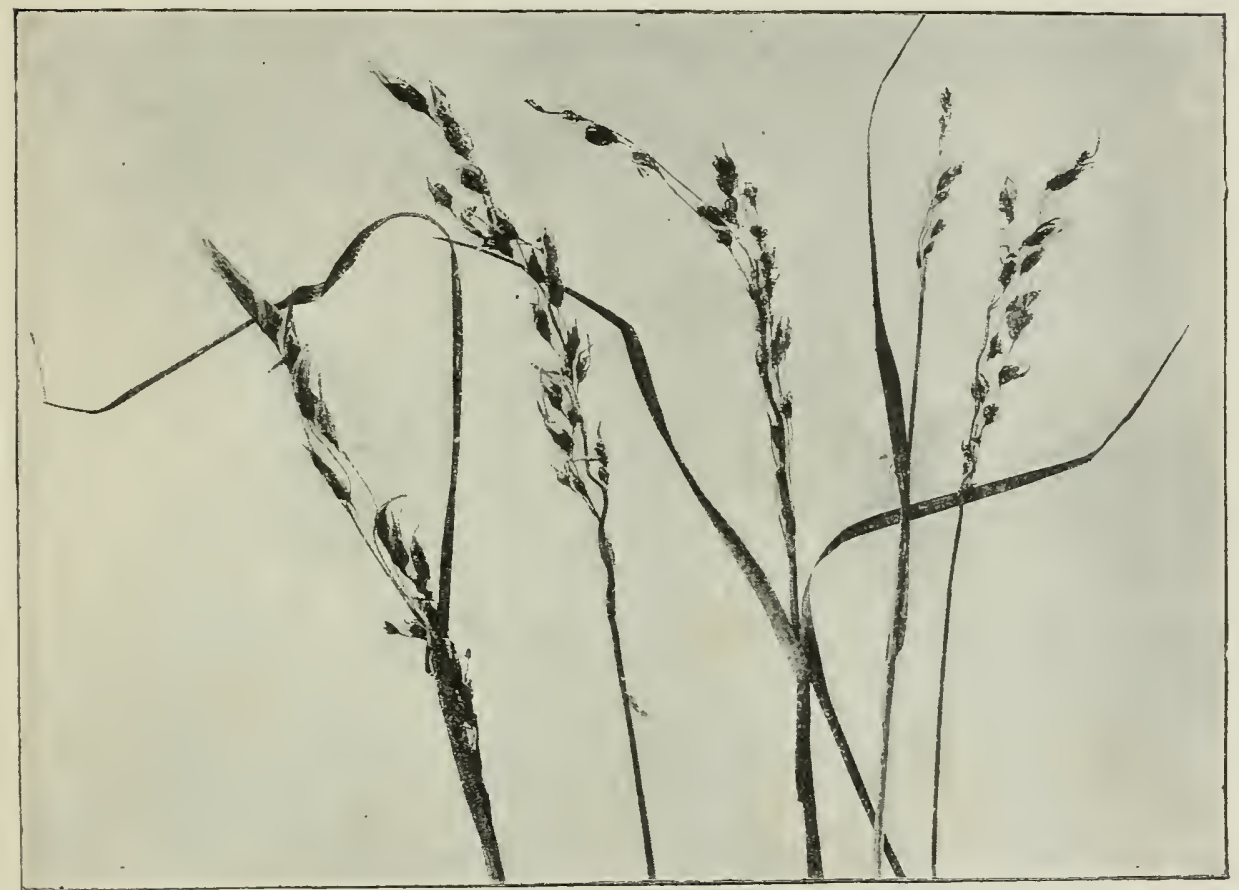

Fig. 156.-Ustilago avenae. The Oat-smut on Avence sativa. (v. Tubeuf phot.)

membrane of the ovary wall. The diseased ears emerge from their enclosing leaf-sheaths, and become exposed to wind and rain, under the effects of which the delicate membrane soon becomes ruptured and the spores are blown or washed away, till only the axes of the spikelet are left with a few ragged remains of the Hower. As a rule every shoot of a plant and all the grains of an ear are attacked; if single grains do escape, they remain poorly developed.

The spores $(5-8 \mu)$ have a smooth or slightly granular coat, and 
retain their capacity for gremination for years. In water they germinate immediately, and produce a single (rarely twon) promycelium consisting of four or five cells, from the ends or partitionwalls of which oblong conidia eontinue to be abjointed for about two days. The cells of promycelia may become connected with one another by lateral branchlets. I) licate germ-tubes are niven off by the promycelial cells, by the coniclia, or by seconclary conidia. In nutritive solutions, on the other hand, the spores germinate much more vigorously, the promycelium is stronger, the coniclia are continuously abjointed from little sterigmata, and go on sprouting in a yeast-like manner till, on exhaustion of the mutriment, they germinate to form vigorous mycelial filaments. The fusion of the cells of promycelia never takes place in nutritive solutions.

The infection of oat-plants takes place on the soil by means of the germ-tubes produced from the conidia, promycelia, or spores. ${ }^{\text {I }}$ These infect the first leaf-sheath-that one which on germination emerges from the ruptured seed-coats as a whitish or yellowishgreen shining shoot, and continues to grow as a sharp-pointed cylinder till, pierced by the first green leaf, it dries up. In 36 to 48 hours after infection, mycelial threads were found to have pierced the epidermal walls, and to have branched freely in the tissues. The mycelium grows from the leaf-sheath into the first green leaf, passes straight through it into the second, and so on till it reaches the hanlm or stem. ${ }^{2}$ The young mycelimm grows steadily onwards, and the plasma of older hyphae passes over into it. In this way the fungus leeps pace with the host-plant, exhibiting externally no symptom of its presence till the flowers are reached, where the chlamydospores are formed.

sterilization of seed-corn by Jensen's hot-water method is strongly recommended. ${ }^{3}$ In America, steeps containing potassium sulphide, copper sulphate, or lime are also used. As preventive against infection, late sowing is advisable. This is founded on Brefell's investigations, in which he found that oat-smut germin-

${ }^{1}$ Wolf, Der Brand des Getrides, 15it.

2 Accorling to Kiuhm, and in Brefeld's infections (Heft XI., 1595), the majority of the germinating conidia are said to penetrate into the young shoot-axis.

3 “Treatment of smuts of Oats and Wheat," U.S. Department of Agriculture. Farmers" Bulletin No. 5, 1S92; "Grais-smuts and their prevention," Yearbook of U.S. Dept. of Agriculture, 1594. 
ated best at $10^{\circ} \mathrm{C}$., and not so well above $15 \mathrm{C}$. This conclusion is supported by experiments of Kellermann and Swingle. Neither these investigators nor Jensen, however, agree

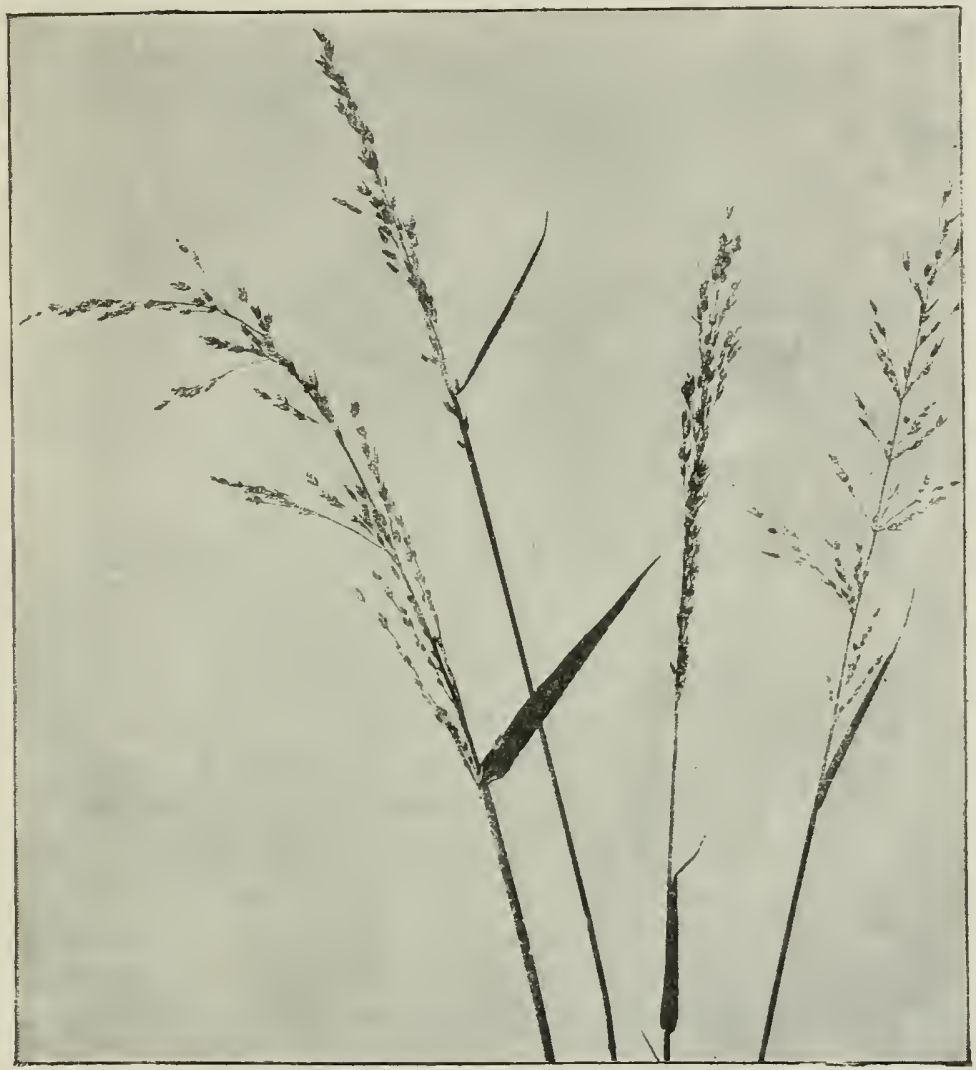

Fig. 157.-Cstilago perennans on Arrhenatherum elatius (Oat grass). The grains are transformed into black smut-masses; the appearance of the infected spikelets is quite distinet from that of the healthy one to the right. (v. Tubeuf phot.)

with Brefeld's view, that the fungus is introduced into fields with fresh farmyard manure.

Kellermann and Swingle have found a smut on oats in America which they distinguish as Ust. avence var. levis.

Ust. Kolleri Wille. This is another species of oat-smut recently distinguished; it has smooth spores, and is sairl to canse even greater damage than Ust. arence. 
Ust. perennans liostr. ${ }^{1}$ This smut or dust-brand occurs frequently in the Howers of Arrhinutherum slatius (Fig. 157). The nycelium peremates in the rhimome.

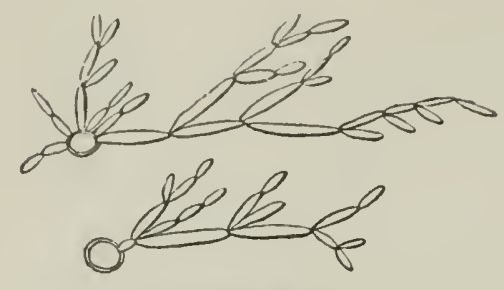

FIri. 155.-Ustilago percinans. Spore-culture in plum-gelatine. (v. Tubeuf del)

An Ustilny" nearly allied to the preceding one occurs also on Frstuca pretensis, Lolium perenne, and other grasses.

The simut of Barley. There are really two species of Ustilago found on barley, Ust. hordsi and Ust. mede.

Ust. hordei (l'ers.) (Ust. . Inscni liostr.) (Britain and U.S. America). This has black spherical spores $(6.5$ to $7.5 \mu$ in diameter), which gerumate and give off conidia from a promycelium. The spikelets generally remain enclosed in their coverings. Treatment of seedcorn with a half per cent. copper steep is a certain remedy.

Ust. nuda (Jens.) (U.S. America). In ears diseased by this smut the epidermis of the glumes is early lost, so that the spore-powder lies freely exposed when the ears emerge from the leaf-sheath. The spores on germination give off a fourcelled promycelium, which however produces no conidia, but develops directly to a septate mycelium. The spores are smooth-coated and oval (5-7 $\mu$ long and $5-6.5 \mu$ broad); they are matured and set free at the flowering season of the barley, and probably infect seedlings in spring. The spores of this smut are very resistant against treatment with copper steeps, and it is recommended to soften the barley for several hours in cold water before applying Jenson's method.

Ust. tritici (Pers.) (Britain and U.S. America). Wheat-brand. The spores are developed in the ovary of the wheat, and are black with a tinge of olive-green. On germination they immediately form a non-septate mycelinm (Fig. 160).

Henning ${ }^{2}$ las described spore-cushions on the leaves and leaf-sheaths of Triticum rulgare in Upper Egypt.

Ust. bullata Berk. on Triticum orientale in Turkestan.

\footnotetext{
${ }^{1}$ Rostrup, Ustilatgineae Daniae, 1590.

${ }^{2}$ Henning, Zeitschrift f. Pflansenkrankheiten, 1894.
} 
Ust. secalis Rabenh. Rye-brand. This occurs but rarely, and destroys only the grain.

Ust. panici-miliacei (Pers.) (Ust. destrucns Duby). simnt of Millet. This smut occurs on the flowers of Punicum milict-

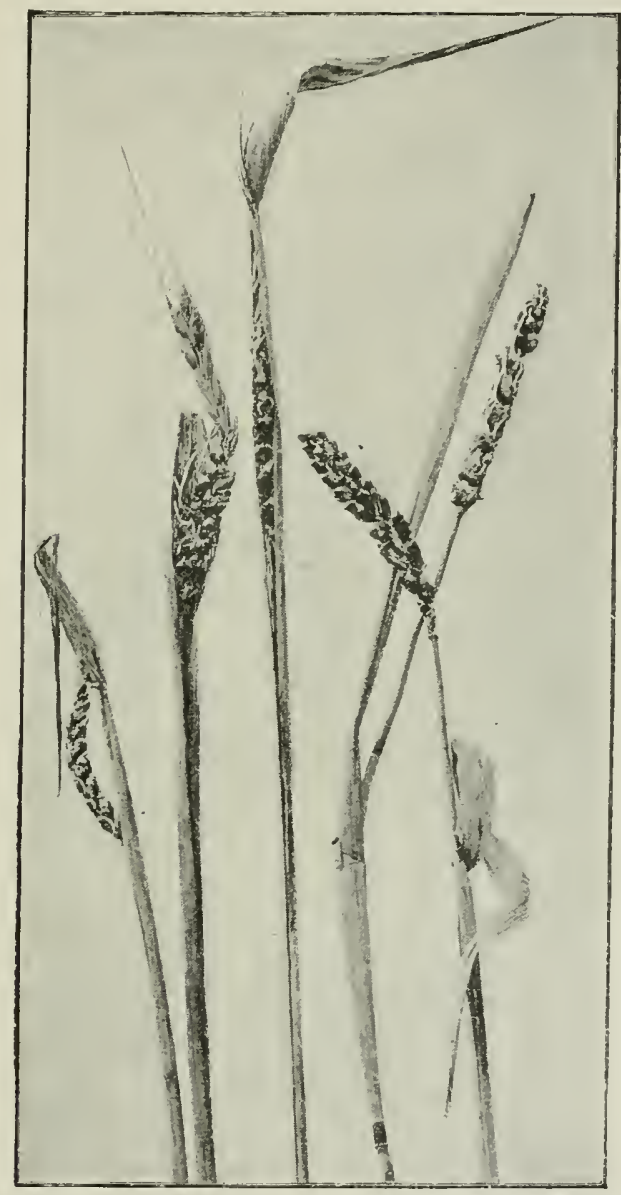

Ell. 159.-Ustilago hordci. Barley-smut on Hordeum distichum. (v. Tubeuf phot.)

coum, P. chartaginiense and $P$. Cruss-galli in Italy, France, Germany, and North America. Sometimes it is very abundant and causes great clamage. The mycelium makes its way into young plants and grows upwards with them, penetrating every 
shoot. Spores are developed only in the inflorescence, which in consequence fuils to reach its full development as a panicle, and remains more or less spike-like and encloser in a leafsheath. 'The parts of the inflorescence become completely filled

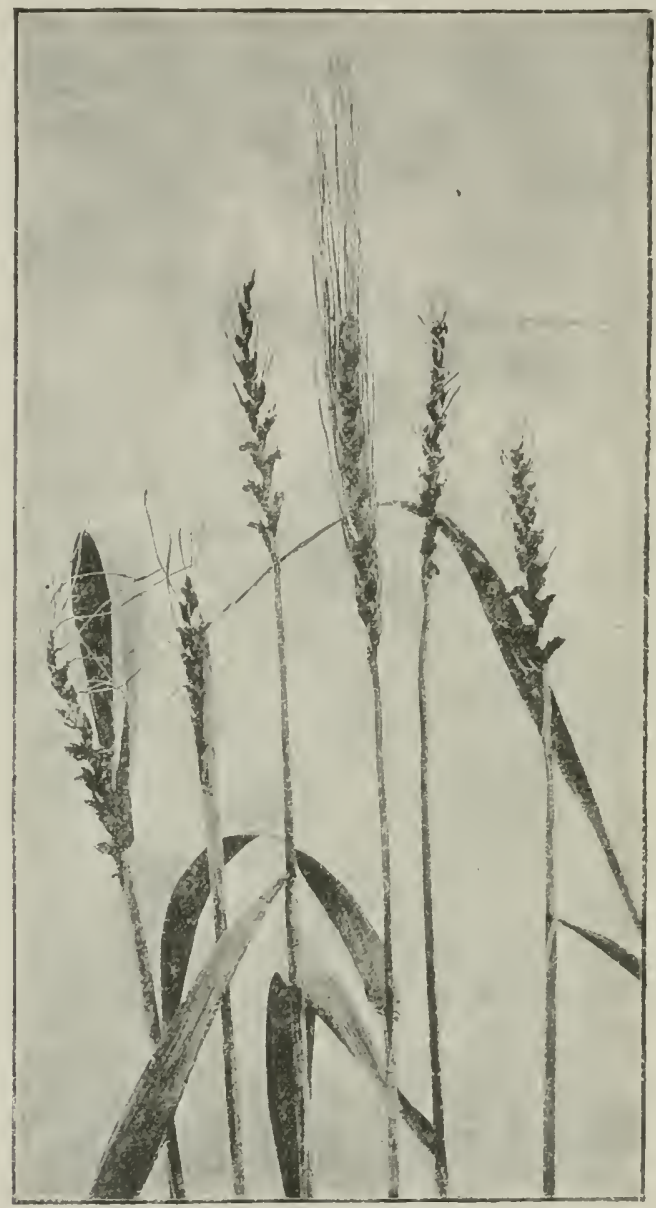

Fut, 160.-Ustilago tritici. Wheat-smut. The eentral enr is normal and healthy, the others are smutted and most of the spores are already shed. (v. Tubeuf phot.)

with a sporogenous mycelium from which arise the spore-masses; these are at first enclosed in whitish coverings consisting of tissues of the host-plant, but when mature they escape as a black dust or powder. 
The spores are smooth-coated and spherical or elliptical, $9-12 \mu$ long; and $8-10 \mu$ broad. According to Brefeld, they germinate in two or three days in water, and produce promycelia with four or five cells; the cells may either bud out directly and become hyphae, or do so after previous fusion.

spores placed in nutritive solutions germinate in about three days, and produce several strong septate promycelia with spindleshaped conidia. The conidia as a rule grerminate directly into branching hyphae; fusion of conidia is not known, and secondary conidia are only rarely formed. The hyphae become septate in their older parts, and produce conidia in two ways, firstly, from hyphae in the solution itself; secondly, from aerial hyphal branches which rise out of the solution and give off conidia in a manner similar to mould-fungi.

Brefeld states that infection takes place by means of the germinating coniclia. Only resting-spores are produced on the plant itself, and these retain their capacity for germination for years.

Ust. Rabenhorstiana Kiihn ${ }^{1}$ (U.S. America). This is found on Prenieum mitiaceun, P. glatrum, P. linere, and $P$. senguinale. It destroys flowers, ears, and upper part of haulms. The spores are browu and spiny; they germinate, but do not produce conidia.

Ust. sphaerogena Burrill. An American species causing distortion of the spikelets of Penicum C'rus-galli. The malformations resemble those produced on the same host by Tolyposporium bullutum, but differ in having a rough surface with short rigid hairs. The spores are free and germinate easily in water, producing promycelia which give off conidia. The conidia frequently spront for a time in a yeast-like manner.

The following are American species:

Ust. diplospora Ell et Ev. On Panicum sanguinale.

Ust. trichophora Lk. On Panirum colinum.

Ust. setariae Rabh. On Panicum sanguinale; probably ilentical with Ust. Liabenhorstiuna.

Ust. panici-leucophaei Bref. On Punicum leucopluaeum in Rio de Janeiro.

Ust. digitariae Kze occurs on the Howers of Punicum (Digitaria) sanguinale, P. glabrum, and P. repens. The spores are smooth-walled. 
Ust. panici-frumentacei Bref. ${ }^{1}$ is fomul on /'unimm firmenforrm, a cultivated Himalayan millet. (Only isolated grains in an ear are attacked, lecoming enlarged to twice their normal size. (iermination of spores takes place spraringly in water, hut abundantly in nutritive solutions. Two-celled promyeelia are prodncerl bearing mumerous sprouting conidia. () exhaustion of nutrition, the conidia give off one or two filaments wn the surface of the liquid, and from these other spronting conidia arise.

Ust. Crameri Korn. completely destroys the ovaries of Setariu itulicu, S. viritis, and $S$. ambigne, leaving only the onter wall as an enclosure for the spore-powder. The spores are brown, smooth-walled, and $6-9 \mu$ broad, $10-12 \mu$ long. The promycelia consist of four or five cells, which in water as well as nutritive solutions grow out into long threals without producing conidia.

Ust. neglecta Niessl fills with its black spore-powder the oraries of Seturin glonce, S. verticillate, and S. viridis. The cells of the promycelium develop into a nycelium without production of coniclia.

Ust. Kolaczekii Kiihn. On Seturiu genirulutu in Rerlin Botanic Garden.

Ust. bromivora Fisch. (Britain and U.S. America). This appears in flowers of species of bromus, so that the ovaries become filled with a dark-brown or black spore-powder, but the glumes or heads undergo no deformation. The spores are smooth, and on germination in water produce only a spindleshaped one-celled (rarely two-celled) promycelium; in nutritive solutions, Brefeld found they generally produced two-celled pronycelia, bearing conidia from which are produced further promycelia with conidia; yeast-like colonies are never formed.

Ust. ischaemi Fuck. attacks Andropogon Ischarmum. The inflorescences remain almosi completely enclosed in the uppermost leaf-sheath, and are destroyed except their axes. The spores are brown and smooth-walled. Brefeld states that in nutritive solutions they produce conidia which remain adherent to the pronycelimu and grow out into long hyphae without coalescing.

Ust. andropogonis-tuberculati Bref. on Andropogon tulverculatum from Simla.

Ust. andropogonis-annulati Bref. on Andropngon ammletum from Cnlcutta.

${ }^{1}$ Brefeld, schimmelpitor, Heft xir., 1s!). 
Ust. grandis Fries. Feed-smut. (Britain.) This frequents the haulms of Phougnites communis (also Typhu lutifolice and $T$. minor); the internodes of the host in consequence swell out and appear as if the stem carried one or more bulnush-heads. The mycelium permeates the whole host-tissue and produces spores, which escape as a black dust on rupture of the epidermis. According to Kiiln, the spores are capable of immediate germination and retain their vitality for a whole year. A four-celled promycelium is produced and becomes detached from the spore; then follows an abjunction of oblong coniclia from the septa of the promycelium. In nutritive solutions, Brefeld found that germination took place in the same way, but more rapidly and vigorously. Numerons conidia are proluced, but these only rarely give off secondary conidia, and then only a single one: more commonly they produce pronycelia, as the spores did, and conidia again arise from these: yeast-like spronting does not occur. The resting-spores may continue to give off promycelia in succession for some time. On exhaustion of nutrition the cells of the promycelium, as well as the conidia, develop into mycelial threads, to which alone Brefeld ascribes the capacity for infection.

Ust. longissima (Sow.) (Britain and T.S. America). This forms elongated brown spore-patches on the leaves of rarious species of Glyceria. Brefeld states that the smooth spherical spores germinate in water, and give off a short unicellular promycelium which undergoes no further development. In uutritive solutions the spores germinate in like manner; but the promycelium becomes thread-like and septate, and gives off conidia laterally; new promycelia continue to be given off from a cell which remains behind inside the spore, and the conidia ultimately develop into hyphae.

Ust. hypodytes (Schlecht). This species forms dark smutty coatings on haulms and leaf-sheaths of Glyeeria fluitans, Diplrechnis fusca, Agropyrum repens, Calamagrostis eprigra, Psamma areneria, Stipa pennata and S. capilluris, Bromus crectus, Triticum repens and T. vulgare, Elymus urenarius, Panieum repens, Phragmites communis, Amudinaria, etc. The spores are hrown, smooth-walled, and irregularly spherical or quadrangular; they germinate in water or nutritive solutions, producing mycelia direct, without previous formation of conidia. 


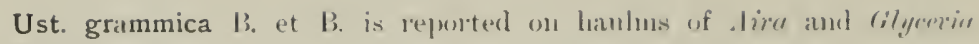
in Englauml.

Ust. echinata Schuret. produces smut-strips on leaves of Phaluris "rundimurure. (I.S. Amer.)

Ust. cynodontis Hemll. () ("ynorlon Incetylon from Simla.

Ust. arundinellae Biref. On Ammelinella near calenttit.

Ust. aristidae-cyanthae Bref. On . Iristida cyonthu from Himataya.

Ust. coicis Bref. On coix lecrymer from Simla.

Ust. esculenta Hemu.' anuse's deformation of plants of Zizanire lutifoliu in Tompuin and Jalyan. The deformed parts are eaten, while the spores are used fon dying of hair and eye-borws, as well as in the mannfacture of a ramish.

Ust. paspalus-dilatati Hem. On I'rspulus dilutatus.

Ust. olivacea J). C. frequents species of Cures. The olivebrown spore-masses hang loose and fleecy from the destroyed ovary. The spores, aceording to Brefeld, are produced from long hyphae which become thickened at intervals and broken up by eross-septa into portions corresponding to the future spores. The liyphae, however, are not completely given up tı spore-formation, but parts remain and form fine filaments which give the fleecy appearance to the ruptured ovaries. Germination in water results in the formation of a single conilium, a secom being rarely formed. In nutritive solutions similas conidia are produced one after another suceessively, and sprout off conidia in a yeast-like mamer without the formation of promycelia. On failure of nutriment, hyphae are finally produced.

Ust. Vuijkii Ondem. et Beyerk. The ovaries of Lusulu compestits become filled with spores, some colourless, some light-brown. The spores germinate in water, giving four-celled promycelia with ovoid conidia, which do not, howerer, eoalesce or develop further, even in nutritive solutions.

Ust. capensis Riees. In funit of Juncus.

Ust. luzulae sitce. In fruit of Luzulu.

Ust. scabiosae (Sow.) ${ }^{2}$ (Ust. flosculom Tul.). (Britain.) The anthers of Kuncutio and Scabrisa attacked by this fungus become filled with a flesh-coloured to violet spore-powder, and swell to little sacs. The flowers otherwise are but little altered. Brefeld found that spores from Kucutio urtensis germinate easily and abmudantly in water, and prodnce promycelia con-

${ }^{1} \mathrm{P}$. Hemings, Mealmigiu, 189.5; Miyahe, Tokio Botanical Maga:ine, 1895.

${ }^{2}$ Fiseher v. Waltheim, Bot. Zeinung, 186\%. 
sisting of three or four cells with conidia, and sometimes secondary conidia. Coalescence of conidia may take place, and thereafter production of little mycelial threads. In nutritive solutions everything proceeds more luxuriantly, and conidia are produced in large numbers; they are easily detached and spront

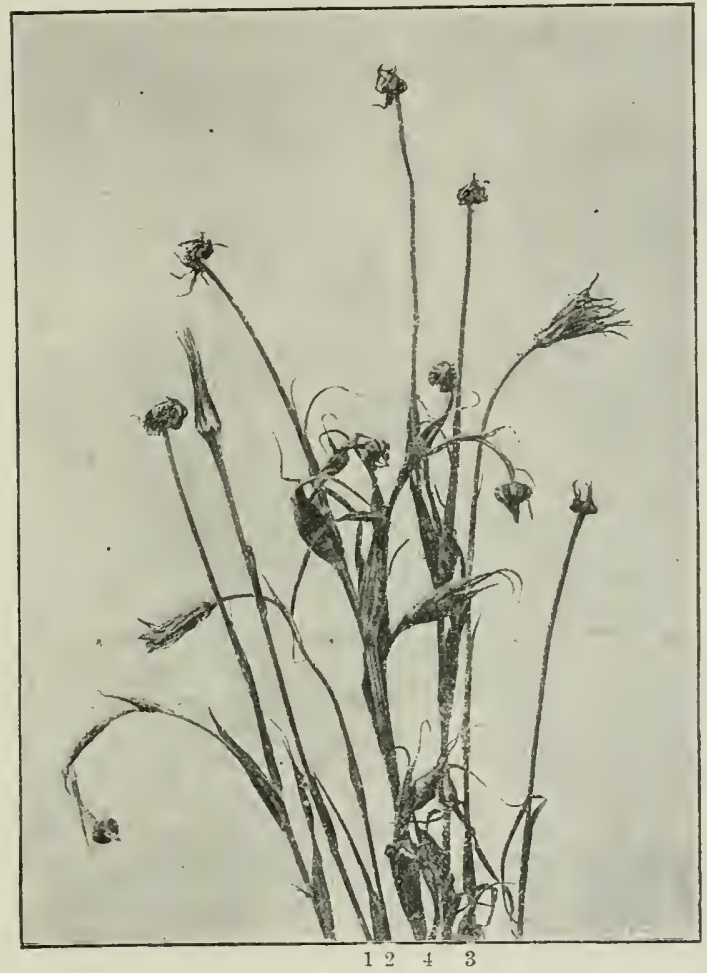

Fig. 161-Ustilaro tragopogonis. Plants of Tragopogon in flower and fruit1, normal fruit; 2 and 3 , normal flowers; 4 , two normal tlower-buds. The remaining specimens are attacked by the fungus, and, in consequence, remain remaining specimens are attacked by the fungus, and, in consequence, remain
in the bud condition, and filled with black spores which escape by the opening of the involuere. ( $\vee$. Tubeuf phot.)

yeast-like, till, on deficiency of nutrition, fusion and subsequent germination takes place.

Ust. intermedia Schroet. (Ust. flosculorum. D. C.) (Britain). The anthers of Scabiosa Columbaria become filled with the dark violet spores of this smut. The spores germinate in water, and, according to Brefeld, produce three-celled promycelia with few conidia; some of these, as well as the cells of the promy- 
celia, may rlevelop to mycelia; coalescence of conidia is molkwown. In mutritive solutions conidia are formed in large numbers, and multiply yeast-like till nutriment fails.

Ust. succisae Magn. ${ }^{1}$ frequents the anthers of Secebinsu Sucrisre, and forms pure white spores, easily distingmished from those of the two preceding species. The anthers appear to be thickly covered with glassy granules. The spores produce tour-etelled promycelia from which conidia are formed. (Britain.)

Ust. tragopogonis (l'ers.) (Britain).

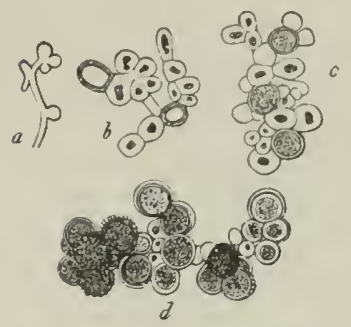

FIa. 162.-Ustilago tragopogonis. Development of spores: successive stiges of development, in order of the letters. a, Sporogenous braneh, just appearing on the surface of young corolla of Tragopogon pratensis, and beginning to form a tuft of branehlets. b and $c$, Formation of spores from the ingcelium. $l$, Sporeclump with several ripe spores, the upisporium of whieh is coloured dark-violet and thickened in a reticulate manner. $(\times 300)$. (After De Biry.)

produced, and coalescence always takes place.

Ust. scorzonerae (Alb. et Schwein.) is at first sight very similar to Ust. tragopogonis. Its spores are found in flowers of Scorzonera humilis, Sc. purpurea, and eultivated species, e.g. Sr. hispanica; while its mycelium hibernates in the perennial root-stocks of these. The spores are produced rapidly and in large numbers; they germinate easily in water, forning a four-celled promycelium, and thereafter conidia which do not pair.

Ust. cardui Fisch. v. Waldh. (Britain). This is the cause of a stunting of the flower-heads of Carduus aranthoides, $C$. metans, and Silybum Marianum, while at the same time they hecome filled with a brownish-violet spore-powder. The spores

${ }^{1}$ Magnus, Hedivigia, 1875. 
are about $20 \mu$ in diameter, and form in water promycelia with conidia. In nutritive solutions Brefeld found conidia produced in large numbers, and multiplying by yeast-budding. The promycelial cells grow out as septate branched twigs, from which conidia are abjointed, and after coalescing in pairs, prodnce germ-tubes.

Ust. violacea (Pers.). ${ }^{1}$ Carnation-smut (Britain and U.S. America). In Silene, Viscrima, Sreponariu, Dirnthus, Stellaria, Malchium, Cercustium, and Lychnis, the pollen sacs of otherwise well-developed flowers become filled with dark-violet spores, which escape and discolour the other floral parts. Yistillate Howers of Lychnis attacked by this fungus develop stamens containing the smut-spores (p. 27). On germination in water, promycelia of three or four cells are formed, and become detached from the spores. Primary and even secondary conidia are produced, while coalescence of promycelial cells and conidia is common; but only a few of them produce germtubes. In nutritive solution, according to Brefeld, everything proceeds much more vigorously: from tiny conidiophores on the promycelia numerous conidia are produced in succession, and from these other conidia are budded off like yeast-cells till nutriment fails, when they grow out to form hyphae. The coniclia are longer than those formed in the water-cultures, and coalesce in pairs to give rise to longer and stronger germ-tubes.

Ust. holostei De Bary on Holosteun umbellatum. The host-oraries become filled with spores which germinate to four-celled promycelia from which pairing sporidia are formed.

Ust. Duriaeana Tul. In the ovary of Cerastium.

Ust. major Sichroet. On Silene Otites. The spores grerminate only in nutritive solutions. (Britain.)

Ust. seminum Juel. In the ovules of Arabis petruea in Scandinavia. The spores on germination produce simple hyphae.

Ust. entorrhiza Schroet. In root-cells of Pisum satizum.

Ust. pinguicolae Rostr. On Pinguicula vulgaris in Denmark. According to Brefeld, the spores germinate equally in water or nutritive solutions, forming three-celled promycelia, which separate from the spore and bud off conidia from each cell.

${ }^{1}$ 'Tulasne, Am. $d$. sciences natur., Ser. III., Vol. vir, $184 \%$.

Atkinson (American Carnation Society, 1S93), describes this and other smuts frequenting American Carnations. (Edit.) 
Ust. betonicae Beck. ${ }^{1}$ oceurs in the anthers of Brtonim Alinucums. Its spores are larger than those of Ust. violmern, and have larger-neshed reticulations on the spore-coat. The spores germinate in water, and as a rule produce a three-cellerl pronycelium from which conidia are abjointed. These at once, or after production of coniclia, coalesce in pairs and give off germtubes. In nutritive solutions germination takes place much more vigoronsly, numerous coniclia are formed and continue to burl off new conidia till the nutriment is exhausted, when coalescence of conidia and (levelopment of hyphae takes place.

Ust. bistortarum D. C. frequents leaves of Polygonum and liumer. (Britain and U.S. America.) Brefeld states that the spores are dark-jerl and germinate to four-celled promycelia, from which conidia are produced and readily coalesce, especially in presence of abundant nutriment.

Ust. marginalis (Lk.) on Polygonum IBistortu. The spore-masses are dark-violet, and occur chietly on the nargins of the leaves. The spores germinate in water and produce a four-celled promycelium with oval coniclia, which do not sprout, but either pair or srow out as hyphae.

Ust. anomala Kunze. On leaves and in oraries of Polygonum (L.S. America .

Ust. utriculosa (Nees). In ovaries and anthers of Polygonum. The grevisl-violet spores, Brefeld says, germinate during the following smmmer, and give off four-celled promycelia with conilia which do not coalesce in pairs. Britain and C.S. America.)

Ust. Parlatorei Fisch. On twigs and leaves of liumex maritimens and li. obtusifolius.

Ust. Kuhneana Wolf. Iuhabits all parts of linimer Acetose and R. Acetrsellu (Britain).

Ust. Goeppertiana Schnet. On Rumex Acetosa, especially in leaves and leaf-petioles. The spores germinate in water or nutritive solution. The promycelimu is micellular and remains inside the spore, giving off a single conidium, which for a time buls off other conidia (L'st. olivacea alone hehaves. in this same way).

Ust. Molleri Bref. On Polygonum lispidum.

Ust. Koordersiana Bref. On Polygonum lrarbatum in Java.

Ust. domestica Bref. On Rumex domesticus in Norway.

Ust. vinosa (Berk.). On fruits of Oryria (Britain and U.S. America). The spores germinate in water or nutritive solutions, and prodnce a four-celled promycelium from which coniclia are given off; especially in nutritive solutions; the conidia ultimately produce germ-tubes.

1 Zooloy.-botan. Gesell., Yiema, 1880. 
Ust. Vaillantii Tul. ${ }^{1}$ appears in the anthers and ovaries of Grayer, Scilla, Muscriri, etc. The perianth of cliseased flowers remains, but is somewhat enlarged. The ovaries and anthers beconve filled with spores; the latter organs are, however, fully developed and may even contain pollen-grains mixed with spores. According to Brefeld, the spores germinate easily in water and in nutritive solution. A promycelium is formed which, after detachment from the spore, becomes three-celled and develops conidia. These spront for some time, then produce three-celled promycelia.

Ust. ornithogali (Schm. et Kze) forms leaf-swellings on Oritithogalum and Gugea.

Ust. tulipae (Hentl.) produces swellings on the leares of the tulip.

Ust. plumbea Rostr. occurs on leaves of Arum maculatum in Denmark.

Ust. ficuum Reich. In the fruits of Ficus (arica in Asia Minor.

Ust. Trabutiana Sacc. In berries of Draccena Diaco in Algeria.

Ust. Vrieseana Vuill. ${ }^{2}$ In the Botanic Garclen at Amster(laur, the roots of several species of Eucclyptus exhibited woorly tumours from which proceeded outgrowths resembling "witches" broons." These contained the mycelium of an Ustilago which produced spores in the cortical tissues.

Ust. (?) adoxae Bref. On Adorre moschetellina in cells of the subterranean stem. The spores produced only simple filaments without conidia.

Ust. Lagerheimii Bref. On liumen from Qunito.

Ust. Schweinfurthiana Thiim. On Imperata cylindricu from Cairo.

Ust. boutelouae-humilis Bref. On Bouteloun humitis from Quito.

Ust. Ulei Hemn. On Chloris.

Ust. spinificis Ludw. On Spinifer lirsuta from Adelaide, Australia.

Ust. Treubii Solms. ${ }^{3}$ This Javanese fungus and the galls produced by it deserve a somewhat lengthened notice on account of their general biological interest. It causes a hypertrophy on Polygomm chinense in Java, which further exemplifies the phenomena already noticed in connection with Cacome deformans on Thujopsis (p. 30).

The stems at attacked places show strong hypertrophy and great change in their anatomical structure. Solms designates the thickenings, in common with those caused by Cucomu!

${ }^{1}$ Tulasne, A nn. d. science natur., Ser. 1II., Vol. vir., 1847, with plates of Musruri.

Worth G. Smith (Gardener's Chronile, xr., 1894, p. 463), gires a figure and note on occurrence of this smut in Bitain. (Edit.)

2 Vuillemin, Compt. rend., 1894.

"Solurs, Annal. du jardin botan. de Buitenzory, Tol. vi., 1S86-8\%, p. 79. 
Irformans and Jeridermiun dutinum, as "vegetative cankergatls." On those places are crowded fleshy brittle outgrowths, consisting of an irregular bent club-like stalk, longitudinally furrowed, and expanded at its upper extremity into a broadened head containing the Ustilayo spores. Solms calls these outgrowths "fruiting galls," and he describes then as follows: " if one of these protuberances be divided, the spore deposit will be found as a flattened violet layer, extending to the margins of the head and roofed in by a slight plate of tissue. This last becomes ruptured, shrivelled, and brown. The violet spores are thus set free, along with a loose woolly capillitiumtissne, which apparently facilitates distribution of the spores by rendering them difficult to moisten, a contingency very likely to happen in the heavy tropical rains of Java, and with the result that germination would ocem before the spores had time to be transported to a new host. After shedding of the spores, the succulent stalk remains. The fruit-galls consist of a hypertrophied tissue developed from the cambium; they first emerge as roundish naked protuberances, covered externally by it smooth epidermis, and containing a meristem from which fibrovascular bundles are developed. The galls are composed of a homogenous parenchyma of large thin-walled cells, elongated in the direction of the long axis of the galls, and containing large cell-nuclei. The epidermis consists of little, polygonal, nucleated cells, and is pierced by a few stomata. The galls are internally permeated by a number of irregularly arranged fibrovascular bundles which show a slightly developed wood and bast region. As the anterior end of the fruit-gall elongates, the bundles keep pace by repeated forkings, and form a system of branches diverging at very acute angles and terminating a short distance from the surface of the gall. The violet-brown sporogenous layer is situated just at the termination of the bundles, and is covered by a slight layer of parenchyma under the epildermis. The sporogenous layer appears as if composed of columns arranged beside one another in a palisacte manner, and connected above and below with the enclosing tissues. At the margins of a section the columns easily separate, and will be seen to consist of a central strand of elongated cylindrical cells filled with a reddish gum-like mass. The cells 
belong to the tissue of the Polygonum and may form simple filaments, or several such filaments may become bound together by lateral connections. Each strand becomes surrounded by spores of the Ustilago which are set free on rupture of the fruit-gall, while the cell-strands laterally bound to each other are loosened from the surrounding tissue as the capillitimu.

"The spores germinate in water, producing short unicellular promycelia and fairly large conidia, which coalesce before they germinate. The mycelinm is confined to a small part of the stem, twigs, or inflorescences of the host-plant. The hypertrophied parts of the stem contain abnormal spongy wood, which easily decomposes and brings about the death of the galls, along with parts of the stem situated beyond them, or even the whole plant. The normal production of cambium is completely destroyed in the galls. The pith and primary rind, however, remain uninfluenced. The cambium produces, both outwards and inwards, such a mass of thin-walled parenchyma that the normal bast is forced asunder and disarranged. In this way rupture of the sclerenchyma-layer ensues, whereby the primary rind is destroyed, and the abnormal tissue formed by the cambium emerges to view. It is from such places that the excrescences described have their origin."

It will be seen we have here the partners of a symbiosis becoming so adapted to each other that the host-plant produces a special tissue for the distribution of the spores. This case goes further than most of those already mentioned in $\$$ but the bushes produced by Cacoma deformans for the formation of its spores are again a distinct advance on the "fruit-galls" of this Ustilago.

\section{Cintractia.}

Spore-nasses developed inside a stroma and passing outwards so that the mature black spores lie freely exposed.

Magnus ${ }^{1}$ has recently separated Lstilago caricis Pers. and $U$. subinclusu Körı., and placed them under this genus, because their spores are developed only in the epidermal cells of the host-ovary.

Cintractia caricis (Pers.) ${ }^{1}$ (Britain and L'.S. America). The

${ }^{1}$ Cornu. Amal. d. scienees natur., Ser. VI., Vol. xv., 1883. Plate XV.

Magnus, Botan. Ferein d. Pror: Braudenhury, xxxvis. Brefeld, Schimmelpitz. Heft XII., 1895. 
mycelium forms a strona on the ovary-wall; there the spores originte and pass out to the periphery as they attain maturity. 'The spores arlhere in black

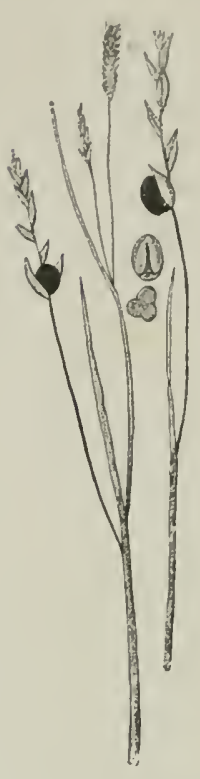

FIf: 163. - Cintractict caricis. Two oritries have been replaced by black spherical fungus-fruits ; an isolated normal triangular ovary is shown in longitudinal and cross section. (v. Tubeuf (del.)

abjointed, while from the lower cell a lateral conidiophore is produced. Numerous conidia are given off from both cells, and grow out without previous sprouting.

C. (?) sorghi (Endothluspis sorghi) Sor. The mycelium envelopes the grain of Sorghum cernurm, and fills it with black spore-masses. It has only been observed in Asia..

Other species of Cintractia occur ontside of Europe, but are of no practical importance.

\section{Sphacelotheca.}

The sporocarp is sharply defined, and consists of a columella round which the loose mass of spores is clisposed, the whole being enclosed in a covering formed by non-sporogenous hyphae.

Sphacelotheca hydropiperis (Schum.). De Bary describes 
this fungus as follows: " "Splacelother" forms its compound sporophore in the ovule of its host. When the ovule is normally and fully developed in the young flower, the parasite, which always grows through the flower-stalk into the place of insertion of the ovary, sends its hyphac from the funiculus into the ovule, where they rise higher and higher and surround and penetrate its tissue to such an extent as almost entirely supplant it, and thus an oroid fungus-body of densely interwoven hyphae talies the place of the ovule. The micropylar end of the integuments alone escapes the change, and remains as a conical tip (Fig. $16+C^{\prime}$ ) on the apex of the fungus-body and gradually turns brown and dries up. The fungusbody is at first colourless and uniformly composed of muchbranched hyphae, which are woren together into a compact mass and have the gelatinous walls of the simple sporophore of Ustilago to be described below. If it has retained its ovoid form as it steadily increased in volume, differentiation begins first in the apical region into a comparatively thick outer wall which is closed all round, an axile columnar cylindrical or club-shaped body, the columella,

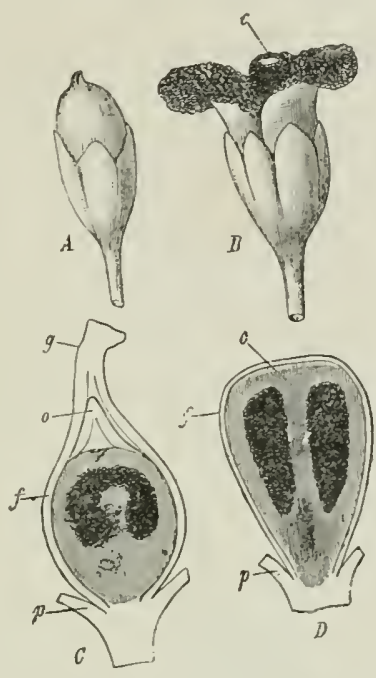

Fir. 164.-Sihacelotheca hydropiperis in the flower of Polygomun Hydropipei. A, Ripe compound sporophore of the fungus project. ing from the perianth of the Polygonum. $B$, The same, with the mass of sporcs emerging from the sporophore. $C$, Jedian longitudinal section through a young fructification and its environment. $D$, Longitudinal section through an older sporophore. $c$, The columella. $\rho$, The perianth. $f$, The wall of the ovary. o, The integument (micropyle) of the orule. $g$, The style. In $C$ and $D$ the sterile or joung tissue of the fungus is shaded by longitudinal lines, the mass of ripening spores is darker. Further explana. tion in the text. (Slightly magnified.) (After De Bary.)

both parts remaining colourless, and a dense spore-mass which fills the space between the two and becomes of a dark violet colour (Fig. $164 \mathrm{C}, D$ ). The lower part which corresponds to the funiculus and chalaza of the ovule remains undifferentiated, and an abundant formation of new hyphae is constantly taking place in it. This new formation is so added from below to the differentiated portion, that the latter constantly increases

${ }^{1}$ De Bary, ILorphology and Biology of the Fungi, English Edition, p. 173. 
in height withont beconing materially brouler, and maintains therefore the form of a cylinder pointed at the "rper end. Irlere the parts below approach the wall, columella, and sporemass, they assume their structure and colour. In other words, each of the three portions grows from its base by arldition of new tissue-elements, which are eonstantly being producel and pushed onwards from a basal formative tissue, and are differentiated and assume their ultinate form in the order in which they are produced (Fig. 16t, $C^{\prime}$ and $D$ ). 'The development and mature structure of the spore-mass are the sane as those of Ustilayo, which will be described presently. The wall in its fully developed state is a thick coat formed of many irregular layers of small round cells not very firmly united together. These cells are formed in the same way as the spores from the hyphae of the primary tissue, and are of about the same size as the spores with a delicate colourless membrane, and for the most part with watery hyaline contents. The columella has the structure of the wall, but it usually incloses in its tissur evident brownish fragments of the tissue of the ovule, and consists at its uppermost extremity of much larger, firmer hyaline cells, the origin of which I an unable to explain. I mat also observe that the upper extrenity in young specimens always ends blindly in the spore-mass $\left(C^{\prime}\right)$, but in some older ones reaches to the apical portion of the wall and passes into it $(D)$; it is still mneertain whether this is a difference in the individual plants or a difference of age.

"The spore-receptacle which has now been described is fomed only from the ovule. The periantl and stamens of the flower continue in their normal state. The wall of the ovary and the style are also not attacked by the fungus; they do not follow the growth of the spore-receptacle, and as this advances the lateral wall is distended and at length bursts transversely: the style with the upper portion of the wall dries up into a small point at the apex of the receptacle, which is borne by the latter as it grows ont of the perianth $(A)$. The wall of the sporereceptacle, especially where it is covered above by the withered remains of the wall of the ovary, is very fragile, and tears asunder at the slightest touch to discharge the spores $\left(B^{\prime}\right)$." $^{\prime \prime}$

The dark-violet spores have a finely-warted exospore. According to Jirefeld, they germinate in water after a resting 
period, and produce three-celled promycelia with elongated ovoid conidia, which sprout indefinitely. In mutritive solutions two or three promycelia may be produced.

\section{Schizonella. ${ }^{1}$}

The spores are produced in series on the reproductive hyphae. At first two-chambered by means of a cross-septum, they later separate into two loosely-joined cells and form twin-spores; each half germinates like an Ustilago-spore.

Schizonella melanogramma (D. C.) (U.S. America). A species found on leaves of various species of Carex. The spores, when mature, escape by short fissures in the upper epidermis of the host; they are black and coupled in pairs by a short connection. They germinate in water and produce a promycelium of three or four cells from which conidia are given off. In nutritive solution the promycelia produce conidia, which fall off and sprout yeast-like for a time.

\section{Tolyposporium.}

The sporogenous hyphae form tangled masses, and produce their spores firmly bound together in balls. The single spores are large, somewhat angular or spherical, and each grerminates like a spore of Ustilago.

Tolysporium junci (Schroet.) causes the formation of gall-like outgrowths on the ovaries, flower-stalks, and haulms of Juncus bufonius and $J$. capitatus. In these the spores are developed and escape as spore-balls. The spores, after a prolonged rest, germinate in water and produce four-celled promycelia, from which ovoid or spindle-shaped conidia are given off. In nutritive solutions many of the cells in each spore-ball germinate and produce promycelia, at first four-celled, later further divided by new septa; the conidia sprout and grow on till they reach the air, where aerial conidia are formed. 
T. bullatum Sichroet. (L.S. America). The ovaries of I'tnicum Cirus-galli are transformed by this fungus into spherical tumourlike bodies, which project fron the otherwise unchanged flower and enclose the llack spore-masses. The spore-balls consist of hundrecls of spores which, Brefeld says, germinate in water in the following year. Each produces one, two, or three twocelled promycelia, which give off teminal spindle-shaped conidia: these sprout in nutritive solutions and ultimately form aerial conirlial.

T. Cocconii MLon. In leaves of Curer recurre in North Italy.

T. penicillariae Bref. On I'enicillarie spicate from Simla.

T. cenchri Bref. On Cenelerus ectinatus.

\section{Tilletia.}

Spores forned from hyphae, which swell up in a gelatinons manner. Conidia spindle-shaperl or tilamentous, and produced in whorls from the extremity of a non-septate promycelimm; they are developed only in air and generally fuse in pairs before being detached from the promycelium.

Tilletia tritici (Byerk.) ( $T$. ceries Tul.) (Britain and U.S. America). Smut, stink-brand or stinking-smut of wheat.

This constitutes one of the most destructive smuts of wheatgrain, not only destroying the grains actually attacked, but the black spores cause such damage to the remainder, when threshed or ground, that it is useless for bread-making. The presence of this fungus is most obnoxious from its strong odour of herringbrine or trimethylamin, hence the name stinking-smut or stinkbrand. The smut also possesses poisonons properties which make flour contaminated with it dangerous to human beings, and the straw or chaff injurions to cattle.

Certain diseases are producel in animals ly the consunption of smutfungi with food. The effects of each species of smut have not as yet been closely investigated, but Tilletia tritici seems to be one of the chief causes of trouble. The following are also suspicious: Lstilago maydis and the various species of C'stilayo which attack oats, barley, wheat, and grasses. The symptoms in the few cases of disease olserved do not agree very closely. A paralyzing effect on the centres of deglntition and the spinal cord seems to be regularly present. As a result one generally finds a continuons chewing movement of the jaws, and a flow of saliva, also lameness, staggering, and falling. Cattle, slieep, swine, and horses are all liable to attack. 
The black spore-powcler is developed as an evil-smelling mass in the ovaries of the host, which are completely destroyed except the outer coats. As a rule every grain in an ear is attacked. The smut is at first oily or greasy, but gradually dries up to form a hard stony mass enclosed in the fruit-glumes and

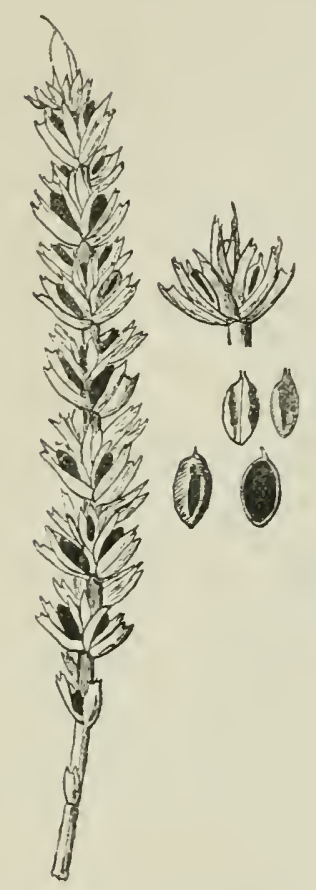

FIG. 166. - Tilletis tritici. Stinking-smut of Wheat. Ear of wheat with smut-grains indicated black. The isolated spikelet contains two smut-grains, which, as well as the isolated examples, show fissures in the original ovary wall. One smutgrain in section shows the interior filled with black spores, but the ovary wall still intact. (ז. Tubeuf del.)

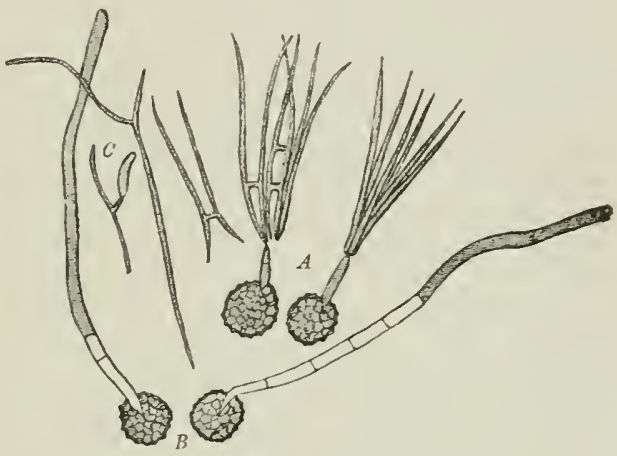

FIG, 167.-Tilletia tritici. A, Two spores germinated in moist air; a short promycelium is developed, and bears a crown of conidia (sporidia), several of which have fused in pairs. Fushion of conidia, germination, and development of a secondary conidium, $C$, are also shown. $B$, Two spores gcrminated in water with prompcelia which elongate till the water surface is reached, where they form sporidia; the promjcelia are septate and the plasma passes over into the 5ounger cells. (v. Tubeuf del.)

pales. The spores, therefore, do not escape as clust on the field, but remain in the heads and are garnered with the crop.

Smutty ears are easily distinguished on the field by their stiff erect position towards harvest-time, as compared with the more or less nodding healthy ears; their florets also lie more away from the axis of the ear, the chaff-glumes are more spread 
out, and the grains are somewhat compressed. In earlier stages of development the diseused ears are less easily distinguished, but they grow more rapidly than the norual, their ovaries are earlier formed, and have a dark greenish-brown

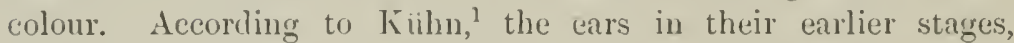
as they energe from the leaf-sheath, possess abmormally thickened seed-conts, especially towards the apex, while in section they show a dark-green colour. He also found the grains to be replaced by “ white and easily detachable mass of fine mycelinm. Sipores are formed as swellings on the ends of the sporogenous hyphae, and into these the plasma-contents of the hyphae pass over. The mature spores are dark-grey and spherical, with netted markings on the episporium. They germinate in water, and produce a promycelimm of varying length. The conidia arise as a whorl of thread-like branches on the end of the promycelium, and into them all the protoplasm passes over, while the promycelium, after being cut off by a cross septum, disappears, leaving the conidia as isolated bodies (Fig. 167). The conicia become united in pairs, frequently before isolation. After fusion comes germination, and the emission of a filament from the end of which sickle-shaped conidia are abjointed. Kiihn states that these coniclia, as well as the whorled primary conidia, if placed in a damp atmosphere, can give rise to a hypha eapable of infection. In water, however, the hyphae continue to grow longer, the plasma from the older parts passing over to the younger, and no conidia are formed (Fig. 167).

The conidia which remain unpaired were found by Brefeld to behave similarly to those which pair, except that the resulting germ-tubes and conidia remained smaller. Spores refuse to germinate in nutritive solutions. Conidia grown in water cultures and placed afterwards in nutritive solutions, give off it fine mycelium, from which short, lateral, aerial branches become cut off by septa, and devote their contents to the production of a few sickle-shaped conidia; these are easily detached, and produce a mycelium capable of giving off further conidia in a manner similar to that just described.

The investigations of Brefeld have also given the interesting result that hyphae which produce conidia may also give rise to spore-like bodies. The hyphae, after growth in length has

${ }^{1}$ Kühn, Die Krankheiten d. Kulturgerë̈chsp, 1858. 
ceased, begin to thicken, at first equally, then more at some places than others, so that they become nodose or rosary-like, with swellings at irregular intervals. The spores originate in the swellings, and between them are formed cross-septa which split and bring about isolation of the spores.

Kiihn's experiments on infection are of considerable interest. He investigated the germination of this and other smut-fungi, cultivating many of them in his garden at Halle, and published his results as early as $1858 .^{1}$ In his artificial infections he dusted seedlings with spores of Tillctia, and investigated the different parts of them microscopically. Sections showed hin that the germ-tubes penetrate direct through the walls into the epidermal cells, and always in the neighbourhood of the lowest nodes. Thence the mycelium grows upwards with the lengthening plant, especially through the pith, and the plasma of the older mycelium passes onwards into younger parts. In this way the hyphae, without greatly disturbing the growth of the wheat-seedlings, reach the ovaries, and with the formation of spores begin the work of destruction.

Kiihn was also able to demonstrate that both germinating sporidia and conidia are capable of infection, and that, where many had infected the same plant, so much mycelium could be produced that death of the host ensued. According to the same anthority, the fungus attacks spring wheat more than winter wheat, and the common forms (Triticum satirum and T. turgidum) with nearly allied varieties, more than "spelt" (Triticum spelta).

As a preventive measure against Tillctia, the experinents of Kellermann, Swingle, Kirchner, and others, lead them to recommend Jensen's method of placing the seed in hot water immediately before sowing. (See Chap. TI.)

Tilletia laevis Kiihn. (U.S. America.) This is another stinking smut of wheat similar to $T$. tritici, except that its spores have perfectly smooth coats.

T. controversa Kiihn. Found in grains of Triticum repriss (couch-grass) as well as Tr. vulgare and 'Tr. glaucum. The spores are distinguished from those of $T$. tritici by the higher ridges and wider meshes on the episporium. The mycelium

${ }^{1}$ Previous to Kiihn, Prevost and Tulasue had in 1853 carried out experiments ; also Gleichen in 1781 . 
perennates in the rhizones. The spores, according to lirefeld, germinate in water after a resting periorl of two years; in two years more they lose their capacity for germination.

T. secalis (Cord.) ${ }^{1}$ is epidenic and destructive in ovaries of Sicrele cripcule.

T. decipiens P'ers. (Britain). In fruits of Agrostis venlyuris and A. stolmifere. Schroeter says the plants remain stunted. Brefeld states that spores germinate in water after a restingperiod of three years, and lose their capacity for germination in the following year.

T. lolii Auersw. frequents the ovaries of cultivated Lolium perenne, and of I. temulentum (darnel-grass).

T. hordei Körrı. necurs in grain of Hordeum fragile and H. murinum in Persia.

T. separata (Kunze). In grain of Apere Spiect-venti.

T. calospora Pass. In grain of Aredropogon cigrestis in Italy.

T. Rauwenhoffii Fisch. In grain of Holcus lanatus in Belginm.

T. olida (Riess.) forms stripes on the leaves of Bruchypodium syluaticum and I3. pinnutum.

T. sesleriae Juel forms similar stripes on leaves of Sesleria coevuleu.

T. striiformis (Westend.) occurs on leaves, leaf-sheatls, and stalks of Alopecurus, Anthoxinthem, Afilinm, Holcus, Arhenatherem, Briza, Poa, Dactylis, Festucu, Bromus, Agrostis, Lolizen, etc. (Britain and U.S. America).

T. calamagrostidis Fuck. On leaves of Culumagrostis epigaea, C. Hallerianu and Triticum repens.

T. epiphylla Berk. et Br. Stink-lurand of Australian maize.

T. Fischeri Karst. In fruits of Carex canescens in Finland.

T. arctica Rostr. On leaves and stalks of Curex festive in Finmark.

T. thlaspeos Beck. In fruit of Thlaspi alpestre.

T. zonata Bref. On Sporobolus liguleris from Quito.

T. (?) glomerulata Cocc. et Mor. oceurs in Italy on leaves of Cynodon Duertylon, Plentago lenceolata, and Medicago.

T. sphagni Nawaschin ${ }^{2}$ was once regarded as a second form of spore of Sphagnum.

T. oryzae Pat. The fungus to which this name was given forms sclerotia in the grain of Oryzu sutive (Rice) in Japan.

Brefeld ${ }^{3}$ found that dark spores are given off from the surface of the sclerotia. These spores, on germination in nutritive solution, produced a septate mycelium which, in dilute solutions, gave off pear-shaped colour-

${ }^{1}$ Kühn, Botan. Zeitung, 1576, p. 470. Colnn, Jahrbuch d. Schles. Ges. f: raterland. Kultur, 1876. Niessl, Hedrigia, 1576.

- Nawaschin, Uëber die Brandlrankheit d. Torfmoose, 1S93; and Mélanıes biologiques, t. xi11., liv. 3, 1893.

${ }^{3}$ Botan. Centralblatt, Lxv., 1596, p. 97. 
less conilia incapable of germination. When the nutritive solution was frequently renewed, the mycelium grew vigorously and formed a sclerotiumlike body, from which the dark spores were laterally abjointed and set free. On this accomnt Brefeld founderl a group with the generic name of Ustilaginoidea; it inclutes this species as Ustiluginoidea oryzue and another similar one on Setariu Crus-Ardeue he calls Ust. seturice. The group has aftinities with the Ustilagineae and Ascomycetes like Claviceps, and Brefeld sees in it a comnecting link between the two families.

Several other American species of Tilletia have been recorded.

\section{Neovossia.}

Characters similar to Tillctic, except that the conidia produced on germination of the spores do not coalesce. Conidia sown in nutritive solutions produce a mycelium with two kincls of secondary conidia.

N. moliniae Körnike. The black spore-powder is developed in enlarged ovaries of Molinia cocrulea. The smooth ovoid spores are enclosed in a transparent mantle, and have a hyaline tail-like appendage. Each spore is produced at the end of a hyphal filament, which remains attached after the spore-mass is freed and forms the appendage. The spores germinate in water at once, and send up a simple aerial promycelium, on the apex of which a crown of many needle-like coniclia are produced. Septation of the promycelia may take place if they become rery long, the protoplasm passing into the apical segunents and leaving the basal empty, as in Tilletia. Branching of the promycelia may also occur. The conidia on being shed give off sickleshaped secondary conidia. In nutritive solutions, however, the conidia produce a mycelium from which either sickle-shaped or needle-shaped conidia may be given off, the latter however never as a crown or circlet.

N. Barclayana Bref. In the fruits of Pennisetum triftorum in Sinla. (This is not synonymous with Lstilugo penniseti Rabh.).

N. (?) bambusae Bref. In fruits of bamboo from Brazil.

\section{Entyloma.}

Mycelium intercellular and never gelatinous. The spores are of intercalary origin, and arise here and there on any part of the inycelium. The spore-clusters appear externally as spots, and the spores never leave the host. The spores on 
germination froduce a thread-like promycelimn bearing apical conidia, which conjugate in pains before emerging from the host-tissues.

The following species form conidia on the host-plant:

Entyloma serotinum Schroet. ocenrs on leaves of Symphytum tuberosum, S. officinalis, and Borago officinalis.

E. canescens Schroet. On M/yowotis (Britain).

E. fuscum Sichroet. On l'reprezer lihoees and l'. Argemone.

E. bicolor \%oplf. On P'upurer likoers and P. rubium (Britain).

E. ranunculi (Bon.) forms white spots on species of Rununculus. Tufts of hyplae energe from the stomata and

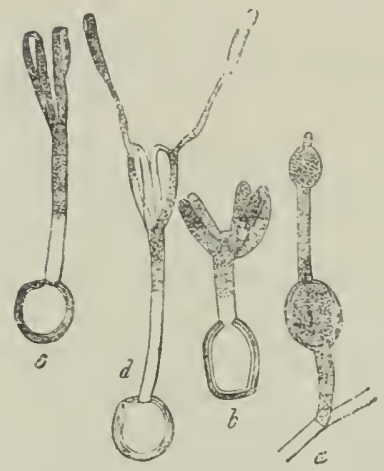

Fic. 168.-Enluloma calendulae. a, My. celial filament, with two young resting. spores. b, Resting-spore germinating ; the anterior pair of prinary conidia shows conjugation or fusion at the base.

Entylona mierosporum. c, Germinating restiug-spore; four vrinary conidia fusing in pairs at their apices. d, The same specimen seren hours later; commencement of abjumetion of a secondary sporidium on caeh pair. (After De Bary.)

\section{E. calendulae (Ondem.) on Calendula, Hieracim, Amoseris, Amicu,} Bellitiastrum, etc. (Britain) (Fig. 168).

E. crastophilum Sacc. on l'oce and Deetylis in Italy.

The following prodnce gall-like swellings:

E. microsporum (Lng.) (E. Cngeriannm De Bary) (Britain and U.S. Anerica). On lianunculus repens, R. bulbosus, and R. Ficurin (Fig. 168).

E. Aschersonii (Ule) on roots of Helichrysum arenarium (Fig. 169).

E. Magnusii (Cle) on roots of Ginaplutium uliginosum and G. luteo-ulbern (Fig. 170).

${ }^{1}$ H. M. Wind, Philowoph transactions of Royul Soc. London, Vol. 17s, 1ss?. 
Still to mention are:

E. Ellissi Halst., known as "white smut." It inhabits spinach (Spinacia oleracea), discolouring the leaves.

E. ossifragi Rostr. on Varthecium ossifragum in Denmark.

E. catenulatum Rostr. on Aira caespitosa in Denmark.

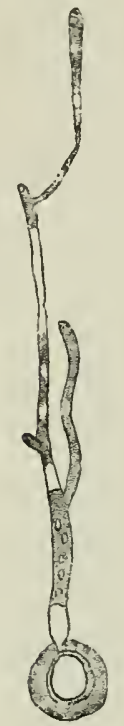

Fig. 169.-Entyloma Aschersonii. Germinated spore with septate promycelium; one pronscelial branch remains rudimentars, the other (to left) has produced two branches, one of which has elongated and bears a conidium. (After Woronin.)

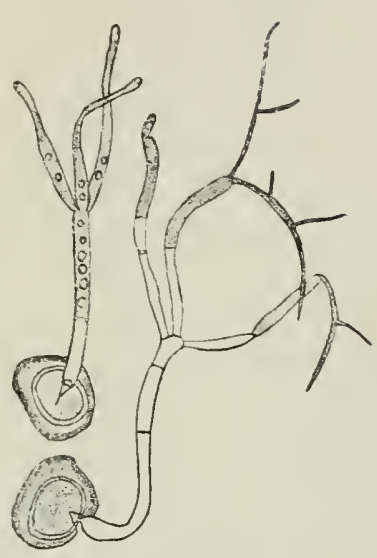

Fig. 170.-Entylonize Magmusii. Germin. ated spores; the promscelium of one shows a whorl of three branches with apices elongating to form germ-tubes; the other shows two, out of three, germ-tubes giring off branched sporidia (conidia). (After Woronin.)

E. leproidum Trab. ${ }^{2}$ [Oedomyces leproides (Sacc.)]. Diseased beet-rout exhibits irregular outgrowths, which enclose spaces filled with the brown spore-powder of this fungus.

E. nympheae (Cumningham) Setch. ${ }^{3}$ on various species of Nymphea in America, Africa, and Europe.

\section{Melanotaenium. ${ }^{4}$}

Spores unicellular in patches on an intercellular mycelium lying deep in the host-plant; they have a thick dark brown

${ }^{1}$ Halsted, New Jersey Agric. Exper. Station Bulletin, No. 70, 1890.

2Trabut, "Sur une Ustilaginée parasite de la Betterave." Compt. rencl. CXviII., 1894.

${ }^{3}$ Setchell, Botanical Gazette, 1894, p. 1SS (with illustrations).

${ }^{4}$ Schroeter, Kryptogam. Flora r. Schlesien. Woronin, Senckenberg Gesell, $18 S 0$. 
eprispore, and the clusters appear black or leaden-crey. Germination as in Entylume.

Melanotaenium endogenum (Lnger) (Britain). This is

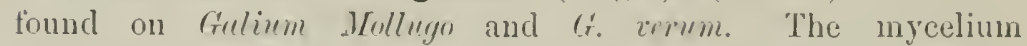
permeates the whole intercellular system of the host, and is

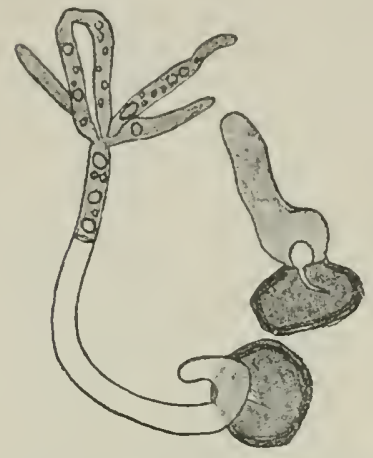

Fxc. 171.-Melairotaenium endogenum. Germinating spores. One has already produced a promycelium with a whorl of five branches, of which two lave fused. (After Woronin.) nourisled by large tufted haustoria. The host-plants remain small, with shortened internoles, shrunk leaves, and undeveloped flowers. The spores ocem in patches in deformed flowers, and on leaves and internodes. They are formed in summer, and by autumn are capable of germination in water; Woronin could not keep them alive over winter. On germination a bifurcate promycelium is produced, one branch of which remains rudimentary, while the other grows on, and, if long, becomes divided by cross-septa. At its apex, a number of conidia arise, and, after many of them have fused in pairs, they germinate directly to a septate filament into which the plasma passes over (Fig. 171).

Mel. caulium (Schneider) causes the stem of Linaric vulgaris to swell up like a quill.

Mel. cingens (Beck.) on Linariu yenistifolia. According to Brefeld, this species only germinates after resting for four years, whereas Juel easily caused Mel. caulium to do so after a short rest.

\section{Urocystis.}

Spores massed into balls, consisting of several spores surrounded by smaller companion-cells incapable of germination. The central spores are clearly distinguished from the others by their larger size, darker colour, and thicker coat. The balls of spores are developerl inside coils of lyphae, which become entwined together and swell up in a gelatinous manner. The central spores on germination give rise to a promycelium, with terminal conidia which do not as a rule fuse in pairs, but grow out clirectly into mycelia. 
Urocystis occulta (Wallr.). (Britain and U.S. America.) This species is common on the haulms, leaves, leaf-sheaths, and less commonly on floral parts of Secule cercule (rye). It causes the

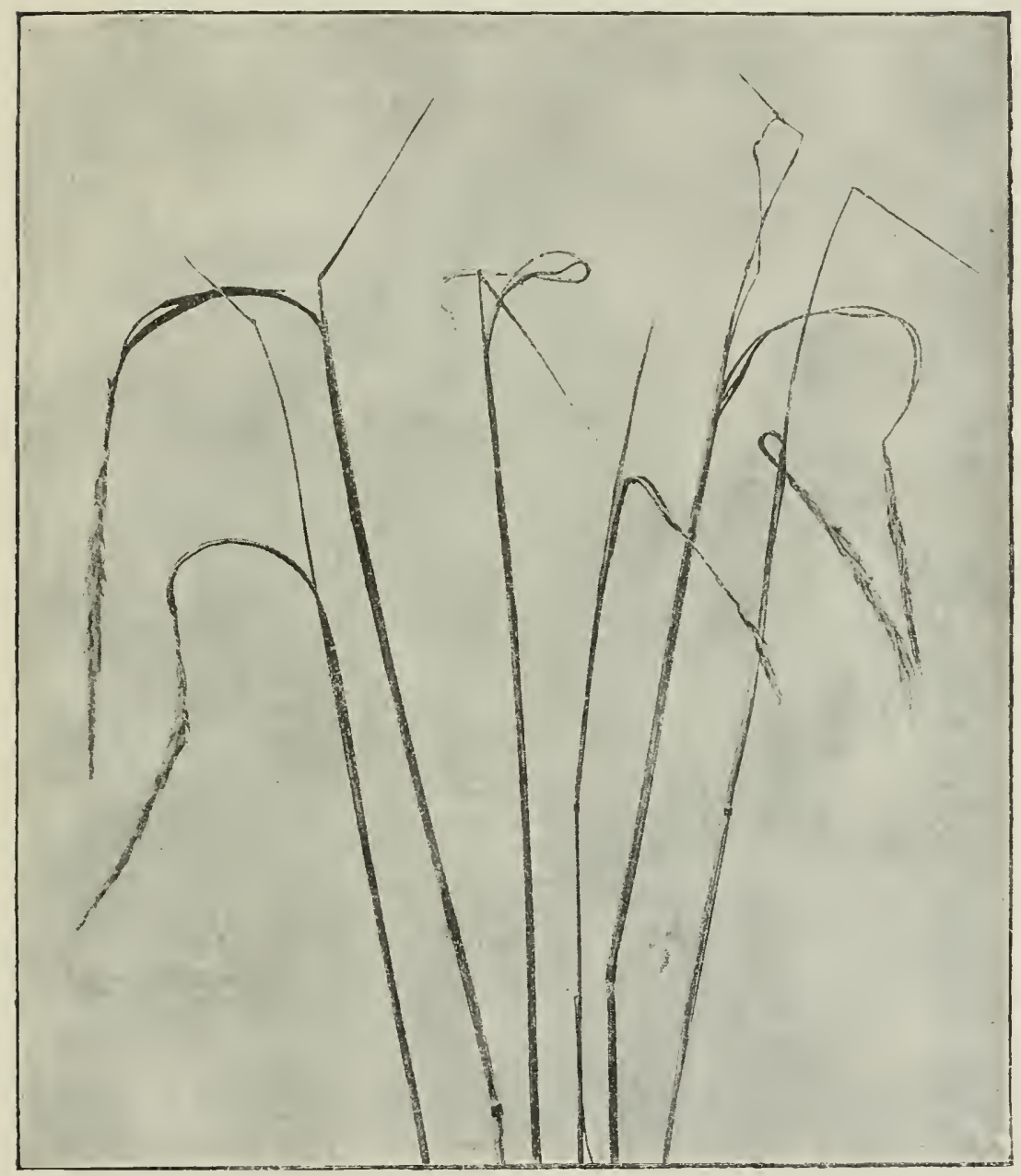

Fig. 172.-Urocystis occulta on R5e. The ears are stunted, and the sporepowder emerges from longitudinal fissures in the upper part of the stems. (v. Tubenf phot.)

formation of grey stripes, from which a black spore-powder escapes. The haulms become diseased and smutty, thereby preventing development of the ear, which remains stunted and 
empty (Fig. 172). Spore-formation causes the parenchyma of the stem to be destroyed in strips, along which rupture takes place, and the haulun, losing its rigidity, falls over. The balls of spores consist of one or two smooth spores enclosed by companion-cells. Germination takes place easily in water, and a cirele of cylindrical coniclia are produced from the end of each promycelium. The conidia, without becoming detached, give off a lateral germ-tube. The mycelium rloes not hibernate.

While this smut does not occur on cereals so commonly as species of Ustilago and Tilletice, still it may sometimes cause severe loss. Treatment of seed by Jensen's hot-water method, or by a copper sulphate steep, may be resorted to, but the results have not as yet been always successful.

The only other smut of rye is Ustilago sccalis in the grain, and it is only rarely found. Winter, however, considers rye amongst the host-plants of Urocystis agropyri.

Urocystis agropyri (Prenss.) (Britain and U.S. America). Leaves and haulms of Trition repens, Arhenatherum elatius, Festuce mbru, and Bromus inermis are the habitat of this species.

U. festucae. Another species distinguished by Ule on Festuca.

U. Ulei Magin. In leaves, more rarely in inflorescences, of Poa pratensiz.

U. luzulae Schroet. On leaves of Luzulu pilosa.

U. colchici (Schlecht.). On leaves of Colchicum autumnale, Museari comosum, M. raccmosum, Paris quadrifolia, and Scilla bifoliu. (Britain and U.S. America.)

U. cepulae Frost. ${ }^{1}$ (U'.S. America). Onion-smut. This frequents the green leaves and subterranean scales, producing pustules, which break when mature and allow the black sporepowder to escape.

U. ornithogali Körn. frequents leares of Ornithogalum umbellatum.

U. gladioli (Req.) is found in tubers and stems of Gladiolus (Britain).

U. anemones (Pers.). (Britain and U.S. America.) Anemonesmut. This may be found in leaves or stems of many Ranunculaceae: Anemone Hepatica, A. nemorosa, A. ranunculoides, Pulsatilla alpina, P. vernalis, P. Pennsylvaniea, P. acutilobr, P. baldcnsis, etc.; also on Atragenc alpina, Aconitum Lencoctonum, Actaea spicata, Helleborus viridis, H. nigro, Ranunculus Ficaria, R. Gulbosus, R. repens, $R$. sardous, Eranthis hicmalis. Brefeld says the spores germinate in water, after resting for half-a-year.

${ }^{1}$ R. Thaxter. Report of Comecticut Agric. Exper. Station for 1559. 
U. Leimbachii (Oertel.) causes globular swellings of the stem-base of Adonis aestivalis at Jena (Fig. 173). Patouillard regards this species as a form of $U$. anemones, differing somewhat on account of its underground habitat.

U. sorosporioides Körn. (Britain). On Pulsatilla alpina, Thalictrum minus, and T. foetidum, forming pustules and swellings.

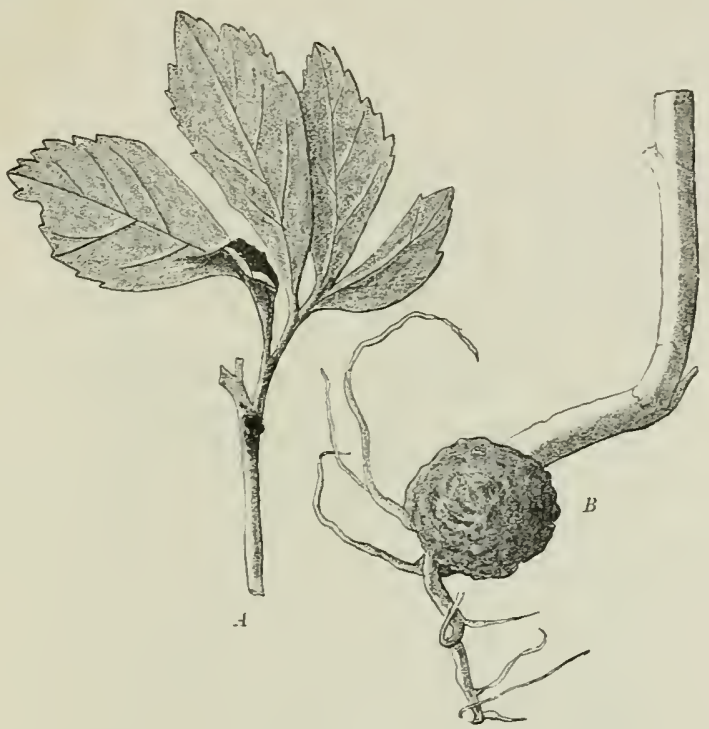

FIG. 173.-A, Urocystis anemones on Hellebore. Spore-patches on stalk and mid-rib. (จ. Tubeuf del. ; specimen from Herr Schnabl of Munich.)

$B$, Urocystis Leimbachii (U. anemones), uausing swelling at base of stem of Adonis aestivalis. (จ. Tubeuf del.; specimen from Prof. Stahl of Jena.)

U. violae (Sow.). (Britain and U.S. America.) The deformations induced by this brand are not uncommon on Viola odorcta in gardens, also on $V$. tricolor, $V$. bactensis, and $V$. hirta. Its presence is shown externally by the marked thickening and malformation of leaf-petioles, runners, leaves, and fruit-stalks (Fig. 174). The swellings extend round the whole stem, and form pustular outgrowths on the leaves; the black spore-masses appear after rupture of the epidermis. The flower may develop normally although other organs are diseased. In a case from the garden of Prof. Hartig, a flower-bud unfolded prematurely in the autumn, its stalk was very much deformed, the flower itself was somewhat stunted, yet 
the plant as a whole did not seem to be much affected. On the other hand, a case was observed near Munich where a large plot of violets was completely killed out in a few years by this fungus.

The anatonical changes induced on Viole orloratu were investigated by Wakker ${ }^{1}$ with the following results: a swelling of the stems, leaves, and flower-stalks occurred, often accompanied by considerable twisting and rupture of the epidermis; these changes were not caused by any enlargement of cells, but

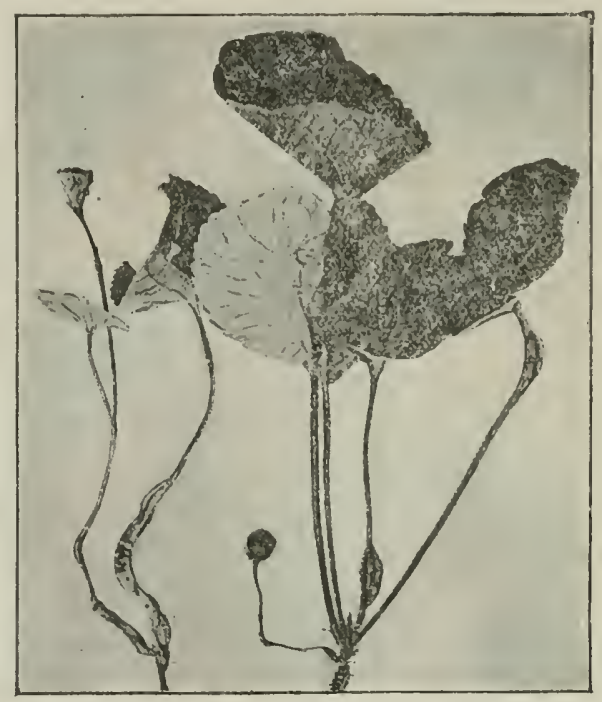

FIf. 174.-Urocystis riolae on Viola. Smut-pustules are present on leaf-stalks and fruit-stalks, accompanied by malformation. (v. Tubeuf phot.)

the eambium remained longer active in the stem, and a secondary division of rind-parenchyma or mesophyll could be observed, along with a disappearance of intercellular spaces; accessory vascular bundles were formed, but the secondary ressels remained incompletely developed. In short, new growth occurred, not in the earlier stages of the host's life, but in the adult. Especially noteworthy is the formation of a small-celled tissue resulting from cell-division in the rind-parenchyma and the mesophyll; this serves as a nutritive tissue for the fungus,

1 Wakker, Pringsheim's Jahrbuch, 1892. 
and is destroyed during spore-formation, so that the balls of spores are found in large cavities in the host-tissne.

In the spore-masses the enveloping companion-cells are more transparent than the spores proper. The latter germinate ${ }^{1}$ easily in water, and prodnce pronycelia which grow towards the air. On the extremities of these several conidia arise, and, without becoming detached, proceed at once to give off short conidiophores with termiual coniclia. As this process is repeated indefinitely, chains of conidia are formed. Fusion of conidia never occurs.

U. Kmetiana Magn. Magnus ${ }^{2}$ describes this as destroying and filling with black spore-powder the ovaries of Viole tricolor (var. arrensis).

U. filipendula Fuck. occurs particularly on petioles and leaf-ribs of Spircea Fitipendula. Brefehl found the spores germinating after a year.

U. (?) italica (Sace, et Speg.). In seed of Castanea vescce.

U. purpurea Hazsl. Ovaries of Dianthus deltoides and 1). prolifera in Hungary.

U. (?) coralloides Rostr. In roots of Turritis glabra in Denmark.

$\mathrm{U}$. orobanches (Fr.). In loots of Orobanche.

U. (?) monotropae (Fr.) In roots and stems of Monotropa in Belgiun.

U. Johansonii ( $U$. Junci. Lag.). In leaves of Juncus filiformis in Switzerland.

\section{Tuburcinia.}

Spores forming balls as in Urocystis, but all are equally capable of gemmation. The spore-aggregations form large or small, slightly thickened spots and crusts, which do not cause very marked deformation of the host. Germination results, as in Tilletia, in the formation of a promycelium bearing a tuft of conidia at one end. White conidia are also produced from the mycelium on the host-plant.

Tuburcinia trientalis (Berk. et Br.) ${ }^{3}$ (Britain and U.S. America). Plants of Trientatis europaea attacked by this fungus are conspicuous in early summer by their swollen dark-coloured stems and their smaller lighter leaves, which fall prematurely. The conidia appear as a white mould-like coating on the lower

${ }^{1}$ Prillieux, Bullet. de la Soc. botan. de France, 1880; and Brefeld (loc. cit.), Heft xiI.

2Magnus, Naturforsch. Fr. d. Prov. Brandenlurg, xxxi.

${ }^{3}$ Woronin, Senclienbery. naturforsch. Gesell., 1881. Plates I., II., III. 
sille of the leaf. The black spore-masses are formed in the rind-parenchyma, and sometimes in the pith; they are set free by rupture of the epiclermis.

In antum the symptoms are different. 'The plants appear normally developed, and have no coating of conidia; lark swollen spots, however, appear on the leaves and leaf-petioles, in consequence of the massing of black spore-balls in the parenchyun under the epidermis.

The summer mycelium consists of colourless irregularly branched and slightly septate hyphae occupying the intercellular

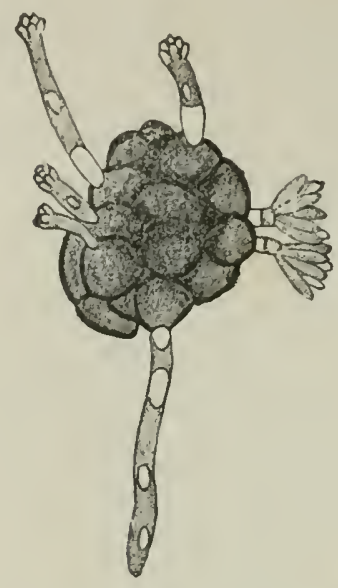

Fif, 175.-Tuburcinia trientulis. Sporemass germinating; several promycelia have been produeed and are proeceding to form whorls of branches. (After Woronin.)

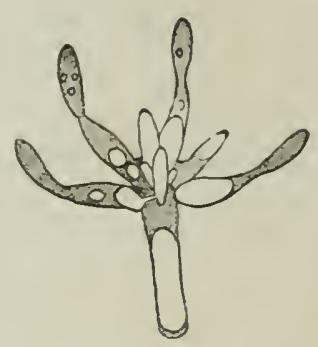

Fic. 176.-Apex of an isolated promscelium from Fig. 175; it carries a whorl of branches, some of which liave fused in pairs; all are developing conidia. (After Woronin.)

spaces of the pith and rind-parenchyma, also the vessels. The hyphae apply themselves closely to the cell-walls, and certain short branched hyphae actually penetrate into the cells. The spore-masses are developed from delicate branched multiseptate filaments of the vegetative mycelium. They begin as two or three little cells round which a coil of hyphae is formed; the central cells, increasing in number and size, become a ball of dark smooth-coated spores, while the enveloping coil of hyphae disappears.

The spores germinate during the same autumn, frequently in the position of their formation. A promycelium is first formed, and on its extremity a circlet of conidia arises; there- 
after the promycelium becomes divided by cross-septa in its upper part, and the conidia too are frequently divided by one or two septa. The two promycelial cells become detached, while the conidia begin to fuse together by means of outgrowths near their base; thereafter each conidium gives out a secondary conidium, into which the plasma-contents pass over. A similar formation of secondary conidia may take place without previous fusion of the primary conidia. The conidia fall apart, and they, as well as the upper promycelial cells thereby left isolated, grow out as hyphae. It must be these hyphae which infect the rudimentary shoots of Trientalis when they are already partially formed for next year. The resulting mycelium permeates the shoots in the following spring, and branches of it emerge through the stomata, or pass between the epidermal cells and break the cuticle, to grow up either at once as conidiophores, or to form on the surface of the leaf a web from which conidiophores arise. The pear-shaped conidia are attached by their broader side, and easily fall off, leaving the conidiophores free to produce new conidia. The conidia are capable of immediate germination, and may produce a lateral germ-tube, which grows directly upwards, and gives oft secondary conidia; or the conidia themselves grow out into hyphae, capable, as Woronin proved experimentally, of carrying out infection. Such hyphae penetrate between the walls of adjacent epidermal cells, and give rise to a mycelium which spreads in a centrifugal direction and forms the sporemasses.

This same fungus has also been found on Euphrasia lutea and Paris quadrifolia. On Euphrasia, according to Winter, it causes formation of large swellings, accompanied by considerable deformation of leaf and stem.

T. primulicola (Magn.) Kiihn. ${ }^{1}$ (Britain). This smut attacks flowers of Primula acaulis, $P$. officinalis, $P$. clatior, $P$. farinosa. In cases described in Germany, the blooms were generally attacked in the filaments or connective of the stamens, but also in the anthers, the ovaries, pistil, stigma, and sometimes in the calyx-tube; while the whole flower-head was more or less discoloured by the black spore-dust. The mycelium permeates

${ }^{1}$ Magnus, Botan. Verein Brandenburg, 1878. Kuihn, "die Entwickelungsgesch. d. Primelbrandes," Naturforsch. Gesell. zu Halle, 1892. 
the whole host and hibernates in the root-stock. The spores are developerl from the ends of hyphae in the host-tissue, and are either isolated or joined into pacliets. 'They germinate easily in water, and prorluce either a fine germ-tube, or a thick promycelium with four oblong conidia on its apex. The conidia are easily detached, and either develop to fine hyphae, or give off secondary conidia. Cremmination on the whole is similar to that of $T$. trientulis. Coniclia may be also produced directly on the host-plant; these were first described by Kiihn, who named them P'aipalopsis Irmischice; later, however, he succeeded in infecting plants of Primula with the conidia, and in proving their relationship to this Tuburcinice.

T. Cesatii Sorok. occurs on geraniums in Riussia.

Here, according to Setchell, the following American genera should be placed :

Burillia : B. pustulata on Sugittaria.

Cornuella: C. lemnae on Lemna polyrtiza.

\section{Doassansia.}

Spore-masses consisting of numerous spores capable of germination, enclosed in a layer of sterile cells. The latter are most conspicuous in the species frequenting aquatic plants, and are filled with air,-Brefeld regards them as swimming-organs. The spore-masses lie in groups embedded in the host-plant. The species inhabit plants with an aquatic or moist habitat, and produce on them leaf-spots with black pustules.

Fisch ${ }^{1}$ investigated the life-history of Doassensia sagittariae. $\mathrm{He}$ found an intercellular mycelium which, inside the stomata, formed sporocarps, consisting of selerotium-like coils of hyphae enclosing several cells which form spores. The spores on germination give rise to promycelia, which produce sporidia in a manner similar to Entylome. The sporidia easily germinate in water, and can immediately infect young leaves. The germ-tubes creep on the surface of leaves, and attaching themselves by an adhesion-disc over the wall between two adjacent epidermal cells, they penetrate this wall. The hypha, while passing

${ }^{1}$ C. Fisch., Ber. d. deutsch. botan. Gesell., 1SS4, p. 40.5. Cornu, Annal. d. sci. natur. Xv., 1S83. Setchell (Botanical Gazette, 1894) records the American species and comments on them. 
through the wall, remains thin, but on emerging into an intercellular space it soon thickens and branches into a mycelium. Infection results in the appearance of yellow spots, due to rapid destruction of the chlorophyll and death of cell-contents. Experiments in germination have been carried out by Setchell and Brefeld. ${ }^{1}$

Doassansia sagittariae (West.) (Britain and U.S. America). In leaves of Saryitaria. The spores, according to Brefeld, germinate in water, after hibernation. They produce unicellular promycelia with a terminal tuft of more or less spindle-shaped conidia, which at once begin to sprout and fall off. On the surface of a mutritive solution they continue to sprout yeastlike, and form close mouldy coatings. (Doassansia is the only genus of the Tilletiae in which Brefeld found yeast-like spronting of coniclia.)

D. alismatis (Nees) (Britain and U.S. America). This inhabits leaves of Alisma Plantago and A. natans, producing knotty swellings. The spores are enclosed in a layer of companion-cells containing air, whereby the masses swim on water. On the promycelium the conidia arise from tufts of conidiophores; they fuse in pairs, and secondary conidia are developed from each pair or even from single conidia.

D. Niesslii (de Toni) forms small spots on leaves of Butomus umbellatus. The spores are surrounded by companion-cells containing air. They germinate before leaving the spore-patch, and produce conidia, even secondary conidia, before rupture of the host-epidermis takes place. Brefeld describes the spores as germinating in water to form a very short promycelium with short thick conidia which fuse in pairs and give off larger secondary conidia from their apices. In nutritive solution conidia are developed, which give off septate filaments whence further conidia arise. Aerial conidia are ultimately developed.

Magnus found that the spores of $D$. alismatis, D. Niesslii, and other species germinated at once on reaching maturity. Brefeld, however, found that this took place only after they had lain over winter. It may be that here, as with some higher plants (e.g. Pinus Cembra), there is an immediate capability of germination, but also a deferred, the latter requiring 1895.

1 Setchell, Annals of Botany, vi., 1892. Brefeld, Schimmelpilse, Heft xir., 
to be preceded by a considerable resting-period, during which germination will not take place.

D. Martianoffiana ('Thiim.). In leaves of L'otamogetone netens and I'. gramineus.

D. occulta (Hotlim.). In fruits of species of I'otumogeton.

D. intermedia (Setch.). An Anerican species found on leaves of Sagitturia variubilis.

D. comari (Berk.). In leaves of Comarum pulustre in Britain.

D. limosellae (Kunze.). In tlowers of Limosella uquatica.

D. hottoniae (Rostr.). In leaves of IIottonia palustris in Denmark.

\section{Thecaphora.}

Spores, large, spherical, and inseparably united into packets of several spores. Germination results in the formation of a

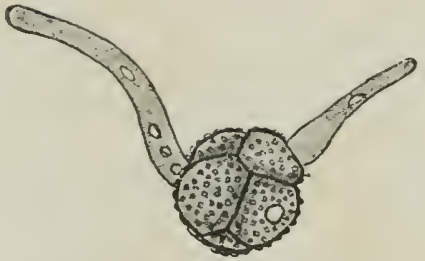

Fio. 177.-Thecaphora hyalina. Pluricellu. lar spore, with two cells (spores) germinating. (After Woronin.)

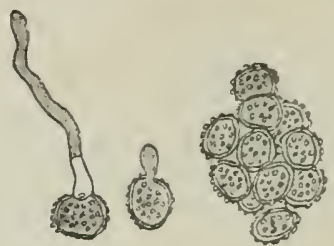

F1G. 17S.-Sorosporium saponarice (var. Lychindis dioicue.) Mature spore-mass, and spores germinating. (After Woronin.)

promycelium fiom the apex of which a single conidium is produced.

Thecaphora lathyri Kiihn. Spore-balls formed in the seeds of Lathyrus matensis, and escaping as a brown powder on dehiscence of the pods. The spores germinate in water with formation of a promycelium bearing a single apical conidium, which produces a hypha, but never secondary conidia. In nutritive solutions the spores produce a mycelium from which coniclia are continuously given off:

Th. hyalina Fingerh. (Britain). This occurs in fruits of species of Convolvulus. Woronin describes the spores as having germ-pores through which a septate germ-tube is emitted; the individual cells of the germ-tubes develop into hyphae, without formation of conidia.

Th. affinis Schneid. In fruits of Astragalus glycyphyllus (U.S. America).

Th. Trailii Cooke. In flowers of Carduzs heterophyllus in Scotland. 
Th. Westendorpii Fisch. In Lotium perenne in Belgium.

Th. pimpinellae Juel. In fruits of Pimpinella Saxifraga in Sweden.

Th. aurantiaca Fingh. In leaves of Urtica dioicu.

Th. pallescens Fingh. In leaves of Fragaria collina.

\section{Sorosporium.}

Spore-formation takes place in a mass of twisted gelatinous hyphae. Spores at first embedded in a gelatinous investment and united into packets, but later becoming separate. Promycelium filiform and septate.

Sorosporium saponariae Rud. This causes deformation of flowers of Dianthus deltoides, Saponaria offieinalis, Silene inflata, and S. velutina, Stcllarie Holosteum, Cerastium arvense, Lychnis dioice, and Dianthus prolifer.

S. dianthi Rabh, on Dianthus prolifer, is probably identical with the preceding species.

We append here as doubtful Ustilagineae, the genera Graphiola Schinzin (Entorhiza), Tubereulinu, and Schrocteria.

\section{Graphiola.}

The sporocarps of this genus are formed on the surface of plant-organs containing mycelium; they are little spherical structures enclosed in a peridium, and contain filamentous septate hyphae. The hyphae may be sterile or fertile; the spores are produced on lateral cells of the fertile hyphae. From the germinating spores, either a thread-like mycelium or spindle-shaped conidia arise.

Graphiola phoenicis Pait. ${ }^{1}$ (Britain.) This fungus is a parasite on leaves of palms (e.g. Phocnix dactyliforce and Chamerops humilis) in the open in Italy and other Mediterranean countries, in hot-houses elsewhere. The sporocarps make their appearance as little black protuberances on both sides of the leaf. The inycelium forms a close hyphal tissue, which encloses and kills parenchymatous cells, displaces the bundles of sclerenchyma, and ruptures epidermis and hypoderm. Deformation is, however, localized to these spots.

${ }^{1}$ Ed. Fischer, "Beitrag z. Kenntniss d. Gattung Graphiola," Botan. Zeitung, 1883. 
The sporocarps eousist of a two-layered peridium, a sporogenous layer, and tufts of sterile hyphac. The outer layer of the peridium forms the onter layer of the black protuberances on the leaves; the inuer layer is delicate. The sporogrenous hyphat originate from the centre of the underlying hyphal tissue, and form a palisade-like layer in the bottom of the sporocarp cavity, the remaining space being filled with spores and tufts of barren hyphae. These latter liyphae rise amongst the sporogenous ones, and project as a fine brush-like tuft ont of the ruptured peridium. The sporogenous hyphae grow vertically upwards, and become septate, forming chains of loosely mited, roundish, hyaline cells or joints. The terminal joints grive off several spherical cells laterally, and die away, leaving the cells loose in the sporocarp cavity. From division of the splerical cells yellow spores result, and, on rupture of the peridimm, are carried out on the tufts of sterile hyphae to be seattered by wind. The spores germinate in water, and produce either a promycelium or conidia.

Gr. congesta Berk. et Rav. occurs on leaves of Chamerops Palmettu.

\section{Schinzia (Entorrhiza). ${ }^{1}$}

Spores produced on the ends of lateral branches of a mycelium in the cortical cells of the root of the host-plant. Ciermination results in production of a simple or branched sporophore (pronycelium), from which kidney-shaped conidia (sporiclia) are produced.

Schinzia cypericola Magn. This canses deformation of the roots of Cyperus flavescens (Fig. 179).

Sch. Aschersoniana Magn. causes swellings on the roots of .Tuncus bufonius [Britain].

Sch. Casparyana Magn. In roots of Juncus Tenagein.

Sch. digitata Latgerh. In roots of Iuneres witiculutus.

Sch. (Naegelia) cellulicola Naeg. In roots of Tris in Switzerland.

Sch. (Entorrhiza) solani Faut." [This is given as the cause of a disease on potato. The plants droop and nitimately rot at the neck, the leaves become yellow, and neither flowers nor tubers are prodnced.] (Edit.)

${ }^{1}$ P. Magnus, at Botan. Verein 1. Pror. Brindenburg, 1878; "Ueber einige Arten d. Gattung Schinzia," Ber. 1. dentsch. Lotan. tres., ISss, p. 100 ; C. Weber, Botan. Zeituny, 1884 .

2 Fautrey, Rerue mycolo!., 1596, p. 11. 


\section{Tuberculina.}

Mycelium parasitic on hyphae and spore-patches of Uredinece. Short rod-like hyphae spring from the spore-patches, and give off from their apices, globose conidia, which on germination produce branched promycelia bearing sickle-shaped conidia.

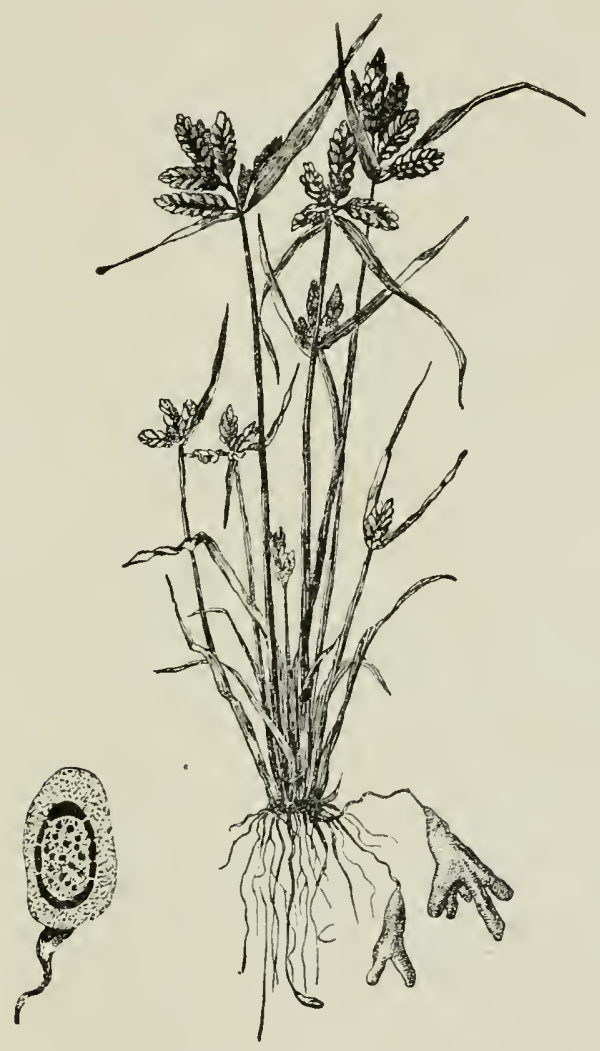

F1G. 179.-Schinzia cypericola on Cyperus favescens. Several roots show palmately. divided swellings. Isolated spore. (After Magnus.)

Tuberculina persicina Ditnt. The lilac-coloured spores are found on aecidia of Peridermium pini and other aecidial forms, also on some species of Caeoma. ${ }^{1}$ (Britain and U.S. America.)

${ }^{1}$ Plowright (British Ustilagineae) gives also Aec, asperifolii, Aec. tussilaginis, and Roestelia lacerata as hosts. 
T. maxima Rostr. Occurs on rust-patches on Weymouth pine. It has larger spores than the preceding species.

\section{Schroeteria. ${ }^{1}$}

Spores joined in pairs, rarely in threes, with their broad faces together. They are developed from single joints of a septate non-gelatinous mycelium, particularly from short curled lateral hyphae. Spherical conidia are produced, like those of Penicillium, by intercalary growth in chains from the end of a conidiophore which is generally unbranched.

Schroeteria Delastrina (Tul.) occurs in seeds of Veronica antensis, $V$. hederifolia, $V$. triphylla, and $V$. praceos. The spores germinate in water, and produce conidia incapable of further development, even when transferred to a nutritive solution. In such, however, spore-germination is more vigorous, and an abundant inycelium results, but it seems to be unable to produce conidia.

Sch. Decaisneana (Boud.). In seerds of Veronica hederifolia at Paris.

\section{UREDINEAE.}

The Uredineae or Runt-fungi possess several forms of spores, one of which, the teleutospore, is rarely, if ever, absent from the life-cycle of any species. The teleutospores consist of one, two, or more cells enclosed in a thick coat of dark colour, and thereby well adapted to carry the fungus over winter. When germination occurs, each cell of a teleutospore gives off a germtube through a pore or thinner place in its wall, and from this a promycelium ${ }^{2}$ is formed, consisting as a rule of four cells. Each teleutospore originates from a sporophore of its own, and in the course of development two nuclei, originally present in each cell of the young teleutospore, fuse together. When germination takes place, and the promycelium is formed, the single cell-nucleus, derived as above, divides into two, then into four, so that a nuclens is produced for each of the cells of the promycelium. From the promycelium four sterigmata are given off, and each produces a single sporidium. ${ }^{2}$ These

${ }^{1}$ Brefeld regards the species as forms of higher fungi, not as Ustilagineae (Heft Xir., p. 204).

${ }^{2}$ Brefeld considers that the promycelimm and sporidium are respectively a basidium and a lasidiospore. 
sporidia on germination give infecting mycelial hyphae. In the case of Colcosporinm, the promycelium is formed inside the telentospore in a manner similar to the Protobasidionycetes.

Besides teleutospores, there occur uredospores. These are given off from patches or sori throughont the summer till autumn, when they are followed by teleutospores on the same sori. The uredospores somewhat resemble the telentospores, but generally consist of one cell only with a thinner coat of lighter colour; they either germinate at once withont a resting period, and give rise to a germ-tube capable of direct infection of new hosts; or less frequently they are resting-spores for a time.

A third form of spore occurring in the life-history of the Uredineae is the aecidiospore, produced in a special structure, the aecidium. The aecidium is developed inside the leaves or other organs of the host-plant, and when mature ruptures the overlying epidermis; it has as a basis a firm hyphal tissue, the upper surface of which becomes a disc of short erect sporophores. From each sporophore there is formed by intercalary growth a chain of cells consisting alternately of spores and smaller intermediate cells, which do not become spores. The youngest cells in an aecidium are those next the sporophoredisc, and they are forced outwards by intercalation of younger cells between them and the disc. The cells so produced become alternately intermediate cells and spores; the former increase for a time, then decrease and disappear, the spores however continue to increase in size as the chain grows forward and to take on the characters of the mature aecidiospore till they are finally shed from the aecidium. The production and distribution of aecidiospores may thus go on continuously for a considerable time. The sporophores at the periphery of the dise do not however produce spores; chains of cells are also produced from them by intercalary growth, but the cells are of equal size, and remain closely connected with their neighbours, so as to form a membranous covering over the spore-sorus, this is the so-called peridium, on rupture of which the aecidiospores escape. In many Uredineae the peridium is suppressed (Cacoma); in others (Phragmidium) it is replaced by other structures, the paraphyses. The spores of the genus Endophyllum are produced in series in aecidia enclosed by a peridium, but in 
germination they behave more like typical teleutospores than aecidiospores.

Before the relationship of these varions forms of spores was known, Arcidium and Cacoma were regarded as independent gromps, and named as such; even yet many isolated forms of uredospores, telentospores, and aecidiospores are known, the relationships of which are quite obscure.

The aecidia are always preceded or accompanied by a further form of spore produced in a special structure of its own. These spores have hitherto been called spermatia, and their sporocarps spermogonia, on the assumption that they were male orgins. Now, however, many of them are known to be capable of germination in artificial nutritive solutions, hence they are more prohably a form of asexual bucl, and better named conidia, their sporocarps pycnidia. The pycnidia are flask-shaped structures sunk in the tissue of the host, with a pore or mouth energing through the host-epidermis; they generally occur in leaves, and occupy the upper epidermis, the aecilia occurring on the lower. From the mouth of the pycnidiun there frequently emerges a tuft of fine filaments, outgrowths from the inner wall of the Hask. The pycnidia possess a lively colour and flowery odour, hence it has been suggested that the conidia may be distributed by insects; but they do not appear to be able to germinate in the open, and infectionexperiments with them have never as yet succeeded. On this account they are regarded as degenerate structures. ${ }^{1}$

The various forms of spores are also distinguishable by the mamner in which they bring about infection. Teleutospores on germination produce sporidia, which pierce the membranes of the prospective host at a spot where two adjoining cells are in contact, and thus make their way into the intercellular spaces. Ureilospores and aecidiospores, however, first seek a stoma and enter the intercellular spaces of the host through it.

The following different forms of Uredineae exist: (1) Those which possess teleutospores alone, e.g. Chrysomyra abictis; (2) those with teleutospores and uredospores, e.g. Puccinice pruni spinosae; (3) those with all the forms of spores, e.g. Puccinin graminis; (4) those without uredospores, e.g. Gymnosporangium.

'Rathay, "Untersuchungen über die Spermogonien d. Rostpilze," Denkschrift d. Wiener Alad. d. Wissensch., 1883. 
The different forms of spore may be found on one and the same host-plant (autoecious Úredineae), or the aecidiospores and pyenidial conidia may frequent a different host from the uredo and teleutospore-forms (heteroecious Uredineae). ${ }^{1}$

A mycelium may be produced from the germinating aecirliospores, uredospores, or sporidia. It spreads throughont the intercellular spaces of attacked organs and causes thickening; distortion of the tissues of its host, or the formation of "witches" brooms." Nutriment is frequently obtained by means of coneshaped or button-like haustoria in the interior of host-cells.

Hibernation of rust-fungus is most commonly attained through the teleutospores, the thick coats of which make them peculiarly suited to pass through a lengthened resting-period. Some forms, however, hibernate by uredospores, by aecidiospores, or by the mycelium remaining on or in living perennating stems, twigs, or underground rootstocks of their host.

Aecidiospores on germination produce, as a rule, a mycelium which gives rise to uredo- or teleutospores, rarely to aecidiospores (c.g. Precinia senccionis and Uromyces erui). ${ }^{2}$ Uredospores on germination, produce a mycelium from which mredospores are first given off, then telentospores. The sporidia of teleutospores give rise to a mycelium which frequently produces pycnidia and aecidia. In rare cases, the sporidia of species, which normally form aecidia, are said to develop a uredo-mycelimm (c.\%. Pucc. graminis according to Plowright).

The Uredineae are for the most part strict parasites, and exhibit marked adaptation to their respective host-plants. Several of the polyxenous members frequenting several species of hostplant have been found to vary accorling to their habitat, so that one and the same species assumes a slightly different form on each

I The phenomenon of heteroecism was till quite recently known only amongst the Uredineae. Woronin and Nawaschin have, howerer, recently pointed out that it exists in Sclerotinia ledi, one of the Ascomycetes (p. 277). The conidia of this species are produced only on Faccinium uliginosum, the apothecia only on Lednm, and alternate with each other, so that the Ledum can be infected only by germinating coniclia, the Vaccinium by germinating ascospores.

${ }^{2}$ Dietel (Naturforsch. Verein in Vienna, 1S94) pointer ont further cases of this kind, in which aecidia were produced the summer through, and no uredospores, while in autumn telentospores were formed. He has more recently stated the general conclusion (Flora, 1S95, p. 394); that with these species of Uromyces aml Puccinia, which prodnce aecidia and telentospores, but no uredospores, the aecicliospores are capable of reproducing aecidia when no perennating mycelium is present. Similarly with those few species which produce a very small number of uredospores. 
host-species. I have previously shown, ${ }^{1}$ with regard to the mistletoe (Viscum album), that the different forms on Pinus, Alics, and various broad-leaverl trees, which some authors regard as distinct speeies, might erually well be regarded as forms of one species differing slightly on account of their different substrata. Magnus ${ }^{2}$ designates as "habitat-races" these forms of heteroecions Uredineae whose aecidial generation has become adapted in some varying degree to each of their respective species of host-plant. Thus the various forms of Accidium concellarica, on its different host-plants, he regards as forms of one and the same fungus, the Pucciniu of which oceurs on Pholuris arundinacer.

The manner in which such adaptations originate is indicated by my experiments with Gymnosporanyium. Thus G. clarariacforme can infect leaves of Crutaegus and produce aecidia without failure; whereas the same infection carried out on Sorbus and Cydonic results in incomplete development of aecidia (see Table, p. 385). In this way there might easily be produced one form which infected Cratargus, and another confined to Cydonia. The same thing occurs with the varions Peridermia of pine-needles; these, according to the investigations of Klebahn, are caused by one or other species of Colcosporium from very different species of host-plant. ${ }^{3}$

The best examples of all, however, are presented by the cereal-rusts, as demonstrated by Eriksson. This investigator believes that the forms distinguished by him as "specialized forms" (by Rostrup as "biological species or varieties") are of common origin. In course of time these have taken on different biological characteristics in adapting themselves to the varier nature of their substrata, their various host-plants, so that in many cases they can no longer suit themselves to the host-plant of the original parental form. In fact, species were found with aecidia of similar shape when occurring on the same host-plant, yet completely specialized from the aecidia on another host. They thus present a stage intermediate to that of the "habitat-races" just mentioned.

${ }^{2}$ v. Tubeuf, Botan. Centralliatt, xL., 1859, p. 312.

"Hedecigia, 1594, p. $7 \%$, and 1895.

"Klelahn's views on this sul)ject, along with further investigations on other fungi, will be found in Zeitschrift $f$. Pftansenkrankheiten, 159.5, p. 153. 
The european Uredineae comprise the following families and genera: Puccinieae (Uromyces and Puccinic); Phragmidieae (Triphragmium and P'hragmidium); Melampsoreae (Melampsora, Melampsorella, Calyptospora, Colcosporium, Chrysomyxu, and Cron(artium); Gymnosporangieae (Gymnosporangium); Endophylleae (Endophyllum); also the genus Uredinopsis on Ferns.

\section{Uromyces.}

Telentospores unicellular and produced in flattened sori. Only one teleutospore is abjointed from each sporophore. Telentospores with a single germ-pore. Ureclospores, aecidia, and pycnidia are not present in every species.

(1) All forms of spore present on the same host-plant:

Uromyces ervi (Wallr.) (Britain). ${ }^{1}$ Vetch-rust. The aecidia are produced on Vicic hirsuta in May and throughout the summer. Scattered amongst the aecidia are the sori from which uredospores are sparingly given off in early summer; the teleutospores are given off abundantly from the same sori from July onwards. The aecidiospores germinate on the vetch plants, and produce therein a mycelium from which the aecidia and teleutospores arise. Infection by means of sporidia, derived from the teleutospores, results in the production of a mycelium which bears aecidia only. Pycnidlia (spermogonia) are absent in this species and also in $U$. fabae.

U. fabae (Pers.), [U. orobi (Pers.)] (Britain and U.S. America). This occurs on species of Ticia and Lathyrus. Sori are formed abundantly and give off both uredospores and teleutosporesthe latter being smooth-coated. No pycnidia have as yet been observed.

U. trifolii (Hedw.). Clover-rust. Parasitic on various species of clover. Uredo- and teleutospores are generally produced; aecidia have been found only on Trifolium repens (Germany and Britain), T. incarnatum (Italy), T. protense (Denmark, Britain, and America). On Trifolium repens both teleutospore and aecidium generations cause swelling and distortion of leaf-ribs and petioles, the deformation being most marked where the mycelium has hibernated and produced teleutospores in spring.

1 The chief authorities used for the occurrence of the Uredineae in Britain and North America are Plowright (British Uredineae, 1SS9), and Farlow and Seymour (Host-Index for U.S. America, 1S91). (Edit.) 
U. appendiculatus (Pers.), [U. phaseoli (Pers.)]. On species of Phascolus. (Britain and U.S. America.) $)^{1}$

U. primulae Lev. On Primula hirsute.

U. limonii (D.C.). On Armeria and Statier. (Britain and U.S. America.)

U. polygoni (l'ers.). On P'olyyonum and Rumex. (Britain and U.S. America.)

U. acetosae Schroet. On Rumex.

U. silenes (Schlecht.). On Silene and Diunthus.

U. euphorbiae (Schwein.). On Euphorbir Preslii in Italy, and some other species in America. ${ }^{2}$

U. geranii (1). C.). On Geraniums. (Britain and U.S. America.)

U. betae (Pers.). On Mangel Wurzel and Beta. (Britain and U.S. America.)

U. parnassiae (D.C.). (Britain.)

U. salicorniae (D. C.). (Britain.)

U. valerianae (Schum.). On Valeriana dioica (Britain).

(2) Pycnidia (spcrmogoniu) and aceidlia produced on one host; the related uredo- and teleutospores on another host:

Uromyces pisi (Pers.) (Britain) Pea-rust. The uredospores and teleutospores are developed in various species of Pisum, Lathyrus, and Vicia. The teleutospores are finely punctured. The aecidia appear on the under surface of the leaf of Euphorbia Cyparissias, and are preceded by pycnidia.

Attacked plants of Euphorbic become completely changed in their appearance. The stems are much elongated, and as a rule remain unbranched. Flowers are seldom or never produced; if so, they are permeated by mycelium and deformed. The leaves are short, thick, and rounded-off; they have a pale-green colour, and are distant from each other on the shoot. Their internal structure is also considerably modified. Wakker states that the cells of the mesophyll become enlarged, while no collenchyma is developed in the ribs. Fentzling ${ }^{3}$ gives the following changes: the epidermal cells become broader; stomata are nore numerous on the upper surface of the leaf, and fewer on the lower; the laticiferous tubes below the upper leaf-

${ }^{1}$ Description, illustration, and treatment in N. York Agric. Exper. Station. Bull., 48, 1892.

2 Magnus, Berichle d. rleutsch. botan. Ges., 1893.

3 "Untersuchung d. Veranderungen welche durch Rostpilze hervorgerufen werden." Inaugural Dissertation. Freiburg, 1592. 
epidermis are reduced in number; intercellular spaces are formed in the normally compact palisade parenchyma, and its cells become shorter and broader, while those of the spongy parenchyma are increased both in size and number; the fibro-vascular bundles remain unchanged, although the cells surrounding them may be more or less abnormal. Where thickening of the stem takes place, it is chiefly due to multiplication of the cells of

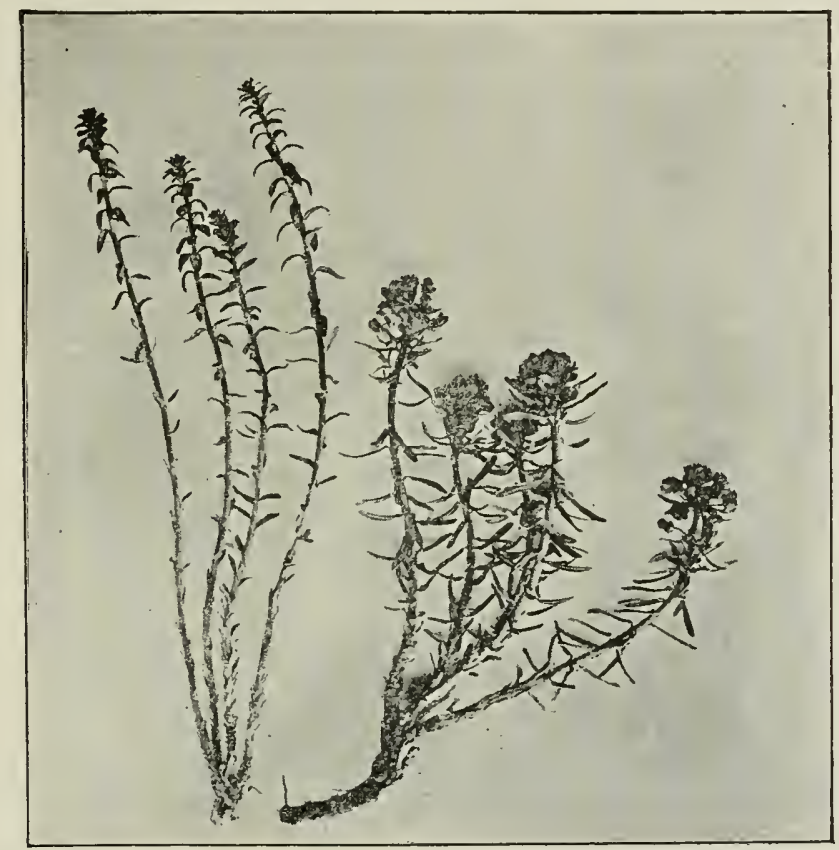

FIG. 180.-Uromyces pisi. Comparison of healthy flowering plant of Euphorbia. Cypurissics, with a much-elongated, non-flowering plant bearing aecidia of Pearust. (v. Tubeuf phot.)

cortex and pith, while at the same time those of the cortical parenchyma become somewhat enlarged and altered in shape; the woody portion is less developed than normally; and laticiferous tubes are neither so large nor so conspicuous as usual.

The aecidia of this species are found only on the lower surface of the leaf; they are sancer-shaped, and have a broad lobed white margin. 
As a preventive measure, it would be advisable to keep down spurge-plants near fields or gurlens where peas are likely to be atticked.

U. striatus Schroet. (U. S. America). Uredo-and teleutospores on species of Lotus, Mulimgo, Trifolium, and sometimes Viciu. Pycniclia and aecidia are produced on Euphorlia Cyporissias; the mycelium incluees. changes in the tissues similar to the preceding species, but the Euphorbir remains stunted instead of elongating as in attacks of $U$. pisi.

U. dactylidis Otth. Ureelo- and teleutospores on species of Pou, Ductylis, Aienu, and Bruchyportium. Aecidia on several species of liamunculus (not on R. Ficariu). (Britain and U.S. America.)

U. poae Rabh. Uredo- and telentospores on I'va; Aecidia on Renunculus Ficariu, R. bulbosus, and R. repens. (Britain).

U. lineolatus Desm. (U. mritimus Plowr.). ${ }^{1}$ Uredo- and teleutospores on Scirpus maritimus. Aecidial forms $=$ Accidium sii latifolii on Sium and Ace. hippuridis on Hippuris, also a form on Glaux maritima in Britain.

U. junci Desm. Urecio- and teleutospores on species of Juncus. Aecidia on Pulicario. (Britain and U.S. America.)

(i) Only uralospores und teleutospores linown; they frequent the same leost.

Uromyces caryophyllinus (Schrank.)2 Carnation Rust. [This attacks carnations at all stages of growth. The mycelium extends inside the plant and forms spore patches which rupture the epidermis. Uredospores are produced first, then the teleutospores; the former germinate at once, the latter only after a resting-period. The use of sprays of potassium sulphide or copper sulphate, and the cultivation of hardy varieties have been recommencled.] (Edit.)

Uromyces scutellatus (Schrank.). On species of Euphorbia. The myeelium is perennial in the root-stock and permeates the whole plant. Teleutospores developed in dark-brown spots on the under surface of leaves. Diseased stems are generally unbranched, and carry only small leaves and no flowers.

\footnotetext{
'Plowright, Gardener's Chronicle, 1890.

${ }^{2}$ Halsted, N. Jersey Agric. Coll. Exper. Station Report, 1S91. Atkinson, "Carnation Diseases," American Carnation Soc.; with Illustrations. $\Gamma$. York Ayric. Exper. Slation Bulletin, 1896.
} 
U. tuberculatus Fuck. On Euphorbia exigua.

U. pröeminens Duby. On species of Eupleorlia.

U. sparsus (Kunze et Schm.). On Spergularia, and Stellaria (Britain).

U. Schroeteri De Toni. On Lychinis and Silene.

U. cristatus Schroet. et Niessl. On Iiscorice and Diunthes.

U. ficariae (Schum.). On lianunculus Ficaria (Britain and U.S. America).

U. astragali (Opiz). On Astrugalus (U.S. America).

U. genistae (Pers.). On Cienista, Cytisus, C'olutea, Galega, Caraguna, Onybryclis, etc.

U. anthyllidis (Grev.). On Inthyllis and Lupinus (Britain).

U. lupini Sace. On Lupinus (U.S. America).

U. trigonellae Pat. On leaves of Trigonella Foenum-yraecum in France.

U. glycyrrhizae Rabh. On Glycyrthiza.

U. cacaliae (D. C.). On Adenostyles and Cucrelio.

U. rumicis (Schum.). On liumex (Britain).

U. alpinus (Schroet.). On Rumer alpinus. Magnus ${ }^{1}$ has recently separated this as the single species of a new genns Schroeteriaster, allied to Tromyces and Puccinia. The uredospores arise from patches of sterigmata withont peridia or paraphyses; they are micellnlar and have lateral germ-pores. The telentospores are also unicellular, and form lentil-shaped patches composed of five or more layers of spores; the spores have a somewhat thickened apex, but no distinct germ-pore.

U. chenopodii (Duby). On Chenopodium aur S'choberia.

U. terebinthi (D. C.). On Pistaciu and Rhus (U.S. America).

U. brevipes (B. et R.). On Rlus Toxicodendron in America.

U. ambiguus (D. (:). On Allium Scorodoprasum.

U. acutatus (Fıck.). On Illium.

U. veratri. (1). C.). On Veratrum.

U. alchemillae (Per's.) (Britain). This is a species which in habit resembles a Phrremidium, and is sometimes regarded as a representative of a separate genus-Trachyspora (Fuck.). It forms patches of reddish-yellow uredospores or brown teleutospores on the lower surface of leaves of Alehemilla vulgaris. Aecidia are unknown.

(4) Pyenidice, aceidia, und teleutospores on the same host-plant; uredospores unkinown.

Uromyces excavatus (D. C.) Magn. On Euphorbic Gerardiana, E. verrucosa, etc.

U. Behenis (D. C.). On Silene. (Britain.)

U. lapponicus Lagerh. On Astragalus in Norway and the Alps; aecidia only in the latter locality.

${ }^{1}$ Berichte d. deutsch. botan. Ges., 1896, p. 130. 
U. minor Schroet. On Trifolium montanum (U.S. Americal).

U. hedysari-obscuri (I. C.). On IIfdysurum in Europe and Anerica.

U. scrophulariae (I). (:). On Sicrophularice and Jerbascum (Britain).

U. erythronii (1). (:). On Lilium, Messeri, Scilla, Allium, Fritillaria. (U... America).

(j) Telrutospores ulone known; after aleath of the host they umlergo a resting-prind, then germinate:

U. solidaginis (Somm.). On Solidugo iirguzrea.

U. phyteumatum (I. C.). On I'hyteuma, accompanierl by elongation of the leaf-stalk.

U. scillarum (Grev.). On Scilla and Muscuri. (Britain.)

U. ornithogali Lév. On Omithogrolum and Gagen. (Britain.)

U. colchici Massee. On Colrhicum spectubilis at Kew. ${ }^{1}$

(6) Telentospores alone linown; germinating at onec on the living loost:

U. pallidus Niessl. On C'ytisus.

(7) Only tcleutospores and pycnidia linown; present on the same host:

Uromyces Tepperianus Sace. ${ }^{2}$ This causes on twigs and branches of Acceic a deformation consisting in an all-round swelling followed by rupture of the periderm and the development of brown teleutospore patches on the exposed wood. Tepper found in South Australia shrubs of Acecia salieinia and $A$. myrtifulice attacked and killed: the former, near Adelaide, being almost exterminated. He also found it prevalent on Acaeia spineseens, A. hetioides, and A. myrtifolia in another part of Australia (Murray Bridge).

The same fungus was found by Wrarburg on Albizzic montence in Java, likewise by Solms-Laubach and Stahl (Fig. 181).

Magnus ${ }^{3}$ found that Warburg's specimens showed the rupture of the rind only on one side, those of Stahl, however, agreed with the Australian specimens. On investigation of the galls, Magnus found a multiseptate and intercellular mycelium with numerous and somewhat branched haustoria. The formation

${ }^{1}$ Grevillea xxi., 1592, p. 6.

${ }^{2}$ Ludwig, "Eine neue Rostkiankheit australischer Akazien," Centralblatt $f$. Bakter u. Parasitenkumde, 1S90, p. S3; further: Hedwigia, 1S89, and Forstlich-uaturwiss. Zeitschrift, 1894.

${ }^{3}$ Magnus, Ber. d. dentsch. botan. Gesell., 1892, p. 195; Hennings, Fungi Warburgiani, Hedwigia, 1893. 
of pycnidia precedes that of teleutospores. The latter have a flattened concave base and rounded apex; their episporium is marked with delicate ribs running from apex to base.

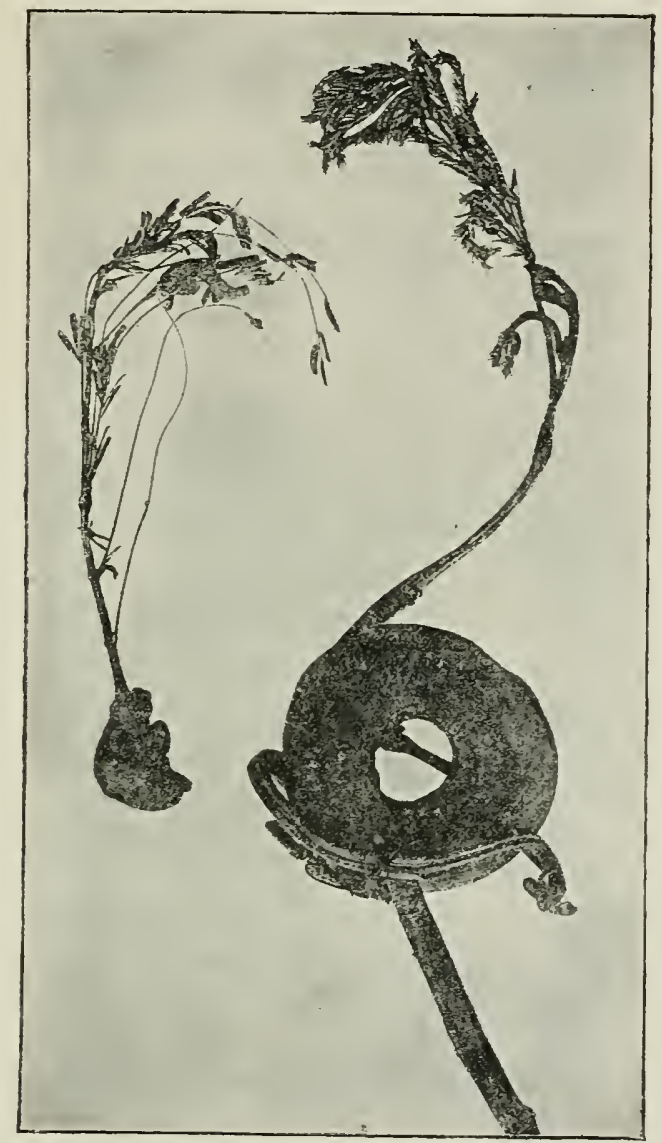

FIG. IS1.-Uiromyces Tepperianus on twigs of Albizzia montana brought by Prof. Stabl from Java. (v. Tubeuf phot.)

\section{Puccinia.}

Teleutospores iwo-celled, and each abjointed from its own sporophore from large distinct sori. Each cell has as a rule only one germ-pore. Uredospores, teleutospores, and pycnidia (spermogonia) are not known in all the species.

(1) Pyenidin, aecirlia, uredospores, and teleutospores develop on the 
living hest. The Intter, hometer, germinate only one dereth of the

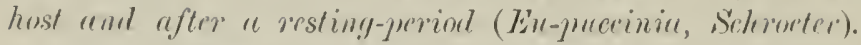

(u) Autcremeceinia: all forms of spore ate prescent on the seme host-plunt.

Puccinia helianthi. schwein. Sinflower-rust. This clangerwus enemy of Holinnthus was first observed in Sonth Carolina and I'ennsylvania, U.S. America. In Europe it appeared first to a serions extent in Russia, where the sunflower is cultivated on a large scale: now it has a very general distribution. In America it attacks both suntower ( $H$. anmuss) and Jerusalem artichoke (H. tuberosins), but its presence on the latter is as yet doubtful in Europe. The mycelium appears first in the lower parts of the plant and thence extends upwards; its presence is indicated by large brown leaf-spots, on which the urerlo-patches arise about the end of June. The telentospores make their appearance in antumn; the aecidia and pycnidia in spring (Are. helianthi Wor.). Combative measures consist in burning, or otherwise destroying, all sunflower debris in autnmn.

P. cirsii Sehroet. On Cortuns lenceoletic. (Britain.)

P. prenanthis (I'ers.). On Prenunthes, Laetuea, and Nulgedinm. (Britain and U.S. America.)

P. lampsanae (Schultz). On Letmpseuue. (Britain.)

P. montana Fuck. On Centeurece.

P. violae (Schum.). (Britain and U.S. America.) The Violetrust. This parasite appents on both wild and cultivated species of Viola, and frequently causes much damage. Malformation and stunting of the host may accompany the formation of aecidia. Fentzling investigated the swollen outgrowths produced on the lower surface of the violet leaves, and found an increase in all forms of the leaf-parenchyma; the spongy parenchyma included more cells, while both spongy and palisade parenchyma consisted of rounder cells more closely packed together than in the normal.

P. aegra Grove. On Viold tomute, etc., and somewhat different from the last species. (Britain.)

P. mirabilissima Peck. On Berberis repens in America.

P. silenes Schroet. On Silene and Lychnis. (Britain.)

P. pimpinellae (Strauss). On Pimpincllu, Chacrophyllum, Anthriscus, Myrrhis, Athamantha, Osterieum, Angeticu, Heracteum, Eryngium, etc. (Britain and U.S. America.) 
P. saniculae Grev. On Sanicula curopecer. (Britain and U.S. America.)

P. soldanellae (D.C.). (Britain.) On various species of Soldanella. This disease is often very common in the momtains, and is conspicuous because it attacks only leaves here and there on a plant. The leaves are yellowish with petioles distinctly elongaterl; their laminae, which bear aecidia on the lower side, are smaller and somewhat cup-shaped. Diseased plants do not seem to bloom.

P. menthae (Pers.). (Britain and L.S. America.) This is in most destructive rust to all kinds of cultivated mint. it attacks species of many genera of Labiatae.

P. calthae Link and P. Zopfii Wint. On c'althre pulustris in Europe and North America.

P. epilobii-tetragoni (D.C.) (P. pulipulente (rrev.). On Epilobium. (Britain and U.S. America.)

P. Peckiana Howe [I. interstitialis (Schlecht.)]. This species occurs on several species of liubus in America, and causes consiclerable damage in blackberry culture. ${ }^{\text {I }}$

P. gentianae (Strauss). On Gentian. (Britain aud U.S. America.)

P. galii (Pers.). On Galium and Asperula (Woodruff). The telentospores hilsernate on the read stems. (Britain and U.S. America.)

P. convolvuli (Pers.). On Con olvulus. (Britain and U.S. America.)

P. primulae (D. (!). On species of Primulu. (Britain.)

P. obtusa Schroet. On Sichlia verticillutu.

P. thesii (Desv.). On Thesium. (Britain and U.S. America.)

P. albescens (Grev.). On Adox' Moschatelliua. (Britain.)

P. aristolochiae (I. C.). On . lristolochia.

P. asparagi (D. C.). (Britain and U.S. America.) Asparagus-rust. The telentospores hibernate in dry remains of the plants, which shond therefore be burnt in antumn.

P. porri (Sow.) Onion-rust. On both wild and cultivated Allium. Sometimes very destructive to chives (1. schoenoprusum). (Britain.)

(b) Hetereupuceinia. Uredospores and teleutospores aleveloped on a host other then that of the myenidia and acridia.

Puccinia graminis Pers. (Britain and C.S. America). Blackrust or suminer-rust. ${ }^{2}$ Uredospores and teleutospores occur on various species of Gramineae, the pycuidia and aecidia on species of Berberis or Mrthonir.

1 Clinton in Report of Agricultural Station of University of Illinois, 1 S93.

${ }^{2}$ A valuable monograph on the rusts of cereals has been published by Eriksson and Henning (Die Getreideroste, Stockholm, 1896). 
The two-celled telentospores arise from cushions or sori which form black lines on the haulns and leaves of grasses; they hibernate on the decayed remains and germinate in spring.

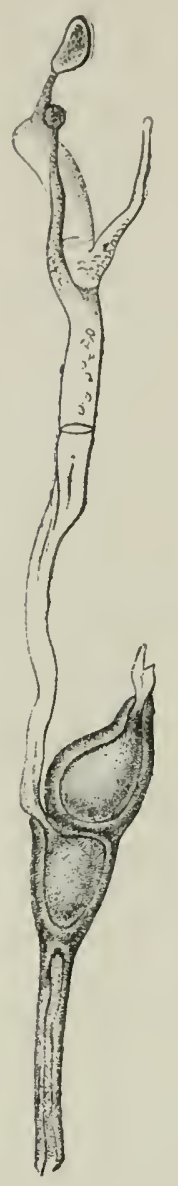

Fra. 182.-Puccinia grum inis. Germinating tclentospole. The promycelium has formed three sterigmata, from the ends of which sporidia are in process of abjunction. (After Tulasne.) the leaf-epidemis, till by their increasing size they rupture both coverings, and project above the surface as cups containing spores (Fig. 184). The aecidiospores originate in a layer of

Each cell of a germinating telentospore gives off a four-cellerl basidiun (promycelinm), with four short sterigmata from each of which a basidiospore (sporidium) is abjointed (Fig. 182). The sporidia are carried off the grass-host and germinate at once if they alight on leaves or flowers of Berberis or Mahonin (Fig. 183). Germtubes are formed which penctrate the outer walls of the host into the epidermal cells. The mycelium which results is a branehed septate one, and spreads through the intercellular spaces of the leaf. About eight days after infection, little yellow spots make their appearance on the upper surface of the leaf. Embedded in the spots will be found the pycnidia (spermogonia), spherical flask-shaped enclosures developed on a web of hyphae, and with their inner walls clad with short rod-shaped coniliophores (sterigmata), each of which gives off a tiny conidium (spermatium) (Fig. 184). A tuft of periphyses arising from the upper part of the pyenidium wall carries the conidia out of the pycnidia in drops of a honey-like fluid emitting a characteristic odour. In regard to the function of these conidia nothing definite is known.

The next stage begins with the appearance of yellow spots on the lower epidermis of leaves. These indicate the presence of a mycelium from which the aecidia take their origin. The aecidia are at first enclosed in a one-layered peridium under 
hyphae forming the bottom of the aecidium-cup. These hyphae give rise to numerous short sporophores, from each of which a single long chain of spores is abjointed in basipetal succession, the spores being at first separated ly temporary intermediate cells. The sporophores round the margin of each aecidium do not, however, give off spores; they also produce chains of cells basipetally, but these grow larger and, withont the intervention of intermediate cells, remain sterile and become joined

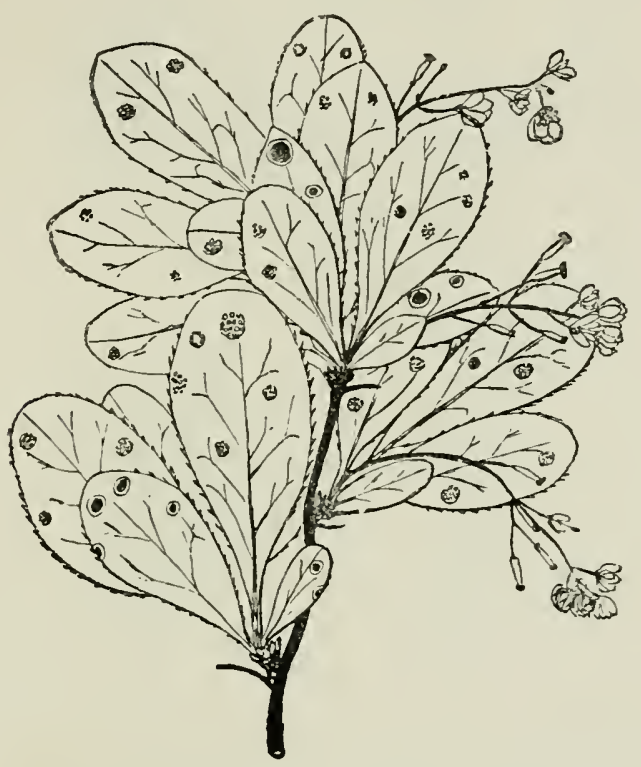

FIG. 183.-Puccinia graminis (Aecidium berberidis) on Berberis communis. The lowest leaf and two others are seen on the upper surface, and show red spots with light margins, in which the pycnidia are embedded. The other leaves sbow the under surface with patches of aecidia. ( $\vee$. Tubeuf del.)

to their neighbours to form the peridium. Diseased portions of leaves become considerably thickened. The cells of the single layer of palisade parenchyma are abnormally elongated, and the intercellular spaces of the spongy parenchyma, instead of being large, are small and filled with myceliunn. The aecidiospores escape in July to germinate on Gramineae. The germtube enters the host by the stomata only, and develops into an intercellular mycelium; this in about eight days produces uredospores from cushions or sori which form lines, and break 
through the epidermis. The yellow uredospores are aljointed singly from long sporophores; they are unicellular and ovoid, with a thiu granular cont beset with germ-pores (Fig. 184). 'The uredospores are easily conveyed to other grass-plants and germinate at once, their germ-tubes entering by a stoma aud developing into a mycelium, which ean produce a new crop of uredospores in a

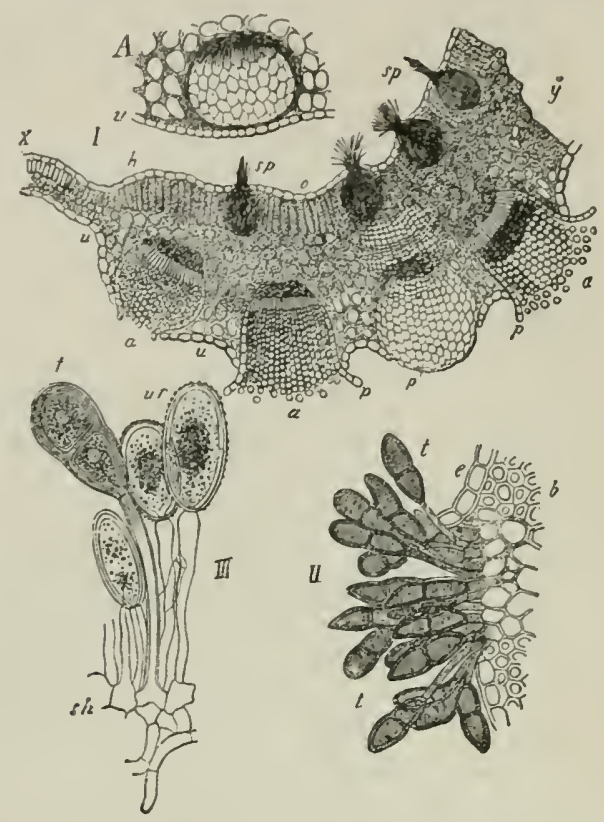

Fig. 18t.-Puccinia graminis. A, Portion of transverse seetion of leaf of Berleris culquris, with a young aecioinm under the efidermis, $u$.

I. Seetion throngh an aecidium-bearing spot of it Barberry lenf. It $x$ the normal structure and thiekness of the leaf is shown, the portion $u$ to $y$ is : abnormally thickened; $h$ to $o$, ulper surface of the leaf; $s p$, pycnidia; $a$, aceidia in seetion; $p$, their peridium. The aecidium marked $p$ alme (without $(t)$ slows a leridium exposed in suface-riew only.

II. Mature teleutospore-patch breaking through the epidermis, $e$, from the tissue, 1 . of a leaf of Triticum rejuins; $t$, teleutospores. $\times 190$.

III. Telentospores, $t$, and uredospores, $u r$. The telentospore has a germ-pore at its apex, the uredaspores have four germ-pores at their equator. $\times 390$ (After De Bary, from Sach's Lehrbuch.)

few days. The uredospores are summer-spores, and spread the fungus during the vegetative period of the host-plant; they may, however, hibernate. The teleutospores are more suited for hibernation; they are produced in autum from dark brown linear sori, distinguished from these of the uredospores by their darker colour and greater length. The teleutospores are two-celled and obovoid with smooth thick walls (Fig. 18t); they are, like 
the uredospores, dereloped from long sporophores, and are in this way distinguished from those of Puce. rubigo-ver are very short. The teleutospores germinate in spring after hibernation, each cell giving off a single germ-tube.

Both uredospores and teleutospores are injurious to our cereals,-wheat, oats, and rye. They may also be found on the following species of grasses: Anthorcuthum, Alopecums Pleleum, Ayrostis, Aire, Aiena, Brize, Arrhenertherum, Por, Dretylis, Festuce, Bromus, Triticum, Secale, Elymus, Hordeum, Lolium, Agropyrum, Andropoyon, Bryzopyrum, etc.

The disease may ruin a whole harrest of grain, and render the straw disagreeable, if not dangerous, for stable use (see also p. 8t). Riemoval of barberry bushes is said to reduce the rust, although many believe that the barberry is not necessary for the existence of the fungus. ${ }^{1}$ Plowright, for example, found that sporiclia from teleutospores infected wheat-seedlings directly, without intervention of the aecidiospore stage. It is also possible that the mycelium hibernates like that of Prce. murgo-rere, in some wild grass, to grow again and produce uredospores in spring.

No very effective measures against this fungus are known. Early sowing has been suggested; and certain varieties of grain, known to be less liable to attack than others, might be useu.

Eriksson and Henniug, ${ }^{2}$ from the results of their infectionexperiments, have provisionally distinguished the following varieties of $P$. grominis:

A. Definite- $(\alpha)$ distinct varieties:

1. Var. secrelis on Secale erreale, Hortrum vulgare, Triticum reperes, and Elymus arenurius.

2. Var. "rence on Avene sritiee, Mitium stfusm, Alopecurns prentensis, Ductylis glomerete (and Avene eletior).

:. Var. virre on Airu carspitose.

$(\beta)$ somewhat uncertain varieties:

t. Var. ugrostis on Agrostis cenine, and A. stolonifere.

j. Var. porre on Poc compresse (and P. pratensis).

B. Not sharply defined:

6. Var. tritici on Triticum velygre.

\footnotetext{
${ }^{1}$ An interesting discussion of this subject is given by Wor. G. Smith (Diseases of Crops: Chap. Xxv.). (Edit.)

"Eriksson and Henning, "Untersuchungen ib.- 1. Getreileroste," Zeitsch. f. Pflantenkrankheiten, IS94.
} 
Puccinia coronata (ordit. (Britain and IT.S. America.) Eriksson, from his own experiments and those of Klebahn, distinguishes the following specialized varieties:

Ser. I. Aecilia on lihummus cutharticu, fih. cluroides, Fih. yrandifoliu, Rh. aluifolin (Pucciniu coroniferu Kleb.).

1. Var. alemar on Alerne settize.

2. Var. alopecuri on Alopecurus protensis.

3. Var. festucac on Festure clation (and $F^{\prime}$. ruturet).

4. Var. Lolii on Lolium pereme.

In addition to these, Klebahn found a form on aterea elatior, and one on Holeus lanatus, in regard to whose specialization nothing is known.

Ser. II. Accidia on Rhammus Fronumula (Puccinier coronatr I., Kleb.).

5. Var. calamagrostis on Calamagrostis arundinacen (and C. lanceolata).

In addition: forms on Dartylis glomerutu, Festuca sylicutica (? Prucc. gibberosa Lagerh.), Agrostis vulgaris, Holcus lunatus (? II. mollis), and Phalaris armandinacea.

Ser. III. Aecidia on lihamnus dafurica (Puce. coronata ver. limalcnsis, Barcl.).

Indian forms on Brachypodium syluaticum, (Piptatherum holciforme, and Festuca gigantea,) of which nothing more is known.

Ser. IV. Aecidia unknown, probably do not exist.

6. Var. melicae on Melica nutans.

Amongst our cereal crops the oat alone is attacked by this species, and much damage may result.

The uredo-patches have no paraphyses like the preceding species, and they form reddish-yellow spots and stripes; the telentospore-patches are black. The upper cell of the teleutospores is surromded by a crown of six or seven blunt teeth.

The presence of aecidia on Rhamnus is accompanied by thickening and twisting of young shoots, and blister-like deformation of leaves, calyces, ant ovaries. Wakker ${ }^{1}$ thus summarizes his investigations on the anatomical changes induced by the fungus on Rhammus Frangula: "It causes the cells of every part to become abnormally enlarged, at the same time giving rise to an orange coloration of the cell-sap and an accumulation of starch; there is no longer any formation of interfascicular cambium, and there is a partial or complete

${ }^{1}$ Wakker, Pringsheim's Jahrbuch, 1592. 
suppression of secondary vasa, mucilage canals, and calcium oxalate."

The deformation induced by $P$. coronata on Iihamnus cathartica was investigated by Fentzling. ${ }^{1}$ The changes were relatively slight: the parenchymatous cells of the rind were enlarged and separated by large intercellular spaces; so also the parenchyma of the bast; vessels were more numerous in the wood affected; the epidermal cells in some parts of the leaf were broadened and those of the mesophyll enlarged, abnormally shaped, and with large intercellular spaces; in diseased leafstalks the epidermal cells are thimner-walled and broader, while all parenchymatous cells become enlarged, thinner-walled, and with many intercellular spaces; the fibro-vascular bundles are enlarged, chiefly from an increase of the wood-parenchyma; this tissue, in normal petioles, occurs as single rows of cells running radially between the vessels, whereas, in diseased places, three parallel layers of cells may separate neighbouring vessels.

P. dispersa Eriks. et Henn. Brown-rust. (Britain.) The following specialized varieties of this species have been distinguished:

Ser. I. Aecidium on Anchuse artensis and A. offeinalis (Aec. (enchusac).

1. Var. seculis on Secule cerecule. ${ }^{2}$

Ser. II. Aecidium unknown. (Whether distinct varieties, somewhat uncertain.)

2. Var. tritici on Triticum vulyare.

‥ Var. bromi on Bromus arrensis (and Br. brizaeformis).

4. Var. agropyri on Triticum repens.

P. rubigo-vera (D.C.) (P. straminis Fuck., P. striaformis West.). (Britain and U.S. America.) This, in its uredo- and telentospore stages, frequents various grasses, while the aecidia occur on Boragineae. A variety on species of Hordeum has been designated P. simplex. The telentospore-patches are enveloped in numerous brown paraphyses; the teleutospores have very short stalks.

The anatomical changes produced in leaves beset with aecidia have been stated by Wakker as follows: The swelling of the leaf-petioles is due to enlargement of their cells; the large intercellular spaces of the spongy parenchyma are no longer

${ }^{1}$ Fentzling, Inaugural Dissertation. Freiburg, 1592.

${ }^{2}$ Found along with the Aecidium at Montrose (Scotland) by Prof. J. W. H. Trail. (Edit.) 
present: the palisinle layer is toubled, and rupture of the epidemis takes place; chlorophyll-formation is suppressed, the cell-sap hecomes yellow, and stareh tends to aceumulate.

I. Nispmise may cause serions damage to wheat and rye; $I$. rmbigo-rem, also on barley and onts. The spore-patches are found on stalks and leaf-sheaths more than on the lamina. The nyycelium nay hibernate in grasses, so that the fungus is not dependent on the aecidial stage; for this reason the disease is not easily combater.

P. glumarum Eriks. et Henn. Golden-rust. This species, hitherto generally inchuded under P. mbigo-rera (I). (.) has been separated by Eriksson and Henning. Experimental infection on Boragineale gave negative results.

Eriksson distinguishes the following specialized varieties of this species:

A. Definite (and undoubtedly distinct).

1. Var. tritici on Triticum vulgare.

2. Var. hordei on Hordenm vulyare (somewhat uncertain).

3. Var. slymi on Elymus nenarius.

4. Var. cypropypi on Triticum repens.

$B$. Not sharply defined:

5. Var. secelis on Sccule cereule.

The uredospore-sori are lemon-yellow in colour, and form lines on the leaf-blade which may run torgether and reach a length of $10 \mathrm{~mm}$. The telentospore-sori form long, fine, brown or black lines: the sori are divided into numerous chambers, each enclosed in a circle of curved brown paraphyses. The spores germinate in the antumn of the sime year. The promycelimn is yellow till the spores, are abjointed; in this way it is distinguished from $P$. disperse.

P. poarum Niels. (Britain). Uredo- and telentospores on Por. According to Nielson, the aecidia ocenr on T'ussilago, Prtasites, and Adenostyles. Fentzling (lor. cit.) has described certain anatomical changes which accompany deformations due to the aecidia.

P. phlei-pratensis Eriks. et Henn. This has a hiberuating mycelium which produces uredospores continuonsly on I'leum and probably also on Festuca. Aeciclia have not as ret heen olserved.

\footnotetext{
${ }^{1}$ Eriksson and Henning (loc. cit.).
} 
P. agrostidis Plowr. ${ }^{1}$ Teleutospores on Agrostis vulyaris; aecidium = Aec. aquilegice Pers. (Britain and U.S. America).

P. festucae Plowr. ${ }^{1}$ Uredo- and telentospores on Festuce orina and $F$. duriuscula ; aecidium =Aec. periclymeni schum. (Britain).

P. phragmitis (Schmm.). Uredo- and teleutospores on Phragmites. Aecidinm $=A e c$. rubellum on Rumer crispus and other species of Rumen; also on Rherm. (Britain and U.S. America.)

P. Trailii Plowr. Uredo- and teleutospores on Pliragmites rommunis. Aecidium on Rumex Acetosu. (Britain.)

P. Magnusiana Körn. Uredo- and teleutospores on Phrugmites communis. Aecidium on Ranunculus repens. (Britain.)2

P. moliniae Tul. Uredo- and telentospores on Molinia coendea. Aecidium (according to Rostrup's out-of-door experiments), on Orchis repens, O. mascula; probably also on other Orchideae. (Britain.)

P. nemoralis Jnel. Ureelo- and teleutospores on Irolinic coerulec ; aecidium (Aec. melampyri Kze. et Sichm.) on Melampyrum pratense.

P. australis Körn. Uredo- and telentospores on Molinia in Tyrol; aecidium (Aec. erectum, according to Pazschke) on Sedum reftexe, S. acre, etc.

P. perplexans Plowr. Uredo- and teleutospores on Alopecurus prutensis; aecidium on Ranunculus acris. (Britain.)

P. persistens Plowr. On Triticum repens. Aecilimm=dec. thalictri (Britain).

P. sesleriae Reich. On Seslevia coerulea. Aecidiun on Rhamnus saratilis.

P. Winteriana Magn. ${ }^{3}$ ( $P$. sessitis, Schn.). Uredo- and teleutospores on Phalaris arundinacea. A ecilium on Allium ursinum (Alec. alliatum Rbh.).

P. sessilis Schn. (including $I$. digrapledis Soppitt and $P$. paridis Plowr.) (Britain.) Uredo- and telentospores on Phalaris arundinacea. Aecilium, according to Soppitt, ${ }^{4}$ on Convallaria majalis, also on Najanthemum, Paris, Polygonatum, Litium cancedense and Streptopus Smilacina. Klebahu's experiments confirm the relationship of the aecidium on Majanthemum, Coniallaria, Polygonatum, and Paris.

P. phalaridis Plowr. On Phaluris arundinaced. Aecidium (Atec. ari) on Arume itulicum and A. maculatum. (Britain.)

P. agropyri Ell. et. Ev. On Agropyrum. Aecidium=Aec. clematidis D. C. on Clematis litalba and C. recta, etc., in Europe and America.

P. caricis (Schum.) (Britain and U.S. America). Uredospores and teleutospores on species of Carex. Aecidia, according to Magnus, on Urtica (Fig. 185). The same author also believes that the uredo-stage can hibernate.

${ }^{1}$ Plowright, Grevillea, xxı., 1893, p. 109.

2Klebahn (Zeitsch. f. Pfanzenkrankheiten, 1892) confirms Plowright's observations on this.

${ }^{3}$ Iagnus, Heduigia, 1594.

${ }^{\star}$ Soppitt, Joumal of Botany, 1890. 
Stems, leaf-stalks, and leaf-nervature often undergo one-sided thickening and curvature as a result of formation of aecilia. Wakker thus summarizes his observations on the anatomical changes in these malformed parts of Urticr: there is an enlargement of cells and an increase in the number of large intercellular spaces; 110 formation of collenclyma, interfascieular cambium, and chlorophyll; a diminished formation of calcium oxalate; an orange coloration of the cell-saj); and a distension or rupture of the epidermis.

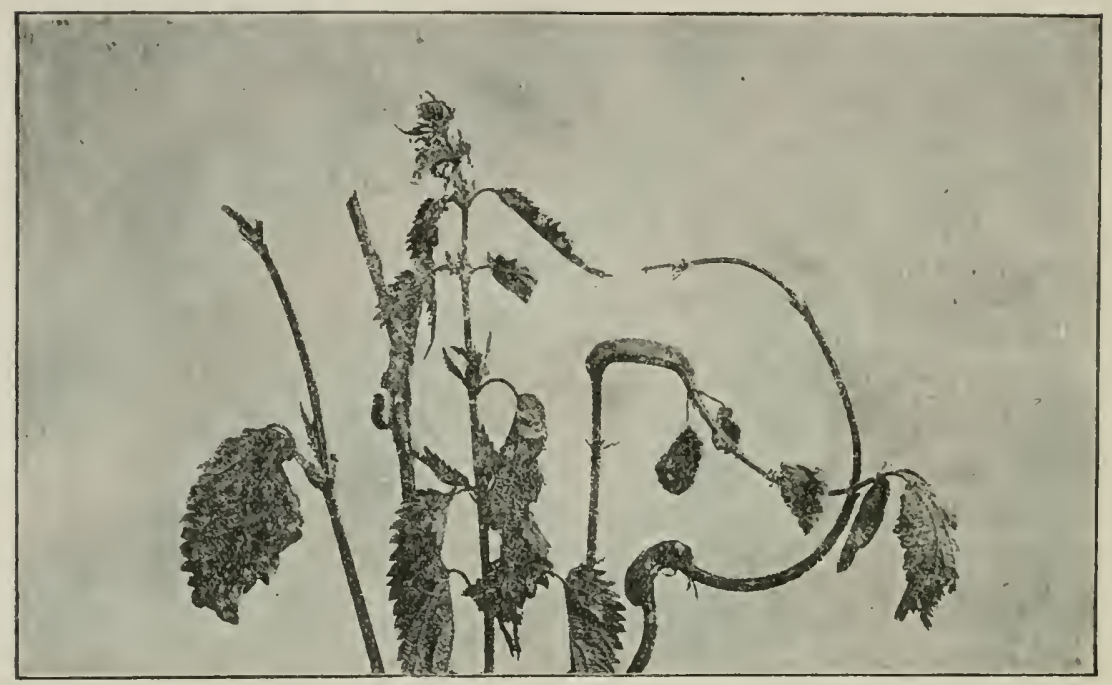

FIG. 1S5.-Puccinia caricis on Stinginy Nettle. The aecidial cushions lrare caused swelling and distortion of stems and leaf-stalks, also swollen outgrowtlss on the leaves. (v. Tubeuf phot.)

Klebahn and Magnus believe that there is a Puccinia on Carcer acute and C. Goodenoughii related to an Accidium on Ribes Grossularia, $R$. rubmu, and $R$. aureum; also a Puccinia on Cerers riparia with an Accidium on Ribes nigrum. On this account Klebahn ${ }^{1}$ distinguishes Puce. curicis I., II., and III., agreeing respectively with $P$. Pringshcimiana Kleb., $P$. caricis (Schum.), and P. Magmusii Kileb.

P. Schoeleriana Plowr. et Magn.2 (Britain). Uredo- and telentospores on Carca arenaria: aecidia on Senecio Jacobara.

${ }^{1}$ Klehahn, Zeitschrift $f$. Pflanzenkranklkten, 1892, 1894, and 189.5.

2 Hederigia, 1886. 
P. sylvatica Schroet. (Britain). Uredo- and teleutospores on Cemer a recidia on some Compositae. Schroeter ${ }^{1}$ regards an Accirtium on Taracacum officinale and Senccio nemorensis as related to the teleutospores on Carex brizoides and C. praceos. Klebahn ${ }^{2}$ reared aecidia on Turacucum after infection with teleutospores from C'urer arenaria; E. Fischer obtained aecidia only on Turascuen officinale. Dietel ${ }^{3}$ regards Accidium Burdenac on Aretium Lappe as related to this species.

Attacked leaves of Torcuxcum are frequently much deformed, stunted, and twisted. Those of $T$. officinale have orange-red warts on the lower surface, and there Fentzling (loc. cit.) found both spongy and palisade parenchyma increased and more or less deformed, the cells being elongated and enclosed in hyphae.

P. leucanthemi Palss. According to E. Fischer, the nredo- and telentospores are found on Carer montana; the aecidia (Aec. Teucanthemi) on Chrysanthemum Lencanthemum.

P. tenuistipes Rostr. Uredo- and teleutospores on Carex muricuta; aecidia on C'enturiece.

P. arenariicola Plowr. et Magn. On Carer arenuric; aecidia =Aec. centanrece on C'. nigru. (Britain.)

Ed. Fischer found that the species of Puccinia on Curex montana (one with its aecidia on Centurea Seabiosa, the other on Centaurea montuna), were specifically different.

P. limosae Magn. [redo- and telentospores on Carex limosa; aecidia on Lysimachir thypsifulia and $L$. melgaris."

P. extensicola Plow. (Britain.) Credo- and telentospores on Carex extensu; aecidia on Aster Tripolium.

P. dioicae Magn. (Britain and U.S. America). Uredo- and telentospores on Cererer dioica and C. Darolliuna ; aecidia on Cirsium (according to Rostrup and schroeter).

P. firma Dietel. Telentospores on Curex firma; aecidia on Bellidiastrum.

P. vulpinae schroet. Uredo- and teleutospores on Carer rulpinu; aecidia on Chrysanthemum Tanocetum. ${ }^{5}$

P. paludosa Plowr. (Britain). Uredo-and teleutospores on Curex vulgaris, etc. Plowright gives Aecidium pedicularis as the aecidial form. The attacked plants of Pedicularis are often considerably deformed.

P. uliginosa Juel. ${ }^{6}$ Uredo- and telentospores on C'ure.x vulgaris;

${ }^{1}$ Pitze Schlesiens.

${ }^{2}$ Klebahn, Zeitschrift f. Pfansenkrankiheiten, II., 189:2.

${ }^{3}$ Dietel, Oesterreich. botan. Zeitung, 1859.

"Magnus, Tagbl. d. Naturforsch. Vereins in Wünchen, 1sit.

sichroeter, Pilse schlesiens.

${ }^{6}$ Juel, Iycoloy. Beit. V'etenscaps-Akad. Förhandl, 1894. 
aecidia (Aer. premerssine Schlecht.) on L'rernassin palustris. Sipenogonial pycuidia are mukuown.

P. scirpi J). C. (Britain). Uredo- and telentospores on Sirripes; aecillia,

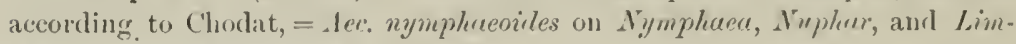
mentlemuin nymphucoides.

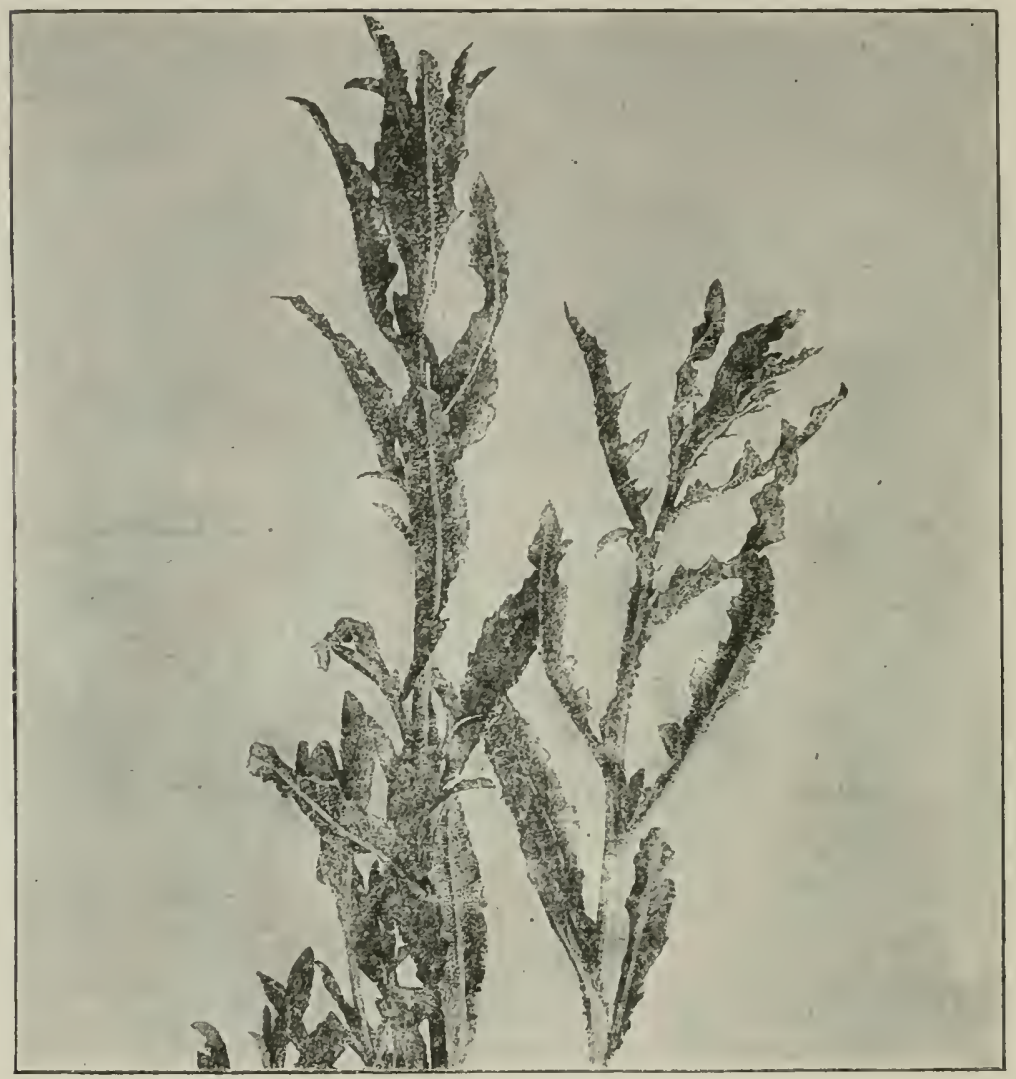

F1G. 1S6.-Puccinic sucurcolens on Cirsiun arvense. The plants are abnormally elongated; the leaves have remained smaller and simpler, and are thickly beset on the lower side with patches of chocolate-brown uredospores. (v. Tubeuf phot.)

P. eriophori Thiim. Uredo- and teleutospores on Eriophonum lutifolium in Siberia and Denmark; Rostrup gives as the aecidial form Aec. cinerariae Rostr.

P. obscura Schroet. Uredo- and teleutospores on Luzula; aecidia on Bellis perennis (Plowriglıt). (Britain and U.S. Anerica.)

P. septentrionalis Juel. Uredo- and telentospores on Polygonum viriparum; aecidia (Aec. Sommerfeltii) on Thalictrum alpinum in Scandinaria, 
Iceland, Greenland, and Switzerland. Juel states that this is the only heteroecious Puccinia whose uredo- and telentospores inhabit a dicotyledonous plant.

(2) Accidia are absent; pycnictia, wrelospores, and telcutospores developed on the same plant. (Brachypuccinia, Schroct.):

Puccinia suaveolens (Pers.) (Britain and U.S. America). One form on Cirsium arvense, and a second on Centanea Cyanus. Pycnidia and uredospores appear first, then teleutospores develop amongst the later-formed uredospores.

The shoots and leaves of attacked plants are permeated with mycelium and rendered conspicuous by their elongated shape, lighter colour, and smaller, less lobed, softer leaves (Fig. 186). Diseased plants bear no flowers. Wakker on investigating the diseased stems found: non-development of those sclerenchymasheaths of the primary tissues situated towards the interior of the stem, whereas those towards the outer side show secondary thickening; irregularities occur in the interfascicular cambium, so that the phloem becomes abnormally developed and proportionately more extensive than the wood, it may also be divided by a band of sclerenchyma.

P. hieracii (Schnm.) (Britain and L.S. America). On numerons Compositae, e.g. Curlina, Cirsizm, Curduns, Centurea, Leontodon, Scorzonera, Crepis, Hieracium, Cichorium, ete.

Plowright distinguishes two allied species on Compositae, viz. I'. centaurene, Mart. on Centaurea nigra, and $P$. taraxaci Plowr.

P. bullata (Pers.) (Britain and U.S. America). On Umbelliferae, e.g. Apium, Petroselinum, Athusa, Selinum, Conium, Anethum, ete. On cultivaterl species (e.g. Parsley, Dill, Celery, etc.) it may prove troublesome. ${ }^{1}$

P. oreoselini (Strauss). On Peucedanum and Seseli. (U.S. America.)

P. helvetica Schroet. On Asperula taurina.

(3) Uredospores and teleutospores alone linown. The related pyenidia and aecilia have either not as yet been traced, or do not crist. (Hemipuccinia, Schroct.):

Puccinia sorghi Scbwein. (Pucc. mayclis Bér.). This rust of Soruhum and Zea Mais occurs in America, Italy, Germany, ete. The leaves become more or less beset with little pustules, in which the sori of uredospores or teleutospores are contained (Fig. 187-189).

P. purpurea Cke. On Sorghum vulgare in India, and Zea in Africa.

${ }^{1}$ Description and figures in N. J. Agric. Exper. Station Report, 1891. 
P. elymi West. (Kostrupin elymi Lagerh.). On Elymus urenurius and E. mollis.

P. Baryi (Berk. et Br.). On Brachypodium in Emrope and Britain, Bambusa Thouersii in India, Andropogon, etc., in America.

P. longissima Schroet. On Foelerin "ristata in Germany; $K$. Berythris in Egypt.

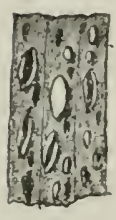

Fic. 1si.-Puccinie sorgh (Pucc. maydis). Portion of Maize-leaf showing sporepatches. (₹. Tubeuf. del.)

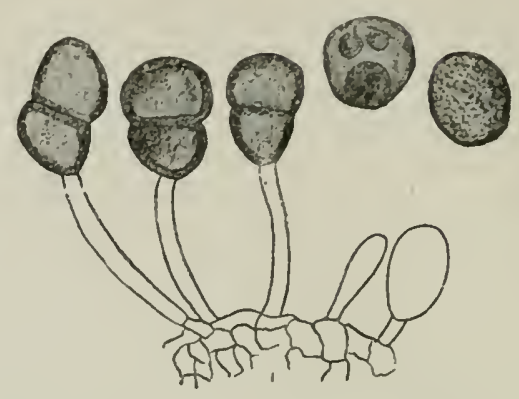

FIf. 15:3.-Puccinia sorghi. Three telentospores and two urcdospores. One of the latter exhibits the tiny point-like projections of the membrane. ( $\nabla$. Tubeuf del.)

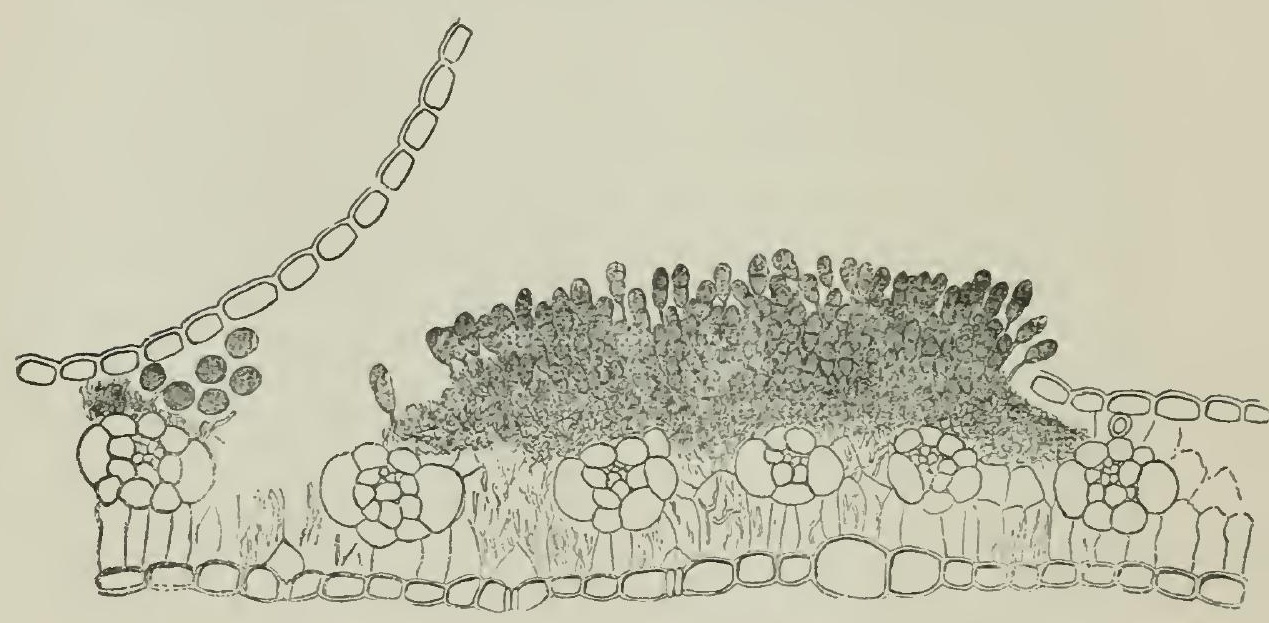

FIG. 18s.-Puccinia sorghi. Section of leaf of Zea Mais filled with mycelium. The epidermis is ruptured br a spore-sorus. At one end there are still the remains of a uredospore-sorus and a few uredospores. (₹. Tubeuf. del.)

P. paliformis Fuck. On Foeleria rristata. (Britain.)

P. anthoxanthi Fuck. On Anthoxanthum odorcetum. (Britain.)

P. gibberosa Lagerh. On Festuca syluatica.

P. angustata Peck. On Scirpus and Eriophomem. (U.S. America.)

P. junci (Strauss). On Juncus. (U.S. America.)

P. oblongata (Lk.). On Luzula. (Britain.) 
P microsora Körn. On Carex vesicaria.

P. caricicola Fuck. On Carex supina.

P. allii (D. C.). Ouion-1'ust. (U.S. America.)

P. iridis (D. C.). Onı Iris. (Britain.)

P. veratri Niessl. On Teratrum album and I. viride. (U.S. America.)

Puccinia pruni Pers. Plum or Prune Rust. [This is a common species in both Europe and the United States; it attacks almost every kind of cultivated drupaceons fruit, including prune, plum, peach, nectarine, apricot, cherry, and almond. The uredospores are brown, the teleutospores clarker, and both are as a rule found only on the under surface of the leaf (Fig. 82). The leaves first show yellowish or reddish spots which rapidly enlarge and darken in colour till rupture of the epidermis takes place, and they rapidly dry up. The fruit is thus altogether lost or much injured, while ripening of the wood is more or less interfered with.

The remedies suggested are: sprayings with modified eau celeste, or ammoniacal copper carbonate (see p. 69)]. ${ }^{1}$ (Edit.)

P. cerasi (Béreng.) Cherry-rust on Prums Cerasus, P. Amygdalus, and P. Persica.

P. oenotherae Vize. On American species of Oenothera.

P. giliae. Hark. On Phlor and Gilia. (U.S. Anerica.)

P. tanaceti D. C. On Tanacetum vulgare. (Britain and U.S. America.)

P. sonchi Rob. et Desm. On Sonchus. (Britain.)

P. endiviae Pass. On Cichoria Enedivia in Italy.

P. carthami Corda. On Curthamus tinctoria.

P. balsamitae (Strauss). On Tanacetum Bulscemita.

P. picridis Haszl. On Picris in Hungary.

P. bistortae (Stranss) (Britain and U.S. America). On Polygonum Ristorta and $P$. viviparum. The telentospores have no papilla on their germ-pores. Soppitt (Grevillea, 1894) claims relationship between this species and an Aecidium on Conopodium denudatum (Aec. bunii (?)).

P. mammillata Schroet. (U.S. America). On Polygonum Bistorte. The upper cell of the telentospore has an apical thickening.

P acetosae (Schum.). On Rumex Acetosa, R. arifolia, and R. Acetosella. Ludwig says it hibernates in the uredo-form.

P. polygoni Pers. (Britain and U.S. America). On Polygoneae.

P. rumicis-scutati (D. ( $)$ ). On Polygonere.

P. oxyriae Fuck. (Britain and U.S. Anerica). On Oxyria.

P. castagnei Thim. On Apium grareolens in France.

P. cicutae Lasch. On Cicuta virosa.

${ }^{1}$ Pierce (Journal of Mycology, vIr., p. 354) gives an account of this disease as found in California, and describes application and results of various remedies. 
P. stachydis D. C. On Ntucleys rertu.

P. argentata (Schult\%). On Impatiess. (Britain and U.S. Anerica.)

P. Berkeleyi P'ass. On l'incr. (Plowright distinguishes also $P$. rincue.) (Britain.)

(4) Uredospores absent or only ruelimentary. The other sporerforms-pyenidia, accidiu, and trlentesporis-derelop on the sormer hust-plant. (Pucciniopsis, Schroet.):

Puccinia tragopogonis (Pers.) (Britain). On Trumpungon, Scor:oncr", Poulospcrmmm, and Galasice. The leaves of diseaserl plants are conspicuous in spring from their slenderness and pale colour.

P. senecionis Lib. ${ }^{1}$ (Britain). The mycelium inhabits species of Srnccio; it probably arises from aeciliospores, and produces both aecilia and teleutospores.

P. ipomeae Cooke. On Ipomen in U.S. America and S. Africh.

P. bunii (D. C.). On ('urum Bulbucastamm and Pimpinella Sarifirago (Britain).

P. smyrnii Biv. On simyrnum Olesutrum. (Britain.)

P. trollii Karst. On Iconitum Lycoctonum and Trollius europaens.

P. valerianae Carest. On Treteriana officinulis and Centionthess Calcitrupu.

P. liliacearum Duby: On Ornithogalum, Scillo, and Gugea. (Britain.)

(5) Teleutospores alone produed; they hibernate in deul hostirmains (Hicropuccinia, Schroct.):

Puccinia fusca (Relhan.). (Britain and U.S. America.) Anemone-rust. The brown spore-patches of this fungus occur on various species of Anemone, Thalictimm, and Pulsatilla. Attacked plants of Anemone nemorosa (Fig. 190,6 and 7 ) have their leaves much altered, the petioles being abnormally long and the laminae much thickened, with narrowed segments, and conspicnously palegreen. The telentospore-patches form chocolate-brown spots on the lower surface of the leaf, and stripes on the leaf-margins. Flowers are rarely developed on diseased plants: Fentzling, however, found flowering plants with aecidia on the leaves; three of the perianth-parts being stunted. The same investigator found a few anatomical changes in deformed plants: in petioles the middle one of the three vascular bundles normally present was larger than those on each side of it; in the diseased lamina the parenchyma-cells were enlarged, while inter-

${ }^{1}$ Dietel, Hedwigia, 1591, p. 291 ; also Zeitwhrift f. Pflanzenkrankheiten, 1593, p. 255 . 
cellular spaces were more numerous and also larger. Other minor differences are also given, but there seems to have been

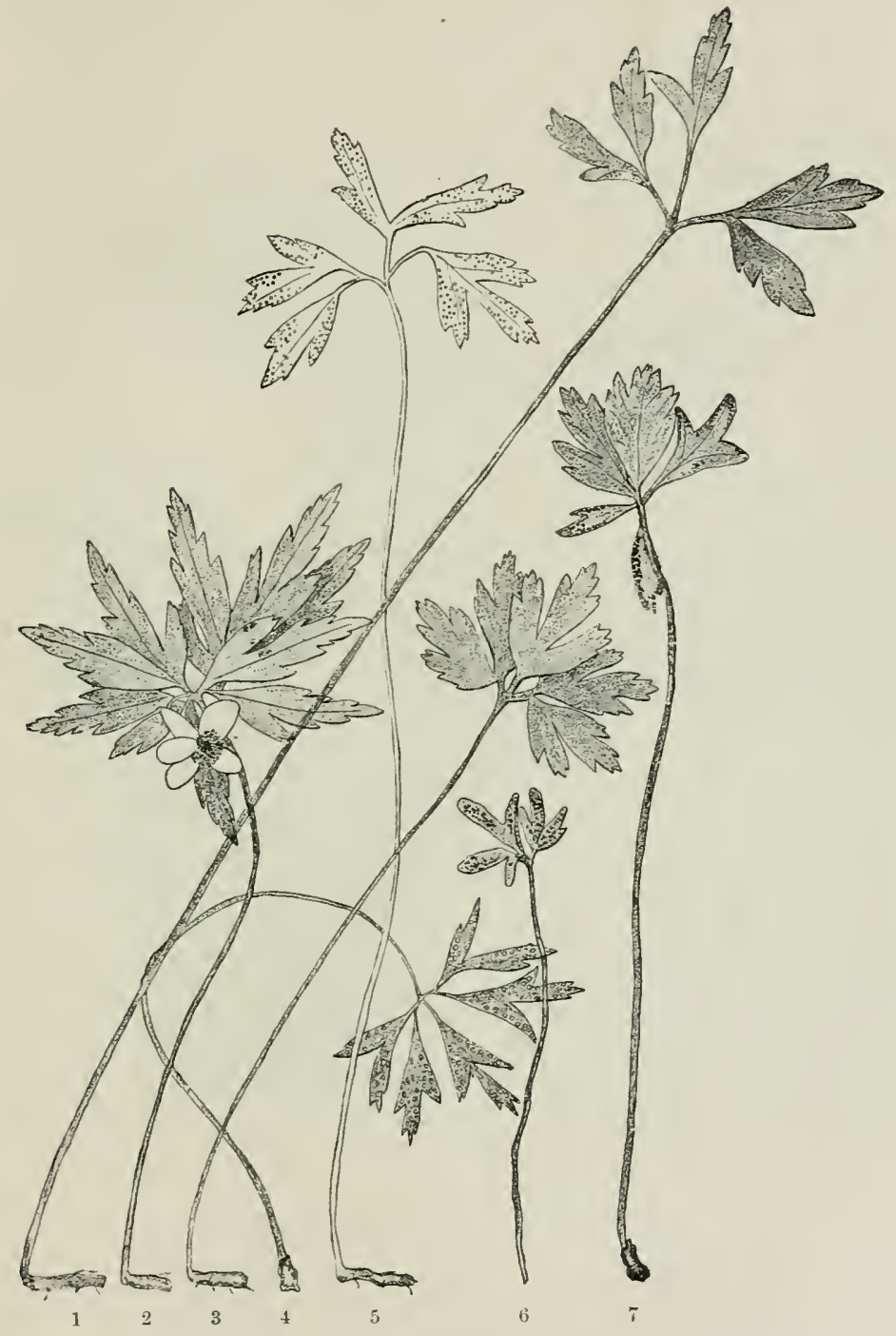

FIG. 190.-Anemone-Rust. 2 and 3, Formal plants of Anemone ranunculoides. 4 , Arcidium punctutu.ir on Anemone ranunculoides; aecidia on the lower surface of the leaf; the plants are abnormally elongated, and the leaf-segments are smaller. 6 and 7, Puccinia jusca on Anemone nemorosa; the plants rem tin small, 6 is completely deformed, $i$ partially. 1 and 5 , Aecidium leucospermum on 6 is completely deformed, $i$ partially. smaller. (v. Tubeuf del.) 
some confusion between plants infested with this P'uccinia and those with species of Aecilium. The changes induced on anemone by either Accirlium Icucospermum D.C. or Acc. punctatum Pers. are quite distinct (Fig. 190).

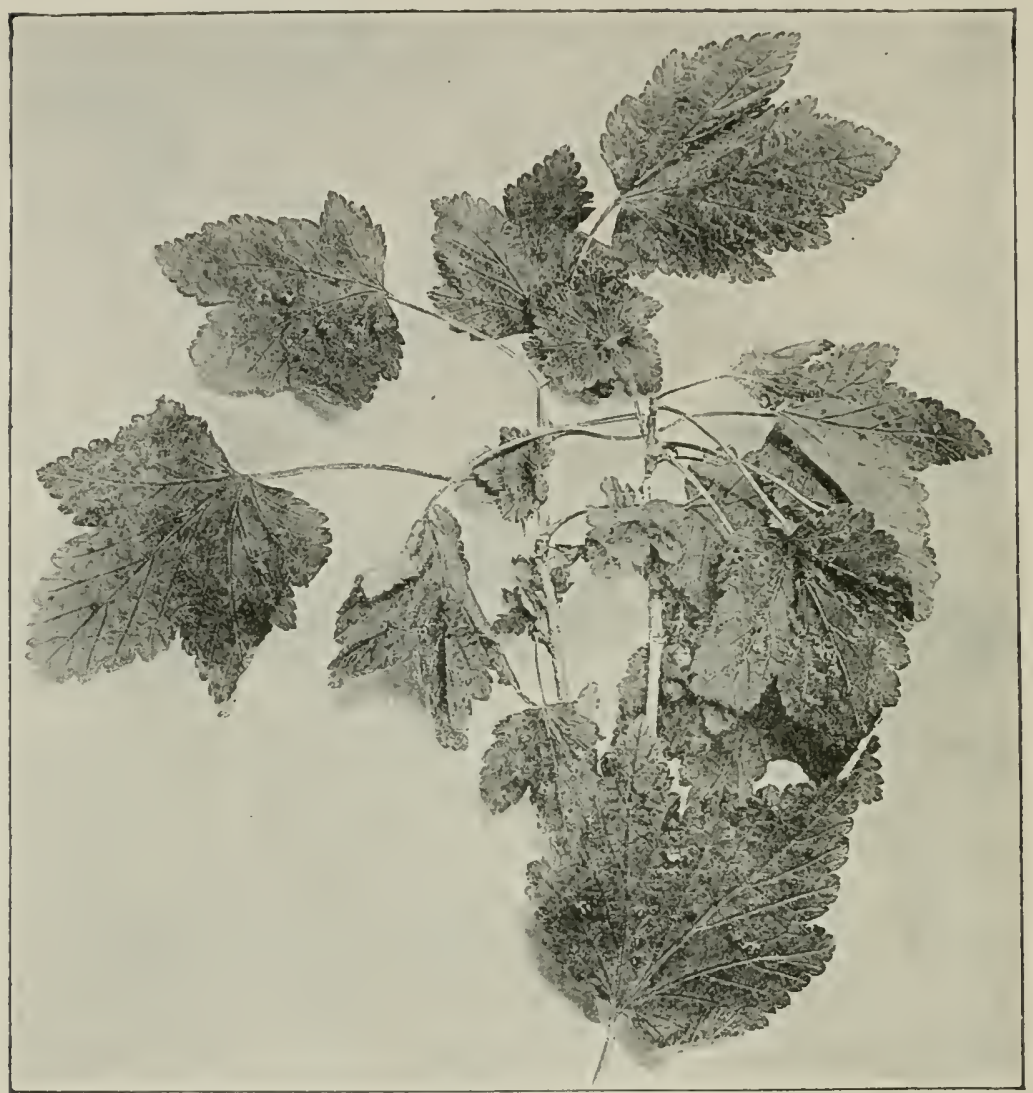

FIG. 191.-Puccinia ribis on Red Currant (Ribrs rubrum). Telentospore-patehes on leaves and fruit. (v. Tubeuf phot.)

P. singularis Magn. Un Anemone ranunculoides in Austria and south-east of Europe. The telentospore germ-pore is situated at the centre of the lateral wall of the lower cell, thereby distinguished from that of I. fisca.

P. atragenis Haussm. On Itragene alpina.

P. thalictri Chev. On species of Thatictrum. (Britain and U.S. Anericis.) 
P. Fergussonii Berk. et Br. On Viola palustris, etc. (Britain and U.S. America).

P. alpina Fuck. On Viola biflora.

P. geranii-sylvatici Karst. On Gercuium sylvaticum.' (U.S. America.)

P. Morthieri Körn. On Geranium.

P. Holboelli (Horn.). On Arabis Holboelli and Erysimum narcissifolizm in Denmark and U.S. America.

P. drabae Rud. On Draba cizoides. (U.S. America.)

P. dentariae (Alb. et. Schwein.). On Dentaria bulbifera and $D$. enneupliylla, causing pustule-like outgrowths on the leaves.

P. ribis (D. C.) Currant-rust. On Ribes rubrum, R. nigrum, R. alpinum, R. Grossulurie, and R. petraenm (Britain and U.S. America). (Fig. 191.)

P. saxifragae Schleclit. On Saxifraga. (Britain and U.S. America.)

(P. Pazschkei Dietel. On Saxifraga elatior and S. Aizoon.)

P. rhodiolae B. et Br. On Sedum rhodiola. (Britain.)

P. sedi Körn. On Sedum elegans.

P. aegopodii (Schnm.). On Umbelliferae, e.\%. Aegopodium, Astrantie, aurl Peucedunum. (Britain.)

P. enormis Fuck. On Chacrophyllum aureum.

P. asarina Knze et Schm. On Asurum. (Britain.)

P. rubefaciens Joh. On Galium boreale in S̈candinavia and U.S. America.

P. campanulae Carmich. On Campanule and Jasione. (Britain and U.S. America.)

P. conglomerata (Str.). On Homogyne ulpinu.

P. expansa Link. On Adenostyles and Senecio.

P. virgaureae (D. C.). On Solidago. (Britain and U.S. America.)

P. cardui Plowr. On Carduets lanceolatus, and C. crispus. (Britain.)

P. Andersoni. B. et Br. On Cardus heterophyllus. (Britain.)

P. bellidiastri (Ung.). On Bellidiust.um. (The aecidium on the same host belongs to Pucc. firma Diet.)

P. adoxae D. C. On Adore moschatellina. (Britain and U.S. America.)

P. betonicae (Alb. et Schwein.). On Betonica officinalis and Sitachys recta. (Britain.)

P. Schneideri Schroet. On Thymus Serpyllum. (Britain.)

P. scillae Lk. Ons Scilla bifolia in Hungary.

P. tulipae Schroet. On Tulipa Gesneriana.

P. Prosti Mong. On Tulipa sylvestris and T. Celsiana in Italy and France.

P. Schroederi Pass. On Nurcissus poeticus.

(6) The teleutospores germinate on the living plants, and again produce telentospores. All other forms of spore are cebsent. (Leptopuccinic, Schroet.) :

Puccinia malvacearum Mont. occurs on varions Malvaceae.

${ }^{1}$ Barclay (Annals of Botany, v., p. 27) describes and figures a rar. himalensis on Geranium uppalense. 
This rust is indigenous to ('hili, and was introduced into Erance abont 1868 , whence it rapilly extended throughout the whole of Europe, and cluring the last ten years has made its appearance in the United states. In many places it has eompletely exterminated both wild and cultivated mallows, and rendered the cultivation of garden hollyhoeks impossible. It appears in

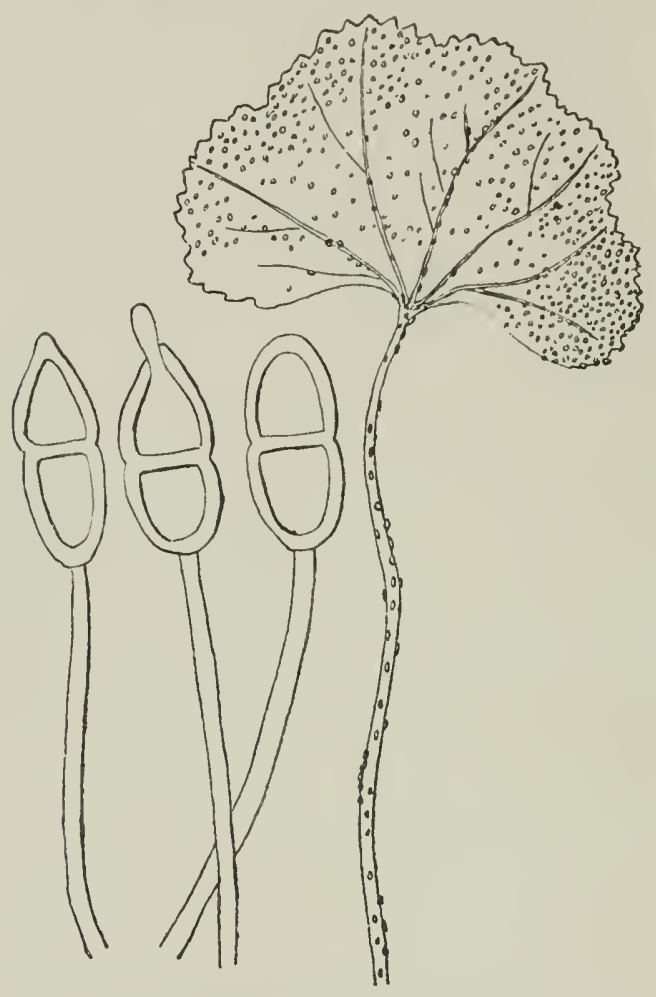

FIG. 192.-Puccinia malvacearum. Mallow leaf, with teleutospore-sori. Threo teleutospores, one germinating. (v. Tubeuf del.)

May or June on the leaves, stems, and petioles of the host; all are more or less deformed, and the leaves may in severe eases wither up long before the flowers appear. Sponging with a solution of permanganate of potash (two tablespoonfuls in one quart of water), has been found an effective remedy.

P. Sherardiana Körn. On mallow in America.

P. heterogenea Lager. On hollyhock in Sonth America.

P. anemones-virginianae Schwein. On Anemone. (U.S. America.) 
P. thlaspeos Schub. On Thlaspi alpestre and Arabis hirsuta

P. spergulae D. C. On Sperguta. (U.S. America.)

P. arenariae (Schum.). On Alsineae and sileneae, e.g. cultivaterl Dianthus burbutus. (Britain and U.S. America.)

P. chryosplenii Grev. On Chrysosplenium. (Britain.)

P. circaeae Pers. On Circaeu. (Britain and U.S. Anerica.)

P. buxi D. C. On Buxus sempervirens. (Britain.)

P. umbilici Guep. On Umbilicus. (Britain.)

P. valantiae Pers. On Gulizm. (Britain and U.S. America.)

P. asteris Duby. (Britain and U.S. America.) On Aster, Artemisiu, Achillea, Cirsium, Scabiosa, Doronioum. Plowright regards I'. millefolii Fckl. on Achillea as a distinct species.
P. veronicae (Schroet.) (Britain).
P. veronicarum D. C. (Britain and L.S. America). $\}$ On leronica."
P. albulensis Magn.
P. glechomatis D. C. On Glechoma (Nepeta). (Britain and U.S. America.)
P. annularis (Strauss). On Teucrizm. (Britain.)

\section{Hemileia.}

Hemileia vastatrix, Berk. et Br. This occurs on the leaves of the coffee plant in Cerlon, Jara, and Sumatra. It causes a very destructive disease. Sadebeck recommends as remerlies: (1) Removal of infected leares and their sterilization by dilute acids or Bordeaux mixture. (2) Spraying the beds with Bordeanx mixture, so as to kill the spores which have fallen there.

Several genera which do not occur in Europe may be mentioned here, viz. : Uropyxis, Diorchidium, Chrysospora, and Sphaerophragmium; also Masseella, Phakospora, and Schizospora. ${ }^{3}$ They contain but few species, and none of practical importance.

\section{Triphragmium. ${ }^{4}$}

Teleutospores three-celled; one cell is attached to the sporophore, and carries the other two; each cell has one or more germ-pores.

Triphragmium ulmariae (Schum.). (Britain.) Uredospores and teleutospores produced on the same plant, Spiraca Ulmaria. The telentospore-patches are dark-brown, the uredo-soni reddishyellow, while the pycniclia (so-called spermogonia) are yellowish

${ }^{1}$ Distinction, see Magnms, Ber. d. deutsch. botan. Ges., 1890, p. 167.

${ }^{2}$ Sadebeck, Forstl-naturuiss. Zeitschrift, 1895. M. Ward, Sessional Papers.2 xvir., Colombo, 1851 .

${ }^{3}$ Dietel, Brrichte d. deutsch. botan. Gies., 1895, p. 332.

${ }^{4}$ Bibliography and Revision, by G. Nassee, Grevillea, xxı., 1893, p. 111., 
points. The so-called aecidia are really a form of uredo-sori; they occur as thick eushions and cause thickening or twisting of the leaves and petioles.

T. filipendulae (Lasch.) (Britain). On Spirmen Fillipentule.

T. echinatum Lév. occurs on Heum; telentospores alone are known (U.S. America).

T. clavellosum Iserk. On leaves of Aralia in the United States.

\section{Phragmidium.}

Teleutospores multicellular, the individual cells forming a single series; they show a variable number of germ-pores. The

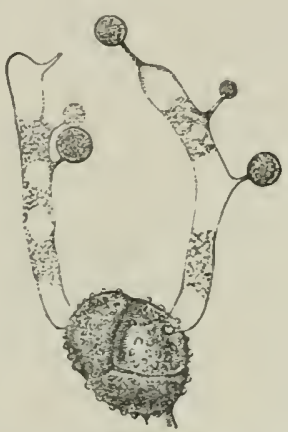

Fic: 193.-Triphregmivis ulnuriue on Spirven Clinctive. Germinating teleutospore, with promycelia and sporidia. (After Tulasie.)

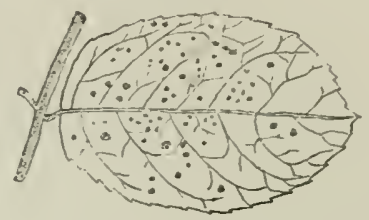

Fig. 194.-Phronnidium subcoiticium on a Rose leaf. The black spots are teleutospore-patches on the undersurface of the leaf. ( $\nabla$. Tubeuf del.)

teleutospores are produced in loose patches. The aecidial patches have no covering, but are surrounded by club-shaped paraphyses.

The genus frequents only Rosaceae.

On species of Rosa: ${ }^{1}$

Phragmidium subcorticium (Schrank.). Telentospores, uredospores, and aecirlia on leaves of wild and cultivated roses. (Britain and U.S. America.)

Phr. tuberculatum J. Miill. All the forms of spore occur on Rosa runina.

Phr. fusiforme schröt. [I'hi. rosue-alpinae (D.C.)]. On Rosa alpina (Britain).

Phr. speciosum (Fr.). On North American roses.

Phr. devastatrix Sor: On roses in Asili.

'J. Müller, "Die Rostpilze d. Rosa. u. Rubus-arten," Ber. d. deutssh. botan. Ge..., 1SS5. 
On species of Potentilla:

Phr. fragariastri (D. C.) (Britain aud U.S. America).

Phr. potentillae (Pers.) (U.S. America).

Phr. tormentillae Fuck. (Britain.)

Phr. papillatum Dietel, from Siberia.

Phr. nepalense Barcl. and Phr. laceianum Barcl. in India.

On species of Rubus:

Phr. rubi (Pers.) ( $1 \%$ r. bulbosum Schlecht.) (Britain).

Phr. rubi-idaei (Pers.). On leaves of rasplerry. (Britain and U.S. America.)

Phr. violaceum (Sehnltz) (Britain).

Phr. rubi-miniatum J. Miill.

Phr. albidum (Kiiln).

Phr. quinqueloculare Barel.

Phr. octoloculare Barel.

Phr. Barclayi Dietel, from Himalaya.

Phr. gracile Farl., America.

And other species.

On Sanguisorla:

Phr. sanguisorbae (D. C.). On Sunguisorber minor. (Britain.)

Phr. carbonarium (Schlecht.) (Britain). This species has also been placed in a separate genus Xenodochus. It oceurs on Sanguisurba. Uredospores are wanting; the teleutospores form firm black crusts; the aecidiospores

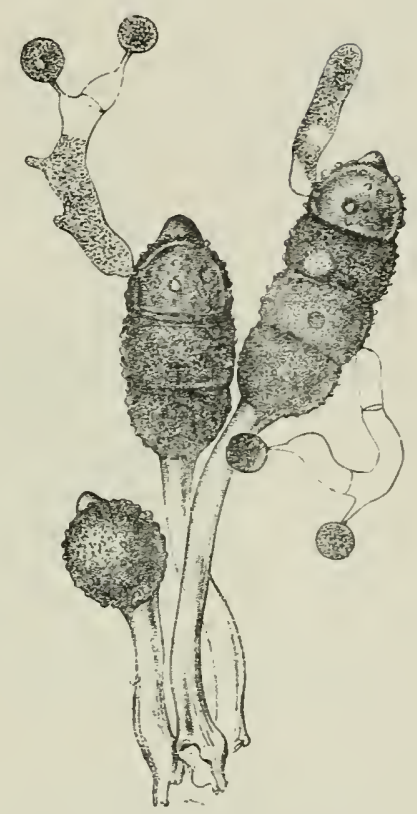

Fig. 195.-Phiagmidium rubi from Rubus Muticosus. One spherical immature teleutospore, and two well-developed and germinating ones. (After Tulasne.) form chains; and the paraphyses are club-shaped. Diseased leaves and petioles are thickened and bent. Wakker's investigation showed: a slight enlargement of parenchymatous cells and rupture of epidermis on spore-formation ; a diminution in the intercellular spaces and in formation of collenchyma and sclerenchyma; a suppression of all production of chlorophyll and calcium oxalate.

\section{Melampsora.}

Teleutospores dark and unicellular, in some cases inulticellular by formation of new walls, generally in a vertical 
direction; their sori form dark sjots which break out from beneath the epidermis. The yellow ureclospores have a coat beset with fine spines, and are given off from sori which may or may not be enclosed in a peridium. The sori of the aecilium-stage have no peridium, and are known under the generic name of C'ucoma; they frequently occur on other hosts than those of the telentospores. P'ycuidia are produced in little yellow patches.

Melampsora tremulae Tul. (Britain). The sori of uredospores appear as little yellow protuberances on leaves or young shoots of Populus tremula. The dark-brown patches of telentospores appear later on the under epidermis, and where they

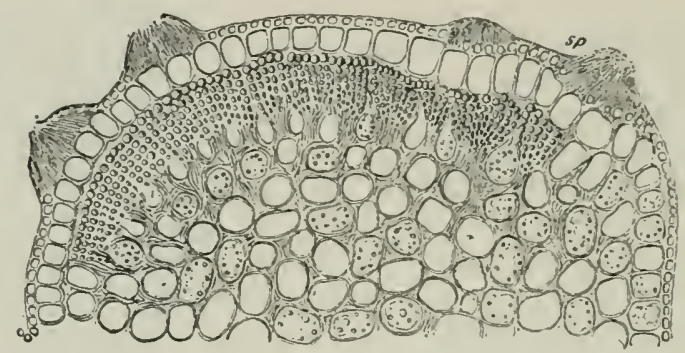

\footnotetext{
Fig. 196,-Cacome pinitorquum. Section showing four pycnidia, from one
of whicl $(x p)$ numerous conidia are being dischirged. Comom-patches are dereloping beneatb the cortical layer, as yet unbroken. (After R. Hartig.)
}

oecur in large numbers, an early fall of the leaf may result. The teleutospores hibernate in dead leares on the ground. In spring the sporidia germinate and infect young shoots of Pinus sylvestris, producing the disease known as Caroma pinitorquum. ${ }^{1}$

This disease attacks pine-seedlings, appearing generally on the needles. It is most frequent in plantations from one to ten years old, rarer in those of ten to thirty years, and not as yet olserved in older. Pinus syliestris is most commonly attacked, but it has also been observel on Pinus montana in Jiitland. After formation of the Cacoma-patches, the young thin shoots generally die off, but thicker ones become twisted at the place attacked, whence the name "pine-twister" commonly given to this disease. If the leading shoot be attacked, the secdlings may succumb altogether. The disease develops rapidly,

${ }^{1}$ R. Hartig, Wichtige Krankheiten d. Naldbünme, 1sit. 
particularly in a damp and cold spring, and may prove very destructive if it appears for several years in succession. The mycelium evidently perennates in pine-shoots, and produces new Cacoma-patches year after year till death of the host results. It grows intercellularly especially in the rind parenchyma, but also in the medullary rays of wood and bast; the contents of the host-cells are absorbed by means of short lateral haustoria.

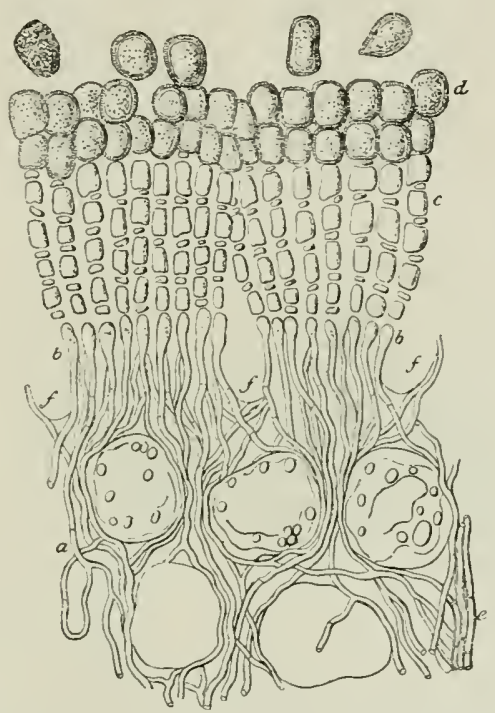

FIG. 145.-Cueome pinitoryum. Portion of Guomu-patch (enlarged). $f$, Corticil cells partially absorbed or much compressed; $b$, basidia from which spores $(c)$ are abjointed in succession: the younger with delicate walls and separated by membranous lamellae, which disappear on formation of the spore-coats $(d)$. (After R. Hartig.)

The pycnidia are produced at end of May or beginning of June, between the epidermal cell-wall and the cuticle of green twigs; before breaking out they may be observed externally as light patches on the shoot. The Cacoma-patches develop later in the second or third layer of the rind-parenchyma (Fig. 196). In each patch the spores are produced serially from short stalks to the number of twenty or thereabout, and ultimately escape about June, when the cells of the parenchyma and epidermis are ruptured. At first the spores are connected together by intermediate cells which are afterwards absorbed (Fig. 197). The mature spores are globose, oval, or polygonal 
in shape, yellow in colour, and their outer coat is beset with spiny projections. The stalk-cells grow out into elongated tubes, after completion of spore-formation. In the vicinity of the scar of a Cacoma-patch, the twig tums brown and its tissues become permeated with resin, while the tissues underlying the patch die even into the pith.

Hartig's ${ }^{1}$ investigations show that this same Melampsora causes Cacoma laricis on the needles of the larch. l'lowright ${ }^{2}$ also produced a similar Cucome-form from Mclampsore betulina, and

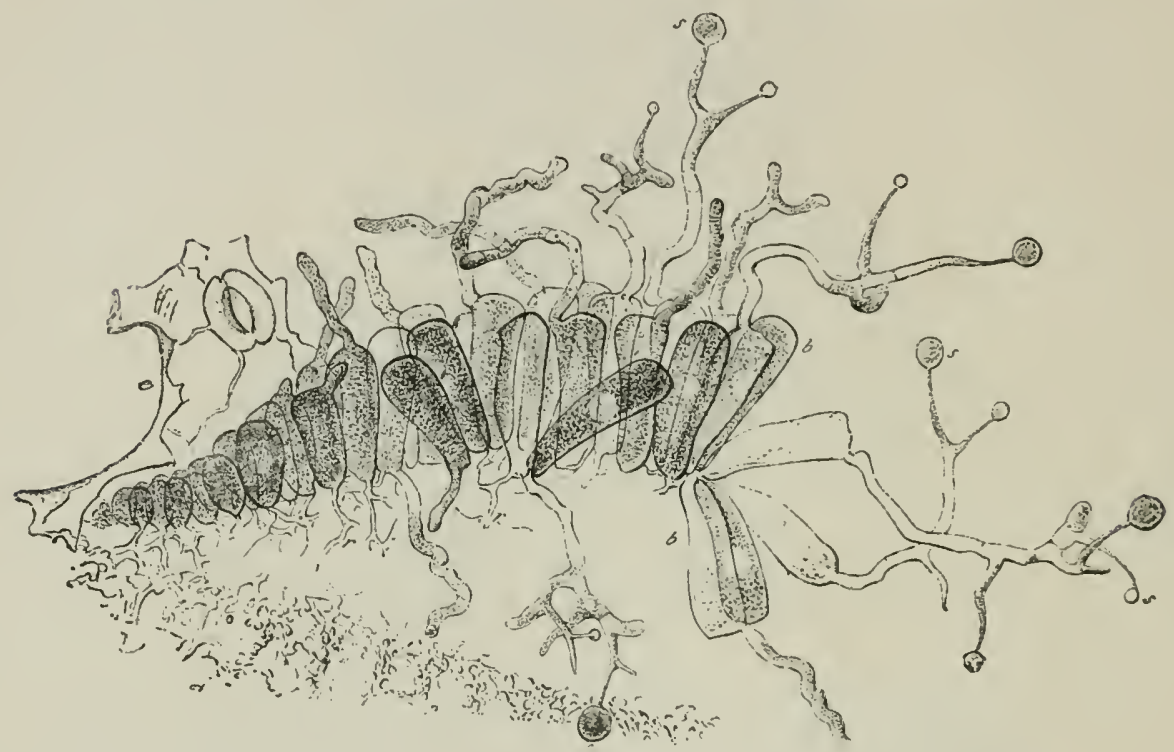

Fı. 19S.-.Helumpsom, betulinu. Telentospore-sorus, with mans of the spores producing promycelia and sporidia (*). 2 , Mycelium ; 2 , parenchyma ; $c$, portiou of ruptured cpidermis. (After Tulasne.)

sncceeled in re-infecting Betula albe from Cacoma laricis. Rostrup obtained Cacoma mereurialis by infecting Mcrcurialis with Mel. tremulae; yet this may have happened because two different species of Mclampsora occurred on the aspen leaves. Klebahn ${ }^{3}$ was successful in infesting Populus tremula with Cacoma laricis but did not succeed with the birch.

${ }^{1}$ R. Hartig, Allegem. Forst. u. Ja!ld-zeitung, ISS5.

2 Plowright, "Impfversuche m. Rostpilzen," Zeitschift f. Pflanzenkrankheiten, IS9].

"Klebahn, Zeit.schrift f. Pflanzenkrankheiten, 1594. 
The patches of Cacoma laricis Hartig, ${ }^{1}$ appear as goldenl-yellow cushions on the underside of the needles. The sporophores from which the aecidiospores are abjointed, form the centre of the patch, the periphery being occupied by numerous sterile threads, which grow out as long paraphyses; it may so happen that the whole cushion consists only of these last. The formation of Cacomapatches is preceded by that of little pycnidia (spermogonia), which break ont from under the cuticle. The mycelium lives intercellularly, and dies after the shedding of the Cacomaspores.

Melampsora betulina (Pers.) (Britain and U.S. America). Uredo- and teleutospores occur on the leaves of the birch (Bctula alba). Plowright ${ }^{2}$ found from artificial infection that this species produced Cacoma laricis on the needles of Larix curopea. A second form of Cacoma laricis was obtained by Hartig, both from infection by Mcl. tremulae Tul. from the aspen, and by Mel. populine Jacq. from the black poplar.

M. populina (Jacq. $)^{3}$ (Britain and U.S. America). Uredo- and teleutospores found

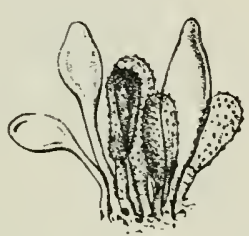

Fig. 199. - Melempsorec betulina. Portion of a uredospore-sorts. (After Tulasne.) on Populus nigra and $P$. balsamifere.

M. populina and M. tremulac are probably identical, for Hartig has found the same Melampsore on black and balsam poplars as on aspen, and in each case he produced Cacoma laricis by means of the uredospores. Schroeter states that the Mclampson" of Populus nigra produces Cacoma allii of Allium.

M. aecidioides D. C. (Britain). Uredo- and telentospores on leaves of silver poplar ( $P$. alba and $P$. canescens). Plowright connects with it a cacoma-form on Mercurialis (Cacoma mereurialis). Schroeter states that the MLclampsore of Populus tremula produces Capome mereurialis.

The Melampsorae of Willows were until recently grouped under a collective name, $M$. salicina; several species are now recognized, others require verification.

${ }^{1}$ R. Hartig, Wichtige Krankheiten d. Waldbäumen, Pl. V.

${ }^{2}$ Plowright (loc. cit.).

${ }^{3}$ R. Hartig, Botan. Centralblatt, xLvi., 1891; "The leaf-rust of cottonwoods," U.S. Dept. of Agriculture Report, isss, p. 390 . 
M. salicis-capreae (l'ers.) (Britain and U.S. America). Uredo- and telentospores on leaves of Sulire Ceppen and several other species. According to Rostrup, Cresomn ruonymi (Gmel.) is a stage of this. ${ }^{1}$

M. Hartigii Thiim." ( $M$. cpitece Thium.) (Britain and U.S. America). Urelo- and telentospores on leaves of Sal ix pruinosa. S. daphnoiles, S. viminalis, etc. Rostrup regards C. ribesii Lk. of Ribes as a eceome-form.

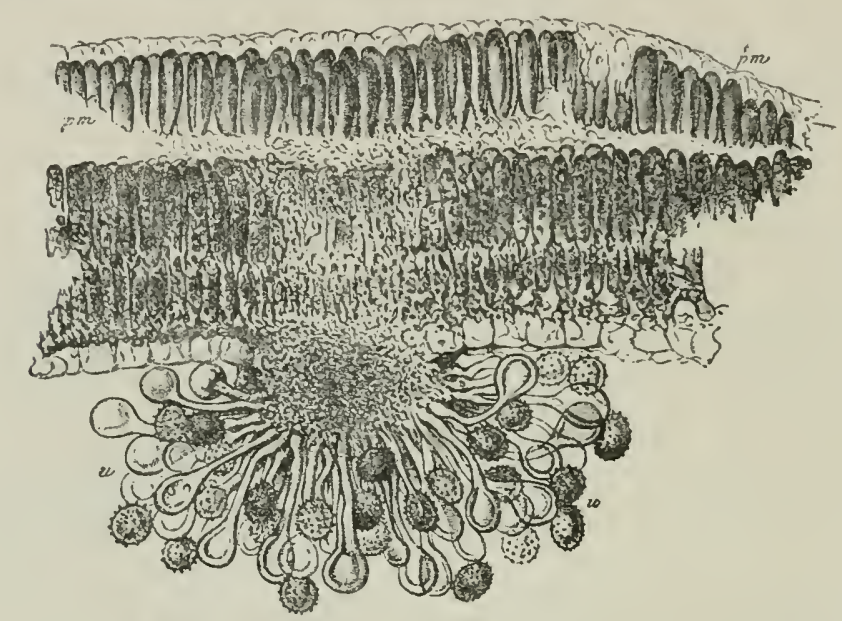

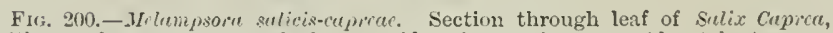
with a uredospore-sorus on the lower epidermis; on the upper side a teleutosporesorus is in process of development, but is as get completely closed over. (After Tulasne.)

M. repentis Plowr. ${ }^{3}$ Uredo- and telentospores on Sialix repens. Caeoma on Orclis muculatu. (The Caeoma orchidis of other orchids is probably identical with this one.)

M. arctica Rostr. on Sulix herbacen, S. glaucu, and S. groenlandica in Greenland.

M. mixta (Schlecht). (Britain). The related Caeoma is unknown.

Thiimen also gives M. Custagnei Thiim. on S. amygdulinu.

M. vitellinae D. C. on Salix fragitis is said by Schroeter to have its Caeomu on Galunthus nivalis (Britain).

The rusts of cultivated willows are very detrimental to them

${ }^{1}$ M. salicis-capreae (M. caprearum D.C.) is divided by some authorities into M. farinosa (Pers.) and M. epitea (K\%e. et Schm.).

"See Thümen, "Mel. salicina," Mittheilungen aus d. forstlich. Versuchswesen. Oesterreich, 1879.

${ }^{3}$ Plowright (loc, cit.). 
and cause great damage. The yellow sori appear in large numbers on the lower surface of the leaves, which wither prematurely, especially towards the ends of shoots (Fig. 201). The teleutospores hibemate on fallen leaves, hence such should be raked together and burnt. Salix mruinosa is found to be much more sensitive to attack than S. pruinosa $\times$ daphnoides, whose leaves are more hairy, a property which seems to protect them from spores.

The following species have only uredospores and telentospores, related Cucoma-forms being unknown:

M. lini (Pers.) (Britain and U.S. America). Flax-rust. The uredo- and teleutospores occur together on Linum. This may inflict serious damage in fields of cultivated flax.

M. sorbi (Oudem.). On leares of Pyrus Aucuparice and $P$. torminalis. Dietel $^{1}$ has recently placed this as the single species of a new genus Ochrospora. The light-yellow spores are at first one-celled, but before the death of the host-leaves they divide into four (rarely three) cells, each of which gives off a sterigma with a single sporidium. In these points the spores follow the development of Colcosporium; the sporidia, however, are quite different, they are spindle-shaperl, $22-25 \mu$ long and $\delta \mu$ hroad.

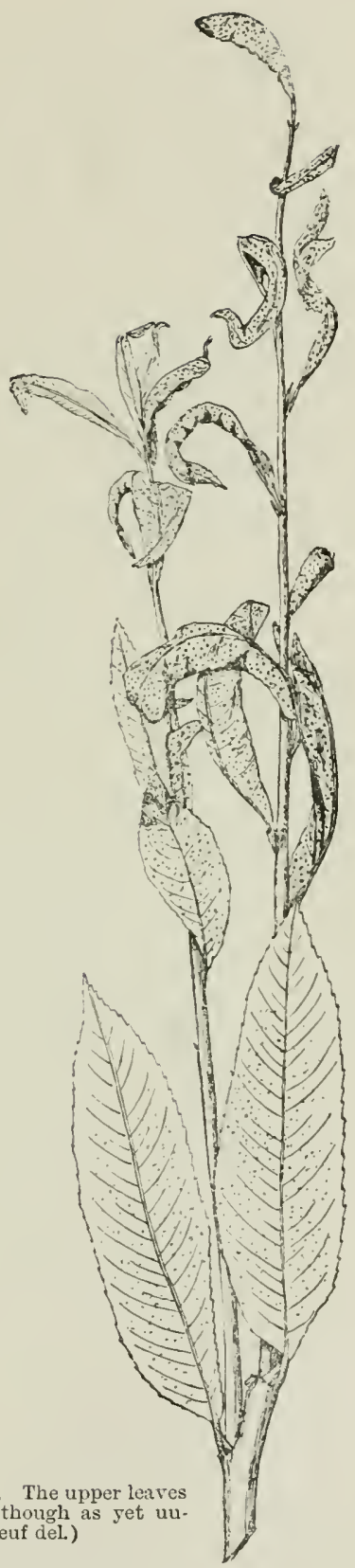

FIG. 201.-Mlelampsora Hartigit ou Salix pruinosa. The upper leaves have already withered aud curled up, the lower, though as yet uu changed, are beset with the point-like sori. (v. Tubeuf del.)

${ }^{1}$ Berichte d. deutsch. botan. Ges., 1895, p. 401. 
M. ariae (Sichleich.). On leaves of Pyyres urir.

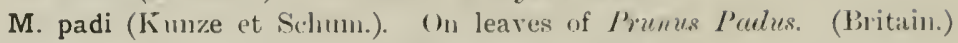

M. hypericorum (D.(:). On IIypericem. (Britain.)

M. pustulata (Pers.). On Epilobium. (Britain and U.S. America.)

M. circaeae (Schum.). On Cirrueu. (Britain.)

M. vaccinii (Alb. et Schlm.). On leaves of Ireccinium. (Britain and I'.S. Americica.)

M. pirolae (Gmel.). (1n Pyrolu. (Britain and U.S. Anerica.)

M. sparsa Wint. (U.S. Aneriea). On Arctostrphylos alpina (also A. officinulis ate. to Rostrup).

M. carpini (Nees.). Onl leaves of lombeam.

M. galii (Lk.). On Giulium.

M. (Thecopsora) agrimoniae (D.C.) On Agrimomia.

M. vernalis Niessl. Telentospores only un Sarifiagu granulutu.

M. helioscopiae (Pers.). On Éphorbia. (Britain.)

M. euphorbiae-dulcis Otth.

\section{Melampsorella.}

The unicellular telentospores are developed in the cells of the epidermis and form reddish patches. The patches of uredospores are enclosed in a periclium.

Melampsorella cerastii (Pers.). Uredo- and telentospores (n) species of Stelluria and Cercastium. (Britain and U.S. America.)

\section{Calyptospora.}

The teleutospores are developed inside the epidermal cells, and are divided into four cells by rertical septa. The aecidia have large peridia. The pycnidia are small and precede the aecilia.

Calyptospora Goeppertiana Kiihn. ${ }^{1}$ (U.S. America). The common disease of cowberry (Tuccinium Vitis-Idece) cansed by this parasite is shown externally by a very marked swelling and elongation of the shoots (Fig. 202). Diseased plants elongate eonspicuonsly above their neighbours, and in this way distribution of their spores by wind is facilitated. The mycelium hibernates in the cortical tissues, and maintains itself for years. It grows intercellularly, sending haustoria into the cortical cells. As a result of its presence, cell-growth is much accelerated, and a marked thickening of attacked twigs frequently occurs:

'R. Hartig, Lehrlush d. Baumkrankheiten, I. Aufl. p. 56 and PI. II. (The Qnd edition and the English translation are somewhat abridged.) 
intercellular spaces become enlarged, and the contents of all cortical cells, except those of the epidermis, takes on a red colour, whereby the young shoots have at first a delicate rosered colour, though they afterwards turn brown. The lower leaves have a similar red colour, but shrivel and fall off early, while the upper ones develop normally and remain attached.

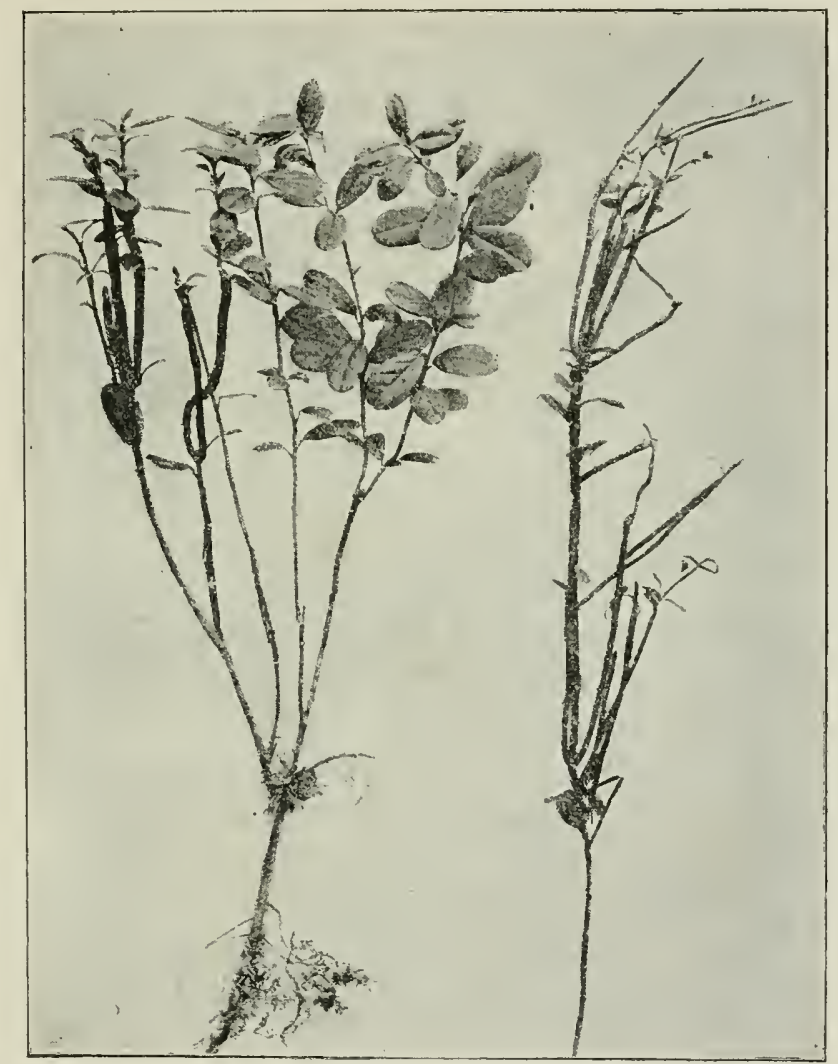

FIt. 202.-Calyptospora Goeppertiana. Normal and malformed shoots of Vaccinium Vitis-Idace. (v. Tubeuf phot.)

Shoots infected one summer show the symptoms in the following year. The swelling is confined to the basal part of a year's growth, and the apices of shoots remain normal to all external appearance, although permeated with mycelium. Hartig has explained this by assuming that the fungus-mycelium only 
influences young cells attacked by it during their period of growth, whereas cells already in the adult condition remain imaffected.

Inside the diseased shoots a well-developed mycelium will be found between the epidermal cells, and nourished by hanstoria.

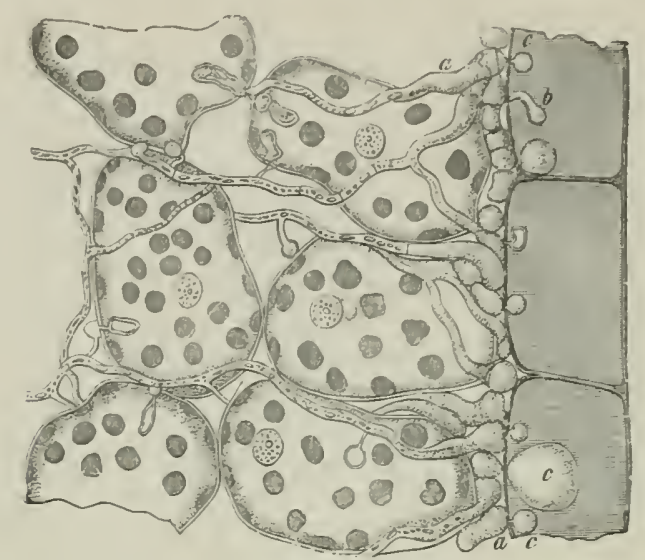

Fig. 203.-Calyptospoia Gouppertiana. Section through elidernais and cortical parenchyma of a diseased shoot of Vaccinium. The mycelim is intercellular, but swollen branches penetrate the cell-walls and become sac-like haustoria. The hyphae under the epidermis become considerably swollen, and give off into the cells either haustoria $(b)$ or the sac-like processes $(c, c)$, which become the mothercells of the teleutospores. $\times 420$. (After R. 11artig.)

The spores originate from processes of the mycelial hyphae, which bore their way into the epidermal cells, and swell up inside to form spherical sacs. The cells thus entered turn brown, and are filled up by four to eight cells produced from the sac-like processes of the mycelium (Fig. 203). From each cell of this lind a four-celled telentospore is formed and hibernates in situ. In spring the teleutospores emit a process through the outer wall of the epidermal cell, and this, after division by cross-septa into four cells, becomes a promycelium with short sterigmata, from each of which a single sporidium is abjointed (Fig. 204). The sporidia germinate, as Hartig proved, abont the middle of May, on young needles of silver fir (Abies pectinata). By the middle of June the mycelimm is distributed through the intercellular spaces, and forms aecidia with long white saclike peridia on the under surface of the leaf (Figs. 205, 206) The accidiospores escape on rupture of the peridium and the 
host-epidermis, to germinate on the epidermis of another cowberryshoot. The germ-tube either enters by a stoma, or forms an adhesion-disc and sends out a process from this through the epidermis.

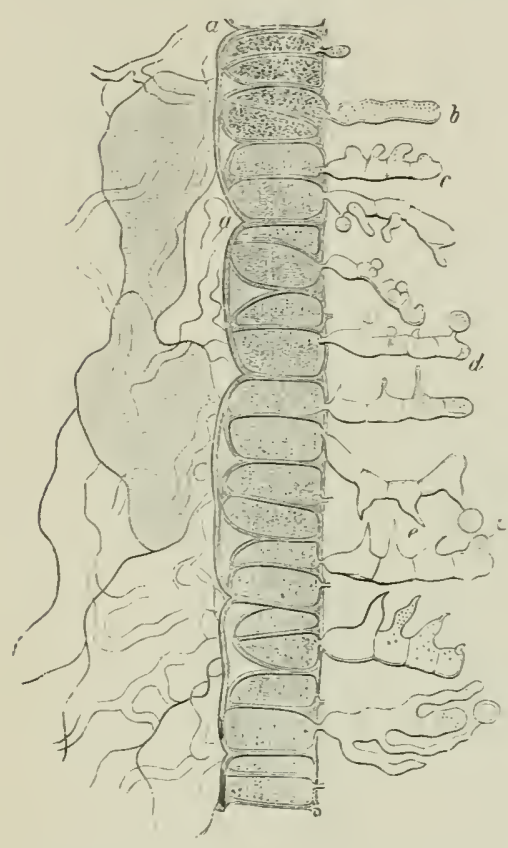

Fig. 204.-Diseased stem of Vaceizium in a later stage than Fig. 203. In each epidcrmal cell $(a, u)$ six mother-cells have been formed, each subdivided into four teleutospores. Promycelia (b) have developed from many of tbe latter, and are in process of abjointing off the sporidia from lateral sterigmata. $\times 420$. (After R. Hartig.)

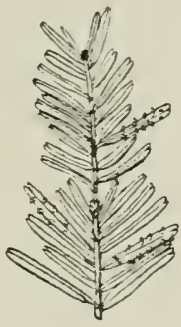

Fig. 205.-Calyptospore Goeppertiune. Aecidia on the under surface of needles of Silver Fir. (v. Tubeuf del.)

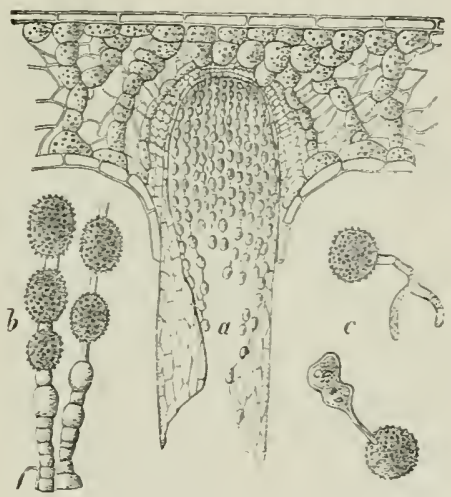

Fig. 206.-Aecidium in a needle of Silver Fir (much enlarged). $b$, Series of aecidiospores and intermediate cells. $c$, Germinating aecidiospores. (After R. Hartig.)

This aecidium is also found on Abies erphalonice in Upper Bavaria.

Barclayella deformans Diet. ${ }^{1}$ This has been found in the Himalara region on needles and young twigs of Picea Morinda (Smithiana). Teleutospore-sori are developed, accompanied by distortion of the host. Aecidia and uredospores are unknown.

${ }^{1}$ Barclay, "On a Uredo of the Himalaya Spruce-fir." Calcutta, 1856 ; and Heduigia, 1591. 


\section{Coleosporium.}

The teleutospores form a soft, reddish, waxy cushion, and germinate in situ producing four-celled promycelia; in these respects they exhibit great resemblance to Auricularic. Uredospores are developed in chains. The aecidia, as yet known, have a distinct peridimn.

Many species infect the needles of pine trees and produce aecidia known by the generic name P'cridermium; other species also known as Peridermium and living on bark are really species of Cronartium. The species here mentioned with their Pcriderminm-form on pine-needles, so much resemble one another as to be almost indistinguishable, and

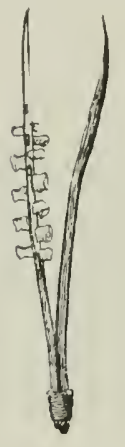

Fig. 207.-Cotensporium sricioitis on a bifoliar. spur of Pinus syleristris. Peridia and scars of the pycnidia are shown. (v. Tubeuf del.) the question arises whether they are really species, or only varieties due to difference of substratum-habitat-races.

Coleosporium senecionis (Pers.). (Britain.) The sori are produced on leaves and stems of various species of Senccio (without doubt on S. vulgaris, S. xyluticus, S. viscosus). The uredospores are shed in June from yellow spots. The teleutospores follow later on dark-red patches, there they hibernate and in spring produce a four-celled promycelium, each cell of which gives off a sterigma with one sporidium. The latter germinate on needles of Pinus syltestris. A nycelium is formed in the intercellular spaces of the needles, and, nourished by means of haustrria sunk into the host-cell, perennates and produces crop after crop of aecidiospores. Hyphae are produced in such numbers that the cells of the needle-parenchyma are tightly pressed together, and those adjacent to pycnidia and aecidia turn brown, secrete resin, and die. The needles themselves, although filled with mycelium, remain on the tree till the time of their normal fall.

Pycnidia are developed by April or May under the cells of the epidermis. They are little obtuse cone-shaped enclosures appearing as brownish-yellow spots scattered over the inner faces of the needles. On attaining maturity they rupture the host-epidermis and give out their conidia. 
The aecidia are produced amongst the pycnidia on needles two or three years old; they have long white peridia and are known as Peridermium oblongisporium Fuck. The aecidiospores are yellow when mature, and originate in chains, which in the earlier stages of development consist of intermediate cells and spores, but the former gradually disappear (Fig 208). The spores have an average length of $30.5 \mu$ and breadth of

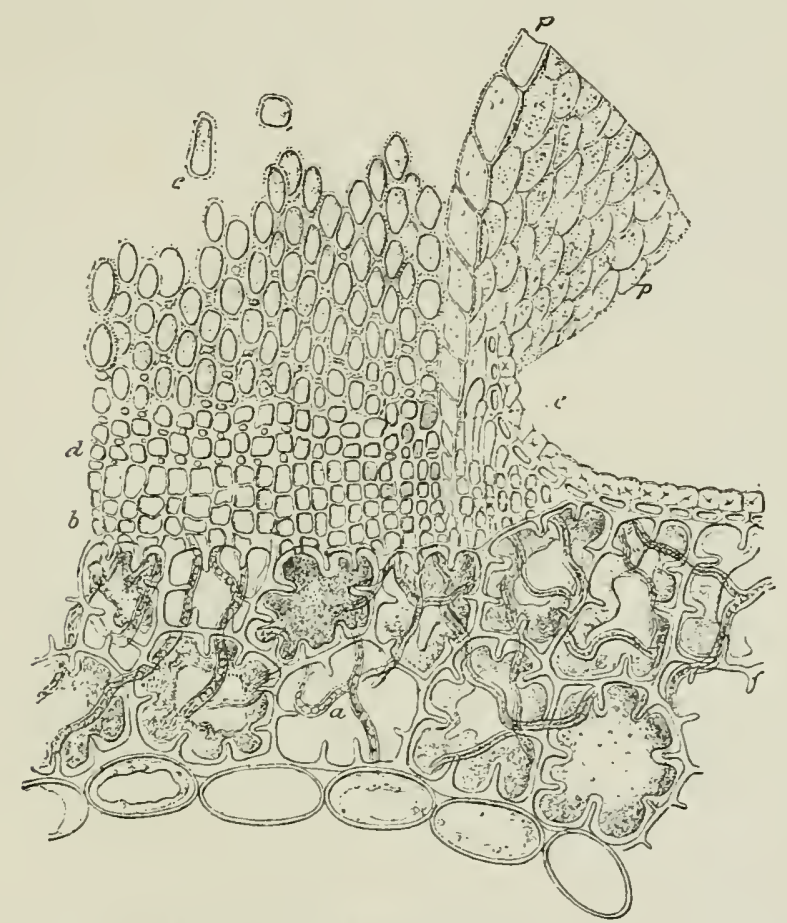

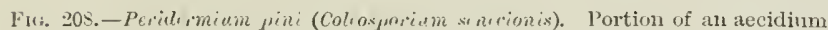
with basidia (li) giving off spores and intermediate cells $(l)$; outside the peridium $(p)$ other basidia ( $)$ with club-shaped ends force up the epidermis: ", the thick mycelium in the leaf-parenchyma. (After R. Hartig.)

$20 \mu$; in form they are generally longish-oval, few leing round; the spore-coat is moderately thick. Aecidiospores are capable of immediate germination, and produce Uredo-patches on Senccio by June.

The uredospores have an average length of $255 \mu$, and breadth $15 \cdot 5 \mu$; they are generally oblong, with a moderately thick coat beset with spiny warts. 
Klebahm and Fischer ${ }^{1}$ assert that several other species of Colcosporium produce their aecidium-stage on Pinus sylvestris.

C. euphrasiae (Schum.) (Britain). Uredospores produced from reddish-yellow, teleutospores from orange-red patches during July and August on various Rhinanthideae (Rhinanthus major, R. minor, Bertsia Odontites, and Euphrasin offeinalis). The spores from Rhinanthus germinate on needles of Pinus sylvestris and produce an aecidium called Peridermium Stahlii Klel. The aecidiospores of $P$. Stahlii average $26 \mu$ in length, $19.5 \mu$ in breadth, and are round or shortly oval, with a coat and markings finer than those of $P$. oblongisporium. The uredospores average $22 \mu \times 15.5 \mu$; they are irregular and somewhat angular, with a thin finely marked coat.

C. melampyri (Reb.) (Britinin). Uredospores on Melampyrum (certainly on M. pratense). The aecidia-Periderminu Sorcuzeri Kleb.-follow after a year on needles of Pinus sylvestris. The spermogonial pycnidia alone are developed in the summer of infection.

C. tussilaginis (Pers.) (Britain). This Colcosporium is found all summer on the underside of leaves of Tussilago farfara, the uredospores forming yellow patches, the teleutospores darkercoloured ones. Aecidia are produced on needles of Pinus sylvestris, and are known as Pridermium Plowrightii. Pyenidia and aecidia are formed in the summer following infection. The aecidiospores average $25.5 \mu \times 19 \mu$ and are shortly oval or round, with coats and markings more delicate than those of $I$. Stahlii. The uredospores average $26 \mu \times 19 \mu$ and are roundish oval with somewhat firmer and thicker coats than those of C. cuphrasiac.

Klebahn's infections of Petasites with aecidiospores from Pimus gave no result.

C. inulae Kunz. Spores of this obtained by Fischer ${ }^{2}$ from Inule Vaillantii and I. Helenium produced Peridermium Klcbahni Fisch. on needles of Pinus syluestris.

C. sonchi (Pers.) (Britain and U.S. America). Klebahn considers this as a provisional species including a number of imperfectly investigated forms whose uredo- and teleutospores

${ }^{1}$ Berichte d. deutsch. botan. Ges., 1594; Zeitschrift f. Pfanzenkrankheiten, 1S94, and 1895, p. 73.

${ }^{2}$ Botan. Centralblatt, LIX., 1894, p. 1. 
oeenr on various speeies of Sonchus (without doubt on $S$. rensis). Aecidia are unknown. He relates it to Periderminm Fischeri Kleb. on needles of Pinus sylvestris.

C. synantherearum Fr. A provisional collective name for aecirlia on Allenostyles, Prtasites, Cacalia, Senecio, etc., the life history of which is as yet unknown.

C. campanulae (Pers.) (Britain). Uredo- and teleutospores on Campanulaceae (Campanula and Phyteuma). The aecidial form is Peridermium Rostrupii on pine-needles.

C. pulsatillae (Str.). Uredo- and teleutospores on Anemone Pulsatilla and $A$. pratensis. Aecidia unknown.

C. ipomoeae (Schwein). Uredo- and teleutospores on speeies of cultivated Ipomoes in United States. Aecidia unknown.

Fischer ${ }^{1}$ obtained pyeniclia on needles of pine by infection with a Colcosporium from Campanula Trachelium.

\section{Chrysomyxa.}

The telentospores are formed closely together in yellow sori; each spore consists of an acropetal series of cells, the distal one of which, without leaving the sorus, germinates to produce a pronycelium of several cells. Uredospores are not always present. The aecidia have well-developed peridia.

Chrysomyxa rhododendri (D. C.). ${ }^{2}$ This is a common rust on the Alps where the Alpine-rose (Rhodorlentron ferrugincum and R. hirsutum) oceurs. Immediately after the break-up of the winter little dark-red cushions of this rust appear on the underside of the leaves. These contain the sori of teleutospores already partially developed during the previous antumn, and now, after hibemation, ready to increase in size and to rupture the host-epidermis (Fig. 211). The teleutospores so exposed germinate without leaving the sorus, and prodnce four-celled promycelia, with sterigmata, from each of which a single sporidium is abjointed. The sporidia make their escape in June, and alighting on the unfolding needles of the spruce (Picce excelsa), they germinate at once and produce Accidium abirtinum, the blister-rust of the spruce (Fig. 212).

An intercellular mycelium is developed in the spruce-needles,

${ }^{1}$ Botan. Centralblatt, LIx., 1894.

² De Bary, Botan. Zeitung, 1879. 
and small yellow pyenidia are produced during .July or August. The aecidia follow from August till September, occupying yellow zones on the otherwise green needles; their white periclia project as much as $21 \mathrm{~mm}$. above the surface of the needle, and rlehisce by rupture of the apex. The aeciliospores are formed in large numbers and, earried by wind, reach leaves and shoots of alpine-rose where they immediately gemminate. The resulting mycelium produces in september yellow clusters of uredospores on brownish spots on the lower epidermis of the leaves, and on the bark of last year's shoots (Fig. 2210).

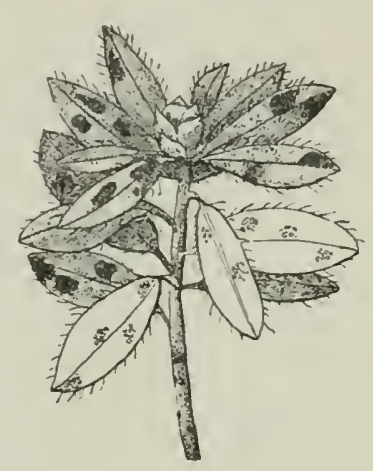

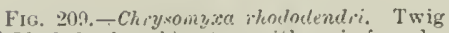
of Rhododcadron himutam with sori of uredospores on the lower ejudermis, cansing discoloured spots on the upper. (v. Tubeuf del.)

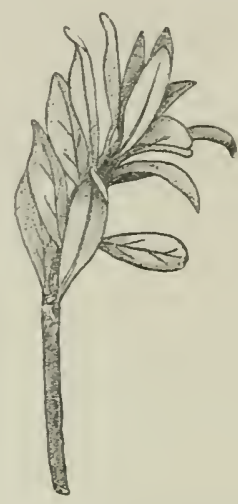

Fif: 210.-Chirysomyxe, hododendri on Rkododindron firugineum. Credosporessori in September as elongated white stripes on the stum below the leaves. (v. Tubeuf del.)

The uredospores are yellow and ovoid, with granular protulerances on their coats; they are developed in series from the sori. ${ }^{1}$ The disease may be further propagated during the same year loy the uredospores. In districts where spruce does not occur, it is probable that these spores hibernate, and in the following spring produce germ-tubes which infect other alpine-rose leaves. It frequently happens that whole forests of spruce are so attacked by this fungus that many of the trees retain only a few healthy needles. Diseased needles die and fall in the summer of attack, so that the trees may be almost wholly stripped, and thereby suffer considerable damage.

Chr. ledi (Alb. et Schwein.) ${ }^{2}$ (U.'. America). This fungus

${ }^{1}$ Raciborski regards the Credo as a Creoma-form.

¿De Bary, Botan. Zeitung, $18 \% 9$. 
occurs on Ledum palustie. It is difficult to distinguish from the preceding species, and causes the formation of similar aecidia on spruces in Northem Germany and other parts where Rhododendron is not indigenous. Its uredospores are also capable of hibernating and of propagating the fungus where spruce is absent.

Chr. himalayensis Barcl. occurs on leaves of Rhododendron riborem in the Himalaya.

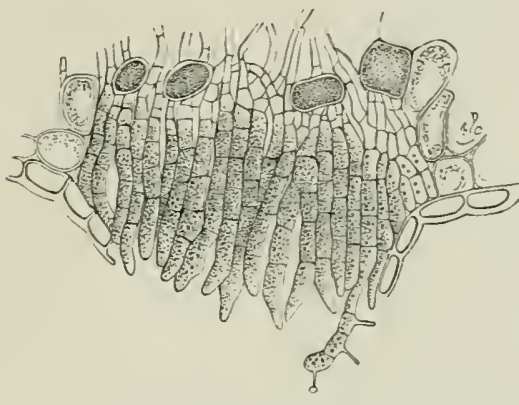

Fre. 211.-Chirsomyse ihodadineli. Telentospore-sorus which has ruptured the lower epidermis of a leaf of Rhododendion his:sutum. The teleutospores are pluricellular, and one of them has germinated, giving a promycelium with sterigmati, from which little sporidia are being abjointed. (After De Bars.)
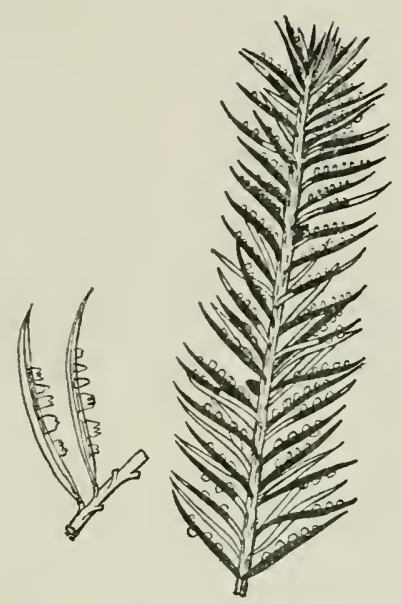

F11. 212. - Chiysonyser ilocloul ndi on spruce. The needles are beset with aecidia; discoloured parts of them are shown black, the normally green being left white. ( 5 . Tubenf del.)

Chr. abietis (Wallr.). ${ }^{1}$ Needle-rust of spruce. This is parasitic on the spruce (Picen rrectsa), and is found on the Alps up to an elevation of over 1700 metres. About the beginning of May the hibemating teleutospores produce promycelia and sporidia. The latter gemminate at once, and the germ-tubes make their way throngh the epidermis into young unfolding needles. The mycelium is well-dereloped and lives intercellularly, sending haustoria into the host-cells; it contains yellow oil-drops, so that by the end of June needles containing it exhibit rellow-coloured stripes. For the remainder of the year reddish-yellow elongated teleutospore-cushions are

1 Reess, Botan. Zeitung, 1S65; Die Rostjitzformen d. dentschen Coniferen, 1 S69. Willkomm, Die mikrosropischen Feinde des Waldes, 1868. 
formed, and in this condition the fungus hibernates, to develop further in the following spring. It is only in very dry cold winters that the needles dry up and fall off; as a rule they remain on the trees. About the berimning of May the sporecushions break throngh the epidermis and give off multicellular teleutospores, which are as a rule branched.

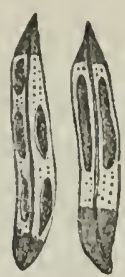

Fig. 213.-Chrysomyxu abielis on Picer excelsu. The sori occupy the middle portion of each needle, which is in eonsequence yellow, while the apex and base arc still greeu. (v. Tubcuf del.) myre rhododendri endangered.

Uredospores are unknown for this species and an Accidium stage has not as yet been discoverecl. Reess has shown experimentally that the telentospores germinate directly on spruce without intervention of an aecidial stage.

Chr. piceae Barc. On needles of Picen morinde in India.

Chr. empetri (Pers.) (Britain and U.S. America). Uredospores on Empetrum nigrum. Cueomu cmpetri (Pers.) is the aecilial form.

Chr. pirolae (D. C.) (Britain and U.S. America). Uredo- and telentospores on Pyrolu. Aecidia muknown.

Chr. albida Kiihn. On Rubus fruticosus in Germany and U.S. America.

\section{Cronartium.}

Teleutospores unicellular and remaining attached together in the form of a long coiled process; they germinate in situ and give off sporidia. The masses of teleutospores arise on the place formerly ocenpied by a uredospore-sorus. The ovoid uredospores are abjointed from short stalklets enelosed in sori with a short peridium. Aeeidia are developed on other 
host-plants, and several species produce blister-rust on the bark of species of pine.

Cronartium asclepiadeum (Willd) (U.S. America). Uredoand teleutospores occur on Cynanchum Vincetoxicum (perhaps

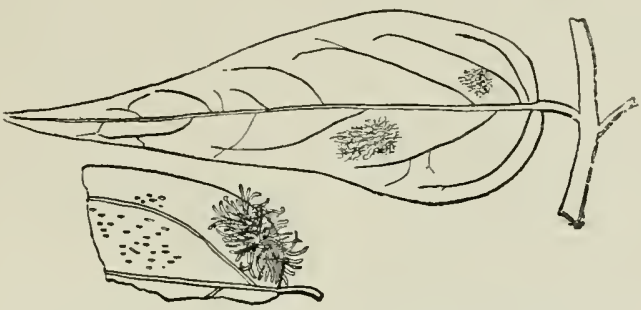

FIG. 214.-Cronatium asclepialcum on Cynanchum Vinectoxicum. The uredosori show as spots, the telentospore-sori as processes on the leares. (v. Tubeuf del.)

also on Genticuna asclepiadea). The aecidial stage, known as Peridermium Cornui Rostr. et Kleb. produces a blister-rust on the bark of Pinus sylvestris.

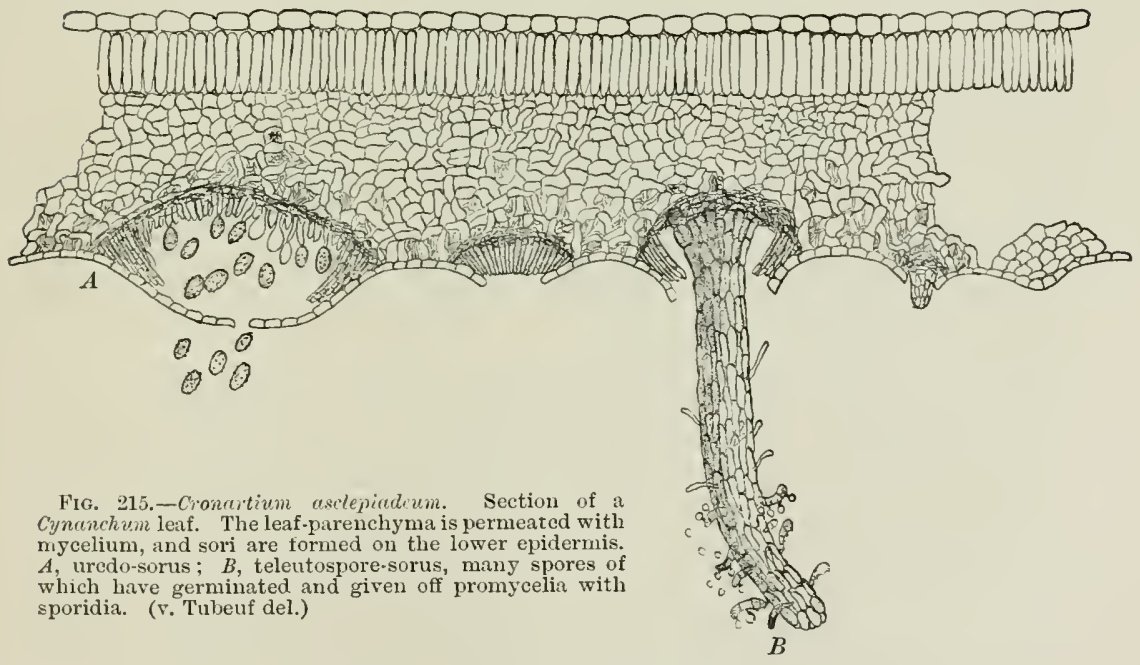

Brown spots may be found on the leaves of the Cynchehum ${ }^{1}$ during July, August, and September (Fig. 214). On examination of the spots with a lens, the leaf-epidermis will be found

${ }^{1}$ A very common plant in Europe though not indigenous to Britain. (Erlit.) 
pierced by a circular opening under which lies the yellow uredospore-patch of the Cronartium enclosed in its periclinn. The ovoid yellow uredospores have al coat beset with short spines and are abjointed singly from short cylindrical sporophores (Fig. 215). From the uredo-sorus there next arises a protuberince which lengthens till it forms an elongaterl slightly curved brown cone or colnmn consisting of cylindrical telentospores firmly built togrether (Fig. 215). The teleutospores germinate without becoming detached from the mass, and produce a four-cellecl promycelium with small sterigmata from which globular sporidia are ahjointed. The sporidia on reaching the branches of Scots pine produce in its bark at first pycniclia, later aecidia. The pycnidia (spermogonia) give off yellow drops of liquid with a characteristic odour. The aecidia are yellow thick-walled sacs; their spores are set free in spring and infect young plants of Cynanchum.

Since the sporidia of the Cronartium-stage are shed by September, the fungus would seem to hibernate only in the form of mycelimm in the branches of pine.

The effects of this fungus on the pine will be considered along with those of Peridermium pini, another blister-rust of pine closely resembling this species (p. 411).

Cr. ribicolum Dietr. Uredo- and teleutospores are developed towards the end of summer on leaves of various species of Ribes (e.g. Ribrs nigrum, rubrum, arueum, alpinum, sanguinsum, americrenum, rotundifolium, sctosum, and (trossularia). The aecidium-stage (Peridermium strobi Klel.) forms the blister-rust of the bark of Weymouth pine (Pinus Strobus). Pycnidia appear in the summer of infection; the aecidia a year later. Externally this bark-rust resembles that of Peridermium Comni and $P$. pini on the Scots pine. It may cause considerable damage to Weymouth pine both in nursery and plantation. ${ }^{1}$

It is probable that other two forms of Accitium are irlentical with this, vize, that on Pinus Lambertiane in America, and $P$. Cembro especially in Russia.

Cr. flaccidum (Alb. et Schwein.) (Britain and U.S. America). Uredo- and teleutospores on Paronia, causing the leares to dry

I Magnus (Gartenflora, 1891) has pointed out that both the Cronartium and the Peridermium are unknown in America, the home of the Weymouth pine. 
and curl up. In some districts very common. Aecidial stage unknown.

\section{Gymnosporangium. ${ }^{1}$}

Teleutospores bicellular and furnished with stalks which have gelatinous walls, so that the spores come to form part of a gelatinous mass. ${ }^{2}$ The first-formed teleutospores are thick-

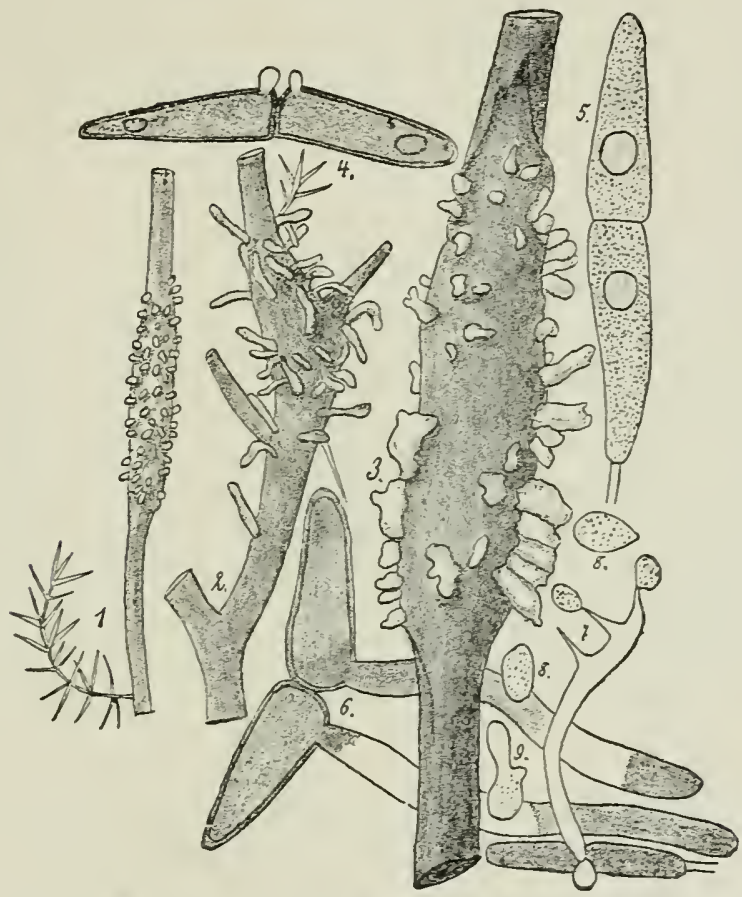

FIg. 216.-Gyiunospoingium clainiariom. 1,2,3, stages in development of the spore-cushions. $4,5,6$, Isolated spores (enlarged) $; 5$ is thin-coated, the others are thick-coated. $i$, Germinating spore with pronycelium abjointing sporidia (s). 9, A germinating sporidium. (After Tubeuf.)

walled, the succeeding ones are thin-walled. Tredospores do not occur. The aecidia have a thick periclium. The teleuto-

${ }^{1}$ v. Tubeuf : (1) Centralblatt f. Bakter. $u$. Parasitenkunde, 1891 ; with a review of the current Literature. (2) "Infectionen mit Gymnosporangium." Forstlichnaturuis. Zeitschrift, 1593, p. 75. Woernle, "Anatomische Untersuchungen d. durch Gymnosporangium-Arten herrorgerufenen Missbildungen," idem., 1594. American Literature, see p. 401.

2 The gelatinous substance is obviously well-adapted to absorb rain-water and so facilitate germination of the teleutospores in situ; the sporidia produced are then carried off by rain or liberated after the cushions dry again. 
spores grow on needles and twigs of Coniterae, the aecidia on the leaves of various liosaccae (Pomaceae). Five sjecies occur in Germany, but there are many in Anerica.

Gymnosporangium clavariaeforme .Taequin. (Britain and U.S. America.) The mycelium of this species perennates in twigs of Juniperus communis. Infection is brought about by aecidiospores. In the following year a swelling of attacked places is evident, and this increases till death of the host ensues. In spring, about the begimuing of April, little lightyellow cone-like structures break out on the swollen places,

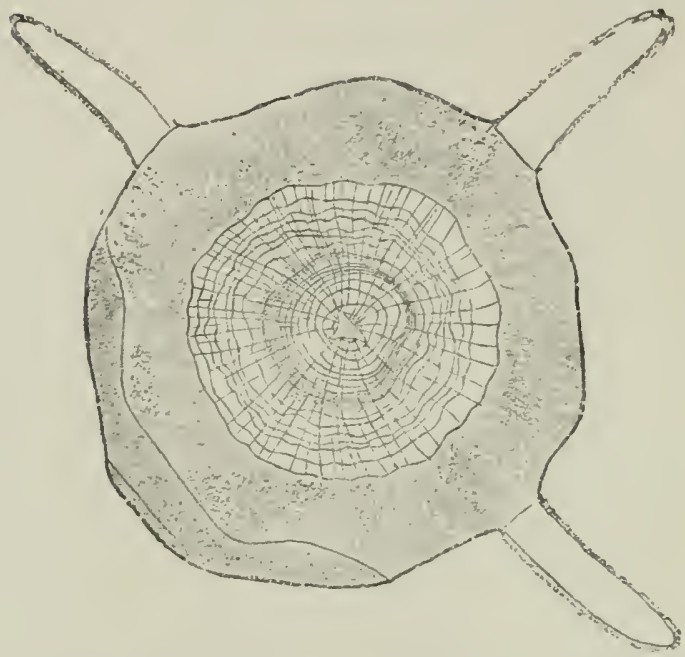

Frr. 217--Section through a swelling on a sixteen-5ear twig of Juniper attacked by Gymnosporangium in its eighth year; three conieal spore-cushions are indicated, also a eushinn-sear with the sear-tissue. (After Woernlc.)

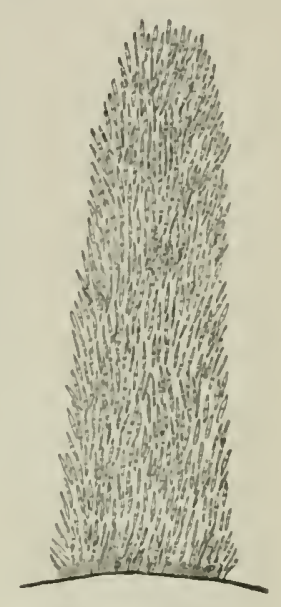

FrG. 215.-1,ongitudinal seetion of a spore-cushion of Gymnosporcinoium clec vorivforme. Somewhat diagrammatic. (After Voernle.)

and during rain swell up into long club-shaped sporophores, containing long-stalked, spinclle-shaped teleutospores, some thickcoated, some thin. The sporophores swell and ultimately form a common mass in which the teleutospores germinate. The spores have four germ-pores, each capable of giving off a promycelium with pointed sterigmata producing sporidia, which are cast loose and distributed by wind.

Germination of sporidia takes place on leaves, cotyledons, petioles, and shoots of various Pomaceae, where they may induce swellings or curvature, often to a considerable extent. 
Experimental infection with teleutospores of Gymnosporangiom clareriaforme from Juniperus communis gave the following results:

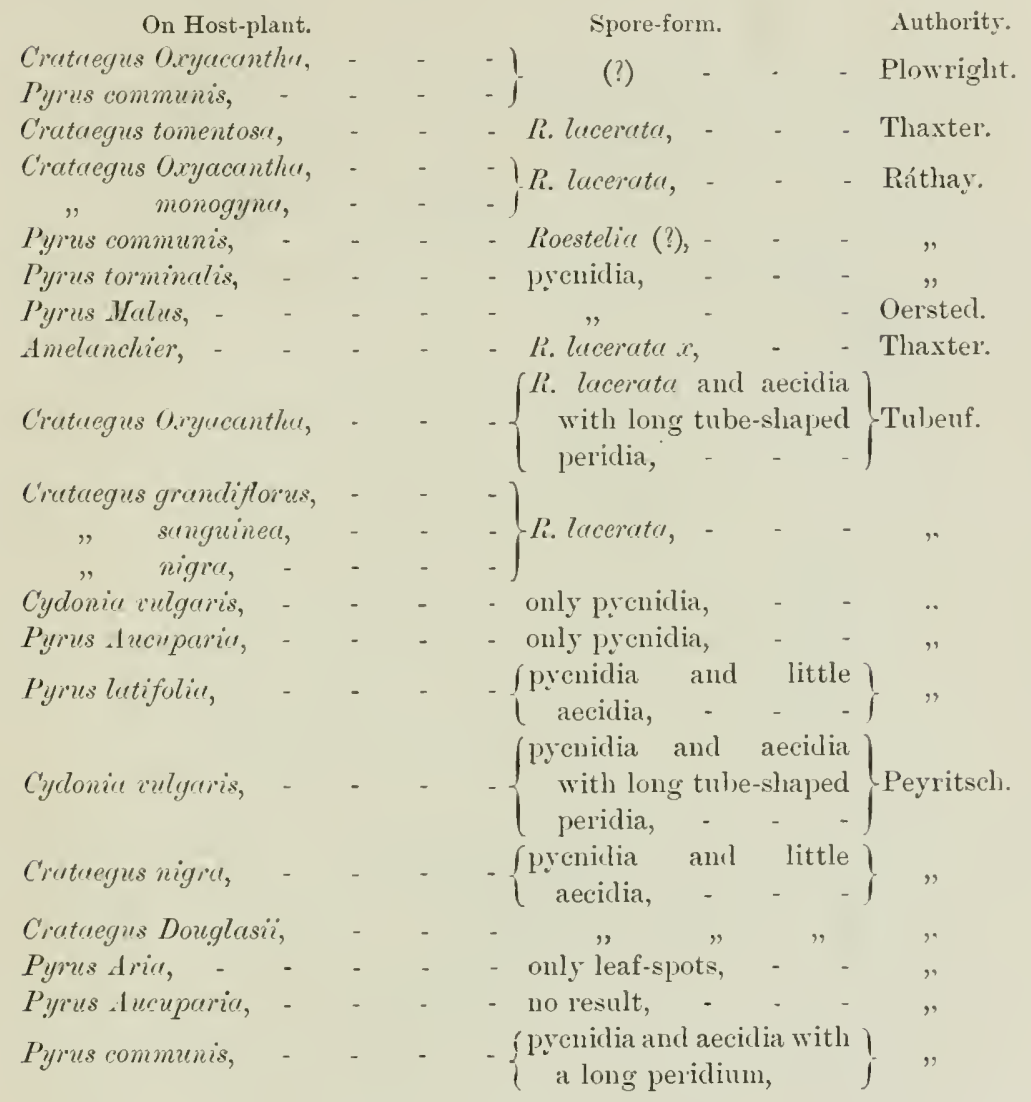

NoтE.-Before the relationship of the telentospore-forms was known, the aecidia were designated respectively : Roestelia lacerata on Crataegus, $R$. romutu

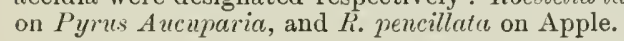

The most abundant germination of sporidia takes place on species of Crutucgus, and pycnidia (spermogonia) may make their appearance within fourteen days after infection on little yellowish sticky spots on leaves and shoots. By the time conidia (spermatia) have made their appearance, deformation may be far advanced. I did not succeed either in procuring germination of the conidia, or infection by means of them. 
The aecidia are developed abont the beginning of June, and on Cratargus their peridia in dehiscing split up into very narrow lobes so as to form a bristly tuft over the mouth of

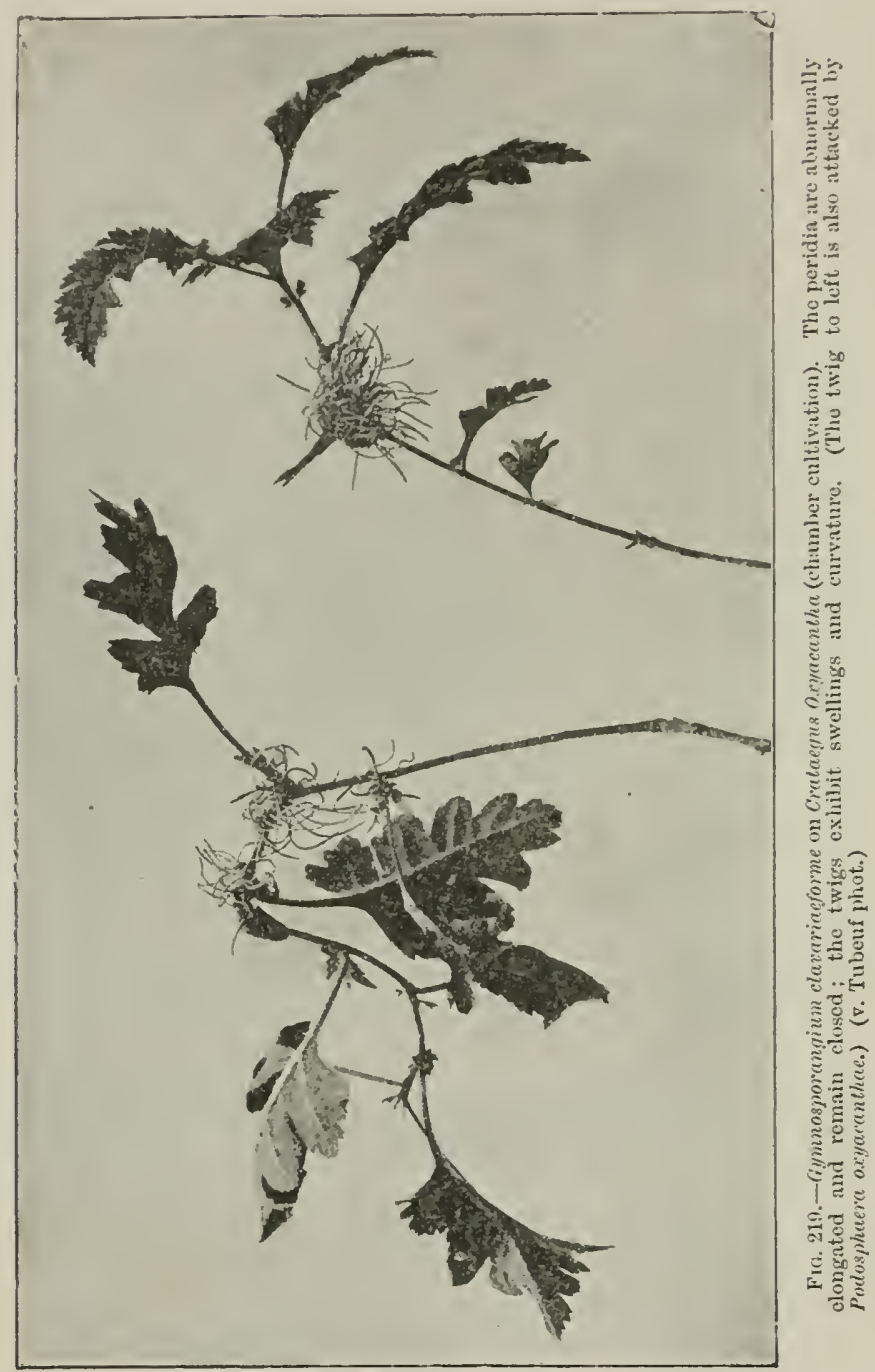

each aecidium. On cultivating infected plants of Crataegus indoors, I found the peridia to develop quite abnormally; they 
may be as long as $10 \mathrm{~m} . \mathrm{m}$. and are bent like a horn (Fig. 219). A similar case is described by Barclay ${ }^{1}$ in which the peridia of aecidia on Phamnus dahurica were very long if produced in dry weather, but short if in moist weather. ${ }^{2}$

The aecidiospores are shed during the early part of June, and germinate at once on the bark of young juniper-twigs; the mycelium growing thence into the spurs or branches to spread and hibernate. Teleutospores which germinate on Pomaceae other than species of Crutaegus have apparently a normal mycelium, but produce pyenidia only, or aecidia with

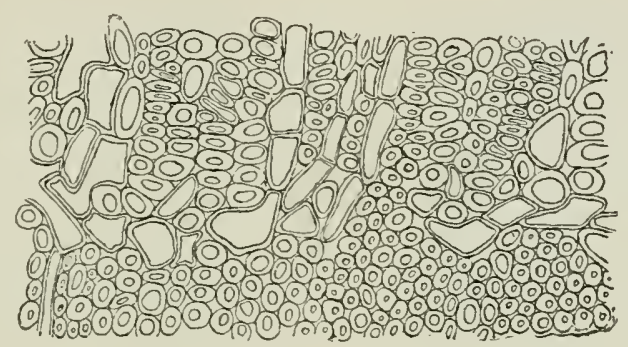

F1G. 220.-Cross-section tbrough a swelling caused by Gimnoxporangium on Juniper-stem; parenchyma with large cells and thin walls is prescnt in abnormal quantity. (After Woernle.)

peridia differing from those on Cretcegus. My own experiments on the quince and mountain ash regularly produce pycnidia only.

Wakker $^{3}$ summarizes the anatomical changes induced in deformed shoots of hawthorn as follows: cork, collenchyma, sclerenchyma, and chlorophyll are not formed, lignification of the cells of medullary rays no longer takes place, and there are few intercellular spaces. Interfascicular cambium is not formed, while activity of the intrafascicular cambium is suspended at an early period, so that the vessels remain incompletely developed. The epidermis is irregularly formed and liable to rupture. All parenchymatous cells undergo enlargement in a radial direction. Starch is stored $u p$ in large quantity, and the formation of calcium oxalate is diminished.

1" On the life-history of Puccinia coronata rar. Himalensis", Trans. Limnean Soc., London, 1891.

2 This probably is the explanation of the long peridia obtained by Peyritsch and described by Magnus (Berichte d. naturwiss. medic. Verein, Innsbruck, 1592-93).

${ }^{3}$ Pringsheim's Jahrbuch, 1892. 
The anatomical changes induced in diseased plants of Juniperus communis by G. elareriunfurme were investigated isy Woernl. under my direction. II is results were these: in vigorous branches, increased growth took place in the woorl, bast, and rind; in weakly and poorly-rgrown branches, the wond increased less in proportion to the bast and rind. The most marked increase took place in the bast, and to an almost equal extent all round the branches. This abnormal growth absorbs so much

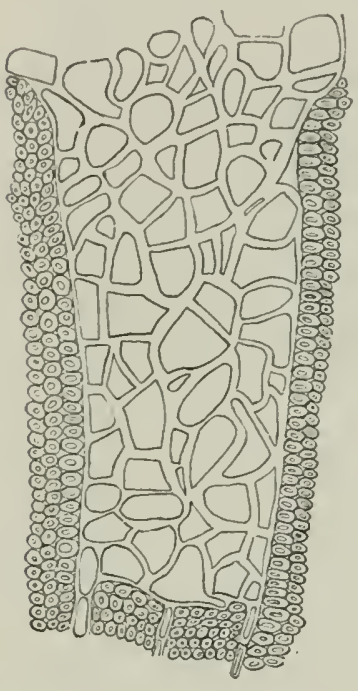

FI(;. 221.-Cross-section of a tract of parenchyma in a malformed Juniper. twig. (After Woernle.)

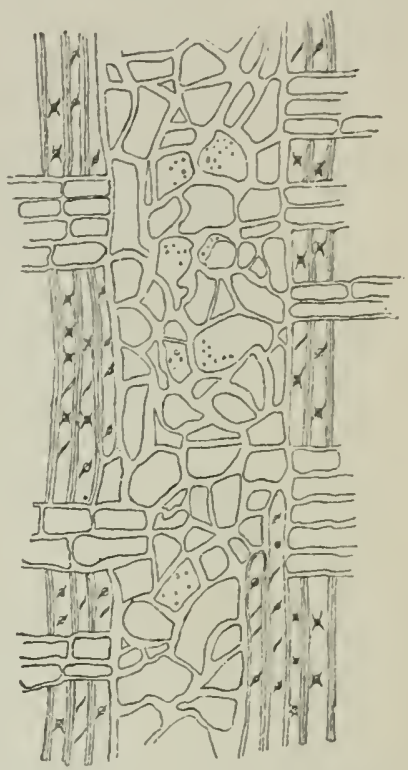

Fıg. 222.-Radial longitudinal section through a zone of parenchyma similar t» Fig. 2:l. (After Woernle.)

water and plastic material that higher parts of the branch gradually die off, and dormant buds break out on the swelling. Increased growth results in increase in the number of medullary rays, while in the tangential section their height is incrensed from 2-10 cells to $10-20$ and more; the wood parenchyma is also more abundant, and together with the rays frequently forms large masses of parencliyma in the wood (Figs. 220-223). The tracheac no longer follow a straight course, and numerous intercellular spaces appear between them; the tracheal walls frequently become thickened and have an increased number of 
fissure-like pores in place of bordered pits. The wood-elements in cross-section are no longer round but polygonal: the bast becomes very irregular, parenchyma grows rapilly, bast fibres remain thin-walled and have no longer a straight course. The mycelium fills the bast and rind, forming masses in the intercellular spaces; it is easiest found in the tangential section. On the fall of the club-shaped sporophores, a scar is left and under it will be found a layer of cork many cells thick; when new sporophores are formed in later years, they seldom break through the cork layer, but emerge through some new portion of the bark.

\section{Gymnosporangium tremel-}

loides Hartig ${ }^{1}$ on Juniperus communis. The sporocarps of this species occur on the branches and neelles; its aecidia-Riorstclia penicillata-on leaves of apple (Pyrus Malus), Pyrus Ariu and $P$. Chamaemespilus. This Roestelir is externally very like that of $G$. claceriaeforme on

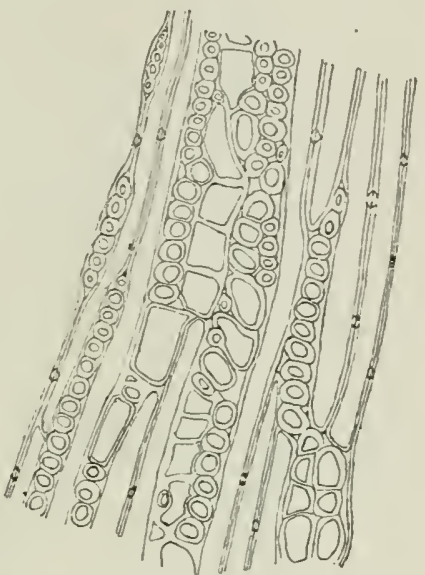

Fro. 223.-Tangential longitudinal sec tion through the parenchyma-zone of Fig. 20.20 (After Woernle.)

\section{C'rretregus. The markings on the}

cells of the peridium consist of somewhat wayy lines, not of short rod-like markings as in 7 . cornuta; and the eells of the peridium are joined by a characteristic hinge-joint (Fig. 224, 19 and 20).

The mycelium perennates in the rind of Juniperus communis and $J$. nana, causing thiekening of the twigs and a premature death of the distal portion above the swellings. The chocolatebrown velvety spore-cushions break out between the bark-seales on the swollen places, about the middle of April (Fig. 225, 1). The teleutospores are two-celled, the earlier formed ones being short, ovoid, and slightly pointed at each end, while the later ones are thinner-walled and often more elongated (Fig. 225, 6-10).

${ }^{1}$ Hartig, Diseases of Trees, English erlition, 1894. Dietel, Forstlich-naturviss. Zeitschrift, 1895 , p. 348 . E. Fischer, Hedwigia, 1895 , p. 1. 
In May or June the eushions swell up and becone large brownish-yellow gelatinous elumps, dotted over with dark points, the teleutospores. P'romycelia arise from one or more germpores in each spore, and give off basidia with sporidia (basillio-

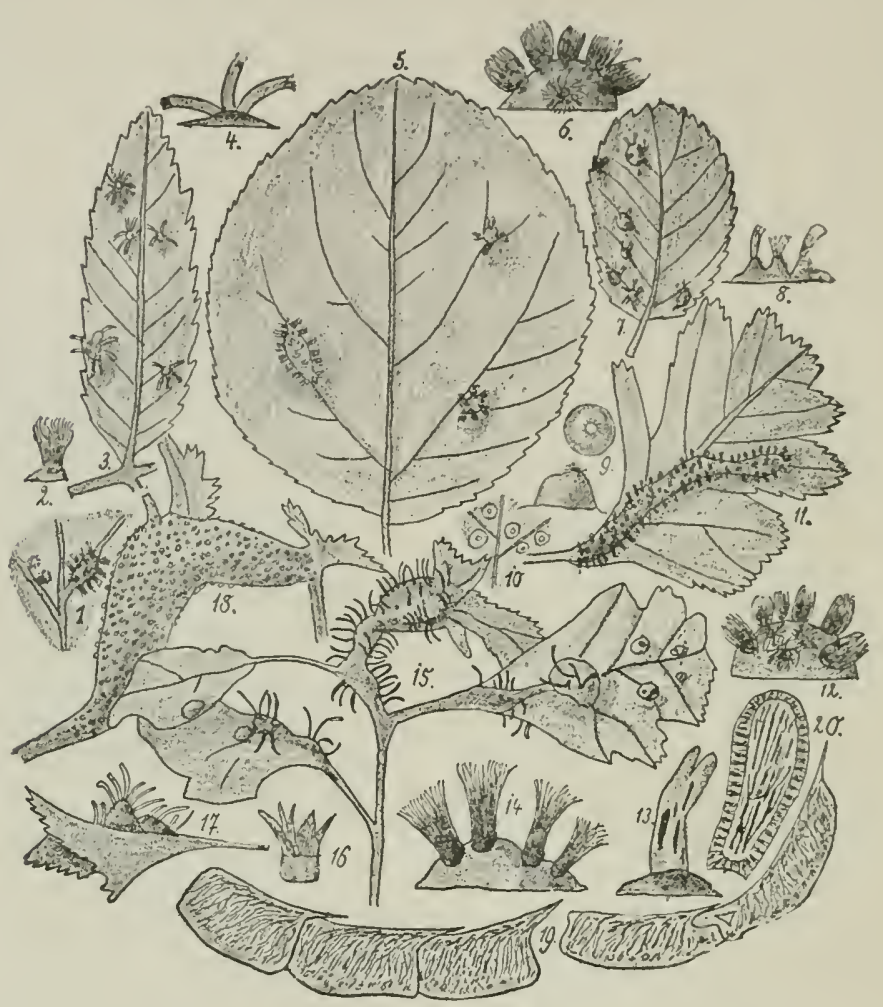

F1G. 224.-Accilia and Pucnidia of various species of Gymnosporangium:

G. tremilloides-1 and 2 , aecidia on leaf of Pyru* Ariu; 5 and 6 , aecidia on leaf of Pyrus Mulus; 14 and 20 , portions of the peridium of an aecidium from $\dot{i}$, showing the peculiar articulation of the cells.

$G$. juniperinum-3 and 4 , aecidia on Pyins Aucuparia; $z$ and $S_{;}$aecidia on Amilenchie, valgaris.

G. clavarinforme- 1 and 10 , aecidia on $P y)$ us latifolia; 11,12 , and 16 , aecidia on Cratregus Oxyacantha, grown out-of-dours; 1/, the same aecidia, enlarged: 13,15 , and 17 , aecidia on Crataerus Oxyectunthe, indoor culture; 15 , deformed twig of Crataegus bearing pscnidia. (After Tubeuf.)

spores) capable of immediate germination. The gelatinous mass dries up from time to time, leaving a bright yellow scar on the swollen part of the host-branch. The sporidia germinate most easily on species of Surtus (Pyrus). Infections with 
Gymnosporangium juniperinum L. and $G$. tremelloides Hart. from twigs and needles of Juniperus communis produced:

On Host-plant.

Pyrus (Sorbus) Azeupariu,

Aronia rotundifolia,

Pyrus Malus,

Pyzrus (Sorbus) Aria,

Cydonia vulgaris,

Pyrus (Sorbus) Aucuparin,

Pyrus Malus,

Amelunchier canadensis,

Pyrus (Sorbus) Aria,

Pyrus Mulus,

Pyrus (Sorbus) Chamaemespilus,

Mespilus macrocarpa,

Pyrus communis,

Pyrus (Sorbus) Aria,

Pyrus (Sorbus) Aria $\times$ Chrmaemesp.,

Pyrus Malus,

Pyrus (Sorbus) Chanaemespilus,

Pyrus (Sorbus) Iucuparia,

Aronia rotundifoliu,

Pyires (Sorbus) torminalis,

Crataegus Pyracantha,

Cydoniu vulgaris,

Pyrus Malus, -
Spore-form.

Rosteliu cornutre,

short aecidia,

- \}pycnidia,

Roestelia (?), -

prenidia,

liostelia cormutr, -

R. penicillata,

R. penicillatu,

R. penicillater,

spots

thick spots, -

pyenidia and aecidia,

thick spots, -

prcnidia and aecidia

- pycnidia only,

- pyenidia and aecidia,

- pycuidia and spots only,

$$
\text { - }
$$

Authority.

Tubeuf.

- Ráthay.

"

"

- Plowright.

- Thaxter.

- Hartig.

- Nawaschin.

- Peyritsch.

"

,

,

,

,

,

,

,

,

,

- Rostrup.

Formation of pycnidial spermogonia always precedes that of aeciclia.

This fungus is of practical import on account of its occurrence on leaves of apple-trees. Its attacks may be very virulent and widely distributed. Eriksson mentions that near Stockholm it is common on apples, and so virulent that many trees have every leaf studded with Rocstelia. (American apple-trees suffer from Roestelia pirata, the aecidia of Gymnosporangium maeropus and other species. See p. 402.)

Gymnosporangium juniperinum (L.) (G. conieum Hedw.) (Britain and U.S. America). This species, also frequenting Juniperus communis, is distinguished by its shorter spores, which, as Dietel pointed out, ${ }^{1}$ have a colourless papilla over each germ-pore. The teleutospores are found on both twigs and needles, on the former, however, they are much smaller

\footnotetext{
${ }^{1}$ Forstlich-naturwiss. Zeitschrift, 1895, p. 378.
} 


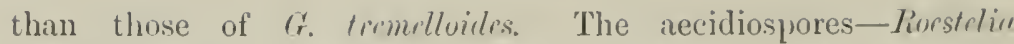
cormuta-veenr on species of Pyrus (Sorthus); they are much sinaller than those of liorstelia minilluta. The fiosstrin themselves are long, eurved, and horn-like, while the walls of the peridial cells are beset with short processes (Fig. 224). Where Pyrus Ancuparia oecurs mixed with P'yrus Malus, it has been observed that livestclio cormutu is confined to the former species exclusively. The Rocstclin. is the cause of a

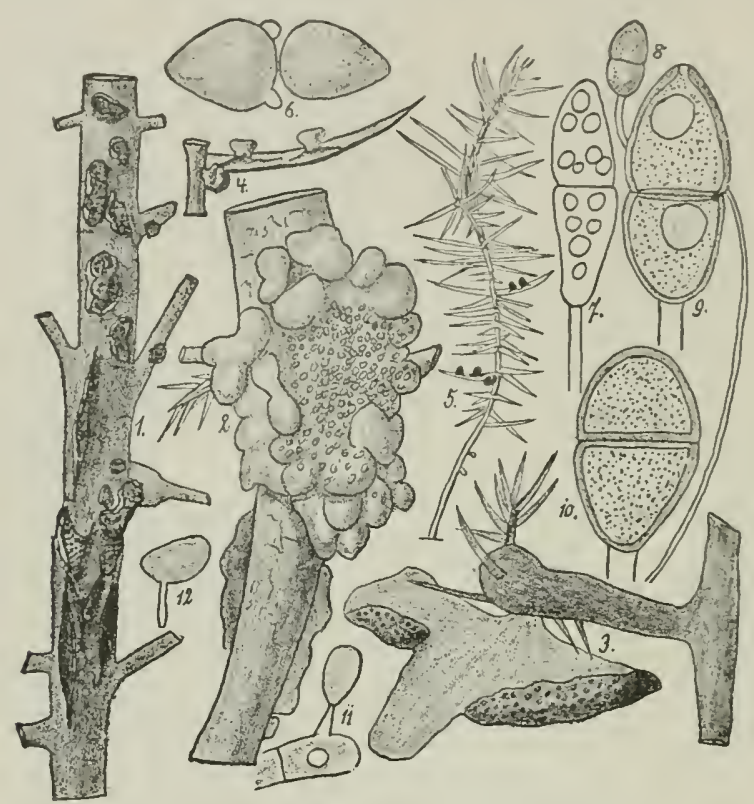

Fig. 225.-Grinnosporangium juniperinum and $G$. tremclloides. 1, Young sporeeushions breaking through the bark; 2 , the same in swollen condition; 3 , gelatinons cushion arranged to show its lower surface; 4, Juniper-needle with three spore-cushions; 5 , young Juniper plant bearing cushions on its needles ; 6 to 10 , spores of various kinds, to show the variation in size, shape, and thickness of wall; 11, cell of a promycelium with a sporidium attached; 12, germinatiug sporidium, (After Tubeuf.)

marked deformation of leaves, petioles, and even (though rarer) fruits of Pyrus Aucuparia and Aronia rotundifolia, both in the lowlands and mountains.

I have produced Rocstelic cornutu on Pyrus Aucuparia by artificial infection with portions of spore-cushions from twigs of juniper, and have observed a mountain ash in elosed forest, with abundant Roestelia, directly beneath an overhanging juniper with diseased needles. 
Wvernle investigated the anatomical changes induced by the various Gymnosporangia frequenting the twigs and needles of Suniperus communis. In the needles the myeelinm lives intercellularly, at first ontside the endodermis, but later also penetrating within this. The sporogenous cushions originate on the upper surface of the leaf to right and left of the middle nerve, where the stomata occur and hypoderm is absent. At these places a eushion or stroma of psendoparenchyma is produced and ruptures the epidermis (Fig. 226). This however is at once healed over by a cork-formation round the margin of the cushion, again to be ruptured as the latter increases in size, once more to be healed by eork-formation, and so on. In
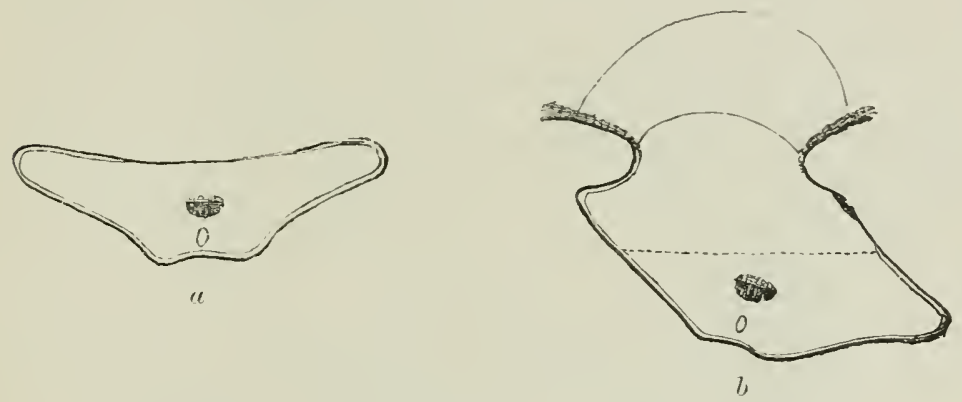

FIG. 226,-Comparison of (u) normal Juniper-needle with one (l) bearing teleutospores of Gymnosporangizm. In a the double outline indicates the hypoderm: the central rascular bundle and an underlying resin-canal are shown. (After Woernle.)

this way a corky layer is formed under the sporogenous cushion and gradually displaces it. If in a following year the cushion be again formed, the scar is ruptured and heals as before. Needles frequently remain in position for two, three, or four years, but most of them fall off in the first autumn. Under the sporogenous cushion the eells of the mesophyll increase both in number and size.

In considering the twig-deformations, Woernle distinguishes the form assumed by the Gymnosporangium on the neelles, as just deseribed, from a form which inhabits the thicker twigs. Both cause deformation of twigs, but their effeets differ as follows: "The needle-inhabiting form can only cause a slight swelling extending almost regularly round the whole twig; the twiginhabiting form, on the other hand, always gives rise to a very 
marked swelling on one side only (Fig. 227). In the needleform the swelling results from increased growth of the rind, with a simulaneous llecrease of growth of the wood; in the twig-form the growth of both wool and rind is much increased. With the twig-inhabiting form the merhllary rays and woodparenclyma increase, and at the same time become filled with mycelium (Fig. 228); whereas with the other form the inedullary rays are at most only somewhat broaler, and no mycelium can be found in the wood. The greatly swollen rind in the case

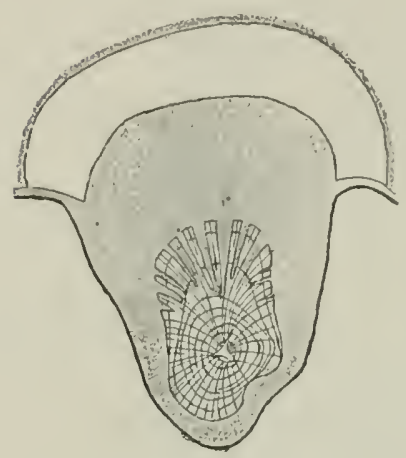

FIG. 227.-Fection of a nine-year twig of Juuiper attacked by Gymnosporangium. The rind under the spore-cushion is much thickened; the wood towards the same side is much broken uy by tracts of parenchyma. (After Woernle.)

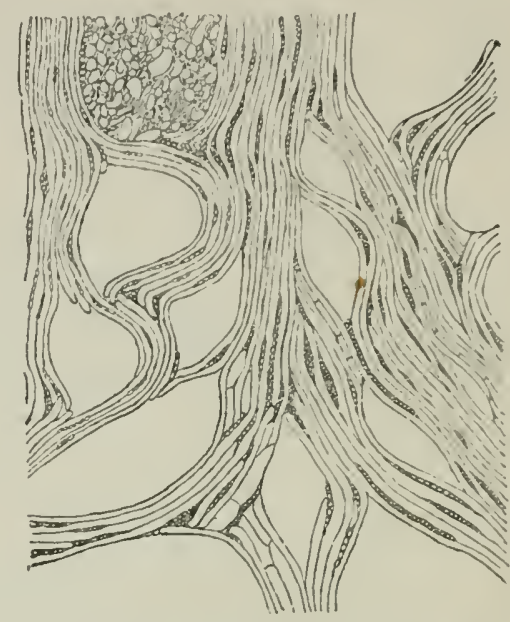

Fut. 22s.--Tangential section througl diseased wood heneath i spore-cushion. The woodelements are much displaced by abnormal tracts of parenchyma. (Only one of the latter has been filled in, the uthers left blank.) (After Wuernle.)

of the twig-inhabiting form is due more to increased growth of the cortical cells than to increase of bast-parenchyma; in the needle-form, however, the swelling is the result of increase of the bast, especially of the bast-parenchyma. In twigs infected by the needle-form, the mycelium may be found all round, but it has difficulty in making its way racially to the cambium; in the twig-form the mycelium, as early as the spring following infection, will be found to be in close contact with the cambium on the infected side, although it requires several year's to pass round to the cambium on the opposite side of the twig. The mycelium and spores of the two forms differ little from each other." - 
The strikingly characteristic cleavage of the wood by the overgrown elements of the medullary rays and the woodparenchyma, in the case of the twig-inhabiting form, will be seen from the figures (Fig. 229). As already noticed, the sporogenous cushions are generally formed on one side. After

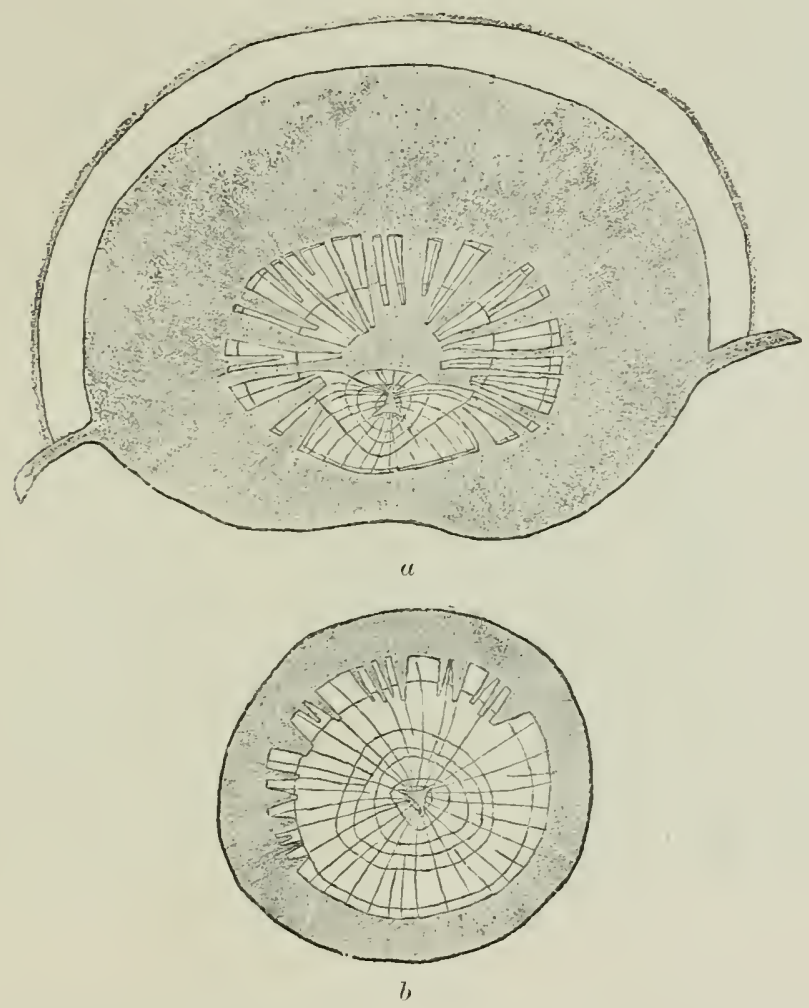

Fig. 229.-Two sections from a swelling on a Juniper-branch. a, From the middle of the swelling; the rind under the spore-cushion is much thickened, and the wood is much broken up by tracts of parenchyma. b, Section from 2 c.m. under $a$; abnormal development of parenchyma in the wood has begun in the outer year-rings. (After Woernle.)

the shedding of the cushion, a corky layer arises in the parenchyma underneath it, and so a bark-scale is produced.

Gymnosporangium sabinae (Dicks.). (Pritain.) The mycelium hibernates chiefly in Juniperus Sabina (Savin), and induces swellings on the twigs. It also occurs on Jun. Oxyectrus, ${ }^{1}$

I I found this host-species near Fimme. 
Jun. viryinimu, and fun. phornices. (A reported occurrener on Pinus helipensis: is probably an error:)

The sporogenous cushions are little dark-brown protuberances which break forth in spring from swellings, or on green

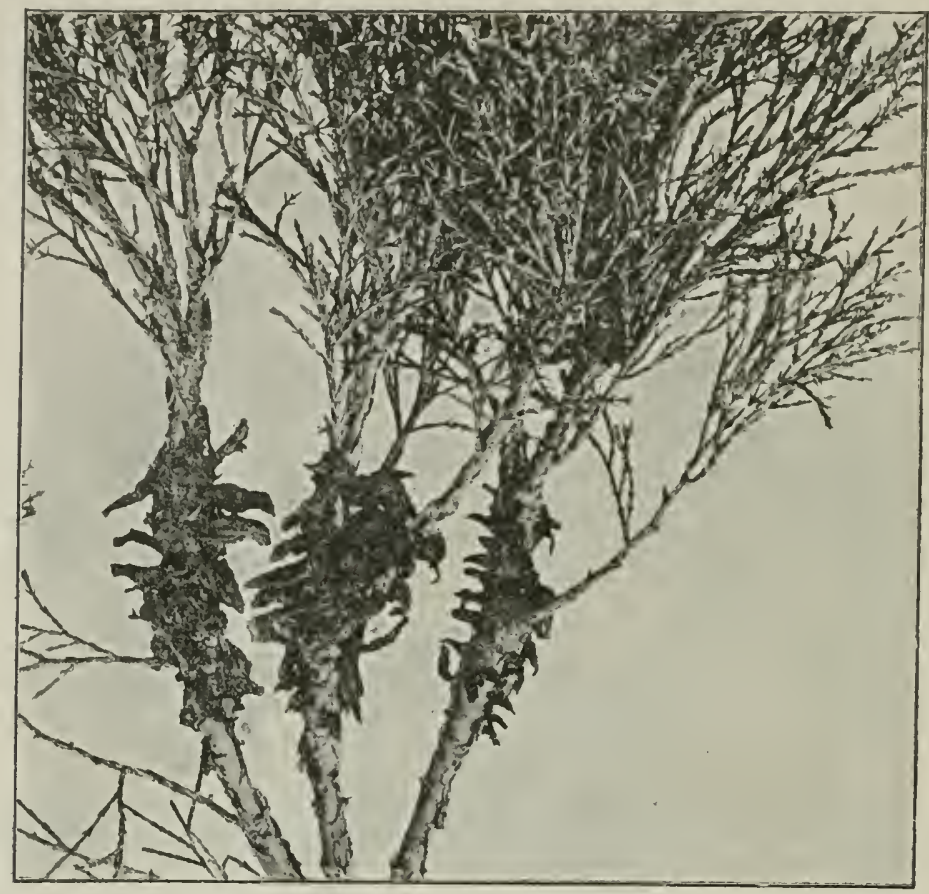

FIc. 230.- Fymzosporangium srebince on twigs of Junipuns subine, at the time of liberition of spores. (v. Tubeuf phot.)

twigs and scale-leaves. These bodies absorb water, swell, and run together, forming transparent gelatinous masses (Figs. 230 and 231). The teleutospores resemble those of G. juniperinum, but have only four germ-pores; they germinate on the gelatinous masses, and produce promycelia and sporidia. The latter germinate at once, chiefly on leaves of Pyrus communis. The pycnidia are produced on the upper epidermis as sticky yellow spots bearing clarker clot-like pyenidia. The aecidia (Roestelia conccllata) are found in September on the under-surface of the leaves of pear, also on leaf-petioles, young shoots, and even on the fruits. The peridia differ from both 
the species already described in remaining closed at the apex, the spores escaping through trellis-like slits on the lateral walls of the peridia (Fig. 234).

This fungus will not germinate on apple-trees, but on pears every leaf may be thickly covered with aecidia and pycniclia, and considerable damage to the crop thereby ensue (Fig. 23:3).

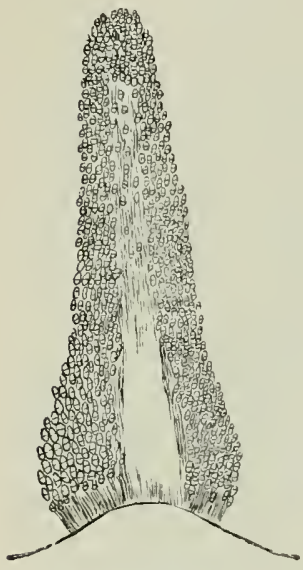

FIG. 231.-Longitudinal section through a conical teleutospore-sorus of Gymnosporangium Sabinae. (After Woernle.)

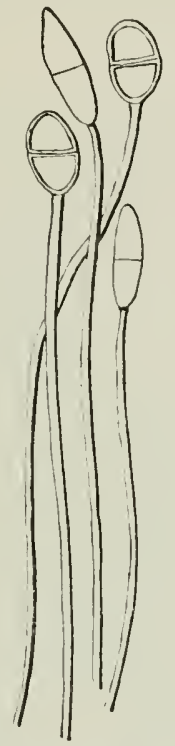

FIG. 232.-Teleutospores of $G$. sabinac. The elongated thin-walled ones are lighter in colour than the thick-walled. (After Woernle.)

Infections on various hosts with Gymnosporangium sabinae from Juniperus Sabine gave:

On Host-plant.

Pyrus communis,

Cratregus Oxyacantha,

Mespilus germunicu,

Pyrus commumis,

Pyrus communis,

, Hichuruir,

" tomentosu,

Pyrus communis,

Pyrus communis,

Crataegus Oxyacantha,
Spore-form.

Authority.

$$
-1
$$

Rostelia cuncellatu, $-\}$

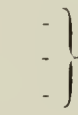<smiles>C1CCCCC1</smiles>

",

",

,
Plowright.

- Oerstedand De Bary.

- Ráthay, Tubeuf, etc.

- Reess.

E. Eischer.

Klebahn.

,, (uncertain). 
The anatonical changes exhibited in diseased parts of pearleaves have been briefly deseribed by Fentzling. ${ }^{1}$ He found a radial elongation of the cells of the spongy parenchyma and an accompanying accumulation of starch. Wakker, about the same time, obtained similar results in the case of Cratacyus Oryacantha deformed by $G$. clarariaforme (see p. 387). Wakker observed a diminished formation of calcium oxalate; Fentzling, however, found increased deposit of the same salt, not only in the form of

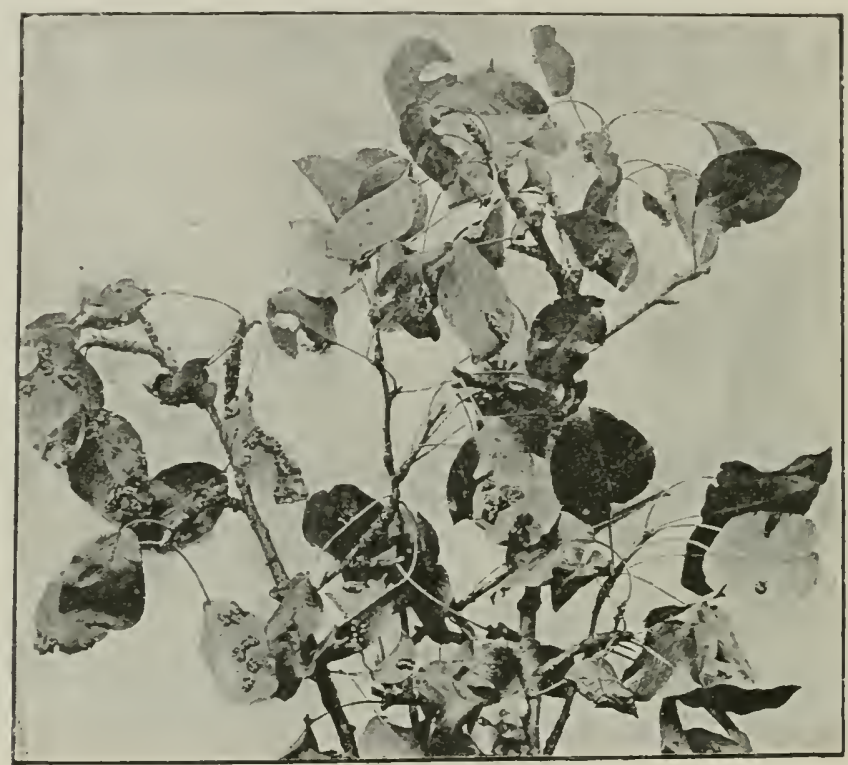

FIg. 233.-Gymnosporangizm sabinae in the form of Rostelin cancellata on leaves of Pear. A few twigs showing the abundance of aecidia orer the whole tree. (v. Tubeuf phot.)

isolated crystals but as masses. Cork-formation was suspended in Wakker's case, while in Fentzling's a partial formation of cork was distinguishable beneath the epidermis. The increased thickness of diseased leaves is due principally to multiplication of the spongy parenchyma, the upper layers of which frequently become more or less palisade-like. When pyenidia (spermogonia) are formed on the upper leaf-surface, the palisade parenchyma

${ }^{1}$ Fentzling (loc. cit.) and Peglion (Rivista di Patologia l'egtale, II.), also describe these alterations. 
of the spot in question is either completely destroyed or transformed into irregular cells, separated by intercellular spaces.

The anatomical changes in swellings (Fig. 235) induced by (r. schinae on Juniperus Sabina were investigated by Woernle with the following results. Wood, bast, and rind are increased round the whole circumference of the stem. Along with the broadening of the year-rings, however, there occurs a change in the structure of the diseased wood. The same

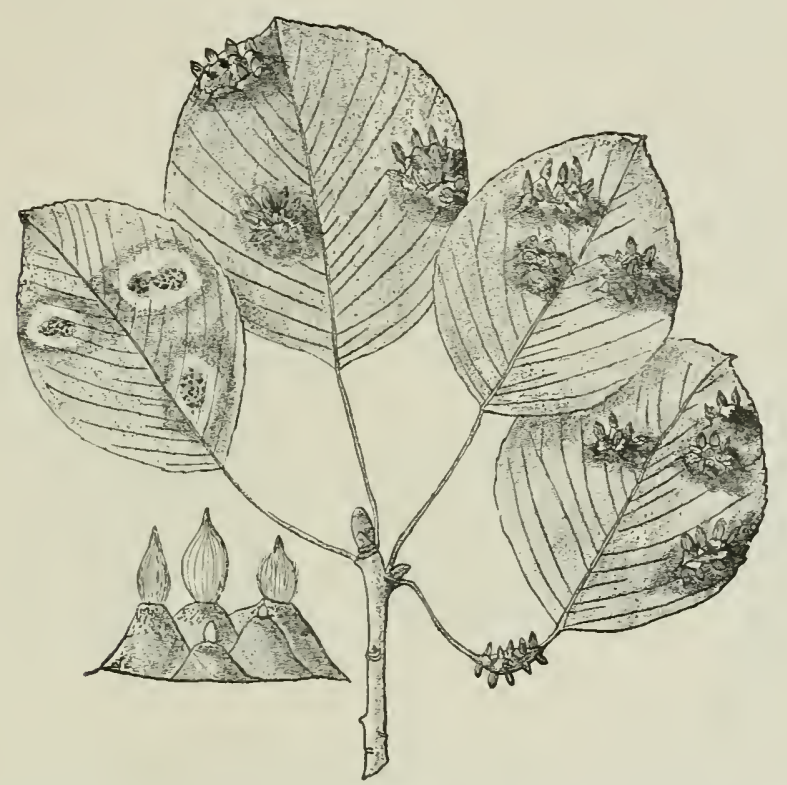

Fig. 234.-A few leaves enlarged from Fig. 233. The leaf to left hand bear pjenidia on red spots on the upper surface of the leaf; the remaining leares bear aecidia on raised portions of their surface. Several aecidia still further enlarged show the peridia dehiscing by longitudinal slits. (v. Tubeuf del.)

tissues occur in the year-rings as already described for $G$. clavariarforme, viz. thickened twisted tracheids, loosely connected together and with fissure-like pits; medullary rays more numerous and broader; the limits of the year-ring difficult to distinguish; and a yellow pigment deposited in the walls of all the elements. A tissue of this nature may be found round the whole circumference of a twig even in the first year after infection, and regularly each succeeding year. Woernle only rarely found zones of irregular cell-formation like those 


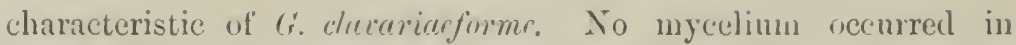
the woorl. A comparison of normal bast with that of infected twigs revealed changes similar to those already described for $G$. cleruriueforme. In ardition, it is to be noted that the thickenel bast-fibres no longer ocenrred in eloserl nasses, but were often completely absent in the first year after infection, while in all diseased twigs every internecliate stage exists between thin-walled bast-elements and thick-walled bast-fibres, such as never occur in the normal twigs; in fact, many twigs harl thin-walled clements only.

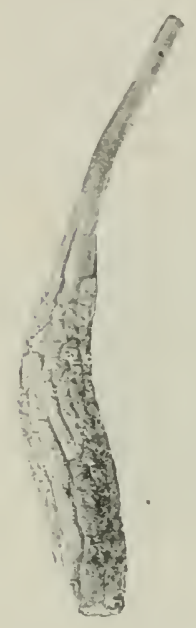

Frc. 23.5.--swelling from a branch of Juniperux siabina attacked bJ Gymnosporrigivin selbinue. Diameter at thinnest part $1 \%$ centimctre, at the thickest 6 c.m. (v. Tubeuf phot.)

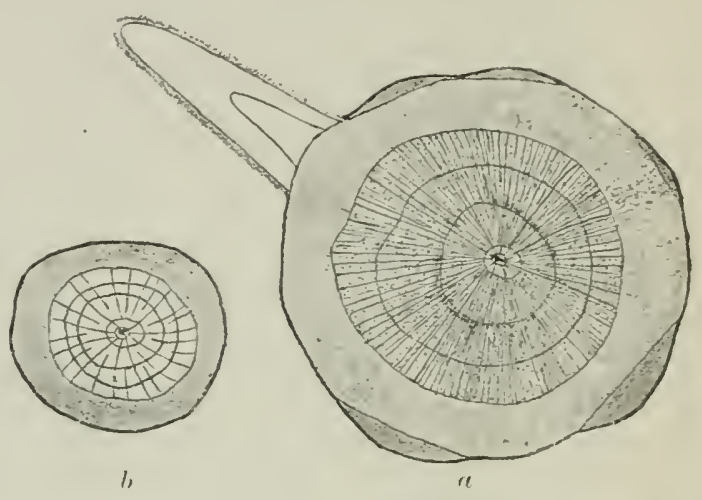

Fig. 236. - Sections of a twig of Sarin attacked by $G_{\text {. }}$ sabinar ", At thickest part of the swelling; $b, 3 \mathrm{~cm}$. under $a$ and normal. lin $a$ is shown one of the hollow teleutospore-cushions; five cushion-scars; in the second-rear ring are two shaded zones of wood, chiefly composed of parenchsma. (x 25.) (After Woernle.)

The sporogenous cushions of $G$. sabinar are formed in quite a different manner from those of $G$. clactriacforms. Beneath each cushion the bast increases very rapidly and forms an outgrowtl, which is still further enlarged by the addition to its apex of six or seven rows of radially arranged cells, rounder and smaller than the bast-cells of the cushion. The mycelium penetrates between these outer cells, and forms over the whole cellular outgrowth a pseudoparenchyma from which the sporogenons tissue arises. 
A sharply defined roundish scar of a light-yellow colour remains after the spores are cast. This is composed of a superficial layer of coloured pseudoparenchyma, with an underlying scar-tissue of characteristic constitution. The latter consists of several layers of cork-cells extending from one edge of the scar to the other, separating the cushion from the twigtissues. This scar-tissue is not broken through next year, but the new sporogenous cushions break out through other parts of the bark (Fig. 236).

G. confusum Plowright. ${ }^{1}$ (Britain.) This is found on Juniperes Scebine along with $C_{r}$. sabinue, from which it is difficult to distinguish. Pycnidia and aecidia are produced generally on Cratacgus Oryacentha and Cydonia vulgaris, rarely on Pypus communis. The aecidia on Crutacgus resemble those of $G$. clevariaforme on the same host, and dehisce by the ruptured apex of the peridium. Those produced on Pyrus communis are distinguished ${ }^{2}$ from aecidia of $G$. sabinae on the same host by dehiscing through the open apex of the peridiun.

Infections of Gym. confusem from Tuniperus communis gave the following results:

On Host-plant.

Authority.

Cydonire vulguris,

Crataegus Oryoucruther,

Pyrus communis,

Cratuegus Giryacantha,

The following American species of Crymnosporengium have been described :

On Arborvitae or white cedar:

G. biseptatum Ellis. On twigs and needles of Chamaceyparis thyoides and Libocedrus decurrens. The aecidia on Cratcegus tomentose and Amelenchier cenodensis.

${ }^{3}$ Plowright, Limnean Soe. Joumal (Botany), 1S5\%. E. Fischer, Zeitschrift f. Pfanzenkrankheiten, I., 1891; with summary of literature. Klebahn, Forstl.naturuis. Zeitschrift, 11., 1893.

${ }^{2}$ F. Fischer (loc. cit.).

"Farlow, The Development of the Ciymosporangia of the United States, 18s6, and other' paper's. Thaxter in various papers on Gymnosporangia, 1886 to 1891. Halsted (Report on Vegetable Pathology for 1SSS, U.S. Dept. of Agriculture) gives a résumé, with description and figures of $G$. macropus and treatment for orchard-rust. Fischer, Zeitschrift $f$. Pfanzenkrankheiten, I., 1891. 
G. Ellisii Perk. On Chumuenpuris thyoutcs. The alecidial stage on Pyrus Malus and P. arlutifolia.

On red cedar (Juniperus rivininiena):

G. macropus Lk. The aecidia and pyenidia occur on P'yrus Walus, P. coronaria, I'. arbutifuliu, Cirutuergus tomentose, C. Ionulusii, and Amelanchirr canadensis: they are known as

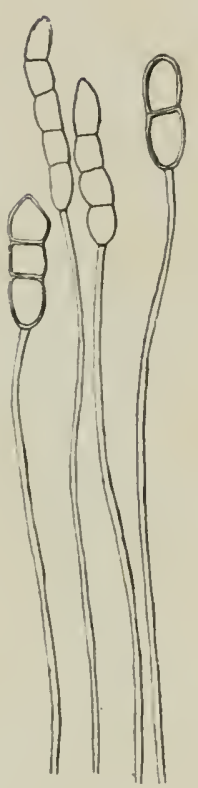

FIG. 237.-Spores of Gym. biscplatum, (After Woernle.)

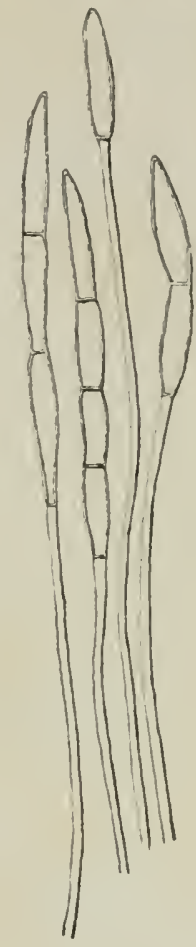

Fis. 235.-Spures of Woernle.)

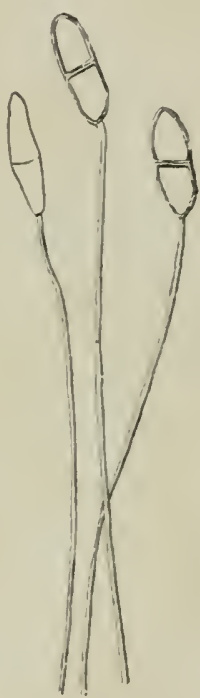

FIG, 239.-Spores of (iym, macropus. (After Woernle.)

Rivestclia pirata. This is one of the commonest canses of apple-rust and of the deformation known as "cedar apples" (Fig. 240). The anatomy of the latter structures has been described by Sanford. ${ }^{1}$

G. clavipes Cooke et Peck, occurs on Juniperus communis. Its aecidia and pycnidia are found on Pyrus MLulus, I. arbutifolia, and Amelanchicr cunadensis.

'Sanford, Amals of Botany, I., 1857. 
G. globosum Farl. Aecidia on Pyrus Malus, P. communis, Cyylonia vulgaris, Sorbus americana, and species of Cratacgus.

G. nidus-avis Thaxt. Aecidia and pycnidia on Pyrus Maclus, Amelanehior cunadensis, and Cydonia vulgaris. On the red cedar it causes the "birl's nest" deformation of the branch-system.

G. speciosum Peck. On Juniper's arcidentelis.

G. Cunninghamianum Barel. On C'ypressus torulose in the Himalaya. Aecidia on Pyrus Prshico.

The following genera do not occur in Europe. Colcopuccinia, Pucenelin, Alecolaria, Trirhosporr.

Ravenelia alone amongst these contains parasitic species of importance. They all occur on Leguminosae and Euphorbiaceae in the warmer parts

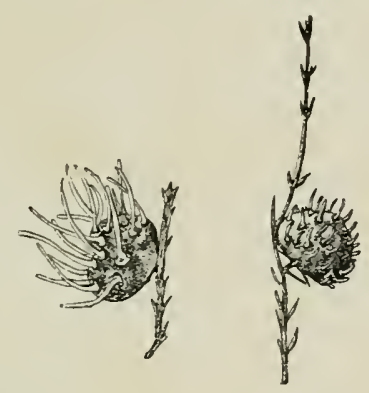

Fig. 240.-Cecire. Apples caused by Gymnospoiangium maciopes. (r. Tubeuf del.) of India, Africa, and America. ${ }^{1}$

Ravenelia Volkensii Hemn. has teleutospore-sori which appear on "witches' broom" deformations of the twigs of an Acacic in Usambara.

Rav. pymaea Lager. et Diet. procluces its telentospores on malformed branches of Phyllanthus in Ecuador.

Certain forms of Accidium which cause deformation of species of Acaciu should probably be included in this genus (see p. 410).

\section{Endophyllum.}

Teleutospores originate serially on cushions which are enclosed in a peridium similar to aecidia; on germination, a four-celled pronlycelium is prodnced." Leaves of Euphorlia, Sedum, or Simperivum inhabited by mycelium develop abnormally.

Endophyllum euphorbiae-silvaticae (D. C.) (Britain). According to Winter, the peridia are regularly distributed over the underside of the leaf of Euphortic amygdaloides; they have white fissured margins either erect or somewhat turned back.

${ }^{1}$ Dietel, "The Genus Ravenelia," Hedwigia, 1894.

2 The telentospores of this genus might lue described as aecicliospores which produce promycelia. 
Sipores yellow and polygonal. Leares when attacked remain broad, short, and pale coloured.

E. sempervivi (Alb, et Schw.) (Iritain). 'The aecidium-like patches of teleutospores occur on wild and. cultivaterl species of Sirtum and Eschererion. The spores produce promycelia from which arise sporidia which germinate on the same host-plant. True aecidia are unknown, but orange-red pycnidia (spermogonia) may occur. Leaves of attacked plants are pale and abnormally lengthened.2

E. sedi (D. C.). Telentuspores occur on species of Sectum.

The genus I'ucciniusion found in Fenardor contains few s]ecies, and none of them important parasites.

\section{Aecidium-Forms}

The iclationsleips of wich aw uncetuin.

Aecidium elatinum Alb. et Sichw. (Britain and U.S. America). The witches' broom of the silver fir. ${ }^{3}$ This Accidium is widely distributed in forest's containing silver fir (Abics pectinata), and produces canker of the stem frequently accompanied by that deformation of the hranch system known as a witches' broom.

In Ciermany it has also been observed on Abies Nordmamiana, A. cepluelonice, A. Pinsupo; in North America on A. balsemira; and in Silueria on $A$. Piclete.

As a result of the presence of this fungus, globose or barrelshaperl swellings make their appearance on stems and branches of all ages and on all parts of the trees. A single stem may carry one or many of these, and they continue to increase with its growth. If, as is frequently the case, the bark covering the swelling becomes ruptured and partially detached, then the wood left uncovered becomes a wound, and falls an easy

${ }^{1}$ Leveillé, Bullet. Science. Natur., xvi, 1525.

2 Illustrated in Kerner's Natural History of Plants, English Edition (Fig. 355).

${ }^{3}$ De Bary, Bolan. Zeituny, 1867. Weise, "Yur Kenntniss d. Weisstannen. krebses," Mïndener Forstliche Hefte, 1891. Heck., "Der Weisstamenkrels." Springer, Berlin, 1894; with Illustrations and Bibliography.

The canker is common throughout Britain, but witches' brooms have not leen often recorded. (Edit.) 
prey to wood-destroying fungi. ${ }^{1}$ The presence of such rotting spots render's the tree liable to break over in their neighbourhood, while they, as well as the swellings on the trunks, canse a considerable depreciation in the value of the timber.

The malformations of the branch-system known as witches' brooms are frequently induced by this fungus. They occur as a rule on the horizontal branches and form a richly branched bush easily clistingnished, even at a distince, by a marked

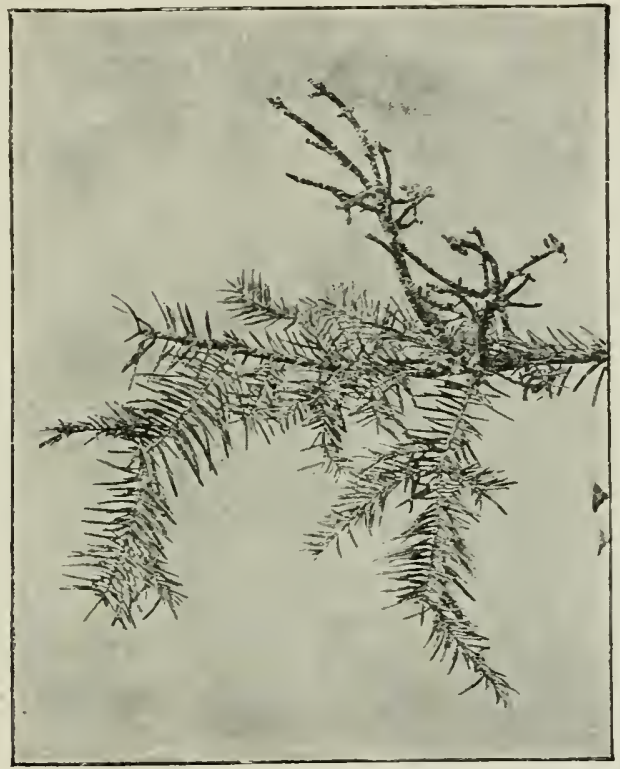

Fig, 241.- W'itches' Binoin of Silver Fi, (winter condition). The needles, with quores of Accidium elatinem, have fallen off, but the normal foliage remains. (v. Tubcuf phot.)

negative geotropy of its twigs. The brooms not unfrequently start from a marked basal swelling. They may be found of all sizes, on young as well as old trees, on any part of the branchsystem, and in all localities where the fir occurs (Figs. 241 and 242).

The aecidia of Acciltium clatinum are developed only on the deformed needles of the witches' brooms. These needles are produced anew each spring, live only one season and are cast

${ }^{1}$ Polyporus Hartigii and Agaricus adiposus in particnlar accompany this canker and bring about decay of the wood. 
the same atutumn; they are small, one-pointed, and pale from an almost complete lack of ehlorophyll. In these respects they are quite distinct from the larger double-pointed normal needles with their dark-green colour and a perind of growth extending over several years. All the needles on a broom are as a rule stunterl in the manner described, yet single branches may be found with needles quite normal; such contain no mycelium, or, if so, it has found its way in too late to have any effect on their growth.

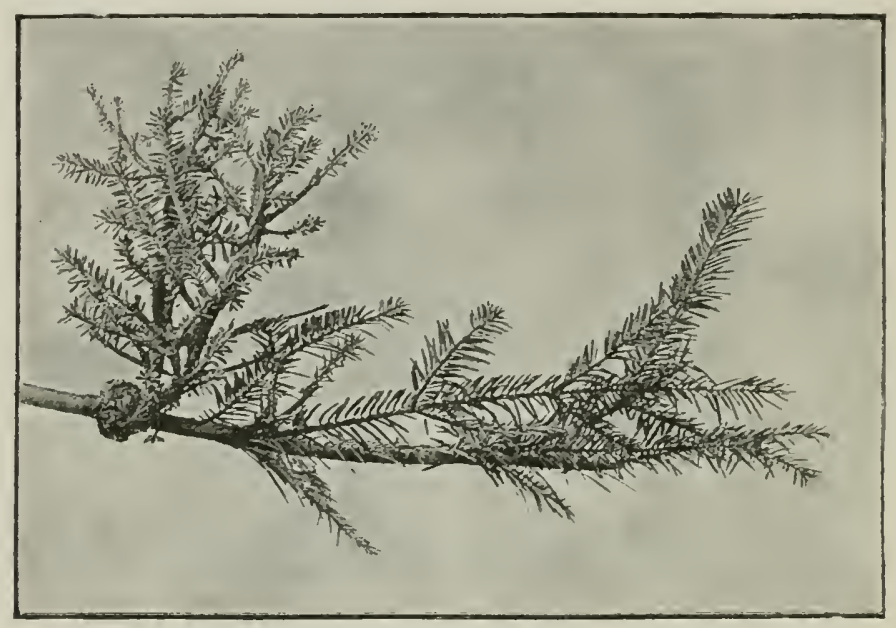

F10. 212.- Hitches" Binom of Silier Fir (summer condition). The untredly negitive gcotrolic broom has its origin in a distinct bisal swelling. ( $\mathrm{v}$. Tubenf phot.)

The various tissues of the witches' brooms also undergo considerable modification as compared with normal twigs. A thicker and softer bark is present, due to the parenchymatous cells of both outer rind and bast having enlarged in size and increased in number; the cork layers are also abnormally increased. The same changes may be observed in the rind of the swellings, and to this their increased size must be chiefly ascribed. The wood hoth in twigs and swellings is much incrensed; the year-rings however are very varial,le, sometimes they are broader than the normal, again they may be diminished or even altogether wanting; where however the wood decreases, there the bast increases in proportion. This lack of uniformity 
in the growth of the wood clisturbs the elements, so that they are irregularly developed and more or less twisted. ${ }^{1}$

A mycelium inhabits the tissues of abnormal twigs and cankered swellings. It grows in the intercellular spaces of the rind, between the bast cells and onter parts of the wood, and derives nutriment by means of haustoria; these either bore through the cell-walls, or only press closely against them so as to cause depressions.

Spore-formation takes place on the needles of the witches' brooms. The pycnidia (spermogonia) are prodnced on the upper side beneath the cuticle and emerge through it as little yellow points. The conidia (spermatia) are tiny globose colourless bodies. The aecidia come later during June and July in irregular rows on the under side of the leaf. Their peridia break ont as low dome-like structures, the apices of which rupture irregularly to allow escape of aecidiospores. In spite of numerons infections, De Bary was unable to observe the penetration of a germ-tube into needles or twigs of silver fir. Weise believes that infection of the fir takes place on twigs which have just emerged from the bud.

As a preventive measure, all witches' brooms should be cut off before spore-formation begins, and

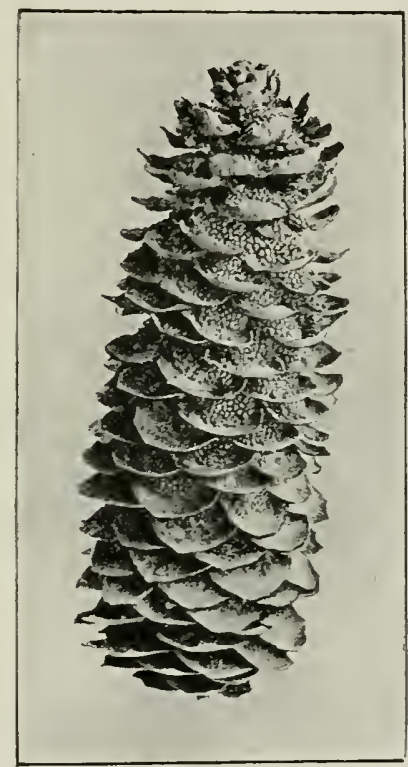

Frg. 243.-Arcidium stiolitimum on $\mathrm{n}$ Spincecone. (r. Tubeuf phot.) stems with canker-wounds should be removed during forest-thinning. For further details the monograph of Heck may be consulted.

Aecidium strobilinum (Alb. et Schw.) (Britain). Spruce-

${ }^{1}$ Note.-Further details of the anatomical changes induced in the tissues of these witches' brooms may be obtained in the German edition of this work (pp. 420-421), or in the original thesis by Hartmann, (Anatom. Irorgleirhung d. Hexenbesen der Weisstanne. Inaugural Dissertation, 1S92.) (Edit.)

¿Reess, Rostpit-formen d. Coniferen., 1869. Oerstedt, Waturh. for Tidensk. $M \in d d ., 1863$, I. 
cone rust. This disease is found on the cones of spruce. 'The aceidia are brown somewhat flattened spheres, and appear in large numbers on cones distinguished by their scales standing stilly open even in lamp weather (Fig. 243). The gemtubes of the fungus find entrance in spring into the flowers or young spruce-cones, and the mycelium lives parasitic in the green seales without cansing any marked change in their growth, although the ovules are more or less injured. No myeclimm has ever been found in the lower cone-axis, nor in the shoots, so that the rlisease must he the result of infection hy spores only.

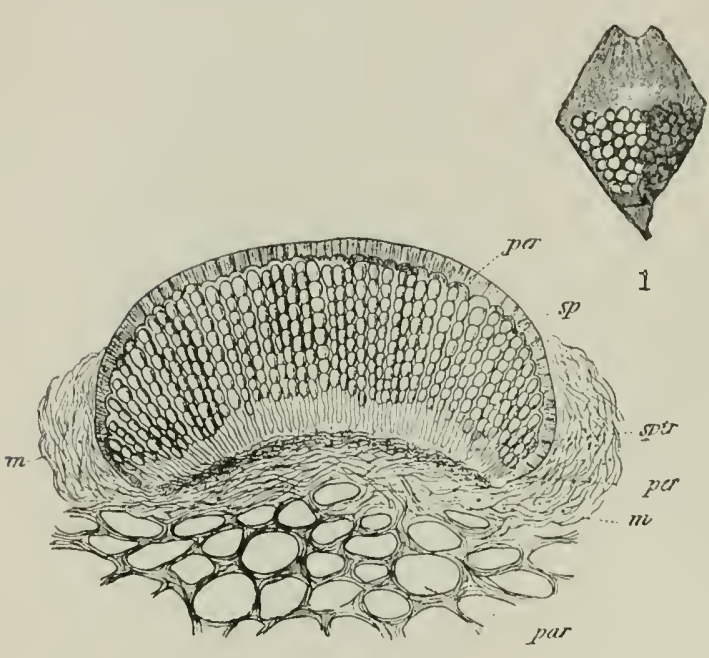

2

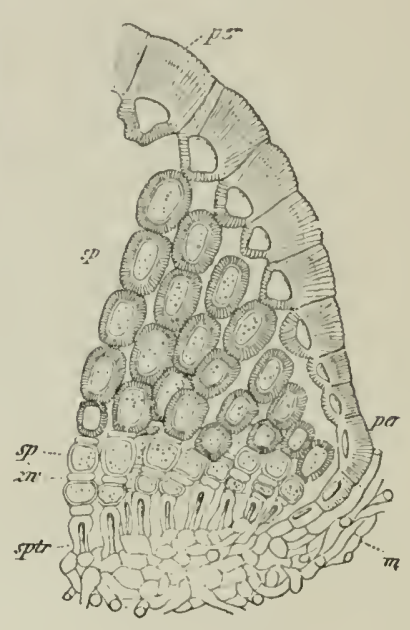

3

Fig, 244.-Acidium strobilinum. 1, Cone-scale of spruce with aecidia, those to left dehiscing their yellow spores, those to right still closed. (v. Tubeuf del.) 2 , Section through an immature aecidium. 3, Part of 2 enlarged-per, peridium; $s p$, spores; $z v$, intermediate eells; $s \rho t r$, sporophores; $m$, nycelium; $p a v$, the scale-purcuchyma. (After Reess.)

The aecidia break out on the imer (rarely the outer) side of the bases of the cone-seales; each is enclosed in a firm brown lignified peridium, which ruptures by a cross-fissure and becomes an open dise. The young spores are joined by small intermediate cells, which are gradually absorbed to form a layer of gelatinous lamellae on the spore-coats (Fig. 244).

Telentospores of this Accidium are unknown. 
Aecidium pseudocolumnare Kiilın. ${ }^{1}$ Occurs on needles of Abies puctinatre in Germany; in Britain, however, on this and several other species of Abirs. It is distinguished by its large white spores from the Ace columnare of Calyptospora (p. 372).

Aec. Magelhaenicum Berk. This species occurs on various species of barberry. The mycelium hibernates in the shootbuds and causes them to develop as witches' brooms, hearing on the lower surface of their leaves aecidia with long, white, sac-like peridia. The allied teleutospore-form is as yet unknown.

Aec. clematidis D. C. (Britain and U.s. America). On Clemetis litalbu, C. rectu, and other species. It is related to Puccinia agropyri Ell. et Ev."

Aec. Englerianum Henn. et Lind. ${ }^{3}$ produces a peculiar antler-like branching of the twigs and leaves of a Clematis at Eritrea (Lytri) in the (irecian Archipelago.

Aec. punctatum Pers. (dec. quedrifidum D.C.) (Britain and U.S. America). This is a common species on Amemone (Fig. 190) and Eranthis. The aecidia have white peridia, which on dehiscence break into four lobes.

Aec. leucospermum 1). C. (Britain and U.S. America). On Anemone urimorose (Fig. 190).

Aec. hepaticae Beck. On Anemone Hepatica.

Aec. ranunculacearum D. C. (Britain and U.S. America). On species of licumenlus. A collective name for aecidia of several species of tromyces (p. 336), and Puccince (p. 349).

Aec. aquilegiae Pers. (Britain and U.S. Anerica). On Alfuitegiu vulguris and other species. (See Pucciniu agrostidis, p. 349.) .

Aec. actaeae (Opiz.). On leares of Ictued spicata in Europe and America.

Aec. barbareae D. C. On speeies of Barbarea (Britain). (See I'nce. festucue, 1. 349.)

Aec. circaeae ('es. On species of Circtece.

Aec. grossulariae Schnm. (Britain and U.s. Anerica). On libes Grossularia and $R$, rubrum. Klebahn believes it is related to a Puccinia on Carex.

Aec. bunii D. C. On Conoporizem elenudutem in Britain. (See Pure. bistortue, 1. 355.)

Aec. periclymeni Schun. On species of Loniceru. (Britain.) (See Puce. festuccee, p. 349.)

Aec. compositarum. A provisional species-name for a large number of aecidia frequenting Compositae, and by no means resembling each other.

Aec. leucanthemi D. C. A European species with its Puccinia-form on Curex montanu.

Aec. cyani D. C. On Centurea Cycrus.

Aec. ligustri Stranss. On Privet.

${ }^{1}$ Hedwigia, 1884.

${ }^{2}$ Dietel, Oesterreich botan. Ztitum, 1892.

${ }^{3}$ Engler's Botan. Jahrbuch, 1593. 
Aec. phillyreae D. C. On species of Ihillyrer (Britain?).

Aec. fraxini Schwein. This causes serions dantge in America to the foliage of Fromus rivilis aud $F \%$ umericaua. ${ }^{1}$ It lats also appeared in Emrope on the latter species introdnced from America.

Aec. nymphaeoidis 1). (: On leaves of Limnenthemum, Niphlear, and rymphrerr. (Britain.)

Aec. pedicularis Lih. On Pediculuris. (Britain.) (See Prer. purludosu, p. 3.1.)

Aec. prunellae Wint. On Prunelle velgaris. (Britain.)

Aec. euphorbiae Gimel. is fomnd on many species of Euphorbio. It in probably the Aecidium-form of Cromycrs pisi. (Britain and U.S. America.)

Aec. convallariae Sichum. (Britain and U.S. America). Prubably a provisional species-ntme for aecidial forms found on Comrallario, l'olygomrtum, Paris, Lilium, etc. (See under I'ucrinir.)

Aec. ari Desm. (Ace. dracontii Schwein.) is found on species of Amm. (Britain and U.S. America.) (See Puce. phaturidis, p. 349.)

The following species are found on Acacia amd seem to har strong affinity with the genus liarenalia:

Aec. esculentum Barcl. produces reformation of twigs of Acrcie eburneu in India. Twigs of this kind, likewise shoots deformed by dec. virtirce wor. himalayense Barcl., and pine-shoots deformed by certain species of P'erirlerminm, are eaten in various parts of the world.

Aec. acaciae (Henn.) on Acecire etbrice in Abyssinia. This is sait ly Magnns to canse witches' brom deformation.

Aec. Schweinfurthii Hem, canses malformation of fruts of Icreio Fistule in Africa.

Aec. ornamentale Kialch. eallses curvature of shoots of Alcueire horridu at the Cape.

The following are some of the more important syecies recorded for North America only:

Aecidium dicentrae Trel. Leaves of Dicentice and Corydalis.

Aec. monoicum Peck. Leaves of Arubis.

Aec. drabae ' $\mathrm{Tr}$. et Gall.

Aec. lepidii $\mathrm{T}_{\mathrm{r}}$. et Gall.

Aec. proserpinacae $B$. et $($ :

Aec. Mariae-Wilsoni Peck. Gon species of I"ioln.

Aec. cerastii Wint.

Aec. pteleae B. et C. On leaves of I'telect trifolirtu.

Aec. xanthoxyli Peck.

Aec. splendens Wint. In the cotylerlons of Croton momranthoymms.

Aec. aesculi EIl. et Kell.

Aec. psoraleae Peck, and Aec. onobrychidis Burr. On species of Psoralea.

${ }^{1}$ Pomul, American Naturalist, 1sss. 
Aec. Peckii De Toni and Aec. oenotherae Mont. On leares of species of Oenothera.

Aec. sambuci Schwein. On leares and stems of Sumbucus.

Aec. ceanothi Ell. et Kell.

Aec. abundans Peck. On species of Sympleoricripus.

Aec. cephalanthi Seym. On Cephalunthrs occidentale.

Aec. erigeronatum Schwein. On many species of Erigeron.

Aec. asterum Schwein. On species of Aster and Solidugo.

Aec. polemonii Peck. On Polemonium and Phlor.

Aec. apocyni Schwein. On leaves of Apocynum.

Aec. Jamesianum Peck, and Aec. Brandegei Peck. On leaves of species of Asclepias.

Aec. myosotidis Burr. On leaves of Myosotis ierma, ete.

Aec. plantaginis Ces. On leaves of species of Pluntugo in Eurne and America.

Aec. pentastemonis Schwein. On species of l'ertstemem.

Aec. giliae Peck.

Aec. lycopi Gerard. On leatres and stems of Lycopus europrens.

Aec. iridis Gerard.

Aec. macrosporum Peck, and Aec. smilacis Stchwein. On species of Smitar.

\section{Peridermium.}

Peridermium pini (Willd.) ${ }^{1}$ is found on pine-trees in Europe, Britain, and United States. A teleutospore-stage of this has not as yet been identified, although a very similar species (Pridermium Comui Rostr. et Kleb.), also occurring on the bark of pines, has been proved to have as its teleutospore-form Cronartium rsclepiculeum.2

The mycelium of Peridermium pini lives intercellularly in the rind, bast, and wood of Pinus syllestris, I'. Laricio, P. halepensis, $P$. maritima, and $P$. montenu. It lives and extends through the stem for years, attacking the living cells and absorbing nutriment from them by little haustoria. The cells of parenchymatous tissues are those most generally attacked, and the mycelium has been found to penetrate along the medullary rays to a depth of $10 \mathrm{c.m}$. into the woor-mass. The cells of attacked parts lose their normal content including starch, and secrete crude turpentine in sucl quantity as to completely permeate their walls, and even to form drops. In this way portions of the wood become completely saturated

${ }^{1}$ R. Hartig, Wichtige Krankheiten d. Waldbüumem.

${ }^{2}$ Klebahn, Berichte d. deutsch. botan. Gesellschaft, 1590. 
with resin, and as the same process goes on in bast and rind, the turpentine overflows from fissures or wounds in the bark. During the smmmer the mycelium grows amongst the dividing cambium-rells and kills them. Where this occurs the year-
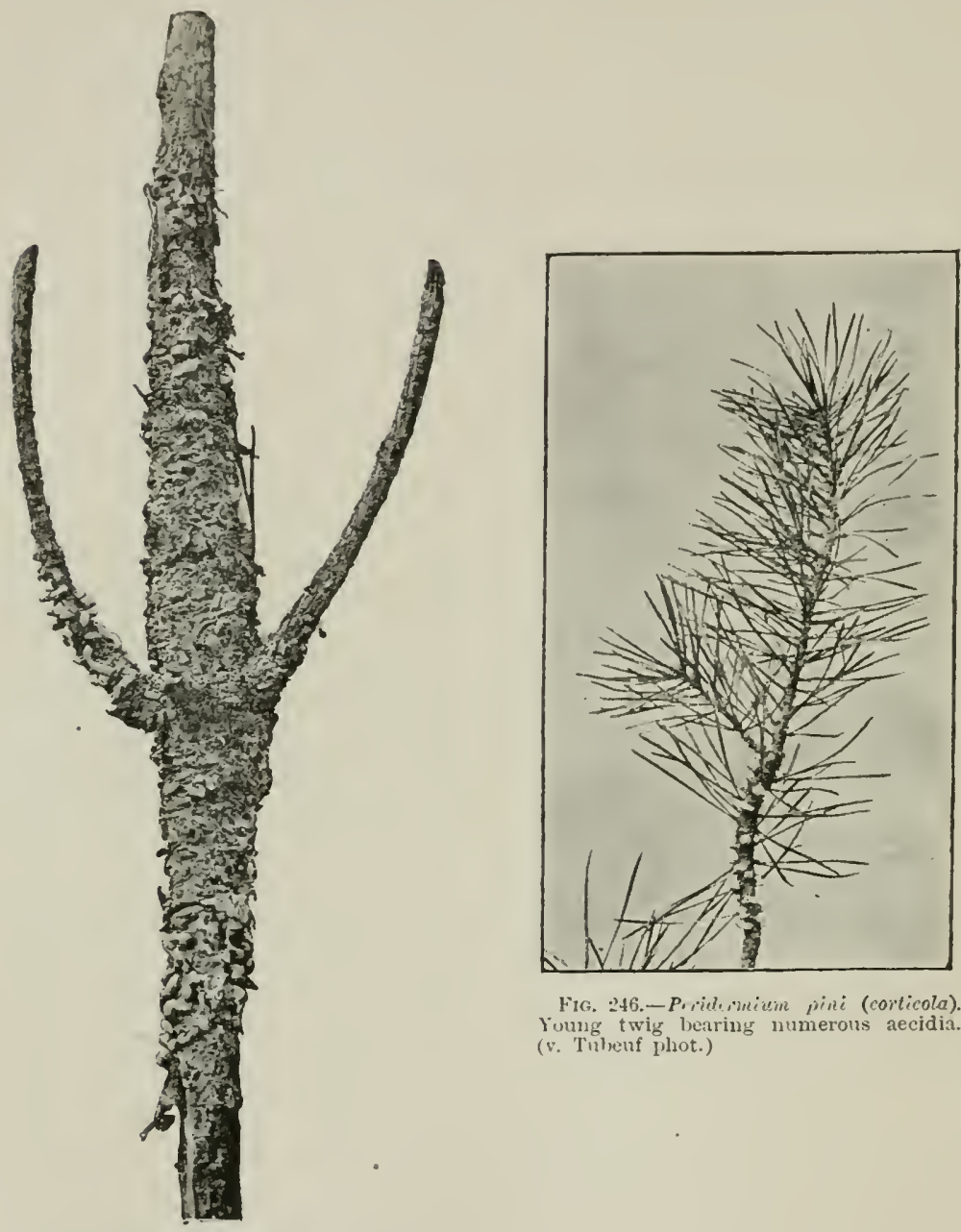

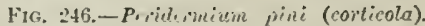
loung twig bearing numerous aecidia. (v. Tinkenf phot.)

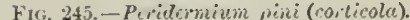
Branch and lateral twigs distinctly swollen where attacked. They also bear aecidia. ( $\mathrm{s}$. Tubeuf phot.)

ring ceases to thicken, but as the mycelium seldom succeeds lluring the first year in killing the cambium all round a 
branch, the living portions of the ring grow on with increased vigour, and even attempt to close over the injured portion. This irregular growth, continned in many cases for years, produces abnormal cross-sections (Fig. 248). The mycelium grows out centrifugally from diseased spots, so that the wounds continue to enlarge, and the disease becomes easily noticeable on account of the deep channels and distorted swellings on the pine branches and stems. As the disease spreads inwards into the stems, the conduction of water is interfered with and the branches above such wounds dry up and clie off. Whereas

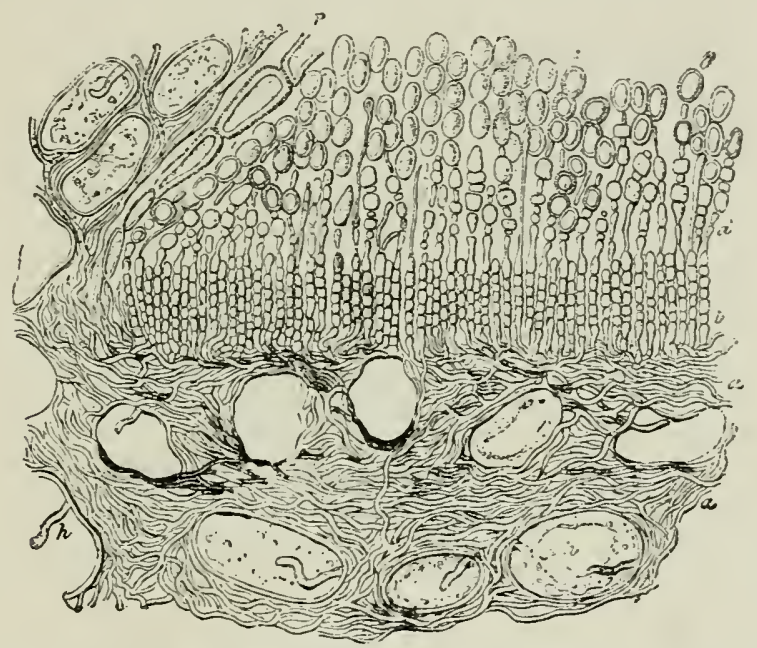

Fif. 24-.-Pitidomium pini (coiticola). ", ", Iscelial stroma dereloped in the rind; the host-cells hare becume isolated from each other and contain haustoria, $h$, of the fungus. $b$, Basidia composed of much smaller cells than in the needle-inhabiting aecidia. $p$, The peridium. (After R. Hartig.)

young plants soon succumb to attack, the struggle with old trees may go on for years. Fresh infection of older stems occurs generally in the higher parts of the tree, where the bark is still thin.

Pycnidia (spermogonia) are developed between the rindparenchyma (periderm) and cork, generally towards the margin of diseased spots. The conidia emerge from the ruptured cork-layers of the bark as a honey-sweet liquid. H. Mayr states that this liquid is given off in such quantity from species of Peridermium in Japan, that it is collected and eaten by the natives. 
The aecirlia appear in .June as wrinkled yellow sacs emerging from the bark of swellings. They continue to develop in succession for years on the living parts of attacked branches, but accorling to Hartig they cease to make their appearance on old stems, even when a mycelium is present. This disease is the eause of great damige to pines, especially where planted as pure forest. One case is recorded ${ }^{1}$ of a forest near Kohlfurt where 90 per cent. of the trees in an old plantation were "starg-headerl" on account of a deficient

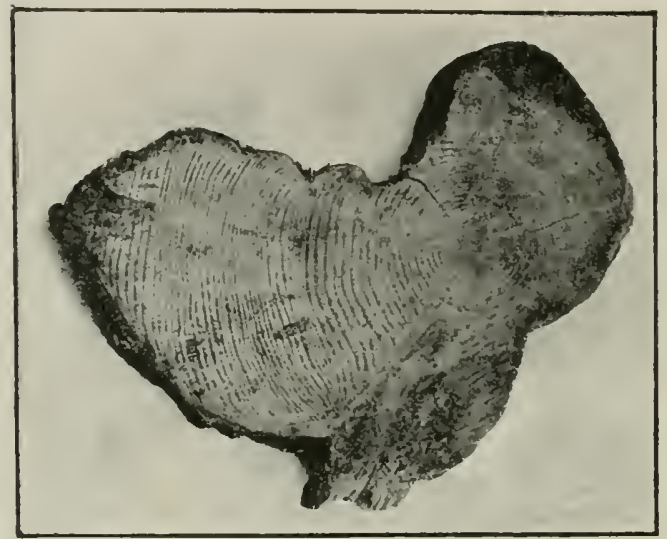

Fsc. 245. - Dridimium pini. Section through a diseased stem of Pine showing the gradual killing of the cambium by the fungus. ( $r$. Tubeuf phot.)

supply of water in the crown accompanying attacks of this fungus. Until more is known of its life-history, preventive measures cannot be well extended beyond cutting down infected trees.

The following species of Peridermium have been observed on species of Pinus:

A. On the needles:

Peridermium oblongisporium Fuck. (now ('olevsporium senecionis) on Pinus sulfestris and $P$. austriace (p. 3it).

P. Klebahni, P. Soraueri, P. Stahlii, P. Plowrightii, anl P. Fischeri. On Pinus sylvestris; related to varions species of Coleosporium.

P. piriforme Peck. On Pinus speciose in U.S. Aneriea.

P. cerebrum Peck. On Pinus rigidu in North America.

'Marker at Schlesien. Forstrerein, 1893. 
P. filamentosum Peck. On Pinus ponderosa, also in America.

P. Harknessii Moore. On Pinus ponderosa, P. insignis, P. Sabineana, and $P$. contorta in California.

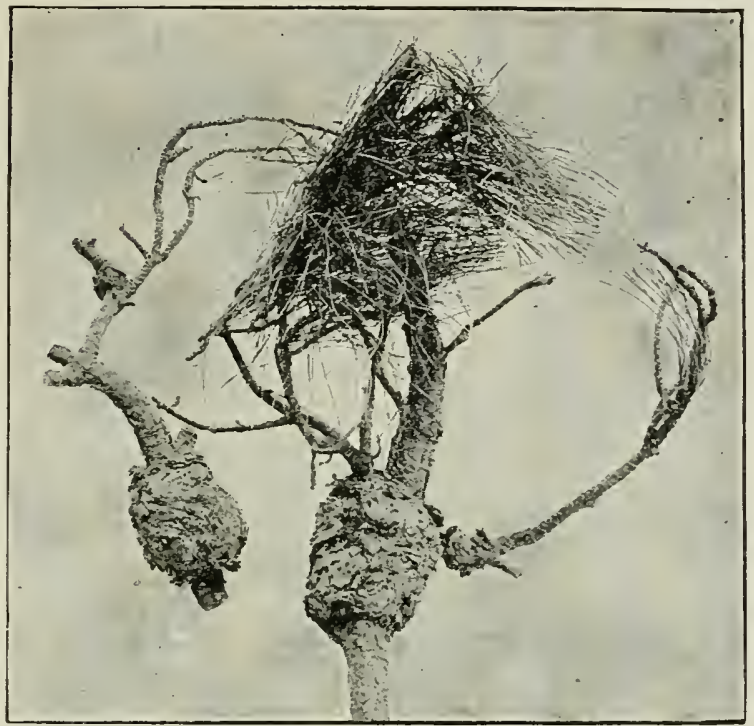

Fu: 249.-Pfidcrmium giganteum on Pinus Thunbergii from Japan. (₹. Tubeuf phot.-the specimen presented by Prof. Grasmann of Tokio.)

P. brevius Barel. On Pinus excelsa in India.

P. complanatum Barcl. On Pines longifolice in Intia: on rind as well as needles.

b. On the rind or bark:

Peridermium Cornui Rostr. et Kleb. (now Cronartium asclepiadenm, p. 3\&1). On Pinus syliestris.

P. strobi Kleb. (now Cronaitium ribinolu, p. 382). On Pinus Strolus, I. Lambertione, (and $P$. ('emlore).

P. pini(Willd.). On Pines syliestris. (Britain anıl U.S. America.)

P. orientale Cooke. On Pinus vigide and $P$. virginiane in America; also $P$. longifolice in India.
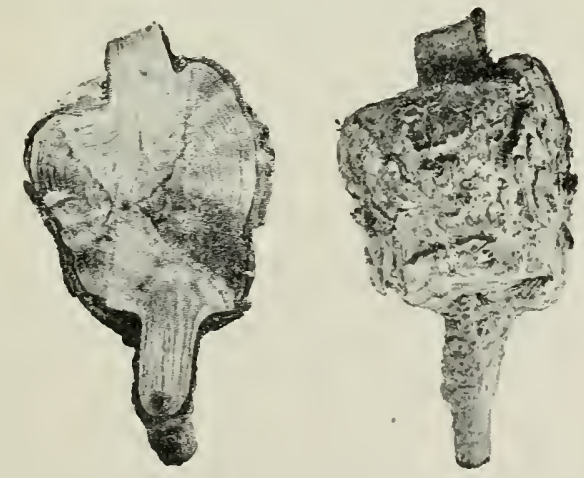

FIG. 250.-Pridermium gigantewn on Pinus densitora from Japan. (v. Tubeuf phot.) 
P. Ravenelii Thiin. On Pinus anstorlis in North America (proball! at variety of $I$ '. oblongisporium).

P. deformans Mavr. (n) Pimss mitis in Anerical.

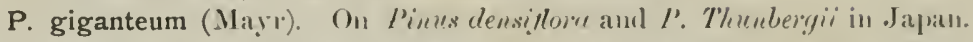
This canses rery comspicuons deformation of its lost (Figs 24!) and 2501).

P. complanatum Barel. On Pines longifulin in India.

The following species frequent other hosts:

Peridermium conorum 'Thim., 'This aecidium first found by De Bary in Thiiringia, has recently been repurted in Demmark,

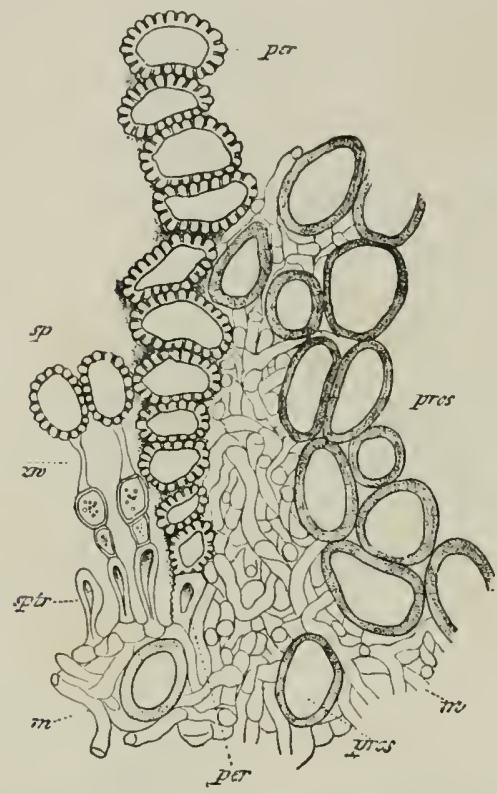

F16. 251.-Aceidium connom-picrec. per, Peridium; $s p$, spore; $z v$, intermediate eells; sple, sporophore; m, inycelium ; pion, prosenehyma. (After Reess.) Riussia, and America; also in Upper Bavaria by r. 'Tubeuf in September, 1895 . It takes the form of two large aecidia, which make their appearance on the outer or inner side of the cone-scales of spruce. The white periclia break through the epidermal tissues which then remain as a brownish sheath around each ruptured peridium (Fig. 251). The spores are separated by intermediate cells, and their outer coats are studded with polygonal writs. The cone-scales bearing aecidia contain a very large quantity of starch. Telentospores of the species are ıuknown.

Peridermium coruscans Fries. ${ }^{2}$ The mycelimm of this fungus seems to peremnate in twigs and buds of spruce. Twigs unfold from the bud as deformed, shortened, cone-like shoots bearing rery short broad needles of a pale colour. The aecidia are produced on the deformed needles as broad lineal cushions with white peridia. They originate under the epidermis which they rupture, and break out on one side of the needle.

${ }^{1}$ Reess, Rostpil: formen, 1869.

"Rostrup, Fidensk: Gelsk. Foihandl., 1S84. 
The soft hypertrophied shoots are eaten. They occur chiefly in Scandinavia, but recently were observed by Gobi and Tranzschel in the neighbourhood of St. Petersburg. ${ }^{1}$

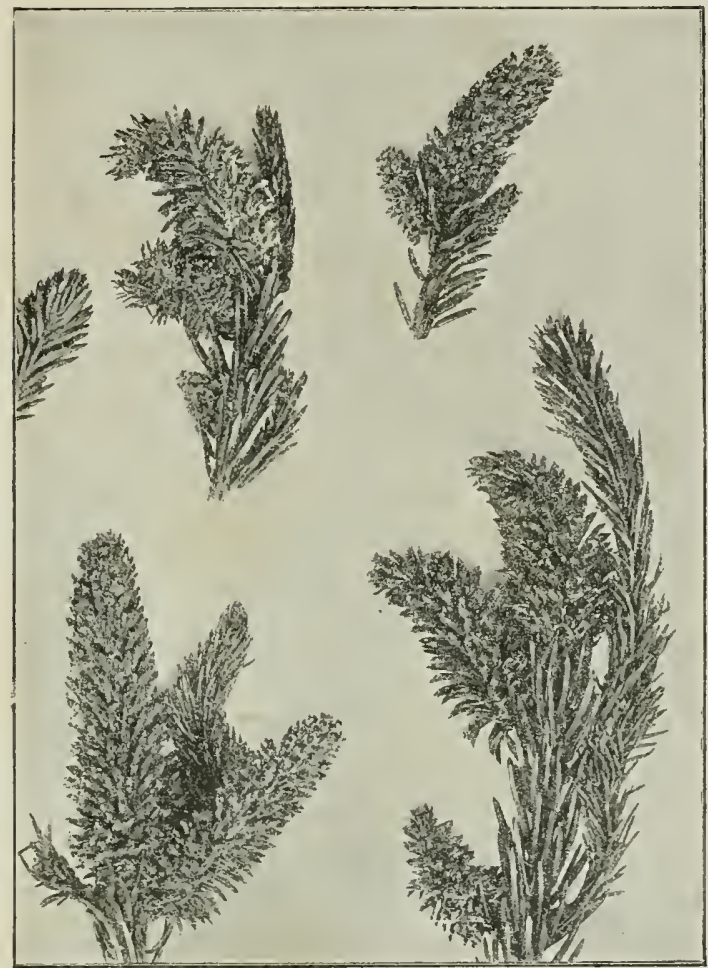

Fig. 252.-Accidium cor uscans on malformed shoots of Spruce. The compact abnormal shoots thickIy covered with white aecidia contrast strongly with the normal portions. (v. Tubeuf phot. from material presented by Prof. Fries, Upsala.)

P. Engelmanni Thiim. On cones of Picea Smithiuna. (U.S. America.)

P. piceae Barcl. On needles of Picen Smithiana.

P. Peckii Thüm. On needles of Tsuga canadensis (U.S. America).

P. balsameum Peck. On needles of Abies balsamea (U.S. America).

P. ephedrae Cooke. On Ephedira in U.S. America.

P. cedri Barcl. On needles of Cedrus Deodare in India.

P. Balansae Corn. On leaves of Dammara orata in New Caledonia.

${ }^{1}$ Also reported at Haslemere (Britain), Grevillea, xix., 1590. 


\section{Caeoma.}

Caeoma abietis-pectinatae lieess. ${ }^{1}$ The aecidiospores may

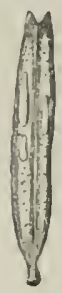

be fomm on the lower surfice of young needles of silver fir; the aecidia are yellow elongated enshions situated on either side of the needle nid-rib, and are withont peridia. Pycnidia (spermogonia) are prodnced before the aecidia. The mycelium is septate and intercellular with few haustoria. I have found the fungus fairly abundant

Fig. 253. - Celenoma whitis pretincilae. Needle of Silver Fir showing Crema-patches on the lower surface. ( $v$. Tubeuf del.) on the Alps and in the Danube valley near Passau. Telentospores are unknown.

Caeoma deformans (Berk, et Br.) Tubeuf (Uromyces deformuns Berk. et Br. ${ }^{2}$ or Cacomu Astunio , Shirai). ${ }^{3}$ This induces the formation of "witches' brooms" or of antler-like

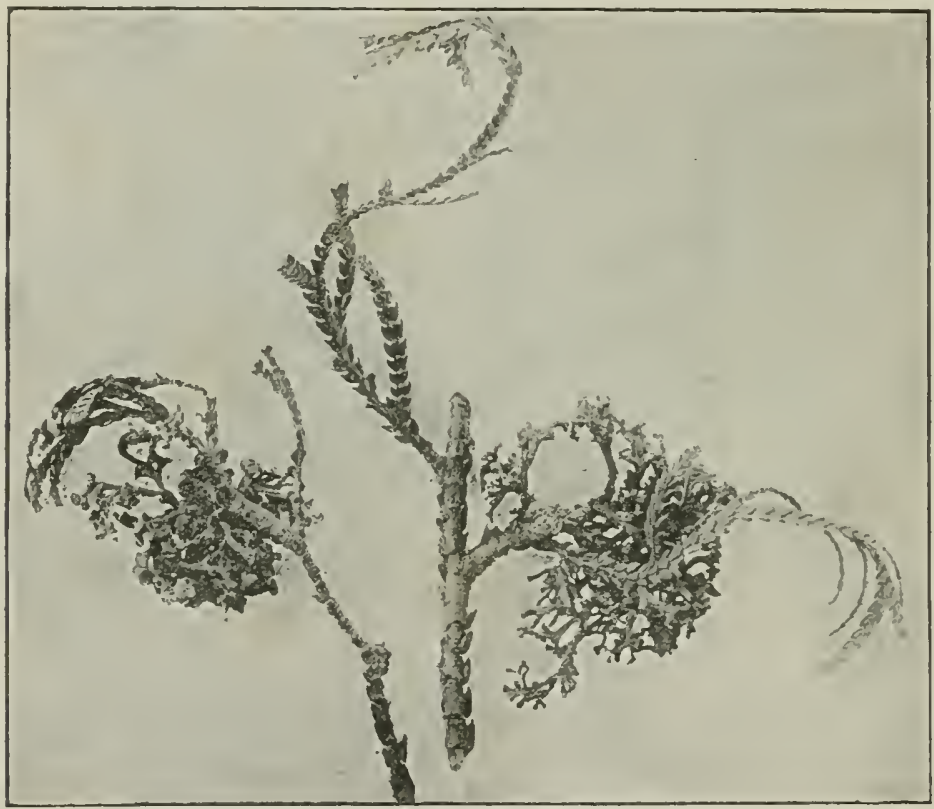

Fig. 254.-Ceroma de jomans on Thuiopsis dolabrata. (v. Tubeuf phot. from dried material presented by Prof. Grasmann of Tokio.)

${ }^{1}$ Reess, Rostpil formen, 1869.

${ }^{2}$ Berkeley, "The fungi collected during the expedition of H.M.S. "Challenger." Jour. of Linnean Sor., xvi., 1876.

3 Shirai, Botanical .Magazine, Tokio, 1 SS9. 
leatless shoots on Thrijopsis dolubitu in Japan, whence they were sent to me (Figs. 254 and 255). One example (not figured) was its large as a young child's head.

The shoots of the witches' brooms are furnished with vascular bundles and possess a parenchyma rich in starch-content. Each branch of the deformed shoot terminates in a hemispherical saucer-shaped cacoma-cushion, at first covered over by the epiclermis, but with no peridium. The cacoma-dises are at first brown, but after the epidermis bursts and rolls back, the yellow dusty spores appear. The spores arise serially from very short basidia; they are yellow and have striped membranes.

'The witches' brooms also exhibit marked

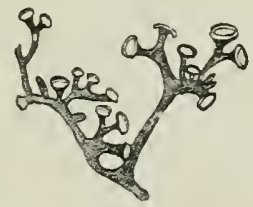

Fis. 255.-Caeoma deformans. Portion of the preceding figure enlarged to show the Caeoma-discs on the ends of twigs. ( 5 . Tubeuf del.)

hypertrophy (Fig. 254). In the supporting branch both wood and bark are considerably increased. Larce medullary-rays occur in the wood, and nests of thin-walled parenchyma are interpolated between the regular tracts of tracheae, so that the general arrangement resembles that shown in juniper by Wörnle's researches on Gymnosporangium. The parenchymatous groups of cells in the wool appear to the naked eye as brown spots. They are permeated by a vigorous intercellular mycelium, which sends off large haustoria into the adjacent cells.

Caeoma laricis (Westend). ${ }^{1}$ On needles of Larix. (Britain.)

C. orchidis A. et $\mathrm{S}$. On orchids. (Britain.)

C. chelidonii Magn. On Chelidonium majus (U.S. America).

C. fumariae Lk. On Corydalis.

C. euonymi (Gmel.). On Euonymus europaens (Britain).

C. confluens (Pers.). On Ribes alpinum, R. mbrum, etc.

C. nitens (C. luminatum) is the well-known Blackberry-1ust so common in the United States. It is probably a forn of Puccinin Pechiuna."

C. aegopodii (Pebent.). On Aegopodium Porlagraria and Chaerophyllum "romaticum.

C. ligustri (Rabh.). On Ligustrum vulgare.

C. ari-italici (Duby). On strum muculatum.

C. alliorum Link. On Allium ursinum, A. oleraceum, etc. ${ }^{3}$

C. saxifragae Strauss. On Saxifraga granulata. ${ }^{3}$

C. mercurialis (Mart). On Mereurialis perennis. ${ }^{3}$

${ }^{1}$ This and most of the other species are only stages of some Melampsora.

2Clinton, Botanical Gazette, 1895, p. 116.

${ }^{3}$ These three species are given as British in Plowright's 'Uredineae.

(Edit.) 


\section{Uredo-Forms of uncertain relationship.}

Uredo agrimoniae (1). (.). On species of Agrimonia (Britain and U.S. America). Dietel regards it as relaterl to Melumpsom (Thecosporu) agrimonice.

U. Muelleri schroet. On Rinliss fiuticosus (Britain).

U. symphyti D. C. On Symplyytum officiurle (Britain).

U. phillyreae Corke. On Plillyiea media (Britain).

U. macrosora 1)e Toni. On Epilobium tetrogrnum (U.S. Anerica).

U. vitis Thiim. This species first attracted notice ats a cliseasermoducing fungus in Jamaica in 18ig, but it had been fomm previonsly in the Uniterl States. It canses spots on the upper surface of leares.. ${ }^{1}$

U. fici Cact. On Frons Carice in Italy and U.S. Anerica.

U. quercus (Brousl.). (On species of Qinercus (Britain and l".s. America).

U. iridis. On many species of Iris (Britain).

U. glumarum Rob. On Zeu Wuis in Belgimn and England.

U. sorghi Fuck. On Sorghum latepense in Freece; (complare with Cromyces and Proccinice on the same host.)

U. gossypii Lager:" This has been observed in Sonth America causing a rust on cotton-plants and injuring the yield, of cotton. It appears as small purple-brown spots; the spores are oval and yellow.

\section{Uredinopsis. ${ }^{3}$}

[This is a new gemus found by Magnus to contain several Uredineae parasitic on Ferns. ${ }^{4}$ The aecidial stage is unknown. The uredospores are abjointed singly from the ends of sporogenous hyphae: they are unicellular and withont germ-pores. The uredospore-sori are enclosed in a pseudoperidium of elongated tubular cells. Unicellular teleutospores (?) are given off from sori similarly to the uredospores. Pluricellular teleutospores are developer from the mycelium in the intercellular spaces of the host-plant, never from crust-like sori. On germination four-celled promycelia with spherical sporidia are produced.

Uredinopsis filicina (Niessl.) Magn. On lower surface of fronds of Plegopteris (Polypodium) iulgaris, cansing death.

Ur. struthiopteridis Stoermer. On sterile fronds of Stmethiopteris germanica.

Ur. pteridis Diet. et Holw. On Pteris aquilina.] (Edit.)

1 Massee (Grevillea xir., p. 119) states this species to lie identical with $U$. Vialce of Lagerhein (Revue gen. de Botanique, 1590).

"Lagerheim, Journal of Mycoloyy, vir. p. 48.

"Dietel, "Uredo polypodii (Pers.)" Oestervich. hotun. Zcitsrhrift, 1S94; also "Der Gattung Uredinopsis," Ber. d. deutseh. botan. Ges., 159.5, p. 326.

+These host-plants do not come strictly within the scope of this work, but a short unte on the genus is necessary. (Edit.) 


\section{BASIDIOMYCETES.}

The sporophores, known as basidia, are structures with a lefinite shape, and with lateral branches, the sterigmata, from which a definite number of exospores-basidiospores-are abjointed, the basidia then becoming functionless. Basidia and basidiospores are characteristic of all Basidiomycetes, conidia and chlamydospores being prodnced only exceptionally.

The basidia generally arise from an extended layer-the hymenimm-which in the higher genera forms part of a conspicuous complex sporophore. The basidia do not therefore originate from the germination of a spore, as do the promycelia of the Uredineae and Ustilagineae, but from special sporophores (rarely from the mycelinm itself), whose surface they occupy, or in which they are enclosed.

In the course of development, two nuclei have been found to copulate in the basidial cells. Thereafter they divide and produce four (rarely two) new nuclei (Antobasidionycetes), or after the division of nuclei, cross-septa are formed, thus making the basidia plmicellular (Protobasidiomycetes). In both eases the nucleus passes through the sterigmata into the developing basidiospores, and on the gẹmination of these spores, it divides into two mnclei, the starting points for further muclear division.

As just indicated two divisions of the group may be distinguished: (1) Protobasidionycetes, (2) Autobasidionycetes.

Protobasidiomycetes.

Under this class are inchuded the Auricularicue, Pilacreue, and Tremellinac, the first two possessing basidia divided, as a rule, by cross-septa into four cells, the last with basidia also divided into four cells, which are formed, however, by two longitudinal walls set at right angles to each other. A sterigma grows ont from each cell and prodnces a single spore, after which the basidinm dies away. The basidia of the Pilacrene are produced inside closed sporocarps (angiocarpous), those of the other two groups are exposed (gymnocarpous). Parasites are mnknown amongst the Protobasidiomycetes.

\section{AvtoBasidionycetes.}

Pasidia unicellular (autobasidia), the sterigmata formed on the apex of the basidim, and each giving off a single basilio- 
spore. The hasidia originate from basidial layers or from complex hymenia, produced either inside some special structure, or on the surface of special sporophores, or on some lefinite part of these.

The group may be sub-divited into the Decryomyertes, Hymenumycetes, and Castermmyectes (including P'halloitleae). Of these only the Hymenomyertes contain species parasitic on plants, the others include harmless saprophytes, which live in the soil, some of them, however, taking part in the formation of mycorhiza.

\section{THE HYMENOMYCETES.}

The unicellular basidia give off from their apices four (any number from 2 to 6 may occur) sterigmata, from each of which a single basidiospore is abjointed. The basiclia arise from free exposed liymenia, which gencrally occupy the whole or part of large compound sporophores. The greatest develop'ment of the sporophore is attained in the umbrellas of the Agaricinace, and the large dises of the Polyporece. It is only amongst the lowest genera, like Erobusidtinm, that the basidial layers are produced directly on the organs of the host, and the basidia arise directly from the hyphac.

Reproductive cells, other than basidiospores, are rare. In a few cases amongst the Pulyporecer, Brefeld and others have observed conidia and chlamydospores (Oidtict, etc.); while some few Agaricinas have the latter form of spore, but never conidia.

The mycelium is of a very varied nature. It frequently inhabits wood, and in many different ways brings about destruction of lignified tissues. Other modifications are seen in the forms of nycelium known as rhizomorphs, rhizoctonia, mycorhiza, and other closely felted masses of rarious shapes, which will be considered in detail as occasion requires. The formation of clamp-comnections is also a special feature of the myceliun of the Hymenonycetes. In many cases the mycelium retains its vitality and peremnates for several years.

The genus Eimolusidium consists of parasites which produce malformation of their host; many of the Polyporcac and Agarisinere are deadly enemies of forest and fruit-garden, while as wound-parasites many of them are specially dangerons. The general means of combating them consist in cutting out 
any sporophores and applying tar to the wound, while diseased stems in the forest should be felled. Immediate artificial closure of wounds in the wood is a very effective preventive measure. ${ }^{1}$

The Hymenomycetes are divided into Tommtellece, Exolasidiacear, Hypochnaceae (included by Brefeld in the Tomentelleae), Thelephorece, Clavarioce, Hydnece, Polyporece, and Agaricinoue. All contain parasitic species.

\section{EXOBASIDIACEAE.}

\section{Exobasidium.}

The basidia are formed on the extremities of branches of the mycelium, which break ont through the cuticle of attacked organs. The mycelium lives inside the host-plant, and induces considerable malformation. The basidia emerge on the surface of the host (similarly to the asci of the Eroasci), and from each of the four sterigmata a single spore is given off.

Exobasidium vaccinii Wor. ${ }^{2}$ (Britain and L.S. Anerica). This is the cause of a very common and conspicuous deformation which affects the leaves, flowers, and shoots of Vaccinium VitisIdacu (Figs. 256). Leaves, where affected, become thickened and form irregular blisters vaulted towards the lower surface of the leaf, so that the lower epiclermis covers the convex side and the upper epidermis lines the concavity. Chlorophyll is absent in the swollen tissues, but where blisters are exposed to direct light a bright red cell-sap is developed. Parts of the leaf adjoining diseased spots may remain normal and green. Flowers or their parts undergo similar malformation: twigs become more or less thickened and twisted, their chlorophyll disappears, and a reddish cell-sap is produced. On sucli diseased places spores are produced during the summer, after which the poorly developed tissues dry up and wither.

When this fungus is present in the young tissues of its hosts, it exerts a very marked influence on their development. The palisade cells of the leaf become enlarged, while their chlorophyll almost wholly disappears, and is replaced by a red

\footnotetext{
${ }^{1}$ Further rletails on this point have alrearly been given, General part, p. T2.

${ }^{2}$ Woronin, Verhant. I. naturfor. Ges., Freiburg, 1867; with 3 plates, Brefeld, Schimmelpile, viI., 18s9. Wakker, Pringsheim's Jahrbuch, 1892.
} 
cell-sap. Cells of the parenchyma in flower and stem enlarge to a still greater degree. Intercellular spaces are as a rule obliterated, but when present are filled with a fine mycelinm. Wakker gives us further results of the fungoid attack; crystal-glands, nornally numerous, are 110 longer formed, but are replaced to some extent by indistinetly defined crystals of calcimn oxalate. Transitory stirrch is stored up in large quantity. The fibro-vaseular bundles

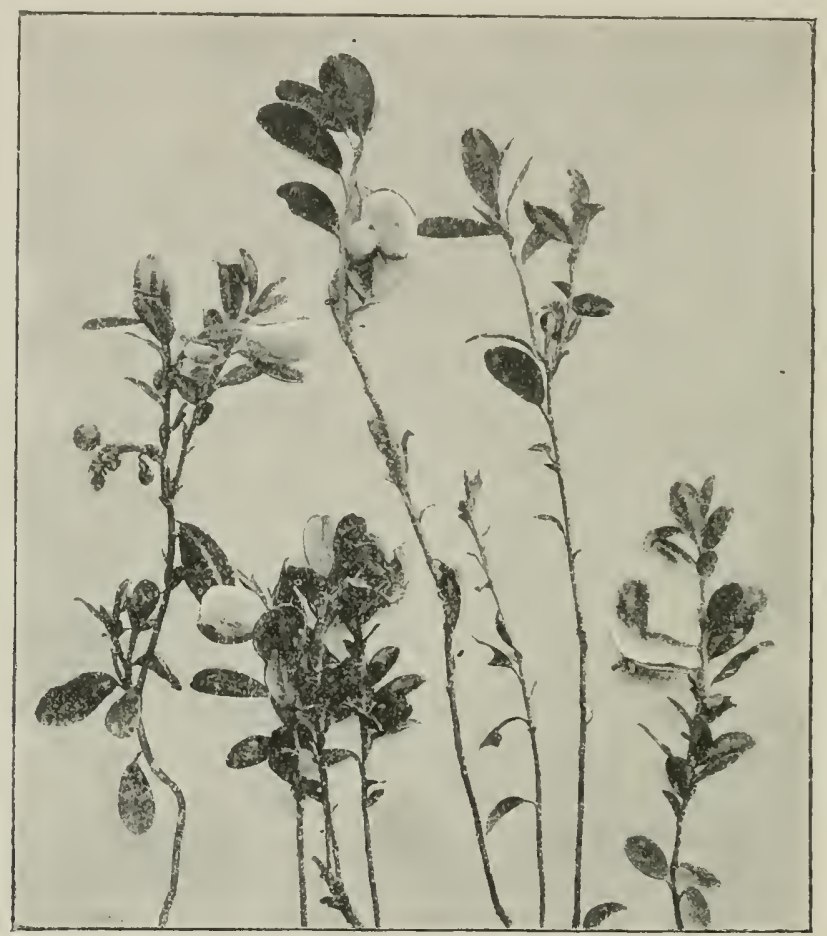

F1G. 256.--Exolasidium vaccinii inducing outgrowths on leaves of Vaccinium Vitis-Idaca. (v. Tubeuf phot.)

present a striking modification, the primary xylem alone is normal, the vessels of the secondary wood remaining rudimentary; other parts are not lignified, and the phloem is only indistinetly laid down.

A mycelium is present in all deformed parts, but absent in normal green tissue. It becomes massed to form a hymenial layer beneath the epidermal cells or between their onter walls and the cuticle. The sterigmata do not exceed four in number, and 
from each a spindle-shaped spore is abjointed (Fig. 257). The hasidiospores divide in water by formation of cross-septa, and a germ-tube arises from each terminal cell. On a young leaf of Vaccinium the gern-tube penetrates and gives rise to a mycelium (Fig. 2258): on other substrata the grem-tube sprouts into several very fine sterigmata, from the extremities of which a series of conidia are abjointed; the coniclia may give off secondary conidia, perhaps also tertiary. In nutritive solution, Brefeld obtained an increased number of germ-tubes and a continuous production of conidia; in air,

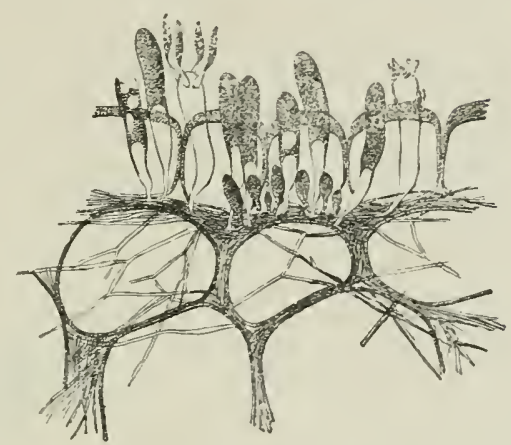

Fig. 257.-Exolsasidiun veccinii. The basidial lajer is shown developing from the intercellular mycelium of the shoots. (After Woronin.) conidia were produced on coniclia, but inside the solution the conidia gave off hyphae from which new conidia arose.

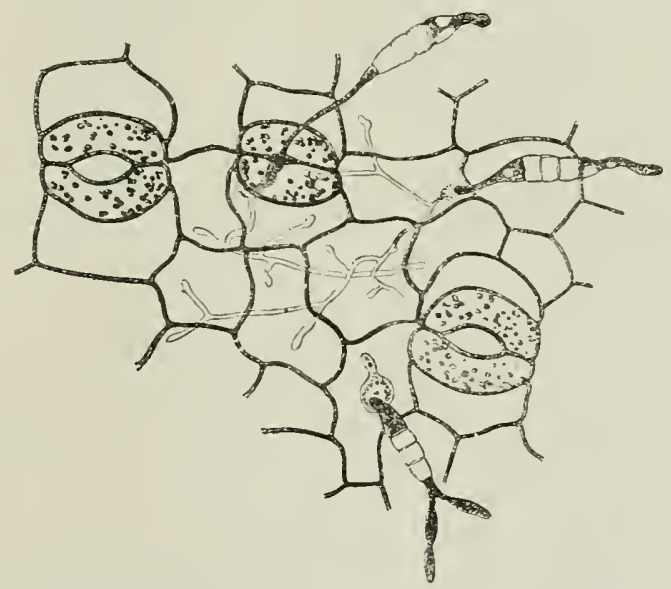

FI(. 258.-Erobasidiun vaccinii, Germinating basidiospores. The septate spores have given off germ-tubes which penetrate into the cowberry leaves, either by stomata or through the epidermis. The lowest spore is forming conidia. (After
Woronin.)

This Exobasidium is very common on the cowberry (Vaccinium Vitis-Idcue $)^{1} \quad$ It occurs less frequently on the bilberry (Vac-

"Several American Ericaceae are given as host-plants in the "Ilost-Index." 
rimim M!frtillus) ${ }^{1}$ eausing a premature fall of the leaf and suppression of the flower. The external symptoms of the discase differ somewhat from those on cowberry. I) iseased leaves arm much larger than the normal, but are neither thickenerl nor blistered: on the under side they hare a whitish or reddish coating, and fall off easily. I have never observed the disease on the stems of bilberry. In spite of these external differences. it is believed that the host-plants are in both eases attacked lyy the same species of Erobasidium, but I do not know of any observations on the reciproeal infection of the two hosts.

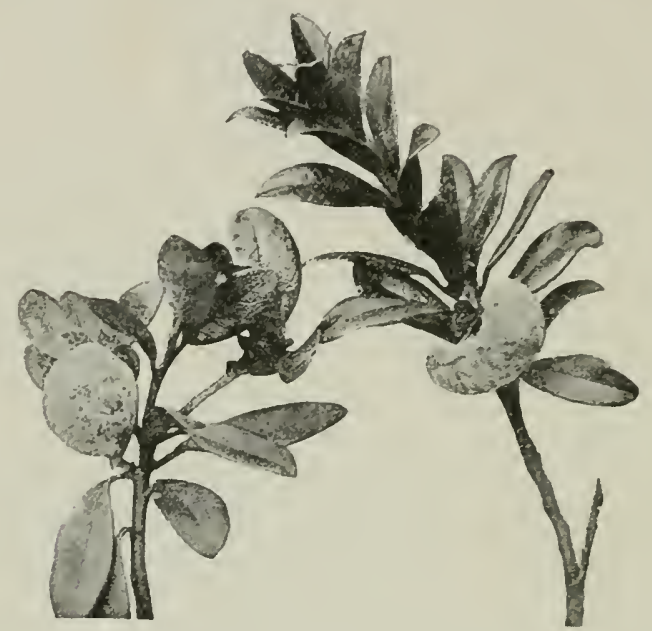

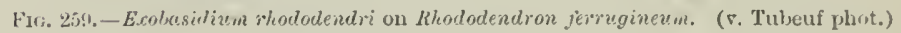

A disease due to an Erobusidium is ly no means uncommon on Vuccinium uliginosum (bog whortleberry). ${ }^{2}$ Shoots of diseased plants are deformed, while their leaves become more or less thickened and assume a beautiful rosy colour.

On Trecinium Orycoccos (true cramberry) the shoots and leatlets also become thickened and rose-colomred. Rostrup distinguishes this as a separate species (Erobusidium arycocci).

Ex. andromedae P'eck. produces on Andromeda polifotin syuntoms similar to those just described for the preceding species. (Britain and U.S. America.)

2Sadebeck (Botan. Centralblat, 1S56) records it in large quantity near Harburg. This is the host-species given by Massee (British Funym-Flora, IS9:2).

"Tubeuf, "Mitheiluugen." Zeitsch. f. Pflanzenhrankheiten, 1s93. 
Ex. rhododendri Cram. (Britain and U.S. America). This canses gall-like outgrowths on the leaves of the Alpine-rose (Rhododendron ferpugineum and Rh. hirsutum). The swellings may be small and fairly hard, or, attaining the size of cherries or plums, they may be soft and spongy so that they shrivel up soon after the twig is cut; in colour they are yellowishwhite, but on the side exposed to sunlight become rose-red; the Erobasidium-galls may even be formed on the small rollectup leaves cansed by attacks of nites.

Ex. Peckii Hals. ${ }^{1}$ [This species occurs in the flowers of Andromede Merience in the United States. It is confined almost entirely to the infloreseences, and causes considerable distortion. The hell-shaperl corollas are replaced liy ones quite polypetalous, and the ovary becomes raised above the receptacle.] (E.lit.)

The following five species have been recorded on Ericaceae in America :

Ex. azaleae Peck. On Rihododendion mediftorm.

Ex. discoideum Ellis. On Rhodortendron riscostm.

Ex. decolorans Hark. On Rhododendion viscosum and R. occidentule.

Ex. arctostaphyli Hark. On lretostaphylos pungens.

Ex. cassandrae Peck. On Crrssundre culyculutu.

Other species to be mentioned are:

Exobasidium ledi Karst. On Ledum prolustre.

Ex. Warmingii Rostr. (U.S. America). This occurs on S'rxifragu lizoon, S. bryoirles, S. asperc, etc: ; it canses marked hypertrophy of the leaves, and in this way, as well as by its many smaller spores, is distinguished from:

Ex. Schinzianum Magn. On the leaves of Suxifmenn rotundifotia, cansing whitish spots which soon become brown and die.

Ex. symploci Ellis. On Symplocus tivertorice in North America.

Ex. graminicolum Bres. Un leares of various grasses, e.g. Bromus, Arhenatherum, etc.

Ex. lauri Geyl. ${ }^{2}$ is said to produce branched ontgrowths of orer three feet in length on Laurus nobilis and L. coneriensis in the Canary Islands.

Crubusidiun rostratum Ghgn. occurs on the "witches' broom," ontgrowths caused by Taphina cormu-cerri Ghgn. on Aspidtum aristutum in India.

\footnotetext{
${ }^{1}$ Halsted, Bulletin of the Torvey Clul, xx., 1593, p. 437.

-Geyler, Botun. Zeitung, 15it, p. 32:2, Pl. VII.
} 


\section{HYPNOCHACEAE.}

\section{Hypnochus.}

The mycelium forms a cobwch-like covering on living or dead parts of plants. The sporophores take the form of superticial coatings composed of club-shitped basidia developed on at felted hymenial layer of fungal tissne. Each basidium gives off two to six colourless smooth-conted spores from fine sterigmata. rome species are parasitic, and canse disease.

Hypnochus cucumeris Frk. ${ }^{1}$ In 1882 Frank found at Berlin, on the surface of withering and dying cuemuber-plants, greyish contings of the hymenial layers of this fungus. They occurred principally near the base of the stem, and cansed its partial destruction. The symptoms consisted in leaves becoming rapidly rellow from tip to base, and dying off the plant, the lower first. Only cucumbers were attacked, and no further stages could be observed on the killed plants.

Hyp. solani Prill. et Del. ${ }^{2}$ Fine grey crusts, consisting of the hymenial lavers of this fungus, were found by these investigators on potato-plants; there was, however, no injurious effect on the crop-yield.

\section{Aureobasidium.}

Aureobasidium vitis Viala et Boyer. ${ }^{3}$ The cause of a vine disease which has done considerable damage in southern France on several occasions since 1882 . The grapes when attacked show spots, then shrivel up, their interior becoming completely permeated by a colonrless septate and branched mycelium. On rupture of the epidermis, a firm yellow tissue emerges, and thereon a hymenial layer is developed. The basidia are thick and club-shaped, with a varying number of short sterigmata: these give off cylindrical micellular light-yellow spores slightly curved in shape and with rounded ends. Leaves are also attacked, and fall off after gradually assuming a deep red colour. If this occurs in April, or early in May, the fruit nerer attains any size.

${ }^{1}$ Frank, Herlwigia, 1883: and Berichte d. dentsrh. botan. Grs., 185:3.

${ }^{2}$ Prillieux and Delacroix, Bulletin de la Soc. mycol. de France, 1891.

${ }^{3}$ Viala and Boyer, Compt. rend. 1591, p. 1148, and xix., 1594, p. 245; Annal. de l'Ecole nat. d'agric. de ITontpellier, vi., 1891. 


\section{THELEPHOREAE.}

\section{Thelephora.}

The sporophores of this genus assume very varied forms, from simple incrustations to mushroom-like structures. They consist of two layers only, the middle one being absent. The basidia are club-shaped and produce four roundish or oval, hyaline or light-coloured spores.

Thelephora laciniata Pers. is not a true parasite, yet it is a dangerous enough enemy to trees. In damp situations, it is common and thrives, growing over young trees and so ellveloping them with its sporophores that suffocation ensues. (Britain and U.S. America.)

Th. pedicellata Schw. has been reported from dmerica ${ }^{1}$ as a dangerous parasite on apple, (pueicus coccinert, and a palm.

Th. perdix Hartig, a parasite on oak-wood. (See Stereum firustulosuin.)

Helicobasidium Mompa. Ichik. ${ }^{2}$ This is injurious to the mulberry tree near Tokro, Japan. It first attacks the roots, and in consequence the rrowth of shoots is arrested, the young leaves die off, and gradually death of the tree follows. The mycelium permeates the tissues of the host, and forms an external velvety coating of basidia.

\section{Stereum.}

Sporophores generally differentiated into three layers, and forming leathery or woody encrustations, or flattened hemispherical structures attached by one edge only.

Stereum hirsutum (IV.) Fr. White-piped or yellow-piped oak. (Britain and U.S. America.) A very common fungus, occurring as a saprophyte on dead branches, on boards, and posts of various kinds of timber, as well as parasitic on living wood, particularly on oak.

The sporophores first appear as crusts, later they become cup-shaped; exterually they are brown and roughly hairy with acute yellowish margins. The smooth hymenial layer is orangered and marked by zones. Between the sterile leathery sporophore and the hymenial layer there lies a firm white intermediate tissue.

1 Galloway, Journal of Mycoloyy, vı., p. 113.

2Nobnjiro Ichikawa, "A new hymenomycetous fungus," Jour. of College of Science. Imperial University, Japan, 1890. 
R. Hartig ${ }^{1}$ has investignted in detail the phenomena accompanying the wood-rlestruction in the oak. This begins in the branches and extends in white or yellow concentric zones throughout the stem, so producing that appearance which has given rise to the name "fly-wool." I'ortions of the wood appear only white-striped, other parts have a more regular yellowishwhite colour. In the white strips the wood has been transformed into cellulose and the middle lamelline of the walls dissolved out; that of the yellow parts has not undergone this transformation into eellulose, but the destruction has begun from the cell-cavity.

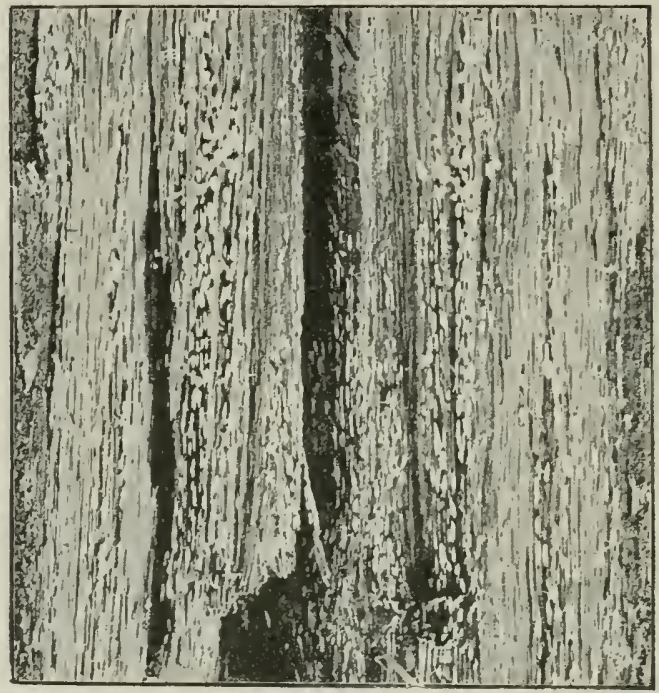

F1s. 260. - Stereun Trustulosum. Iestruction of ()ak-woor. Longitudinal section showing the brown wood with isolated hollow spots containing white ingcelium. (v. Tubeuf plot.)

Stereum frustulosum Fries. (Thelephora perdix Hartig)." (Britain and U.S. America.) The sporophores form greyishbrown plate-like crusts with concentric markings; they are small, never exceeding the size of a finger-nail, but generally occur in numbers together. The hymenial layer is composed of clubshaped basidia beset with hair-like outgrowths; some of the basidia produce four spores, others are sterile and grow on to form the hymenial layer for the followiug year.

${ }^{1}$ R. Hartig, Zersetzungserscheinunyen d. Holzes, 1s7s, Plate XVIII.

2R. Hartig, Zersetzungserscheinunyen, Plate XIII. 
The very charaeteristic destruetion of oak-wood eaused by this fungus was investigated by R. Hartig. The diseased wood has a miform dark-brown colour, broken at intervals by white rounderl spots or hollow eavities: hence it reeeives the name of "partridge-wood." In the white spots the wood has by the aetion of the myeelium become transformed into cellulose, the middle lamellae and starch-grains being dissolved ont. In the neighbourhood of old eaten-out cavities the process of deeomposition is slightly ehanged, so that the eellwalls disappear without previous transformation into cellulose.

\section{CLAVARIEAE.}

\section{Typhula.}

sporophores filamentous, and, as a rule, developed from sclerotia. Basidia, with four colourless smoothcoated spores.

Typhula graminum Karst. ${ }^{1}$ 'This appeared on wheat plants in Sweden, killing them and forming yellow sclerotia (Sclerotium fulium $\mathrm{Fr}_{\mathrm{r}}$.).

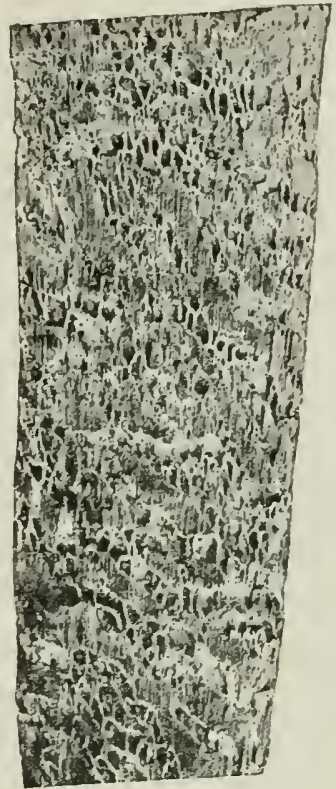

Fici. 201. - Stercuin finstulosum. Later stages of Oak-wood destruction. Longitudinal section showing holes in the timber. (v. Tubeuf phot.)

\section{HYDNEAE.}

\section{Hydnum.}

Sporophores very variable in form and strueture. The hymenial layers are spread over teeth-like projections. The hasidia bear four white spores.

Hydnum diversidens Fr. ${ }^{2}$ (Britain). The sporophores form yellowish-white erusts or brackets, with spiny outgrowths on the lower side. The hymenial layer eonsists at first of basidia only, later, however, hyphae grow up through it and build

${ }^{1}$ Eriksson, Landtbr. Alad. Hand. r. Tid.k\%\%, 15,9.

2R. Hartig, Zersetzungserscheinumgen. 
over it a new hymenimm; this is continued for some time so that the sporophore consists of successive layers, and the spiny outgrowths become much thickened. Infection, as was experimentally shown by Hartig, takes place on wounds.

The woor-destruction, consisting of a white-rot, was sturlierl by Hartig, chiefly on the oak and beech. It begins by the

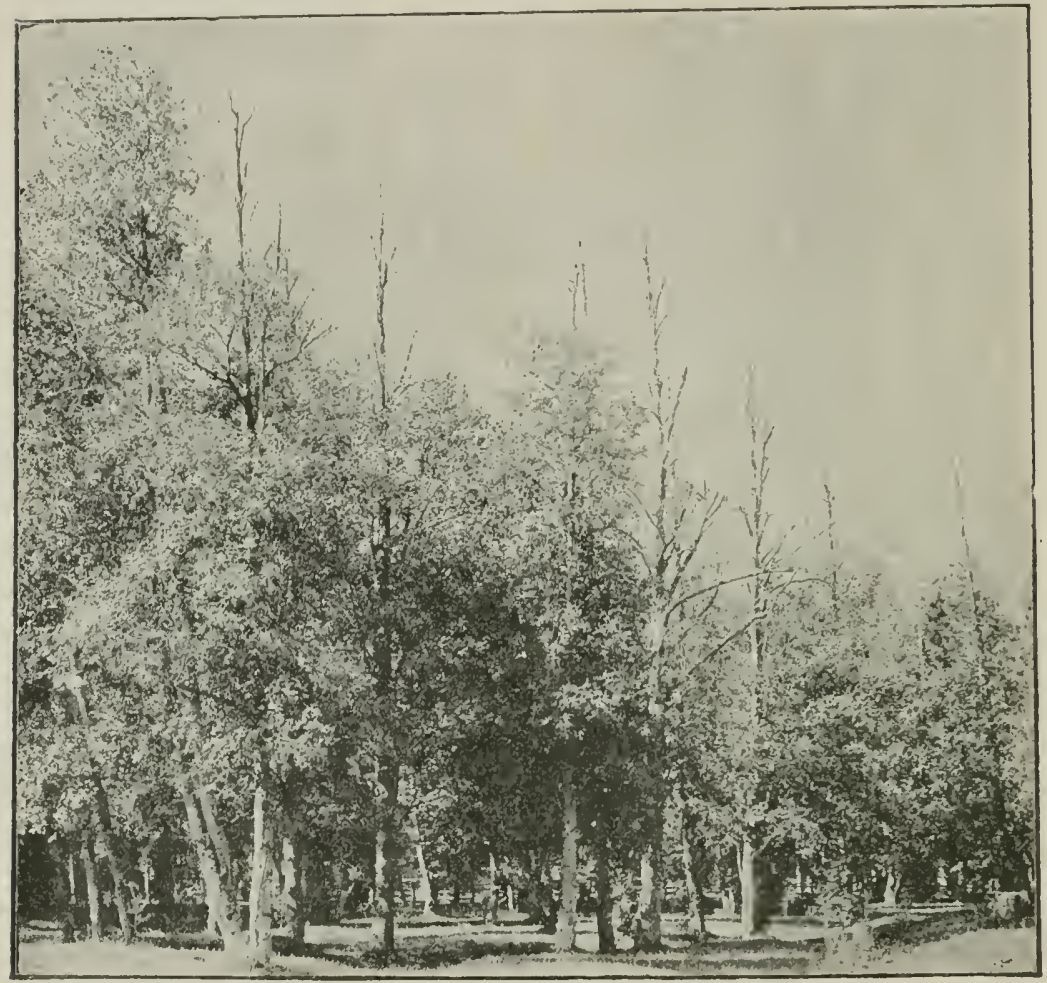

F'1G, 262.-Polyporus igniarius. Causing death of : White Alder plantation at Petneu, Stanzer Thal, Tyrol. The stems bear sporophores, and die from above downwards. (v. Tubeuf phot.)

appearance of yellowish longituclinal bands (not white as with Stermm hirsutum), and extends gradually till the wood becomes uniformly yellow. The mycelium causes the inner layers of the cell-walls to swell gelatinonsly without previous transformation into cellulose, and finally to dissolve out leaving the middle lamellae longest intact. 
Hydnum Schiedermayeri Heufl. (U.S. America). Sporophores fleshy, with a sulphur-yellow colour both ontside and inside, and with a smell of anise. They occur on living apple-trees, less frequently on other species of Pyrus. According to Schroeter, Thiimen, and Luclwig, the mycelium spreads throngh the stems and kills the trees.

Thiimen ${ }^{1}$ thus describes the diseased wood of the apple: "It has a greenish-yellow colour, which passes over gradually to the normal colour of the wood: it becomes soft and friable, smelling, like the sporophore, faintly of anise."

Sistotrema fusco-violaceum Schrad. (Britain.) This according to Skiljakow ${ }^{2}$ is parasitic on living pines, entering by wounds, and carrying destruction throughont the wood.

\section{POLYPOREAE.}

\section{Polyporus.}

Sporophores large and usually shaped more or less like a hoof or small bracket. The sporogenous layer is composed of cylindrical tubes, which generally occupy the

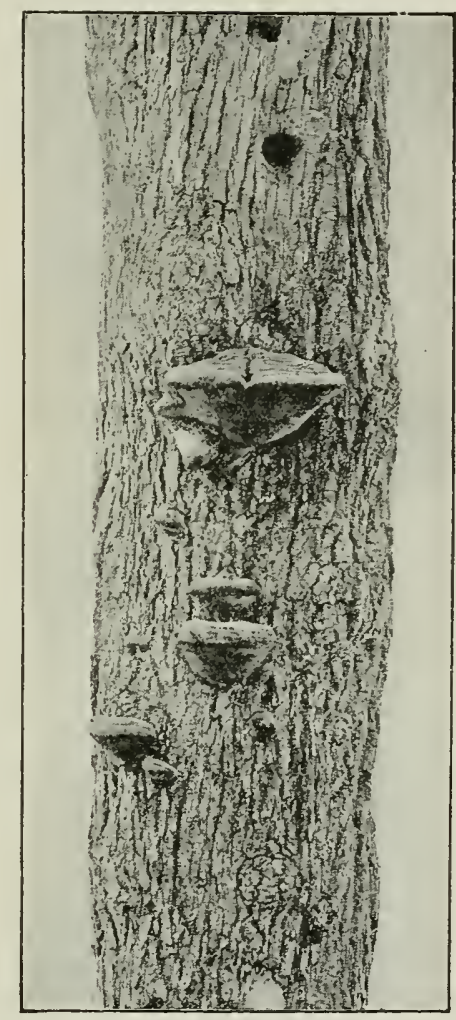

Fig. 263.-Polyporus igniarius on Uak. At the upper end a wood-pecker's nest-hole. (v. Tubeuf phot.) lower surface of the sporophore. The substance between the tubes is different from that of the rest of the sporophore.

Polyporus (Fomes) igniarius (L.). ${ }^{3}$ (Britain and U.S. America). Sporophores on living stems of oak, alder, apple, willow, and other

${ }^{1}$ Thumen, "Ein Apfelbaum-Schälling." Zeitsch. f. Pflanzenkrankheiten, 1891.

"Skiljakow, Scripta botan. horti universitatis Petropolitanae, 1890.

${ }^{3} \mathrm{P}$. Hartig, Zersetzungserscheinungen, Pl. XV. and XVI. 
deciduous trees. ${ }^{1}$ They are brown or grey in colour, tuluer-like or hoof-shaped, and eontinue to grow for several years; the upper

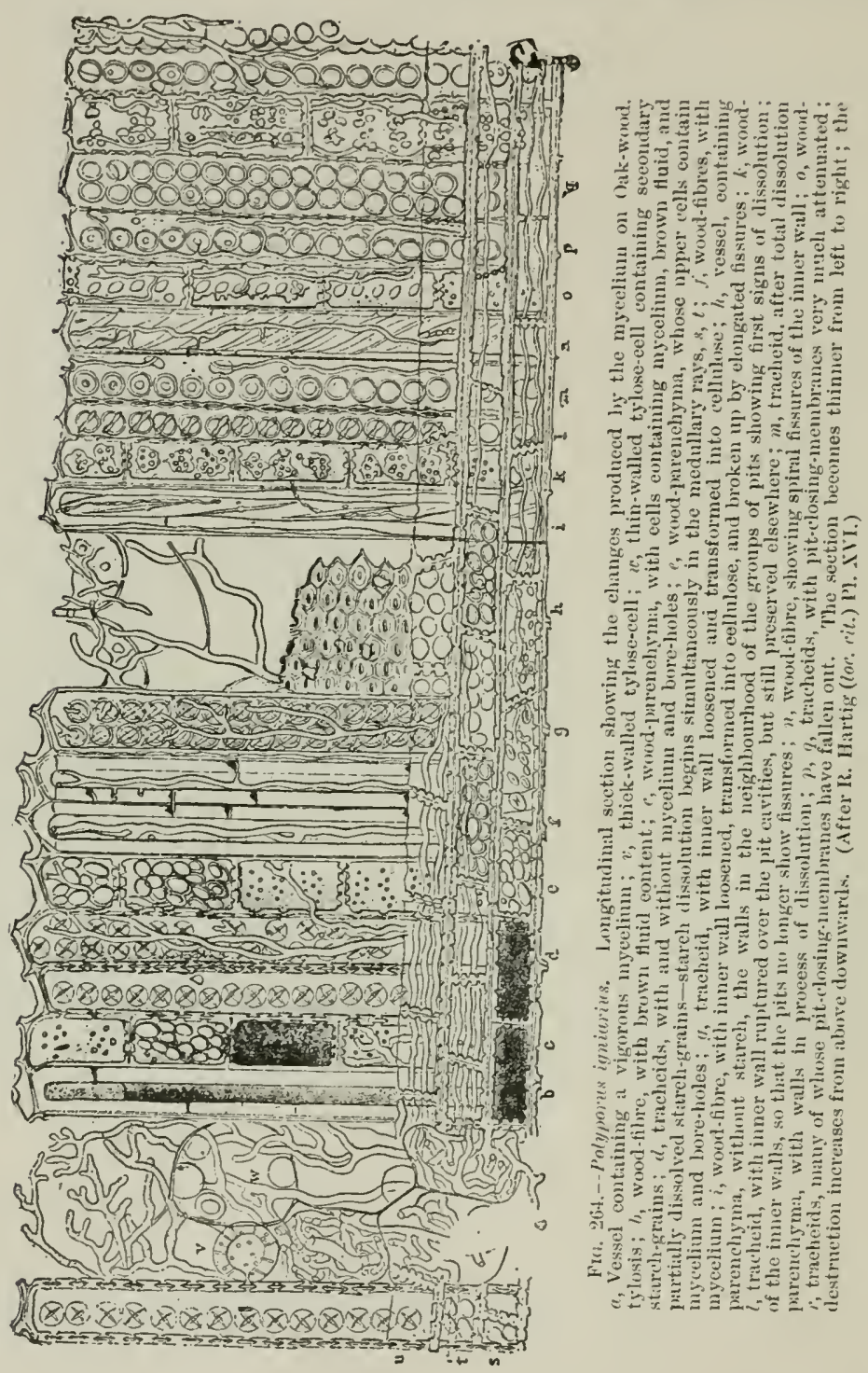

v. Tubeuf (Forstl.-naturmis.s. Zeitschrift, 1993) describes a plantation of Alnu incana in Tyrol, which was being killed out by this fungus (Fig. 26:2). It is a common British species. (Elit.) 
side is concentrically marked, and has a stone-hard coating which is generally more or less cracked; several zones and layers of tubes will be found when the sporophore is cut in section.

This fungus produces a white-rot in the wood, and is one of the most common and dangerous of wound-parasites. The wood attacked by the mycelium is at first dark in colour, then yellowish-white and soft. According to Hartig, a delicate mycelium fills up the elements and eats away the inner layers of the walls; then the middle lamellae are transformed into cellulose and absorbed by it (Fig. 264).

Polyporus fomentarius (L.) (Fomes fomenterives (L.) Fr.) ${ }^{1}$ (Britain and U.S. America). "Tinder-fungus." Sporophores broad and shaped like reversed brackets or hoofs. Their upper side, at first brownish and velvety, becomes afterwards smooth, grey, and marked with broad concentric zones. The margin is rounded and uniformly grey. The pore-layer is smooth and greyish-brown. A longitudinal section shows a homogenous tinder-like mass, covered on its lower surface by layers or zones of pores.

The tinder-fungus is parasitic on beech, elm, and mountain maple. It is particularly common in beech-forests, and was even more so at one time when the infected trees were allowed to remain standing. The sporophores may be found on living stems, on remnants of trees broken by wind, and on felled trees. For some distance above and below the seat of the sporophore runs a furrow on the stem, marking a tract where the mycelium has penetrated to the cambium and killed it, so that growth in thickness ceases (Fig. 266, a).

The mycelium causes in the wood a white-rot of a light yellow colour. Where the wood is still firm, though diseased, it will be found to be divided into cubical portions by white tracts of mycelinm which run both radially and vertically. A very characteristic feature of the destruction consists of broad white leathery bands of mycelium, formed in a radial direction through the wood; these are best seen on stems shattered by storm, or on wrought timber.?

\footnotetext{
${ }^{1}$ Rostrup, Tidsskrift pa Skorburg, 18s3. Tubeuf, "Mittheilungen," Alleg. Forst., u. Jagd-Zeitung, 188\%. A common British species. (Edit.)

${ }^{2}$ Krull (Schles. Ges. f. raterland. Kult., 1593) distinguishes a gelatinous mycelium and a cushion-nycelium.
} 
Tinder, prepared from the soft central part of the thick sporophores, was at one time used, with the help of steel and flint, for procuring Hame. It is very effective in stopping

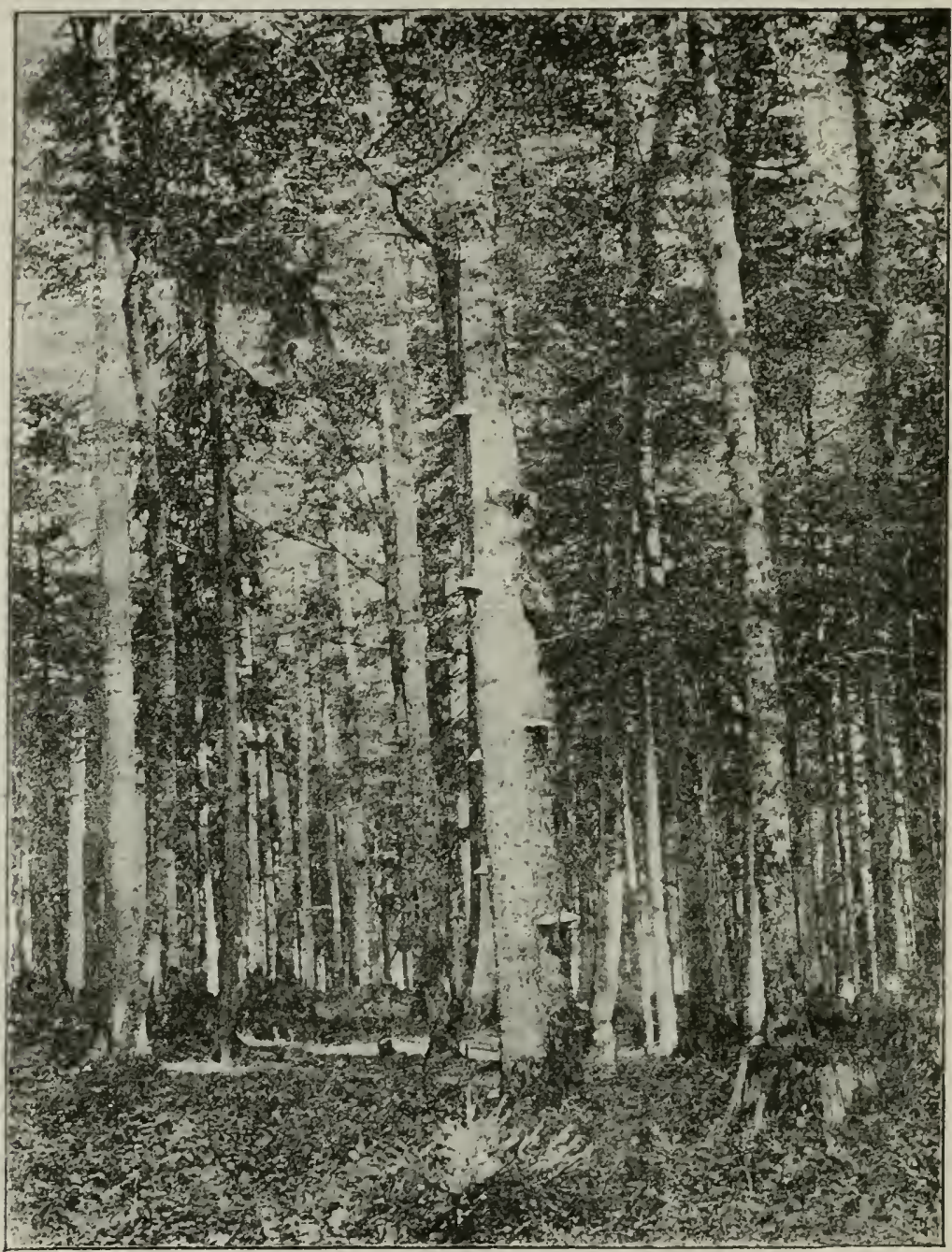

F10. 265.--Scene in the Bavarian forest near Bíschoffsreut. In the foreground, a living Beech with seven sporophores of Polyporus fomentarius. (

haemorrhage from cut blood-vessels, and is still used in surgery. The larger pieces can be manufactured into caps, gloves, vests, 
and hose. The privilege of collecting the tinder-fungi was rented out and regarded as a source of forest-revenue, while the tinder-industry was formerly an important one in many districts, where sporophores were more frequent and larger than now.

Measures against this fungus have already been considered in our General Part (\$ 12).

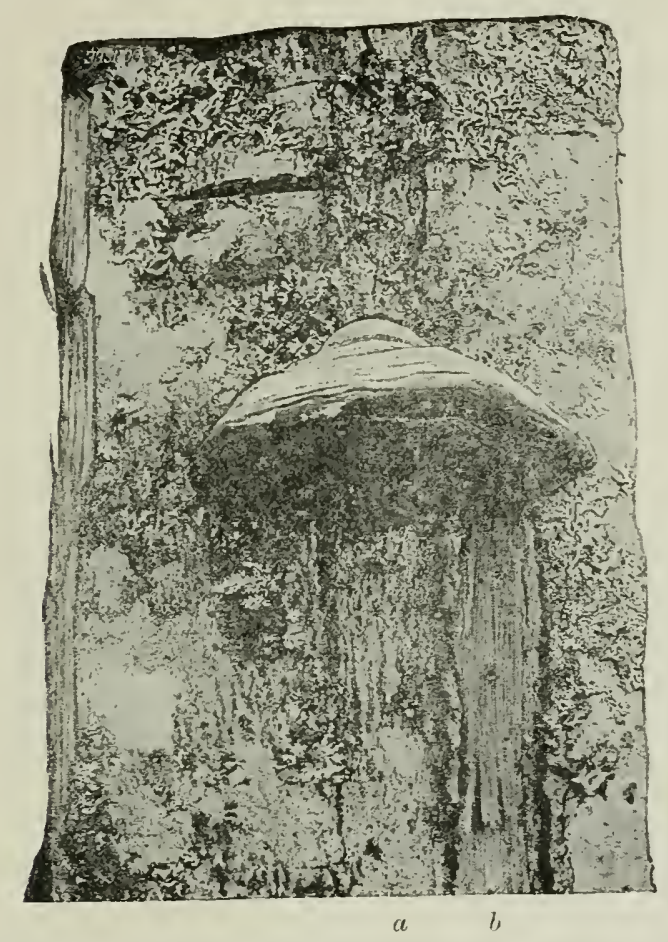

Fig. 2tit,--Polyports iomentarius on living Beech. ", A furrow extending above and below the insertion of the sporophore. $b$, An injury produced by tearing of the wood in felling. (v. Tubeuf phot.)

Polyporus sulphureus (Bull.) ${ }^{1}$ (Britain and C.S. America). The sporophores are flat and soft, the upper side being bright orange-red and the lower sulphur-yellow. They last only for one year, hence are small; they frequently occur in masses, one above another in tiers. After death they lose colour, become brittle, and are easily detached. According to De

${ }^{1}$ R. Hartig, Zersetzungserscheinungen. A very common species in Britain. (Frit.) 


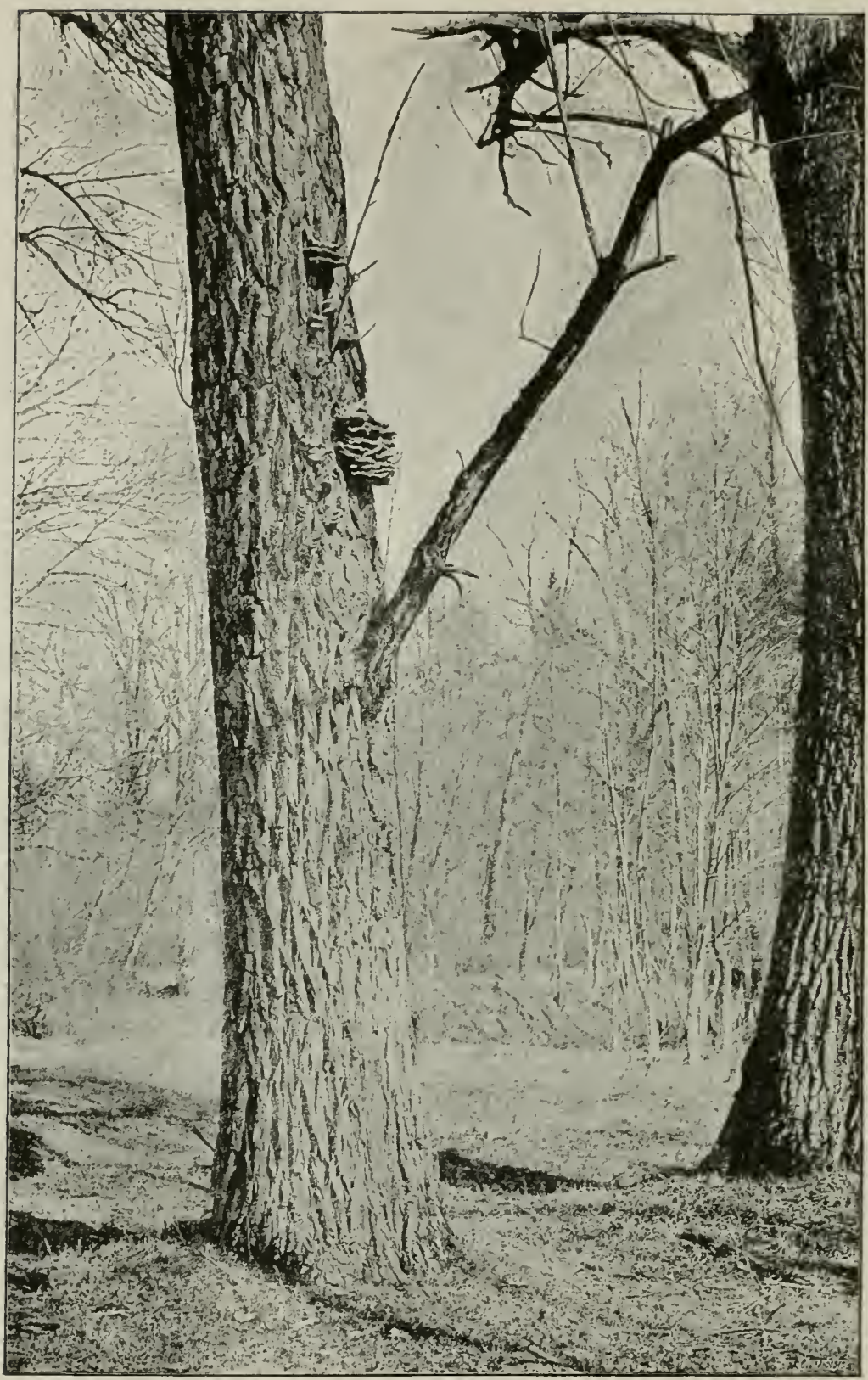

FIG. 26i.-Polyporus sulphureus on a Willow (Salic alle) at Hirschan, near Munich. (v. Tubeuf phot.) 
Seynes, ${ }^{1}$ three other kinds of spores are produced in addition to basidiospores.

Trillow, poplar, oak, sweet chestnut, alder, ash, hazel, pear, cherry, robinia, larch, silver fir, etc., are cormmon hosts of this parasite.

Woor infested by the mycelium darkens in colour, exhibiting a redrot. Vessels and all clefts or spaces become filled with white felted masses of mycelium. The wood, in course of destruction, becomes richer in carbo-hydrates, and the walls of the wood-fibres shrink so that fissures with an npward right to left direction are formed, but do not reach the middle lamellae. Finally the

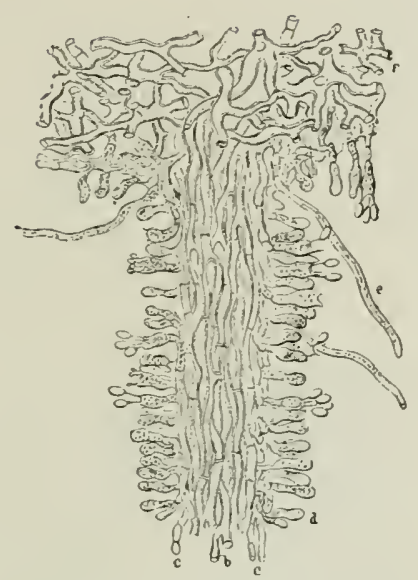

F1g. 268. - Polyporus sulphureus. Hymenial laser, with basidia and spores. (After R. Hartig.) wood becomes iry, brittle, and powlery.

Polyporus borealis (Wahlenb.) Fr. ${ }^{2}$ (Britain and U.S. Anerica). Sporophores amual, white, and Heshy; the upper

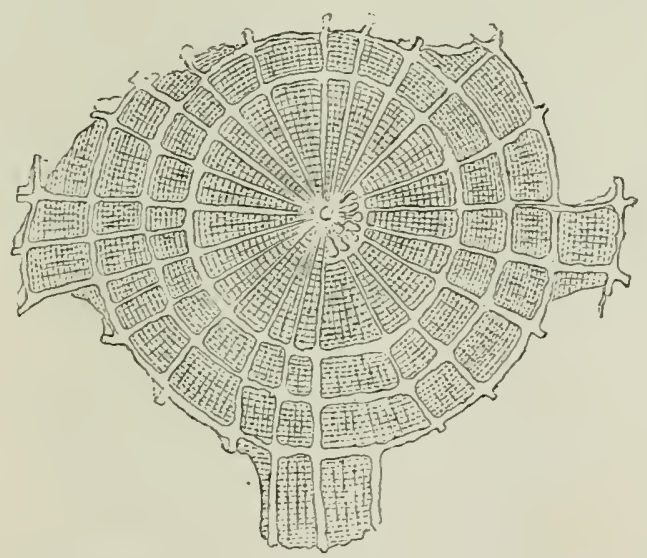

F1G. 269.-Polyporus sulphureas. The white mycelium forms concentric zones and radial lines on the cross-section of Oak. (After R. Hartig.)

surface is shaggy when fresh, and no internal zones are exhibited. The shape is somewhat cushion or bracket-like, but very variable;

${ }^{1}$ De Seynes, Annal. de Sci. nat., Ser. V., Vol. I., 1864.

${ }^{2}$ R. Hartig, Zersetsungserscheinungen, Pl. X. 
many generally grow near each other. The pores have a torn margin and cystids are frequent between the hasidia.

The sporophores ane common in spruce plantations, and ane accompanied by a very characteristic wood-rlestruction. The wood, in the earlier stages, becomes brownish-yellow and intersected by rulial and vertical canals filled with a white nycelium (Fig. 270). (iradually, however, it breaks up into small cube-

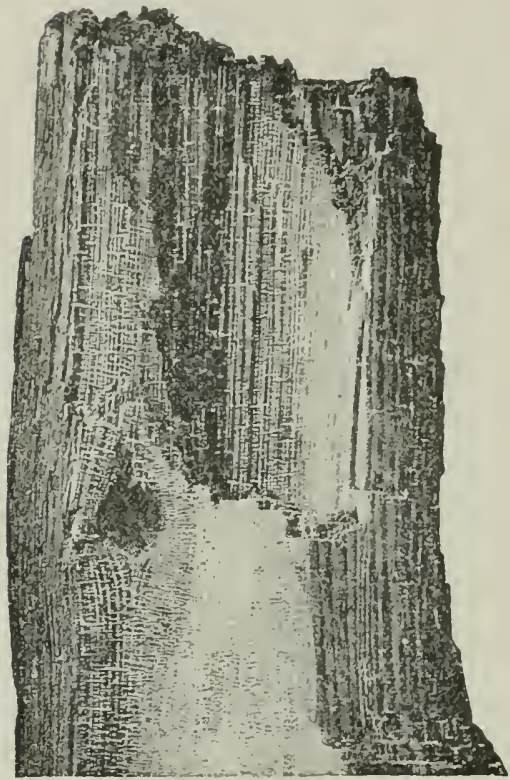

Fur. 2T0.--Polyporus borelis. Destruction of Spruce-wood. The white mycelium is prescnt, dividing the decayed wood into cubical pieces. (v. Tubeuf phot.)

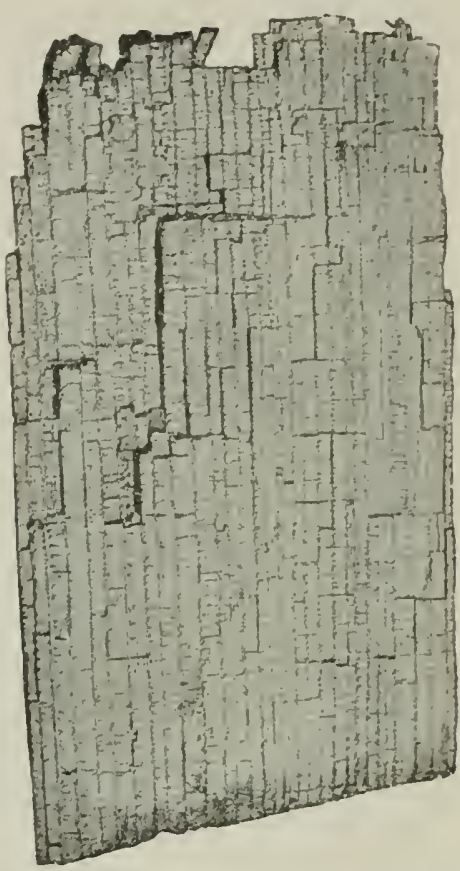

Fig, 271-Polyu0*us borealis. Later stage of destruction. The Spruce-wond is brokeı up into eubical pieces, and the niscelium has disappeared. (i. Tubeuf phot.)

like pieces, particularly evident when the woorl is broken (Fig. 271). The cell-walls are dissolved from the cell-carity outwards, the lignified wall being first converterl into cellulose and disappearing, finally the middle lamella.

Polyporus dryadeus Fr. ${ }^{1}$ (P. pseudoigninius Bull.) (IBritain and U.S. Americat). Sporophores, annual, large, shaped like tubers or hoofs, and generally sitnated towards the base of the

${ }^{1}$ R. Hartig, Zersetzungserscheinungen, Pl. XVII. A common British species. 
stems of oak-trees. At first they are soft, later hard and brown with grooves on the upper sicle. The dark heart-wood of the oak exhibits white or yellowish longitudinal stripes of rotten wood converted into cellulose (Fig. 272). In the white portions

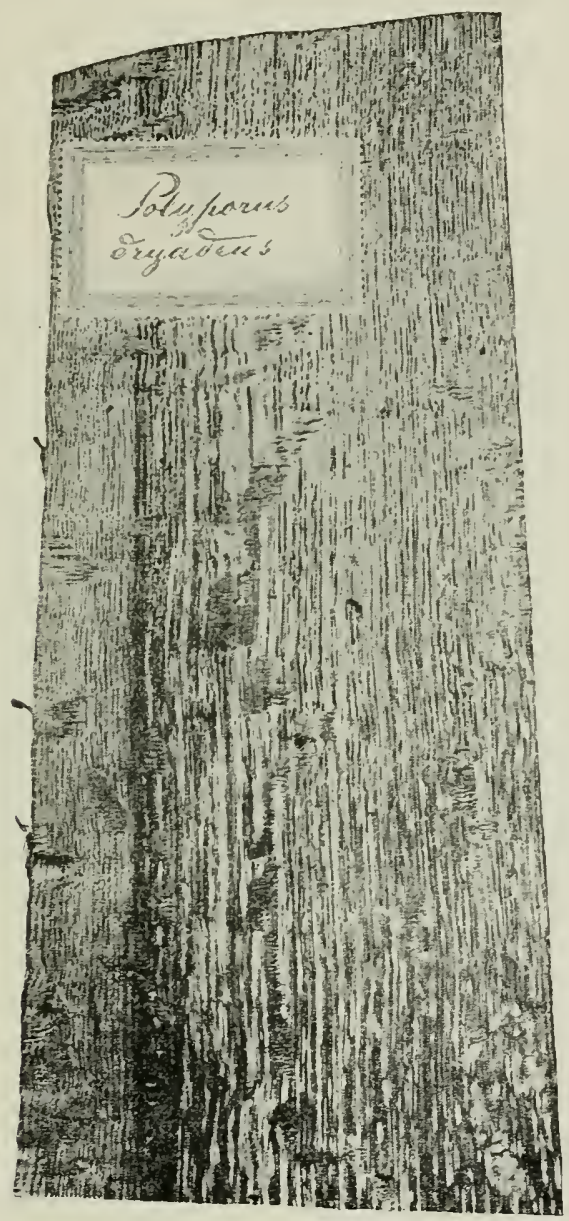

Fra. 2i2.-Polyporus dryadeus. The mycelium forms longitudinal stripes in the Oak-wood. (v. Tubeuf phot.)

the destruction is more complete than in the yellow, where dissolution of the lamellae has not as yet taken place (Fig. 273).

A simultaneous destruetion of the wool by $P$. dryaders and $P$. iyniarius may occur (Fig. 27t); in this case, the medullary 
rays appear snowy white at the place where the two forms of rot meet; this is due to an accumulation of starch left after the cell-walls have been almost completely dissolverl.

Polyporus (Poria) vaporarius (l'ers.) ${ }^{l}$ (Britain and U.S. America). The sporophores are white, and have a pungent olour; they form crusts (never mackets) closely arlherent to dead substrata, especially to heams and other timber in buildings,

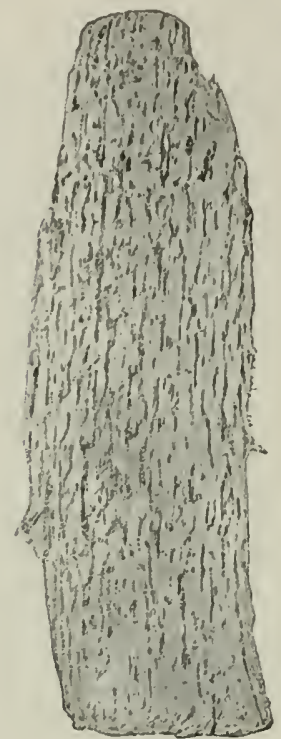

Fic. 273.-Polyportes diyadeus. Later stage of dccay of Oak-wood. The darker wlices still consist of firm brown wood: the white, however, are soft cellulose. (v. Tubeuf phot.)

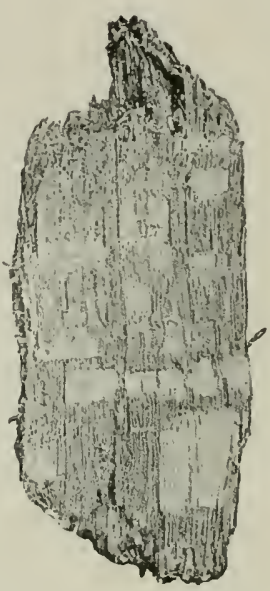

Fic. 274.- Polyporeselryaders and Polyports igninrius. Hestruction of Oak. wood under the combined agency of both fungi. The wood is yellowish and perforatcd; the medullary rays are snowy-white, from the accumulation of unchanged starch. (v. Tubeuf phot.)

where this fungus does great harm. They are also found, however, on bark of living stems of spruce and fir. The destruction takes the form of a red-rot, the wood attacked becoming redbrown, cracked, and soft. The mycelium is found in stems and roots of trees; in cracks in the wood and below the bark, and on the surface of timber in buildings, it forms fan-shaped strands of a permanent white colour. The mycelial strands of the "Ary-rot fungus" (Merulius lacrymans) differ from it in being

${ }^{3}$ Very common in Britain on dead wood, less so on living trees. (Edit.) 
at first white but beconing grey, and in exhibiting an internal differentiation which those of $P$. vaporarius do not. ${ }^{1}$

The hyphae in the course of their growth do not seek out the pits, but grow straight through the walls and bring about dissolution of the middle lamella for some distance around. At the same time numerous short oblique fissures in the walis are produced vertically one over the other, especially in the elements

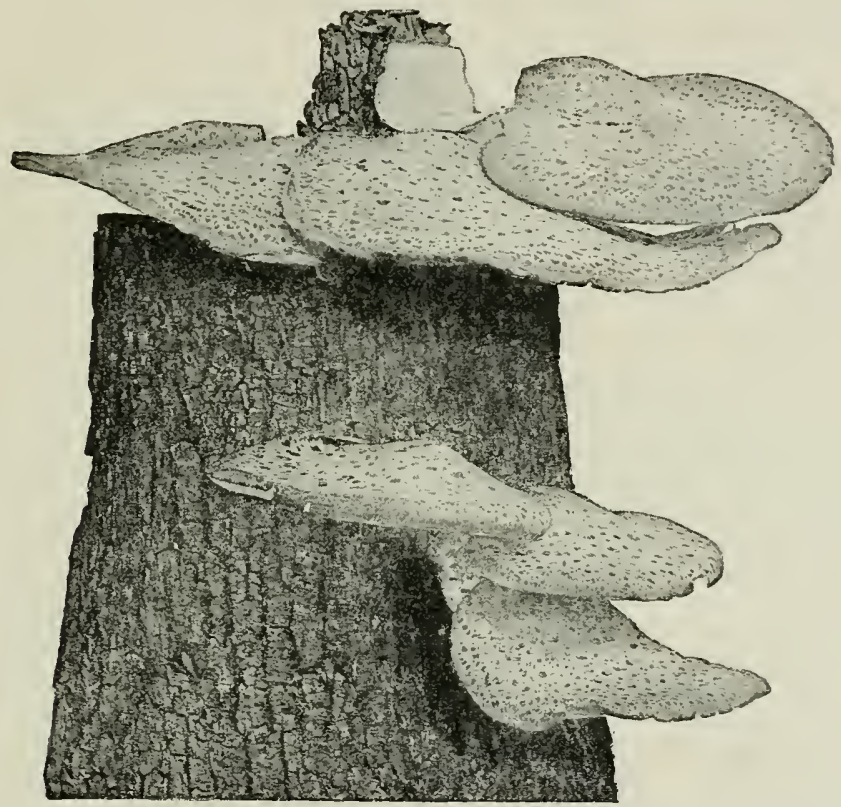

Fuc. 275.-Polyporus squamosus on Acer Negundo. The three upper sporophores are borne on a separate piece of wood, from which a fourth bas been cut off. (v. Tubeuf phot.)

of the thick-walled autumn wood. (Compare with $P$. sistoticmoides, Fig. 280). The phenomena accompanying destruction of wood by this fungus are so characteristic that Conwentz ${ }^{2}$ could distinguish it quite clearly in tree-remains enclosed in amber.

Brefeld succeeded by artificial culture of the spores, in raising a mycelium on which basidia were formed, at first directly, afterwards from large sporophores.

Polyporus squamosus (Huds.). (Britain and U.S. America.)

${ }^{1}$ F. Hartig, Der erhte Hausschuamm, Berlin (Springer), 1855.

${ }^{2}$ Conwentz, Monographie d. baltischen Bemsteinbäume, 1890. 
Sporophores annual, occurring from spring to autumn; at first tender and fleshy, later leathery or almost woody. In form they are short-stalked, flat, semi-circular or kidney-shaped, and attached by one elge; they may also be stalked and eircular or cup-shaped. Their upper sulfice is yellowish, with flat brown scales arranged in eoncentric lines. The hymenial layer is continued well on to the thick fleshy stalk of the sporophore; it is yellow in colour, and consists of short angular pores.

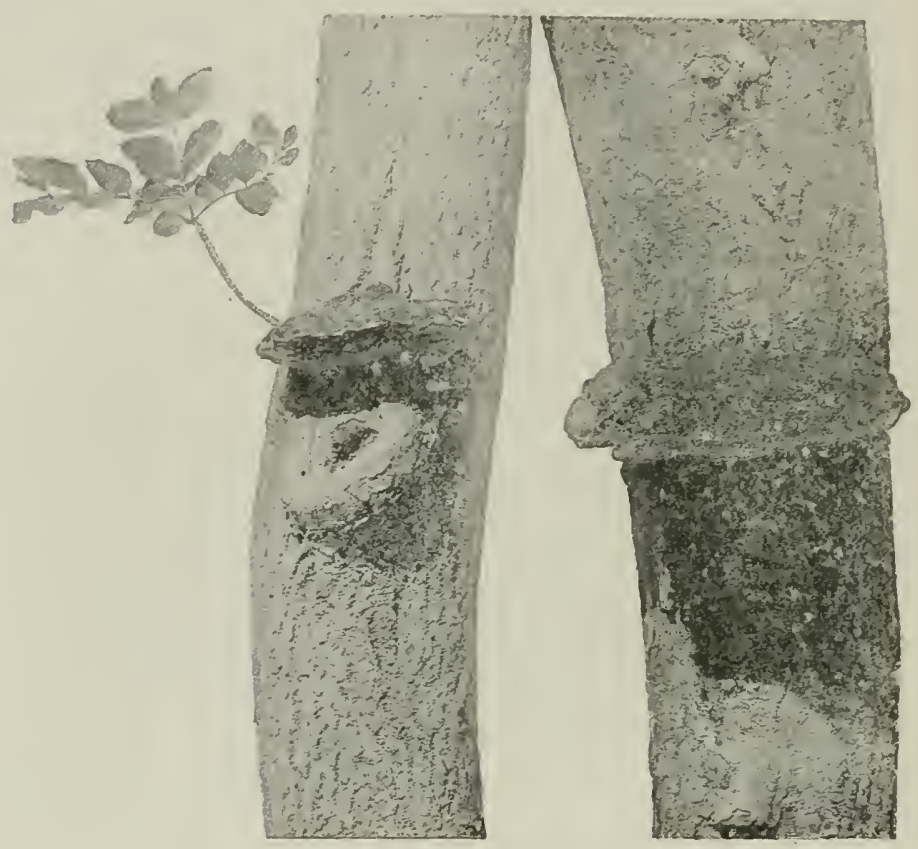

FIG, 276.-Polyporres hizpidus on pieces of living Ash. (v. Tubeuf phot.)

The spores are spindle-shaped and colourless. The fungus is especially common on living hazel, ash, species of maple, beech, mountain ash, horse-chesnut, elm, oak, willow, pear, lime, etc.

The wood of the specimen in Fig. 275 exhibited extensive white-rot, the inner parts being completely converted into a soft white spougy mass of mycelium.

Polyporus hispidus (Bull.). ${ }^{1}$ (Britain and L.S. America.) Sporophores annual, soft and spongy, with a rough brown upper

${ }^{1}$ A very common form on ash trees in Britain. (Edit.) 
surface, and a smooth yellowish hymenial surface. They are large and flat, the thickest part being at their insertion (Fig. 277). Several frequently occur on the same stem, especially if wounds or frost injuries are present. The spores are brown and roundish. Conidia are said, by Schroeter, to be formed on the upper surface of the sporophores.

This species is a deadly enemy of Iruit-trees, especially apple. In the vicinity of Munich the sporophores are conmon on ash. Schroeter gives elm and plane as hosts, and Prilliemx

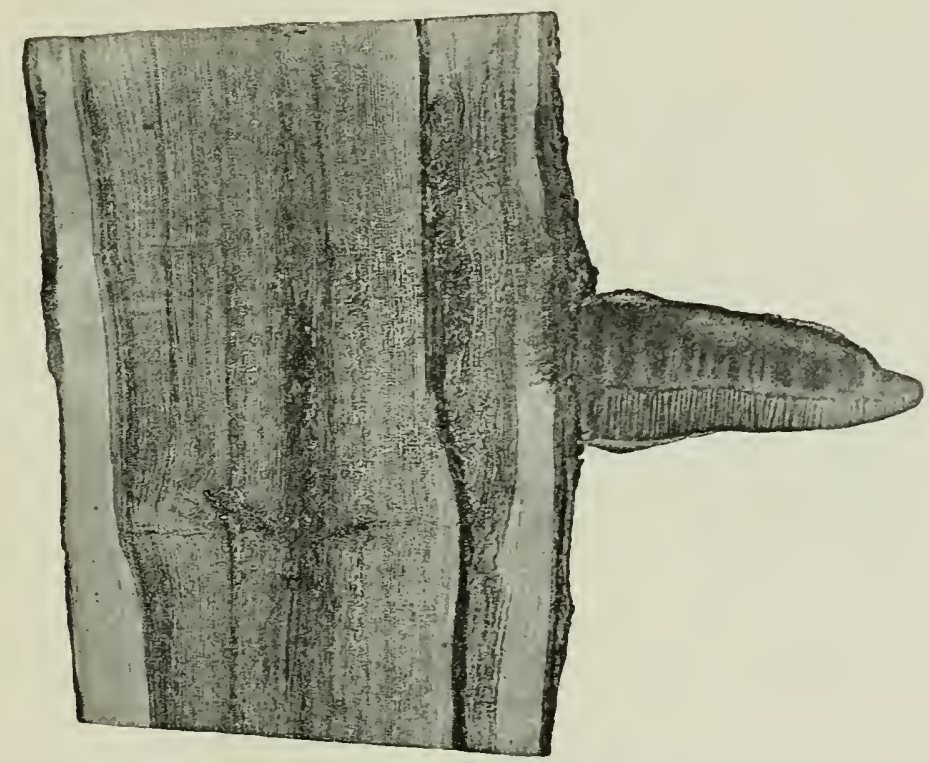

FIG. 277.-Polyporus hispidus. Longitudinal section through a living stem of Ash, and a sporophore of $P$. hispidus. The stem shows symptoms of wooddestruction, in that it becomes brown and has short white longitudinal and radial stripes. (v. Tubeuf phot.)

and Delacroix state the fungus to be very dangerous to the mulberry in France.

It causes ${ }^{1}$ brown discoloration of the wood accompanied by characteristic short white lines in both radial and vertical directions, so that the wood becomes marked out in squares.

Polyporus (Poria) laevigatus Fr. ${ }^{2}$ Sporophores dark-brown

${ }^{1}$ Prillieux (Bullet. de la Soc. mycolog. de France, Ix., 1893), gives details of the destruction of the wood.

2Mayr, Botan. Centralblatt, xix., 1854. 
and forming crusts on the bark of birch. Spathulate eystidia occur between the basidia. Spores colourless, and acutely ovate in shape.

This is parasitic on birch. The myeelium kills and permeates the wood-parenchyma which forms the greater mass of the later-formed parts of each year-ring, with the result that the varions year-rings of the wood separate from each other as concentric hollow cylinders. The inycelium varies according as its pabulum consists of cells just killed, or of wood, or of elements in the last stages of decomposition; in this latter case it suffers from want of food. In woody elements in contact

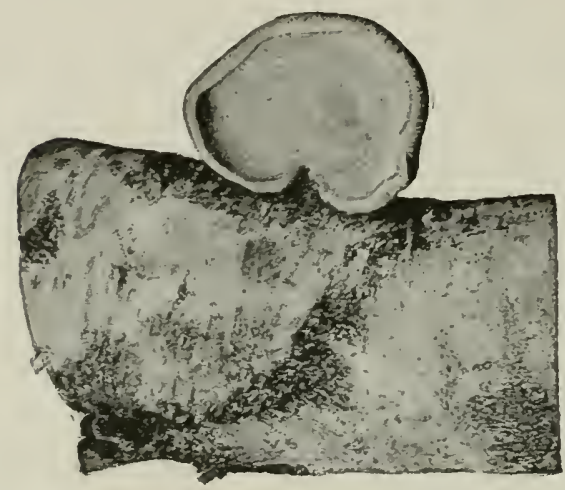

FIG. 27S. - Polyporus betulinus on Bitvila verrucosa. The sporophore was developed horizontally on a fallen stem; it is here, however, set up vertically and photographed from the lower side. (v. Tubeuf phot.) with air, or those destroyed ly Polyporus betulinus, the mycelium is brown and forms vesicular tyloses similar to Agrericus melleus.

Polyporus betulinus Fr. (Britain and U.S. Anerica). The sporophores are annual, and emerge as spherical struetures from the uninjured bark, or from boreholes of Beetles, or other wounds. When mature they are hoof-like or senicircular and short-stalked: when dead they become soft and break off. The upper side is light-brown in colour, the pore-layer is white. A section through the sporophore shows it to be white and homogeneous without zones. Lanceolate cystidia occur between the basidia. The spores are rod-like. The porelayer and the upper brown layer are easily detached, and strips of the remaining tissue are sometimes utilized as razor-strops.

This parasite frequents living birches, ultimately cansing death. It is known to oceur on both Betula rerrucose and B. pubeseris.s in Britain, America, and Europe. Its parasitism and injurious results were first demonstrated by Rostrup. ${ }^{1}$ Mayr² investigated

\footnotetext{
${ }^{1}$ Rostrup, "Snyltesvamper Angreb paa Skovtraeerne," Tidsskrift pa skor. bur\%, 1883.

"Mayr, Botan. Centralblatt, xix., 1554.
} 
in greater detail the destruction brought about by its mycelium. He found that it penetrates lignified eell-walls, entering the living elements and causing their death; it spreads most rapidly in the vertical direction through wood, bast, and rind, growing through parenchyma and sieve-tubes, and even boring its way into the selerenchymatous stone-cells; it absorbs the secondary thickening by dissolving out first the ligneous incrustation, next the cellulose, while the middle primary lamella remains behind untouched.

Polyporus (Fomes) fulvus (Scop.) (Britain). Sporophores woody and rery hard, at first hairy but later smooth, dark, and cracked; in form they are tuberous or triangular. Internally they show no stratification. The fungus is very common on living plum where it causes undoubted injury; it also oecurs on hormbean and aspen.

Polyporus fulvus var. Oleae Scop. In northern Italy may be frequently olserved a peculiar splitting of the stems of olive trees into two or more portions; the fissures occur generally on the lower parts of the tree, and may extend so deeply that the stem appears to stand on stilts or props. Hartig ${ }^{1}$ ascribes this phenomenon to the presence in the olive stems of the mycelium of Polyports fulvus causing rotten places which are cut out by the Italian cultivators; the clisease, however, continuing to make progress, it may be necessary in course of time to cut so deeply into the stem, that traets extending right through may be reurved; this takes place all the more rapidly if several diseased spots are being simultaneously operated on. The destruction of the olive-rood by this parasite is similar to that proulueed by $P$. igniurius on oak and other trees. The sporophores appear on rotten spots, but are generally quickly removed by the eultivator. Infection takes place on wounds, hence it is advisable at once to apply tar after eutting out any decayed wood, and also to paint pruning-cuts or other exposed surfaces with tar. Neighbouring fruit-trees, liable to suffer from this same fungus, should be similarly treated, both for their own safety and that of the olive trees.

Polyporus (Fomes) Hartigii Allescher ${ }^{2}$ ( $P$. igniarius var.

\footnotetext{
1893.

${ }^{1}$ R. Hartig, "Die sjpaltung der Oelbäume." Forstlich-naturmiss. Zeitschrift,

${ }^{2}$ R. Hartig, Zersetwungserscheinnngen, PI. VII. Forstlich-naturuss. Zeitschrift, 1893, p. 61 .
} 
pinum Bresalula or I'. fulrus Scop. of R. Hartig). Sporophores on silver fir, less eommonly on spruce. Their form varies much, according as they oceur on a branch or wn the sten. In the former case, the sporophore forms a swelling below and on each side of the more or less horizontal branch. On the stem they are more or less bracket-like. The spormphores are reddish

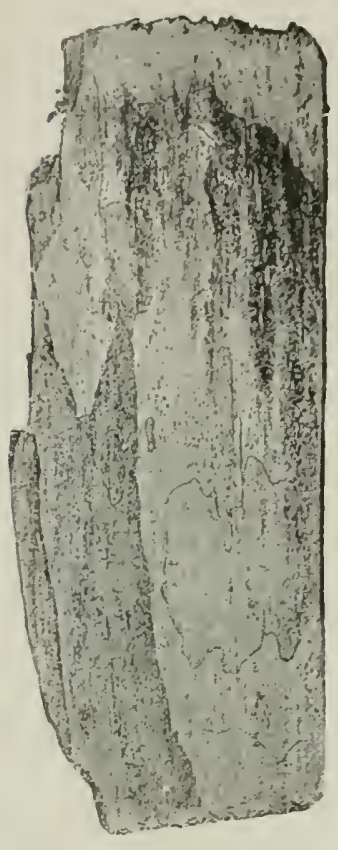

F1G. 279.-Polyporus Hartigii. Destruction of wood of Silver Fix. The decayed wood is yellow, but shows dark points and black lines. (v. Tubeuf plot.) brown with a smooth upper surface on which zones are only faintly inclicated or altogrether alssent. Intemally they are of a brownish or tawny enlour, and exhibit concentric strata, which do not extend into the pore-layer; they are thus distinguished from sporophores of $I^{\prime}$. iynimizes and others. The sporophores are very frequent on eankered stems of fir where the canker-spots afford easy entrance for the spores.

The woorl-destruction consists in a white-rot. The wood becomes yellowishwhite with elear spots and fine dark lines, especially where in eontact with healthy parts. The mycelium is yellowish, and eonsists of thick hyphae with lateral branches forming tangled masses which frequently fill up the eavity of the bordered pits. This myeelium gives off very fine branches which bore through the cell-walls and dissolve them in such a way that the middle lamellie disappear first and leave the remainder of the wallthickening for a time isolated before it too is used up. In this way large holes are formed in the elements of the wool.

Polyporus sistotremoides (Alb. et Schw.) (P. Schweinitzii Fr. or $P$. molli. Fr. of li. Hartig) ${ }^{1}$ (Britain). Sporophores almost eircular with a short thick central stalk; while young they are light brown and spongy, but when older become dark brown and corky. The upper surface is downy; the hymenial layer extends far clown the stalk, when young it is yellowish green,

${ }^{1}$ R. Hartig, Zersetzungserscheimunyen, Pl. IX. 
but later becomes brown, and, on being touched, deep red. The spores are white, and various forms of hairs ocenr among the basidia. Young sporophores appear as little brown cushions on felled timber, also on living stems of pine, and, according to Magnus, on Weymouth pine.

The disease generally makes its first appearance in roots and lower parts of the stem, spreading thence into higher parts. Diseased wood has a characteristic odour of turpentine; it has a reddish-brown colour, and, as destruction proceeds, it gradually shrinks and disintegrates till it becomes so soft as to be easily powdered between the fingers. Where broken over, the wood is often corered with a thin white coating of mycelium incrusted in resin so as to appear like chalk.

The mycelium penetrates the cell-walls in all directions. A very characteristic feature of this parasite is furnished by shrinkage-fissures in the thick walls of the tracheids of the summer-wood (Fig. 280). These are numerous and run upwards from right to left extending through the whole wall to the ontermost layers. They differ from the fissures in tracheids destroyed by $P$. caporarius, in that they run round the whole circumference of the cell, instead of being small and set vertically above each other.

Polyporus (Fomes) pinicola (Sw.) (U.S. America). Sporophores thick, hoof-like or

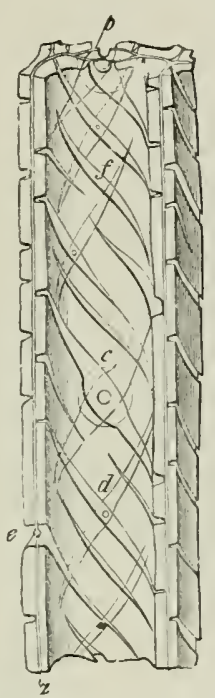

Fig. 2s0. - Tracheid of Pinusdestroyed by Polypon:es sistotinoides. The cellulose has been for the most part extracted, and the walls con. sist of liguin (wood-gurm). Cracks oceur in tlee dry secondary wall, while the wall $(a, b)$ remains intact. The spiral structure of the secondary wall causes crossing of the fissures in the walls of adjoining cells at the bordered pits, $c$, and at bure-holes, $d$, $e$; where neither pits nor holes are present the fissures are simple, $f$. (After R. Hartig.) bracket-shaped, with a smooth dark-grey upper side and a bright red rounded margin. The hymenial layer is smooth and yellowish, the spore-powder white. In section the sporophores are white. The species is frequent on living stems of spruce, pine, and fir, also on birch and cherry.

Polyporus (Fomes) marginatus Fr. (U.S. America). Sporophores with red margins, and otherwise very like those of the preceding species, yet generally much larger, and more extended. 
The two species are held by many authors to he identical. It occurs chietly on stems of beech, also on oak and birch. In regard to its parasitism nothing further is known.

Polyporus (Fomes) annosus Fr. (Trametes radiciperda Hartig ${ }^{1}$ ) (Britain and U.S. America). The sporophores vary' much in form, according as they occur more above or more below ground on tree stems, or on timber in mines. The upper surface is brown and marked in zones, the margin being lighter. The section through the woody sporophore is white. The hymenial layer is also white. Spores ovoid and colourless, germinating easily in water. In artificial cultures, Brefeld states $^{2}$ that they produce only coniclia.

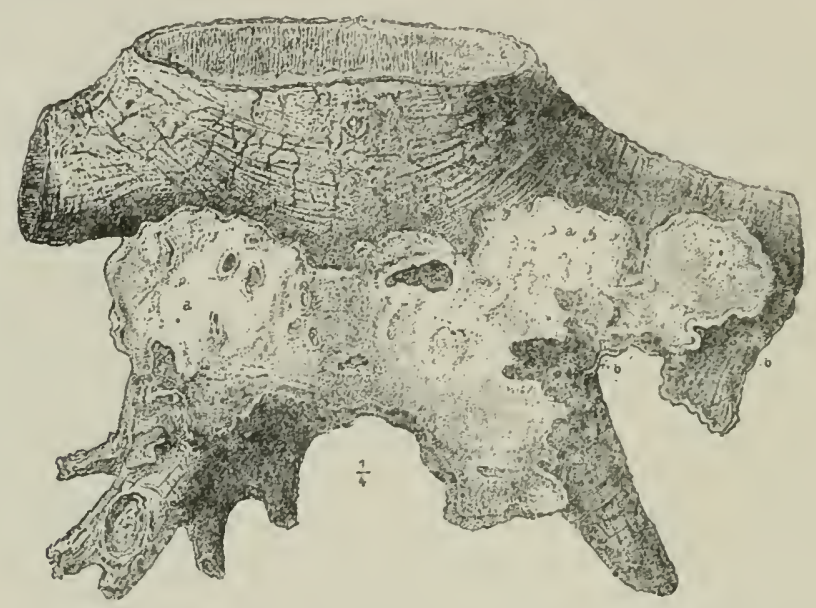

Fus, 2s1,--Polyjo, "us "nnoxus Fr. (Trametes redicipiela Hartig). Stool of :1 forty-year Spruce, which lias been dead for two or three sears. The sporophote is several years old. $\quad$, $a$, White open-pored layer forming over the dead basidial layer, $b, b$; at $c$ a narrow strip of wood still remains firm, the remainder is completely destroyed and rotten. (After R. Hartig.)

This species was first investigated in detail by R. Hartig, ${ }^{1}$ and is described by him as the most dangerons of all parasites in the conifer forest. It is most frequent on Conifers, e.y. pine, Weymouth pine, spruce, silver fir, Douglas fir, balsam fir, juniper, and Thuju; it also ocems on various broad-leafed trees, r.g. beech ${ }^{3}$ and hawthorn.

${ }^{1}$ R. Hartig, Zerset:angserscheinungen, I'. I.-IV. Michtige Krankheiten, Pl. 111. Zeitschrift f. Forst-und Jagrt-wesen, 1859, p. 428. Botan. Centrallslat, XILIT, 1890.

3refeld, Schimmelpil::e, Heft S, 1859.

"Rostrup, Afbildnin! of Beskrivelse of de farligste Suylterrampe, 1589. 
The mycelium penetrates both bast and rind causing a very acute red-rot in the wood, so that death of the tree attacked rapidly follows. The disease makes its appearance on plants of all ages, and in forests of spruce or pine causes gaps which rapidly extend in a centrifugal direction. The roots and lower parts of the stem are generally the parts first attacked. On the roots, the parasite is easily distinguished, even in the absence of sporophores, by the very delicate white mycelial membranes formed between the bark-scales. Destruction of the wood becomes first evident by the appearance of vertical clark lilaccoloured stripes indicating the stage when the parenchyma cells are killed. At a later stage, the wood becomes brown, and shows isolated black spots with white margins (Fig. 282). These last consist of coils of dark mycelium surrounded by wood from which the incrusting substance has been dissolved away, leaving only cellulose, readily dis-

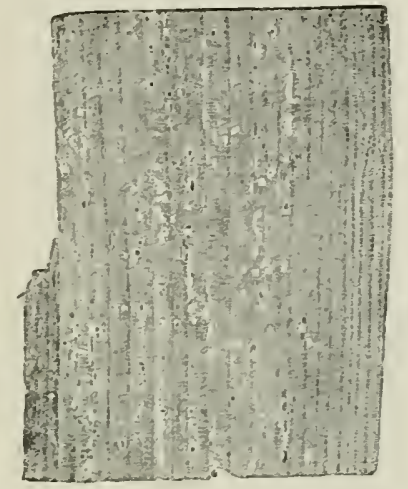

Fig. 2×2.-Polyporus unnosus. Destruction of spruce-wood. Longitudinal section showing white (cellulose) spots with black (njcelium) centres. (r. Tubeuf l.hot.) tinguished by turning blue on treatment with chlor-zinc-iodine; here too, the middle lamellae are ultimately dissolved out, so that the elements become isolated. A colourless mycelium may also be found in the other parts of the wood, both inside the elements, and extending in all directions through the cell-wall, leaving holes where it itself has disappeared. Dissolution of the lignifying substance proceeds from the cell-cavity, the middle lamella remaining intact till the last. The resin of the decayed wood passes over into all healthy parts and flows from the bark of diseased stems as a resin-flux.

The most effective method for combating the ravages of this parasite is isolation of infected areas. In one case which I investigated in Baden, several spots in the forest formed very evident starting points, and sporophores were everywhere present at the base of stems amongst the moss. Such spots should be enclosed by ditches with vertical sides, and deep 
enough to ent through all roots, eare being titken to leave no diseaser stems or roots ontside the circle; after remaining open for a time, the ditch must be refilled with soil to prevent development of sporophores on the exposed roots. Diseaserl stems should the felled, and, along with all root-remains, burned on the spot, where there is no risk of forest fire; failing this, they and their stumps should be deeply covered over with soil, to prevent ilevelopment of sporophores.

The following species of Polyporus have been observed on living trees, but details in regard to their parasitism and mode of destruction are still wanting:

P. officinalis Fr. On larch, chiefly in Russia, but also in France and Switzerland. The sporophores are white irregular masses, and at one time were used in medicine. The mycelinn forms bands in the wood sinilar to those of $P$. sulphureus.

P. albus (Corda), according to Ludwig ${ }^{1}$ is a canse of a disease of ('onifers, which extends from the root upwards. (U.S. America.)

P. spumeus (Sow.). On apple trees. (Britain and U.S. America.)

P. fumosus (Pers.). On willow, ash, maple, and other broad-leaved trees. (Britain and U.S. America.)

P. picipes Fr. On willow and other broad-leaverl trees. (Britain and (.... America.)

P. (Fomes) cinnamomeus Frog. On cherry trees. (Britain.)

P. radiatus (Sow.). On alder (.l. incunu), birch, and beech. (Britain and U.S. America.)

P. (Fomes) ribis (Fr.). On black currant and gooseberry shrubs. (Britain and U.S. America.)

P. (Polystictus) hirsutus Fr. (Britain and U.S. America). On living hombeam, aller, oak, birch, and service. A variety, scruposus, is common and injurious on cherry.

P. ulmarius Fr., is, according to Cavara, ${ }^{2}$ parasitic on living elm near Pavia. (Britain and U.S. America.)

P. (Fomes) nigricans. On birch. (Britain and U.S. America.)

P. salicinus (Per's.). A dangerons eneny of willow. ${ }^{3}$ (Britain and U.S. America.)

Rostrup ${ }^{+}$gives Corticium comedens as a wound-parasite of nak and alder.

Hartig llescribes Fistulina hepatica, the liver-fungurs, as causing a darkbrown colour in oak-wood.

${ }^{1}$ Ladwig, Lehrbuch l. niederen Kryptoyamen.

"Cavara, Reme Mycol., 1891.

"Tursky, Russian translation of R. Hartig's "Lehrluch d. Baumkrankheiten."

${ }^{+}$Rostrup, Fortsatte Unclersoyclser, 1883. 


\section{Trametes.}

Sporophores as in Polyporus, except that the substance between the pores does not differ from that of the rest of the sporophore. ${ }^{1}$

Trametes pini (Brot.) Fr.2 Ring-scale of Pine. This is a dangerous forest parasite in Northern Germany; also in Britain and C.S. America. On the pine the sporophores develop from branch-scars, and assume a bracket form. The fungus has also been observed on spruce in Bararia and elsewhere, but in this case, the sporophores are more frequently found as a coating over the bark on the under sicle of a branch. Larch, silver fir, and the Douglas fir (in America), have also been mentioned as hosts.

The sporophores are brown and woody, and continue to form ammual hymenial zones for a number of years. The hymenial layer consists of pore-tulues lined with basidia, between which thick-walled cystirlia are formed. The spores are elliptical, and on germination penetrate into wounds or broken branches not protected by an outflow of resin. The older branches of pine and larch have a central heart-wood from which no resin is secreted, and these branches, when broken over, offer the necessary access to the germinating spores: for this reason, infection takes place most frequently in old plantations. The mycelium spreads through branch and stem, particularly upwards and downwards in the same year-ring. In this way longitudinal stripes and peripheral zones are formed in the wood, griving rise to the popular name "ring-scale." single hyphae bore through the cell-walls, and a ferment secreted by them dissolves the incrusting substance, so that walls affected show the reactions for cellulose almost at once. A very characteristic feature is the appearance of isolated. white spots or holes, indicating where the wood, after becoming cellulose, has been dissolved ont entirely. The middle lamellae are dissolved ont first in attacks of this fungus, the tertiary lamellae remaining longest intact (Fig. 12). The dark centres of $11 \mathrm{ycelium}$ inside

${ }^{3}$ The distinction between the genera Polyporus and Trametes is badly defined. A reinrestigation of the systematic relationships of the whole gromp of Polyporeae would in fact be advisable.

2R. Hartig, Zersetzungserscheinungen, Pl. T. and VI.; Wichtige Frankheiten, Pl. III. ; Lehrbuch 1. Baumkrankheiten, IS94 (English translation by somerville). 
white wool-spots, so characteristic of Polyporus annosus (Tram. renticiperelce, appenr only rarely in this species.

The destruction of spruce and fir goes on from pith to bark; in the pine, however, it seems to be confined to the heart-wood,

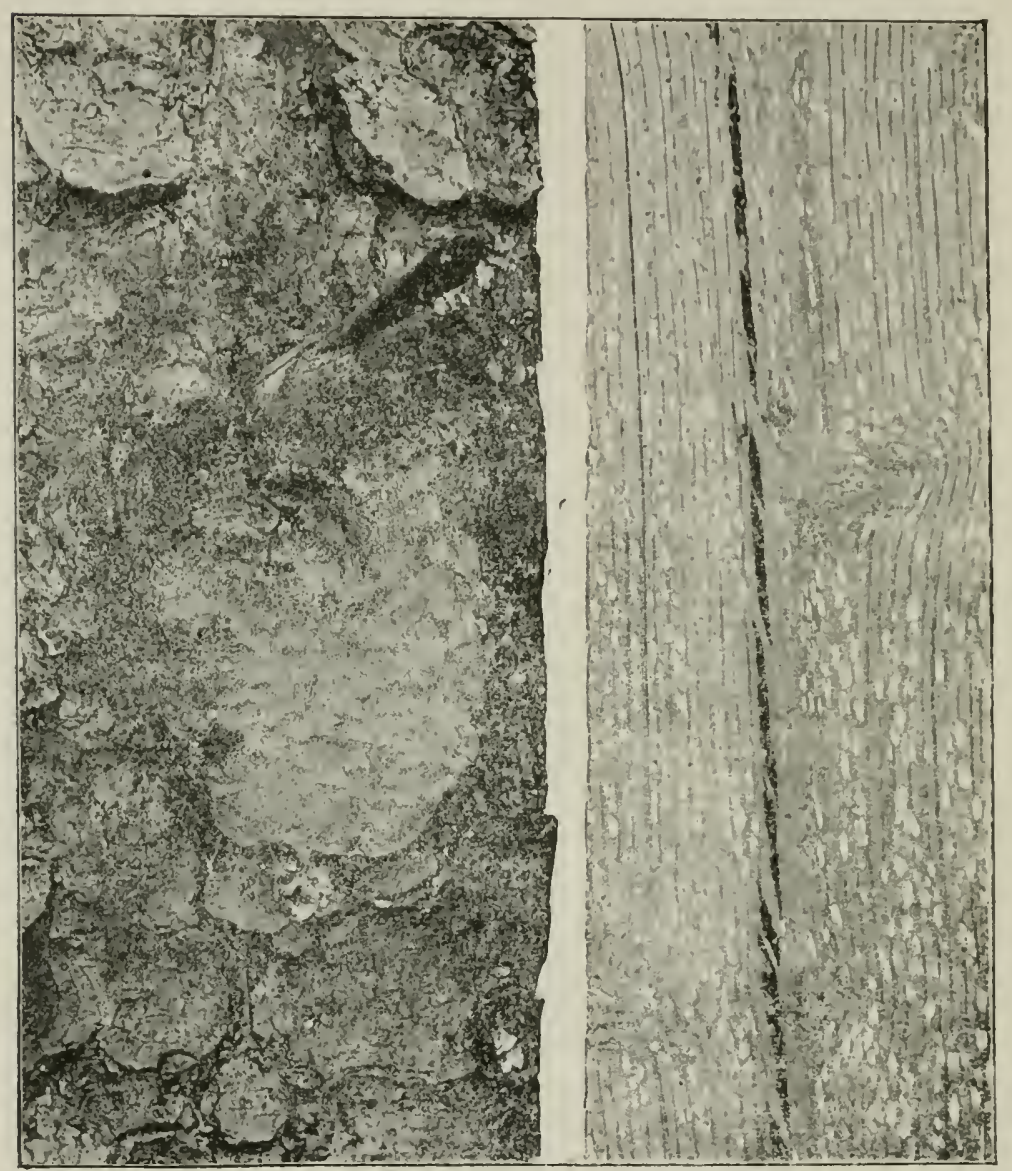

Fig, 253. - Trumetes pini on Spruce (Picu r.celect). Sporophore on the stem beneath a suag-branch. (v. Tubeuf phot.)

Fig ast-Tiame te pini on spruec. Boird showing the characteristic white ccllulose-spots in the wood. (v. Tubeuf phot.)

and is prevented from entering the sap-wood by a firm zone permeated with resin.

Remedial measures are the removal of all diseased stems 
at thinning; and the prevention of unnecessary injuries to living branches ol' stems.

Trametes suaveolens (L.), common on dead willow, is also reported as parasitic on living stems. (Britain and L.S. America.)

\section{AGARICINEAE.}

\section{Agaricus.}

Siporophores umbrella-shaped and fleshy; and decaying soon after discharge of the spores. Hymenium on the under side of the umbrella, and spread over a series of radiating gills or lamellae, easily divisible in a longitudinal direction.

The genus is divited into sections and subgenera distinguished by the colour of the spores; the Coprinarii are black-spored; the spores of the Pratelli are dark purple, brownish-purple, or dark brown; of the Dermini brown, yellowish-brown, or orange: of the Hyporhudii rosy or salmon-coloured; of the Lencospori white.

Agaricus (Armillaria) melleus Vahl. ${ }^{1}$ (Pritain and T.S. America.) 'The honey-fungus or "hallimasch." The sporophores are present in numbers towards the close of smmer on treestools of all kinds, and on the bark of dead or living Conifers; also on timber, and even on earth. The fleshy stalk is somewhat thickened towards its base, and towards the upper part bears the membranous yellowish annulus (Fig. 286). The cap surmounting the stalk is honey-coloured or brownish with dark scales. The spores are white and bestrew adjacent objects with a mealy dust. The sporophores are edible.

The connection between the sporophores and the rhizomorphstrands was proved by Hartig. These rhizomorphs are very common and vary much in form; they occur as round brown strands running through the earth from root to root of attacked trees; inside hollow stems and in wooden water-pipes, they retain their rounded form, but under the bark of trees they become dark brown flattened bands (Fig. 2SS). They are not uncommon on timber: in mines they may be frequently seen hanging from the woodwork as tangled clumps, with

${ }^{1}$ R. Hartig, Wichtige Krankheiten, Pl. I. and II. ; Zersetzungserscheinungen, Pl. XI. De Bary, Botan. Zeitun!, 18.ig. Brefeld, Srhimmelpilse, Heft. III., $187 \%$. 
numerous branches like the rumers of some hanging plant, c.g. Aaron's Beard (Sirifinge sarmentosu). The rhizomorphs live as saprophytes and have been long known to emit phosphorescent light. Sporophores are developer directly on them, and if one sows the spores, a delicate hyphal tissue is produced, which, muder suitable conditions, passes gradually over into the rhizomorph-strand. Brefeld succeeded in raising rhizomorphs from spores in artificial nutritive media.

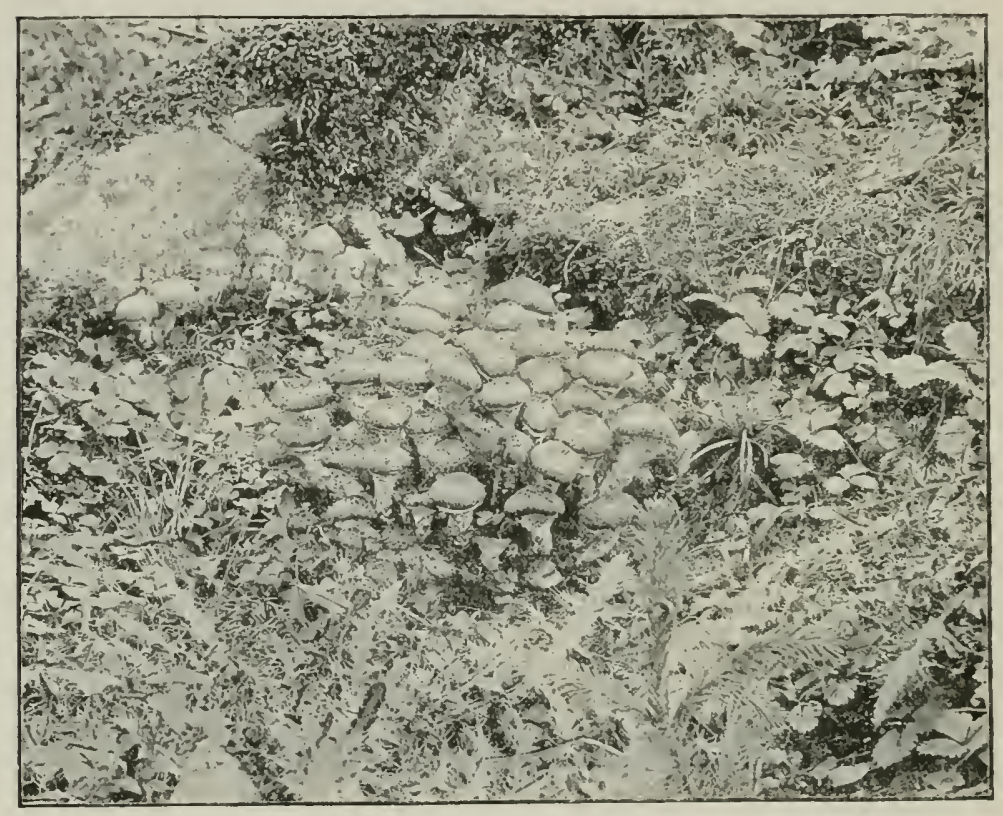

Fic. 285.-Agaricus mulleus near a Beceh-stool. (v. Tubeuf phot.)

The Ayaricus-mycelium forms fan-shaped snowy-white firm membranous expansions under the bark of newly killed or still living trees. They are quite distinct from the much more delicate mycelial expansions of Polyporus annosus, and offer a particularly easy means of distinguishing between the two species. Another indication of Agaricus is the great outtlow of resin from the bark at the base of the stem and from roots, whereby hard clumps of earth are formed round the roots. The passage of the rhizomorphs into the white membranous mycelium is easily observed. The 
rhizomorphs distribute the fungus in the earth and other dear substrata, as well as bore into the bark of healthy Conifers.

This parasite attacks not only the indigenous Conifers (spruce, silver fir, pine, larch, and juniper), ${ }^{1}$ but also the introduced forms-Weymouth pine, Douglas fir, Pinus riyicla, Abies Pichta, Picen sitchensis, various Cupressincac, etc. It also seems to attack broad-leafed trees, at least as a wound parasite. ${ }^{2}$

In regard to the interesting structure of the rhizomorphs, and the characteristic mode of wood-destruction caused by

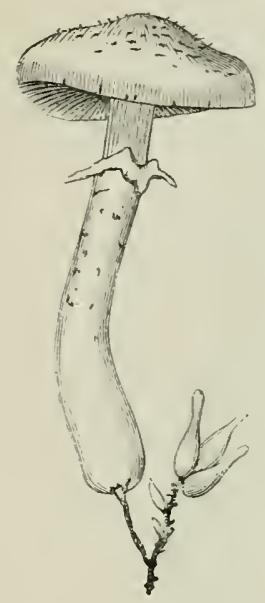

Fig. 256-4agims malleus singophore developed from a rhizomorph-strand; the other branch bears arrested sporophores. (After R. Hartig.)

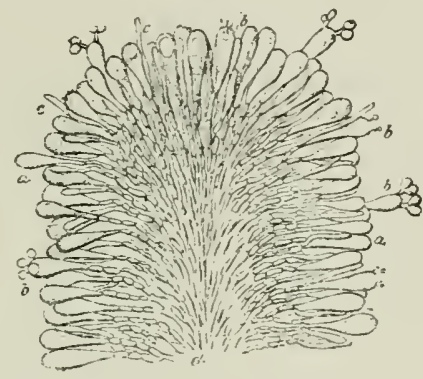

$\mathrm{FIG}_{\mathrm{IG}} \mathrm{x} \mathrm{i}$ - Adericus melleus Section through a lamella. $d$, The hyphae forming the substance of the lamella are much branched, and send twigs outwards which end in club-shaped basidia, $a$; on mans of these are dereloped sterigmata with apices swollen into spores, $b ;, c$, isolated threadlike arrested basidia lirojecting above the lymenial layer. (After R. Hartig.)

this fungus, I give directly the account by Hartig in his "Lehrbuch." ${ }^{3}$ "The pathological symptoms can only be explained in the light of the peculiar organization of the mycelial growth that lives in the cortical tissues. The apex of the rhizomorphs consists of delicate psendoparenchyma, which, elongating by the division and growth of the cells, produces delicate hyphae on the inside at a certain distance from the

${ }^{1}$ I found it on juniper in the pine-forests near Eberswalle. (Auth.)

2 The mycelium does not seem capable of penetrating uninjured broacl-learerl trees, but R. Hartig (Forstl.-natmwiss. Zeitschrift, 1894, p. 4:28) mentions attack and death of cut roots of healthy oaks.

${ }^{3}$ R. Hartig, Lehrbuch a. Baumbrankheiten, Iss9. The translation given here is from Prof. Sonnerville's English edition of Hartig's text-book, p. 210. (Edit.) 
point, whereby a felted tissue, called the medulla, is produced in the interior. The outer parts of the psendoparenchyma, on the other hand, coalesce to form the so-called rind, which when young gives off mumerous delicate hyphae, and these, taking advantage of the medullary rays, penetrate the wood, and especially the resin-lucts, should such be present. In the wood the growth is upwards. This filanentous mycelium, which progresses much more rapilly in the interior of the woorl than the rhizomorphs which grow in the cortex, completely destroys

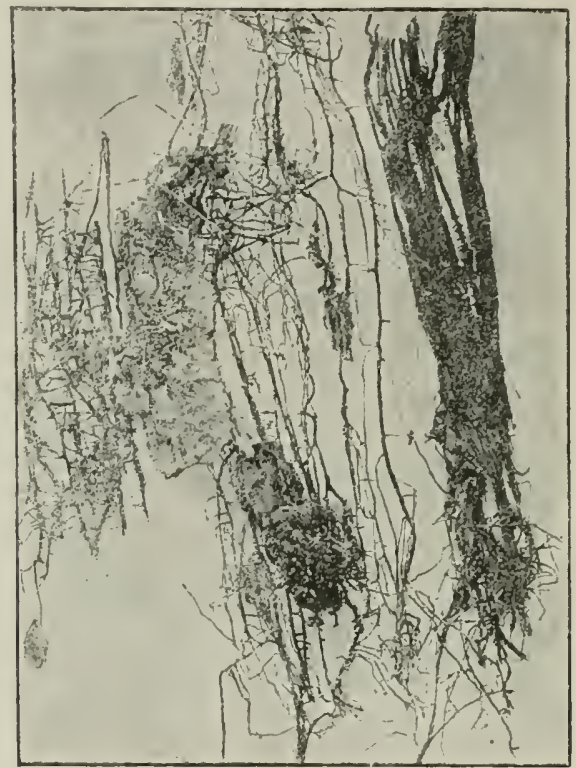

Fui. 2s5.-Aocricus mellus. Rhizomorphs in the form of dark anastomosing binds, developed between the bark and wood of a tree. (v. T'ubeuf phot.)

the parenchyma that exists in the neighbourhood of the resinducts, and to all appearance this is accompanied by a partial conversion of the cell-contents and the cell-walls into turpentine. The turpentine sinks down under its own weight, and in the collar, where the cortex is withered, having been killed by rhizomorphs, it streams outward, pouring partly in between the wood and the cortex, and partly into the surrounding soil at places where the cortex has ruptured owing to drying. On this account the disease was formerly called 'Resin-flux' or 
'Resin-glut.' In the upper parts of the stem, where the cambium and cortex are still sound, the turpentine also flows laterally, by means of the ducts of the medullary rays, from the injured canals towards the cambium and cortex. In the latter this accumulation induces the formation of large resin-blisters. When, during the summer, the cambium is forming a new ring, the plethora of resin has the effect of causing the production of numerous resincanals, which are usually large and abnormally constructed, and these impart to the wood-ring formed during the year of sickness a very striking and characteristic appearance.

"The mycelium gradually spreads from the cells of the medullary rays and from the resin-ducts into the vascular elements of the wood, where it produces a form of decay which may be termed a variety of white-rot. During the progress of the decomposition from the surface of the sten inwarls a certain stage is reached, which is highly favourable to the development of the mycelium. While previously it was simply filiform and furnished with numerous lateral hyphae, it now deveiops large bladder-like swellings, and at the same time the hyphae change into a kind of large-nneshed parenchyma, which, like the tyloses in the vessels of many dicotyledonous trees, completely fills up the lumina of the tracheides. On account of the mycelium assuming a brown colour when in this condition, it makes the portion of diseased wood which it infests appear, to the naked eye, like a black line. As this kind of mycelimm soon dies off and is dissolved, being replaced by a delicate filamentous mycelimm, it seldom happens that the zone which it occupies exceeds the breadth of three to four tracheids. The walls of the elements of the wood afterwards display a cellulose reaction, and speedily dissolve from the lumen outwards.

"On account of the trees drying up, after the rhizomorphs have spread from the point of infection on the roots into the stem, and again from the stem into the hitherto sound roots, decomposition of the stem usually ceases before the mycelinm has advanced from the alburnum into the duramen. It is only in the stool and roots that decay rapidly spreads throughout the whole of the wood."

Methods for exterminating this parasite are unknown, beyond removal of diseased plants and collection of sporophores. It would certainly be advisable not to plant young conifers on 
eleared forest-lam where the fungus sporophores are numerous on dearl stools or roots.

Agaricus (Pholiota) adiposus Fr. (Britain and U.S. Americi). This is a conspicuous bright yellow or loney-yellow toadstool, with a glistening slimy cap which, as well as the stalk, is beset with eoncentric darker seales (Fig. ㅇ9). The scales and clelicate innulus become indistinet or clisappear on old sporophores or after much rain. The stalk is thick, Heshy, and stifl, and while growing so changes its direction as to keep the eap always in a horizontal position. The pileus or cal, at

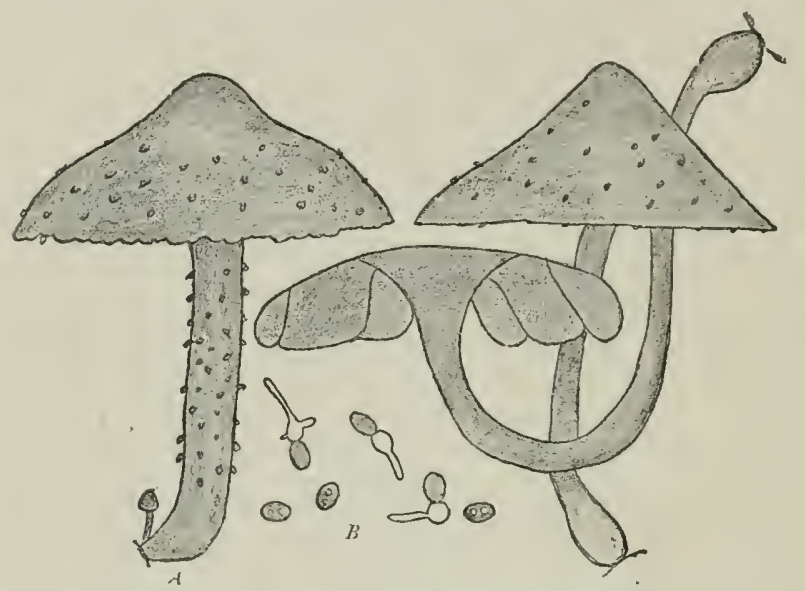

Fu, 2s!r,-Aguricus adipoxus. A, A mature and a very young sporophore grown in the forest; the other sporophores were raised on Fir-wood in a eellar. The latter have longer thinner stalks, and a basal swelling beset with white down. $B$, Itature and germinating spores. (

first glohose, opens out cone-shaped or tiat with a dianeter of about 5 c.m. Remains of the velum adhere to the margin. The underside of the cap is at first yellow, later monse-grey. 'The lamellae are of three sizes, the largest extending from margin to stalk. From the lancllae arise the bisidia, with four sterigmata each giving off a single spore. The spores fall at matmity, and cover neighbouring objects with a brown dust. They are oval with a length of $7-10 \mu$ and a breadth of $5-6 \mu$.

The sporophores spring up rapidly in large numbers on

${ }^{1} v$. Tuhenf, "Eine neue Krankheit d. Weisstanne." Zritschr. f. For w uagrlwesen, $1 \mathrm{~S} ! 0$. 
living stems of silver fir, beech, etc., and on felled wood. ${ }^{1}$ In the forest, on newly erected piles of firewood, the jellow stools may frequently be found in every stage of development growing from the cut billets, while they are especially numerous on the rotting useless timber left lying. In cellars or other moist

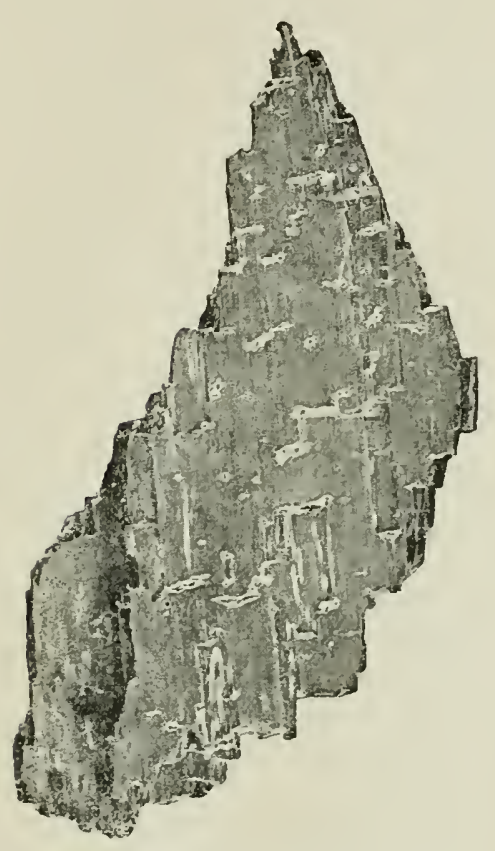

FIG. 290.-Agaricus adiposus. Destruc. tion of Fir-wood. The deeply-corroded cross-fissures contain white mycelium; the remainder of the wood is yellow. (v. Tubeuf phot.)

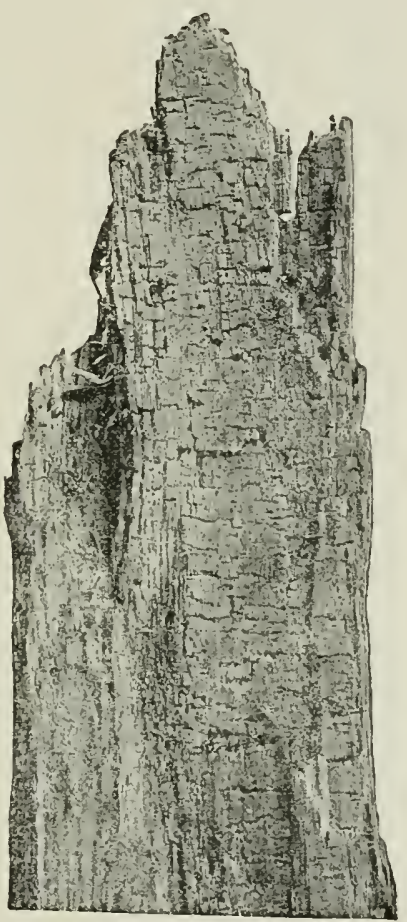

Fig. 291.-Aguricus adiposus. Destruetion of Fir-wood. Later stage. The corroded fissures no longer contain mycelium. (v. Tubeuf phot.)

chambers, the sporophores may be abundantly produced till Christmas, but out-of-doors, August is the time of fructification.

The mycelium forms felted masses under the bark or in cracks of the wood, and thence the sporophores arise as little paleyellow buttons, which gradually unfold and become differentiated into cap and stalk. While quite young, they show the darker

\footnotetext{
${ }^{1}$ Previous to the publication of $v$. Tubeuf's investigation the fungus had only
} been observed on living beech and felled wood. 
scales arranged regularly in concentric lines. The stools break out from living stems through cracks in the bark or from wounds,

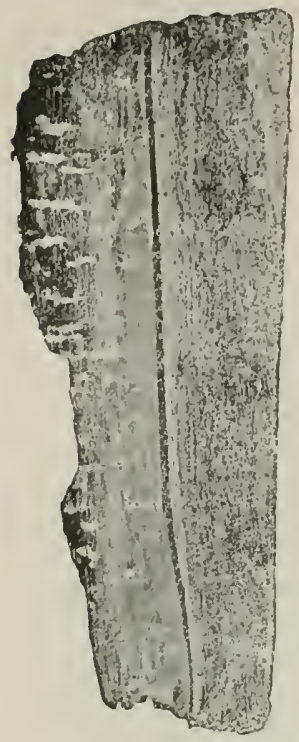

Fxa. 292. - Agrericus rediposus and Polyporus Hertigii. Destruction of Fir-wood. The boundary of the regions affected by th. two fungi is formed by a very dark line of demarkation. To the right the destruction is that produced by Polyporous Hertigit, to the left by Agaricus adiposus. (v. Tubeuf phot.) e.y. those made by wood-peckers.

The fir-wood, normally white, assumes, when diseased, a yellow or honey-colour, more or less like the sporophore, while here and there, parts may become light brown. The hyphae grow in all directions, but especially as white strands up and down the year-rings, while others in horizontal and vertical direction break up the wood into irregular patches (Fig. 290). In the final stages of destruction the wood will be found laminated into its separate year-rings and very much broken up into inregular pieces (Fig. 2.91).

The sporophores of this Agaricus are not uncommon protruding from barkcankers caused by Accidium clatinum, and its mycelium assists in the destruction of the stem.

Agaricus (Pholiota) squarrosus (Miill.). On living and dead stems of broad-leaved trees. (Britain.)

Ag. (Ph.) destruens (Brond.). On living and dead stems of poplar. (Britain.)

Ag. (Ph.) aurivellus (Batsch.). On living and dead stems of broad-leaverl trees. (Britain.)

\section{"FUNGI IMPEREECTI."}

The fungi placed here have life-histories which as yet have not been completely investigated, most of them being known only in the form of pycnidia or conidia. The number of species was at one time much larger, but it is gradually being reduced as the forms are proved to be stages in the life of some species of definite systematic position in the other groups already considered.

The gromp may be divided into the provisional sub-groups, the Sphacropsidece, Melaneoniere, and Hyphomyectes. 


\section{SPHAEROPSIDEAE.}

Conidia abjointed from conidiophores contained in darkcoloured pycnidia somewhat spherical in form. The various species are provisionally arranged in genera according to the colour of the conidia and the number of cells contained in them. The families here included are the Sphacrioidece, Nertrioidecte, Leptostromaceae, and Excipulaceae.

\section{FAM. SPHAERIOIDEAE.}

HYALOSPORAE.

\section{Phyllosticta.}

Fungi with colourless spores, and producing sharply defined spots on living leaves. They occur on all kinds of woody plants, but as a rule the injury caused is too slight to be called a clisease.

From the long list given by Saccardo (Vols. III., 1x., and $x$.) the following have been selected:

Phyllosticta persicae Sace. This produces on leaves of peach brownish-yellow spots, frequently marked by concentric zones. The name "shot-hole fungus" has sometimes been applierl to this and other allied forms, because the leaves become more or less perforated by the withered spots falling out. The pycnidia on reaching maturity rupture the lower epidermis of the leaf in a star-like manner. Briosi and Cavara do not regurd this parasite as very harmful, becanse leaves attacked by it remain alive without serious prejudice to their function.

$\mathrm{Ph}$. pirina sace. has been observed injurious to pear-trees at Geisenheim (Germany).

Ph. prunicola Sacc. is the canse of spotting of leaves of apple, plum, cherry, and apricot. (U.S. America.) ${ }^{1}$

Ph. cytisi Desm. On leaves of Cytisus Laburnum in Britain and Europe.

$\mathrm{Ph}$. acericola Cook et Ellis. On various species of maple (Acer dasycarpum, etc.). It is described by Galloway ${ }^{2}$

I The chief authorities for the occurrence of the "Fungi imperfecti" in Britain and North America are Massee (British Funyus Flora, 1595), Farlow and Seymour (Host-Iudex for U.S. America, 1891), and Saccardo (Sylloge fungorum). Professor J. W. H. Trail kindly revised the records for Britain. (Edit.)

${ }^{2}$ Galloway, "Report of sect. of Teget. Pathology for 18s8." U.S.A. Dept. of Agriculture, Washington. 
as injurious, especially in nurseries and groves where the trees are grown in number.

Ph. sphaeropsoidea E. et E. is another American species which has become prominent on account of its ravages in nurseries of horse-chestnut. The disease appears about the end of Iune, and hy August the folinge of attacked trees is almost entirely dead.

Ph. grossulariae sace. Un leaves of libes Girossuluric in Italy and North Anerica.

Ph. vulgaris Desm. A common species on leaves of species of Lonirerr. (Britain and U.S. America.)

Ph. sambuci llesm. On species of Sumlucus. (Britain.)

Ph. cornicola (D.C.). On leaves of species of Corms in America.

Ph. limbalis Pers. On oblong white spots on leaves of box. (Britain.)

Ph. tiliae Sace. et Speg. On leaves of Tiliu. (Britain.)

$\mathrm{Ph}$. maculiformis Sace. is probahly it stage of spherevelle maculiformis Auersw. It is a langerous parasite causing a leaf-spot on sweet chestunt (Castumece) and other trees.

Ph. violae Desm. A somre of considerable rimage to violets in America; it also oceurs in Europe and Britain.

$\mathrm{Ph}$. althaeina sacc. las been reported as dangerous to hollyliock in the United States. ${ }^{1}$

Ph. phaseolina Sace. appears occasionally as a parasite on leaves of kidney beans. (U.S. Americis.)

$\mathrm{Ph}$. viciae (Lil).). On Ticin sepinm. (Britain.)

$\mathrm{Ph}$. cirsii Iesm. On leaves of rimsium. (Britain.)

Ph. apii Hals. ${ }^{1}$ produces a leaf-spont on celery, and has caused considerable loss in America.

Ph. tabaci Pass. occuls on leaves of tobacco in Italy.

Ph. bataticola Ell. et Mart., and others, have been recorded on sweet potato in America.

Ph. betae Ouxl. occurs on leaves of sugar beet and mangel.

Ph. tabifica Prill." Prillieux believes the disease of beetroot known as "heart-rot," to be lue to this Plyyllosticta. It is probably a conidial form of Sphacrella tabifica P'rill. The symptoms of disease are withering of the onter leaves, followed by the appearance of whitish spots with withered tissue filled up with mycelium. Thence the disease spreads into the younger parts and causes "heart-rot" of the root.

Frank is of opinion that "heart-rot" is cansed by Sporides-

${ }^{1}$ N. I. Agric. Exper. Station Repror, 1891.

${ }^{2}$ Prillieux et Delacroix, Bullet. de la soc. mycol. de France, vir., 1891. 
mium putrefaciens Fuck. This is probably the cause of the gradual blackening of the leaves, yet it does not appear to lose its saprophytic nature.

Frank also gives Phoma betce Fr. as one cause of the heartrot of the sugar beet (comp. Phoma).

It will thus be seen that the canse of the rotting of beetroot, sugar beet, and mangold is still very obscure. ${ }^{1}$

Ph. galeopsidis Sace. On leaves of Galeopsis Tetiahit. (Britain.)

$\mathrm{Ph}$. atriplicis Desn. On leaves of Chenopodium and Atriplex in Europe and Britain.

Ph. chenopodii Sacc. has been found injurious to spinach in America.

$\mathrm{Ph}$. podophylli (Curtis). In leaves of I'odophyllum peltatum in America.

Ph. primulicola Desm. On withering leaves of Primula. (Britain.)

Ph. ruscicola Dur. et Mont. On leaves of species of Ruscus. (Britain.)

\section{Depazea.}

A provisional genus including species of which the spores or conidia are unknown, so that the forms included in it will probably be found to be related to various groups. They live in many cases on living leaves, cansing discoloration. Some of thenl are:

Depazea acetosae Op. On lizmex Acetosa.

D. impatientis Kirchn. On Impatiens Noli-tangere.

D. geicola (Fries). On Geum urbanum.

\section{Phoma.}

Conidia unicellular and colourless. Pycnidia black and embedded, but having a distinct pore. The species produce spots with ill-defined margins.

Phoma abietina Hartig ${ }^{2}$ (F'usicoccum abietinum Prill. et Delac). This parasite is a frequent cause of death to the silver fir. The branches become brown, yet retain their needles, hence when they occur isolated amongst neighbouring green branches they are at once conspicuous. On close examination of the clead or dying branches, areas of shrunk or con-

${ }^{3}$ According to Karlson (Petrousk. Akad. f. Landwirthschaft, 1590) and Hellriegel (Zeitsch. des Verein $f$. Rïbenzuckerindustrie d. deutsch. Reiches, 1890) insects take no part in it.

${ }^{2}$ Hartig, Lehrbuch d. Baumkrankheiten, Ed. II. (English Edition by W. Somerville). Ner, E., Journal de Botanique, 1893. 
stricted tissue will be found extending quite romnd the twig (Fig. 29.3). At these places the bark and cambium have been

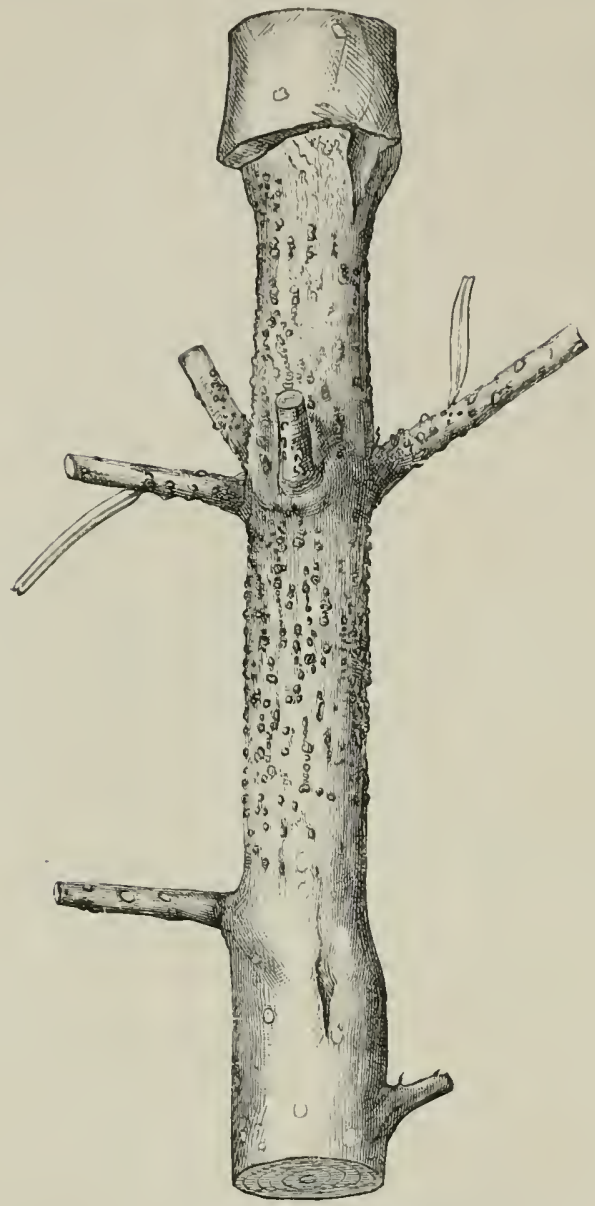

Fig. 293.-Phoma abietine. Twig of Silver Fir showing the constriction characteristic of this disease, dotted over with pyenidia. (After R. Hartig.) killed, whereas the higher portions of the twigg have continned to increase in thickness. Numerous small black pycnidia break out on the bark of diseased places and give off small unicellular spindle-shaped coniclia, which convey infection to new hosts in August or September. Killed branches die and dry up without casting their needles. ${ }^{1}$

$\mathrm{Ph}$ pithya Sacc. causes a disease similar to the preceding on the Donglas fir (Pscudotsuga Donglesii). The pyenidia of the fungus are found on dead constricted parts of twigs, and they, as well as other symptoms of the disease, closely resemble those of Phoma abietina. Rostrup ${ }^{2}$ defined and described it as $P h$. pithya Sacc. Magnus also records it on branches of Pinus sylvestris in Berlin botanic garden.

Other species of Phoma frequent other conifers and broad-

${ }^{1}$ Bihm (Zeitsch. f. Forst- $u$. Jagd-uesen, 1896, p. 15t) describes and figures an attack of this parasite on Pseudotsuga Douglasii in North Germany. One cannot, however, avoid suggesting some confusion between this and 1 'h. pithya described next. (Edit.)

2E. Rostrup Undersopylser over Snyltes rampes Angreb paa Skovtraeer, 1SS3-1SSS. 
leaved trees, but details in regard to their parasitism are wanting.

Ph. Hennebergii Kühn. ${ }^{1}$ Brown-spot of wheat-ears. This produces, on the glumes of wheat, brown spots with projecting pycnidia from which unicellular conidia emerge. The grains of attacked ears shrivel up and become spotted, while the value of the chaff as fodder is much diminished. Whole fields may be attacked, showing marked discoloration, and producing but few healthy ears. ${ }^{2}$ The fungus may also appear on the leaves and produce pycnidia.

$\mathrm{Ph}$. lophiostomoides Sacc. ${ }^{3}$ Lopriore regards this as a parasite on cereals, but Cavara looks on it as saprophytic on the dead plants.

Ph. ampelinum De Bary (Sphacelome umpelinum De Bary). Anthracnose of the Vine. ${ }^{4}$ The mycelium of this fungus can penetrate into leaves, green bark, or fruit, and kills the tissues. Spots are first prodnced, then enlargement of the neighbouring tissues takes place, causing the spots to appear as if sunk in depressions, and reminding one of hail-wounds. On leaves and grapes, the spots are sharply defined, at first dark-brown, later with greyish centres and dark-brown margins. In the

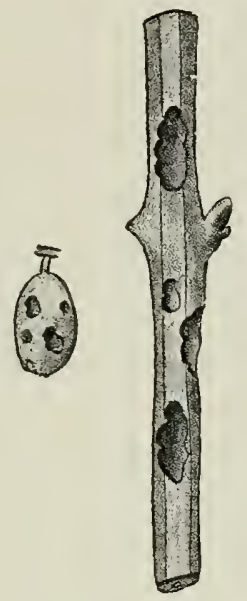

Fig. 294.-Phoma ampelinum. Brown concave spots on shoot and berry of Vitis. (v. Tubeuf del.) later stages the dried-up spots may drop out of the leaves.

Anthracnose, or "birds-eye rot," constitutes one of the dreaded vine diseases of America and Europe, so that it has received much attention, both as to its life-history and remedial measures; as yet however with but partial success. Copper sulphate solutions seem to be fairly successful remedies, as shown from results of the many experiments recorded in the Journal of

${ }^{1}$ Kühn, Hedwigfia, 1877, p. 121 ; also in Rabenhorst's Fungi europ. No. 2261. Frank, Zeitsch. für Pfanzenkrankheiten, 111., 1893, p. 28.

${ }^{2}$ Eriksson (Mitthl. der k. Landb. Akud. Stockholm, 1890) records a case of this kind, but the conidia are drawn two-celled as in a Diplodina, whereas Kuhn's original drawings have only one-celled conidia.

${ }^{3}$ Cavara et Eriksson, Zeitsch. f. Pflanzenkrankheiten, III., p. 23.

* Goethe, Mitthl. ïb. den. schwarzen Bremer d. Reben. Leipzig, 1s7s. Cornu, Bullet. de la Soc. botun. de France, 187s. Prillieux (idem), 1S79. Ráthay, "Der Black-rot," 1S91. Scribner, Report of U.S. Aner. Dept. of Agriculture, 1 SS6. 
Mycology and the bulletins and reports of the American experimental stations. (Compare also riloensporiem ampeloplungum (Pass.) p. 484.)

$\mathrm{Ph}$. betae lrank. 'The younger leaves of well-developed beet-root become black, and the disease extends into the root. Mycelium fills the diseased parts and penetrates into healthy tissnes. l'yenidia are developed on the diseased spots. The fungus is no relation of Sporidesmizm putrefaciens, a form to which a root-rot is ascribed by Frank. It is however probably identical with Prillienx's Phyllostictu tabifice. Kriiger found the disease so eommon, that in many localities as many as 80 per cent. of the plunts were destroyed. Soraner regards the root-rot of beet to be sometimes caused by Phoma, sometimes by Sporidesmium, perhaps in some cases by both together.

$\mathrm{Ph}$. sanguinolenta liostr. ${ }^{2}$ attacks carrot plants in their first year, causing greyish-brown depressed spots on the bulbs without however appearing to be very injurious to them. When the seedlings are planted out in spring, the mycelium extends into the stem aud causes the umbel to wither at flowering so that no seed is formed. Pyenidia are developed from all attacked spots and give off conidia as red tendril-like bodies-hence the species-name. Certain varieties of carrot appear to resist attack by this parasite better than others.

Ph. solani Hals. This causes damage to the egg-plant (Solanum melonyenu). ${ }^{2}$ Young plants die off on the hot-beds, their stems dying near the earth and shrivelling up. The pycnidia of this Phoma appear on the killed parts.

$\mathrm{Ph}$. cydoniae Sacc. has been reported as injurious to quince trees. (U.S. America.)

Many species cause leaf-spot diseases. Some of the more important British and American species are:

Ph. pinastrella Sacc. On Pinus sylcestris and others. (Britain.)

Ph. strobi (B. et Br.). On Pinus Strolus. (Britain.)

Ph. taxi (Berk.). On yew. (Britain.)

Ph. Candollei (Perk. et Br.). On box. (Britain and U.S. America.)

Ph. sorbi (Lasch.). On leaves of Pyrus Aucupurice. (Britain.)

${ }^{1}$ Frauk, Zeitsch. f. I'flanzenkrunhheiten, III., p. 90, and Dentsche landiv. Pr. No. 89, 1893. Kringer, Zeitsch. f. Pflanzenkrankheiten, Iv., 1894, p. 195.

${ }^{2}$ Described and figured by Halsted in Bnlletin 91, $1 . J$. Ayric. Exper. Station. 1892. 
Ph. malvacearum West. On mallows and hollyhock in Europe.

$\mathrm{Ph}$. longissima (Pers.). In species of Umbelliferae and Chenoporliaceae in Europe and America.

Ph. errabunda Desm. In stems of l'erbascum. (Britain.)

Ph. cucurbitacearum ( $\mathrm{Fr}$.). On fruits of various species of Cucurbitaceae in Europe and America.

\section{Dendrophoma.}

Pycnidia similar to Phoma, conidiophores however bearing several conidia either on lranches or little processes

Dendrophoma Marconii Cav. attacks Hemp (Cannalus sativa), cansing dark oblong spots on the green stem. The pycnidia are embedded and break through the epidermis with a round pore. The conidiophores are branched, with swollen ends carrying little short rocl-like unicellular conidia. In case of attack, which generally occurs towards the close of the vegetative period of the hemp, it is suggested to cut the crop somewhat prematurely, and thereby prevent maturing and spreading of the fungus.

D. convallariae Cav. prorluces dark elongated spots on leaves of Convallaria majalis.

D. valsispora Penz. is recorded by Penzig on living leaves of Citrus Limonum (Lemon).

\section{Sphaeronaema.}

Pycnidia embedded, nembranous, and long-beaked. Conidia ovoid or oblong, unicellular, and almost colourless.

Sphaeronaema fimbriatum (Ell. et Hals.), (Ceratocystis fimbricatce Ell. et Hals.). Black rot or black shank of sweet potato. ${ }^{1}$ The parasite shows itself as black depressed spots on the lower parts of young plants, and these may extend over the whole shoot. The disease is best recognized on the tubers, where it consists of dark, somewhat greenish spots, varying from $\frac{1}{4}$ to 4 inches in diameter, and extending some distance into the tissue. These spots when once seen cannot be mistaken, as they are sunk areas with distinct margins, like spots burned into the potato with a piece of metal which has left the skin uninjured. The mycelium consists of thick-walled olive-brown hyphae, which cause death and destruction to the

${ }^{1}$ Halsted and Fairchild, Jour. of Mycology, Vol. vir., 1891, with Figures. 
cells of attacked tissues. There are three modes of spore production: (1) brown macro-conidia insile the tissues; (2) colourless micro-conidia on the spots; (:3) spherical pyenidia with long necks ending in a fringed opening. A sclerotial form is also strongly suspected. Remedial measures recommended are, destruction of all cliseased parts, change of crop on diseased tields, and selection of healthy seer and strong sprouts.

Several other species of this genus are recorled from North Anerica, but details in regard to their mode of life are wanting.

\section{Asteroma.}

Fungi forming star-like, dark-grey, mycelial patches on the surface of plants. Pyenidia very small and containing tiny ovoid or short eylindrieal spores. Several species frequent living leaves. ${ }^{1}$

Asteroma impressum Fuck. On Tussilago farfar

A. prunellae Purt. On leaves of Prinellu rulgaris. (Britain.)

A. ulmi Klotsch. (Britain), and A. maculare Rud. On LTmers.

A. padi (D.C.) causes a leaf-fall on Prumus Pudus. (Britain.)

A. geographicum Desm. is found on the leaves of species of Cratacgus. Prunus, and Pyrus in Europe and America.

\section{Pyrenochaeta.}

Pycnidia emergent or sessile, beset with bristles. Conidia oblong, on branched conidiophores.

Pyrenochaeta rubi-idaei Car. forms black spots on leares of Rubus Idaeus. The pyenidia are spherical with a tuft of bristles projecting from their terminal pore. The conidia are little, oval, and with one or two cells; they are produeed from slightly branched conidiophores.

\section{Vermicularia.}

Conidia unicellular, rarely bicellular, generally spindle-shaped; they are produced inside pycnidia, and are embedded amongst brown septate hairs. The species are a frequent cause of leafspot, but most of them have not yet been sufficiently investigated.

${ }^{1}$ Cicinobulus Cesatii De Bary, allied to this genus, is a parasite on Oidinm. Tuckeri, the dreaded vine-parasite. 
Vermicularia trichella Fr. occurs on living leaves of iry and other plants. (Britain.)

V. ipomoearum Schw. On species of Ipomoea in America.

V. microchaeta Pasc. On living leaves of Camellia japonica in Italy.

V. circinans Berk. Onion rot in Britain and U.S. America.

Placosphaeria and Cytospora are genera containing forms parasitic on living plants, but of little practical importance.

\section{Phaeosporale.}

\section{Coniothyrium.}

Pycnidia brown or black. Conidia brown, unicellular, spheroid or ovoid, and borne on short conidiophores.

Coniothyrium (Phoma) diplodiella Sacc. ${ }^{1}$ White-rot of the vine. This disease has a wide distribution in Hungary, and has also been olserved in France, Italy, and America. It has caused considerable damage, especially in Northern Italy, where it was for a long time regarded as the black-rot.

According to Mezey, this parasite is distinguished from Lacstadic (black-rot) in the following points:-The pycnidia and conidia are larger; the mature pycnidia are greyish or light brown (never black), the mature conidia are brownish. The disease attacks the fruit only, causing it to fall off. Táthay, however, states that it also attacks young shoots, infection taking place from the fruit. Diseased grapes become soft, rotten, and wrinkled; the ridges are beset with pycuidial pustules, as in black-rot, but the grapes never become brittle and hard.

Viala and Ravaz ${ }^{2}$ have recently succeeded in rearing perithecia from twigs and fruit-stalks set in sterilized moist sand. None could be found on grapes. The perithecia are globular, enclosed in a black covering several cells thick, and with a large craterlike aperture. The asci and paraphyses arise only from the depth of the perithecium, the latter being longer than the former and frequently branched. The asci are club-shaped and short-stalked, and contain eight spindle-shaped colourless or yellowish ascospores, divided by one to three cross-septa. They germinate and produce one or more germ-tubes.

1 Ráthay, "Der White-Pot," Dic Weinlaube, 1892.

General description in Report 9, New York Ayric. Exper. Station, 1890.

'Viala and Ravaz, Compt. rend., cxix., 1894, p. 443. 
A new genus Charrinia, belonging to the sphacriaceace of the Ascomycetes, has been formed to reeeive this species.

\section{Sphaeropsis.}

l'ycnidia black and spherical, with an aperture. Conidia ovoid or oblong, unicellular, dark-coloured, and on stalk-like conidiophores.

Sph. malorum Peck. The canse of a disease in Anerica, known as the black-rot of apple and quince. The mycelium permeates and destroys the skin of the fruit, which, in consequence, becomes dried up and mummified. It also occurs in Britain.

Other species attack plants of various liosacene.

\section{Phanodidyane.}

\section{Diplodia.}

Pycnidia, small, spherieal, and dark-coloured; the conidia are two-celled when mature.

Diplodia gongrogena Temme. Temme discovered a mycelium and the pycnidia of this Diplodia in aspen (Populus tremulae) exhibiting hypertrophied outgrowths of wood and rind. As yet it has not been possible to artificially produce these malformations on the aspen, nor other somewhat similar ones which occur on the willow.

Other species of this genus attack many trees, e.g. holly, lilac, horse-chestnut, mulberry, and various conifers.

\section{HYALODIDYMAE.}

\section{Ascochyta.}

Conidia ovoid or oblong, bicellular, and hyaline. The pycnidia have a central aperture, and are embedded in discolonred portions of leaves or twigs.

The following species are of practical importance:

Ascochyta pisi Lib. (Britain). Briosi and Cavara state that

${ }^{1}$ Temme, Landwirth. Jahrluch, 158\%.

Thomas, Verhand. (d. botan. Verein d. Pror. Brandenlnrg, 1sit. 
this fungus is injurious to Pisum sativum, Phaseolus vulgaris, Vicia satira, etc. It causes spots on leaves and pods, followed by drying up of the former and deformation of the latter. The pycnidia appear as tiny points on the spots, and give out bicellular cylindrical conidia.

\section{As. Boltshauseri Sacc. ${ }^{1}$} This species was first observed in Switzerland on bean (Phascolus vulgaris). Leaves of all ages become brown-spotted, and premature defoliation may follow. The spots are marked by concentric zones, and bear pycnidia. The conidia are two- to three-celled, being distinguished in this and by their larger size from the preceding species.

The following species frequent living leaves:

Ascochyta tremulae Thüm. On

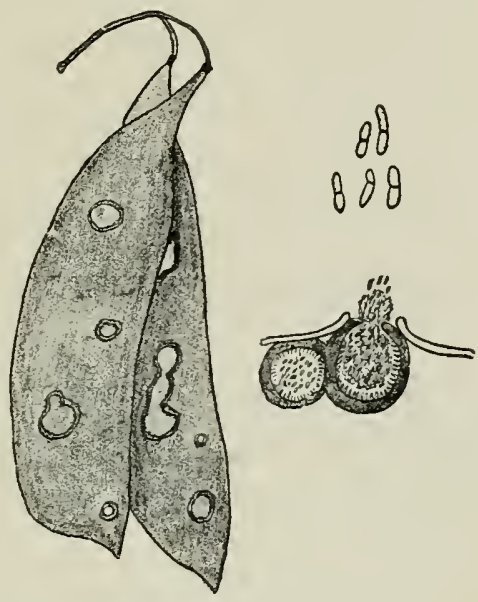

FIG, 295.-Ascochytu pisi on Pea. Enlarged section of pycnidia, and still more enlarged conidia. (v. T'ubeuf del.) the aspen.

A. metulispora, B. et Br. On leaves of the ash in Scotland.

A. armoraciae Fuck. On Armoracia misticana (Horse-radish). (Britain.)

A. periclymeni Thüm. On Lonicera Periclymenum.

A. maculans Fuck. On Hedera Helix.

A. Ellisii Thïm. On Vitis Labrusca in America.

A. brassicae Thiim. On Brassica oleracea.

A. dianthi (A.S.). On Dianthus. (Britain.)

A. pallor Berk. On Rubus telueus. (Britain.)

A. viciae Trail. On Ficia sepium, etc. (Britain.)

A. malvicola Sacc. On Malice sylicestris. (Britain.)

A. graminicola Sacc. On various grasses. (Britain.)

A. scabiosae Rabh. On Knautia artensis.

A. nicotianae Pass. On Nicotiana Tabaccum.

A. digitalis Fuck. On Digitalis purpurea.

A. fragariae Sacc. has been found injurious to the strawberry crop in the United States.

A. aspidistrae given (Gardener's Chonicle, XviI., 1895) as a parasite on Aspicistra in Britain.

${ }^{1}$ Boltshanser-Amrisweil, Zeitschrift f. Pfanzenkrankheiten, I., p. 135. 


\section{Actinonema.}

Pycuidia small and sitnated on a gossamer net of my'celinm. Conidia hyaline and divided by one or more cross-septa.

Actinonema rosae Lib. (Astromn muliosum Fr.). This prodnces black ralliating spots on rose-leaves, on which bycuillia with bicellular coniclia are developed. A prematmre defoliation takes place, which in turn causes the upper buds to unfold in antumn before their time. The mycelium is distributed both inside the leaves and superficially. Timely removal of diseaser leaves and defoliated shoots might be recommended as remedial measures.

A. tiliae Allesch. shows itself in spotting of the leaves and petioles of line, and may bring about defoliation of the whole tree.

A. fagicola Allesch. produces white spots with dark margins on living beech leaves, and causes gradual discoloration of the whole leaf. According to Allescher ${ }^{1}$ this disease brings about premature defoliation of beech. As yet it has been observed only in Upper Bavaria.

A. fraxini Allesch. On living leaves of the ash.

A. crataegi Pers. attacks leaves of Pyrus Aria, P. torminalis, anl I'iburnum Opulus.

A. podagrariae Allesch. On living leaves of Aegopodium Podugrario, and Chaerophyllum hirsutiem.

\section{Darluca.}

Darluca genistalis (Fr.). On living leaves of Cytisus sagitulis. This nuay, however, be only a parasite on Uromyces cytisi with which it is frequently olsserved, just as Dur. filum ocurs on several Uredineae.

\section{Diplodina.}

Similar to Diplodia, but laving colourless coniclia.

D. castaneae Prill. et Delac. ${ }^{2}$ procluces canker-spots on the stems of chestnut, and brings about death.

\section{Phraghosporae.}

\section{Hendersonia}

Pycnidia formed under the host-epidermis, which is later ruptured. Conidia brown, two-or more-celled.

${ }^{1}$ Allescher, Hedwigic, 1594.

${ }^{2}$ Prillieux et Delacroix, Bull. soc. mycol. de France, 1893. 
Hendersonia foliicola (Rerk.) (Britain and Europe). The black globular pyenidia are produced superficially on leaves of Juniperus communis. The conidia are elliptical in shape, three- to five-celled, and abjointed from filamentous conidiophores. (This species is not identical with Podiosoma Juniperi $\beta$ minor Corda, which is more like the needle-frequenting form of Gymnosporangium juniperinum. $)^{1}$

Several species are found on living leares:

H. cydoniae C. et Ell, on quince in America.

H. mali Thim, on apple.

H. rhododendri Thiim, on lihododendron hirsutum in Northern Italy and Germany.

\section{Cryptostictis.}

Similar to Hendersonia, but having ciliate spores.

Cr. cynosbati (Fuck.). Soraner ${ }^{2}$ regards this as parasitic on liosa canina, and causing death of portions of the rind.

Stagonospora, Couturea, Asteromidium, and Camarosporium contain species said to frequent living leaves of various plants.

\section{SColecosporae.}

\section{Septoria.}

Spores generally multicellular and hyaline; produced from short conidiophores, contained in lens-shaped embedded pyenidia.

Septoria parasitica Hartig. ${ }^{3}$ This disease may be frequently observed in young plantations and seed-beds of spruce. The symptoms are very like those following damage by frost, brown needles appearing in May towards the base or middle parts of young shoots, and followed by a premature needle-cast. The disease is most apparent on lateral shoots, which become sharply bent downwards, the green needles hanging limply till they wither and fall as the whole shoot shrivels up.

The pycnidia are little, black, and spherical: they are prodnced during the summer, particularly towards the lower end

${ }^{1}$ K. v. Tubeuf, "Generations-wechsel Gymnosporangium-Arten," Centralb/. $f$. Bakteriologie u. Parasitenkunde, 1891.

${ }^{2}$ Handbuch d. Pfanzenkrankheiten, II., 1876, p. 385.

${ }^{3}$ R. Hartig, Zeitsch. f. Forst. u. Jagl-uesen, 1890 ; and Forstlich-naturwiss. Zeitschrift, 1893 . 
of the shoots, and either rupture the epidermis or urow ont from the leaf-scar cushions (Fig. 297). The eonidia are abjointed from filamentons conidiophores inside the pycniclia, and energe as tendril-like structures. They are two-celled, small, cylindrical,

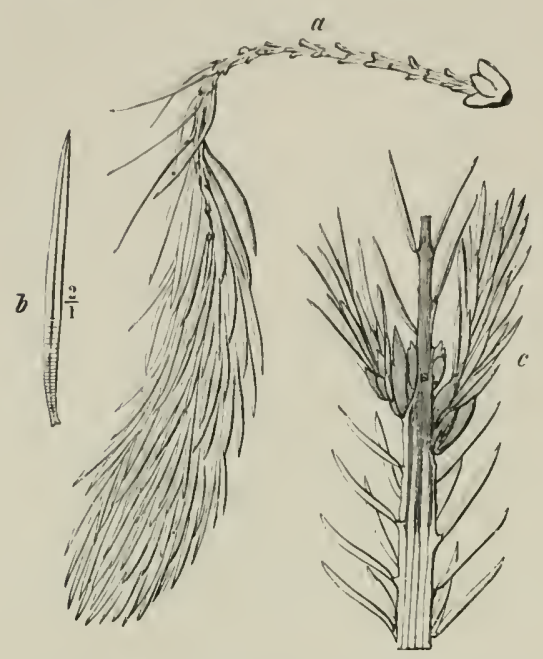

Frg. 296. - Si ptoria printsiticu. a, Young disensed shout of spruce, with apex still fresh and green. b, Needle diseased tomards base. c, Apex of a two. year-old shoot, into which the disease bas extended backwards from the rounger shoot; the brown discoloration of cortex and pith is indicated by shading. (After R. Hartig.)

Septoria rubi (Westend.). ${ }^{1} \quad$ Blackberry leaf-spot. This is a parasite of some economic importance in the United States, where it interferes with the blackberry eulture. It also occurs in Europe and Britain.

S. ribis Iesm, produces a somewhat similar disease on leaves of currant and gooseberry. ${ }^{2}$ (Britain and U.S. America.)

S. piricola Desm. occurs throughont all Europe, causing little greyish spots on leaves of pear trees. It is probably a pycnidial form of spluerella lucillue Sacc.

S. crataegi Kich. A common species on leaves of Cratuegrs in Europe.

S. cerasina Peck. On leares of Prunus serotina in the United States.

Many forms of Siptoriu infest cultivated vegetables:

S. petroselini Desm. is the canse of dry spots appearing on leaves of

${ }^{3}$ Description in Bulletin, No. 6, Ohio Agric. Exper. Station, 1891.

${ }^{2}$ Description in Bulletin, No. 13, Iowa Atrric. Exper. Station, 1891. 
cultivated parsley in Europe and Britain. A variety (upii Br. et Cav.) is an enemy of celery in the United States.

S. armoraciae Sacc. On horse-radish in America.

S. consimilis Ell. et Mart. frequents lettuce in America.

S. lycopersici Speg. This parasite, originally observed in America, has recently been described by Briosi and Carara on tomatoes in Italy. It causes spots on leaves, stems, and fruits, inflicting thereby consiclerable loss on cultivators.

The following are important forms on other cultivated plants:

S. graminum Desm. causes light spots on leaves of wheat, oats, and grasses. It has been observed to injure the cereal crop in Italy, It is recorded for Britain and U.S. America.

S. cannabis (Lasch.). This on leaves of hemp produces spots, which are at first whitish, then yellowish with dark margins. The pycnidia are embedded in the upper sicle of the leaf.

The following species have caused injury to garden plants:

S. dianthi Desm. Carnation-spot." The disease appears on the leaves and stems as rounded spots of

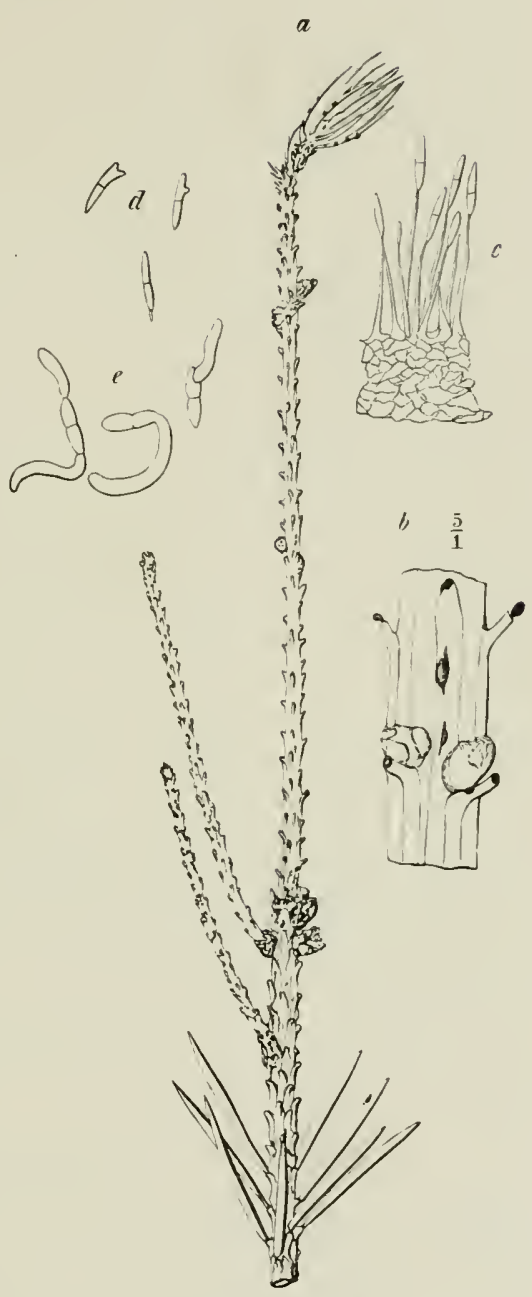

Fıg. $29 \pi .-\cdots a$, Leader-shoot of spruce, partially killed and defoliated. b, Pycnidia emerging from the rind and the leaf-scars $(x 5)$. c, Formation of conidia inside a pycnidium $(\times 240)$. $d$, spores germinating in water. $c$, Spores germinating in nutritive gelatine. (After R. Hartig.)

${ }^{1}$ Cavara (Zeitsch. f. Pflanzenkrankheiten, III., p. 23) regards this and S. tritici with its varieties, as forms of a single species; also Eriksson (Om $\mathrm{Nägra}$ sjukdomar ä odlade Växter, 1S90).

2Atkinson, "Carnation Diseases," at Anerican Camation Society, 1893. 
dirty white or brownish colour with a darker margin. The pycniclia appear as black points on the spots, and rupture the epidernis before giving off their septate spores.

S. anemones Desm. On Anemone. (Britain.)

S. Iychnidis Desm. On Lychenis diuma. (Britain.)

S. epilobii West. On Épilubium. (Britain.)

S. stachydis D. et R. On Stachyss. (Britain.)

S. urticae D. et R. On Urtica dioica. (Britain.)

S. cyclaminis Dur. et Mront. This produces romdish spots with concentric markings on the leaves of Cyclamen which then gradually wither.

S. chrysanthemi Cav, causes a leaf-spot on Chrysanthemum japonicum and C. indicum.

S. exotica Speg, attacks cultivated New Zealand species of Veronica.

S. hydrangeae Bizz. canses injury to cultivated Hydrangea.

S. sedi West. injures Sedum under cultivation in the United States and Britain.

Other species on many other herbs in Britain and America.

Nany species of Septoria have been recorded on trees and shrubs, e.g.:

S. rosae Desm. On roses. (Britain.)

S. hederae West. On ivy. (Britain.)

S. fraxini Desm. On the ash. (Britain.)

S. nigro-maculans Thum. Qn green walnuts, stmuting their growth.

S. castaneae Lev. On the sweet chestnut.

S. aesculi (Lib.). On the horse chestmut. (Britain.)

S. pseudoplatani Rob. et Desm. On leaves of sycamore.

S. populi Jesm. On leaves of poplar.

S. didyma Fuck. On Salix triandra and S. alba.

S. cornicola Desm. On leaves of Cornus sanguinea.

\section{Phleospora.}

True pycnidia are not formed, but the conidia are abjointed from cavities in the stroma; they are hyaline, rod- or spindleshaped, and consist of two or more cells.

Phleospora aceris (Lib.). On living leaves of Acer Psendoplatanus. (Britain.)

Phl. mori (Lev.). On living mulberry leaves; probably related to Sphaerella mori. (Britain.)

Phl. ulmi (Fr.). On living leaves of elm. (Britain and America.)

Phl. oxyacanthae (K. et S.). On living leaves of Crataegus Oxyacantha. (Britain.) 


\section{Dilophospora.}

Dilophospora graminis Desm. (Britain.) This attacks rye, wheat, and various grasses. Oblong light spots are produced and bear the pycnidia; when these occur in the flower heads, stunting of the grain takes place. (See also Dilophic, p. 222.)

\section{FAM. NECTROIDEAE.}

The fungi of this family are chiefly pycnidial forms of the Ascomycetes, and as such have already been considered.

\section{FAM. LEPTOSTROMACEAE.}

Hyalosporate.

\section{Leptothyrium.}

Pycnidia black and discoid. Spores oroid or spindle-shaped, unicellular, and hyaline.

Leptothyrium periclymeni (Desm.). On living leaves of species of Lonicerce. (Britain.)

L. alneum (Lév.) produces roundish leaf-spots on species of Alnus. (Britain and America.)

L. acerinum (Kunze) causes spotting of the leaves of Acer campestre and $A$. platanoides. (Britain.)

Several other species occur both in Europe and America.

\section{Melasmia.}

The black pycnidia occupy black extended stromata. Conidia simple and unicellular, borne on rod-like conidiophores.

Melasmia berberidis Thiim. et. Wint. On living leaves of barberry. Brown spots are produced, bearing the pycnidia as black points; the spots cause total or partial death of the leaves, frequently ending in defoliation of the shrubs.

M. empetri Magn. (Britain.) This species was observed by Magnus ${ }^{1}$ causing an epidemic disease on crowberry. The symptoms were abnormal elongation of young twigs, and the leaves remained smaller than usual. The rind of the stem was found to be permeated by a mycelium which produced black

${ }^{1}$ Berichte rl. deutsch. botan. Gesell., 18S6. With illustrations. 
pustules bearing the pyenidia of this Mclasmic. The cells of the cortex dried up, and the rind becane detached from the wood in the following year. 'The leaves were never found attacked. (The species is not a lihytismu; nor does any species of Rihytisma produce similar hypertrophy of its host.)

M. acerina, M. punctata, and M. salicina are now recognized only as pycnidia of the species of lihytism bearing these same specific names.

\section{Leptostroma.}

Pycnidia oblong, black, and Hattened. Conidia ovoid or oblong, unicellular, and whitish.

Leptostroma punctiforme Wallr. Found on the leaves of Salis, Rosa, Burus, Exphorlia, etc.

L. caricinum Fr. frequents leaves of Carex and Eriophorum in Europe and Nortl America.

The parasitism of other species is uncertain.

Labrella and Discosia are genera whose species have not as yet produced diseases of any serious economic importance.

\section{Phragmospoliae.}

\section{Entomosporium.}

Entomosporium maculatum (D.C.) Lev. ${ }^{1}$ This fingus, under the name of leaf-blight of pear and quince, is the cause of considerable loss in the cultivation of these crops. Defoliation takes place early in the season and young seedlings are forced to form a new set of leaves, whereby their reserves of food are exhausted. If this be repeated several times the plants become exhausted and are killed off in winter. Stocks already budded seem to remain immune if not already diseased. The leaves are first attacked, but later the succulent growing apex of the twigs may also succumb. The parasite hibernates on the bark in small depressions containing the pycnidia; thence it spreads in early spring, so that pustules appear on the young leaves before they are fully developed.

Spraying with Bordeaux mixture, or solution of copper acetate

\footnotetext{
${ }^{1}$ Galloway and Southworth (Report for 1885 of Section of Vegctable. Patholoyy, Dept. of Agriculture, U.S. America) give a historical account of the fungus and a bibliography. (E.lit.)
} 
(6 oz. in 26 galls. water) have both produced good results in checking the disease. ${ }^{1}$

E. mespili (D.C.). (See Stigmatea mespili, p. 210.)

\section{SCOLECOSPORAE.}

\section{Brunchorstia.}

Brunchorstia destruens Erikss. (B. pini Allesch.). In Norway almost all the plantations of Austrian black pine (Pinus Laricio) from five to thirty years old have become diseased and died out. Similar ravages have also been observed in Germany. Brunchorst ascribes this to a parasitic fungus whose mycelium may be found in all parts of diseased twigs and neerlles, and whose pycnidia are formed on the killed remains. The disease begins in young first-year twigs, the mycelium growing in the cortex, pith, and wool. The needles are attacked in summer, become brown from the base upwards, and the pycnidia make their appearance under the scale-leaves.

Brunchorst ${ }^{2}$ describes the fungus as follows: Pycnidia partially embedded in the tissues of the host-plant; the smaller ones being simple, the larger divided by complete or partial partitions. The inner wall as well as the partitions of the pycnidium are closely beset with straight basidia, from the apices of which stylospores with two to five septa are abjointed. Paraphyses are never present. The perithecia are black, oblong or rounded, slightly grooved, and $1-2 \mathrm{~mm}$. in diameter; they dehisce by one or more irregular pores in the wall. The spores are very minute $(30-40=3 \mu)$, tapering, and rounded at each end.

Schwarz considers Brunchorstic as a conidial form of Cenanguim abietis already described (p. 251).

It may be here mentioned that drying-up of pine-twigs may be due to heating by the sun in frosty weather, or to frost itself $;^{3}$ these are, however, quite distinct from the disease just described.

\footnotetext{
${ }^{1}$ Fairchild (Journal of Mycology, Vol. VII.) gives results of treatment with various fungicicles on several varieties of pear and quince. (Edit.)

2 "Ueber eine neue Krankheit d. Schwarzföhre." Bergens Museum, 1889.

${ }^{3}$ R. Hartig, "Vertrocknen u. Erfrieren 1, Kiefernzweige," Forstlichnaturwiss. Zeitschrift, 1892 and 1895 .
} 


\section{FAM. EXCIPULACEAE.}

The parasitic nature of the species of this fanily has not as yet been investigated to any extent.

\section{MELANCONIEAE}

True pyenidia are not formed, but the conidia are developed in clusters or aggregations covered over at first ly the epidermis of the host-plant, which is ultimately ruptured.

HYALOSPORAE.

\section{Gloeosporium.}

Conidial clusters colourless or grey, never black; they rupture the overlying epidernis and give off unicellular conidia, one from each conidiophore.

Gloeosporium fructigenum Berk. (1)ritain and U.S. America). Apple liot or Ripe-rot. This is a very serious dlisease for American cultivators. It not only attacks apple, but also the grape, pears, peaches, and egg-plants. ${ }^{2} \quad O_{11}$ the apple it appears first as brown spots which become more conspicuons as the fruit enlarges. The spots on first sight look like decay, but they are quite firm and soon bear pustules of a white or pinkish colour turning to black. The attacked part of the apple has an intensely bitter taste, and should be carefully removed before enting the fruit. On grapes the fungus produces tiny raised pustules, which on the white varieties are situated on spots with a purple centre and a brown margin; the pustules when mature give off flesh-coloured conidia. The grapes gradually shrivel up, but do not become black as in the case of the black-rot, nor do they assume a bitter taste as the apples do.

The apple bitter-rot makes rapid progress amongst stored fruit, especially before it has been sorted out. Care should therefore be taken that diseased apples are removed as soon as possible.

The spraying of trees benring young fruit with copper car-

${ }^{1}$ Southworth, Journal of Mycoloryy, vi., p. 164.

"Halsted, Bulletin of the Torrey Club, IS93, p. 109.

Inassee, Gardener's Chronicle, Vol. xIv., IS93. 
bonate or potassium sulphide solutions has goor effects on the yield of the orchards. In vineyards under treatment for blackrot or mildew, there is little chance of the ripe-rot fungus appearing.

It is probable that the species known as 61. phomoides sace. on tomato, Gl. pipercutum E. et E. on peppers (Capsicum (nnmum), and G\%. melangeae E. et Hals. on the egrg-plant, are identical with $G$. fructigenum. At least they very much resemble each other, even on their widely differing substrata, and cross-infections have been carried out.

Gl. venetum Speg. (Gl. necrtor Ell. et Ev.) Anthracnose of raspberry and blackberry. ${ }^{1}$ This disease appears on both canes and leaves. On the young shoots it produces small reddishpurple spots during early summer; as the season arlvances the spots run together into irregular blotches of more or less greyish colour with a dark purple margin. The ripening fruit remains small and shrivels up. Leaves may also bear spots, but they more frequently remain smaller and have an unhealthy look. The conidia are at first enveloperl in a thin covering, which becomes gelatinous when wet, so that they escape. The mycelium is believed to perennate in stems or decayed remains, and so to carry the parasite from season to season. Owing to the delicate nature of raspberry foliage, fungicides must be used with great care. Dilute Bordeaux mixture is said to be safe and beneficial. The burning of diseased canes should certainly be carried out each autumm.

Gl. ribis (Lib.). This attacks currant bushes throughout Europe and America in much the same way as Gl. venctum. The leaves wither and fall, so that the fruit-crop suffers. (Britain.)

Gl. amygdalinum Brizi." This has recently been described as destructive to almond cultivation in Italy. The mycelium inhabits twigs and fruits, and gives off tufts of conidiophores bearing conidia; as a result, wounds are produced in the epidermis and stunting of the host-tissues takes place.

Gl. rosae Hals. is described as injurious to rose-culture in America. It may be identical with some of the species of Glocosporium already mentioned as frequenting Rosaceae.

${ }^{1}$ U.S. America Dept. of Agriculture, Report for 1889, contains a good account.

${ }^{2}$ Brizi, Zeitsch. f. Pflansenkranklkiten, 1896, p. 65. 
Gl. ampelophagum (P'ass.) ${ }^{1}$ Black-rot of the vine. This risease is very injurious and has a wide clistribution in Europe. It is known uncler many names such as "Pock, Brand, Rost, .Jansch, Brussone, and Nebbia nera," though probably these names include several distinct disenses. The identity of this flocosporinm is somewhat uncertain, and it may really be identical with Phoma rempelinum (p. 467). liathay ascribes the black rot to Sphacelome (Phoma) ampelinum, while Thiimen regards Glocosporium as the cause. Briosi and Cavara consider the two species of fungi as distinct. Thiimen says that the patches of Clocosporium are for a considerable time dise-like and of a light-grey rose colour; those of Phoma, on the other hand, are always depressed and brown. Ríthay, however, describes the spots of Phoma as at first dark brown, and later asliy grey with a brown margin.

The spots appear on green parts of the vines during April and May. Those on the leaves frequently fall out, leaving holes. On the grapes the spots are smaller and produce a brown coloration extending deep into the fruit. The conidia are small, hyaline, oval, and unicellular; they are abjointed from very short conidiophores arranged in little elusters. The conidial patches rupture the host-epidermis, and the conidia are liberaterl.

Thiimen suggests that the soil of vineyards should he kepit well cleaned, and that the stake mode of eulture be used in preference to an overhead trellis; he also recommends the washing of all parts of suspected vines during winter with 10 to 15 per cent. solution of sulphate of iron. This treatment is saicl to have been very beneficial in keeping many vineyards quite healthy and free from fungi.

Gl. nervisequium. ${ }^{2}$ This parasite oceurs on species of Platanus in Europe and America. Brown spots appear on the leaves, especially on the veins; these as they extend cause sudden withering and fall of the leaves. Pustnles containing a stroma develop on the spots, and unicellular, ovoid, hyaline conidia are abjointed from club-shaped conidiophores.

\footnotetext{
${ }^{1}$ Thumen, Die Pocken an Wein u. Obst. 1855; Die Bekëmpfung d. Pilskrankheiten, 1S56; De Bary, Amalen d. Oenologie, IF.; Viala, Les maladies de la I'igne; Briosi e Cavara, Fungli parasit., III. : E. Ráthay, "Der Black-Rot," 1891.

"U.S. America Department of l'egetalle l'athology, Report for 1sss, gives a general account of this disease.
} 
Several fungi of very near relationship, if not actually identieal, occur on Platanus. ${ }^{1}$ All cause considerable disfigmration of the foliage, so that a systematic destruction of all yonng diseased branches is strongly recomusended.

Gl. cingulatum Atks. ${ }^{2}$ This is the eause of Anthraenose on Privet (Ligustrum vulgare) in the United States. The following is Atkinson's diagnosis: "Affeeted areas light brown, either oblong on one side of the stem or completely girding it. Acervuli 100 to 150 in diameter, rupturing the epidermis, in age black from the dark stroma lying in the base or extending irregularly up the sides, frequently forming a pseudopyenidium. Basidia numerons, erowded, simple, liyaline, or when very old perhaps faintly fuliginous. Spores obloug, or elliptical, straight or little eurved, usually pointed at the base. From pustules on the stem they measure $10-20$ by $5-7$; in artificial eultures they are frequently mueh larger, but when crowded in the media, or when the nutrient sulsstances are nearly exhausted, they may be considerably smaller. On stems of Ligustmum vulyure.

"This is quite distinet from Glocosporium ligustrinum Sace."

Many species of Glocosporium frequent broad-leaved trees and cause more or less injury to the foliage.

Gl. rhododendri Br. et Cav. attacks the leaves of onteloor entivated rhododendrons in autuun, or indoor species in winter. Large yellow spots marked with eoneentrie zones are formed, and bear the pycnidia; finally the leaves dry up and fall off.

Gl. violae B. et Br. attaeks violets in Britain and U.S. America.

Gl. vanillae Cke. et Mass. (C'ctnsponce ictuillue Massee. ${ }^{3}$ ) This eauses a dangerous disease on Tanilla planifolic and other Orehideae in Mauritius and other parts of the tropies. Death is bronght about by the Gloeosporium (Huinsen) form of the fungus, the ligher reproductive organs only appearing when the leaves are killed.

Other speeies are known, but their economie importance is not great.

${ }^{1}$ v. Tavel, Botan. Zeitung, 1856 ; Leclerc du Sablon, Revue gen. de Botunique, 1892.

"Atkinson, "A New Anthraciose of the Privet," Cornell Enir. Agric. Exper. Station Bulletin, No. 49, 1892.

${ }^{3}$ Massee, Kew Bulletin, 1892, p. 111. 


\section{Myxosporium.}

Conidia oroid, hyaline, and abjointed from rod-shaped basidia situated in carities of the cortical tissnes of arboreous plants: a true pycnidium is not former, and the reproductive mycelium is only covered over hy the epillermal layers of the host.

Myxosporium devastans liostr. ${ }^{1}$ is said to attack and lill young twigs of Brtule remperuse. The conidial patches are developed in the killed rind, and give off unicellular colourless conislia.

M. carneum Lil, is parasitic on twigs of leech.

M. laneola Sacc, et Romm. causes death of oak-twigs.

The other known species have as yet been observed only as saprophytes.

\section{Colletotrichum.}

Conidial patches suromuled by setae; characters very like Glucosporium.

Colletotrichum Lindemuthianum (Sace. et Magn.). ${ }^{2}$ This disease, first observed by Lindemuth in 1875 , has assumed great importance as a clisease of the kidney bean (Phuscolus: vulgaris) both in Europe and America. Young pods are most frequently attackerl, but neither stems nor leaves are exempt. The pods show brown depressed spots with a distinct margin. The unicellular and oblong conidia are given off from short conidiophores developer on the spots. Germination takes place at once, the germ-tube forming an adhesion-dise on the hostepidermis, and from this a hypha penetrates into the tissues to develop into a brown mycelium. Frank obtained brown spots and mycelium on young beans twenty-four hours after infection.

C. Lagenarium (P'ass.) (C. oligochactum Car.). This parasite is very injurious to seedlings of water melon (Cucumis citrullus), melon (C:Mrlo), and the gourt (Cucurtita Lagenuria). Leaves and fruits may be attacked, but it is the cotyledons and stems of the seedling plants which most frequently fall a prey. Spots

${ }^{1}$ Rostrup, Tids.lvrift f. Skorrap*n, 1893.

$\because$ For the relationship of this with the following species, as well as their synonomy, see Halsted in Bulletin of Torrey Botanical Chub, 1893, p. 246. Description, treatment, and bibliography by Beach, "Bean-spot cliscase," Generce N.Y. Exper. Station Bulletiu, No. 4 . 
appear on the leaves, and depressions on the stem, sometimes extending so far round that the whole shoot dries up. The conidial patches are very much the same on the different hosts, and consist of short conicliophores from which oval, unicellular, hyaline conidia are abjointerl.

C. lycopersici Chest. is the cause of a spot-disease on the fruit of tomato in the Uniter States.

C. spinaciae Ell. et. Hals. causes a destructive disease on cultivated spinach.

C. malvarum Br. et Casp. (C. althacae Southw. ${ }^{1}$ ) produces a disease of cultivated hollyhock. It is most injurious to the seedling plants, and has caused great loss in America and Sweden. The fungus may attack any organ, and produces spots which enlarge so rapidly that death of the host may result.

C. gossypii Sonthw. ${ }^{2}$ Anthracnose of Cotton. This disease, although it may be found on stems and leaves, is most frequent and most conspicuons on the fruits or "bolls" of the cotton-plant. The first signs are tiny depressed spots of a reddish-brown colonr, and as these

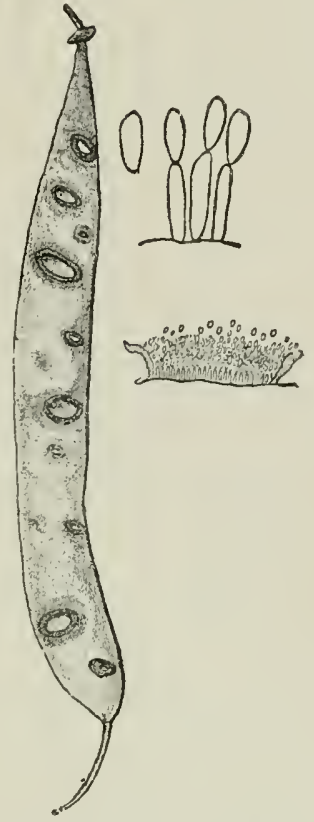

F1G. 295.-Colletotrichum Lindemuthianum on pod of Kidney Bean. Enlarged pustule and conidia. enlarge they canse blackening of neighbouring tissue. When the spores are developed the spots become dirty grey, or perlaps pinkish if the spores are present in large numbers. Fruit attacked in this way does not mature well, and the yield of cotton is greatly prejudiced. Atkinson found the cotyledons easy to infect with the disease. The spores are oblong and tapering, with a shallow constriction in the middle; they are borne either on short colourless basidia or on long, olive-coloured, septate setae, both kinds of conidiophore being produced in acervuli or patches.

C. adustum Ell. is the cause of a leaf-spot on orange in Elorida.

${ }^{1}$ Southworth, "A New Hollyhock Disease," Journal of Myrolory, V., 1890.

2 Southworth, Joumal of Mycology, vi., 1890, p. 100.

Atkinson, Alabama Atric. Exper. Station Bulletin, No. 41, 1892. 
Faded spots appear on the leaves, becoming later greyish brown dotten over with mimute hlack points, the conidial patches. ${ }^{1}$

C. ampelinum Cav. canses little hry spots on the leaves of vine, fuequently in such numbers that the whole leaf ilries up.

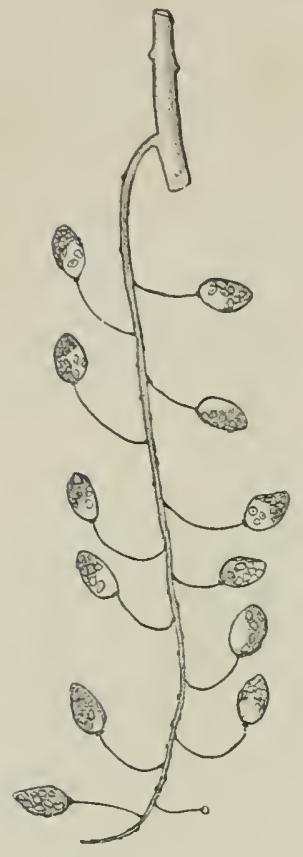

FIG. 209. - Cylindrosporium Tubeurienum on frits of Prunus Pallus. The unshaded parts represent parts still green and living, although bearing pustules here and there; the remaining parts nre completely beset by pustules, so that the eells are killed and brown. $\frac{4}{5}$ natural size. (v. Tubeuf del.)
C. kentiae Hals. attacks paln-seedlings sn that their leaves do not unfold.

C. cyclameneae Hals, outurs on Cyclamen.

\section{Cylindrosporium.}

The white and shining conidial cushions are embedded in the hostplants. The conidia are filamentous, frequently somewhat twisted.

Cylindrosporium Tubeufianum Allescher. This attacks the living green fruit of the bird-cherry, and canses the formation of brown spots from which pustules break out; the premature dropping of diseased fruits follows. In the locality where I observed this disease, numerous trees were attacked and most of the frui on each was badly diseased. The mycelium spreads through epicarp and mesocarp, but does not penetrate into the endocarp, so that the development of the embryo is not directly interfered with. The conidia originate in pycnidial cavities without any special peridium; their shape is given in the annexed diagnosis. $^{2}$ The pycnidial cavities arise under the epidermis which is afterwards ruptured and with the cells underlying it becomes brown and dead.

2 This note is taken from Underwood, Jommal of Myrology, vir, but no mention is made of it in the later paper by Welber and Swingle " Diseases of Citrous Fruits in Florida," U.S.A. Dept. of Agriculture Bulletin, 8, 1896). (Edit.)

"Allescher gives the following diagnosis of this species: Pustulis mimum coniexis, epicarpio tectis, dein applanatis scutiformibnsie, epicarpio mpto cinctis, subcircularibus, saepe caespitosis vel confluentibus, lutco-brunneolis, subfurfuraceis; acerulis, minutis, innatis, ermpentibus ; conillis filiformilns, curvatis rel tex. nosis multiguttulatis, hyalinis $40-60=2-3 \mu$. Hab. in fructibns immaturis Proni Padi, quos necat. 
As yet the disease has been observed in quantity only in the neighbourhood of Oberammergau (Upper Bavaria).

C. padi Karst. Leaf-blight of cherry and plum. This disease is most destructive in the nursery, causing premature defoliation of young trees; it may also cause severe injury to fruit-bearing trees. The leaves become spotted and perforated by holes caused by the falling out of withered spots. Spraying with dilute Bordeaux mixture early in the season is said to have good effects. ${ }^{1}$

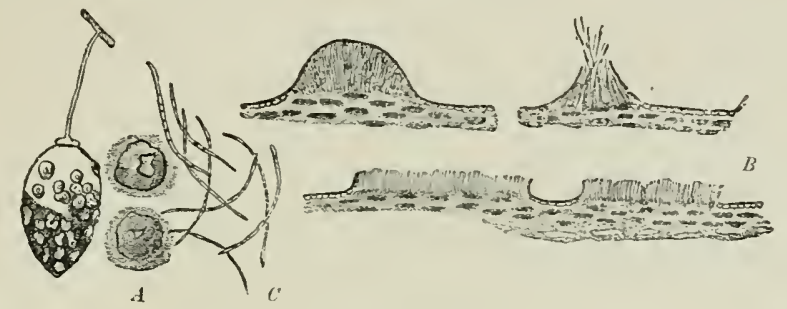

Fig, 300.-A fruit from Fig. 290 (enlarged). A. Two pustules still further enlarged. $B$, Pustules before and after rupture of the epidermis. $C$, lsolated conidia. (₹. Tubeuf del.)

C. filipendulae Thiim. occurs on leaves of Spiraea Fílipendula.

C. ficariae Berk. On leaves of Ranunculus Ficaria. (Britain.)

C. viridis E. et E., and C. minus E. et E. On leaves of Frurinus viridis in the United States.

C. cercosporoides E. et E. On living leaves of tulip-tree.

C. saccharinum E. et E. On living leaves of Acer saccharinum in the United States.

\section{Cryptosporium.}

Conidial cushions shaped like pycnidia. Conidia rod-like or spindle-shaped.

Cryptosporium leptostromiforme Kiihn.." This fungus forms rows of black stromata on the stems of lupines; in the stromata are formed pyeniclia-like cavities with several neck-like openings, and in them conidia are given off from conidiophores. The conidia are rods with rounded ends $7-8.5 \mu$ long and about $2 \mu$ broad: they emerge from the necks of the cavities as long tendril-like chains, and may be continuously given off

${ }^{1}$ Fairchild (Journal of Mycolofy, vir., p. 249) gives results of remeclial treatment.

?.J. Kühn, Berichte d. landwirth. Inst., Halle, 1580.

Fischer, "Ciyptosporium leptostromiforme." Breslau, 1893. 
throughout the whole summer. Fischer has prover experimentally that the coniclia gerninate easily in water, that the germ-tubes penetrate into living lupines, and produce a mycelium which spreads through stems and leaves to develop stromata on all the organs of the plant. The formation of both pyenidia ant conidia goes on throughout the antumn and following spring on dead plants, the fungus being capable of living as a saprophyte and of hibernating. The disease may oceur with great severity. Fischer describes cases where more than the half of the plants in a field were attacked and died hefore flowering or soon after. There is thus a loss not only in lupine seed, but also in the good effects which the crop has as a "gleen manure."

Fischer gives the following measures for keeping this pest in check: "Where the fungus has obtained a footing, lupines should not be planted till at least the year after next, and then only as a catch-crop on stubble: it wonld be still safer to keep lupines off the land till the third or fourth year. After lupines as a catch-erop, they may safely be sown again in spring as a seed crop, after the lapse of a elear year. No lupines should be eultivaterl near diseased fields. Instead of plonghing-in a catch-erop of lupines directly, it should be dried and used as litter for cattle, because the excrement has been founcl to kill the fungus: the lupines after lying over winter in the manureheap could then be used as manure in spring. Similarly when the lupines have been grown for seed, they should be closely mowed down so that little stubble is left; the straw may then be used for litter."

This fungus has not as yet been observed on plants other than lupines.

\section{DIDYMOSPORAE.}

\section{Didymosporium.}

Conidia brown, oval or spindle-shaped, bicellular, and not produced in chains.

Didymosporium salicinum Vuill. Tuillemin reports this as very destructive to the Osier cultivation in Bourgogne.

\section{Marsonia.}

Conidia transparent, two-celled, and not produced in chains. The species live on leaves. 
Marsonia juglandis (Lib.) produces on leaves of Juglans little greyish yellow spots with brown margins; thereon stromata are formed, which rupture the epidermis and liberate the large sickleshaped conidia. (Britain.)

M. populi (Lib.). On leares of species of Populus in Europe and Britain.

M. potentillae (Desm.). On species of Potentillo. (Britain.)

M. campanulae Bres. et All. On Campanula latifolia.

The following are North American species:

M. toxicodendri (Ell. et Mart.). On Rhus Toxicodendron.

M. quercus Peck. On (puercus ilicifolia.

\section{Phragmosporae.}

\section{Coryneum.}

The conidial patches are black and disc-like, and rupture the host-epidermis. The conidia are oblong or spindle-shaped, rellowish, and pluriseptate; they are abjointed from short conidiophores.

Coryneum Beyerinkii Oud. ${ }^{1}$ This is stated by Beyerink to be the canse of a "gunu-flux" of cherry and allied species of Rosaceae. It is the conidial form of Ascosporce (see p. 211).

C. camelliae Mass. ${ }^{2}$ occurs on living Camellice leaves at Kew. (Britain.)

\section{Pestalozzia.}

Conidia spindle-shaped, with two or more brown median cells and hyaline terminal cells, the one at the free end carrying several ciliate processes.

Pestalozzia Hartigii Tub. ${ }^{3}$ The external effects of this disease have been long known, although the fungus causing it has only been recently detected. It attacks young plants of various trees and shrubs. The symptoms are yellow discoloration of the foliage, and constriction of the stem just above the level of the soil, followed by death of the whole plant. At the constriction of the stem the rind gradually dries up, whereas neighbouring portions continue to grow in thickness till finally the bark is ruptured (Fig. $30^{\circ}$ ). In the living part of the

\footnotetext{
${ }^{1}$ Ondemans, Hedwigia, 1853.

${ }^{2}$ Cooke, Grevillea, xx., p. 8, 1891.

${ }^{3}$ v. Tubeuf, Beitrüge zur Kenntniss d. Baumkrankheiten, 18s8; and Forstlirh. naturwiss. Zeitschrift, 1892 .
} 


$$
14
$$


rind of young plants of spruce and silver fir; I succeeded in finding near the place of constriction, a delicate mycelial stroma enclosing some cavities (pseudopycnidia). Conidia were formed inside these cavities and emerged to the exterior. They belong to the genus Pestalozia, and have two brown median cells, a transparent stalk-cell to which the long stalk is attached, and a transparent terminal cell carrying two or three transparent threadlike appendages (Fig. 303). Germination results in the emission of a strong germ-tube from one of the three lower cells. If at any time the conidia dry up, the two clear transparent cells

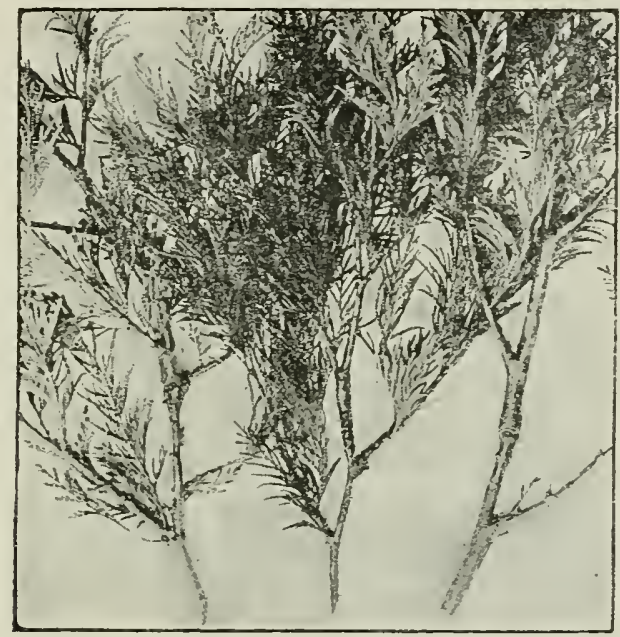

\footnotetext{
FiG. 304.-Pestalozzice funcrea on Chamecyparis Menziesii. At the places marked $X$ cambium and rind have been killed, so that growth in thickness no longer takes place; the higher parts, however, have coutinued to thicken, but are gradually dying. (v. Tubeuf phot.)
}

collapse and the appendages easily fall off, so that on material of this kind the conidia are only two-celled and brown. The mycelium after cultivation in nutritive gelatine soon produces conidia.

This fungus was found by Rostrup on beech, producing much the same effects as just described. On this host it has been found very destructive in young naturally regenerated forest, the loss in Bavaria and Wurtemburg within very recent years having beelı estimated at 30 per cent. It also occurs on ash, sycamore, and other trees.

P. funerea Desm. (Britain and U.S. America). The spores of 
this fungus were found by Boehm ${ }^{1}$ on diseased cypress trees, and although investigations are not yet complete, it is believed that this Pestalorzia is the cause of a well-known disease on eypress. The symptoms on Chamacyparis Mentirsii are local constrietion of stems and branches, and death of portions beyond. The rind and cambinm of constricted places are killed, the lark becomes split, and the wood dries up. $P$. funeren is a well-known saprophyte on twigs and needles of Cupressus, Juniperus, and other Conifers; its occurrence as a parasite has been suggested several times.

P. gongrogena Temme $e^{2}$ is said to canse the canker of willow. In diseased willows Temme found an intercellular and an intracellular mycelium with pyenidia and conidia of Prstulozica, but other pycnidia of unknown affinity were also present.

P. insidiens Zab. On bark of Ulmus americana. (U.S. America.)

P. phoenicis Grev. canses a disease on indoor enltivated palms. The following are some of the more important forms frequenting living leaves:

P. Guepini Desm. ${ }^{3}$ (U.S. America). The conidia of this species are found on large spots with dark margins on living leaves of Cumcllia japonica, MIagnoliu, Citrus, Phododcnutron, and other plants. Spore-patches appear on the epidermis, and give off conidia embedded in a mucilaginous slime. The conidia have three dark median and two hyaline terminal cells, the distal one bearing the characteristic appendages. The leaves are permeated with mycelium and fall prematurely.

P. inquinans C. et Hark. On Eucalyptus in California.

P. stictica B. et C. On Platunus occidentalis and Tilia in United States.

P. concentrica B. et Br. On leaves of Cratuegus, Pyrus, Custunea, and Quercus in North America.

P. suffocata E. et E., and P. discosioides E. et E. On cultivated and wild rose shrubs in America.

\section{Pestalozzina.}

Conidia sinilar to those of Pcstalozzia, but all the cells hyaline.

${ }^{1}$ Zeitschrift f. Forst. u. Jaydd-wesen, 1S94, 1. 63.

${ }^{2}$ Thiel's landwirth. Jahrbuch, 1857; and Ber. d. deutsch. botan. Ges., 1590.

"Annal. des Science natur., Sér. II., Vol. xir., 1S40; Briosi et Cavara, Funghi parasit., vI. 
Pestalozzina Soraueriana Sacc. ${ }^{1}$ occurs on foxtail grass (Alopecurus pratensis). The conidial tufts develop on spots which apjear on the gradually withering leaves. The bristle-appendages on the terminal cell of the conidia are lateral, only one being terminal. This disease was first observed by Weinzierl at Vienna,

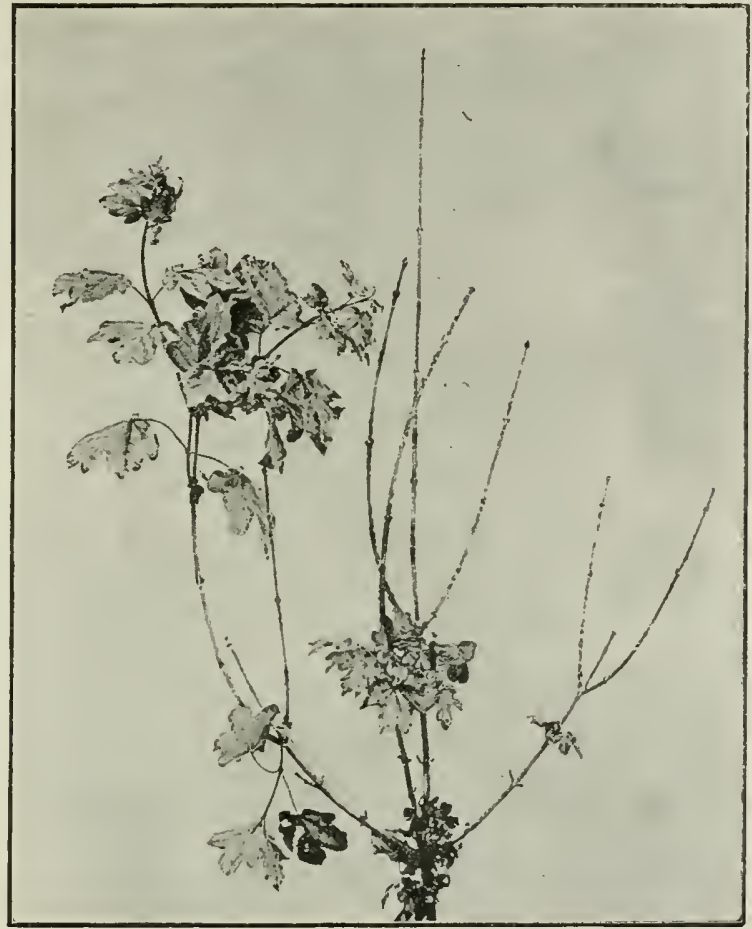

Fig. 305.-Siptogloeum Hartigionum on Acer campestre. The dead twigs exhibit black points and lines-the pycnidia of the parasite. (v. Tubeuf phot.)

and has not as yet been found out of that neighbourhood; it attacks the pure-culture seed-beds only.

\section{Septogloeum.}

Like Gloeosporium, except that it has pluricellular conidia.

Septogloeum Hartigianum Sacc. ${ }^{2}$ Twigs of the common maple (Acer compestre) are subject to a disease, which exhibits

1 Soraner, Zeitschrift f. Pfanzenkrankheiten, 1894, p. 213.

${ }^{2}$ R. Hartig, Forstlich-naturwiss. Zeitschrift, 1892, p. 289. 
itself in the drying-up of young twigs before their buds open in spring. The older branches, however, assume their normil foliage. Examination of diseased twigs reveals the mycelium of a parasitic fungus living both inside and between the cells of rind and wood. Conidial patches break through the host's epidermis about May as long greyish-green lines. The conidia are hyaline, three-celled, and cylindrical with rounded ends; the conirliophores are short thick rods. In May and Jume the spores are capable of infecting new hosts, and germinate in a few hours. Infection of twigs takes place in summer, and the mycelium spreads through the first-year shoots, without, however, giving any external indication of its presence till the following spring, when the twigs dry up as already iescribed.

S. ulmi (Fr.) may be a form of Phyllachora ulmi. The mycelium lives in parenchymatous cells, and causes the formation of brownish-yellow spots on leaves of the elm. The conidial patches form tiny points on the lower surface of the leaf; they consist of pycnidia-like structures without a peridium, arising from a stroma developed under the epidermis. The conidia are spindle-shaped and pluricellular.

S. mori (Lév.) is stated by Briosi and Cavara to produce yellow spots with brown margins on the leaves of Morus alba and M. nigra. Death and premature defoliation of the host then take place. The conidial patches develop under the epidermis, and rupture it as the conidiophores emerge; they have no real peridium, hence the fungus camnot belong to the group Phlcospora, as Saccardo supposed. The conidia are long, cylindrical or filamentous, and pluricellular.

Amongst the more important North American species are:

S. profusum (E. et E.). On living leaves of Corylus americana.

S. fraxini Hark. On Fraxinus Oregana.

S. apocyni Peck. On Apocymum cannabinum.

\section{HYPHOMYC'ETES.}

Conidia produced neither in pycnidia as in Sphaeropsideae, nor from a special stroma as in Melanconideae, but free on conidiophores given off from the mycelium. 
The group is subdivided into the families of the Muccdineae, Dematicae, Stilbece, and Tubercularicce. ${ }^{1}$

\section{FAM. MUCEDINEAE.}

1. SECT. AMErosporaE.

1. Subsect. Micronemeae.

\section{Oospora.}

Conidia, transparent or only slightly coloured, globose or ovoid, non-septate, and produced in regular chains from simple short conidiophores; they thus resemble the genus Torula in the Dematicue.

Oospora scabies Thaxt. ${ }^{2}$ is said to cause the well-known scab or scurf on beet and potato. This consists in portions of the surface of the subterranean tubers swelling out as rough brown excrescences. Other anthors ascribe this disease to bacteria.

\section{Microstroma.}

Conidia unicellular, transparent, oval, and shortly stalked.

Microstroma album (Desm.). This, although common on living leaves of several species of Qucreus, is not a serious disease. The conidial patches on the under side of the leaves are white and very thin. (Britain.)

M. juglandis (Béreng.) frequents the leaves of Juglans regia and $J$. cinerca in Europe and North America.

\section{Monilia.}

Conidia oval or spindle-shaped, and produced in chains from branched conidiophores.

Monilia fructigena Pers. (Britain and U.S. America.) This is the cause of certain widespread diseases-the brown-rot of cherry and plum, the peach-rot, and a rot on apples and pears. It has been the subject of many papers since Thïmen first described it in $1879 .^{3}$ All parts of the host are attacked, and

1 This is the arrangement followed by Massee, "British Fungus Flora," Vol. III.; there the characters of the various sub-divisions may be obtained. (Edit.)

2 Thaxter, Connecticut Agric. Exper. Station, Report, 1890.

${ }^{3}$ Amongst the more important descriptions are: Thümen, Fungi Pomicola, 1879 ; Smith (Worth. G.), Gardener's Chronicle, 1SS5, p. 52 ; Arthur, New Yorh. Agric. Exper. Station, IV., 1 SS5. 
exhibit reddish or yellow spots; therein the mycelium spreads rapidly and gives off tufts of conidiophores which rupture the epidermis. The conidiophores are septate, branched, and give off chains of unicellular oval conidia. Meanwhile the affected fruit becomes rotten and gradually shrivels up, it remains, however, hanging on the tree throughout the winter. I)uring
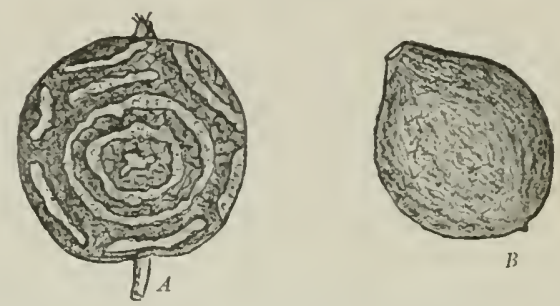

Fic. 306.-Monilice fiructigena. A, Apple showing the grcy conidial patches as more or less concentric lines. $B$, Young Peach, shrivelled up in consequence of attick. (v. Tubeuf del.)

next spring, when the fruit is again moist, further conidia are given off. Infection takes place by wounds or even through the epidermis of young leaves and blossoms. The conidia have

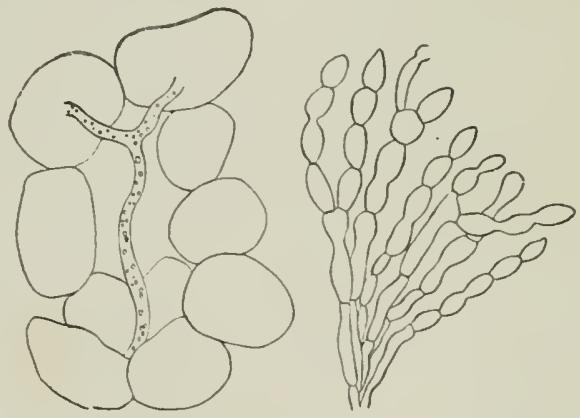

FIG. 307.-Monilia fiuctigcna. Branched conidiophore with chains of conidia. a, Branched hypha of Monilia in the tissue of an Apple. (v. Tubeuf del.)

been found to retain their vitality for two years. Smith ${ }^{1}$ found that twigs were also affected by the disease, so that a gummy degeneration took place in the soft bast and cambium.

As remedial measures, the gathering of all diseased fruit left hanging over winter is strongly recommended. This, as well as other diseased parts, should be burned as soon as possible.

${ }^{1}$ Smith (Erwin), Journal of Ifycology, vir., p. 36. 
Washing of stems with a solution of iron sulphate in spring before the buds unfold is suggested, also spraying of young foliage with dilute Bordeaux mixture.

\section{Oidium.}

Mycelium epiphytic on living plants. Conidia unicellnlar and barrel-shaped, produced in chains on erect conidiophores. Many have already been proved to be conidial forms of Erysipheae.

Oidium erysiphoides Fr. frequents living leaves of hop, clover, cucumber, etc., and is probably the conidia of species of Erysiphe on these hosts. (Britain and U.S. America.)

0. Tuckeri Berk. On leaves and berries of the vine (see Uneinula, p. 176).

0. leucogonium Desm. On roses; probably the conidial form of Sphacrothece pannosa (see p. 172).

0. farinosum Cooke. On living leaves of apple-trees. (Britain.)

0. chrysanthemi liabh. On leaves of cultivated chrysanthemum. (Britain.)

0. aceris Pabach. On leaves of Acer Pscudoplatanus. It is probably the conidial stage of Uncinulc bicomis. (Britain.)

0. mespilinum Thim. On leaves of medlar. (Britain.)

0. destruens Peck. On Amclanchicr canadensis and Prunus scrotina in America.

0. tabaci Thüm. On leaves of tobacco.

0. monilioides Link, probably the conidial stage of Erysiphe graminis, occurs on living grasses over the whole world (see p. 175).

\section{Sub-sect. Macronemeae.}

\section{Botrytis.}

Mycelium grey. Conidia more or less spherical, and produced in aggregations on the ends of branched conidiophores. Many of the species are saproplyytes, others are parasitic on plants or insects, and others form sclerotia; the latter have already been considered under Selcrotinia (see p. 267). The following are known to be parasitic on plants:

Botrytis cinerea Pers. This enemy of many plants has already been noticed as Selerotinia Fuckcliana; so also B. Douglasii Tubeuf. 
B. galanthina Sacc. occurs on the bulbs of Galanthus niralis in Britain.

B. parasitica Cav produces sclerotia and conidis on Tulipre Gesneriane in Italy (Sclerotium tulipar).

B. vulgaris Fr. $^{1}$ This is a very common species, and includes several well-marked varieties. It is said to be parasitic on cultivated lettuce causing a "leaf-rot."

B. fascicularis Sacc. is reputed to be the cause of a "fruitmould" on the egg-plant (Solanm Mclongcna) in the United States.

A Botrytis is figured by Atkinson ${ }^{2}$ as frequent on diseased carnation-plants.

\section{Ovularia.}

Conidiophores simple except for tooth-like projections near the apex on which the conidia are developed. Conidia unicellular, colourless, solitary, rarely in chains.

"Closely allied to Ramularia, but distinguished by the onecelled conidia" (Massee).

Ovularia pulchella (Ces.). Briosi and Cavara distinguish this as a disease of Lolium italicum in Italy. The leaves become black-spotted and permeated with an intercellular mycelium, from which arise the erect, branched, septate conidiophores. The more vigorous conidial patches have a delicate rose colour.

0. necans Pass. produces large spots on the foliage of quince and medlar, so that the leaves gradually wither and dry up. Conidia appear as a white powder on the dead remains. This fungus is recorded from both Italy and France.

The following are British species occurring on leaves; several of them, however, are placed by Saccardo under Ramularia:

Ovularia lychnicola (Cke.) Mass. On Lychnis diurna.

O. senecionis (Sacc.). On Senecio vulgaris.

O. lactea (Desm.). On species of Viola.

O. armoraciae (Fuck.). On cultivated horse-radish. It is leported as somewhat destructive in the United States.

O. interstitialis (B. et Br.). On under surface of leares of primrose, forming yellow spots in the angles of the reins.

O. primulana Thim. On leaves of I'rimula.

O. cochleariae (Cke.). On Cochleuria officinulis.

I Wehmer on species of Botrytis, Zeitschrift f. Pfanzenkrankheiten, 1894.

${ }^{2}$ Atkinson, "Carnation Diseases," at Amer. Carnation Society, 1893. 
O. alnicola (Cke.). On Alnus glutinosa.

O. scelerata (Cke.). On Ranunculus sceleratus.

O. rosea (Fuck.) produces irregular brown spots on the leares of varions species of willow.

O. asperifolii (Sacc.). On Symphytum officinalis.

O. veronicae (Fuck.). On spots on leaves of Veronica Chamaedrys, etc.

O. lamii (Fnck.). On Lamizm.

O. syringae (Berk.). On Syringa.

O. sphaeroidea Sacc. causes spots on leaves of Lotus.

O. carneola Sace. On spots on leaves of Scrophularia nodosa.

O. bistortae (Fuck.). On spots on leaves of Polygonum Bistorta.

O. obliqua (Cke.). On leaves of Rumer.

\section{Sect. Didymosporae.}

\section{Didymaria.}

Conidia two-celled, colourless, and produced singly at the extremity of simple erect conidiophores.

Didymaria prunicola Cav. Cavara states that this causes raised roundish spots on the upper surface of leaves of plum; finally the leaves gradually dry up and fall off. Slender twocelled conidiophores are prodnced, and give off each a two-celled obovoid conidium.

D. Ungeri Cord. On living leaves of Ranunculus repens. (Britain.)

D. astragali (Ell. et Hol.). Found on leaves of Astragalus canadensis.

D. spissa Hark. On leaves of Solidago occidentulis; both species in North America.

\section{Bostrichonema.}

Conidiophores erect, spirally twisted, unbranched, and nonseptate. Conidia elliptic or oblong, two-celled, and hyaline.

Bostrichonema alpestre Ces. On living leaves of Polygonum viviparum and $P$. Bistorte. (Britain.)

B. modestum (B. et B. Thite). On leaves of Alchemilla alpina. (Britain.)

\section{Sect. Phraghosporae.}

\section{Ramularia.}

Conicliophores emerging in tufts from the stomata; they give off a terminal conidium, then bend over and produce a lateral conidium, and so on they branch in a sympodial mamner, pro- 
ducing conidia at the end of each branch. Conidia septate oval or eylindrical, and light-coloured.

"The parasitic haljit, simple or sparingly branched hyphae, denticulate and bearing the septate conidia at the tips, characterize the genus, which differs from Orularin only in the septate conidia" (Massee).

Ramularia cinarae sacc. is said by Prillien ${ }^{1}$ to have caused great destruction in the cultivation of artichokes. The leaves became spotted and died, so that no flower-heads were producerl.

The following are British species:

Ramularia hellebori Fuck. On leares of Helleborus foctidus and $I I$. virictis.

R. epilobii (Schn.). On leaves of Epitobium.

R. ulmariae Cooke. On leares of Spiraea L'lmuria. (U.S. America.)

R. geranii Fuck. On under surface of leares of rarious species of Gercenium.

R. lampsanae (Desm.). On Lampsanu and IIypochoeris.

R. pruinosa Speg. On Senecio jucolea.

R. plantaginis El. et Mart. On leares of P'luntago major. (U.S. Am.)

R. variabilis Fuck. On leaves of Irgitulis and Verbascum. (U.S. A merica.)

R. calcea Ces. On leaves of Gilechoma hederacert.

R. urticae Ces. On leaves of species of C'rtica. (U.S. America.)

R. pratensis Sace. On Rume.r Aretose.

R. rufibasis (B. et $\mathrm{Br}$.). On Mryrica (iale.

Some of the more important North American species are:

Ramularia rufomaculans Peck. On the buckwheat (Fagopyrum esculentum), it has proved a somewhat injurious fungus.

R. albomaculata Peck. On leares of Curyin umericana.

R. viburni E. et E. On leares of Vibumum Lentugo.

$\mathbf{R}$. celtidis $\mathrm{E}$. et $\mathrm{K}$. On leares Celtis occidentulis.

R. desmodii C'noke. On leares of varions species of Desmodinm.

R. brunnea Peck. On living Tussilugo furfur

R. areola Atks. ${ }^{2}$ This causes spots on the foliage of cotton. "Spots amphigenous, pale at first, becoming darker in age; irregular in shape, limited by the veins of the leaf, conidia in profusion giving a frosted appearance to the spots. Conidiophores fasciculate, in small clusters distributed over the spots. Conidia oblong, usually abruptly pointed at the ends" (Atkinson).

R. Goeldiana Sacc. is said to kill leaves and twigs of Coffece aratice in Jirazil.

1 "Maladie d. Artichauts," Bulletin de la soc. mycolog. de France, 189?.

"Atkinson, Botanical Gazette, xv., 1590, p. 166. 


\section{Piricularia.}

Conidia grey, pluricellular, somewhat pear-shaped, and produced from the apex of simple erect conidiophores.

Piricularia oryzae Br. et Cav. This species is described by Briosi and Cavara as causing a disease of rice in Northern Italy. The plants become spotted and reddish-brown in summer, finally withering. The conidiophores arise on the spots on the lower surface of the leaf, and bear light-grey three-celled

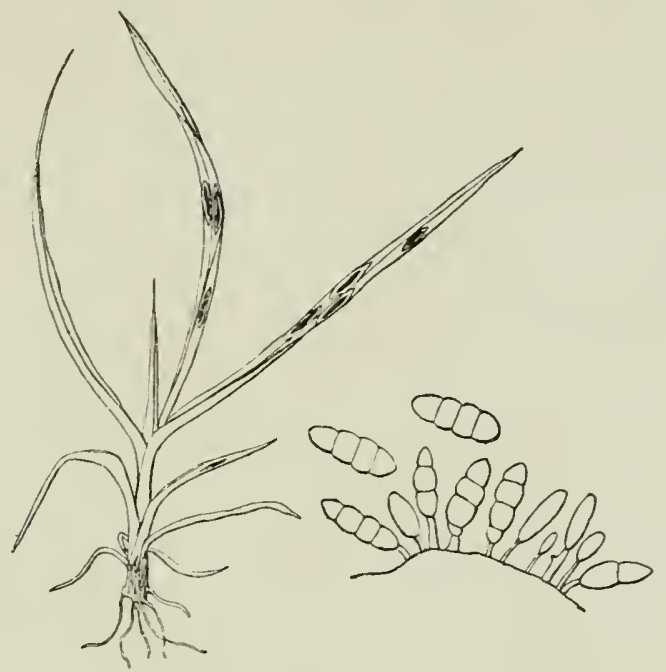

Fs. 30S.-Mastigosporium album. (จ. Tubeuf del.)

conidia. Diseased plants may be found bearing this fungus only, frequently however it is in company with other fungi.

\section{Cercosporella.}

Conidia hyaline, similar to those of cereospore, and produced from simple or branched hyaline conidiophores.

Cercosporella persica Sacc. is parasitic on living leaves of peach. In America it has been known since 1890, and receives the name of "frosty mildew:" It causes yellow spots on the lower surface of the leaf.

C. pastinacae Karst. occurs on living leaves of cultivated parsnip. 


\section{Mastigosporium.}

Conidia hyaline and four-celled, frequently bristled.

Mastigosporium album Riess. produces oblong dark spots with light margins on leaves of living grass. The conidia are produced on the margins of the spots (Fig. 308).

\section{Fusoma.}

Similar to Fusarium, but the mycelium is loose and not aggregated into a tuft. Conidia spindle-shaped and septate.

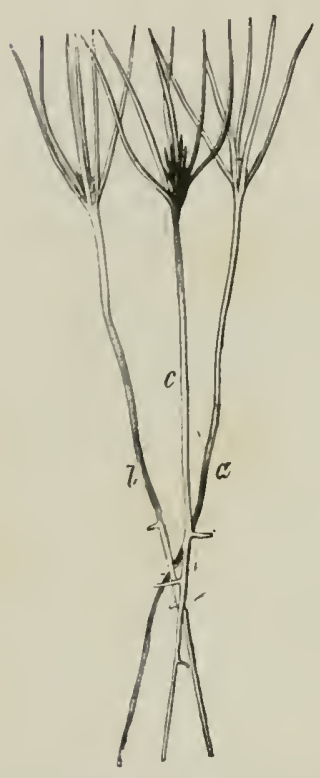

Frg. 309.-Fusoma parasiticum. Diseased Pine-seedlings, with, $\alpha$, root killed; $b$, hypocotyl killed; $c$, first leaves and plumule killed. (After R. Hartig.)

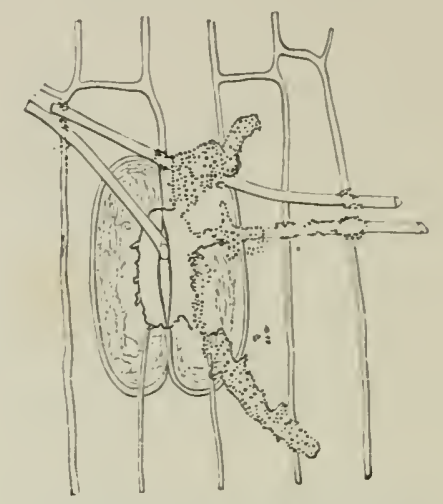

Fig. 310.-Epidermis of a Pine-seedling with a stoma. Some hrphae of Fusoma have produeed partial dissolution of cellwalls. (After R. Hartig.)

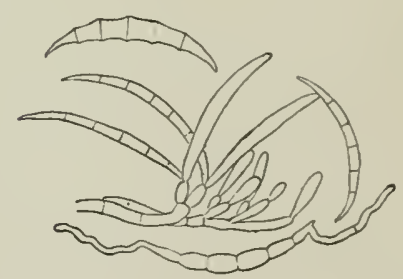

Frg. 311.-Fusoina parasiticum. Conidia-immature, mature, and germinating. (After R. Hartig.)

Fusoma parasiticum Tub. ${ }^{1}$ is the cause of a disease of seedlings, particularly those of Conifers. The first symptoms are dark patehes on the seedlings, followed by their collapse. There-

${ }^{1}$ R. Hartig, Forstlich-naturviss. Zeit.schift, 1593, p. 432. 
after in moist weather or moder artificial cultivation, a light-grey mycelium appears bearing numerous slightly curved, tapering, pluriseptate conidia (Fig. 311). In Bavaria and Baden this parasite has caused great loss in the seed-beds of conifers.

F. inaequale Hoyer. On living leaves of Taraxacum officinale.

\section{Septocylindrium.}

Conidia cylindrical, hyaline or pale-coloured, with two or more septa, and produced in chains.

Septocylindrium aromaticum Sacc. occurs on living Acoms C'rlamus, killing leaves and even plants. The mycelium grows intercellularly and produces spots. The conidiophores emerge in tufts from stomata inclucled in the spots, and give off long thread-like, pluriseptate, hyaline conidia.

\section{FAM. DEMATIEAE.}

1. Sect. Amerosporae.

1. Subsect. Micronemeue.

Many of the genera of this subsection contain species fom on the living leaves of plants, but none of them are yet of economic importance.

\section{Subsect. Macronemene.}

\section{Hormodendron.}

Mycelium grey, epiphytic, and creeping. Conidiophores erect, branched, and septate. Conidia spherical or ovoid, micellular, and produced in chains.

Hormodendron hordei $\mathrm{Br}^{1}{ }^{1}$ This produces a characteristic spotting of the haulms and leaves of barley, accompanied by a stunting of the whole plant and poor development of the ears. This is not a true parasite, but when it appears in quantity it has considerable effect, attacking whole fields and cansing great injury. The spots and conidia are found also on wild Hordeum muriuum on the margins of roads and fields. ${ }_{1894 .}^{1} \mathrm{Br}$

${ }^{1}$ Bruhne in Zopf's Beitrage s. Physiol. u. Morphol. nied. Organismen, Iv., 
2. Sect. Didrmosporate.

1. Subsect. Mirronemene.

\section{Dicoccum.}

Conidia oblong, two-celled, and arising from short simple conidiophores. Mycelium subcuticular.

Dicoccum (Marsonia) rosae (Bon.) causes brown spots on living leaves of roses, and a premature leaf-cast takes place. Little mycelial stromata (levelop between the epidermal cells and their cuticle, and give off two-celled hyaline conidia.

D. uniseptatum B. et Br. forms dark patches on twigs of Clematis vitalba. (Britain.)

D. lathyrinum Ell. et Gall. On living leaves of Lathymus ochrolcucus in America.

\section{Cycloconium.}

Mycelium subcuticular. Conidia one- to three-celled.

Cycloconium oleaginum Cast. ${ }^{1}$ When this fungus is present, the leaves of the olive show rommdish light-brown spots with dark margins, then becoming discoloured, they roll up and drop off. The mycelium grows in the walls of the epiclermal cells, branching dichotomonsly; branches of the hyphae break out through the cuticle as sac-like cells, which become the conidiophores. The conidia consist of one to three cells. Kruch states that Cercosporce cladosporioides is often present along with this disease of the olive, and may take some part in cansing it.

Peglion states that this or an allier species occurs on leaves of Quereus Iler.

\section{Subsect. Macronemeae.}

\section{Passalora.}

Conidia oblong or spindle-shaper, two-celled, and borne on the apex of greenish pluriseptate conidiophores, arising from an olive-green mycelium.

Passalora bacilligera M. et Fr. occurs on living leaves of Alnus glutinosu. (Britain.)

P. microsperma Fuck. This frequently covers the whole lower surface of the leaves of Alnus incena witl little tufts of

${ }^{1}$ Kruch, Bulletin soc. bot. ital., 189:2.

Boyer, Recherches sur les maladies de l'Olivier, Montpellier, 1892. 
brown septate conidiophores, bearing long, two-celled, obovate conidia.

\section{Fusicladium.}

Mycelium greenish and sparingly septate. Conidiophores in tufts, short, erect, and bearing terminal conidia. Conidia ovoid or clavate, and one or two-celled.

The species are conirlial forms of Venturia, and have already been considered. Some of the better-known forms are:

Fusicladium dendriticum Wallr. (Britain and U.S. America). This attacks the leaves, shoots, and fruits of the apple (see p. 218).

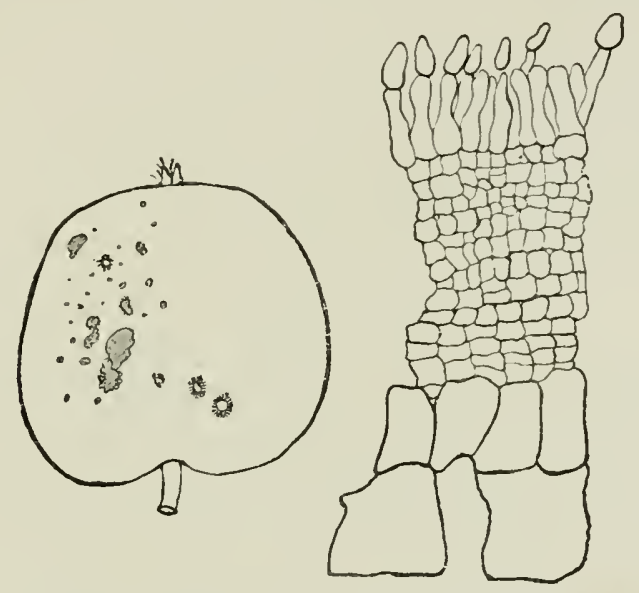

FIG. 312.-Venturia (Fusicladium) dendriticum forming brown spots on an apple; those still in the earlier stages have a radiate margin and bear conidia. 'The enlarged section shows two rows of large-celled parenclym ma of the apple, covered by a stroma of pseudoparenchyma bearing conidiophores and conidia. (v. Tubeuf del.)

F. pirinum (Lib.) (U.S. America). This is a cause of "spotting" on leaves and fruits of the pear, also of species of Crataegus and Amclanchier. The conidial patches are brownish in colour. Peglion states that this parasite forms sclerotia in the bark of twigs. It is probably a conidial form of Venturia ditricha var. pyri.

F. cerasi (Rabh.) attacks the cherry orehards with such virulence that the crop may be rendered quite unsaleable.

F. eriobotryae Cav. ${ }^{1}$ Cavara states that this attacks the

${ }^{1}$ Cavara, Rivista di Patologia I'egetale, 189.2. 
leaves of Mrspilus (Eriobotrya) juponica causing them to become spotted and to wither. The hyphae live in the epidermis, and form a stroma from which conidlia are given off.

F. tremulae Frank. Frank ${ }^{-1}$ gives this as the cause of a disease of the aspen (Populus tremula). The leaves turn brown and fall, the shoots in conserquence soon drying up. Conidia are developed on the surface of dead leaves and germinate on living leaves of aspen, producing a germ-tube which, after forming an adhesion-disc, penetrates into the eavity of the epidermal cells.

F. depressum $\mathrm{B}$. et $\mathrm{Br}$. is found on living leaves of Ingelica syluestris. (Britain and U.S. America.)

F. praecox Rabh. On living leaves of Trayopogon orientalis.

F. sorghi Pass. On living leaves of Surghum halepense.

The following are North American species:

F. caryogenum Ell. et Langl. On leaves of Caryu olivaeformis.

F. effusum Wint. On leaves of Carpinus amerirana.

F. destruens Peck. On living Avena sutiva.

F. fasciculatum C. et E. On leaves and stems of Euphorliu.

\section{Scolecotrichum}

Mycelium greenish. Conidia oblong or oval, produced both terminally and laterally on the conidiophores.

Scolecotrichum melophthorum (Prill. et Del.)." This produces a melon disease in France known by the name "Nuile." It consists in the fruits and stems becoming spotted, the tissue being completely destroyed.

Sc. graminis Fuck. Occurs on grasses, especially on the oat. Pammel ${ }^{3}$ reports it as also injurious on barley during 1891, in some parts of the United States: the diseased leaves were marked with brown or purplish brown spots.

Sc. fraxini l'ass. On living leaves of Frusinus cxcelsior and F. Ornus.

\section{Cladosporium.}

Mycelium greenish. Conidia globose or ovoid, one to fourcelled, and of variable form. The species are inostly saprophytes on substrata of all kinds.

${ }^{1}$ Ber. d. deutsch. hotun. Gesell, 1Ss3, p. :-9.

- Bulletin de la sor. mycolou. de France, 1891.

"Sournal of Myrology, vil., p. 96. 
Cladosporium herbarum (Pers.). This species is found everywhere on dead plant remains, but it is also common on living leaves of many plants. The first suggestion that this form might occur as a parasite came from Haberlandt ${ }^{1}$ and Frank. ${ }^{2}$ It possesses a dirty-grey, thick, septate inycelium, which may be colourless when young or growing iuside a substratum; it applies itself closely to the surface of plants and even penetrates through the stomata or cell-walls into the tissues. The conidiophores are erect, otherwise variable in form; they give off conidia from the apex or from lateral processes. The conidia are oval and contain a variable number of cells. Organs of plants attacked show grey spots, and withered parts if they are still alive.

The following are sume of the papers describing Cladosporium herbarum as, in certain circunstances, a parasite. Prillieux and Delacroix, ${ }^{3}$ on apple-trees and raspberry-bushes; Cavara, ${ }^{4}$ on raspberry, cycads, agave, and other plants: Sorauer, ${ }^{5}$ on peas. Lopriore " describes this fungus as the cause of a "blach" disease on ears of wheat; the results of infection were however somewhat variable.

Ritzema Bos reports it as producing disease, and in some cases death, in fields of oats. Kosmahl and Nobbe ${ }^{6}$ found that seedlings of Pinus rigide blackened and died suddenly in the beginning of May, apparently from the attacks of this fungus. Janczewski ${ }^{\top}$ states that this Cladosporium is a conidial form of Sphaerella Tulasnei, a new species of Ascomycete established by him. ${ }^{8}$

Cl. elegans Penz. This causes on the orange a disease or "scab," which has been injurious both in Southern Europe and the Southern States of America. ${ }^{2}$ It attacks chiefly wild orange

${ }^{1}$ Frühling's landwirth. Zeitung, 1878.

${ }^{2}$ Die Krankheiten der Pfanzen, 2nd Edit., 1896, Ir., p. 29:2.

"Bulletin de la soc. mycolog. de France, viI.

${ }^{4}$ Rerue mycologique, 1891.

${ }^{5}$ Handbuch $d$. Pflanzenkrankheiten, 1886.

${ }^{6}$ Berichte d. deutsch. botan. Gesell, 1892; Landwirth. Jahrbuch, 1894.

${ }^{7}$ Extraits du Bulletin de l'Academie des sci. de Cracorie, 1592, 1593, 1594.

${ }^{8}$ Schostakowitsch (Flora, 1895 (ergzbd.) distinguishes Cladorporium from other genera.

${ }^{9}$ Scribner, Bulletin of Torrey Club, xIII., 1856, p. 181. Underwood, Journal of Mycology, viı., p. 34. Swingle and Webber, "Diseases of Citrous Fruits," U.S.A. Dext. of Agriculture Bulletin s, 1896. 
trees, more rarely the sweet ornnge and lemon. The disease first appears as whitish or cream-coloured spots on leaves, young twigs, or frut. If the spots are numerous the leaves become badly curled or twisted, and covered with wart-like eruptions.

Cl. viticolum Ces. is regarded as a dangerous parasite of the vine.

Cl. carpophilum Thim. This species has been found parasitic on plum and peach in the United States. Its nycelium crecps over the surface of leaves and fruit, causing pale-coloured spots which extend and run together, spoiling the appearance of the fruit. The disease as yet does not appear to have a very wide distribution, nor is it directly very injurious, but as cracking of the ripe fruit occurs when it is present, the way is opened for entrance of fruit-destroying fungi.

Cl. condylonema Pass. also occurs on leaves of the plum. It causes leaf-spot and leaf-curl. The mature conidia have fine spines on their coat.

Cl. fulvum Cooke. (Britain and U.S. America.) This is the cause of a disease of tomato. It attacks leaves and shoots of plants cultivated indoors, and soon causes their death. Prillieux and Delacroix ${ }^{1}$ have described a somewhat similar discase in France, found, from artificial infection, to be produced by some species of Cladosporium, but whether this particular species, they did not state.

Cl. cucumerinum Ell. et Arth. ${ }^{2}$ causes a disease of cucumber Frank $^{3}$ describes a disease which he found to be due to a Cladosporium ( $\mathrm{Cl}$. cucumeris $11 . \mathrm{sp}$.). This attacked the fruit of both cucumbers and melons in cultivation under glass at Berlin, and ciused great damage; brown rotten depressions appeared on the fruits, and thereon the tufts of conidiophores.

Cl. macrocarpum Preus. causes a "scab" disease of spinach in the United States (N.J. Agric. Exper. Station Bulletin, 70, 1890).

Other species that may be parasitic are:

C1. pisi Cug. et Mace. On living pouls of Pisum sativum in Italy.

C1. epiphyllum Mart. On leaves of Quercus, Platanus, Populus, Hedera, etc. (Britain and U.S. America.)

Cl. juglandinum Cooke. On leaves of the wahnut. (Britain.)

${ }^{1}$ Bulletin de la soc. mycolog. de France, 1891.

${ }^{2}$ Description in Mass. Agric. Exper. Station Report, 1892.

"Zeitschrift $f$. P'fanzenkrankheiten, III., 1893. 
Cl. Scribnerianum Cav. On leaves of Betula populifolia in America and Italy.

Cl. hypophyllum Fuck. On leaves of Ulmus campestris.

C1. tuberum Cooke. In the tubers of Batatas edulis in Carolina, U.S.A.

3. Sect. Phragmosporae.

\section{Subsect. Nicronemeue.}

\section{Clasterosporium.}

Conidia brownish, cylindrical or spindle-shaped, and consisting of three or four cells.

Clasterosporium amygdalearum (Pass.) attacks the leaves of almond, peach, apricot, cherry, and plum. An intercellular mycelium has been found, and roundish dry spots with reddish margins are formed. Thereon tufts of short conidiophores are developed, bearing eylindrical, thick-walled, pluricellular conidia.

Cl. glomerulosum Sacc. (Sporidesmium glom. Sacc., 1878, and Pleospore conglutinata Goebel, 1879). Goebel ${ }^{1}$ first described this species as a parasite on Juniperus communis. A colourless intercellular mycelium is present, and in consequence the needles turn brown, die, and fall off prematurely. On the upper side of the needle the mycelium emerges through the stomata, and forms dark-grey coils from which the grey, ovoid, pluricellular conidia are given off.

\section{Ceratophorum.}

Conidia brownish, spindle-shaped or cylindrical, three or more celled, the upper cell with terminal bristles.

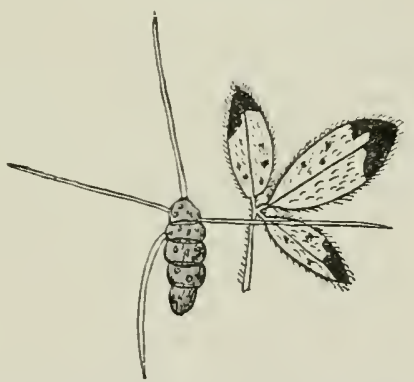

Fig. 313.-Ceratophorun setosum on Cylisus capitatus. Leaf with diseased apices. An isolated spore with its appendages. (After Kirchner.)

C. setosum Kirch. Dark spots occurring on the leaves, petioles, and shoots of young plants of Cytisus Laburnum, etc., were found to enlarge and bring about death and defoliation. Kirchner found the leaf-tissue permeated by a colourless septate mycelium, which gives off conidia on both sides of the leaf. The conidia resembled those of Pestalozsia, but their cell-number

1 II urtemburg naturuiss. Jahreshefte, 1879.

Zeitschrift $f$. Pflanzenkrankheiten, 1892, p. 324. 
was variable, and the terminal cells, although lighter than the median, were not quite hyaline. The terminal cell bore several very long bristles.

C. ulmicolum E. et $\mathbf{K}$. On living leaves of Ulmus fulve in America.

\section{Helminthosporium.}

Conidia brown, cylindrical or spindle-shaped, and pluricellular. Mycelium well-developed and brownish.

"I)istinguished from Cladosporium by the conidia being more than one-septate at maturity" (Massee).

Helminthosporium gramineum (Riabenl.) ${ }^{1}$ This causes a disease on barley, both in Europe and the United States; as yet, however, it is not very common. It attacks generally the lower leaves, producing long, narrow, dark-brown spots with yellow margins. The leaves so attacked gradually wither, but do not prejudice the yield of grain seriously. On the spots are developed the black septate conidiophores, each with a large black conidium with from two to eight cross-septa.

H. turcicum Pass. causes long spots on the leaves of Zea mais both in Italy and America. The spots are yellow with indistinct dark margins, and from then arise patches of grey septate conidiophores. The conidia resemble those of the species last described, so that some anthorities regard the two forms as one. Briosi and Cavara describe the mycelium as consisting of branched septate hyphae, the cells of which frequently become irregularly swollen. The young Indian corn leaves are killed, and the crop may, in consequence, be seriously injured.

H. teres Sacc. This is a form of $H$. gramineum which Briosi and Cavara distinguish as occurring on oats. Infection takes place at the apex of the leaves, and the mycelium spreads through the parenchyma causing elongated dry spots, so that the leaf ultimately dries up and dies. The conidiophores are developed singly, not in tufts, and the conidia are smaller thau those of $H$. gramincum. The conidia are greenish, thick-walled, pluricellular, and produced terminally.

H. gracile (Wallr.) causes long marginate spots on the leaves of Iris germanica.

1 Eriksson, Botan. Centralblatt, xxıx., 18s7. Kirchner, Zeitschrift f. Pftansenkrankheiten, I., 1891, p. ㄴ4. 


\section{Cercospora.}

Conidia elongated and slender, olive-green, and septate. Mycelium greenish.

"Distinguished by the vermiform septate coniclia" (Massee).

Cercospora circumscissa Sacc. ${ }^{1}$ This is a parasite which occurs on cultivaterl almond, peach, and nectarine, as well as on wild Prunus scrotina in the United States. The leaves are attacked while still young, and exhibit by reflected light a yellowish spot with a dark centre. The conidia arise on the spots as dark-green clusters, thereafter the diseased tissue shrinks, becomes detached, and falls ont, leaving "shot-holes" not unlike those prodnced by species of Phyllostirta. Defoliation may occur in severe cases of attack. As a result of the injury to the foliage, the new wood does not mature well, and second growth may take place during the same season; shoots of this kind will probably dry up during winter. The fungus may also directly kill the tissue of twigs as far as the cambium. The fruit is never attacked directly, but may be seriously affected through the injury to leaves or twigs.

In order to minimize the disease, it is recommended to burn all fallen foliage, and to turn the earth thoroughly below infected trees. Pierce obtained a crown of very healthy foliage on almond trees treated with (1) ammoniacal solution of copper carbonate, and (2) morlified ean celcste.

C. persicae Sace. On leaves of peach. (U.S. America.)

C. acerina Hartig ${ }^{2}$ appears on brown spots on the cotyledons, young leaves, and stalks of young plants of Acer. The conidia are grey, pluricellular, and slightly curved (Fig. 314). The mycelium inhabits the intercellular spaces of the parts attacked, and forms resting sclerotia in the tissnes of dead leaves.

C. viticola (Ces.). ${ }^{3}$ This fungus is found in Europe and the United States on Vitis vinifere and $V$. Labrusca. It causes spots on the leaves, and from these arise close columns of septate conidiophores which give off thick pluricellular conidia.

C. beticola Sacc. ${ }^{+}$inflicts considerable injury on cultivated

${ }^{1}$ Pierce, Journal of Mycology, VII., p. 66 and p. 232.

${ }^{2}$ R. Hartig, Untersuchungen aus d. forstbotan. Institut, I., Munich.

${ }^{3}$ Description and treatment in New York Agric. Exper. Station Report for 1890 , p. 324 .

4 Thiimen, Die Bekïmpfung d. Pil krankheiten unserer Kulturgenüchse, 1856. 
sugar beet and beet-root. It is easily recognized by the numerous sharply defined spots produced on the leaves. The conidia are very long and pluriseptate. In the Vnited States this is one of the most serious of beet diseases. ${ }^{1}$ As preventive treatment, great care should be taken to destroy all infected material. A long rotation should also prove a good remedy.

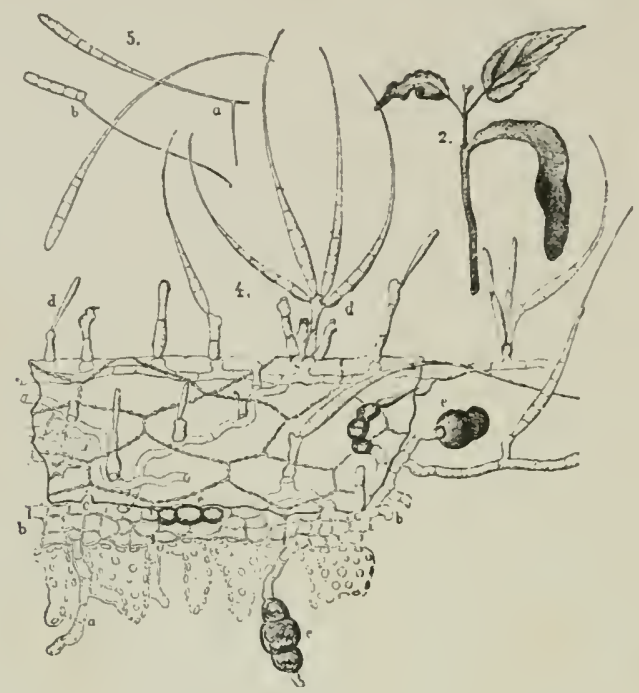

Fis. 314,-Cicosporre werine. 2, Seedling of Acer, with a cotyledon brown and withered, and a leaf partially so. 4 , Section through a diseased cotyledon; the conidiophores (d) emerge from the epidermis, and bear long tapering septate conidia ; $\ell$, sclerotia formed inside the diseased tissues for hibernation. 5, Germinating conidia. (After R. Hartig.)

C. apii Fres. Common on celery (Apium graccolens) and parsnips (Pastinace sativa) throughout all Europe and North America. It causes leaf-spots at first yellowish then enlarging and turning brown. The mycelium grows in the intercellular spaces of the leaf, and gives off tufts of conidiophores through the stomata. The conidia are long, tapering, obclavate borlies with an attachment-scar at their larger end.?

C. asparagi Sacc. occurs on asparagus in Italy; C. caulicola Wint. frequents the same host in America.

C. Bloxami B. et Br. On Brassica in Britain.

C. armoraciae Sace. On horse-radish.

${ }^{1}$ Pammel. Ioura Agric. Exper. Sfation Bulletin, 15. 1591.

${ }^{2}$ Description in New Jersey Agric. Exper. Station Bulletin 2, 1891. 
C. resedae Fuck. ${ }^{1}$ This fungus is the cause of a garden mignonette disease very common in America and Europe. It causes little depressed spots with brownish or yellowish horders, which begin as reddish discolorations of the leaf. The leaves gradually wither and dry up, so that the flowers suffer. The mycelium grows insicle the leaves, and gives off tufts of conidiophores through the stomata. The conidia are elongated, septate, and spindle-like or elub-shaped. Spraying with Bordeaux mixture was found to give good results.

C. cheiranthi Sace. produces roundish leaf-spots on wallflower, and, if severe, causes death of the leaves and premature defoliation of the plants.

C. rosaecola Pass. This causes leaf-spot on cultivated and wild roses in the United States. The first indication of disease is the appearance of black spots with reddish margins. The conidiophores emerge from the stomata in tufts, and carry long obclavate conidia.

C. angulata Wint. is one of the causes of leaf-spot on currant, and occurs often in company with Septoria ribis. (U.S. America.)

C. violae Sacc, occurs on leaves of liolu odorata.

C. malvarum Sacc. On species of Mulva.

C. althaeina Sace. On hollyhock in the United States.

C. neriella Sacc, causes leaf-spot on Nerizm Oleunder.

C. Bolleana (Thiim.) produces olive-brown spots on leares and fruits of the Fig, injuring the crop.

C. capparidis Sacc. On Capparis spinosa in Italy.

C. gossypina Cooke is given by Atkinson as a fungus frequently present on diseased plants of cotton. ${ }^{2}$

Saceardo records over 230 species of Cercospora, most of which canse spotting of living or fading leaves of many plants, e.g. Phaseolus, Lupinus, Trifolium, Vicia, Gleditschia, Solanum nigrum, Datura, Ricinus, Ampelopsis, Liviodendron, Tilia, Rosa, Potentilla, Rubus, Cydonia, Ptelea, Rhamnus, Enonymus, Ailanthus, Rhus, Sambucus, I'iburreum, Olea, Syringa, Morus, Fraxinus, Coffea, Ligustrum, Mercurialis, etc.

\section{Heterosporium.}

Conidiophores simple or branched. Conidia olive, oblong, pluriseptate, and with a spiny or warty outer coat.

\footnotetext{
${ }^{1}$ Fairchild in Report of Section of Vegetable Pathology for 18s9, U.S. Dept. of Agriculture.

${ }^{2}$ Botanical Gazette, 1891, p. 61.
} 
"Resembling Helminthosporium in general habit and structure, in fact only distinguished by the minutely warted conidia" (Massee).

Heterosporium echinulatum (Berk.). ${ }^{1}$ (Britain and U.S. America.) The "fairy ring spot" of Carnations. This is a serious enenry of enltivated carnations, and causes great damage. It was first described by Berkeley in 1870 as a carnation pest. The symptoms are light-coloured spots on which are concentric rings of dark-colonred conidiophores. These arise from darkcolonred portions of the mycelimm inside the leaf and give off conidia with three or more cells. The conidia are at first terminal, but after one has been formed the conidiophore branches laterally and produces another conidinm, repeating this process for a considerable time. The spots are produced on leaves, leaf-stalks, and sepals, causing them to wither: In consequence the flowers do not unfold and the plants are rendered unsightly.

Cultivation of the carnation in dry airy conditions is said to keep this disease in eheck.

The following are British species occurring generally on fading leaves:

H. variabile Cooke, On spinach.

H. ornithogali Klotzsch. On Ornithogalum, Convallaria, and other species of Liliaceae.

H. typharum (? et II. On Typha angustifolia.

H. laricis C. et M. On larch needles.

H. asperatum Massee. ${ }^{2}$ Occurs as a parasite on Similecina stellata.

\section{Napicladium.}

Conidia oblong, three or more celled, and produced singly on the end of short conidiophores.

"Somewhat resembling Helminthosporium and Brachysporium, but distinguished by the less rigid fertile hyphae and the large solitary conidia" (Massee).

Napicladium (Helminthosporium) arundinaceum (Cord.). (Britain.) This lives parasitic on the leaves of Phragmites communis, and spreads rapidly from plant to plant. The leaves

${ }^{1}$ Worth. G. Smith, Gardener's Chronicle, Xxvi, 1S86, p. 244.

Atkinson, "Camation Diseases" at American Carnation Society, 1893.

"Massee, American Journal of Nicroscopy, February, 1893. 
become coated with conidia and assume a learlen grey colour, so that in many cases only the points remain green. Finally the attacked leaves die and dry up.

4. Sect. Dictrosporaz.

1. Subsect. Nicronemeae.

The forms ineluded under genera of this group (e.g. Sporodesmium and Coniothecium) have as yet been little investigated in regard to their parasitic nature.

2. Subsect. Hacronemeae.

\section{Macrosporium.}

Conidia grey, muriform, and borne on the apex of simple or branched conidiophores.

Macrosporium sarcinaeforme Cav. ${ }^{1}$ Cavara describes a browning and death of a whole field of red clover (Trifolium prutense), and aseribes it to this fungus. Minute spots were produced, at first light-coloured, then brown, finally coalescing so as to cause drying-up of the whole leaf. The short thick conidiophores were developer on the lower surface of the leaf, and gave off pluricellular terminal conidia.

M. solani Ell. et Mart. This is deseribed² as oceuring along with the "black-rot" of the tomato in the United States. It is said to cause a rot in the fruit and a leaf-blight on both tomato and potato. Along with this species there also occur a Fuscrium. (p. 520) and frequently a Cludosporium; as yet the relationships of the different forms, and the part they take in causing the diseases ascribed to them, is but imperfectly investigated.

Soraner $^{3}$ ascribes a disease on the potato in Germany to this species or to an Alternaria (A. solani). He also believes that it is the cause of the "early blight" of American potato erops, but further investigation is still required.

Many other species of Macrosporium have been deseribed on plants of economic importance, yet most of them oceur only on parts somewhat faderl or languid, so that they cannot be regarded

${ }^{1}$ Briosi and Cavara, Funghi parasit., v.

2Report of the Section of Vergtable Pahology for 18ss, U... Department of Agriculture.

${ }^{3}$ Zeitschrift $f$. Pflan:enkrankheiten, 1596, p. 1. 
as important parasites. Amongst these are the following British and North American species:

M. brassicae Berk. On eablage, generally somewhat decayed.

M. sarcinula Berk. (n cucumber.

M. nobile Vize. On lianthus.

M. alliorum ('ke. et Mass. On onion.

M. ramulosum sitce. (n) celen'y

M. catalpae Ell. et Mart. On C'atulpa Bignonioides.

M. nigricantium Atks. is a semi-parasite accompanying other diseases of the cotton plant.

\section{Mystrosporium.}

"Allied to Macrosporium, but distinguished by the more rigicl and darker-coloured hyphae and conidia" (Massee).

Mystrosporium abrodens Nemmam. ${ }^{1}$ This is cleseribed as the cause of a disease which destroyed one-tenth of the total wheat-crop in the Haute-Garomne of France. The fungus attacked the nodes and leaves, forming dark patehes; the nodes were weakened and frequently broke over, while the ears were badly developed.

\section{Alternaria.}

Conidia grey, muriform-septate, flask-shaped, and borne on short simple conidiophores.

"Distinguished by the elavate or Hask-shaped muriformly septate olive conidia being united in chains aml comnected by narrow isthmus-like portions" (Massee).

Alternaria brassicae (Berk.) (Britain). This species causes on leaves roundish black spots marked with concentric brown zones. The mycelium lives in the leaf-parenchyma and gives off tufts of conidiophores through the stomata. Briosi and Cavara state that it causes considerable damage to Bressirn oleracea, Cochlaria officinalis, and Amoracia. (Probably the same species as Polydesmus critiosus Kuhn.)

Other diseases have been ascribed to species of Altcrnuria.

\section{Septosporium.}

Conidia brown, and muriform-septate. Conidiophores of two kinds-short and fertile, or elongated and sterile.

Septosporium heterosporum Ell. et Gall. causes a leaf1 "Un nouveau parasite de ble." Société de Biolog. ¿̀ Toulouse, 159:. 
spot on Vitis californica in California. The leaves become quite black on the lower surface, brown on the upper. The fungus has not as yet been reported on cultivated rines.

\section{Fumago.}

Coniclia grey and two- or three-cellecl.

The species belong to Capnodium (see p. 181).

\section{FAM. STILBEAE.}

1. Ser. Hyalostilbeae.

Sect. Amerosporde.

\section{Stysanus.}

Conidia pale-coloured, more or less spherical, and developed on a dark cylindrical or clavate erect stroma.

Stysanus veronicae Pass. ${ }^{1}$ This produces irregular spots on the leaves of cultivated Veronica longifolia in Italy, and causes the plaut to wither. The columnar stromata are produced on the lower surface of the leaves, and give off unicellular conidia.

St. ulmariae $\mathrm{M}^{\prime} \mathrm{T} \mathrm{T}^{2}$. On Spirea Ulmaria in Ireland.

\section{Isaria.}

Stroma erect, clavate, generally branched and bearing conidiophores all over. The conidia are abjointed from the apex of the conidiophores, and are unicellular, hyaline, and rounded.

Isaria fuciformis Berk. ${ }^{3}$ This disease, first observed in Australia, is described by Smith as occurring in England. It attacks grasses, especially Festuca, during summer. The stems and ears are glued together by the fungus-stroma, and conidia are developed on all parts of the plants.

\section{‥ Ser. Phaeostilbeae.}

Sect. Plirugmospoicce.

\section{Isariopsis.}

Conidia pale-coloured, cylintrical, and pluricellular.

Isariopsis griseola Sacc." produces spots on leaves of living

Hedrigia, 1877, p. 123.

${ }^{2} \mathrm{M}$ 'Weeney, Irish Naturalist, 1595, p. 273.

${ }^{3}$ Worth. (x. Smith, Diseases of Field and Garden Cropis, London, 185t, p. 55.

${ }^{4}$ Briosi and Cavara, Funghi parawit. 
cultivated kidney bean. The mycelimn lives in the leaf-tissues and forms stromata under the stomata, from which the conidiophores arise in tufts. The fungus often occurs along with Uromyces phascoli.

Other species of Isariopsis are recorded on the living leaves of various host-plants, e.g. Cerestium and Stellaria.

\section{FAM. TUBERCULARIEAE. \\ Volutella.}

The conidial patch or sporodochium is disciform, regular, and fringed, or studded over with elongated spine-like hyphae. Conidiophores simple or branched, and bearing elliptical or oblong conidia.

The majority of the species of Vulutclle frequent only dead plant remains. Atkinson, however, describes and figures a widespread carnation-disease in North America, which is ascribed to a species as yet unnaned. Fresh cuttings are most commonly attacked, and exhibit dirty brown depressed areas, which soon ruin the cutting for purposes of cultivation.

\section{Fusarium.}

Sporodochium more or less effused. Conidia spindle-shaped or sickle-like, pluricellular when mature. The conidiophores are branched, and give off the conidia from their apex.

Fusarium heterosporium Nees. Frank ${ }^{2}$ found a field of rye near Kiel completely destroyed, and the ears quite overgrown by this fungus. I have found it on ears of Lolium perenne and Molimia eoerules in Pavaria.

Species of Fuscirum have been frequently described as causing injury to cereal and grass-crops, ${ }^{3}$ in some cases to a serious extent.

While most of the species of Fusurium are found only on dead or dying plant-remains, a parasitic mode of life has been ascribed to some.

Fusarium lycopersici Sacc. " The "Sleeping Disease" of

1 "Camation Diseases" in Report of American Carnation Society, 1893.

${ }^{2}$ Jahrbuch d. deutsch. landwirth. Gesell., 1892.

"Worth. G. Smith, Diseaves of Crops, 1854, p. 208.

Rostrup (Fusarium arenaceum on Oat) Landiboskrifler, v., 1893.

¿Massee, Gardener's Chromicle, xviı, 1995, p. 707. (Edit.) 
tomatoes. This tomato disease has proved very destructive during recent years in Britain, particularly in the Isle of Wight and the Chamnel Islands. Plants are attacked when quite young, but the disease seldom manifests itself ontwardly till the plant is full grown. The first symptom of disease is drooping of the leaves, with or without discoloration. At this stage the roots of attacked plants will be found to have a yellowish brown colour in the wood region. The mycelium of this fungus will be found in the vessels and other elements of the root. They are believed to originate from resting-spores which have hibernated in the soil and given off germ-tubes by which young rootlets were infected. The mycelium makes its way up the tomato stem, discolouring the vascular bundles as it goes. The conidia are produced on all diseased organs as a whitish bloom on the epidermis. The earlier conidia (Diploclculium) are oval and one- or two-celled, but they are soon replaced by pale orange crescent-shaped conidia of the true Fusarium type. The resting-spores are produced on the hyphae in the tissues of the decaying host-stem; after hibernation, they germinate and produce hyphae which give off the Diplocladium stage. Massee found that only the germ-tubes from restingspores were able to infect tomato plants. The same anthor does not consider fungicides of much avail on account of the disease begrinning from the roots. Careful removal and destruction of all infected material, and a liberal application of lime to the soil are measures recommended.

Fus. limonis Briosi (Fusisporium limonis Briosi). This is given by Briosi as the cause of "mal-di-gomma" of orange and lemon trees in Italy and elsewhere; ${ }^{1}$ Webber and swingle ${ }^{2}$ ascribe the disease of the orange and lemon in Florida known as "foot-rot" to the same fungus. In Florida the damage done is great and much more serious than that caused by any other disease of the same plants. It may be recognized by the exulation of gum from patches near the base of the tree. The patches enlarge and the disease spreads round the trunk and downwards into the roots, passing inwards from bark to cambium and wood, killing the tissues as it goes. Other symptoms

\footnotetext{
${ }^{1}$ Briosi, "Nal di gomma," Memoria della R. Acad. dei Lincei, Rome, 1878.

2 Webber and Swingle, "Diseases of citrous fruits in Florida." U.S. Americce Dept. of Agricnlture Bulletin, No. 8, 1896. (Eilit.)
} 
are sparse foliage, small yellowish leaves, and death of the smaller branches over the tree. Sweet seedling orange (Citrus (rurantium) and lemon (C. limonum) are most subject to this malady, the grape-fruit ( $C$. decumana) is only slightly liable, and the sour orange $(C$. bigaradia) is almost wholly exempt. For this reason sour orange stocks should be used on lowlands and flatwoods, and grape-fruit stocks on the higher lands. The most effective treatment is to remove the soil around the crown roots by using a jet of water. Diseased bark should also be cut away and the wounds painted over with carbolic acid or sulphur wash. Good drainage to promote root aeration and the avoidance of excessive use of nitrogenous manures are also recommended.

Fus. vasinfectum Atks. ${ }^{1}$ A species found by Atkinson to cause a cotton-disease known as "frenching." This consists in a discoloration of the leaf from the margins inwards, at first pale or yellow, but turning to brown. A mycelium was found in the tissues of the stem, causing the vascular bundles to assume a light brown colour. The host-plants are either killed or so seriously affected that the crop is injured. The conidia formed are of the pleuriseptate slightly curved Fusurium type.

Atkinson ${ }^{2}$ in the course of his investigations on carnation diseases found a Fuscrium present in all cases of the "camation rosette." The stems remain short and stunted with their leaves small and crowded together. A mycelium was present in the tissnes of the stem and caused discolonred spots.

\section{THE PATHOGENIC SLIME-FLNGI.}

\section{MYXOMYCETES.}

The Myxomycetes ${ }^{3}$ rank amongst the lowest of plant-forms. They show so close relationship to the lowest animals that certain groups (Monculina) receive greater consideration from the zoologist than from the botanist. They exhibit in their

${ }^{1}$ Atkinson, "Cotton Diseases," Alabama Agric. Exper. Station Bulletin, No. 41,1892 . (Edit.)

2 "Carnation Diseases" at American Carnation Society, 1893.

${ }^{3}$ The more important literature dealing with this family will be found in: De Bary. Morphology and Biology of the Fungi (English Edition); Lister, The Mycelozoa, London, 1895; 'Zopf in Schenk's Handluch der Botanik, III., 1SS7; Schroeter," Myxomycetes" in Die nat ̈̈rlirh. Pflanzenfamilien, 1., 1592. 
mode of reproduction a close resemblance to the Fungi, and as a result of their lack of chlorophyll, they share witl Bacteria and Fungi the peculiarities of saprophytic and parasitic nutrition.

The vegetative body of the Slime-fungi consists of naked protoplasm without a firm membrane. Multiplication is effected chiefly by spherical spores with the same external appearance as the usual fungus-spore. Immediately on reaching maturity the spores germinate in water and burst, setting free a mass of plasma provided with a nucleus and vacuoles, and in which an outer movable hyaloplasma can be distinguished from an enclosed granular plasma. The hyaloplasma gives off delicate pseudopodia eapable of extension and retraction, it may also take the form of a flagellum or of eilia. The organism is enabled by means of the psendopodia to ereep over firm objects as an "amoeba"; by the cilia it can propel itself through water, as a "swamel" or "zoospore." A zoospore in the course of its development generally loses its cilia and becomes an amoeba, and both forms can multiply by division. The annoebae creep together in large numbers, and either coalesce completely into masses, or remain simply in contact as aggregations. In this way plasmodia are formed, frequently of eonsiderable size and of conspicnous eolour. The plasmodia maintain a constant movement, both as a whole and in the form of internal streamings. Piesting stages have been observed at each motile stage of the life-history: thus swarm-spores rest as microcysts, young plasmodia as thick-walled eysts, and mature plasmodia as multicellular sclerotia.

Multiplication of the Myxomycetes also takes place by sporeformation. In the Acrasieae and Phytomyxinae the spores are developed freely from the plasma. The Exosporeae, a very small division, have their spores developed on the outside of sporophores. In the greater number (Endosporeae) the spores are formed in special enclosures, which may be a sporangium produeed from a single plasmodium, or an aethalimm-a cushion-like structure consisting of numerous imperfeetly defined sporangia. The sporangia are often of considerable size, sometimes not unlike the sporocarps of the Gasteromycetes, spherical or pear-shaped and stalked. Sporangia of this highly dereloped kind may even exhibit a certain differentiation into a wall or 
rind of compact plasma enclosing the spores, and frequently a supporting skeleton or capillitium is present consisting of numerons filaments of hardened plasma.

Schroeter divides the Myxomycetes into three divisions, the Acrasieae, Phytomyxinae, and Myxogasteres (including the Exosporeac and Endosporeae). Parasitic forms occur only in the second of these groups. If, however, all the forms included by Zopf in his group of Mycetozoa be taken into account many of them will be found to act as parasites and to cause frequent epidemics amongst algae and lower fungi.

We shall here consider only the genera Plasmodiophora, Tetramyxe, and Sorospharre. The genus Phytomyxa of Schroeter, containing those micro-organisms which canse the root-tubercles of Leguminosae, has already been considered in our general part (see p. 101).

\section{Plasmodiophora.}

Spores spherical and developed inside the host-cells. This genus causes diseases of considerable economic importance.

Plasmodiophora brassicae Wor. ${ }^{1}$ This species attacks all kinds of cabbage, kale, turnip, kohl rabi, and other varieties of Brassica Rapa, B. Napus, B. oleracea, and other edible Cruciferae; also other plants from the same order, such as Iberis umbellata, Capsella bursa-pustoris, Mathiola ineance, etc.

The symptoms of the disease are manifold swelling, outgrowth, and branching of the roots at all stages of growth, with a more or less marked stunting of the foliage, according to the season of attack (Fig. 315). The forms assumed by leformed roots are very variable and have gained the disease many designations. In Britain it is known as "finger and toe disease," "club-root," "clubbing," and "aubury"; in Belgium as "maladie digitoire" or "Vingerziekte"; in Germany is "Kropf" or "Kohlhernie."

The disease was first recorded in Scotland about 1789, but now it has a very wide distribution, appearing in all places where cabbage, turnips, and allied regetables are cultivated on a large scale. The roots after swelling become rotten and

'Woronin, Prinysheim's Jahrbuch, xi., 157s, p. 54S. Eycleshymer (Jomrnal of Ifycoloyy, vir, p. 79) gives a good account of its distribution in America. Ilassee, Transactions of Royal Soriety of London, Lvin., 1S9.j. 
decay, so that not only is the root itself worthless, but the aerial shoot is badly developed. The destruction is greatly favoured by moist rainy years.

The malformations of the root are the result of hypertrophy of the host-cells due to a stimulus exerted by the plasmodium of Plasmodiophora, not only on the contents of cells inhabited by it, but also extending into the cells of the whole neighbouring tissue. The cells so influenced enlarge in size and

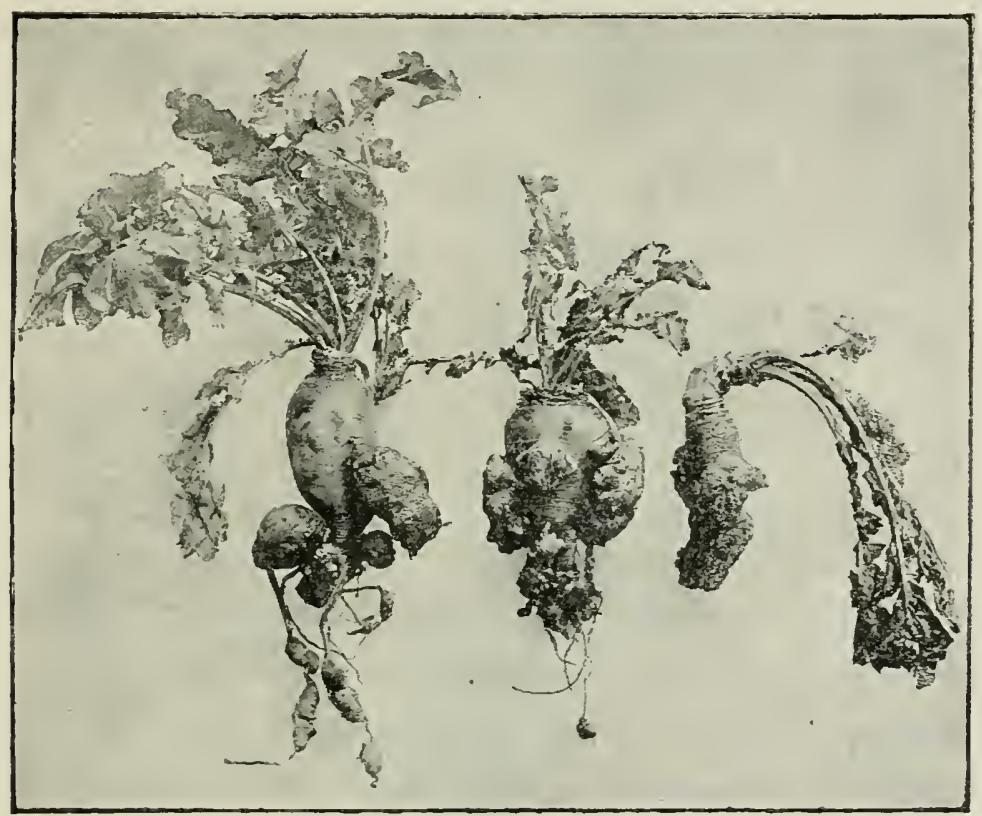

Fig. 315.-Plasmodiophora brctssicae. Effects on Turnips grown in Scotland. (v. Tubeuf phot.)

become divided up by new cell-walls. The plasmodium makes its way from cell to cell by means of the wall-pits, and by absorbing the contents it grows and fills the whole cell. On exhanstion of food, and without previous enclosure in a membrane, the plasmodium forms itself into spores, so that the tissues of attacked roots become completely filled with thickwalled spores, which are set free only after decay of the surrounding tissues and cell-membranes. The spores hibernate, and in spring myxamoebae slip ont, capable of infecting 
young roots of newly germinated cabbage, turnips, ete. They do this by penetrating the cell-wall, probably that of a hair to bergin with, and the malformation ensues. The myxamoebae possess a flagellum and pseurloporlia, so that they are fitted for

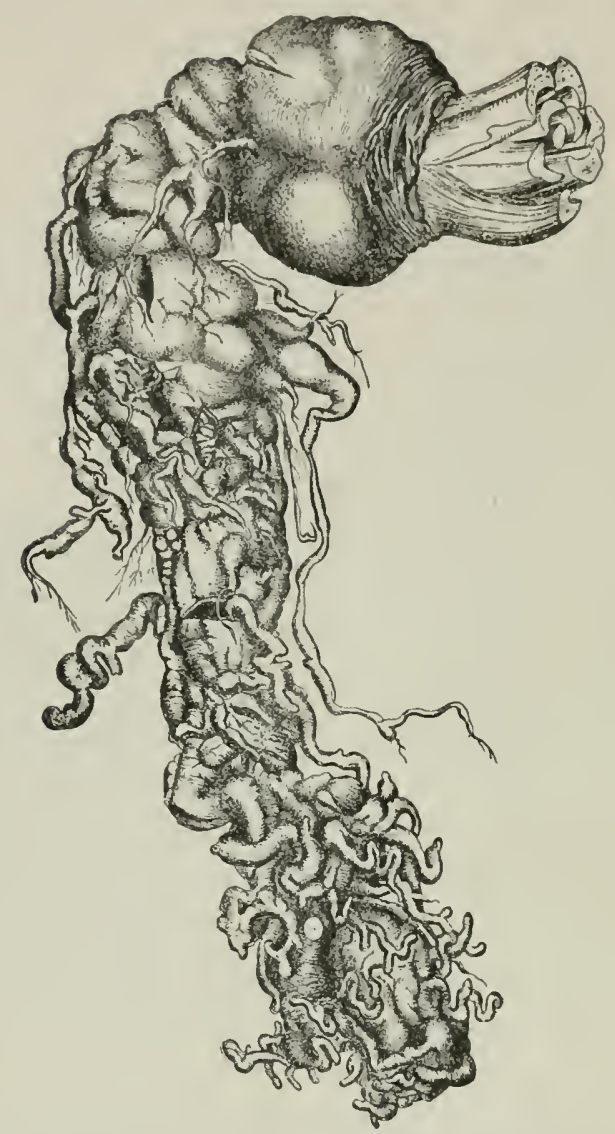

Fig. 316.-Plasnodiophora brassicae. Effects on Turnip grown in Russia. (After Worouin.)

different modes of locomotion. When entrance into a host-cell has been effected, a plasmodium is formed and growth proceeds as just described.

Wakker ${ }^{1}$ describes, an enlargement of the attacked cells and an irregular growth of the roots, associated with a rudi-

${ }^{1}$ Pringsheim's Jahrbuch, 1892. 
mentary condition and twisted course of the vessels, and an accumulation of transitory starch in the tissues.

[The methods at our disposal for combating this parasite all work indirectly. Its spores seem to retain their vitality for two, three, or more years, hence one very evident measure is not to plant the same crop in succession on land which has been attacked. As, however, all Cruciferae are liable to injury from this source,

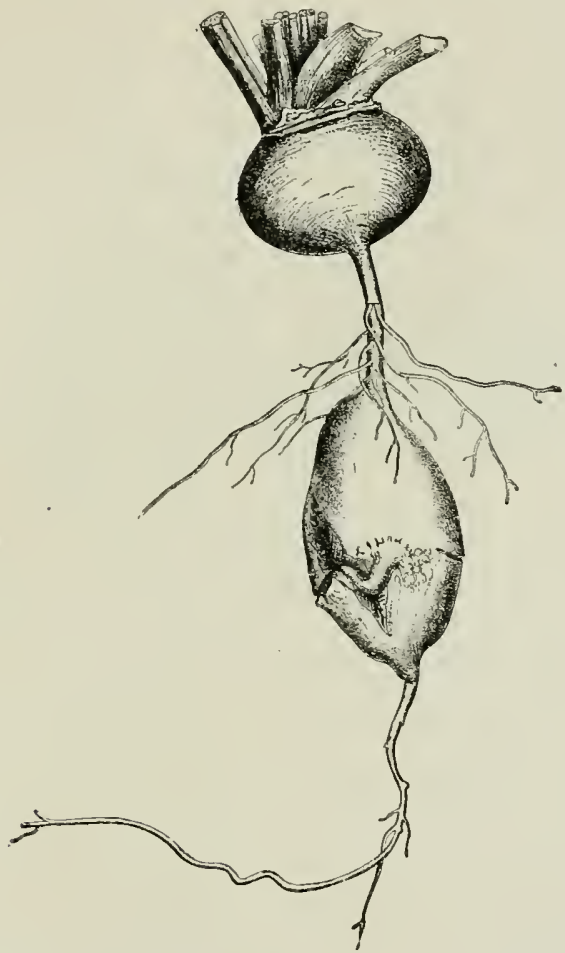

F1G. 317.-Plasmodiophore bressicue on Turnip. (After Woronin.)

neither would it be advisable to let say, turnips follow cabbage or kohl rabi on infected land. For the same reason weeds belonging to the order Cruciferae should not be allowed to obtain a footing near land where plants liable to "finger and toe" are under cultivation. In Scotland, where turnips are necessary in all crop-rotations, a four-year rotation does not give complete exemption from this disease, nor is five years 
considered quite a safe interval, but seven years is, and with good management the disease, though ly no means uneommon, only then attains serious dimensions in moist seasons. Massee points out that the development of the fungus is favoured by acirls and checked by alkalis; this explains the well-known beneficial effects of dressings of lime or potash in keeping the disease in eheck. With a six or seven-year rotation, and the application of lime once in the rotation, the disease should

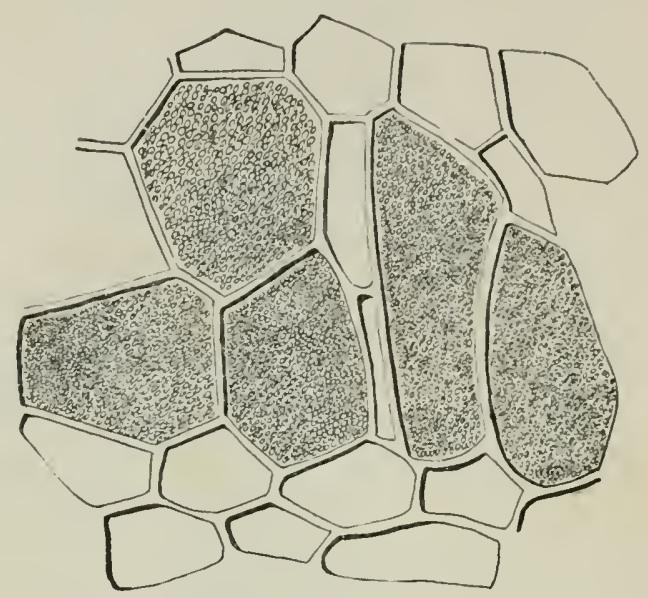

Fic. 31s,-Hypertrophied cells from a Cabbaye-root attaeked by Plasmodiophore brassicri. Several of the cells are filled with spores. (v. Tubeuf del.)

never be very injurious. The direct application of farmyard manure to the turnip crop should also be avoided, especially if the stock which made the manure was fed on diseased turnips; this is necessary because it has been found that the spores are not killed when eaten by animals.] (Edit.)

Plasmodiophora vitis Viala et Saur. ${ }^{1}$ This is said to cause a Vine disease known as "Brunissure," which within recent years has caused considerable loss in France, North America, and Southern liussia. ${ }^{2}$ The early symptoms are lightbrown star-shaped spots on the upper surface of the leaves between the ribs. The spots enlarge and cause a premature fall of the leaf, whereby the grapes are prevented from maturing.

1 Viala et sauvageau, Compt. reul., cxiv., 1892.

${ }^{2}$ Cooke (Gardener's Chronicle, 1893) refers swellings found by him on roots of the vine in England to the action of this fungus. (Fidit.) 
The above-named investigators found plasmodia in various stages of development in the palisade cells, and later in the spongy parenchyma of diseased leaves. On treatment with "eau de javelle" the plasmodia remained visible, whereas the contents of healthy cells disappeared. Spore-formation has not as yet been observed. The same parasite has been seen in vines in the Phine district.

Recently Debray and Brive ${ }^{1}$ have, in consequence of their researches on Brunissure, removed the fungus from the genus Plasmodiophora, and founded for it a new group Pseudocommis, with a position near Vampyrella and Myxomycetes. This same fungus they also found in a large number of plants from thirty different natural orders.

Plasmodiophora californica Viala et Saur. ${ }^{2}$ is another vine parasite which causes greater danrage than the preceding species. Reddish leaf-spots are produced, and extend so rapidly that the leaves may drop early in spring. The parasite also affects the shoots to such a degree that an abnormal number of shortened branches are developed, the wood of which exhibits brown stripes in autumn.

It has not as yet been quite proved that the plasma observed in withered vine leaves really consists of plasmodia of the above two species of Plasmodiophore, nor have spores been found. The true cause of the diseases has probably still to be explained.

In cases of root-deformation in pear, Miiller-Thurgau ${ }^{3}$ observed a slime-fungus in cells of the root-parenchyma.

\section{Tetramyxa.}

Spores united four together as tetrads and enclosed in a delicate membrane.

Tetramyxa parasitica Goeb. ${ }^{4}$ First found by Goebel in ditches of marshy meadows, causing tuberous balls of a whitishgreen to brown colour on leaves, flowers, and stalks of Ruppic rostellata. Sections of the swellings showed the parenchyma to be divisible into a dark brown central part consisting of

${ }^{1}$ Compt. rendu., cxx., 1595; and "La Bmnissure," Perue de Viticulture, 1895.

${ }^{2}$ Compt. rent., cxr., 1892, p. 67.

${ }^{3}$ Jahresbericht d. Vers.-Stat. Wädensueil, II.

${ }^{4}$ Goebel, Flora, 1884. Identified in Scotland by Prof. Trail. 
killed cells, and a lighter coloured peripheral part. The cells of young tubercles contain multinuclear plasmolia, which at the time of spore-formation lreak up into portions round each nucleus (spore-mother cells). These portions then divide into four spores, each with a nucleus. 'The spores remain enclosed in a delicate membrane as spore-tetrads, the characteristic feature of this species. The upper part of leaves containing galls frequently died.

\section{Sorosphaera.}

spores enclosed in large numbers in a delicate inembrane, and forming a single layer round a central cavity.

Sorosphaera veronicae Schroet. ${ }^{1}$ causes quill-like ontgrowths and malformations in the stems and leaf-petioles of species of Veronica ( $V$. hederifolia, $V$. triphylla, $V$. chamaedrys). The galls consist of enlarged parenchymatous cells containing numerous spherical or elliptical light-brown balls about 15 or $22 \mu$ broad. The balls are enclosed in very delicate membranes, and consist of a single layer of spores surrounding a small cavity. The individual spores are elliptical or oblong in shape, about $8-9 \mu$ long and $t-4 \cdot \tilde{j} \mu$ broad.

\section{THE PATHOGENIC BAC'TERIA.}

\section{SCHIZOMYCETES.}

Although the bacteria and allied forms included in this group are the cause of many diseases of mankind and of warm-blooded animals, yet very few diseases of plants are ascribed to their agency. The true Fungi, on the other hand, which we have seen to cause so many diseases amongst plants, only very rarely appear as enemies of the higher animals. The few cases in which bacteria have been stated to cause injury to plants are all as yet incompletely investigated and uncertain in two respects. Thus although a plant-disease undoubtedly exists accompanied by the appearance of bacteria, these bacteria may not be the cause of the lisease: nor need it follow that the phenomena accompanying an attack by bacteria are necessarily symptoms of disease. On this account we shall

${ }^{1}$ Schroeter, Engler-Prantl natïrlich. Pflanzenjamilien. 
consider those phenomena, which have been described as bacterial diseases of plants, very briefly and with a certain reserve. This part of the work has been considerably facilitated by the use of Ludwig's compilation of bacterial diseases, ${ }^{1}$ and by Migula's account of them from the bacteriological point of view.

Migula considers that only five diseases of plants have been definitely proved to be due to bacteria, namely, pear or apple blight, sorghum blight, the bacterial disease of the maize, the bulb-rot of hyacinths, and the wet-rot of potatoes. We shall, however, indicate briefly some other plant diseases which are suspected to have a bacterial origin. The slime-fluxes of trees have been already considered along with the genus Endomyces (p. 141), so that we omit them here.

\section{Pear and Apple Blight.}

This destructive disease of the apple and pear in North America has been proved by the investigations of Burrill ${ }^{2}$ and Arthur to be, withont doubt, of bacterial origin. The disease has been known for over 100 years, and occurs with disastrous effects on fruit-trees in the orchards, as well as on crabs and other wild species. Pear trees seem to suffer most in the Eastern States, apple trees in Iowa and elsewhere, while none of the species of Pyrus, Cydonic, and Sorbus are exempt from attack.

The disease appears first on the bark as little dead spots; these, however, rapidly enlarge till death of twigs, branches, and even stems may follow. As a result of death of twigs, the leaves turn brown and fall, while a dark fluid exudes from the diseased bark. The presence of bacteria has been proved in this exuded sap as well as inside the cells, and infections have been successfully carried out from pure cultures. The name Micrococcus amylovorous was given by Burrill to the organisun. It flourishes on the sour unripe fruit, and in the tissues of

${ }^{1}$ Lehrbuch der niederen Kryptogamen, 1592.

Migula, Kritische Uebersicht d. Pflansenkrankikeiten durch Baktevien verur. sacht, 1892.

Prillieux et Delacroix. "Maladies baccillaires." Comptes rendu, 1894.

"Burrill, The American Naturalist, 1881.

Arthur, Report of New York Agric. Exper. Station, 1887.

Waite, Yearbook of U.S. Dept. of Agriculture, 1S95; description and treatment. 
diseased branches, and is one of those forms which does not liquefy gelatine. One characteristic reaction is, that as rlestruction of the trec-rind proceeds, fermentation takes place with production of carbon dioxide, hydrogen, butyric acid, and alcohol.

The bacterial colonies should be carefully cut ont when letected.

\section{Bacteriosis of Carnations.}

Arthur and Bolley have recently described a bacterial disease of carnations common in North America. ${ }^{1}$ It attacks the leaves almost exclusively, causing pale spots which later become whitish depressed areas. The plants are seldom lilled outright and the leaves remain attached, but they are stunted in size, and the yield of flowers is prejudiced. The disease is favoured by poor cultivation in moist surroundings, and is more prevalent indoors. A very efficient remedy is to avoid watering the foliage, except at long intervals; by means of wire-netting it is possible to water the roots without touching the foliage. (Edit.)

\section{Twig-galls of the Olive" ("Logna or Loupe").}

Twigs of the olive are frequently beset with knots varying from the size of peas to that of hazel-nuts. These consist chiefly of parenchyma which begins to decay intermally before the gall has ceased growing; finally the gall also dies. In this way carities in the twigs are formed in which P'rillieux found large masses of bacteria (Bacillus oleac), to whose action he ascribes the formation of the galls, as well as the decay of the tissues. Infection from pure cultures is yet required to show whether the galls are really due to the action of the bacteria, and whether the above-mentioned Broillus is the real cause. I had the opportunity of personally inspecting the disease on olives near Riva, and found that the galls really contained nests of bacteria, while death of twigs above the galls was very frequent.

Similar symptoms of disease occur on willow, birch, pine, and other trees, but they have not been investigated.

${ }^{1}$ Arthur and Bolley, Purdue Unirersity Agric. Exper. Station, Bull., 59, 1896.

2Prillieux. "Les' tumeurs bacilles de rOlivier, etc.," Rerue gener. de botanique, 1859. 


\section{Twig-galls of the Aleppo Pine. ${ }^{1}$}

The galls occurring on the twigs and branches of Pinus halepensis are even larger than those on the olive; they are particularly common in the woods near Coaraze in the Maritime Alps. The galls contain masses of bacteria situated in canals and cavities in the parenchyma, and throughont the woody tissues inside the galls. Prillieux regards bacteria as the cause of the galls, and he believes that they penetrate the healthy bark and form nests which kill the parenchyma. Experimental infection has, however, not yet been earried out.

\section{Canker of the Ash.}

Soraner ${ }^{2}$ regards the well-known ash-canker as the result of the action of bacteria, but Noack thinks this improbable. Bacteria were found in the canker-spots only in summer, and might easily have got there accirlentally after the formation of the galls. Galls of the ash caused by attacks of the insect Phytoptus may frequently contain bacteria.

\section{Canker of the Ivy.}

Lindau 3 describes a cancerous formation on ivy-twigs, accompanied by death of portions of the leaves. The diseased places contained slimy masses of bacteria, and the canker-spots, though at first isolated by formation of wound-cork, continued to extend till they reached the wood, which was ultimately killed. Pureculture and infection-experiments were not carried ont, and the author himself was unable to determine whether the bacteria were primary agents in the canker-formation or only late arrivals.

\section{Lilac Disease.}

Soranert observed masses of bacteria enclosed in cavities in young twigs of lilac which after becoming black-spotted had in many cases broken over. The attack and the part taken in it by the bacteria were not however investigated further.

\footnotetext{
TVuillemin, "Sur une tumeur du Pin d'Alep," Compt. renrl., crir., I8S8; Prillienx (loc, cit.).

"Sorauer, Atlas d. Pflanzenkrankleiten ; Noack, "Der Eschenkiebs," Ze itschirift f. Pflansenkrankheiten, 1893 , p. 193.

"Lindau, Zeitschrift f. Pflunsenkronkheiten, 1594, p. 1.

tSorauer, Zeitschrift f. Pflonvenlirunkheiten, 1591, p. 156, and 1892, p. 344.
} 


\section{Bacterial Disease of the Mulberry. ${ }^{1}$}

Cavities containing bacteria have been found in brown spots on diseased leaves and twigs of the mulberry. A form "Bacterium mori" was isolated and found to reproduce the disease when used to infect healthy leaves. I have myself observed, in the arboretum of the forest experimental station at Munich, most of the new twigs of an old nulberry tree besct with brown spots over the whole green tissue. The leaves on such twigs were not spotted, but died off prematurely. The spots indicated cavities filled with bacteria and a slimy substance.

\section{"Mal nero" of the Vine.}

This name is given to certain diseases of the vine, the calse of which has never been satisfactorily explained. Baccarini ${ }^{2}$ succeeded in obtaining all the symptoms of the disease after infecting healthy twigs by grafting on diseased pieces. Prillienx and Delacroix ${ }^{3}$ describe a similar disease prevalent in Tunis and throughout France, with the name "Aubernage." The wood when attacked exhibits black points which rapidly enlarge and coalesce, causing it to decay. All diseased elements were found to contain a brown gunmy substance in which a form of Leptothrix-bacterium swarmed. Inoculation of liealthy vines produced the disease in the following year.

Certain discases of the grape have also been ascribed to bacterial action, and investigations are at present in progress.

\section{Sorghum Blight.}

A disease of species of Sorghum has been long known in America, especially on S. saccharatum, one of the sources of sugar. The symptoms are red or black spotting of the leaves and other parts of the plant. The disease may even be severe enough to cause death of the host-plants. Burrill in 1886 found a bacterial form present in the spots, and named it Bucillus sorghi. Kellermann and Swingle ${ }^{4}$ obtained pure cultures,

${ }^{1}$ Boyer and Lambert, "Deux maladies du Mûrier," Compt. rend., cxriı., 1893.

"Malpighia, vı; ; also Bullet. d. Soc. botan. Ital., 1894.

3 "La gommose bacillaire d. Vigues," Comptes rend., cxrill., 1894.

"Report of botanical department of Kansas State Ayric. College, 1559. 
and carried out successful experiments in infection of healthy Sorghum.

Diseased fields should have the Sorghum stubble burnt out, and other crops cultivated on them for several years.

\section{Bacterial Disease of Maize. ${ }^{1}$}

From dark slimy spots on young maize-plants which had died from some unknown disease, Burrill isolated Bacillus secales. Pure cultures were obtained and minutely described, but no record is given of its use in infection-experiments.

\section{Red-coloration of Wheat.}

This is a phenomenon not uncommon on wheat-grain, where it may be epidemic. Prillien ${ }^{2}$ ascribes it to a Micrococcus which he found associated with it; as, however, neither pure cultures were made nor any experiments in infection carried out, the cause of the disease is still doubtful. Examination of diseased grain showed that the starch-grains and even cell-walls had been dissolved.

\section{Mosaic Disease of Tobacco.}

This disease of the tobacco is well known in the Netherlands. It makes its appearance as a mosaic-like pattern on the leaf, due to isolated spots becoming light-green, then dying. Mayer ${ }^{3}$ ascribes the disease to the influence of bacteria, although infection-experiments have hitherto failed; other observations on the disease do not confirm this conclusion.

\section{Potato-Rot. ${ }^{4}$}

Kuhn described a dry-rot or tuber-rot of the potato which had been known since 1830. The disease appears generally after harvest and lasts till spring. The tubers shrivel up and become very brittle.

${ }^{1}$ Burrill, Agric. Exper. Station, Unir. of Illinois, 1889.

${ }^{2}$ Annales d. sri. natur., Ser. vi., S, 1878, p. 248.

3 "Ueber die Mosaik-krankheit des Tabaks," Versuchs-station, Vol. 32, 1886.

"Kühn, Die Krankleiten d. Kulturgerëchse, 1858.

The text-books of Frank and Sorauer.

Reinke and Berthold, Die Zersetzun! d. Kartoffel durch Pilze, 1879.

Krämer, Oesterreich. landuirth. Centralblatt, 1891. 
Another clisease of potato-tubers quite distinct from the above is "wet-rot," which is willely distributed, and has been known since 1845 . It appears on the field and shows itself by a putrefaction of the tubers. Krimer investigated tubers whose contents had liquefied inside the swollen skin. They contained unaltered starch-grains, remains of the protoplasin, and numerous bacteria. The mass in the earlier stages was acid, later it became alkaline, and smelt strongry of butyric acid. Krimer obtained pure cultures of the bacteria and infected potato tubers in various ways, obtaining in every case the characteristic rot. The Bucillus was obtained in the form of rods with rounded ends, or as long wayy filaments, or as spores. On nutritive agar-agar, the colonies form little dirtywhite slimy drops with a listinct margin and a brownish centre. On gelatine the margin of each colony makes a groove or funnel in which the colony lies, and liquefaction of the gelatine proceeds rapidly. This Bucillus is aerobic, in this respect differing from C'lostridium butyricum Prazm, which is anaerobic. It also differs from Bacillus butyricus Hueppe, in that it is able to decompose milk. It appears quickly on wounds of all kinds, and infection can easily be performed artificially by pricking or otherwise wounding the periderm. Infection also takes place throngh minjured shin, and in this case the Bacillus must enter by the lenticels of the tuber.

The disease begins with the formation of a soft spot under the periderm of the tuber. This extends rapidly, the tissue being completely destroyed, and leaving great cavities containing the almost minjured starch-grains. At this stage carlonic acid and butyric acid are formed, so that the reaction to litmus is acid; later the decomposing fluid becomes alkaline from formation of ammonia, methylamine, and trimethylamine. Varions putrefactive bacteria and fungi make their appearance in the later stages of decomposition after the periderm las been ruptured.

A somewhat similar disease is reported by Halsted ${ }^{1}$ from the Southern States of America. Diseases of a similar nature are also reported on tomato, cucumber, and melon.

${ }^{1}$ Zritschrift f. Pdan:enkrankheiten, 1s95, p. 337. 


\section{Potato-Scab.}

The symptoms of this common disease consist in the formation of areas of dry corky tissue on the surface of the tubers. These soon fall a prey to bacterial forms, and rotting takes place, soon, however, to be cut off from the healthy tissue by a layer of cork. The disease continues to spread deeper into the tuber, till the reserve materials are used up or rendered useless. Bolley ${ }^{1}$ ascribes the disease to a particular Buttcrittm which he isolated and used to carry out infections on healthy tubers. Withont doubt this Bacteriztm is common in tubers exhibiting "scab," but other conditions may have caused the disease in the first instance.

Thaxter ${ }^{2}$ believes that the scab-disease of both potato and beetroot is caused by a fungus Oospora scetbies (p. 497).

Schilberszky ${ }^{3}$ in investigating a potato-scab, found a fungus which he places amongst the Chytridiaceae; its life-history has not as yet been followed out.

\section{Bacterial Diseases of Beetroot.}

Beetroot and sugar beet have shown themselves very liable to diseases which have been ascribed to bacterial agency. Thus in sugar beet which yielded a low proportion of sugar, Arthur and Golden ${ }^{4}$ found the cells inhabited by a multitude of bacteria. These inhabited both roots and leaves, without, however, giving any external evidence of their presence.

Hiltner ${ }^{5}$ observed that beetroot died in consequence of loss of its root-hairs. This loss was traced to bacteria, and, after these had been killed by disinfection, the same roots again produced normal root-hairs and grew well.

More recently Soraner ${ }^{6}$ describes a disease of these crops in Germany. The lower ends of the plants become black, while from the undiseased portions of the surface there exuded a gummy fluid containing bacteria, yeasts, and fungi. He consider's

'Bolley, "Potato-Scab." Ayricultural Science, 1890.

" Thaxter, Reports of the Comnerticut Agric. Exper. Station, 1890 and 1591.

3 Schilberszky, Vorläuf. Jittheilung, Ber. d. deutsch. hotan. Ges., 1896, p. 36.

4"Diseases of the Sugar Beetroot." Indiana At/ric. Exper. Station, Bull. 39, 1892.

${ }^{5}$ Hiltner, Sächisch. landrirth. Zeitung, 1594.

${ }^{6}$ Blütter $f$. Zuckerrïbenban, 1894 ; also Centralblatt of. Bakterioloyje und Paretsitenkï̈urle, xirII. 1595, p. 29.5. 
that the disease was in the first instance due to bacterial action. Other diseases have already been noticed anongst the "Fungi Imperfecti" (p. 46t).

\section{Gummosis of Plants.}

There are many diseases characterized by a gummy outtlow from the diseased parts or from their neighbourlood. Amongst. plants exhibiting this are trees like the mulberry, olive, vine, fig, and regetables like potatoes, turmips, beetroot, and many others. As yet, however, no investigations have been carrier out carefully enough to give satisfactory explanations of them. It is, however, probable that they are primarily due to errors in cultivation, while the bacteria which are always found associated with them are of secondary importance as disease-producers.

\section{Bacteriosis of Bulbs.}

Hyacinth-bulbs, when stored up, are liable to several diseases which bring about rot and decay. Bacteria have been found in the earlier stages of the rot by several observers. One of these bacterial forms described by Wakker ${ }^{1}$ occurs as yellow masses, particularly in the decaying fibrovascular bundles of the bulbs; it has been named Bucillus hyccinthi Wakk. Wakker succeeded in carrying out infections with it, and it seems to be a definite bacterial disease. The extemal symptoms were yellow lines on the leaves, lue to yellow masses of the Bacillus in the vascular bundles and intercellular spaces of the parenchyma.

Another bacterial disease of hyacinth and other bulbs was investigated by Heinz. ${ }^{2}$ The disease starts from the bulb, and rapidly extends into the leaves and inflorescences, so that the leaves wither and the flower-buds drop off. Shortly afterwards the diseased tissues break up and become a foul-smelling slime containing an almost pure culture of a bacterial form which Heinz uamed Bacillus hyacinthus septicus. The Bucillus is easily cultivated on gelatine, which it does not liquefy. When applied to the base of the leares it easily infects them, penetrating in

Wakker, Botan. Centralblalt, xiv., 1583; Wakker, "Onderzoek d. Ziekten van Hyacinthen, etc.," Algem. Vereenig. roor Bloembollenkultur, 1SS3, S4, 85.

"Heinz, Centrallslatt fur Bakteriologie und Parasitenkimele, 1589, p. 535. 
twenty-four hours to a distance of 5-10 c.m. through the leaftissue. Infection of leaves and bulbs of common onion with the same Bacillus was also successfully carried out, and the same symptoms of disease followed.

Sorauer, in his "Handbuch," describes a bulb-rot said to be due to bacteria; but whether it be the same disease as this or not we cannot say.

\section{Bacterial Disease of Beans.}

Halsted $^{1}$ describes a disease on cultivated beans, which caused considerable loss in the United States. Bacteria were present in large numbers in all diseased parts, but to what extent they were responsible for the disease could not be exactly determined.

\section{THE PATHOGENIC ALGAE.}

The Cyanophyceae or Schizophyceae, though generally placed with the Bacteria in the group of the Sichizophytes, are here included with the true Algae on account of the great resemblance in their mode of life when they play the part of symbiotes or parasites.

The Diatomaceae contain no endophytic species.

The Algae differ from the groups of the Fungi, Myxomycetes, and Schizomycetes, in their possession of chlorophyll and their power of assimilation. The relationship of the Algae to other living organisms may be expressed under the following heads:

I. Symbiosis of Algae with Fungi. (Lichens.)

II. Symbiosis of Algae with animals.

III. Symbiosis of Algae with chlorophyllons plants.

(a) Epiphytes.

(b) Endophytes.

1. Inhabitants of free spaces in other plants.

2. Inhabitants of domatia.

IV. Parasitism of the endophytic Algae.

(a) In relation to animals.

(b) In relation to plants.

1. Inhabitants of the cell wall.

2. Inhabitants of the cell cavity.

3. Destroyers of tissues as a whole.

${ }^{1}$ New Jersey Ayric. Exper. Station, Report, 1892. 
The lichen-symbiosis is the most marked exannple of mutual symbiosis we know. Amongst the partnerships of Algae with animals every form exists from inntual symbiosis to true parasitism or to typical epiphytism. The last condition is, however, more frequently met with amongst Algae or Lichens epiphytic on other chlorophyllous plants. The phenomenon of "shelter-parasitism" is also a frequent one, the Algae inhabiting cavities already present in the host, or "domatia" - places of abode formed with the assistance of the Algae.

The full discussion of these and other symbiotic relationships may be had by reference to the works dealing with subject; some of the more important of these are given:

De Bary, Die Erstkeinung der symbiose, 18 is.

O. Hertwig, Die Symbiose im Thierreich, 1883.

Klebs, "Symbiose mgleichartiger Organismen." Biolog. Centralblutt, 1882.

Klebr, "Beiträge zur Kemntniss niederer Algenformen," Botun. Zeitung, 1881.

Geza Entz, "Das Konsortialverhaltniss von Algen und Thieren," Biolog. C'entralblatt, 1882.

Brandt, "Die morphologische und physiologische Pedentung des Chlorophylls bei Thieren." Mittheil. d. Zoolog. Station Neapel., 1883.

Van Beneden, Animal parasites and Messmates. (English Edition), International scientitic Series.

Only these algae which are parasitic on the higher plants come, strictly speaking, within the limits of the present work; we shall, however, also take into consideration the interesting symbiotic adaptations presented by several algae which live endophytic, but not truly parasitic, in higher plants. ${ }^{1}$

There is a distinct resemblance between the parasitism of algae and that of parasitic fungi. Some parasitic algae live in the intercellular spaces of their host, others inside the host's cells, and many of them inhabit algae and other aquatic plants. A large number of algae live as endophytes, many of them in cavities occurring naturally in other plants; such we can hardly regard as parasites; nor those which cause the formation of "domatia" on their hosts, since these structures are an indication of a symbiotic rather than of a parasitic

\footnotetext{
'Altmann (Botan. Zcituny, 1894, p. 207) describes a number of marine algae parasitic on Fucacecue; Moebius, "Enclophyte Algen," Biolog. Centralblatt, 1891 ; also Conspectu: algarum endophyturum, etc., 1591, with coinplete bibliography.
} 
relationship. The manner in which typical chlorophyllous plants gradually become shelter-parasites, and pass from this into the condition of true parasites, is well demonstrated amongst the algae. Few of the parasitic algae can be said to affect their host injuriously by causing death of its tissues; Phyllosiphom is the most marked case of this kind.

\section{A. THE CYANOPHYCEAE.}

These, the blue-green algae, possess a homogenous bluish green plasma, with a colouring matter consisting of phycocyan and chlorophyll. Multiplication takes place only by celldivision; sexual reproduction does not occur. Many of the forms are adapted to a symbiotic life, yet without prejudice to their ability to live as independent organisms. Numerous species form licheus. They are in many cases capable of long resistance to drought.

The Cyanophyceae are common both as eudophytes and epiphytes on other algae and on higher plants. Amongst them will be found examples of purely shelter-parasitism, of true parasitism, and all internediate stages, ret no cases are known of real injury or death to host-plants resulting from members of this group. Amongst forms endophytic in Phanerogams nray be noticed Nostoc gumneree in Angiosperms, and Ancibaena cyeadearum in Gymnosperms; in Pteridophyta only Anabaenu azollae is known, and in Bryophyta, Nostoe lichenoides. In evely case the Nostoc penetrates as a shelter-parasite into fissures or cavities already existing in the host, and becomes as a rule entangled in a slime occupying the carity. The Nostoc in Gunnerc becomes parasitic at a later stage, and makes its way into the cavity of cells. The other species are never endophytic in the host-cells, though they may affect the cells surrounding a cavity and stimulate them to further growth, apparently, however, without any injurious effect on the host-plant.

Nostoc punctiforme (Kutz.) P. Hariot ${ }^{1}$ (Nostoc (Scytonema) gunnerac Reinke). ${ }^{2}$ This occurs in various species of Gunnera, natives of South Africa, New Zealand, and South America: or cultivated frequently in Europe. The occurrence of the Nostoc is in every case the same, its presence being indicated to the

\footnotetext{
${ }^{1}$ Hariot, Compt. rend. cxr., 1892.

"Reinke, Morphologische Abhandlungen, Leipsic, 1873.
} 
naked eye by bluish-green spots on sections of stems and rhizomes of the host (Fig. 319).

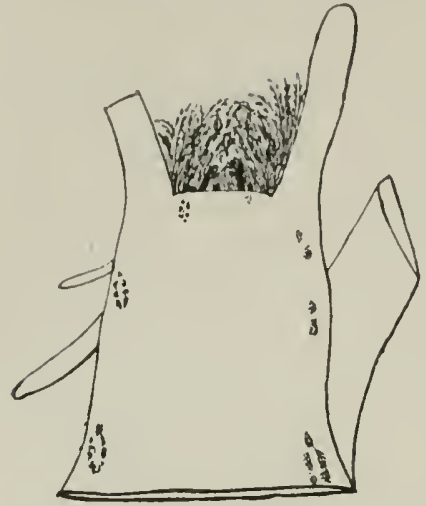

Fic. 319.-Nortoc gunnerce. Longitudinal section through the apex of a stem of Gunnera manicate. The punctated spots indicate the position of Nostor-colonies. (v. Tubeuf del.)

These originate as follows: the species of Gunnerre possess characteristic mucilage-secreting organs, in the form of fissures of the leaf-tip, collaters on the leaves, and glands on the stems. Merker ${ }^{1}$ found that these glands originated endogenously in the growing point between each pair of leaves. The mature glands are covered only by the epidermis, and when activity commences the nppermost cells of the gland-tip, after swelling, become detached and converted into slime (Fig. 320). Ultimately the epidemis is ruptured by the pressure of the slime, and the remaining glandular cells are in turn rapidly transformed into the same substance.

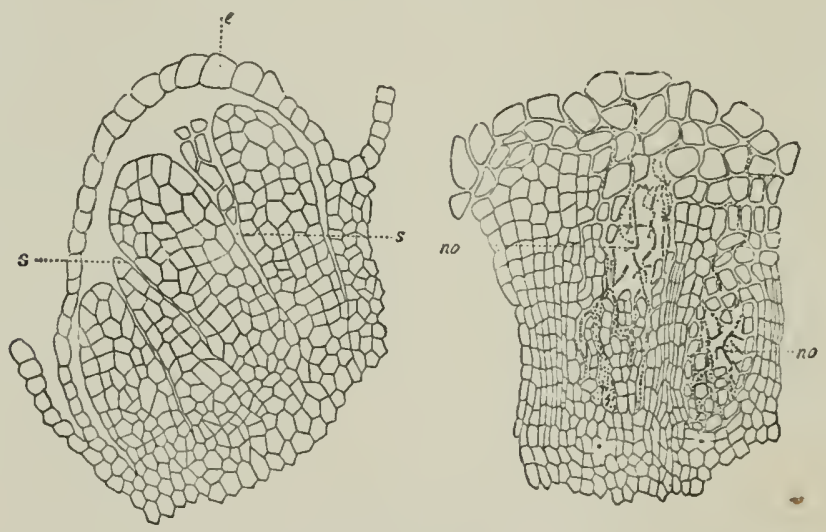

Fig. 320.-Nostoc gunnerae. Longitudinal sections through a gland in stem of Gunnere macrophylla. e, Epidermis; s, slime-canal; no, colony of Nostoc. (After Merker.)

The Nostoc finds its way into the gland as soon as the epidermis is broken, apparently attracted there by some secretion. Merker found that the Nostoc filaments pass down

"Merker, "Gunnerce macrophylla," Inaugural Dissertation, 1888. 
the slime-canal into the gland itself, and there occupy the space left by the glandular cells on their conversion into slime. Thence the filaments find their way into the intercellular spaces of the starch-containing parenchyma surrounding the gland, and become closely applied to the cell-walls. The Nostoe then bores through or dissolves the cell-wall, absorbs the starch, and grows vigorously till it fills the whole cell. In this manner the Nostoe spreads through the cortical parenchyma of the Gunnere stem from cell to cell. The stem glands in course of time become inactive and the canal closes up, so that the Nostoc is

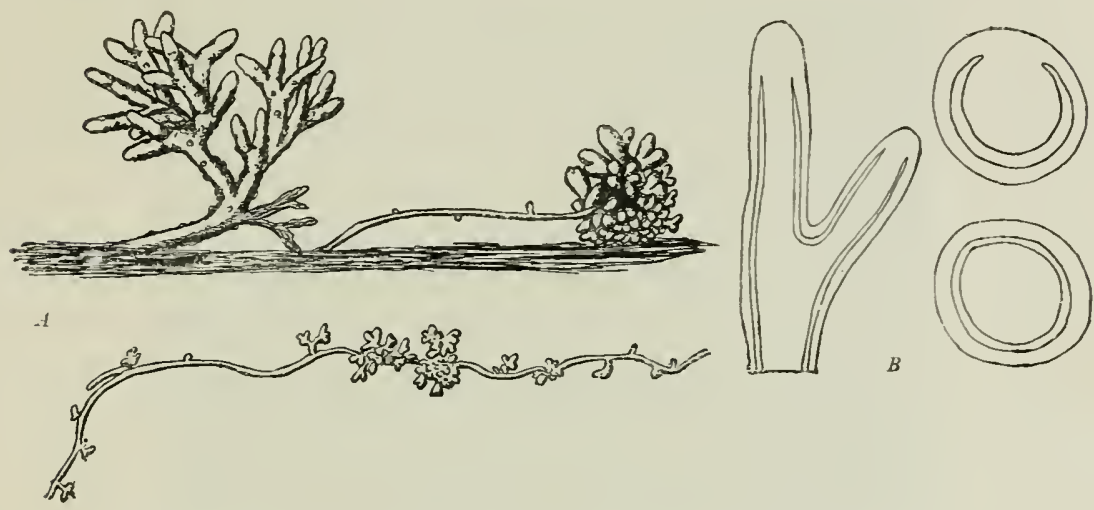

Fig. 321.-Anabaena cycudeamem. A, Coral-like surface-roots of $C y c a s . \quad B$, Transverse and longitudinal sections of $A$; the double line indicates the distribution of the Fostoc. (v. Tubeuf del.)

completely shut in. In this condition it is absolutely dependent on nourishment derived from the host-cells, and seems to thrive on it. No outward symptoms of disease can be observed on Gunnera with enclosed Nostoc, the local destruction of the cell-contents, the loss of starch, and the filling up of the tissues with filaments of Nostoc having apparently no effect. The species of Gunnerce have a very short stem with a growing point hardly raised above the level of the soil, so that the Nostoc easily finds its way there. No algae have been found in the petiole and lamina of the gigantic leaves. Gunnerce may easily be cultivated although it contains no Nostoc.

Jönsson ${ }^{1}$ regards Sostoe gunnerce as identical with $N$. puncti-

${ }^{1}$ Jönsson, Botan. Notiser, 1594. 
forme (the earlier name); he also helieves that it exists on damp soil and independently of finnere.

Anabaena cycadearum (Reinke). ${ }^{1}$ [Nostoc commune (Schneider). ${ }^{2}$ ] The following account of this species is taken from De Bary." Seedlings of Cycadeae have a thick tap-ront which branches in the soil; from the proximal end of the primary root a few pairs of root-branches grow up perpendicularly, and, after forking once or twice, their ends swell to form tubercles (Fig. 321). Similar clmmps of forked twigs

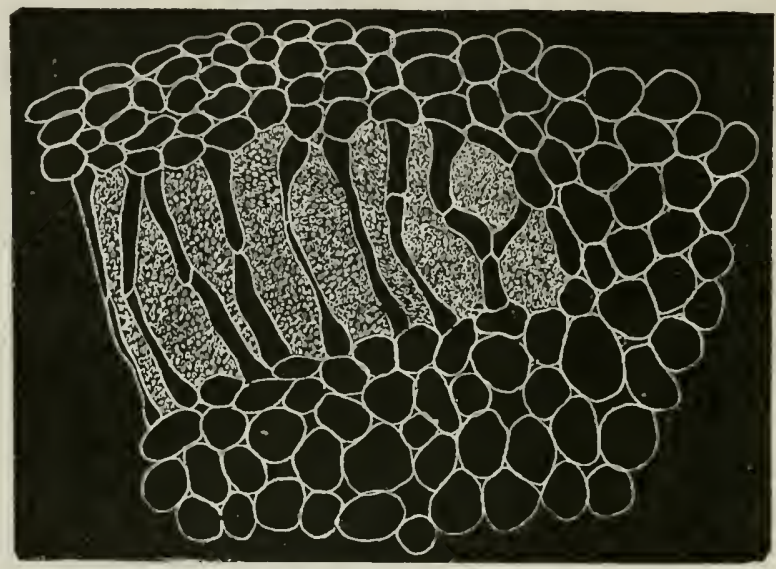

F1G. 322.-Anabaena cycuderium. Section of a Cycad-root, as in Fig. 321 , and in the condition shown in the upper transverse section $B$ of that figure. The Nostoc-filaments crowd the intercellular spaces and cause alteration in shape and growth of the adjacent cells as shown. (v. Tubeuf del.)

arise later on other branches which arise from the tap-root and spread over the surface of the ground.

It is into these forked twigs that the Nostor makes its way and causes the following characteristic alteration in their structure. A layer of parenchyma, which in normal roots does not differ from the surrounding compact polygonal tissue, becomes in attacked roots a definite zone round the axile vascular bundle. The zone consists of parenchymatous cells much elongated in one direction, and with their interspaces filled with masses of algal filaments (Fig. 322). In cross-sections of attacked roots the Nostoc

${ }^{1}$ Reinke, Botan. Zeitung, 1S79, and Abhandlungen, 1573.

2 Schneider, Botanicrl Gazette, 1894, p. 25.

${ }^{3}$ De Bary, Die Eracheinun! der Symbiose, 1879, p. 14. 
zone generally forms a circle; in longitudinal section the cylinder of blue-green algae does not extend quite up to the growing point. According to Reinke, the alga penetrates into the newly-formed intercellular spaces of the developing periblemcortex, and remains confined to the zone which it has first excited to increased growth. It is not certain whether the Nostoc penetrates only into injured places or into natural fissures.

The branched aerial masses of tubercles on Cycad-roots are prochuced independently of the Nostoc, ${ }^{1}$ but their function is unknown beyond a suggestion that they are organs of respiration. They certainly receive no injury from invasion by the Nostoc. Since the Nostoc lives completely cut off from the outer world and frequently in subterranean roots, we must assume that it receives nourishment from the host.

Reinke found Anabaena in roots of Cycas, Cercetosamia, Dioon, and Encephalartos.

Reinke has also found very fine fungal mycelia in the roots of Cycads. Schneider observed intracellular bacteria in roottubercles free from Nostoc.

Anabaena azollae Strasb. ${ }^{2}$ This endophyte is never absent from $A$ zolla, neither $A$. caroliniana so much cultivated in hothouses, nor the wild species found in America, Africa, Asia, and New Holland. The algal filaments are present even in the neighbourhood of the vegetative point and in the closed indusia of the sporangia. They are, however, most abundant in the cavities formed in the epidermis of the fleshy Hoating leaves. ${ }^{3}$ The Anabance filaments do not enter the cavity by the opening found in the completed structure, but find their way in during the formation of the cavity, and probably influence its development. As the cavity becomes filled with Anabaena, some cells of its inner walls grow out as segmented branched filaments amongst the coils of the alga, probably in consequence of a stimulus exerted by the Anabaena.

No endophytic Schizophyceae are lnown in the true mosses,

${ }^{1}$ Moebius (loc. rit.) states that the roots of Cycads at the Botanic Garden, Heidelberg, never contain Anabaena.

2Strasburger, Ueber Azolla, Jena, 1873 ; also Practical Botany (Euglish Edition by Hillhouse, 1S59).

${ }^{3}$ The leaves of Azolla are divided into two parts, the upper fleshy one of which tloats on the water, the under membranous one being submerged. 
but several inhabit Mepaticue, chiefly species of Anthocros, Blasia, Pilliu, Anenre, Itiplulucure, Śnuterin, and Riccin.

Nostoc lichenoides Vauch. ${ }^{1}$ is a common endophyte in the mucilage-cavities of Anthocros laeris. The motile algal filaments gain admission through the stomata or mucilage-fissures on the lower side of the thallus. Only one filament is admitted into each cavity, then the opening is closed by an increased turgescence and growth of the guard-cells; the imprisonel Nustoc nultiplies to form a colony.

Leitgeb states that after infection has successfully taken place, and frequently before the stoma has quite closed, the guard-

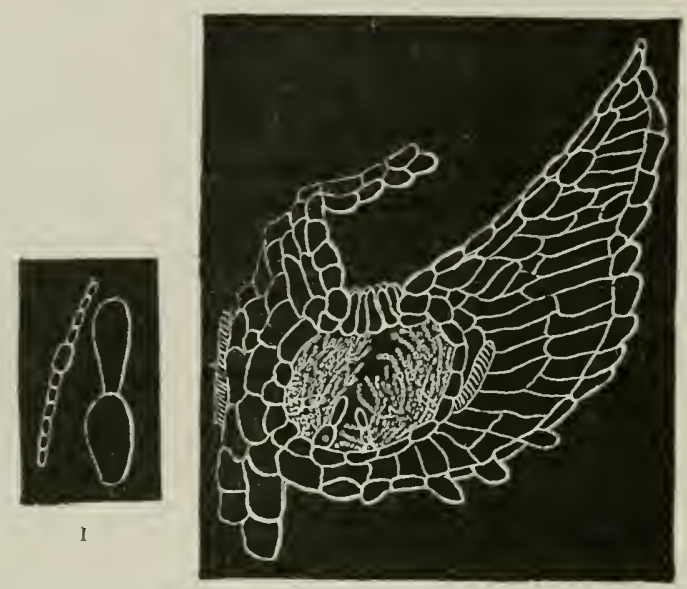

\footnotetext{
FIG. 323.- Andurenu azollae. Longitudimal section through the posterior lobe of a floating leaf of Azolla cuoliniana. The cavity is filled with Nostoc-filament. and septate hairs.

1, A septate hair, and a filament of Analuena. (v. Tubenf del.)
}

cells divide and ultimately form a three-layered covering of cells over the intercellular space. Simultaneously all the thalluscells round the infected cavity undergo radial division and grow into the cavity, first as papillae, then as much-branched and septate tubes of various lengths; the space left between them becomes meanwhile filled with the Nostoc. In the case of Anthoceros lacvis the tubes form a kind of pseudoparenchyma

${ }^{1}$ Bibliography: Janczewski, Botan. Zeitung, 1S72, and Annales d. sci. natur., Ser. 5, xvi. Milde, Botan. Zeitung, 1551. Leitgeb, Akademie d. Wissenschaften in Wien, 1878; also Untersuchungen über Lebermoose, 1. Goebel, "Die Muscineen," in Schenk's Handbuch d. Botanik, 1S52. 
with interspaces filled with Nostoc. If other algae, e.g. Oscillaria, enter the cavities, the opening is neither closed nor do the walls grow out as processes. Infection by Nostoc only occurs when the mucilage-cavities lie near the apex of the thallus and are secreting mucilage, the substance which evidently stimulates the Nostoc to enter.

Leitgeb found many Anthoceroteae (Denulroccros, Nototyles, Anthoceros) with mucilage-cavities containing Nostoc, not sunk in the thallus as with Anthoccros lacvis, but forming warty projections above it. In the case of Dendioceros these occurred on the upper side of the thallus as well as on the lower. The openings of the cavities of Notothylas do not close after infection, but distinctly open wider.

Janczewski observed that chlorophyllous cells of Hepaticae, though at first uninfluenced by the intruding alga, afterwards lose their chlorophyll and plasma; hence he assumed that the imprisoned Nostoc begins in time to live a parasitic life, and to kill the host-cells. This, however, is not supported by other authorities. Goebel, on the other hand, believes that the Nostoc, like the mucilage amongst which it grows, is useful to the thallus, and that it ultimately completely replaces the mucilage. Prantl held that the alga assimilated free nitrogen, giving up the product to the hairs in the cavity; but this is extremely unlikely, especially when the Nostoc is completely enclosed in its host.

Nostoc lichenoiles is also very frequent in the leaf-auricles on the under side of the thallus of Blasia pusilla. The auricles contain mucilage, which probably induces the Nostoc to enter. As a result of the Nostoc invasion the auricle enlarges and continues to live, whereas without this it would soon have died off. Branched filamentons processes are produced from the inner wall of the auricle and grow amongst the Nostoc. ${ }^{1}$

\section{B. THE TRUE ALGAE.}

In these Algae the green chlorophyll is limited to certain portions of the plasma, the chromatophores. The true Algae are capable of sexual reproduction. They are all more or less adapted to an aquatic life. Many of them live in symbiosis, some are true parasites.

${ }^{1}$ Waldner, Akad. d. Wissenschaften in Wien, 1878. 
The true Algae may be grouped as follows: (1) Conjugatur: (2) Chloropleyecar; (3) Rihorlophygecae; (4) Phacopihyecac; Chumecar.

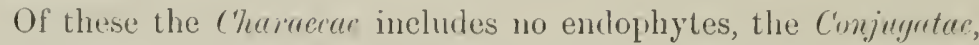
Phreophyceae, and Rholopleycece only species endophytic in other algae or in animals. The Chlorophyccue, however, include a large number of speeies which live as "aerial algae" endophytic in I'hanerogams, either as shelter-parasites or as true parasites.

\section{CHLOROPHYCEAE.}

'These are divicled into three groups: ${ }^{1}$

1. Protococcoileae including the families Volvocacar, Trtrasporaceac, Chlorospharreccae, Plenrococcacene, Protococcaecue (Endosphacraecue, Charaeieae, Sciadincene), and Hyatrodictyaecae.

2. Confervoideae including the families Ulvaccae, Ulothrichacear, Chactophoraccac Mycoidcaceac, C'ylindrocapsaecac, Ocdogoniaccac, Coleochactaccae, Cladophoracear, Cromontiaecre, and Sphacropleaciac.

3. Siphoneae including the families Botrydiaceae, Plyyllosiphonaccae, Derbesiacer, Vancheriuccae, Bryopsidaccac, Caulerpraceac, Codiacrae, Valomiacear and Desystadaccer.

\section{Chlorosphaeraceae.}

Chlorosphaera endophyta Kilebs. This is found between the living epidermal cells of Lemna minor, and produces there spherical cell-masses visible to the naked eye as wart-like swellings. According to Frank, this is related to Endoclonium polymorphum Frank.

Entophysa charae Möb. This lives under the cuticle of the epidermal cell-wall of Cham Homcmanni in Brazil.

\section{Endosphaeraceae.}

Most of the species ean penetrate into living organs, but they may also live as saprophytes or vegetate as independent organisms. That all the Endosphacraccae are injurious to their host has not as yet been proved.

Chlorochytrium includes eight European species all endophytic in living plants.

\footnotetext{
${ }^{1}$ The arrangement nsed by Wille in Engler-Prantl. natur. Pfanzen-familien.
} 
Chlorochytrium lemnae Cohn. ${ }^{1}$ The zygozoospores have four cilia and swarm for a short time in water. On plants of Lemna trisulca, the ciliated end becomes applied to the epidermis at the place where two cells are in contact, the zoospore hecomes spherical, forms a nembrane, and comes to rest (Fig. 324). It remains resting for a day or two, and assimilates so that a starch-grain is formed inside it. Next, a transparent process is given off which finds its way between the epidermal cells, widens out, and absorbs the cell-contents, while the portion of the algal

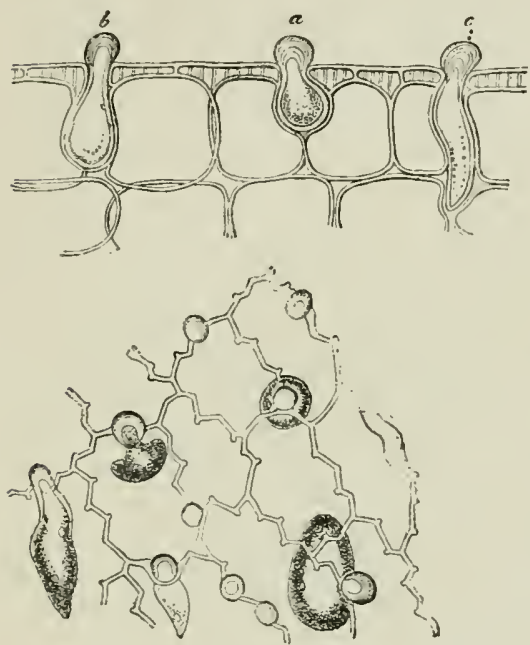

FIG, 324.-C\%lorochytrium lemince. "b, c, Ger. minating spores penetrating through the epidermis and between the cells of the parenchyma. A surface view shows the germinating spores from abore. (After Coln.)

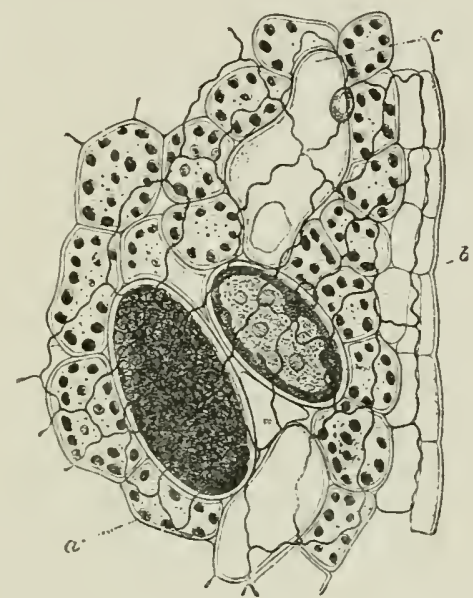

Fig. 335.-Chlorochytrium lemnae ia L mane trisulea. a, Hature; (1, young; $c$, diseharged sporangia. (After Klebs.)

cell remaining outside becomes filled with cellulose and forms a firm button-like process. The young alga continues to make its way between the cells into the interceliular spaces of the subepidermal layers of parenchyma, preferably taking up its quarters in the thin anterior margin of the thalloid shoot, and avoiding the larger air-spaces. The zoospores are formed by repeated division of the plasma of the original cell; they are enclosed in a gelatinous mass which swells and ruptures the membranes of the alga as well as the tissue of the Lemnu.

${ }^{1}$ Cohn, Beitrage zur Biologie d. nierl. Organismen; Klebs, Botan. Zeitun!, $18 \varepsilon 1$. 
The zoospores (gumetes) copulate in the gelatinous mass which escapes, and break out from it as free swarming zygozoospores. When the Limma falls to the botton in autumn, or when it dries up, the cells of the alga become resting-cells capable of sustaining drought. Plants of Lemm seem to be little disturbed loy attacks of the endophyte, and develop their flowers normally.

Chl. Knyanum Kirchn. Frequents Lemene minor and L. gibler, Crratophyllum demersum, Eloder canadensis, but not Ismna trisulcu. It forms zoospores only, and these on penetrating into a host do not proluce a cellulose button like the speeies just described. They appear to be alle to enter the host only by the stomata.

Chl. pallidum Klebs. Grows in the intercellular spaces of Lemna trisulce.

Chl. viride Schroet. Found in the respiratory cavity of Tiumex obtusifolius.

Other species vecur in dead Ihanerogams or in Algae.

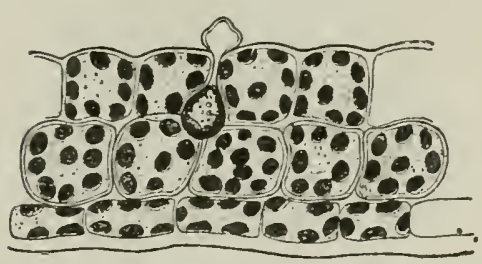

Frg. 326.-Endospharia birnais in Potamogeton lucens. Cell of the Alga, which has penetrated throngh the epidermis a few weeks previously. (After Klebs.)

cells of dying leaves of Hymum

Endosphaera biennis Klebs. The zygozoospores have four cilia, and swarm in water till they reach a living leaf of Potamogrton lucens. They generally come to rest on the underside of a leaf at the boundary wall between two cells, and become invested in a membrane. A process is next sent in between the epidermal cells, and all the cell-contents pass over into it, the onter portion dying away. The young alga now makes its way into the intercellular spaces of the sub-epidermal tissue and becomes a resting spore. In spring this spore gives off biciliate gametes, which, after copulating, become zygozoospores. This shelter-parasite has not yet been observed 
to have an injurious effect on its host, beyond killing a few isolated leaves.

End. rubra Schroet. occurs in leaves of Mentha aquatica and Peplis Portula.

Phyllobium dimorphum Klebs. Found in leaves of Lysimachice Nummularia, Ajugu reptans, Chlora serotina, Erythrace. Centcurium. This endophyte may either penetrate into living leaves and there go through its life-history, or it may do so in dead leaves. The zygozoospores have only two cilia, and enter the leaves chiefly through the stomata of the lower surface. Inside the leaf they form long filaments, which make their way between the elements into the vascular bundles of the leaf-ribs, and follow the course of the spiral vessels. Resting-spores are formed, and give the reins of the leaf a rosary-like appearance. Male and female gametes are produced from the resting cells, and copulate to form zygozoospores. The host-plants are not injured by this endophyte.

\section{Chaetophoraceae.}

Most of the species are aquatic algae which live independent or as epiphytes.

Endoclonium polymorphum Frank (see Chlorosphaera rndophyta Klebs). This form lives endophytic and sometimes intracellular in living or dead leaves of Lemna.

Entoderma Wittrockii Wille
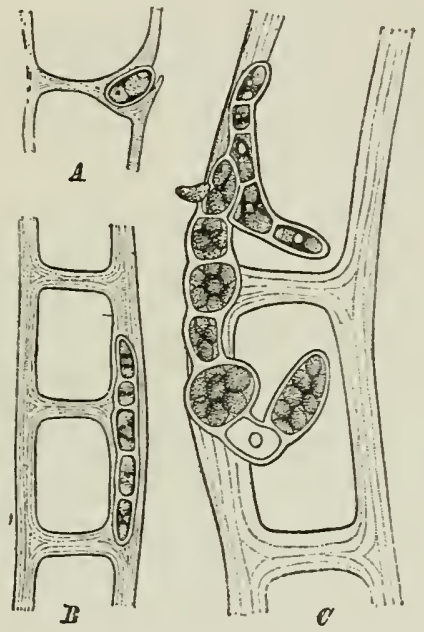

FIG, 30- Entodema Wittrockii in the membrane of a species of Alga (Eitocarpus). $A$, A young one-celled plant just after penetration into the alga. $B$, Plant composed of several cells in the wall of Ertocoipus. C, Plant which has formed sporangia of swarmspores, one of which is discharged and another is in the act. (After Wille.) occurs inside the wall of Ectoccippus (Fig. 327).

Periplegmatium and Phaeophila live endophytic in living algae.

Trentepohlia endophytica (Reinsch). In living cells and intercellular spaces of Jungermanniaceae (e.g. Frullania dilatuta) and kills them. 


\section{Mycoidaceae.}

Cephaleuros Mycoidea, Karsten ${ }^{2}$ (Mycoidru purcesiticu, Cunning.). ${ }^{2}$ This alga is epiphytic on the leaves of most trees and shrubs in the tropics. It varies considerably in its appear-

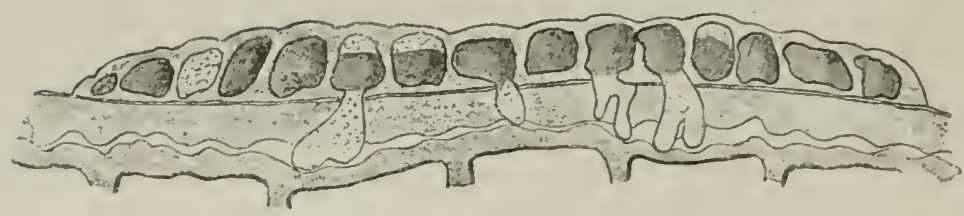

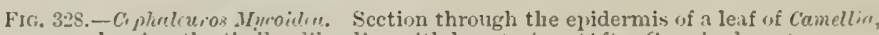
shuwing the thallus-like disc with haustoria. (After Cunuingham.)

ance, but generally forms flattened thalloid dises several layers of cells thick and attached firmly to leaves by means of rhizoids (Fig. 328). Hairs are produced from the thallus-rliscs, especially

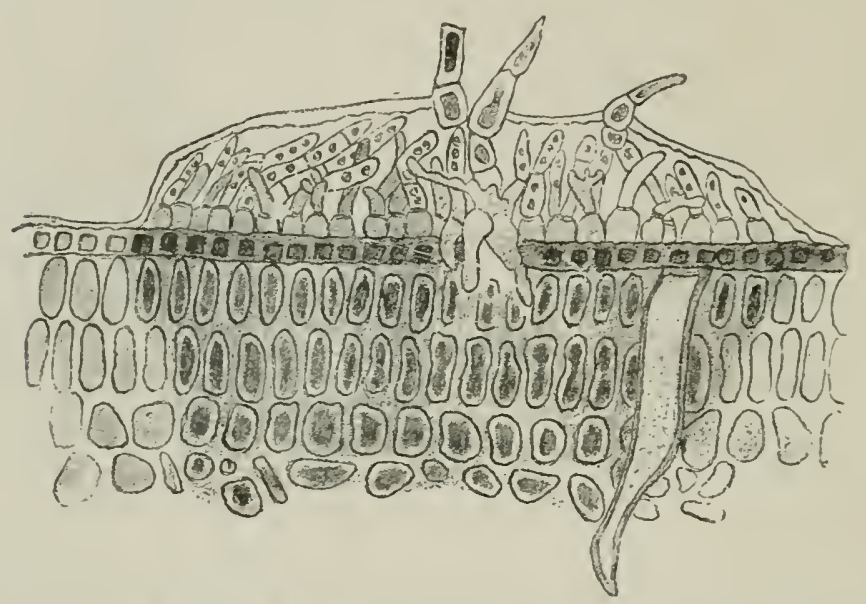

F10. 329.-Crphuluros Hycoidea. Section through part of an attacked leaf of Camellia. The epidermal layer has been ruptured, and haustoria from the algal dise penetrate to the tissues. The dark-shaded portion is that killed by the alga. (After C'umingham.)

the older ones: in addition, sporangial structures are also developerl and give off biciliate swarm-spores. The discs form a kind of cuticle which becomes completely fused with that of the leaves.

${ }^{1}$ Karsten, Annal du jardin. botan. de Buitenzory, Vol. x., 1891.

2' 'unningham, Trans. of Limean Soc. of London, 1850; H. M. Ward (idem), 1854. 
Where this oceurs, black patches are frequently formed so that the leaves become spotted, but the injury to the host-plant is by no means so severe as in the following species.

Ceph. parasiticus Karsten. This species is common on the leaves of Calathece and Pandenus at Buitenzorg. It spreads through the whole leaf-tissue blackening and killing it. The epidermis is blistered and its cells filled with the alga; ultimately the cuticle is ruptured and the stalked sporangia are produced. The swarm-spores germinate in the stomatal cavity, or in the adjacent intercellular spaces.

Ceph. minimus Karsten is parasitic on leaves of Zizyphus Jujuba at Buitenzorg. It permeates the leaf-parenchyma and kills it, the cells after death becoming completely occupied by the alga.

\section{Phyllosiphonaceae.}

Phyllosiphon arisari Kuhn. ${ }^{1}$ This is a true parasite as yet observed only on Arisarum vulgare in Italy and the South of France. It eanses death of the leaves and is frequently very abundant.

The thallus consists of unicellular, non-septate, much branched filaments containing chlorophyll, and filling up the intercellular spaces of the spongy parenchyma of the host. The wall of the filaments gires the reactions for cellulose and consists of an outer and a later-formed inner layer, the latter capable of swelling very much to assist in ejaculating the spores. The chlorophyll corpuscles at first contain no starch, only oil, which, however, decreases during spore-formation, while the starch increases. The spores (aplanospores) are formed inside the algal threads, and are ejected with great force from the extremities of filaments which lie under stomata, and therefore in the position where least resistance is offered to the swelling inner wall. Chlorophyll is not present in the young filaments, but it appears in the older parts, especially about the time of spore-formation, and seems to be stored in the spores. The spores have a nuclens and chlorophyll disc. They germinate to a filament which grows between two epidermal cells into the intercellular spaces of the leaf.

"Kuhn, "Eine neue parasitische Alge," Sitzungster. d. naturforsch. Ges., Halle, 1S7S; Just, Botan. Zeitung, 1SS2; Schmitz (idem). 
Parts of the leaf and petiole inhabited by this algat appear externally as yellow spots. Only one individual alga inhabits each spot, sending its numerons branches into the intercellular spaces. Attacked leaf-cells lose their chlorophyll and starch, the latter being at first replaced by oil. The cells, however, remain alive and turgescent, even when deprived of almost their whole content; they die, when spores are produced in the filaments. Cells undisturbed by the alga remain unaffected. A

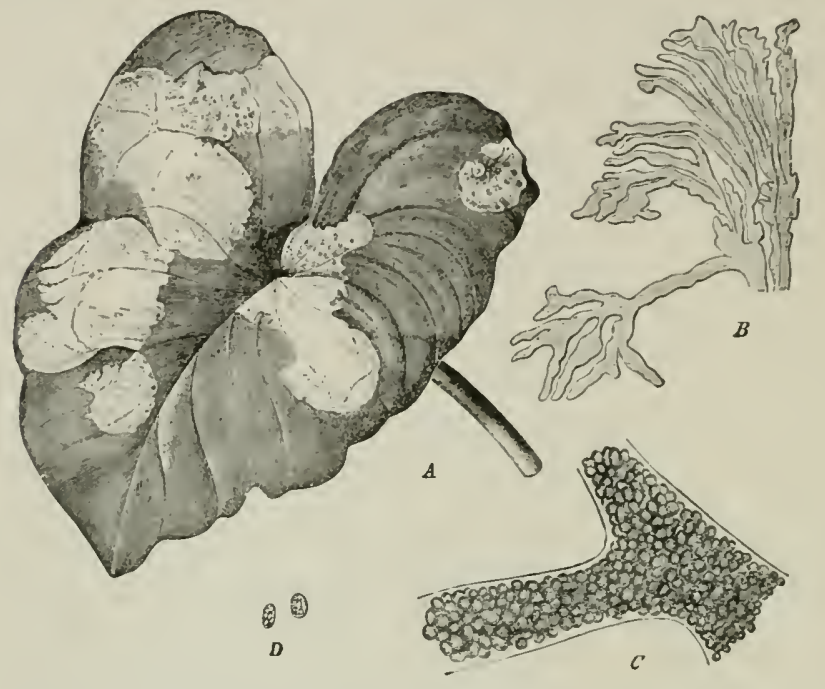

Fic. 330.-Phyllnsiplenn arisari on Ariscrum vulgare. A, Leaf with yellowish siots; $B$, the branclied alga isolated from a spot; $C$, spore-formation inside a flament; $D$, spores. (After Just and Engler-Praitl.)

single leaf niay bear a large number of spots, and all the plants of a locality are generally attacked. The spots were found by .Tust only from December to April, then they disappeared, indicating that the algal spores must have a resting-period outside of the Arisarum, and return to young plants again in autumn.

Phytaphysa Treubii Weber et v. Bosse. Forms characteristic galls on a species of Pilea in .Tava.

\section{PHAEOPHYCEAE.}

These algae live only in other living algae, and are not endophytic in higher plants. 
Streblonemopsis irritans Val. forms wart-like galls on Cystosira opentioides.

Entonema grows between and into the cells of Rhodophycere and Melanophyceae.

\section{RHODOPHYCEAE.}

The Rhodophyecae or Florideae occur endophytic only in other algae; e.g. Harveyella mirabilis (Reinsch) vegetates in thalli of Rhodomeleae and Polysiphoneae, but reproduces itself outside its host. Species of Choreocoler and other genera have a similar mode of life. 


\section{INDEX OF PARASITES.}

A

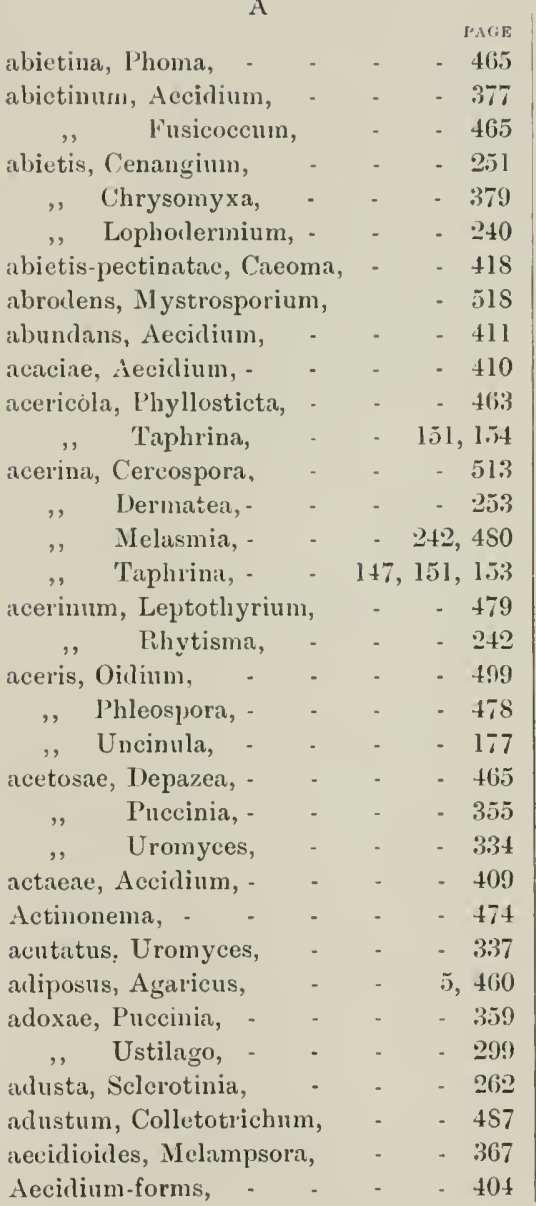

aegopodii, Caeomi, -

Puccinia,

aegra, Puccinia,

aesculi, Aecilium,

, Septoria, -

,, Taphrina, -

affinis, Thectuphora,

Agaricineae, - -

Agaricus,

aggregata, Sclerorlerris, -

Aglaospora,

agrimoniae, Nclampsora,

$$
\text { , Uredo, }
$$

agropyri, Puccinia,

Urocystis,

agrostidis, Puccinia,

albescens, Didymosphaeria,

$$
\text { ,, Puccinia, }
$$

albidum, Phragmidium, - _ _ $\quad 363$

albomaculata, Ramularia, - - 502

Albugo (see Cystopus), - - - 123

albulensis, Puccinia, _ _ - \$61

album, Mastigosporium,- - - 504

„, Microstroma, - - 497

albus, Polyporus, - - - - 452

alchemillae, Coleroa, - - $\quad 195$

, Uromyces, - - - . 337

Algae, - - - - 539, 547

alismatis, Doassansia, - - $\quad 323$

" Pseulopeziza, - - 255

alliatum, Aecidium, - $\quad$ - 349

allii, Caeoma, - $\quad$ - $\quad$ - $\quad 367$

„Puccinia, . - - 355

", Rhiznctonia, - - . 202 
PAGE

alliorum, Caeoma, - - - - 419

„ Macrosporium, - - 515

alneum, Leptothyrium, - - - 479

alni, Frankia, - - - - - 101

, Microsphaera, - - $\quad 176$

,, Sclerotinia, - - $\quad$ - 262

"Stigmatea, - - - 211

alni glutinosae, Taphrina, 150, 152, 157

alni incinae, Taphrina, $147,150,152,157$

alnicola, Ovularia, - - - 501

alpestre, Bostrichonema, - - $50 \mathrm{I}$

alpina, Puccinia, - $\quad$ - $\quad$ - $\quad$ - 359

, Taphrina, - $14 \overline{7}, 149,153,161$

alpinum, Synchytrium, - - - 112

alpinus, Uromyces, $\quad$ - $\quad$ - 337

alsinearum, Peronospora, - - 134

alta, Peronospora, - - _ _ 134

Alternaria, - - - - 517,51S

althaeae, Colletotrichum, - - 487

althaeina, Cercospora, - - $\quad$ - 515

,, Phyllosticta, - - - 464

Alveolaria, - * - * 403

ambiguns, Uronyces, - - - 337

amentorum, Exoascus, - - 157

ampelinum, Colletotrichum, - - 4Ss

" $\quad$ Phoma, - - $\quad$ - 467

"Sphaceloma, - 12, 467

ampelophagum, Gloeosporium, - 484

amphigenum, Rlytisna, - $\quad 246$

anygdalearum, Clasterosporium, - 511

amygdalinum, Gloeosporium, - - 483

anylovorous, Micrococcus, - $\quad 531$

Anabaena, - $\quad$ - $\quad$ - $\quad$ - $\quad .544$

anceps, Leptosphaeria, - - 221

anchusae, Accidium, - - - 34 i

Andersoni, Puccinia, - - 359

andromedae, Coleroa, - - $\quad 195$

" Exobasidium, - - 426

," Rhytisma, - - - 246

," Stigmatea, - - - 211

andropogonis-annulati, Ustilago, - 292 -tuberculati, Ustilago, 292

anemones, Septoria, - - $\quad 47 \mathrm{~S}$

"Synchytrium, - - 112

," Urocystis, - - - 316

anemones-virginianae, Puccinia, - 360

angulata, Cercospora, - - 515

angustata, Puccinia, - - $\quad 35$

Anixia, - - - . - 178 annosus, Polyporus,

annularis, Pucciuia, - - $\quad 361$

anomala, Ustilago, - - - - 295

anomalum, Synchytrium, - - 112

Antennaria, - - - - 181

Anthostoma, - - - . - 226

Anthostomella, - $\quad$ - $\quad$ - $\quad 226$

anthoxanthi, Puccinia, - - $\quad 3.54$

anthyllidis, Uromyces, - $\quad$ - 337

apii. Cercospora, - . $\quad$ - 514

„, Pbyllosticta, - - - - 464

Apiosporium, - - - - 181

apocyni, Aecidium, - - $\quad 411$

,, Septogloeum, - - - 496

appendiculatus, Uromyces, - 334

aquilegiae, Aecidium, - $\quad 349,409$

arborescens, Peronospora, - - 133

arctica, Nelampsora, - - - $36 \mathrm{~S}$

" Tilletia, - - - 310

aretostaphyli, Exobasidium, - - 427

arenariae, Peronospora, - - $\quad 134$

, Puccinia, - - $\quad 361$

arenariicola, Puccinia, - - $\quad$ - 351

areola, Piamularia, - $\quad$ - $\quad$ - 502

argentata, Puccinia, - $\quad-\quad 356$

ari, Aecidium, - - $\quad 349,410$

ari-italici, Caeoma, - $\quad$ - 419

ariae, Nlelampsora, - $\quad$ - 370

aristidae-cyanthae, Ustilago, - - 294

aristolochiae, Puccinia, - - $\quad 341$

Armillaria, - - - - - 455

armoraciae, Ascochyta, - - $\quad 473$

, Cercospora, - - . 514

, Ovularia, - $\quad$ - $\quad 500$

, Septoria, - - $\quad 47$

aromaticum, Septocylindrium, - 505

Arthuri, Peronospora, - - $\quad 134$

arundinaceum, Helminthosporium, 516

Napicladium, - - 516

arundinellae, Ustilago, - - $\quad 294$

Asanuro, Caeoma, - - - - $41 \mathrm{~S}$

asariua, Puccinia, - $\quad$ - $\quad 32,359$

Aschersoniana, Schinzia, - $\quad 326$

Aschersonii, Entyloma, - - $\quad 312$

asclepiadeum, Cronartium, - - 381

Ascoboleae, - $\quad$ - $\quad$ - $\quad 253$

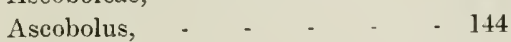

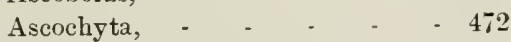

Ascodesmus, - $\quad$ - $\quad$ - 138 
Ascoilea

Ascomyces,

Ascomycetes,

Ascospora,

asparagi, Cereospora,

, Prnccinia,

isperatum, Heterosporium,

Aspergillus,

asperifolii, Ovularia,

aspiclistrae, Ascochyta, .

Asterina,

asteris, Puccinia,

Asteroma,

Asteromiclinm,

asterum, Aecidium,

astragali, Didymaria,

,, Microsphaera,

,, Uromyces,

astrantiae, Fabraea,

astroidea, Piggotia,

atragenis, Puccinia,

atriplicis, Phyllosticta,

ancupariae, Sclerotinia,

aurantiaca, Thecaphora,

anrea, Taphrina,

]48, $150,154,166$

Aureobasidium,

$48,150,154,160$
$-\quad-\quad 428$

aureum, Synchytrium, - - - 111

Auricularieae, - $\quad$ - $\quad$ - 421

aurivellus, Agaricus, - - $\quad-462$

iurstrale, Rhytisma, - $\quad$ - $\quad$ - 246

anstralis, Peronospora, - _ - 134

". Puccinia,

" Taphrina,

Auteupuccinia,

Autobasidiomycetes,

autumnale, Rhytisma,

avenae, Ustilago, -

azaleae, Exobasidium,

azollae, Anabaena, -

B

baccarum, Sclerotinia,

bacilligera, Passalora,

260

Bacillus,

506

Bacteria,

- 530

Bacterium, - - 101, 143, 534, 537

Balansae, Peridermium, - - $\quad 417$

balsameum, Peridermium, - 417
PAis

lalsamitac, P'uccinia, - - 35.

bambusac, Neovossia, - . $\quad 311$

barbareate, Aecidium, - _ _ 411 !

Barclayana, Neovossia, - _ - 311

Barclayelliı, - - _ _ - 373

Barclayi, P'hragmidinu, - _ - 363

Bardanac, Accillium, - _ _ 351

Bargellinia, - - - . - I:3s

Barya, - - - - . - 184

Baryanum, P'ythiuın de, - - $\quad 4,116$

Baryi, Puccinia, - $\quad$ - $\quad$ - 354

basicola, Thielavia, - $\quad$ - 182

Basicliomycetes, - . - . 421

Basidiopliora, - . - . 127

batatas, Rhizoctonia, - - $\quad$ - 202

bataticola, Phyllosticta, - . 464

Batschiana, Sclerotinia, - - $\quad 270$

Behenis, Uromyces, - _ $\quad$ - 337

bellidiastri, Precinia, $\quad$ - $\quad$ - $\quad 359$

Beloniella, - $\quad$ - $\quad$ - $\quad$ - $\quad$ - 255

berberidis, Aecidium, - - $\quad 341$

,, Melasmia, - - - 479

,, Microsphaera, - - 176

Berkeleyi, Puccinia, - $\quad$ - $\quad 356$

betae, Phoma, - - - $\quad$ - 468

,, Pliyllosticta, - - - 464

,, Rlizoctonia, - . - 202

, Uromyces, - - - - 334

beticola, Cercospora, - _ $\quad$ - 513

betonicae, Puccinia, - $\quad$ - $\quad 359$

,, Ustilago, - - . $\quad 298$

betulae, Hommomyia, - $\quad$ - $\quad 262$

, Sclerotinia, - - $\quad 261$

, Taplirina, - 145, 149, 154

betulina, Dothidella, - $\quad$ - 230

,, Melampsora, - - 366, 367

, Taphrina, 147, 149, 152, 159

betulinus, Polyporus, - - $\quad$ - 446

Beyerinckii, Ascospora, - - $\quad$ - 211

,, Coryneum, - - 211,491

bicolor, Entyloma, - - $\quad$ - 312

Bidwellii, Laestadia, - $\quad$ - $\quad$ - 216

biennis, Endosphaera, - - - 555

biseptatmm, Gymnosporangium, - 401

bistortae, Ovularia, - $\quad$ - $\quad 501$

,, Pseudopeziza, - - 256

,$\quad$ Pseudorlytisma, - - 255

,, Puccinia, - - - 355

, Rhytisma, - $\quad$ - $\quad$ - 246 
bistortarım, Ustilago, - _ $\quad$ - 298

Bivonae, Unciuula, - _ _ - 178

bliti, Cystopus, _ _ _ $\quad$ - 127

Bloxami, Cereospora, _ _ _ 514

Bolleana, Cercospora, - _ $\quad 515$

Boltshauseri, Ascochyta, _ _ $\quad 473$

borealis, Exoascus, - - $\quad$ - 158

,, Polyporus, - $\quad$ - 4.39

Bostrichonema, - $\quad$ - $\quad$ - $\quad 501$

Botrytis, - $\quad$ - $\quad$ - $\quad 4,267,499$

boutelouae-humilis, Ustilago, - 299

brachysporum, Lopliodermium, - 233

Brachypuccinia, - $\quad$ - $\quad$ - $\quad 3.5$

Brandegei, Aecidium, - _ $\quad$ - 411

brassicae, Alternaria, - $\quad$ - 518

,, Asochyta, - - $\quad 473$

,, Chytridium, - - 107

,, Macrosporium, - - 5ls

," Olpidium, _ _ 107

," Plasmodiophora, _ _

brassicicola, Sphaerella, - _ . 215

Bremia, - . - . - . 131

brevipes, Uromyces, _ _ $\quad$ - 337

brevius, Periderminm, - _ - 415

bromivora, Ustilago, - . . 292

Brunchorstia, - - $\quad$ - $\quad$ - $\quad$ - 481

Brunchorstii, Frankia, - _ _ 101

brunnea, Ramularia, - $\quad$ - $\quad 502$

bulbormm, Sclerotina, - $\quad$ - $\quad 266$

bulbosum, Phragmidium, _ _ $\quad 363$

Bulgaria, - $\quad$ - $\quad$ - $\quad$ - 253

bullata, Puccinia, - . $\quad$ - 353

, Taphrina, - $148,150,154,168$

, Ustilago, - - - $\quad 258$

bullatum, T'olyposporium, - $\quad$ - 306

bunii, Aecidium, - _ _ $\quad 355,409$

Puccinia

Burillia, -

butomi, Cladochytrium, - _ $\quad$ - 114

buxi, Laestadia, . $\quad$ - $\quad$ - $\quad 217$

, Puccinia, - . - $\quad$ - 361

Byssothecium circinans, - . $\quad 201$

C

cacaliae, Uromyces,

337

Caeoma, - - - - $\quad 364,418$

ealamagrostidis, Tilletia, . - 310

calcea, Ramularia, - _ $\quad$ - 502

caleudulae, Entyloma, - $\quad$ - $\quad 312$ californica, Plasmodiophora, - . 529

Calonectria, - . - . . 184

Calosphaeria, - $\quad$ - $\quad$ - $\quad$ - $\quad$ - 226

calospora, Tilletia, - _ _ _ $\quad$ - 310

calthae, Psendopeziza, - - . 25.)

,, Puccinia, - - - $\quad 341$

Calyptospora, - $\quad$ - $\quad$ - $\quad$ - 370

Camarosporium, - - - - 47.5

camelliae, Coryneum, - - $\quad$ - 491

Meliola, - - - - 182

campanulae, Coleosporinm, - - 377

, Marsonia, - - $\quad 491$

, Puccinia, - - $\quad 359$

cancellata, Roestelia, - _ $\quad$ - $\quad 396$

candida, Peronospora, _ _ $\quad$ - 134

candidus, Cystopus, _ _ _ $\quad 123$

Candolleana, Sclerotinia, _ _ $\quad$ - 266

Candollei, Phoma, - _ _ $\quad$ - $\quad 468$

canescens, Entyloma, - _ $\quad 312$

caunabis, Septoria, - _ _ _ _ $\quad$ - $\quad 47$

capensis, Ustilago, - _ _ $\quad$ - $\quad 294$

Capnodium, - - _ - $\quad$ - 181

cappariclis, Cercospora, - - - . \$1j

carbonarium, Phragmidium, - - 363

caprearum, Melampsora, - - 368

cardui, Puccinia, - $\quad$ - $\quad$ - $\quad 3.59$

,, Ustilago, - $\quad$ - $\quad$ - $\quad$ - 296

caricicola, Puccinia, _ $\quad$ - $\quad$ - 35.5

caricis, Cintractia, - $\quad$ - $\quad$ - $\quad 301$

" Puccinia, - . . - 349

, Ustilago, - - - $\quad 301$

caricinum, Leptostroma, - - 480

caries, Tilletia, $\quad$ - $\quad$ - $\quad$ - $\quad$ - 306

carnea, Taphrina, - $148,149,154,167$

carneola, Ovularia, - _ _ $\quad 501$

carneum, Myxosporium, - _ _ $\quad 486$

carpinea, Dermatea, _ $\quad$ - $\quad$ - 253

carpini, Melampsora, - - $\quad$ - 370

,, Taphrina, - $147,150,153,162$

Carpoasci, - $\quad$ - $\quad$ - $\quad$ - 168

carpophilum, Cladosporium, - - 510

carthami, Puccinia, - $\quad$ - $\quad$ - 35.5

caryogenum, Fusicladium, - $\quad 508$

caryophyllinus, Uromyces, - $\quad$ - 336

Casparyana, Schinzia, - $\quad$ - $\quad$ - $\quad 326$

cassandrae, Exobasidium, - . 427

castagnei, Melampsora, - _ $\quad$ - 368

,, Podosphaera, - - $\quad$ - 173

, Puccinia, - - $\quad$ - 35.5 
custagnei, Sphaerotheca, castaneae, Diplodina,

Septoria,

catalpae, Macrosporium,

citenulatum, lintyloma, -

caulicola, Cercospora,

ciulium, Melanotaenium,

c'canothi, Aecirlium,

eecidomophilus, Taphrina,

cedri, Perillermium,

celiulicola, Schinzia (Naegelia).

celtidis, liamularia,

celtis, Taphrina,

Cenangium,

cenchri, Tolyposporium

centaureae, Aecidium,

Puccinia,

cephalanthi, Aeciclium, -

Cephaleuros,

Cephalotheca,

cepulae, Urocystis, -

cerasi, Fusicladium,

,, Puccinia,

"Taphrina, 19, 147, 1.51, 153, 163

cerasina, Septoria, - _ _ - 476

cerastii, Aecidium, - - - - 410

Melampsorella, - - $\quad 370$

cerastiorum, Fabraea, - _ $\quad$ - $25 \bar{J}$

Ceratocystis fimbriata, - - $\quad$ - 469

Ceratophorum, _ _ _ $\quad$ - 511

cerealis, Gibellina, - _ _ $\quad$ - $\quad 20$

cerebrum, Peridermiun, - - 414

Cercospora, - $\quad$ - $\quad$ - $\quad$ - $\quad$ - 513

Cercosporella, - . - $\quad 503$

cercosporoides, Cylindrosporium, - 489

Cesatii, Tuburcinia, _ _ $\quad$ - 322

chaetomium, Coleroa, - $\quad$ - $\quad$ - 195

Chaetophoraceae, - $\quad$ - $\quad$ - $\quad$ - 551

Charrinia, - $\quad$ - $\quad$ - $\quad$ - $\quad$ - 472

cheiranthi, Cercospora, - - - 515

chelidonii, Caeoma, _ $\quad$ - $\quad 419$

chenopodii, Phyllosticta, - $\quad$ - 465

Uromyces, - - $\quad 337$

Chlorochytrium, - $\quad$ - $\quad$ - $\quad$ - 549

Chlorocystis Colınii, _ $\quad$ - $\quad$ - 550

Chlorophyceae, - - . $\quad$ - 548

Chlorosphaera endophyta, - $\quad 548$

Chlorosphaeraceae, - _ $\quad$ - 548

Choreocolax, - $\quad$ - $\quad$ - $\quad$ - $\quad$ - 555 chrysanthemi, Oidimm, _ _ _ $\quad 499$

Septoriat, . 478

Chrysochytrium, - - - - 111

Chrysomyxa, - - - 20, 54, 377

chrysosplenii, Entyloma, - $\quad 312$

Puccinia, - . . 361

('hrysospora, - - $\quad$ - $\quad$ - $\quad 361$

Chytridiaceae, - - $\quad$ - 11, 106

Ciboria, - - . - . $\quad 270$

cichoriacearum, Erysiphe, - - 175

Cicinobolus Cesatii, - _ $\quad$ - $\quad 470$

cicutae, Puccinia, - - $\quad$ - 355

cinarae, Riamularia, $\quad$ - $\quad$ - $\quad$ - 502

cinerariae, Aecidium, - $\quad$ - $\quad 352$

cinerea, Botrytis, - $\quad$ - $180,267,499$

„, Monilia, - - - $\quad 261$

cingens, Melanotaenium, - $\quad 314$

cingulatum, Gloeosporium, - - 485

cinuabarina, Nectria, - $8,17,71,185$

cinnamomeus, Polyporus, - - 452

cinnumonea, Dermatea, - - $\quad 253$

Cintractia, - $\quad$ - $\quad$ - $\quad$ - 301

circueae, Aecidium, $\quad$ - $\quad$ - $\quad$ - 409

„, Melampsora, - - $\quad 370$

, l’uccinia, - _ _ $\quad 361$

circinans, Coleroa, - _ $\quad$ - $\quad$ - 195

, Leptosphaeria, - 201, 221

,, Vermicularia, - . . 471

circinata, Uncinnla, - _ - 178

circumscissa, Cercospora, - $\quad$ - 513

cirsii, Pliyllosticta, _ _ $\quad$ - 464

,, Puccinia, - . - . 340

citri, Capnodium, - _ _ _ - 182

,, Meliola, - $\quad$ - $\quad$ - $\quad$ - 181

Cladoclyytriaceae, - . . $\quad$ - 113

Cladochytrium, - $\quad$ - $\quad$ - 114

Cladosporinm, - - $\quad$ - $\quad$ - $50 \mathrm{~S}$

cladosporoides, Cercospora, - - 506

Clasterosporium, - $\quad$ - $\quad$ - $\quad$ - 511

clavariaeforme, Gymnosporangium, 354

Clavaricae, - $\quad$ - $\quad$ - $\quad$ - $\quad$ - 431

clavellosum, Triphragmium, - - 362

Claviceps, - $\quad$ - $\quad$ - $\quad$ - 191

clavipes, Gymnosporangium, - - 402

claytoniae, Peronospora, - . 134

clematiclis, Aecidimm, - - 349, 409

Clithris, - $\quad$ - $\quad$ - $\quad$ - $\quad$ - 248

Cocconii, Tolyposporium, - $\quad$ - 306

cochleariae, Ovnlaria, - $\quad$ - $\quad 500$ 
PAfiE coerulescens, Taphriua, 148, 150, 154, 167 coicis, Ustilago, - $\quad$ - $\quad$ - $\quad$ - 294 colchici, Urocystis, - $\quad$ - $\quad$ - $\quad 316$ ,, Uromyces, - - - 338 Coleopuccinia, - $\quad$ - $\quad$ - $\quad$ - 403 Coleosporium, - - - $\quad$ - 374 Coleroa, - $\quad$ - $\quad$ - $\quad$ - $\quad$ - $\quad$ - 195 Colletotrichum, - $\quad$ - $\quad$ - $\quad$ - 486 Colpoma, - $\quad$ - $\quad$ - $\quad$ - 248 columuare, Aecidium, - . 372, 409 comari, Doassansia, - - $\quad 324$ commune, Nostoc, - $\quad$ - $\quad$ - $\quad$ - 544 communis, Erysiphe, - $\quad$ - $\quad 175$ ,, Taphrina, 147, 151, 152, 157 complanatum, Peridermium, - 415, 416 compositarum, Aecidium, - $\quad 409$ concentrica, Pestalozzia, _ - $\quad 494$ condylonema, Cladosporium, - - 510 confluens, Caeoma, - _ 419 coufusa, Taphrina, · - $\quad 147,151,152$ confusum, Gymnosporangium, - 401 congesta, Graphiola, - - $\quad$ - 326 conglomeruta, Puccinia, - _ $\quad 359$ conglutinata, Pleospora, - - $\quad 511$ conicum, Gymnosporangium, - $\quad 391$ Coniothecium, - $\quad$ - $\quad$ - $\quad 517$ Coniotlryrinn, - - - $\quad$ - 471 conorum, Aecidium (Peridermium), 416 consinilis, Septoria, - - $\quad$ - 477 controversa, Tilletia, - $\quad$ - $\quad$ - 309 convallariae, Aecidium, - _ $\quad$ - 410 ,, Dendrophoma, - - 469 convolvulacearum, Cystopus, - . 127 convolvuli, Puccinia, - . $\quad 341$ coralloides, Urocystis, - _ $\quad$ - 319 Cordyceps, - - $\quad$ - $\quad$ - 184 cornicola, Phyllosticta, - - - 464 Septoria,$-478$ cornu cervi, Taphrina, 29, 147, 149, 153 Cornuella, - 322 Cornui, Periderminm, - - 381,415 cornuta, Roestelia, - - 355, 391, 392 coronata, Puccinia, - $\quad$ - $\quad$ - $\quad 346$ coronifera, Puccinia, - - $\quad 346$ Corticium comedens, - - $\quad$ - 452 coruscans, Peridermium, - - 416 corydalis, Entyloma, - - $\quad$ - 312

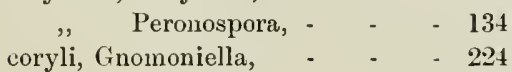

coryli, Mamiania, - $\quad$ - $\quad$ - 224

Coryneum, - - - $\quad$ - 211, 491

Conturea, - - - - - $\quad$ - 475

Crameri, Ustilago, - $\quad$ - $\quad$ - $\quad$ - 292

crastophilum, Entyloma, - $\quad 312$

crataegi, Actinonema, - - $\quad$ - 474

,, Septoria, - - - $\quad$ - 476

,, Taphrina, $147,150,153,166$

cristatus, Uromyces, - - $\quad$ - 337

crocorum, Rhizoctonia, - $\quad$ - $\quad$ - 202

Cronartium, - $\quad$ - $\quad$ - $\quad$ - $\quad$ - 380

cruenta, Ustilago, - - - $\quad$ - 282

Cryptomyces, - $\quad$ - $\quad$ - $\quad$ - 246

Cryptosporium, - $\quad$ - $\quad$ - $\quad$ - 489

Cryptostictis, - $\quad$ - $\quad$ - $\quad$ - $\quad$ - 475

Ctenomyces, - - $\quad$ - $\quad$ - 138, 170

cubensis, Peronospora, - $\quad$ - $\quad$ - 134

cucumerinum, Cladosporium, - $\quad 510$

cucumeris, Cladosporium, - $\quad 510$

,, Hypnochus, - - - 428

cucurbitacearm, Phoma, - - 469

Cucurbitaria, - $\quad$ - $\quad$ - $\quad$ - 206

Cucurbitarieae, - $\quad$ - $\quad$ - 204

cucurbitula, Nectria, - . - 188

Cunninghamianum, Gymnosporangium 403

cupulatum, Synchytrium, - - 111

eyani, Aeciclium, - - - $\quad$ - 409

Cyanophyceae, - $\quad$ - $\quad$ - $\quad 541$

cycadearum, Anabiena, - . . - 544

cyclameneae, Colletotrichum, - - 488

cyclaminis, Septoria, - - $\quad 478$

Cycloconium, - $\quad$ - . 12,506

cydoniae, Hendersonia, - - - 475

,, Phoma, - - $\quad$ - 468

Cylindrosporium, - - - - 485

cynodontis, Phyllachora, - . 229 ,, Ustilago, - - $\quad$ - 294

cynoglossi, Peronospora,- _ - . 134

cynosbati, Cryptostictis, - - 475

cypericola, Schinzia, - - $\quad$ - 326

Cystopus, - $\quad$ - $\quad$ - $\quad$ - 28, 123

, haustoria, - $\quad$ - 13

, oogonia, - - - 47

, spore-germination, 47,60

cystosiphon, Pythium, - - 117

cytisi, Diplodia, - $\quad$ - $\quad$ - $\quad 209$

, Peronospora, . . - 133

, Phyllosticta, - - $\quad$ - 463

Cytospora, - - $\quad$ - $\quad$ - 471 
I)

Dacromycetes, dactyliclis, Uromyees,

Darluca,

Dasyscypha,

Dccaisneana, Schroetcria,

recipiens, Endonyces, .

, iynchytrium, -

,, Taphrina, .

., Tilletia, -

decolorans, Exobasidium,

deformans, Barclayella, -

$\begin{array}{ll}\text {, } & \text { Caleoma, - } \\ \text {, } & \text { Periderinium, } \\ \text {, } & \text { Taplinima, 147, } \\ \text { ". Uromjees, - }\end{array}$

Dehnii, Beloniella, -

Delastrina, Schrocteria, -

Dematieae,

Dematophora,

dendriticum, Fusicladium,

$$
\text { Venturia, - }
$$

Dendrophoma,

densa, Plasmopara,

densissima, Microsphaera,

dentariae, Puccinia,

Depazea,

depazeaeformis, Sphaerella,

depressum, Fusicladium,

Dermatea,

Dermateaceae, -

Dermatella,

desmodii, Ramularia,

destruens, Agaricus,

$\begin{array}{ll}\text {, } & \text { Brunchorstia, } \\ \text {, } & \text { Fusicladium, - } \\ \text {,, Oidium, - } \\ \text {,, Ustilago, . }\end{array}$

devastans, Myxosporium,

devastatrix, Phragmidium,

Diachora,

dianthi, Ascochyta,

$$
\text { , } \quad \text { Septoria, - - }
$$

Diatrypeae, - -

dicentrae, Aecidium,

Dicoccum

dictyospermum, Pythium, didyma, Septoria,
DAGE

422

$: 3: 36$

474

$2 \% 0$

$3: 28$

141

10 ()

$147,15 \mathrm{I}, 153$

- 310

427

373

30,415

- 416

$1.33,16.5$

- 418

- 256

- 325

- 505

- 202

21S, 507

- 218

- 469

131

176

359

465

215

508

253

251

252

502

462

252,481

- $50 \mathrm{~s}$

499

289

486

362

-230

- 473

- 477

325

- 226

- 410

- 506

117

- 478
I)irlymaria, - $\quad$ - $\quad$ - 501

Dirlymospliacria, - . . . $\quad 218$

Dillymosporium, - . $\quad$ - 490

digitalis, Ascocliyta, _ _ . 473

ligitariae, Ustilag(), - . - 291

digitata, Schinzia, - - - $\quad$ - 326

digraphiclis, Puccinia, - - $\quad$ - 349

Dilophia, - $\quad$ - $\quad$ - $\quad$ - 222

Dilophospora, - - . $\quad$ - 479

Dinerosporium, - . . . 178

dioicae, l'uecinia, - $\quad$ - $\quad$ - 3501

1)iorchidlium, - - $\quad$ - $\quad 361$

Diplodia, - . - . - 472

diplodiella, Coniothyrium, - $\quad 471$

Diploclina, - . - . . 474

diplospora, Ustilago, : . $\quad 291$

Dipodascus, - . - . $\quad$ - 138

dipsaci, Peronospora, _ _ $\quad$ - 132

discoideum, Exobasidium, - - 427

Discomycetes, - . . - 240

Discosia, - - - - $\quad$ - 480

discosioides, Pestalozzia, - - 494

dispersa, Puccinia, - _ - 347, 348

ditissima, Nectria, - _ - 186

diversidens, Hydnum, - . $\quad 431$

Doassansia, - $\quad$ - $\quad$ - $\quad$ - $\quad$ - 322

domestica, Ustilago, - - $\quad 298$

Dothidea, . . . - 230

Dothideaceae, - - - 184,229

Dothidella, - . - . $\quad 230$

Dothiora, - $\quad$ - $\quad$ - $\quad$ - $\quad$ - 249

Douglasii, Botrytis, $\quad$ - 4, 269, 499

drabae, Aecidium, - - $\quad$ - 410

„Puccinia, - $\quad$ - $\quad$ - 359

dracontii, Aecidium, - - $\quad$ - 410

dryadeus, Polyporus, - - $\quad$ - 440

dryadis, Didymosphaeria, - $\quad 218$

Duriaeana, Ustilago, - - $\quad 297$

Djscomycopsis rhytismoides, - - 245

E

echinata, Ustilago, - $\quad-\quad 294$

echinatım, Triphragmium, - 362

echinulatum, Heterosporium,- - 516

Ectrogella, - - - - - 107

effusa, Peronospora, - - $\quad 132$

effusum, Fusicladium, - - - 50s

Ehrenbergii, Sorosporium, - - 282

Elaphomyces, - - - $\quad$ - 97,183 


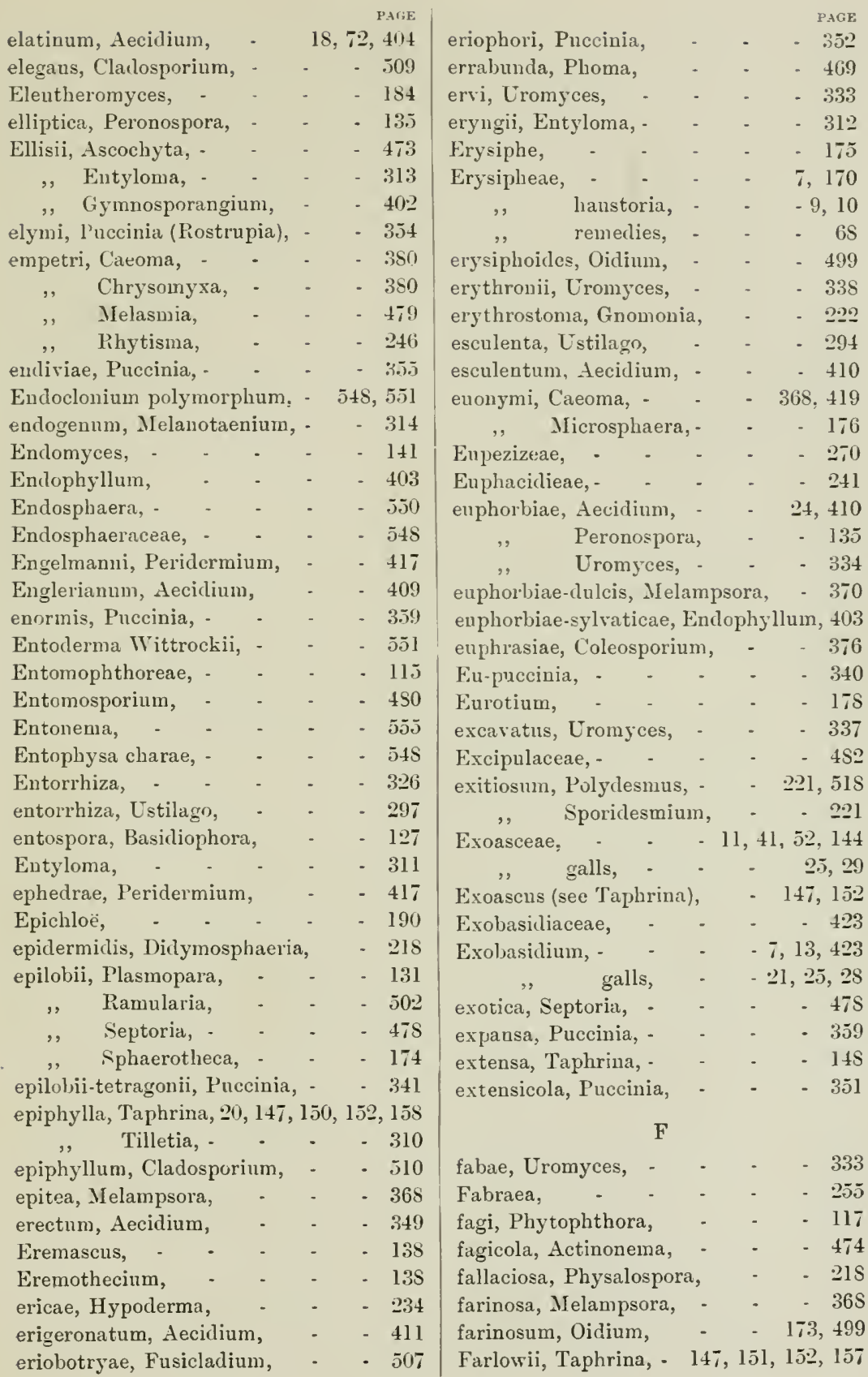




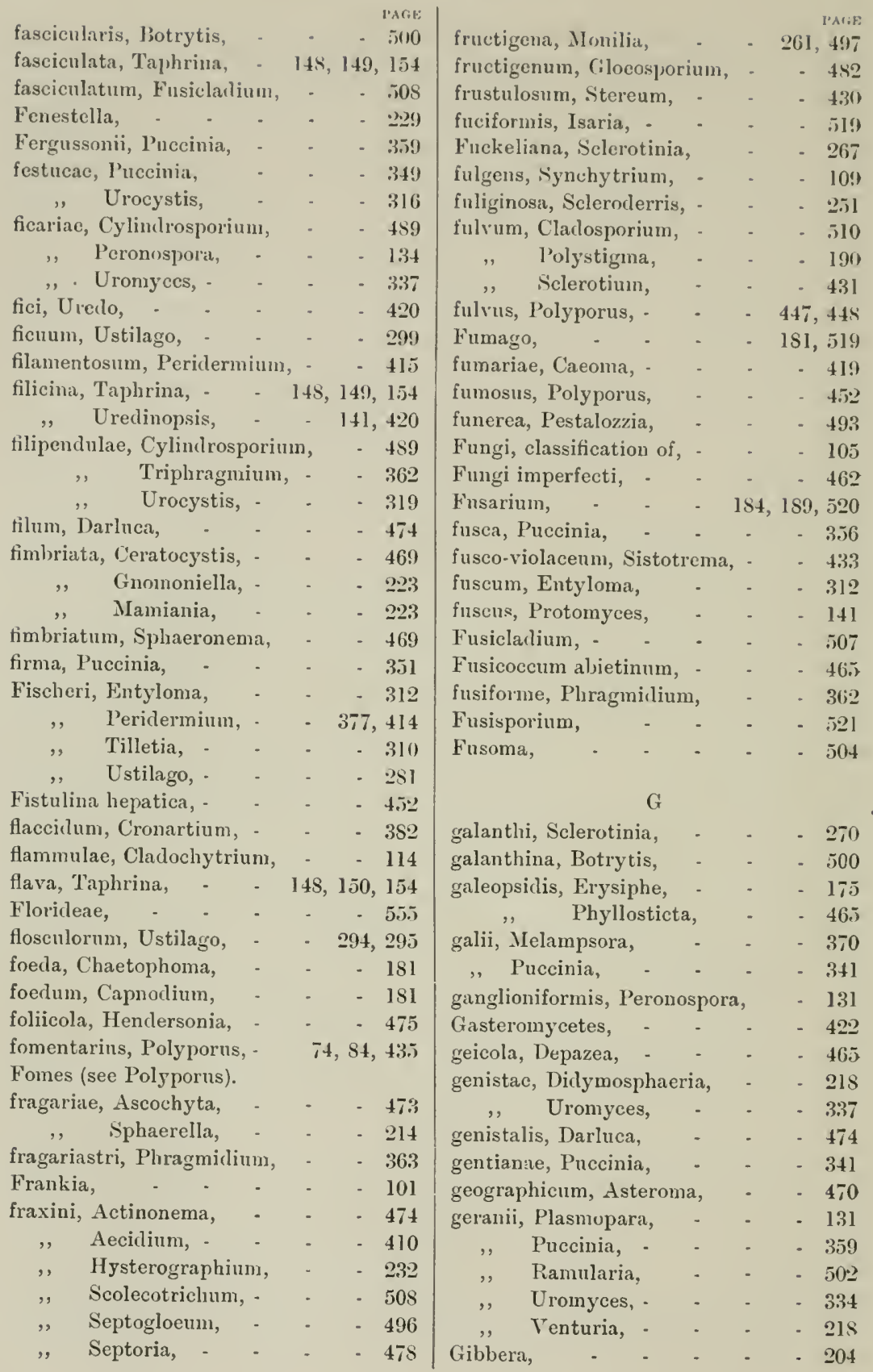




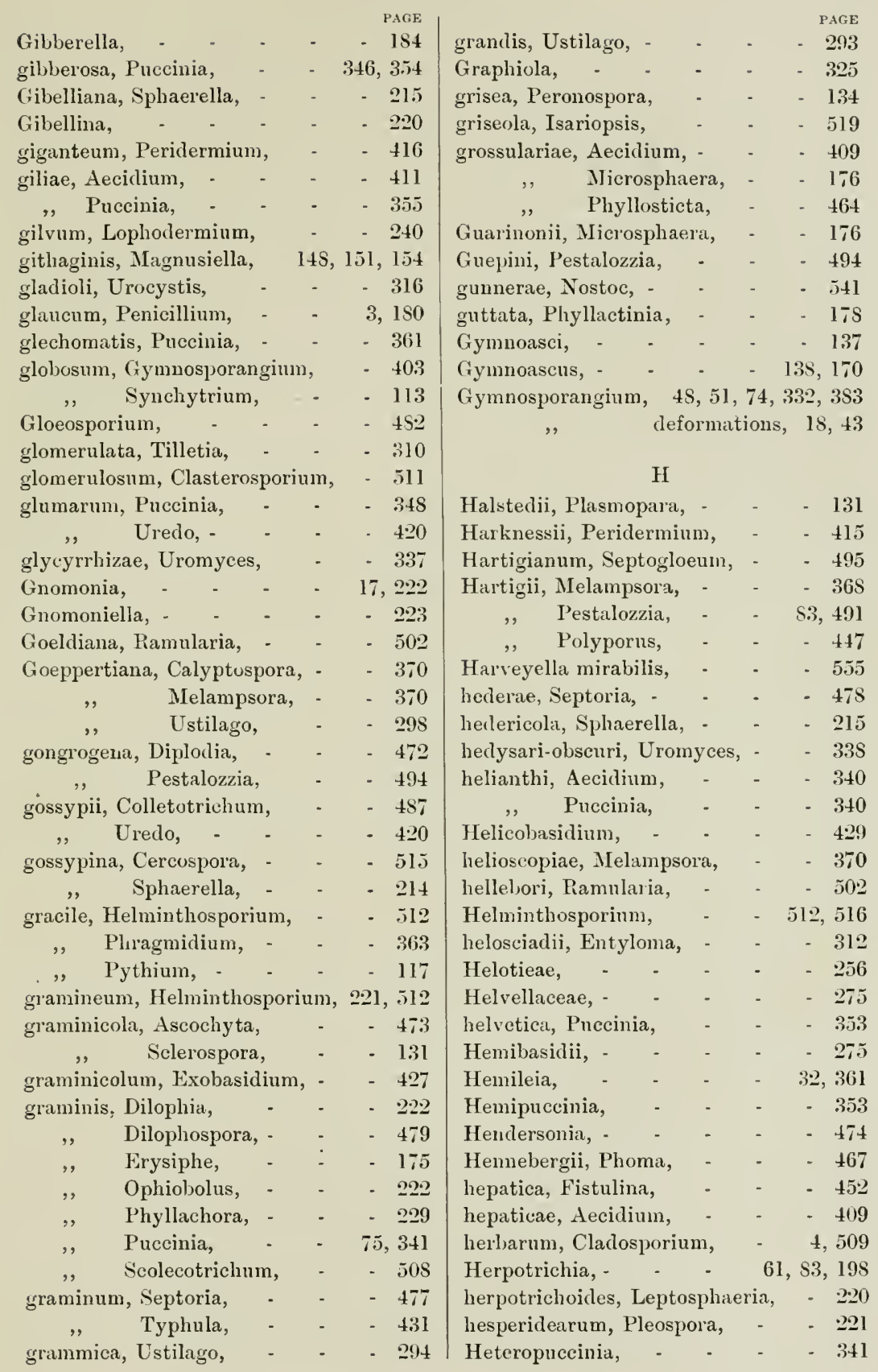




\begin{tabular}{|c|c|c|c|}
\hline \multirow{2}{*}{\multicolumn{2}{|c|}{ heterogenea, P'uccinia, . }} & \\
\hline & & & $-\quad 360$ \\
\hline heteroica, seleroti & niat, & - & - $\quad 263$ \\
\hline Heterospliaeria, & - & $\cdot$ & $-\quad 249$ \\
\hline Heteresporium, & - & - & - 51. \\
\hline lieterosporium, $F_{41}$ & sariun, & - & $-\quad 520$ \\
\hline heterosporum, Sel & tosporiun, & & - $51 \mathrm{~s}$ \\
\hline hieracii, l'uccinia, & - & - & - $\quad 3 . \overline{3}$ \\
\hline himalayensis, Chry & y.somy xa, & - & -379 \\
\hline hippurillis, Aecili & $\mathrm{um}$, & - & - 3336 \\
\hline hirsutum, Sterenm & , & & $-42 ! !$ \\
\hline hirsutus, Polyporu & is, & - & -452 \\
\hline hispirlus, Polyport & is, & . & $-\quad 444$ \\
\hline Holboelli, Puccini & $a$, & & - $\quad 3.59$ \\
\hline holostei, Ustilago, & - & & - 297 \\
\hline hordei, Hormorlen & dron, - & & -50.5 \\
\hline ", Tilletia, & - & - & -310 \\
\hline ", Ustilago, & - & - & - $2 S S$ \\
\hline Hormodendron, & - & 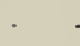 & 50.5 \\
\hline hottonize, Doassar & isia, - & - & 324 \\
\hline hyacinthi, Bacillus & s, & - & 538 \\
\hline "Pleospo & ra, & 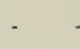 & 221 \\
\hline hyalina, Theeapho & ra, & - & 324 \\
\hline Hydnea, & $\cdot$ & - & 431 \\
\hline Hydnum, & - & - & 431 \\
\hline hydrangeae, Septo & ria, - & - & $47 \mathrm{~s}$ \\
\hline hydropiperis, Spha & acelotheca, & - & 302 \\
\hline Hymenomycetes, & - & . & $4 \cdot 2 \cdot 2$ \\
\hline hyoscyami, Peronc & ospora, & - & 134 \\
\hline hypericorum, Mel & ampsora, & . & 370 \\
\hline Hyphomyeetes, & - & - & 496 \\
\hline Hypnochaceae, & - & - & 428 \\
\hline Hypnochus, - & - & . & - 428 \\
\hline Hypocreaceae, & - & - & -184 \\
\hline Hypoderma, - & - & - & - 233 \\
\hline Hypodermieae, & - & - & - 233 \\
\hline Hypodermella, & - & - & - 234 \\
\hline hypodytes, Ustila & go, & - & - 293 \\
\hline hypogaea, Niptera & , & - & -254 \\
\hline Hypomyces, - & 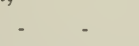 & . & 154 \\
\hline hypophyllum, Clas & dosporium, & & . 511 \\
\hline Hysteriacene, - & - $\quad$ - & . & - 232 \\
\hline Hysterineae, . & - & - & - 232 \\
\hline Hysterium, - & . & - & - 237 \\
\hline Hysterographium, & , - & - & $-2: 3: 2$ \\
\hline
\end{tabular}

\section{I}

igniarius, Polyporns, - $\quad 35,433,441$ impatientis, Depazea, - - $\quad$ - 4 (i.)

impressum, Asteroma, - _ . 470

inaerjuale, Fusoma, _ _ . 505

infestans, Phytophthora. - $\quad 7,119$

inflata, Rlizina, - . - - $\quad 273$

inruinans, Bulgaria, _ _ . $\quad 253$

,, l'estalozzia, - - _ 494

insidiens, Pestalozzia, - - - 4 (14

insititiae, Taplnina, $147,151,1.33,164$

intermedia, Doassansia, - _ _ _ 324

, Ustilago, - - - 29.5

intermedium, Pythium, - - - $11 \%$

interstitialis, Orularia, - - - 500

" Puccinia, - - . 341

imulae, Coleosporimu, - - $\quad$ - 376

ipomoeae, Coleosporium, - $\quad$ - 377

, Nectria, - - $\quad 189$

, Puccinia, - . $\quad 3.56$

ipomoearum, Vermicularia, - - 47l

ipomoeae-panduranae, Cystopus, - 127

irillis, Aecillium, - - $\quad$ - 411

, Cladochytrimm, - . . 114

, Puccinia, - . - $\quad$ - $35 j$

,, Uredo, - - . . . 420

Irmisehiae, Paipalopsis, - _ _ $\quad 322$

Isaria, - $\quad$ - $\quad$ - $\quad$ - $\quad$ - 519

Isariopsis, - . - . - 519

ischaemi, Cstilago, _ $\quad$ - $\quad 292$

italica, Urocystis, - - - - 31!

italicum, Penicillium, - _ $\quad$ - 180

\section{J}

Jamesianum, Aecidinm, - - - 411

Jenseni, Ustilago, - - - - - 285

Johansonii, Taphrina, 147, 150, 152, 157 ,, Urocystis, - - $\quad 319$

juglandinum, Cladosporium, - - 510

juglanrlis, Marsonia, . - - 491

, Microstroma, - - . 497

junci, Puccinia, - $\quad$ - $\quad$ - 354

,, Tolyposporium, - - $\quad 305$

., Urocystis, - $\quad$ - $\quad$ - 319

, Uromyces, - - _ $\quad$ - 336

juncicolum, lihytisma, - - $\quad-246$

juniperi, Clithris, - - - $\quad 248$

,, Stigmatea, - - . 211

juniperinum, Gymuosporangium, - 391

Lophodermium, - $\quad 240$ 
h

Káfmanniana, Peziza, - $\quad$ PAGE

kentiae, Colletotrichum,- _ _ - 488

Kemeri, Sclerotinia, - - $\quad 270$

Klebahni, Peridermim, - $\quad 376,414$

Kmetiana, Urocystis, - - $\quad 319$

knautiae, Peronospora, - - 132

Knyanum, Chlorochytrimm, - - 550

Kochii, Strickeria, - - - - 205

Kolaczekii, Ustilago, - 292

Kolleri, Ustilago, - - - $\quad$ - 287

Koordersiana, Ustilago, - _ _ 298

Kriegerianum, Cladochytrium, - 114

Kruchii, Taphrina, - - $\quad 147,150,153$

Kiihneana, Ustilago, - _ $\quad$ - $29 \mathrm{~s}$

I.

Labrella, -

laburni, Cucnrbitaria,

Physalospora,

laceianum, Phragmilium,

lacerata, Roestelia,

Lachnella,

laciniata, Thelephora,

lactea, Ovularia,

Laestadia, - $\quad$ - $\quad$ - $\quad$ - 216

laetum, Synchytrium, - _ - 111

laevigatus, Polyporus, - - $\quad$ - 445

laevis, Tilletia, - $\quad$ - $\quad$ - 309

Lagenarinm, Colletotrichum, - _ $\quad 486$

Lagerheimii, Lenconostoc, - - 143

,, Ustilago, - - - 299

lamii, Ovularia, - _ _ $\quad$ - 501

lampsanae, Puccinia, - $\quad$ - 340

Ramularia, - - $\quad 502$

laneola, Myxosporium, - - - 456

lapponicus, Uromyces, - $\quad$ - $\quad$ - 337

laricina, Sphaerella, _ _ $\quad$ - 211

laricinum, Leptostroma, - $\quad$ - 212

$$
\text { ,, Lophodermium, - } \quad 240
$$

laricis, Caeoma, - - $\quad 366,36 \overline{7}, 419$

, Heterosporium, - - $\quad 516$

,, Hypodermella, - - - 234

Lasiobotrys, - $\quad$ - $\quad$ - $\quad$ - 182

lathyri, Thecaphora, - - $\quad 324$

lathyrinum, Dicoccum, - - $\quad 506$

Laurencia, Taphrina, $\quad 29,145,149,153$

laureolae, Sphaerella, - $\quad$ - $\quad 215$ lauri, Exobasidium,

PAGE

31,427

leti, Chrysomyxa, - _ . - $\quad 37 \mathrm{~S}$

, Exobasidium, - - - 31, 427

,, Sclerotinia, - $\quad$ - $\quad 263$

leguminosarum, Rhizobium, - . 101

Leimbachii, Urocystis, - - $\quad 317$

lemnae, Chlorochytrium, - $\quad 549$

,, Cornuella, - $\quad$ - $\quad 322$

, Olpidium, - . - $\quad 107$

lepidii, Aecidium, - - - $\quad$ - 410

lepigoni, Cystopus, - - - $\quad$ - 127

leproides, Oedomyces, - _ $\quad$ - 313

leproidum, Entyloma, - - - 313

Leptopuccinia, - $\quad$ - $\quad$ - $\quad$ - 359

leptosperma, Peronospora, - - 134

Leptosphaeria, - $\quad$ - $\quad$ - 220

Leptostroma, - - - - - $\quad$ - 480

Leptostromaceae, - $\quad$ - $\quad$ - $\quad$ - 479

leptostromiforme, Cryptosporium, - 489

Leptothyrium, - - - - 479

Letendraea, - $\quad$ - $\quad$ - $\quad$ - 184

leucanthemi, Aecidium, - _ 351, 409

$$
\text { ,, Pnccinia, - - } \quad 351
$$

Leucochytrium, - _ _ $\quad$ - 112

leucogonium, Oidinm, - $\quad$ - $\quad$ - 499

Leuconostoc, - _ _ _ _ $\quad$ - 143

leucospermum, Aeciclium, - - 409

lichenoides, Nostoc, - $\quad$ - $\quad$ - 546

ligustri, Aecidium, - - _ - 409

,, Caeoma, - - $\quad$ - $\quad 419$

liliacearum, Puccinia, - $\quad$ - $\quad 356$

limbalis, Phyllosticta, - $\quad$ - 464

limonii, Uromyces, - _ _ - $\quad$ - $\$ 34$

limonis, Fusarium, - - $\quad$ - 521

limosae, Puccinia, - _ _ $\quad$ - 351

limosellae, Doassansia, - $\quad$ - $\quad 324$

linariae, Entyloma,- $\quad$ - $\quad 312$

,, Peronospora, - $\quad$ - 134

Lindemuthianum, Colletotrichnm, - 486

lineolatus, Uromyces, - . $\quad 336$

Linhartiana, Monilia, - - $\quad$ - 261

lini, Melampsora, - $\quad$ - $\quad$ - $\quad$ - 369

,, Peronospora, - - $\quad$ - $\quad$ - 134

lolii, Tilletia, - $\quad$ - $\quad$ - $\quad 310$

longipes, Taphrina, - $\quad$ - $147,151,152$

\begin{tabular}{|c|c|c|c|}
\hline , & Puccinia, & - & \\
\hline ,' & Sphaerella, & $\cdot$ & 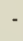 \\
\hline & Ustilago, & - & - \\
\hline
\end{tabular}

longissina, Phoma,- $\quad$ - $\quad 469$ 


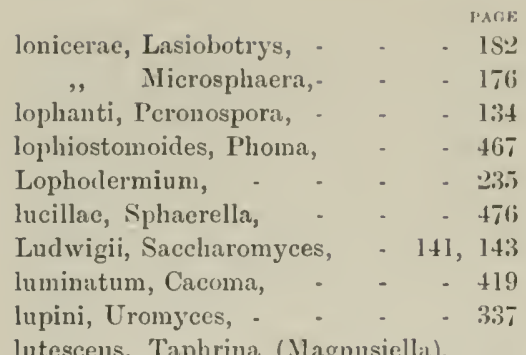

lutescens, Taphrina (Mlagnusiellit),

luzulae, Urocystis,

,, Ustilago, - - $\quad$ - $\quad$ - 294

lychnicola, Orularia, . . 500

lyclmidis, Septoria, - - - 478

lycii, Microsphaera, - - . 176

lycopersici, Colletotrichum, - - 4ST

" Fusarium, - - - 520

, Septoria, - - - 477

Iycopi, Aecidium, - . . - 411

\section{II}

macrocarpum, Cladosporium, macropus, Gymnosporangium, 391,402 macrosora, Uredo, - _ $\quad$ - 420 Macrosporium, - _ _ $\quad 517$ macrosporum, Aecidium, - 411 , Hysterium, - . 237 ,, Lophodermium, 34, 237 macrosporus, Protomyces, - 31, 135 maculaeformis, Venturia, - - $21 \mathrm{~S}$ maculans, Ascochyta, - _ $\quad$ - 473 maculare, Asteroma, - . $\quad 470$ maculatum, Entomosporium, - 480 maculiformis, Laestadia, - 216 ,, Phyllosticta, - - 464

Magelhaenicum, Aecidium, - $\quad 409$ Magnusia, - $\quad$ - $\quad$ - $\quad$ - $\quad$ - 178 Magnusiana, luccinia, - $\quad$ - $\quad 349$ Magnusiella (see Taphrina), 146, 145, 151 Magnusii, Endomyces, - - $\quad 143$ , Entyloma, - - $\quad 312$ , Puccinia, - - $\quad 350$ major, Ustilago, - - - $\quad$ - $\quad 297$ mali, Hendersonia, - - $\quad 475$ malorum, Sphaeropsis, - - $\quad 472$ malvacearum, Phoma, - • - 469 „, Puccinia, - $\quad 359$ malrarum, Cercospora, - - - 515 malvarum, Colletotrichum,

malvicola, Ascochyta, - . $\quad 473$

Mamiania, - $\quad$ - $\quad$ - $\quad 223$

mammillata, Pnccinia, - - $\quad 355$

Marconii, Dendrophoma, - . 469

marginalis, Ustilago, - - $\quad 298$

marginatus, Polyporus, - - . 449

Mariae-Wilsoni, Aecidium, - . 410

maritimus, Uromyces, - - $\quad 3: 36$

Miarsonia, - - . - 490, 506

Martianoffiana, Duassansia, - $\quad 324$

martii, Erysiphe, - - - $\quad 175$

Masseela, - - $\quad$ - $\quad$ - 361

Mastigosporium, - - . $\quad$ - 504

maxima, Tuberculina, - - $\quad 328$

maximus, Cryptomyces, - $\quad 246$

maydis, Puccinia, - - $\quad$ - $\quad 353$

,, Ustilago, - - - 67, 279

megalospora, Sclerotinia, - 260

Melampsora, - - - 4S, 53, 74, 363

Melainpsorella, - $\quad$ - $\quad 370$

melampyri, Aecidium, - - $\quad 349$

", Coleosporium, - - 376

Melanconideae, - $\quad$ - $\quad$ - $\quad$ - $2: 26$

Melanconieae, $\quad$ - $\quad$ - $\quad$ - $\quad$ - 482

melangeae, Gloeosporium, - - 483

melanogramma, Schizonella, - 305

Melanomeae, - - _ . $\quad 200$

Melanospora, - - - $\quad$ - S, 184

Melanotaenium, - $\quad$ - $\quad$ - 313

Melasmia, - $\quad$ - $\quad$ - $\quad$ - $\quad$ - 479

Meliola, - - - . - 181

melleus, Agaricus (Armillaria), 6, 455

melophthorum, Scolecotrichum, - 508

menthae, Puccinia, - - - 341

menyanthis, Cladochytrium, - - 114

mercurialis, Caeoma, - $\quad 366,367,419$

,, Synchytrium, - $\quad 113$

Merulius lacrymans, - $\quad 40,46,442$

Mesochytrium, - $\quad$ - $\quad$ - $\quad$ - 110

mespili, Entomosporium, - - 4SI

, Northiera, - . $\quad 210$

, Stigmatea, - - $\quad 210$

mespilinum, Oidium, - - $\quad 499$

metulispora, Ascochyta, - _ . $\quad 473$

microcephala, Claviceps, - - 194

microchaeta, Termicularia, - . 471

Micrococcus, - - - 143, 531, 53

Micropuccinia, - $\quad$ - $\quad$ - 356 


\begin{tabular}{|c|c|c|c|c|c|}
\hline & & $P_{A G}$ & & & \\
\hline microsora, Puccinia, & & -3.55 & myrtillina, Podosphaera, & & -175 \\
\hline microsperma, Passalora, & & - 506 & Mystrosporium, & - & . 518 \\
\hline Microsphaera, - & & -176 & Myxomycetes, & - & 135,522 \\
\hline microsporum, Entyloma, & & -312 & Myxosporium, & - & $\cdot 486$ \\
\hline Microstroma, & & -497 & & & \\
\hline icrothyrium, - & & -179 & $\mathrm{~N}$ & & \\
\hline illefolii, Puccinia, & - & - 361 & Naegelia, - - & - & \\
\hline minimus, Cephaleuros, - & & -553 & Naevia piniperda, - & - & $-\quad 238$ \\
\hline minor, Taphrina, - & 47 & $150,153,164$ & nana, Taphrina, - & $14 \overline{7}, 140$ & $9,153,161$ \\
\hline ,, Uromyces, - & - & $-33 S$ & napi, Pleospora, & - & - 221 \\
\hline minus, Cylindrosporium, & & $-\quad 489$ & Napicladium, .. & - & - 516 \\
\hline irabilis, Taphrina, & & $147,151-153$ & necans, Ovularia, - & - & - 500 \\
\hline irabilissima, Puccinia, - & & - 340 & necator, Gloeosporium, & - & - $4 S 3$ \\
\hline psora, & & - 368 & necatrix, Dematophora, & , - & - 202 \\
\hline odestum, Bostrichonem & & -501 & Nectria, - & . & -185 \\
\hline oliniae, Neorossia, & - & -311 & Nectriella, & - & - 184 \\
\hline Puccinia, & - & - 349 & Nectroicleae, - & $\cdot$ & -479 \\
\hline Iolleri, Ustilago, - & - & - 298 & neglecta, Ustilago, . & - & - 202 \\
\hline Polyporus, - & - & -448 & nelans, ()vularia, - & - & - 261 \\
\hline Collisia, & - & -254 & nemoralis, Puecinia, & - & - 349 \\
\hline Iollisieae, & 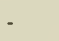 & $-\quad 253$ & Neovossia, & - & -311 \\
\hline Mompa, Helicolsasidium, & & -429 & nepalense, Phragmidium & & - 363 \\
\hline$-\quad-\quad-$ & ? & $-\quad 261,497$ & neriella, Cercospora, & & - 515 \\
\hline ides, Oidium, & 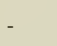 & $-175,499$ & nervisequium, Gloeosfon & orium, - & - $\quad 229,484$ \\
\hline , Aecidium, & - & $-\quad-410$ & Lophoder & rmium, & \\
\hline , - - & - & - 135 & nicotianae, Ascochyta, & - & \\
\hline ae, Urocystis, - & - & -319 & nidus-avis, Gymnospora & angi & \\
\hline ontana, Puccinia, & - & -340 & Niesslii, Doassansia, & - & $-\quad 3: 3$ \\
\hline orbosa, Plowrightia, & - & - 231 & ," Sphacrotheca, & - & -174 \\
\hline ori, Ba & - & -534 & nigra, Herpotrichia, & - & . 199 \\
\hline , Clai & - & .114 & nigricans, Claviceps, & - & \\
\hline , Phl & - & -478 & , Polyporus, - & - & \\
\hline , Sep & - & -496 & nigricantium, Macrospo & oriux & - ils \\
\hline "Spl & - & 215,478 & ans, Septori & & - $47 \mathrm{~S}$ \\
\hline oricola, Gibberella, & - & -184 & - & - & $-\quad 2.54$ \\
\hline nors-uvae, Sphaeroth & & -173 & Caeoma, & - & - 419 \\
\hline Morthieri, Mollisia, & & -254 & nivea, Plasmopara, & - & - 128 \\
\hline Puccinia, & 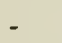 & - 359 & osporium, & . & - 518 \\
\hline Mucedineae, - & . & -497 & toc, - - - & - & 541,546 \\
\hline lucor, - - & 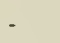 & 4,150 & nuda, Ustilago, & 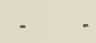 & - 288 \\
\hline elleri, Uredo, & - &.$\quad 420$ & nymphaeae, Entyloma, & & -313 \\
\hline mutila, Dothiora, & & - 249 & nymphaeoides, Aecidiun & & 351,410 \\
\hline Mycoidaceae, & & -552 & & & \\
\hline Mycoidea, - & - & - 5.52 & $\mathrm{O}$ & & \\
\hline Mycoidea, Cephaleuros, - & & $-\quad 5.52$ & s, Plasmopara, & - & \\
\hline Nycomycetes,- - & - & -135 & Ovularia, - & - & - 501 \\
\hline yosotidis, Aecidium, & - & - 411 & oblongata, Puceinia, & & -354 \\
\hline " Peronospora, & & -134 & oblongisporium, Peric & & $375,4 i 4$ \\
\hline Synchytrium & & -111 & obscura, Puccinia, - & - & -3.52 \\
\hline
\end{tabular}




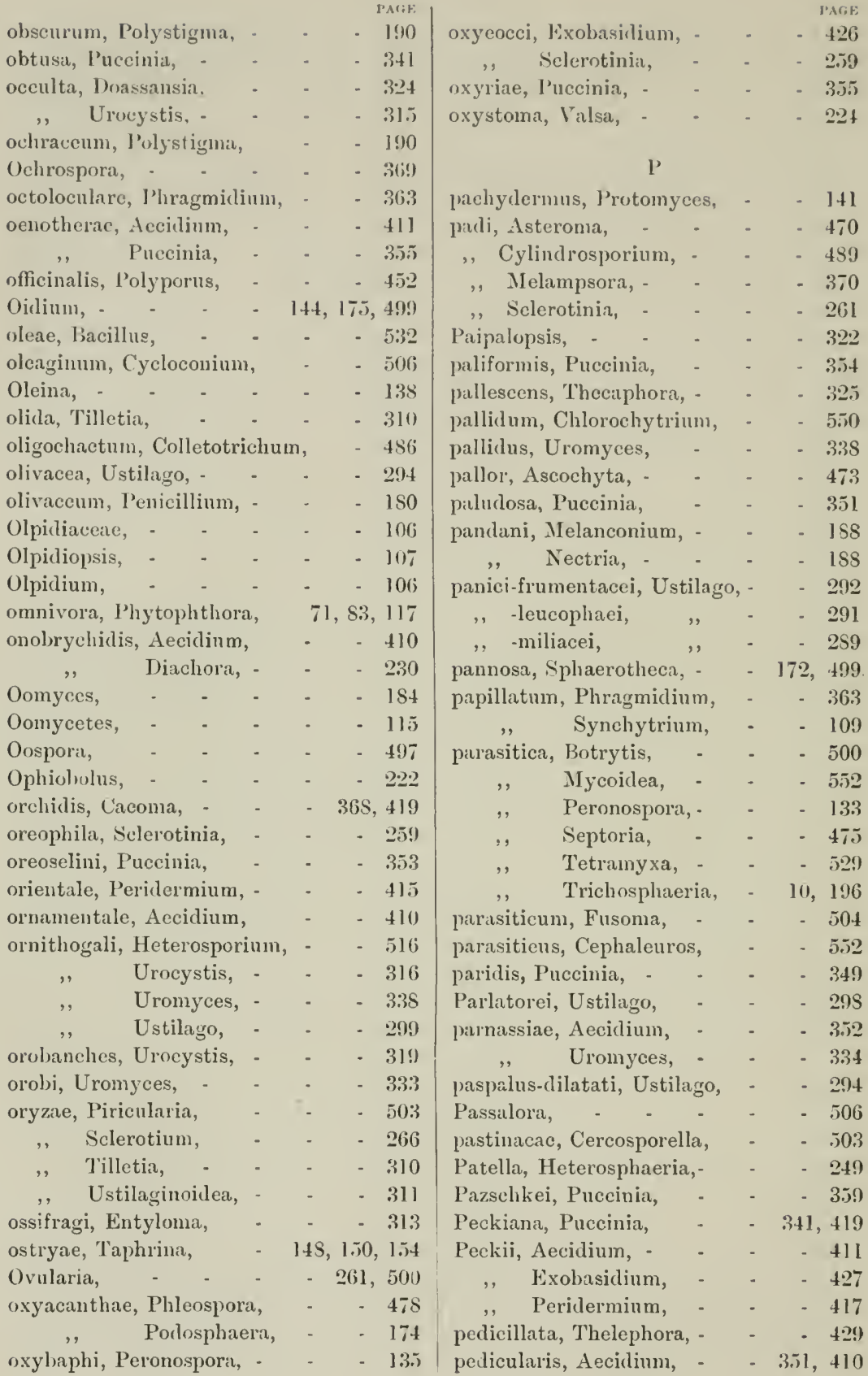


Pellicularia, - $\quad$ - $\quad$ - $\quad$ - 181

penicillariae, Tolyposporium, - - 306

penicillata, Roestelia, - $385,389,391$

Penicillium, - - $\quad 3,4,180$

pentastemonis, Aecidium, - - 411

Penzigi, Meliola, - $\quad$ - $\quad$ - 181

perdix, Thelephora, - $\quad 35,429,430$

pcremnans, Ustilago, - $\quad$ - $\quad$ - 288

periclymeni, Aecidium, - $\quad$ - 349, 409

Ascochyta, - - - 473

," Leptothyrim, - $\quad 479$

Peridermium, - - - - 374,411

Periphlegmatium, - _ _ _ $\quad$ - 551

Perisporiaceae, - $\quad$ - $\quad$ - $\quad$ - 170

Perisporieae, - - - $\quad$ - $\quad$ - 178

Perisporium, - $\quad$ - $\quad$ - $\quad$ - $\quad$ - 179

Peronospora, - $\quad$ - $\quad$ - $\quad$ - $\quad$ - 132

Peronospoleae, $\quad-\quad \quad \quad-7,13,115$

,, remerlies, - $\quad 68$

perplexans, Puccinia, - _ $\quad$ - 349

persicae, Cercospora, - _ $\quad$ - 513

, Cercosporella, - - $\quad 503$

,, Phyllosticta, - . $\quad 463$

persicina, Tnberculina, - - 327

persistens, Puccinia, - $\quad$ - $\quad$ - 349

Personii, Quaternaria, - _ _ $\quad$ - 226

Pestalozzia, - $\quad$ - $\quad$ - $\quad$ - $\quad$ - 491

Pestalozzina, - $\quad$ - $\quad$ - $\quad$ - $\quad$ - 494

petasitidis, Coleroa, $\quad$ - $\quad$ - $\quad$ - 195

Petersii, Aecidinm, - _ . 410

petroselini, Septoria, - _ $\quad$ - 476

Pezicula (see Dermatea), - _ $\quad$ - 253

Peziza, - - - - - $\quad$ - 271

Pezizeae, : - - $\quad$ - 253

Phaciliaceae, - - - $\quad$ - $\quad 241$

phacidioides, Sphaeronema, - - 25.5

Phacidium, - - - - 241, 25.5

Pliaeophila, - - - - $\quad$ - 551

Phaeophyceae, - $\quad$ - $\quad$ - 554

Phakospora, - $\quad$ - $\quad$ - $\quad$ - $\quad$ - 361

phalaridis, Puccinia, $\quad$ - $\quad$ - $\quad$ - 349

phaseoli, Phytophthora, - $\quad$ - 122

, Uromyces, - - - 334

phaseolina, Phyllosticta, _ $\quad$ - 464

phillyreae, Aecidium, - _ _ $\quad 410$

,, Ureclo, - - $\quad$ - $\quad$ - 420

phlei-pratensis, Puccinia, - - 348

Phleospora, - $\quad$ - $\quad$ - $\quad$ - $\quad$ - 478

ploenicis, Graphiola, - - $\quad 325$

phoenicis, Pestalozzia,

PAGE

Pholiota $=$ Agaricus.

Phoma, - - - $\quad$ - $\quad$ - 465

plomoides, Gloeosporinm, - . 483

Phragmidium, - $\quad$ - $\quad$ - 362

phragmitis, Puccinia, - $\quad$ - $\quad 349$

Phycomycetes, - - - $\quad$ - 106

Phyllachora, - _ $\quad$ - $\quad$ - $\quad$ - 229

Phyllactiuia, - - - - - 178

Phyllobium dimorphum,- - $\quad$ - 5.11

Phyllosiphon arisari, _ _ $\quad$ - $\quad$ 5.53

Pliyllosticta, - - $\quad$ - $\quad$ - $\quad$ - 463

Physalospora,- $\quad$ - $\quad$ - $\quad$ - $\quad$ - 217

Physorlerma, - - - - $\quad$ - 114

Phytaphysa Treubii, - $\quad$ - 554

pliyteunatum, Uromyces, - $\quad$ - 338

Phytomyxa, - - _ _ 101, 524

Phytophthora, - $\quad$ - $\quad$ - 117

piceae, Chrysoniyxa, - _ $\quad$ - 380

,, Peridermium, - - $\quad$ - 417

picipes, Polyporns, - - $\quad$ - $\quad 452$

picridis, Entyloma, - $\quad$ - $\quad 312$

, Puccinia, - $\quad$ - $\quad 355$

Piggotia astroidea, - $\quad$ - $\quad$ - 230

Pilacreae, - - $\quad$ - $\quad$ - $\quad$ - 421

pilificum, Synchytrium, - - $\quad$ - 111

pimpinellae, Puccinia, - $\quad$ - 340

," Thecaphora, - $\quad 325$

pinastrella, Phoma, - $\quad$ - $\quad 468$

pinastri, Lophodermium, - - 235

pinguicolae, Ustilago, - $\quad$ - $\quad 297$

pini, Brunchorstia, - - $\quad$ - 481

,, Lachnella, - - - $\quad 272$

, Peridermium, - - 411,415

,, Trametes, - - - 35,453

pinicola, Hyporlerma, - $\quad$ - $\quad 234$

, Polyporus, - $\quad$ - $\quad$ - 449

pinitorquum, Caeoma, - _ $\quad$ - 364

pinophilum, Apiosporium, - - 181

piperatum, Gloeosporium, - - 483

Piptocephalis, - $\quad$ - $\quad$ - 11

pirata, Roestelia, - $\quad$ - $\quad$ - 391,402

piricola, Septoria, - - $\quad$ - $\quad$ - 476

Piricularia, - $\quad$ - $\quad$ - $\quad$ - $\quad$ - 503

piriforme, Periılermium, - - 414

piriformis, Mucor, - . $\quad$ - 180

pirina, Phyllosticta, - $\quad$ - $\quad$ - 463

pirinum, Fusicladium, - $\quad 218,507$

- 218 

,, Melampsora pisana, Antlostomella, pisi, Ascochyta

,, Claclosporinın,

, Uromyces,

pithya, I'homa

pityophila, Cucurbitaria,

Placosphaeria,

plantaginis, Accidium,

Plasmodiophora,

Plasmopara,

platani, Fenestelli,

Fusarium, -

Pleolpidium,

Pleonectria,

Pleospora,

Pleosporeae,

Pleotrachelus,

Plowrightia, .

Plowrightii, Peridermium,

plumbea, Ustilago,

poae, Uromyces

poarum, Puccinia,

pollagrariae, Actinonema, , Playllachora,

Podiosoma juniperi,

Porlocapsa,

podophylli, Phyllosticta

Podosphaera,

polemonii, Aecidium,

polygoni, Peronospora, -

,Puecinia,

,, Uromyces,

polygonorum, Stigmatea,

polymorpha, Bulgaria,

polypodii, Sphaerella,

," Uredo, .

Polyporeac, action on starcli, ,, remedies,

Polyporus, polysporal, Taphrina,

Polystictis,

145,

Polystigma, - . -

Polythrincium, - -

populi, Marsonia, -

, Septoria, 


\begin{tabular}{|c|c|c|c|c|c|c|}
\hline \multicolumn{7}{|l|}{ 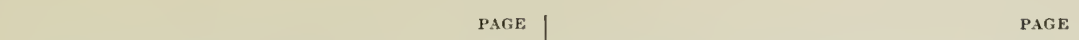 } \\
\hline \multirow{4}{*}{\multicolumn{2}{|c|}{$\begin{array}{c}\text { pseudotuberosi, Sclerotinia, } \\
\text { psoraleae, Aecidium, - } \\
\text { ptarmicae, Leptothyrium, } \\
,, \quad \text { Schizothyrium, }\end{array}$}} & - 270 & quercinum, Capuodium, & & - & 181 \\
\hline & & -410 & quercus, Marsonia, & - & - & -491 \\
\hline & & - 242 & Uredo, - & - & 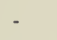 & . 420 \\
\hline & & -242 & quercus-ilicis, Gnomonia, & & - & - 223 \\
\hline pteleae, Aecidium, - & $\cdot$ & - 410 & quinqueloculare, Phragm & midiur & & \\
\hline teridis, Cryptomyces, & - & - 248 & & & & \\
\hline Fusidium, - & - & -248 & $\mathrm{R}$ & & & \\
\hline Uredinopsis, & - & -420 & Rabenhorstiana, Ustilage & & - & - 291 \\
\hline Puccinia, & - & - 339 & racemosus, Mucor, - & - & - & - 180 \\
\hline Pucciniosira, - & - & - 404 & radiatus, Polyporus, & - & - & -452 \\
\hline Pucciniopsis, - & & $-\quad 356$ & radiciperda, Trametes, & - & - & - 450 \\
\hline pulchella, Ovularia, & - & -500 & a, Bacterium, & - & - & -101 \\
\hline licaris, Gibberella, & - & - 184 & radicolus, Protomyces, & - & - & - 141 \\
\hline , Cladochytriun & & -114 & m, Asteroma & - & - & -474 \\
\hline pulsatillae, Coleosporium & & .377 & Ramularia, & - & - & - 501 \\
\hline tal, Puccinia, & & -341 & ramulosum, Macrosporiu & $\mathrm{um}$ & - & - $51 \mathrm{~S}$ \\
\hline Melasmia, & - & -480 & ranunculacearum, Aecid & dium, & & -409 \\
\hline inctatum, Aecidium, & - & 23,409 & ranunculi, Entyloma, & - & - & - 312 \\
\hline , Rhytisına, & - & - 244 & ,, Fabraea, & - & - & -255 \\
\hline ", Synchytrium & & -112 & atea, & - & - & -210 \\
\hline punctiforme, Leptostr & & -480 & Rauwenhoffii, T & - & . & \\
\hline ,, Nostoc, & & -541 & Ravenelia, & - & - & -403 \\
\hline metiformis, Phyllachor & & . 241 & Ravenelii, Peridermium & & - & \\
\hline netum, Synchytrit & & .111 & Reessia, - - - & & . & \\
\hline purascens, Taphrin & & $147,151,153$ & a, Ustilago, - & & - & \\
\hline rpurea, Clavic & . & $-7,29,191$ & lium, & & . & \\
\hline$" \quad$ Pucci & . & $-\quad \cdot 353$ & sora, & $:$ & - & \\
\hline Urocystis, & - & - 319 & Cercospora & . & - & \\
\hline isilla, Claviceps, - & - & - 195 & Aecidiun, - & - & - & -346 \\
\hline , Plas & - & . 130 & thi, Sclerotium, & - & - & -266 \\
\hline ustulata, Burillia, - & - & -322 & $a,-\quad-\quad-$ & - & - & - $\quad 272$ \\
\hline , Melampsora, & . & -370 & rhizipes, Taphrina, & . & & 151,152 \\
\hline putrefaciens, Sporid & ium, & - $\quad 221,465$ & Rhizobium, - & - & - & - 101 \\
\hline hroa, Calonectria, & - & - 184 & Rhizoctonia, - & . & - & 201,274 \\
\hline is, - - - - & - & - 226 & rhizoides, Sclerotium, & - & - & - 266 \\
\hline nochytrium, & - & - 109 & rhizophora, Taphrina, 1 & 147,15 & 50, & 152,157 \\
\hline ginaea, Plasmopara, & - & -130 & rhodiolae, Puccinia, & - & - & $-\quad 359$ \\
\hline aea, Ravenelia, & - & -403 & rhododendri, Apiosporiv & um, & - & -181 \\
\hline chaeta, & - & - 470 & Chrysomy & xa, & - & - 377 \\
\hline yrenomycetes, & - & $-\quad 183$ & Exobasidir & un, & . & $-\quad 427$ \\
\hline Pyroctonum, - & . & - 114 & Gloeospori & ium, & - & -485 \\
\hline Pythium, & . & 4,116 & Henderson & nia, & & -475 \\
\hline & & & Sclerotinia & & & \\
\hline Q & & & es, - - & - & & - 143 \\
\hline , Aecidium, & & & yceae, & . & & - 555 \\
\hline uaternaria, - & - & $-\quad 226$ & , - - & . & & 71,242 \\
\hline ercina, Clithris, - & • & - 248 & des, Dyscom & $\operatorname{cop}$ & & - 245 \\
\hline , Colpoma, & & - 248 & roderris, & - & - & - 251 \\
\hline Rosellinia, & - & - $\quad 200$ & ribesii, Caeoma, & - & & \\
\hline
\end{tabular}


ribicolit, Plasmopara, ribicolum, Cronartium, ribis, Gloeosporinm,

,, Polyporus,

,, Puccinia,

,, Sieptoria,

robertiani, stignatea,

mhiniae, Dothiorella,

Robinsoniana, 'Taphrina,

rosac, Aetinonema,

, Dicoccum,

, Glocosporium,

, Marsonia,

, Septoria,

rosae-alpinae, 1'hragmidium, rosaccola, Cercospora,

rosea, Ovularia,

Rosellinia

rostratum, Ul'ol,asidium

Rostrupia, - - 354

Rostrupiana, Taphrina, 147, 15I, 152, 1.56

Rostrupii, l'ericlermium, - - 377

Rousseauana, Fabraea, - _ $\quad$ - 255

Ronselliana, Nectria, - _ $\quad$ - 188

rubefaciens, Puecinia, - $\quad$ - $\quad 359$

rubellum, Aecidium, - - - 34!)

rulsescens, Ascoidea, - - - $14 \mathrm{I}$

rnbi, Fxosporinm, - - - - 195

, Phragmidium, - - $\quad 363$

„, Septoria, - - . $\quad 476$

,, -idaei, Phragmidium, - . 363

, ,, Pyrenochaeta, - - 470

, -miniatum, Phragmidium, - 363

rubigo-vera, Puccinia, - $\quad$ - $\quad 347$

rubra, Endosphaera, - - - 5.jl

rubrocinctum, Synehytrium, - 112

rubrum, Polystigma, - $\quad$ - $\quad$ - 159

rufibasis, Ramularia, - - $\quad$ - 502

rufomaculans, Ramularia, - $\quad$ - 502

rumicis, Uromyces, - $\quad$ - $\quad 337$

,, Venturia, - . - . 215

rumicis-scutati, Puccinia, - $\quad$ - 355

ruscicola, Phyllosticta, - - - 46j)

\section{S}

sabinae, Gymnosporangium, sacchari, Trichosphaeria,

74,395

Ustilago, - -
, - siccharinum, Cylindrosporium, PATE:

Saccharomyces, - $\quad$ - $\quad 8,143$

Sarlebeckianum, Pythimm, - . 117

Sirlebeckii, 'l'aphrina, 145, 150, 1.54, 165

sugittariac, Doassansia, - - 322,323

salicina, Melanpsora, - • - 367

, Melasmia, - $\quad$ - $\quad$ - 480

silicinum, Capnodium, - . - 181

" Diclymosporium, - - 490

,, Rhytisma, - - - 245

salicinns, P'olyporus, - - - 452

salicis, Uncinula, - . - - 178

salicis-caprcae, Melampsora, - 368

salicorniae, Cromyces, - _ $\quad 334$

sambnei, Aecidium, - . . 411

,, Phyllosticta, - - - 464

sanguineum, Synchytrium, - - 109

sanguinolenta, Phona, - - - $46 \mathrm{~S}$

sanguisorbae, Phragmidium, - . 363

saniculae, Puccinia, - - $\quad 341$

saponariae, Sorosporium, - - 325

S'ilprolegniaceae, - . - - 115

sarcinceformac, Macrosporium, - 517

sareinula, Macrosporium, - $\quad$-. 518

saxifragae, Caeoma, _ $\quad$ - $\quad$ - 419

,$\quad$ Puccinia, - - $\quad 359$

scabies, Oospora, - . - - $\quad$ - 497

scabiosae, Ascochyta, - $\quad$ - $\quad 473$

, Ustilago, - $\quad$ - 294

scelerata, Ovularia,- $\quad$. $\quad 501$

Schachtii, Peronospora, - _ - 132

Schierlermayeri, Hyduum, - 433

Schinzia, - - - - - $\quad$ - 326

Schinzianum, Exobasidium, - $\quad 427$

Śchizomycetes, - . . . . \$30

Śchizonella, - $\quad$ - $\quad$ - $\quad$ - 305

Schizospora, - . - - $\quad$ - 361

Schizothyrium, - - - $\quad$ - 242

Schleirleni, Peronospora, _ - 132

Schneideri, Precinia, - $\quad 359$

Schoeleriana, Puccinia, - - $\quad$ - 350

Schroederi, Puccinia, - $\quad$ - $\quad 359$

Schroeteri, Uromyces, - - $\quad 337$

Schroeteria, - . - - $\quad 32 S$

Schroetcriaster, - - . $\quad 337$

Schweinfurthiana, Ustilago, - - $\quad 299$

Schweinfurthii, Aecidium, - $\quad 410$

\begin{tabular}{c|ccc}
$2 S 4$ & Schweinitzii, Polyporus, - & - & -448 \\
284 & Ustilago, - & - & -281
\end{tabular} 
PAGE

scillae, Puccinia, - $\quad$ - $\quad$ - $\quad \begin{gathered}\text { PAGE } \\ 359\end{gathered}$

scillarum, Uromyces, - - - 338

scirpi, Puccinia, - $\quad$ - $\quad$ - $35 \%$

Scleroderris, - $\quad$ - $\quad$ - $\quad$ - $\quad$ - 250

Sclerospora, - $\quad$ - $\quad$ - $\quad$ - $\quad$ - 131

Sclerotiuia, - $\quad 3,7,16,29,256$

sclerotiorum, Peziza, - $\quad$ - 263 $\begin{array}{llr}\text { ", Sclerotinia, } & -\quad 2,4,263 \\ \text { otium, } & -\quad & 266,431, j 00\end{array}$

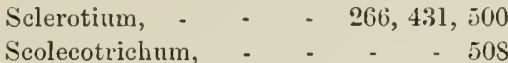

scorzonerae, Ustilago, - - $\quad$ - 296

Scotinosphaera paradoxa, - - 550

Scribuerianum, Cladosporium, - 511

scrophulariae, Uromyces, - $\quad$ - 338

scutellatus, Uromyces, - - $\quad$ - 336

Scytonema, - - - $\quad$ - $\quad$ - 541

secales, Bacillus, - $\quad$ - $\quad$ - $\quad$ - 535

secalis, Tilletia, - $\quad$ - $\quad$ - $\quad$ - 310

,, Ustilago, - $\quad$ - $\quad$ - $\quad$ - 289

sedi, Endophyllum, - _ - 404

"Puccinia, - $\quad$ - $\quad$ - 359

"Septoria, - - $\quad$ - 478

Selinia, - - _ _ _ $\quad$ - 184

senuinum, Ustilago, - $\quad$ - $\quad 297$

sempervivi, Endophyllum, - 13, 404

senecionis, Coleosporium, _ $\quad$ - $\quad 374$

,, Ovularia, - $\quad$ - 500

,, Puccinia, - $\quad$ - 356

sentina, Spliaerella, - $\quad$ - $\quad-216$

separata, Tilletia, - $\quad$ - $\quad$ - $\quad$ - 310

septentrionalis, Puccinia, - $\quad 352$

Septocylindrium, - $\quad$ - $\quad$ - $\quad$ - 505

Septoglocum, - - . - . 495

Septoria, - $\quad$ - $\quad$ - $\quad$ - 475

Septosporium, - - . $\quad 518$

serotinum, Entyloma, - - $\quad$ - 312

sesleriae, Puccinia, - $\quad$ - $\quad$ - $\quad$ - 349

,, Tilletia, - $\quad . \quad$ - 310

sessilis, Puccinia, - $\quad$ - $\quad$ - $\quad$ - 349

setariae, Ustilago, - _ _ $\quad$ - 291

Ustilaginoidea, - - $\quad$ - 311

setosum, Ceratophorum, - - $\quad$ - 511

setulosa, Claviceps, - - - - 195

Sherardiana, Puccinia, - $\quad$ - 360

sii latifolii, Aecidium, - $\quad$ - $\quad$ - 336

silenes, Puccinia, - - $\quad$ - $\quad$ - 340

,, Uromyces, - _ - . 334

simplex, Puccinia, - $\quad$ - $\quad$ - $\quad 347$

simulans, Olpidium, - $\quad$ - 107 siucrularis, Puccinia, PAGE

Sistotrema, Pliccinia, -

sistotremoides, Polyporus, - - 445

Slime-fungi, - $\quad$ - $\quad$ - $\quad$ - $\quad$ - 522

smilacis, Aecidium, - _ _ _ $\quad 411$

smyrnii, Puccinia, - $\quad$ - $\quad$ - 356

solani, Alternaria, - $\quad$ - $\quad$ - $\quad$ - 517

,, Hypnochus, - - - - $42 \mathrm{~S}$

, Macrosporium, - - $\quad$ - 517

,, Phoma, - . - - 468

," Rhizoctonia, - - $\quad 202$

,, Schinzia (Entorrhiza), - $\quad$ - 326

soldanellae, Puccinia, - $\quad$ - $\quad 341$

solidaginis, Uromyces, - - - 338

Sommerfeltii, Aecilium,- $\quad$ - $\quad 352$

sonchi, Coleosporium, - $\quad$ - $\quad$ - 376

,Puccinia, - - - $\quad 355$

Soraueri, Periderminm, - - 376, 414

Soraueriana, Pestalozzina, - - 495

sorbi, Cucurbitaria, - $\quad$ - $\quad$ - 210

, Melampsora, - - $\quad$ - $\quad$ - 369

,, Phoma,- - - - . $46 \mathrm{~s}$

sordida, Peronospora, _ _ $\quad$ - 134

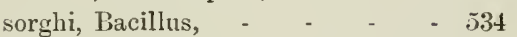

,, Cintractia, - - _ $\quad 302$

,, Endothlaspis, - _ $\quad$ - 302

, Fusicladium, - _ $\quad 508$

, Precinia, - . $\quad$ - 353

,, Uredo, - - - $\quad$ - 420

,, Ustilago, - - $\quad$ - $\quad$ - $\mathbf{2 8 4}$

Sorosphaera, - $\quad$ - $\quad$ - $\quad$ - $\quad$ - 530

sorosporioides, Urocystis, - $\quad$ - $31 \%$

Sorosporium, - $\quad$ - $\quad$ - $\quad$ - $\quad$ - 325

sparsa, Melampsora, - $\quad$ - $\quad 370$

,, Peronospora, - _ $\quad$ - 133

sparsus, Uromyces,- $\quad$ - $\quad$ - 337

speciosum, Gymnosporangium, - 403

,, Phragmidimm, - $\quad$ - 362

spergulae, Puccinia, _ _ . $\quad$ - 361

Sphaceloma, - $\quad$ - $\quad$ - $\quad$ - $\quad$ - 467

Sphacelotheca, - $\quad$ - $\quad$ - $\quad$ - 302

Sphaerella, - $\quad$ - $\quad$ - $\quad$ - $\quad$ - 211

Sphaerelloideae, - $\quad$ - $\quad$ - $\quad$ - 210

Sphaeriaceae, - - _ _ - 1\$4, 195

Sphaerioideae, - - $\quad$ - $\quad$ - 463

sphaerogena, Ustilago, - - - $\quad 291$

sphaeroidea, Dothidea, - - 230

- 501

sphaeroides, Dothiora, - - 218, 249 
Sphacronema, -

PAIE

siphaerophramiuu,

sphacropsis,

sphaeropsoidea, Phyllosticta,

Sphaerostilbe, -

Sphaerotheca, -

sphagni, Tilletia,

spinaciae, Colletotrichum,

spinificis, Ustilago,

spinulosus, Cystopus,

spiralis, Uncinula, -

spissa, Didymaria, -

splendens, Aecidium,

Sporidesmium,

spororlesmium,

spumens, Polyporus,

spurium, sphaeronema,

squamosus, Polyporus,

squarrosus, Agaricus,

stachydis, Puccinia,

$$
\text { , Septoria, }
$$

stagonospora, -

Stahlii, Peridermium,

stellariae, Synchytrium, -

Stemphylium, -

stereum,-

stictica, Pestalozzia,

stictoides, Leptosphaeria,

Stigmatea,

Stilbeue, -

stolonifer, Mucor, -

Stomatochytrium, -

straminis, Puccinia,

Straussii, Venturia,

Streblonemopsis irritans,

striaeformis, Puccinia,

striatus, Uromyces,-

Strickeria,

striformis, Tilletia,

strobi, Peridermium,

, Phoma,

strobicola, Hypoderma, -

strobilinum, Aecidium, -

stu'uthiopteris, Uredinopsis,

Stysanus,

suaveolens, Puccinia, -

$$
\text { , Trametes, - }
$$

subcorticium, Phragnidium, subinclusa, Cintractia,

, Ustilago, - - - 301

subtecta, Leptosphaeria,- _ - 221

subtilis, C'olerna, - - - - 19.5

succisae, Synchytrium, - - - 110

, Ustilago, - - - - 296

suffocata, Pestalozzia, - $\quad$ - $\quad$ - 494

suffulta, Phyllactinia, - - - $17 \mathrm{~s}$

sulcigena, Hyporlermella, - - 234

sulphureus, I'olyporus, - - $\quad 6,437$

sylvatica, Puccinia, - - 351

symmetricum, Rhytisma, - 246

symphyti, Uredo, - - - - 420

symploci, lixobasillium, - - 427

synantherearum, Coleosporiun, - 37

Syncephalis, - - - $\quad 11,28$

synchytriaceae, - - $\quad-107$

Synchytrium, - - - $\quad-108$

syringae, Ovularia. - - - 501

tabaci, Oidium, $\quad$ - $\quad-\quad \ldots \quad 499$

" Phyllosticta, - - . 464

tabifica, Phyllosticta (Sphaerella), - 464

taleola, Aglaospora, - $\quad$ - 226

, Diaporthe, - - - $\quad 226$

tanaceti, Puccinia, - - - $\quad 355$

Taphria = Taphrina, $\quad-\quad \cdot \quad-146$

Taphrina, - - $\quad 7,29,146,148$

Taphrinopsis, - $\quad$ - $\quad$ - $\quad \cdot \quad-148$

taraxaci, Puccinia, - $\quad-\quad 353$

," Synchytrium, - - 2.2, 108

taxi, Capnodium, - - - 181

,, Phoma, - - - - 468

, Sphaerella, - - - - 215

tenuistipes, Puccinia, - - $\quad 351$

Tepperianus, Uromyces, - - 333

terebinthi, Uromyces, - - - 337

teres, Helminthosporium, - $\quad 512$

Tetramyxa, - - - - $\quad$ - 529

thalictri, Aecidium, - $\quad$ - $\quad 349$

,, Entyloma, - $\quad$ - $\quad 312$

," Puccinia, - - - 358

Thecaphora, - - - - - 324

Thecopsora, - - - - 370

thelebola, Aglaospora, - - - 226

," Melanconium, - - 226

Thelephora, - - - - - 429

thesii, Puccinia, - - - $\quad 341$ 
Thielavia, - _ - $\quad$ PAGE

Thielaviopsis, - $\quad$ - $\quad$ - $\quad$ - 183

thlaspeos, Puccinia, _ _ $\quad$ - $36 \mathrm{I}$ , Tilletia, - . $\quad 310$

tiliae, Actinonema, - - $\quad$ - 474 ,, Phyllosticta, - - $\quad$ - 464 Tilletia, - - - - $\quad 46,6 \mathrm{~S}, 306$ Tilletieae, - $\quad$ - $\quad . \quad-\quad 275$ Tolyposporium, - - $\quad$ - 305 Tomentelleae, - - - . 423 tormentillae, Pliragmidium, - - 363 tortilis, Erysiphe, - $\quad$ - $\quad$ - $\quad$ - 175 Torula, - - - - - 143, 181 Tosquinetii, Taphrina, 147, 150, 153, 166 toxicodendri, Marsonia, - - . 491 Trabutiana, Ustilago, - . $\quad 299$ Trachyspora, - - - . $\quad$ - 337 tragopogonis, Cystopus, - - - 127

,, Puccinia, - - . 356

Ustilago, - - - 296

Trailii, Puccinia, - $\quad$ - $\quad$ - $\quad 349$

,, Thecaphora, - $\quad$ - 324

Trametes, - - - - 450, 453

Trematosphaeria circinans, - $\quad 201$

Tremellinae, - _ _ _ - . $\quad$ - 421

tremelloides, Gymuosporangium, - 359

tremulae, Ascochyta, - • $\quad 473$

,, Fusicladium, - - $50 \mathrm{~S}$

,, Melampsora, - - 364, 367

,, Napicladium, - - $\quad$ - $21 \mathrm{~s}$

Trentepohlia endophytica, - $\quad 551$

Treubii, Ustilago, - - - 30, 299 , Phytaphysa, - - $\quad$ - 554

trichella, Vermicularia, - _ - $\quad 471$

trichophora, Ustilago, - - . 291

Trichosphaeria, - $\quad$ - $\quad$ - $\quad 61,195$

Trichosphaerieae, - $\quad$ - $\quad$ - 195

Trichospora, - - - - $\quad$ - 403

tridactyla, Podosphaera, - $\quad$ - 174

trientalis, Tuburcinia, - $\quad-\quad 319$

trifolii, Olpidium, - - - 107

, Phacidium, - - - 255

, Phyllachora, - $\quad$ - $\quad 229$

,, Polythrincium, - - $\quad$ - 229

, Pscudopeziza, - - $\quad$ - 255

,, Synchytrium, - * 107, 109

,, Uromyces, - - $\quad$ - 333

trifoliorum, Peronospora, - $\quad$ - 132 Sclerotinia, - - $\quad 265$ trigonellae, Uromyces, - . $\quad 337$

Triphragmiun, - - . $\quad$ - 361

tritici, Leptosphaeria, - . $\quad$ - 221

,, Tilletia, - $\quad$ - $\quad$ - 306

, Ustilago, - - . - 285

trollii, Puccinia, - $\quad$ - $\quad$ - $\quad$ - 356

tropaeoli, Pleospora, - - - 221

Tuberaceae, - $\quad$ - $\quad$ - $\quad$ - $\quad$ - 183

Tubercularieae, - - - $\quad$ - 520

tuberculatum, Phragmilium, - 362

tuberculatus, Uromyces, - - 337

Tuberculina, - . - - . $\quad$ - 327

tuberosa, Sclerotinia, - - - 266

tuberum, Cladosporium, - . 511

Tubeufianum, Cylindrosporium, - 4Ss

Tuburcinia, - $\quad$ - $\quad$ - $\quad 319$

Tuckeri, Erysiphe, - - - 176

, Oidium, - - - 177,499

T'ulasnei, Ramularia, - $\quad$ - 214

$$
\text { , Sphaerella, - } \quad \text { - } 509
$$

, Uncinula, - - - 178

,, Ustilago, - . $\quad \mathbf{2 8 4}$

tulipae, Puccinia, - $\quad$ - $\quad$ - $\quad 359$

,, Sclerotium, - - $\quad 500$

, Ustilago, - - - $\quad 299$

turcicum, Helminthosporium, - 512

turgida, Taphrina, $147,150,152,159$

tussilaginis, Coleosporium, - $\quad$ - 376

typharum, Heterosporium, - - 516

typhina, Epichloë, - - . 191

Typhula, - $\quad$ - $\quad$ - $\quad$ - $\quad$ - 431

\section{$\mathrm{U}$}

Ulei, Urocystis, - $\quad$ - $\quad$ - $\quad 316$

, Ustilago, - $\quad$ - $\quad$ - $\quad$ - 299

uliginosa, Puccinia, - - $\quad 351$

ulmariae, Ramularia, - - $\quad$ - 502

,, Stysanus, - $\quad$ - $\quad$ - 519

,, Tripliragmium, - - 36I

ulmarius, Polyporus, - - $\quad$ - 452

"lmi, Apiosporiun, - _ - 181

,, Asteroma, - - . - 470

,. Dothidella, - $\quad$ - $\quad 230$

," Phleospora, - - - - 478

,, Phyllachora, - - _ - 496

, Pleospora, - - - $\quad 221$

, Septogloeum, - - . 496

,, Taphrina, - - 148, 149, 154

ulmicolum, Ceratophorum, . - 512 
umbelliferarum, Erysiphe, $\quad$ Pañ ,, Magnusiella, 14S, 151, 154 umbilici, P'uccinia, umbonatum, Rhytisma, - _ _ . 246 Unciumla, Ungeri, l)iclymaria, Ungerianum, Fintyloma, - . - 31:2 uniseptatum, Dicoceum,

Uredimeite, - -

$7,13,21,45,328$

Uredinopsis,

Uredo-forms,

Unmuli, Selerotinia, - - - 256

Urobasidium, - . - . - 427

Urocystis, - $\quad . \quad \ldots \quad . \quad \ldots 14$

Uromyces, - . - . - 333

Urophlyctis, - - - $\quad$ - 113

Uropyxis, - - - - $\quad$ - 361

urticae, Peronospora, - _ $\quad$ - 135

$$
\begin{aligned}
& \text {, Ramularia, - } \quad \text { - } 50 \% \\
& \text {," Rhytisma, - . . } 246
\end{aligned}
$$$$
\text { , Septoria, - - - } \quad 478
$$

Ustilagineae, $\quad 7,13,16,21,28,47,275$

$$
\begin{aligned}
& \text { infection, - } \\
& , \quad \text { remedies, - }
\end{aligned}
$$

Ustilaginoidea,

$52,5 t$

Ustilago,

utriculosa, Ustilago,

uvicola, Phoma

V

vaccinii, Exobasidium,

, Gibbera, -

, Melainpsora,

,, Sclerotinia,

, Synchytrium,

vagans, Fumago,

Vaillantii, Ustilago,

valantiae, Puccinia,

valerianae, Puccinia,

Valsa, - $\quad$ - .

Talseae,

valsispora, Dendrophoma,

vanillae, Calospora,

,, - Gloeosporium,

vaporarius, Polyporus, .

variabile, Heterosporium, variabilis, Pamularia,

PAQE

varius, Exoascus,

vastatrix, Hemileia, - . . 361

venetum, filoeosporium, - . 483

Venturia, - . - . . 2IS

veratri, l’uccinia, - _ _ - 355

, Uronyces, - - $\quad$ - 337

Vermicularia, - . - . $\quad 470$

vermiculariaeformis, Venturia, - $21 \mathrm{~S}$

vernalis, Endomyces, - . - 14:3

, Melimpsora, - - - 370

veronicae, Ovnlaria, - . $\quad 501$

," l'uccinia, - - - 361

,, Sorosphacra, - - $\quad 530$

, Stysallus, - - 519

veronicarum, Puccinia, - - - 361

verruculosum, Entyloma, - $\quad 312$

Vialae, Uredo, - $\quad$ - $\quad$ - $\quad$ - 420

viburni, Plasmopara, - $\quad$ - $\quad$ - 131

,, Ramularia, - : . 502

viciac, Ascochyta, . _ _ . . $47 \%$

„, Peronospora, - . . . 132

, Phyllosticta, - . - 464

vincae, P'uccinia, - - $\quad$ - 356

vinosa, Ustilago, - . - . $\quad 295$

violacea, Rhizoctonia, - - $\quad 201$

, Ustilago, - - - 27,297

violaceum, Phragmidium, - - 363

violae, Cercospora, - . - . 515

, Gloeosporium, - - - 485

, Peronospora, - - - 134

,, Phyllosticta, - - $\quad$ - 464

, Puccinia, - - - $\quad 340$

, Urocystis, - - 16, 21,31,317

virganreae, Pnccinia, - $\quad$ - $\quad$ - 359

virginica, Taphrina, - $148,150,154$

virgultorum, Dothidea, - - $\quad 230$

viride, Chlorochytrium, - - $\quad$ - 550

viridis, Cylindrosporium, - . 459

vitellinae, Melampsora, - - $\quad 368$

viticola, Cereospora, - $\quad$ - 513

, Plasmopara, - - - 125

viticolum, Cladochytrium, - $\quad 114$

,, Claclosporium, - 510

vitigena, Leptosphaeria, . . 2.21

vitis, Aureobasidium, - - $\quad 425$

, Plasmodiophora, - . - $52 \mathrm{~S}$

, Sphaerella, - . - . 21j 


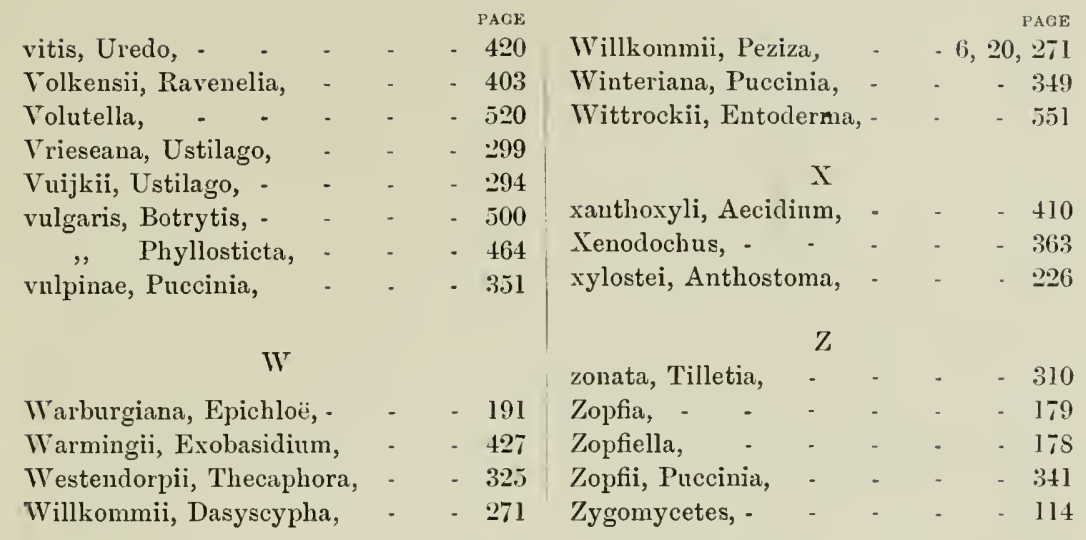




\section{GENERAL INDEX}

OF HOST-PLANTS, COMMON NAMES, Ete.

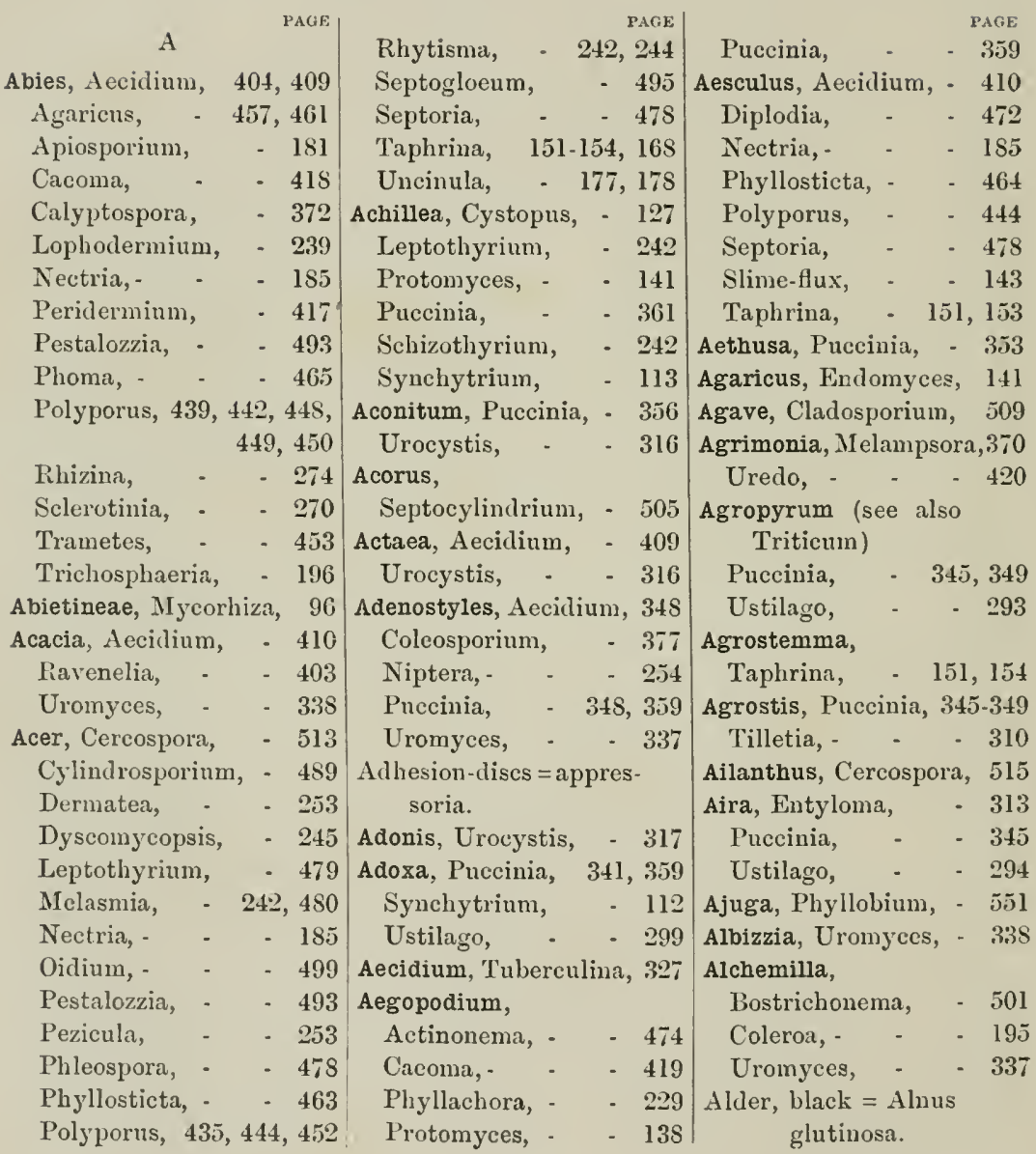


Alder, white=Alnus incana. Aletris, Physalospora, 218 Algae, Chlorocystis, - $\mathbf{5 5 0}$

Entoderma, - - 551

Entonema, - - 555

Harveyella, - - 555

Olpidium, - 107

Periphlegmatium, - 551

Phaeophila, - - 55l

Pythium, - - 117

Streblonemopsis, - 555

,, blue-green,. - 541

", pathogenic, 539, 547

Alisma, Cladochytrium, 114

Doassansia, - - 32:3

Pseudopeziza,- - 255

Allium, Aecidium, - 349

Bacteriosis, - $\quad 539$

Caeoma,- $\quad 367,419$

Cladochytrium, - 114

Macrosporium, - 518

Peronospora, - - 132

Puccinia, - 341,355

Rhizoctonia, - 202

Sclerotinia, - - 266

Urocystis, - $\quad 316$

Uromyces, - 337,335

Vermicularia, - 471

Almond (see Amygdalus)

Alnus, Corticium, - 452

Fraukia, - - 101

Leptothyrium, - 479

Microsphaera, - 176

Mycolomatia, - 99

Mycorhiza, - $\quad 99$

Ovularia, - - 501

Passalora, - $\quad 506$

Polyporus, 433, 439, 452

Sclerotinia - - 262

Stigmatea, - - 211

Taphrina, 150, 157, 158,

166,168

Talsa, - - - 224

Alopecurus,

Pestalozzina, - - 495

Puccinia, $\quad 345,346,349$

Tilletia, - - 310

Alpine-rose (see Rhododendron)
Alsineae, Puccinia, - $361 \mid$ Anthoceros, Nostoc, Page

Althaea, Cercospora, - 515 Anthoxanthum,

Colletotrichum, - 487 Pnccinia, - 345, 354

Phoma, - - 469 Tilletia, - - 310

Phyllosticta, - 464 Anthracnose,

Puccinia, - 360 Blackberry, - - 483

Amarantaceae, $\quad$ Cotton, - - - 487

Cystopus, - - 127 Privet, - - - 485

Amelanchier, $\quad$ Raspberry, - - 483

Fusicladium, - - 507 Vine, - - - 467

Gymnosporangium, 385, Anthriscus, Plasmopara, 128

391, 401, 402, 403 Puccinia, - $\quad 340$

Oidium, - - $\quad 499$ Anthyllis, Uromyces, 337

Podosphaera, - - 173 Apium, Cercospora, - 514

Roestelia, 385, 391, 402 Entyloma, - - 312

Ampelopsis, Cercospora, 515 Macrosporinm, - 518

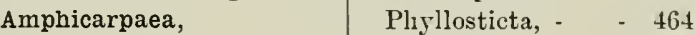

Synchytrium, - 109 Puccinia, - 353,355

Amygdalus (see also $\quad$ Septoria, - $\quad 477$

Prunus)

Ascospora, - - 211

Cercospora, - - 513

Gloeosporium, - 483

Polystigma, - $\quad 189$

Taphrina, 150, 153, 165

Anbury, - - - 524

Anchusa, Aecidium, - $34 \bar{\imath}$

Andromeda, Coleroa, 195 Exobasidium, 426, 427

Rhytisma, - - 246

Stigmatea, - - 211

Andropogon, Clariceps, 195

Puccinia, - 345, 354

Tilletia, - - 310

Ustilago, - $\quad 292$

Androsace,

Peronospora, - 134

Anemone, Aecidium, 23, 409

Coleosporium, - 377

Protomyces, - - 141

Puccinia, 356, 358, 360

Sclerotinia, - - 266

Septoria, - - 478

Synchytrium,- - 112

Urocystis, - - 316

Anethum, Puccinia, - 353

Heterosphaeria, - 249

Angelica, Fusicladium, 508

Puccinia, - $\quad 340$
A pocynum, Aecidium, 411

Septogloeum, - - 496

Apple (see Pyrus Malus)

-blight, - - - 531

-rot, - - - 482

powdery mildew, - 174

Appressoria, - - 9

Apricot (see Prunus)

Aquilegia,

Aecidium, - 349, 409

Arabis, Aecidium, - 410

Puccinia, - 359, 361

Ustilago, - - 297

Aralia, Triplragnium, 362

Arctium, Aecidinm, - 351

Arctostaphylos,

Exobasidium,- - 427

Nelampsora, - $\quad 370$

Arisarum, Phyllosiphon, 553

Aristida, Ustilago, - 294

Aristolochia, Puccinia, 341

Armeria, Uromyces, - 334

Armoracia, Ascocluyta, 473

Alternaria, - - 518

Cercospora, - - 514

Cystopus, - - 126

Orularia, - - 500

Septoria, - - 477

Arnica, Entyloma, - 312
Arnoseris, Entyloma, - 312 


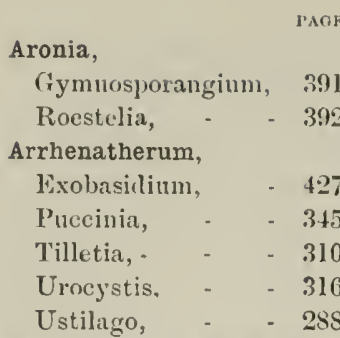

Arrowroot (sce Maranta)

Artemisia, Peronospora, 134

Puccinia,

Artichoke (see Cynara)

, Jerusalem (sec

Helianthus)

Arum, Aecidium, 349, 410 Caeoma, - - $\quad 419$

Ustilago, - $\quad 299$

Arundinaria, Ustilago, 293

Arundinella, Ustilago, 294

Asarum, P'nccinia, 32, 359

Asclepias, Aecidium, - 411

Ash (see Fraxinus excelsior)

Ash-canker,

Asparagus; Cercospora, 514

Puccinia, - - 341

Phizoctonia, - - 202

Aspen (see Populus tremula)

Asperula, Phacidium, 241

Puccinia, - 341,353

Aspidistra, Ascochyta, 473

Aspidium $\}$ (sce Ferns)

Aster, Aecilinm, 3.51, 411

Basidiophora, - 127

Pucciıia, - - 361

Astragalus, Didymaria, 501

Microsphaera, - 176

Polystigma, - 190

Thecaphora, - 324

Uromyces, - $\quad 337$

Astrantia, Fabraea, - 25.5

Puccinia, - $\quad 359$

Athamantha, Puccinia, 340

Atragene, Puccinia, - 358

Urocystis, - - 316

Atriplex,Cladochytrium, 114
Phyllosticta, - $\quad 46.5$

Atroplig, - - $\quad 22,26$

Aubernage, - 202,534

Antoecism, - - 45

Avena, Cladosporium, 509

Erysiphe, - - 175

Fusarium, - - 512

Fusicladium, - 505

Helminthosporium, 512

Phoma, - - - 467

Puccinia, $345,346,348$

Scolecotrichum, - 508

Septoria,- - - 477

Uromyces, - $\quad 336$

Ustilago, - 284, 287

Azolla, Anabaena, - 545

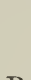

Bacterial diseases or

Bacteriosis, - - 530

Bacteroids, - - 102

Bambusa, Neovossia, 311

Puccinia, - - 3a4

Barbarea, Aecidinm, 409

Barkerry (see Berberis)

Barley (see Hordenm)

Bartsia, Coleosporium, 376

Batatas, Ceratocystis, 469

Cladosporium, - 511

Cystopus, - - 127

Nectria, - - 189

Phyllosticta, - - 464

Rhizoctonia, - 202

(see also Ipomoea)

Bean (see Vicia)

,, Kidney (see Phaseolus)

Beech (see Fagus)

Beet-root and sugar Beet (see Beta)

Beet, heart rot, - - 464

, -scab, - 497, 537

Bellidiastrum,

Aecidium, - - 351

Entyloma, - $\quad 312$

Puccinia, - - 359

Bellis, Aecidium, - 352

Berberis, Aecidiun, 341, 409

Didymosphaeria, - 218

Melasmia, - $\quad 479$
Jicrosphaeril, PAGB

Puccinia, - 340

Beta, Bacteria, - - 537

Cercospora, - 514

Entyloma, - 313

Oospora, - - 497

Peronospora, - 132

Phoma, - - 468

Phyllosticta, - - 464

Pytlium, - - 116

Rhizoctonia, - - 202

Sclerotinia, - 264

Sporidesmium, - 221

Uromyces, - - 334

Betonica, Puccinia, - 359

Ustilago, - - 298

Betula, Clarlosporium, 511

Dothiclea, - - 230

Dothidella, - 230

Hormomyia, - - 262

Nelampsora, - 366, 367

Microsphaera, - 176

Myxosporium, - 486

Phyllactinia, - - 17S

Polyporus, 446, 449-4.52

Sclerotinia, - $\quad 261$

Slime-flux, - - 143

Taphrina, 149-154,

159-161, 167

Twig-galls, - - 532

Uncinula, - - 178

Bilberry (see Vaccinium

Nyrtillus)

Birch (see Betula alba, etc.)

Bitter-rot, - - - 482

Black-knot, - - 231

, -rot, Vine, 216, 484

, -rust, - 341, 419

,. -shank, - . 469

Bladder-plums, - - 155

Blanc des Racines, - 202

Blight, a common name for diseases

Boragineae, Erysiphe, 175

Puccinia, - 347,348

Borago, Entyloma, - 312

Bordeaux mixture, 69, 172

Bonillie-Bordelaise, . 69

Bouteloua, Ustilago, 299 


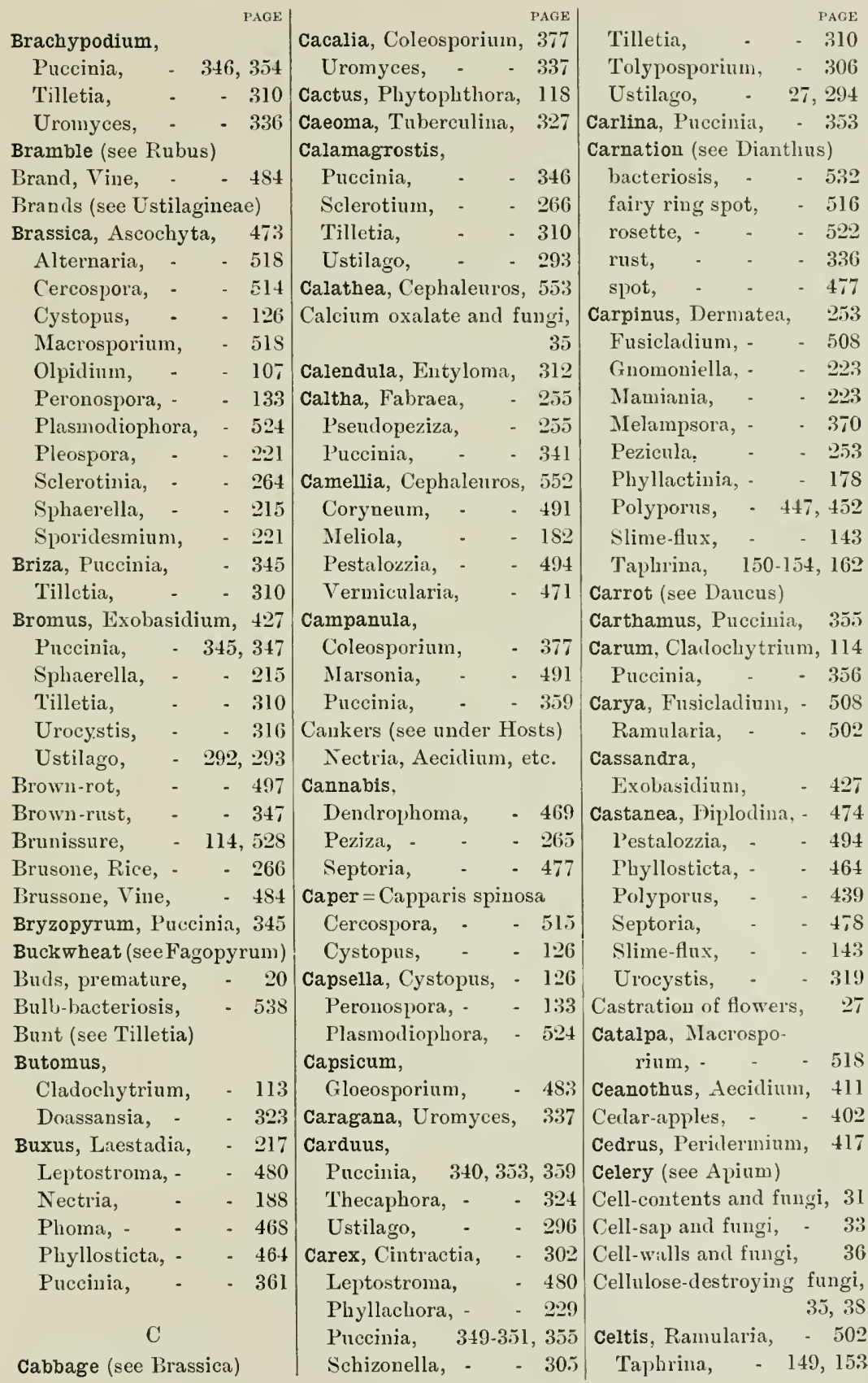




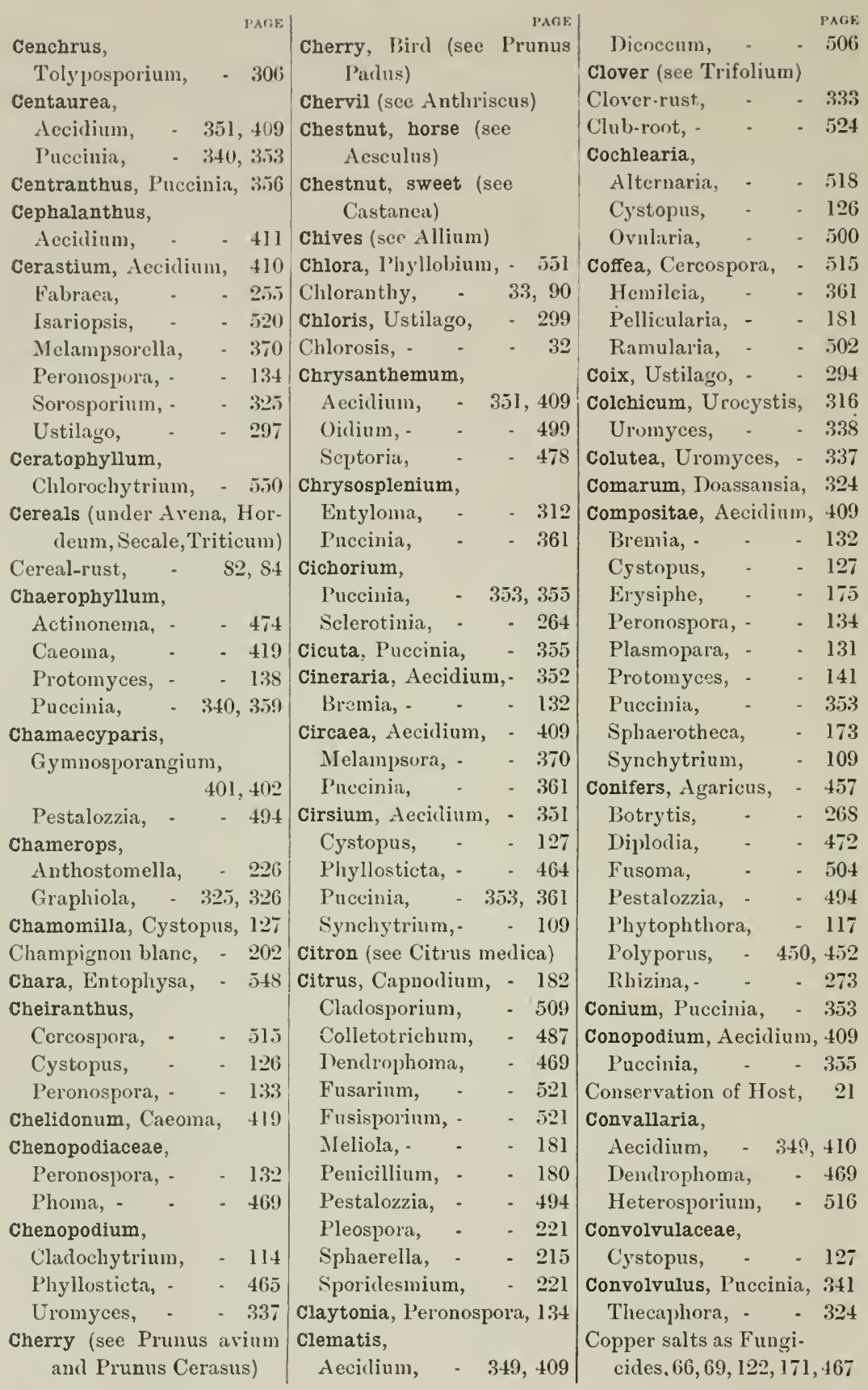


Coralliorhiza, Mycorhiza, 97 Cork (see ITound-cork)

Cornus, Cryptomyces, 248 Erysiple, - - 175 Phyllosticta, - - 464 Septoria, - - $47 \mathrm{~S}$

Corydalis, Aecidium,- 410 Caeoma, - - 419 Entyloma, - $\quad 312$ Peronospora, - - 134 Corylus, Gnomoniella, 224 Mamiania, - $\quad 224$ Phyllactinia, - - $17 \mathrm{~s}$ Polyporus, - 439, 444 Septogloeum, - - 496 Cotoneaster,

Sclerotinia, - - 261

Cotton (see Gossypium)

,, frenching, - 522

Cottonwoods (see Populus)

Couch-grass (see Triticum)

Cowberry ) (see Vaccinium)

Crataegus, Asteroma, 470

Fusicladium, - $\quad 507$

Gymmosporangium, 355, 391, 397, 401-403

Pestalozzia, - $\quad 494$

Phleospora, - - 478

Podosphaera, - $\quad$ - 174

Polyporus, - - 450

Roestelia, $355,397,402$

Septoria, - - 476

Taphriua, $150,153,166$

Crepis, Puccinia, - 353 Synchytrinm, - 109

Cress (see Lepidium)

,, water (see Nasturtium)

Croton, Aecidium, - 410

Crowberry (see Empetrum)

Cruciferae, Cystopus, 124 Erysiphe, - - 175

Perouspora, - - 133

Plasmodiophora, - 524

Pythium, - - 116

Cucumber (see Cucumis)

Cucumis, Bacteria, - $\mathbf{5 3 6}$

Cladosporium, - 510

Colletotrichum, - 486

$$
\text { PAGE }
$$

Erysiphe, - 175, 499

Hyprochus, - - 428

Macrosporium, - 518

Peronospora, - $\quad 134$

Pythium, - - 117

Scolecotrichum, - 508

Cucurbita, Bacteria, - 536

Colletotrichum, - 486

Peronospora, - - 134

Cucurbitaceae, Phoma, 469

Sclerotinia, - - 265

Sphaerotheca, - 173

Cupressus, Agaricus, 457 Gymnosporangium, 403

Pestalozzia, - - 494

Cupuliferae,

Mycorhiza, - 93, 94

Cycads, Anabaena, - 544

Cladosporium, - 509

cyclamen,

Colletotrichum, - 488

Septoria, - - 478

Thielavia, - - 183

Cydonia, Bacteria, - 531

Cercospora, - - 515

Entomosporium, - 450

Gymnosporangium, 3ร5, $391,401,403$

Hendersonia, - - 475

Ovularia, - $\quad 500$

Phoma, - - - 468

Roestelia, - - 391

Sphaeropsis, - - 472

Taphrina, 150, 154, 168

Cynanchum,

Cronartinm, - - 381

Cynara, Ramularia, - 502

Cynodon, Phyllachora, 229

Tilletia, - - $\quad 310$

Ustilago, - - 294

Cynoglossum,

Peronospora, - $\quad 134$

Cyperus, Schinzia, - 326

Cytisus, Ceratophorum, 511

Cucurbitaria, - $\quad 206$

Darluca, - - 474

Diplorlia, - 209

Microsphaera, . - 176

Peronospora, - - 133
PAGE

Phyllosticta, - - 463

Physalospora, - 218

Uromyces, - 337,338

\section{D}

Dactylis, Entyloma, - 312

Epichloë, - $\quad 191$

Puccinia, - 345, 346

Sclerotium, - $\quad 266$

Tilletia, - - $\quad 310$

Uromyces, - - 336

Dahlia, Sclerotinia, - 264

Dammara,Peridermium, 417

Damping-off, - - 116

Dandelion (see Taraxacum)

Daphne, Sphaerella, - 215

Datura, Cercospora, - 515

Daucus, Heterosphaeria, 249

Phoma, - - - 468

Plasmopara, - - 128

Polydesmus, - - 221

Protomyces, - - 138

Rhizoctonia, - - 202

Sclerotinia, - - 264

Sporidesmium, - 221

Desmodium,

Microsphaera, $\quad-176$

Ramularia, - - 502

Dentaria, Puccinia, - 359

Dianthus, Ascochyta, 473

Bacteriosis, - - 532

Botrytis, - - 500

Fusarium, - - 522

Heterosporium, - 516

Macrosporium, - 518

Puccinia, - - 361

Septoria, - - 477

Sorosporium, - - 325

Urocystis, - $\quad 319$

Uromyces, 334, 336, 337

Ustilago, - - 297

Volutella, - - 520

Dicentra, Aecidium, - 410

Peronospora, - - $\mathbf{1 3 4}$

Digitalis, Ascochyta, 473

Ramularia, - - 502

Digitaria (see Panicum)

Dill (see Anethum)

Diplachne, Ustilago, - 293 


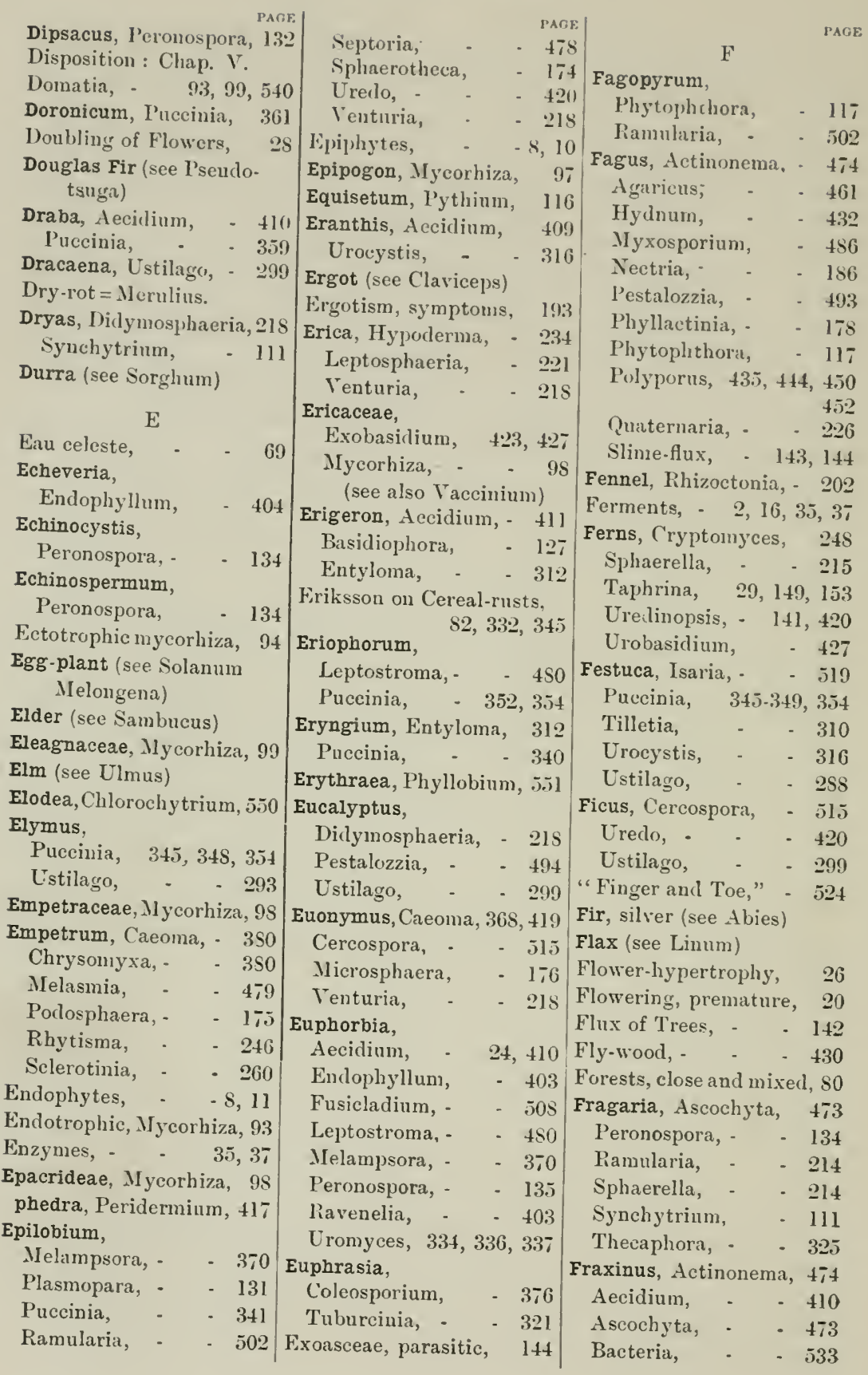




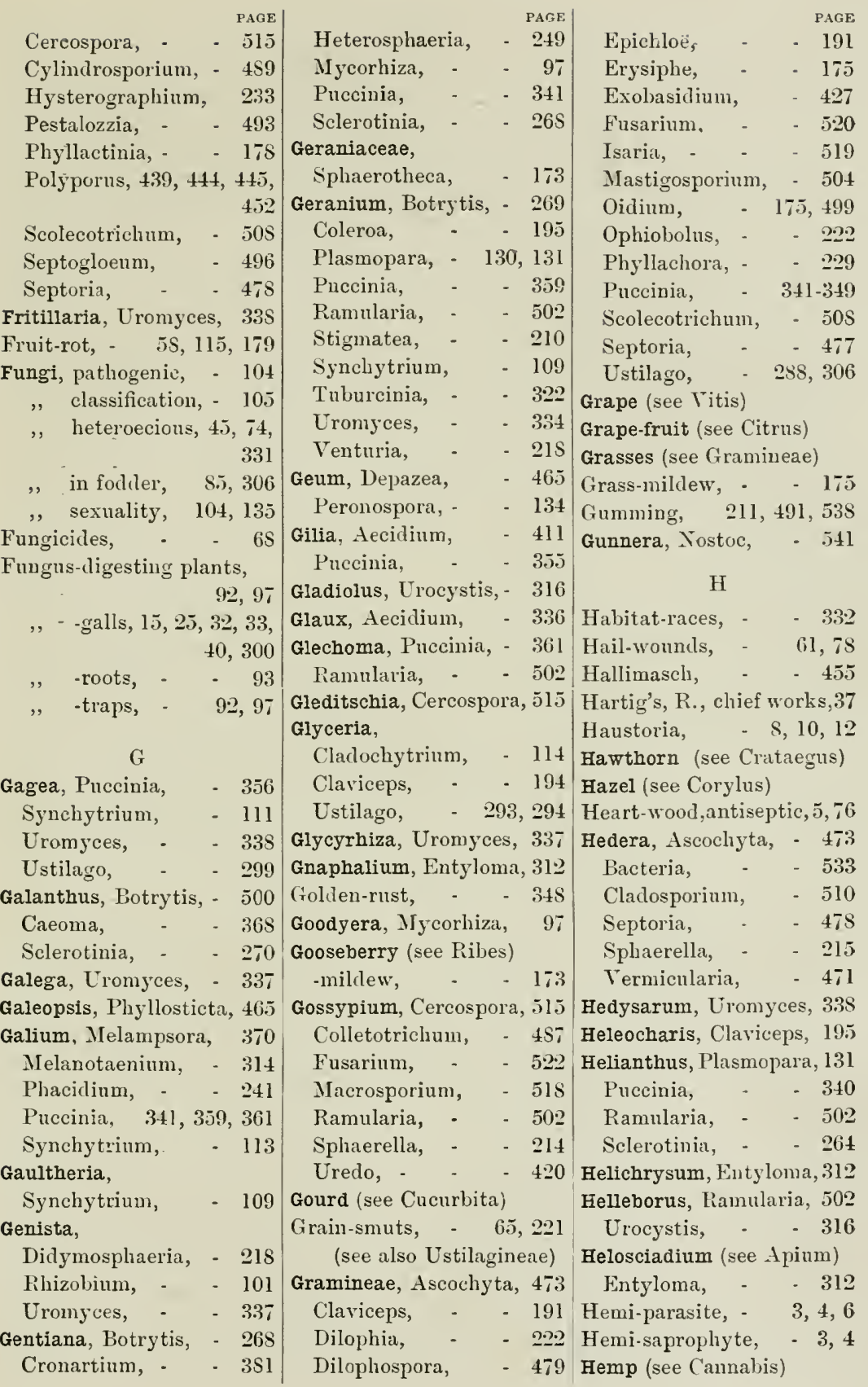




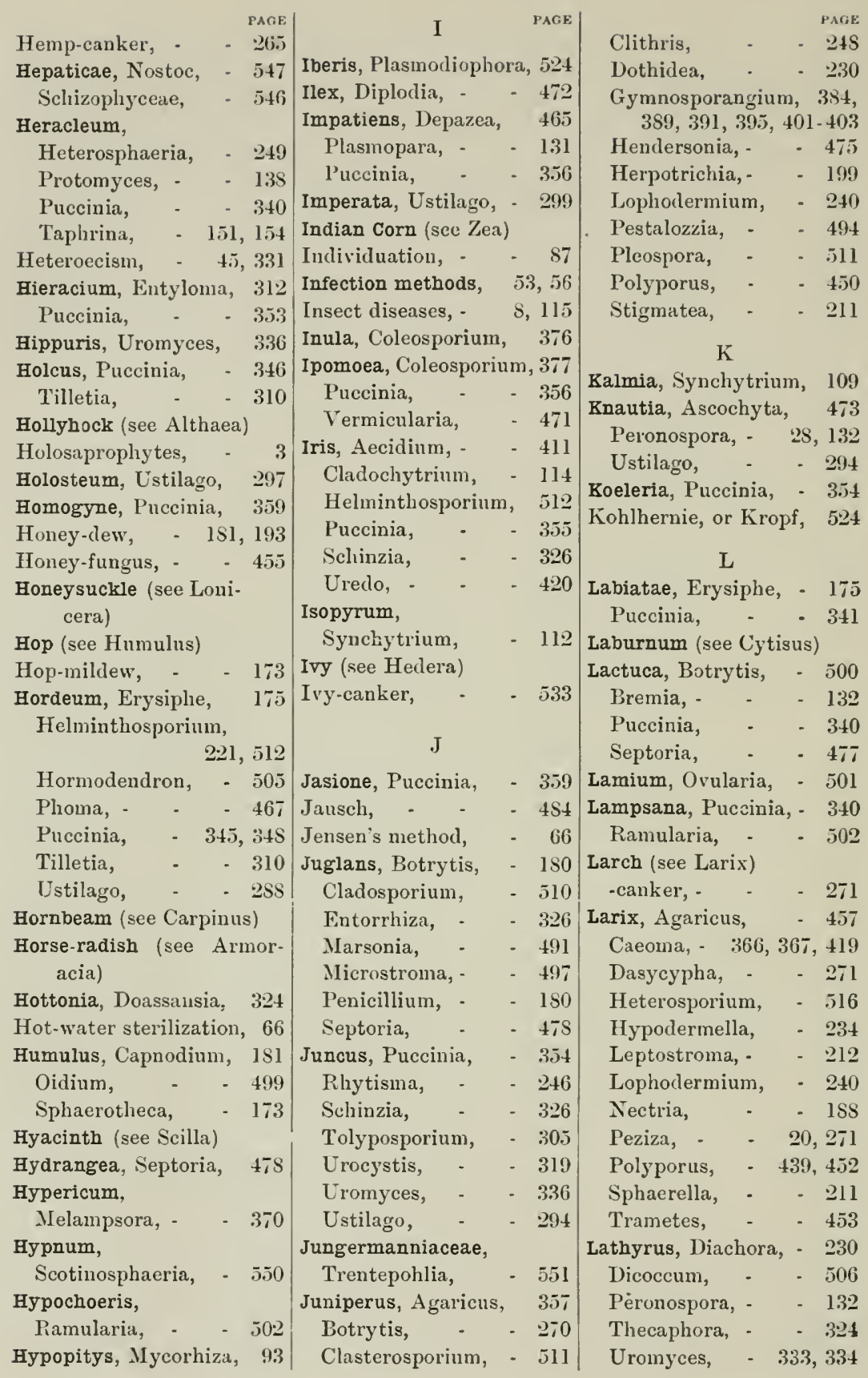


II. GENERAL INDEX.

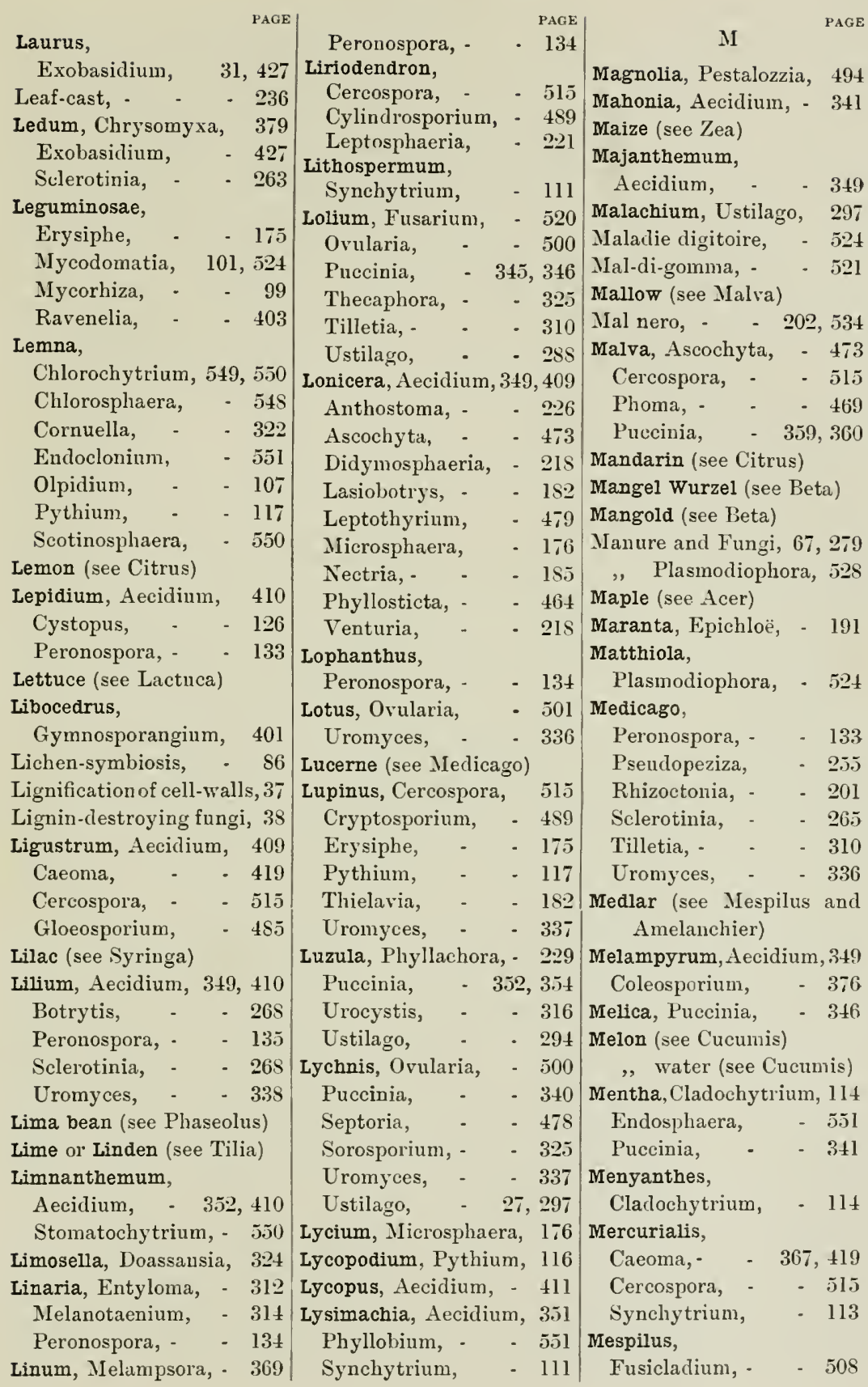




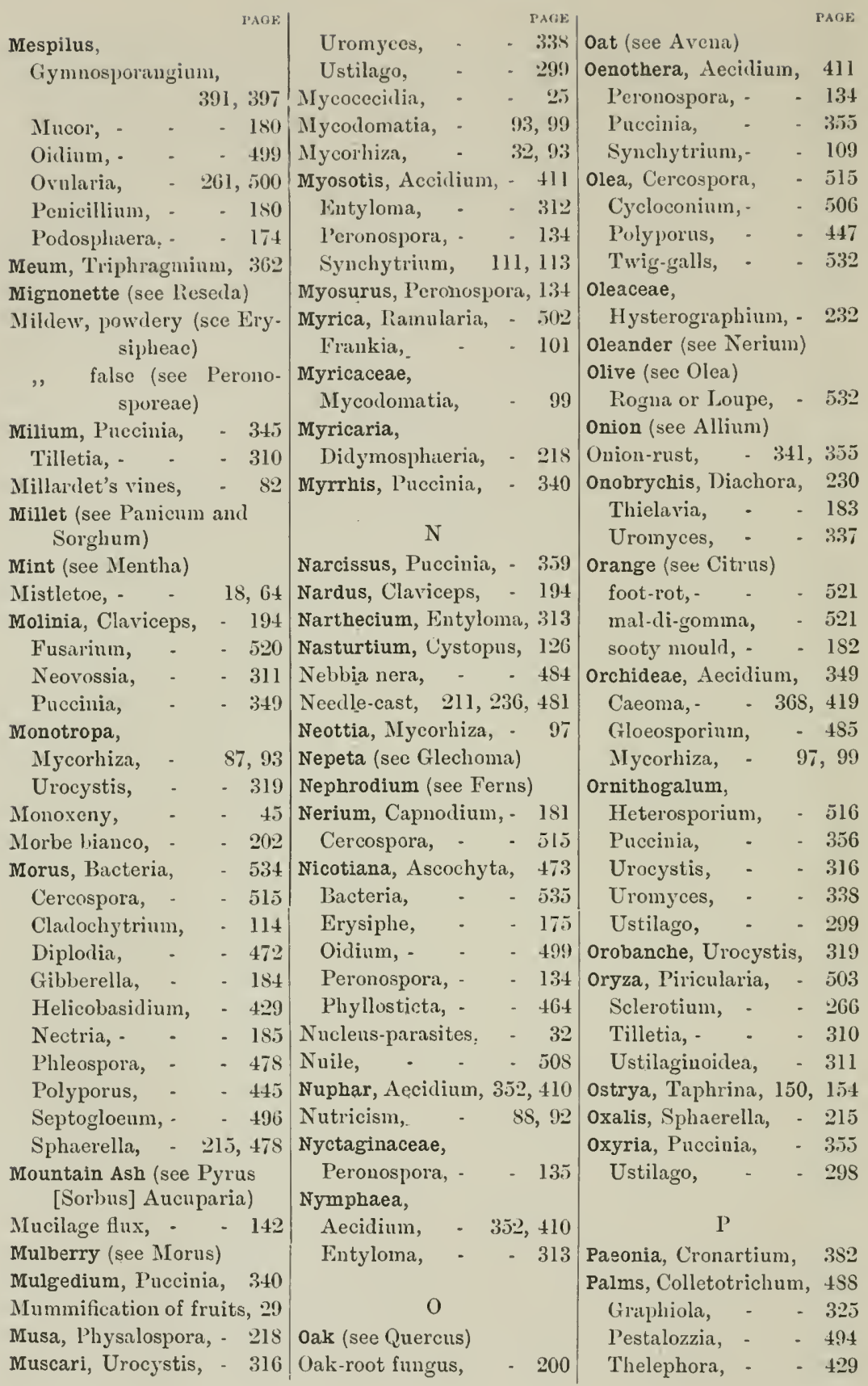


Pandanus, Cephaleuros, 553 Nectria, - - - 188

Panicum, Pythium, - 116 Tolyposporium, - 306 Ustilago, 289, 291, 293

Papaver, Entyloma, - 312 Peronospora, - - 133

Papilionaceae, Erysiphe, 175 Peronospora, - - 132

Parasites, - $\quad 1-3,7,14$ classification, - $\quad 3$ modle of life, - $\quad 7$

Paris, Aecidium, 349, 410 Mycorhiza, - $\quad 32$ Tuburcinia, - - 321 Urocystis, - - 316

Parnassia, Aecidium, 352 Uromyces, - - 334

Parsley (see Petroselinum) Parsnip (see Pastinica)

Partridge-wood, 431

Paspalus, Ustilago, - 294

Pastinaca, Cercospora, 514 Cercosporella, - 503 Heterosphaeria, - 249

Pea (see Pisum)

Pea-rust, - - $\quad 334$

Peach (see Persica) -curl, - - - 165 frosty mildew, - 503 -rot, - - - 497

Pear (see Pyrus communis) -blight, - - - 531

Pedicularis, Aecidium,

Penicillaria

Tolyposporium, - 306

Pennisetum, Neovossia, 311

Pentstemon, Aecidium, 411

Peplis, Eudospliaera, 551 Peridermium,

Tuberculina, 327

Persica (see also Prunus)

Cercospora, - - 513

Cercosporella, - 503

Cladosporium, - 510

Clasternsporium, - 511

Gloeosporium, - 482

Monilia,
Phyllosticta, - $\quad \begin{array}{r}\text { PAGE } \\ \text { P }\end{array}$

Puccinia, - - 355

Sphaerotheca, - 172

Taphrina, 150, 153, 165

Petasites, Aecidium, - 348

Coleosporium, - 377

Coleroa, - - - 195

Petroselinum,

Heterosphaeria, - 249

Plasmopara, - - 128

Puccinia, - - 353

Septoria, - $\quad 477$

Petunia,

Phytophthora, - 122

Sclerotinia, - $\quad \mathbf{2 6 4}$

Peucedanum,

Puccinia, - 353, 359

Taphrina, - 151,154 Phalaris,

Cladochytrium, - 114

Puccinia, - 346,349

Sclerotium, - - 266

Ustilago, - - 294

Phaseolus, Ascochyta, 473

Bacteria, - $\quad 539$

Cercospora, - - 515

Colletotrichum, - 486

Isariopsis, - - 520

Phyllosticta, - - 464

Phytophthora, - 122

Sclerotinia, - - 264

Uromyces, - - 334

Phegopteris (see Ferns)

Phillyrea, Aecidium, - 410

Uredo, - - - 420

Phleum, Epichloë, - 191

Puccinia, - 345,348

Phlox, Aecidium, - 411

Pnccinia, - - 355

Phoenix (see Palms)

Phragmites, Claviceps, 194

Helminthosporinm, 516

Napicladium,- $\quad 516$

Puccinia, - - 349

Ustilago, - - 293

Phyllanthus, Ravenelia, 403

Phyteuma,

Coleosporium, - 377

Uromyces, - . $33 \mathrm{~s}$
Picea, Aecidinm, 377 . $379,407,416$

Agaricus, - - 457

Barclayella, - - 373

Chrysomyxa, - $\quad 379,380$

Herpotrichia, - - 199

Lophorlermium, 237, 240

Mycorhiza, - $\quad 95$

Naevia, - - . 238

Nectria, - - $\quad 188$

Peridermium, 416, 417

Pestalozzia, - - 493

Polyporus, - 440-450

Septoria, - - 475

Trametes, - - 453

Trichosphaeria, - 197

Picris, Entyloma, - 312

Puccinia, - - 355

Pilea, Phytaphysa, - 554

Pimpinella,

Puccinia, - 340,356

Thecaphora, - - 325

Pine (see Pinus)

,, Cembran (see Pinus Cembra)

, Mountain (see Pinus montana)

,Scots (see Pinus sylvestris)

,, Veymonth (see Pinus Strobus)

Pine-twister, - $\quad 364$

Pinguicula, Ustilago,- 297

Pinus, Agaricus, $\quad-457$

Brunchorstia, - - 481

Caeoma,- - $\quad$ - 364

Cenangium, - 251, 481

Cladosporium, - 509

Cuenrbitaria, - - 210

Elaphomyces, - 183

Gymnosporanginm, 396

Lophodermium, - 240

Melanpsora, - $\quad 364$

Mycorhiza, - $\quad$ - 96

Periderminm, - 376,

$382,411-416$

Phoma, - - 466, 468

Polyporus, - 449, 450

Rhizina,- - - 273 


\begin{tabular}{|c|c|c|c|c|c|c|c|}
\hline & & & & & & & \\
\hline storent & & 433 & rium, & 0 & iza, & 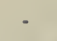 & \\
\hline Trametes, & & 453 & & - 229 & rus, & 439, & 447 \\
\hline -galls, & & 533 & ium, & -484 & oria, & 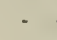 & \\
\hline & & 481 & ia, - & -494 & -flux, & & \\
\hline$a$, & & & Poly & 445 & $150-15$ & 54,1 & 15 \\
\hline ia, - & & 210 & Plum (see Prunus don & mestica) & & & \\
\hline & & 158 & $t,-$ & 154,156 & la, & & \\
\hline $\mathrm{m}$ & - & 415 & - & - 355 & Cystop & & \\
\hline a & & & ceps, - & . 195 & Pota & & \\
\hline & & 199 & Eu & $-\quad 312$ & $a, \quad$ - & & \\
\hline & & 234 & 11 & & era, - & 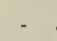 & \\
\hline & & 364 & - 3 & 345,348 & Iphid & & \\
\hline & & 411 & Tilletia, - & & Sole & & \\
\hline s, & & & Urocystis, & - 316 & & & \\
\hline & & 457 & $\mathrm{Ur}$ & - 336 & $-d$ & - & \\
\hline & & 364 & oct & & ight, - & & \\
\hline , - & & 234 & odc & & . $\quad$. & 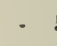 & \\
\hline & & 234 & a, - & - 465 & -si & - & \\
\hline & & 272 & Podo & cinia, 356 & sweet (see & Batat & \\
\hline Lo & & 235 & Aecidiv & ium, 411 & Pote & & \\
\hline & & 364 & Poly & & - & & 51 \\
\hline & & $\begin{array}{r}376 \\
415\end{array}$ & $\begin{array}{r}-3 \\
\text { Puccini }\end{array}$ & $\begin{array}{l}349,410 \\
\text { ia, } \quad 355\end{array}$ & bytriun, & - & \\
\hline & -466 & 468 & Polys & & $\mathrm{M}$ & - & \\
\hline & & 450 & ma, & 501 & ra, - & - & \\
\hline & & 453 & 0 & - 501 & & 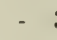 & \\
\hline (2) & garicu & 1,457 & $\mathrm{Pe}$ & - 135 & & 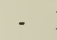 & 11 \\
\hline & & 233 & iza, & - 255 &.$\quad 15$ & 51, & \\
\hline & & 415 & tisma, & - 255 & e of Vine, & & \\
\hline & & 468 & -3 & 352,355 & ldew (see & & \\
\hline & & 450 & $\mathrm{Rh}$ & -246 & & & \\
\hline & & 3 & reca, & - 302 & ccinia & & \\
\hline$P_{n}$ & eccinia &, 346 & - & . 211 & Prir & - & \\
\hline c & ces, & 33 & Ur & - 334 & , - & - & \\
\hline & & 473 & -2 & 298,299 & - & & \\
\hline & 509 & & $\mathrm{Fer}$ & erns) & - & & \\
\hline & & 175 & oly & & . & & \\
\hline & & 132 & 1 & & & & \\
\hline & & 117 & pave & & ora, - & 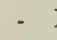 & \\
\hline & & 183 & ricus, & - 462 & Ligustrun & & \\
\hline & & 334 & - & -473 & idiu & um, & 41 \\
\hline & & & & $-\quad 181$ & dium, & & 4 \\
\hline & 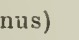 & & $\mathrm{m}$, & - 510 & - & - & 47 \\
\hline & , - & 411 & eria, & - 218 & - & - & \\
\hline & & 13 & - & $-\quad 472$ & sporn, & - & 21 \\
\hline & & 50 & & 218,249 & - & - & 4 \\
\hline & & & - & . & - & - & \\
\hline & & 3 & - & - $4 !$ & , & - & 51 \\
\hline ta & & & & 364,3 & porium, & 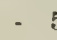 & 51 \\
\hline
\end{tabular}




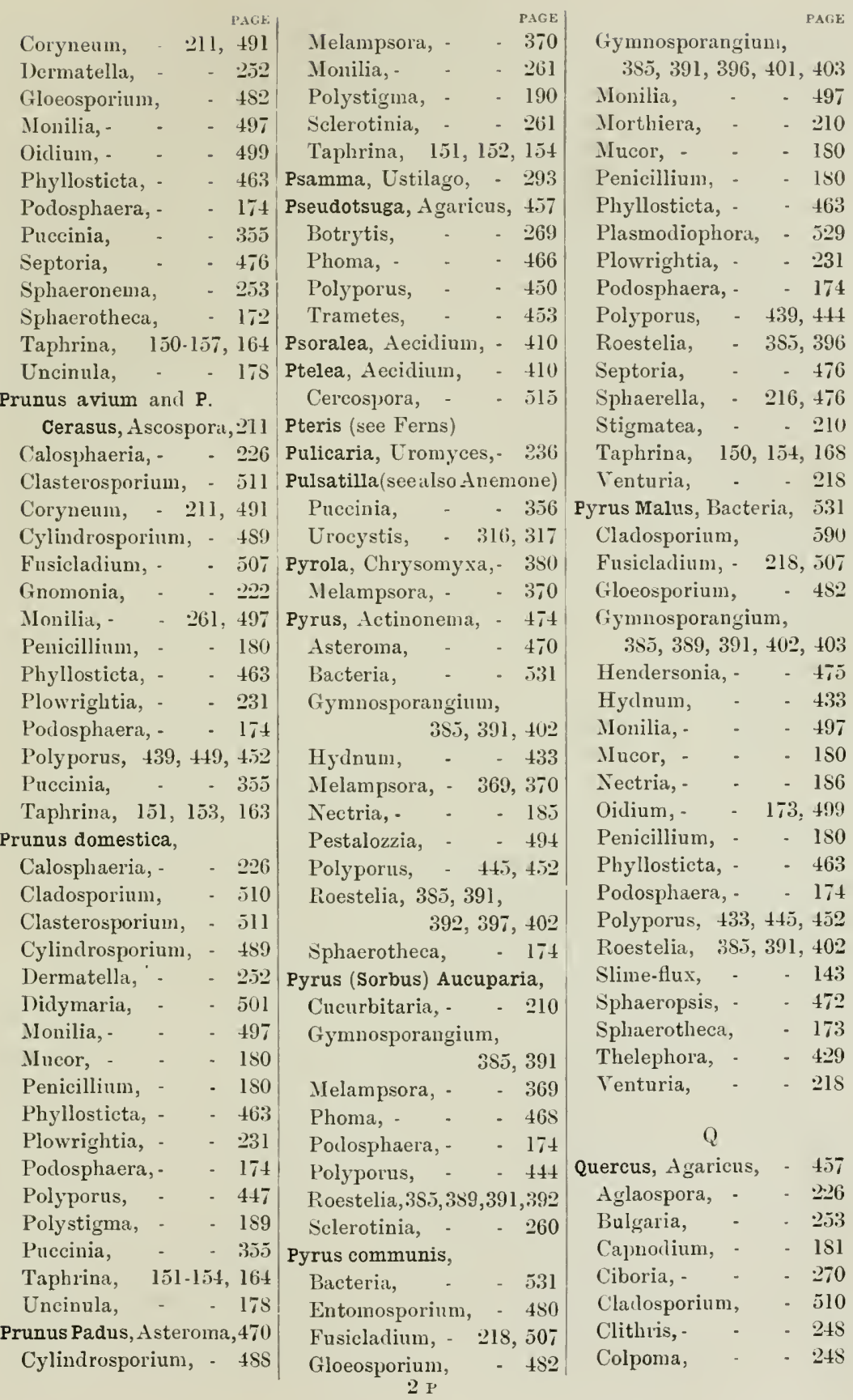




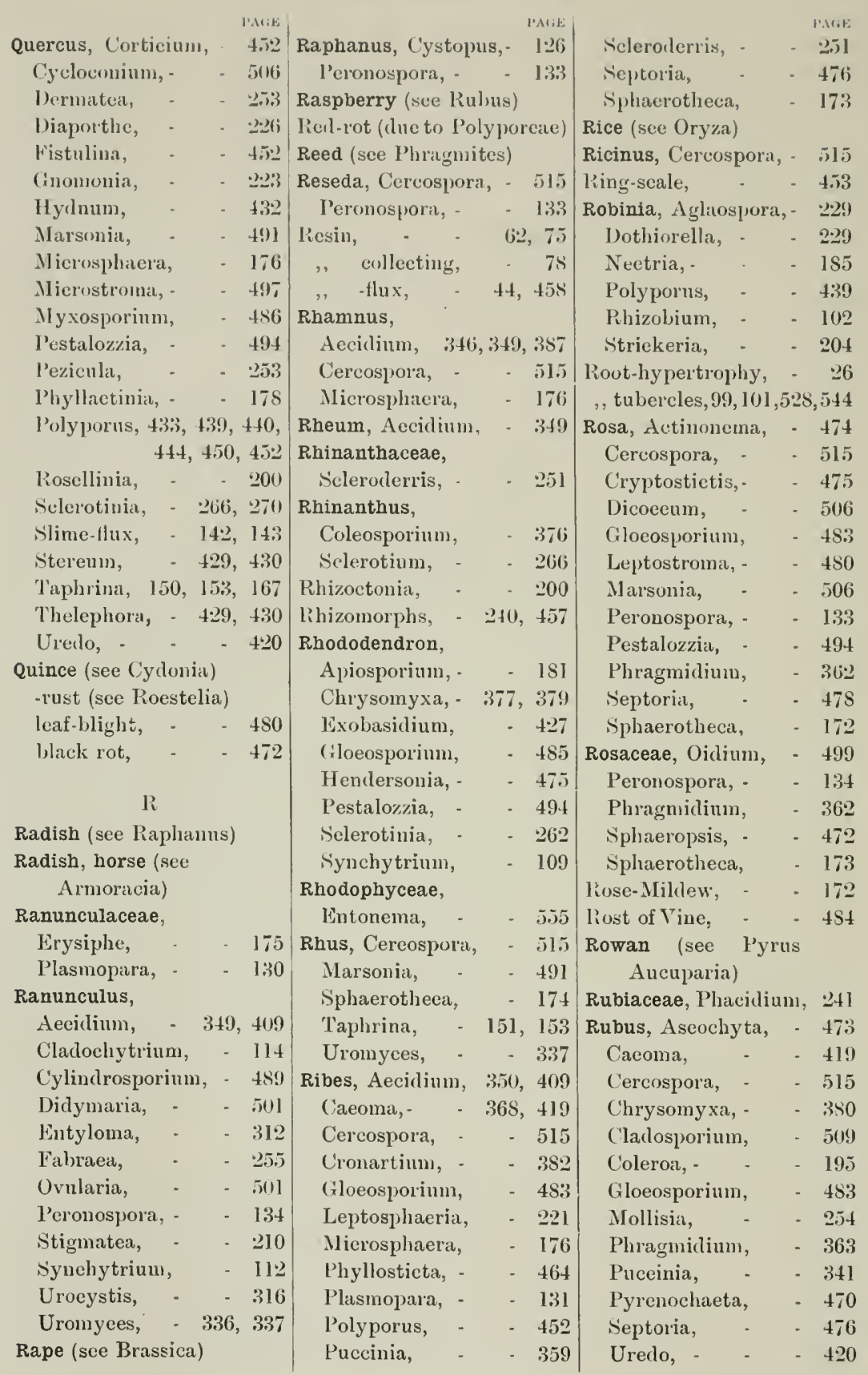




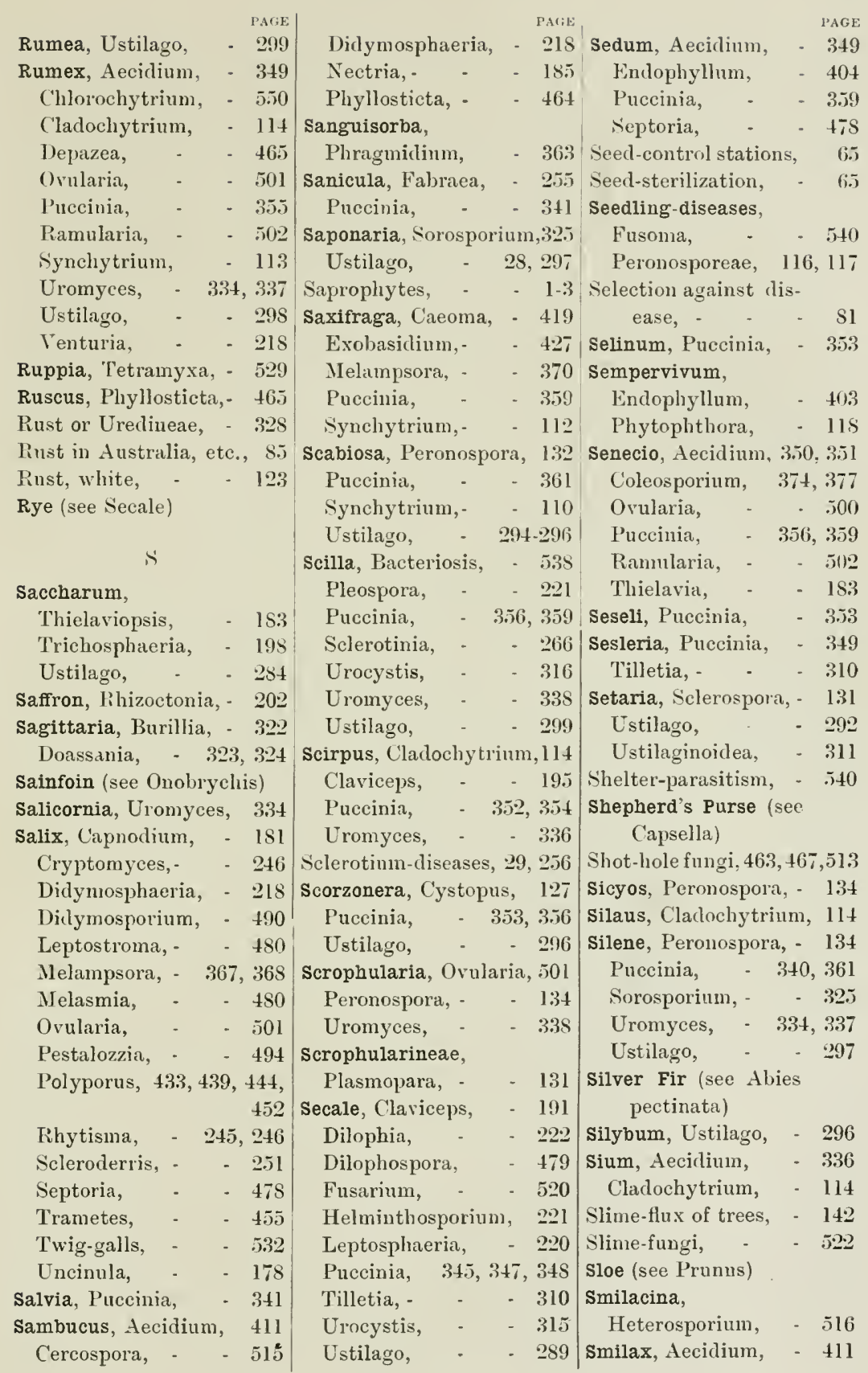




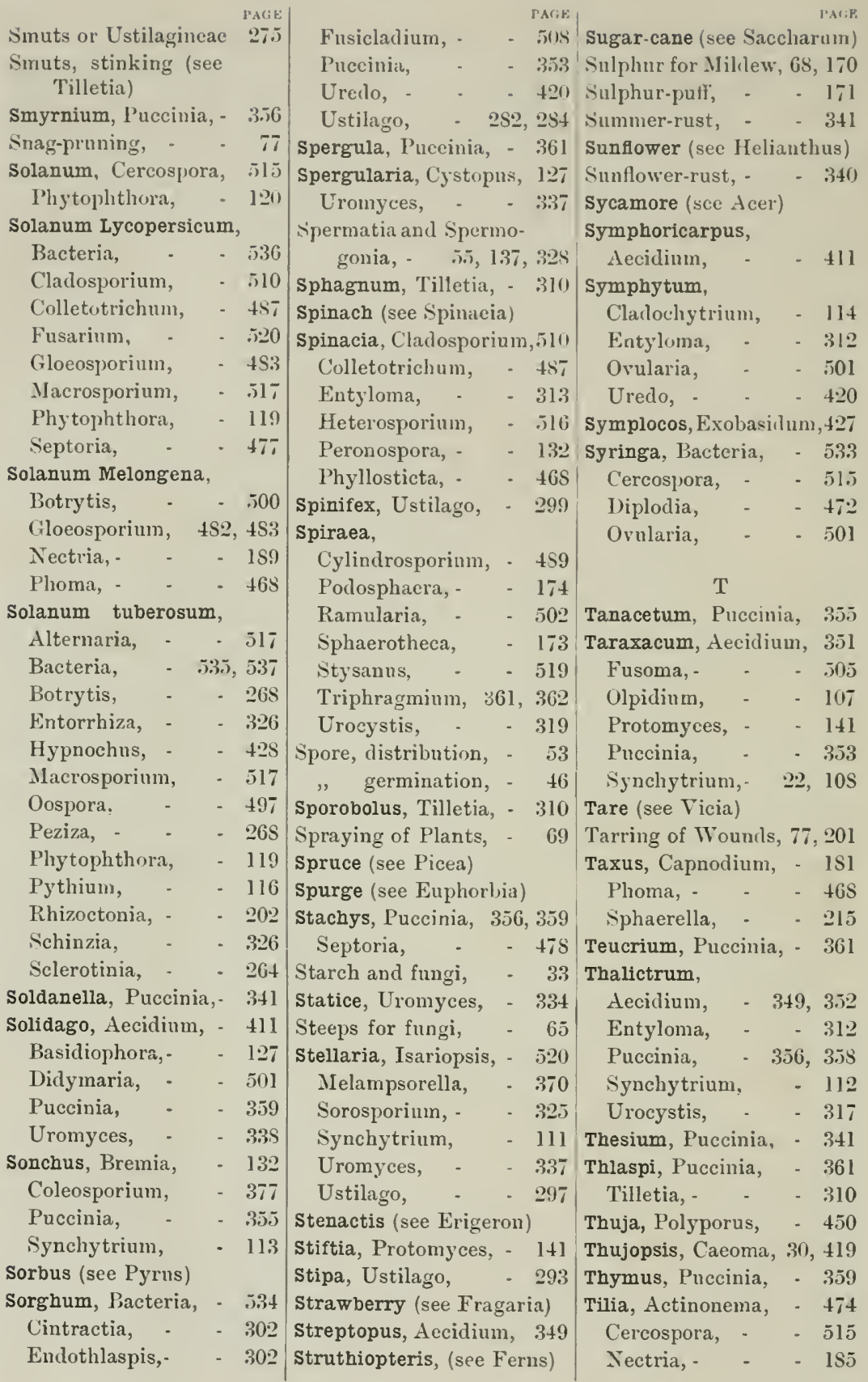




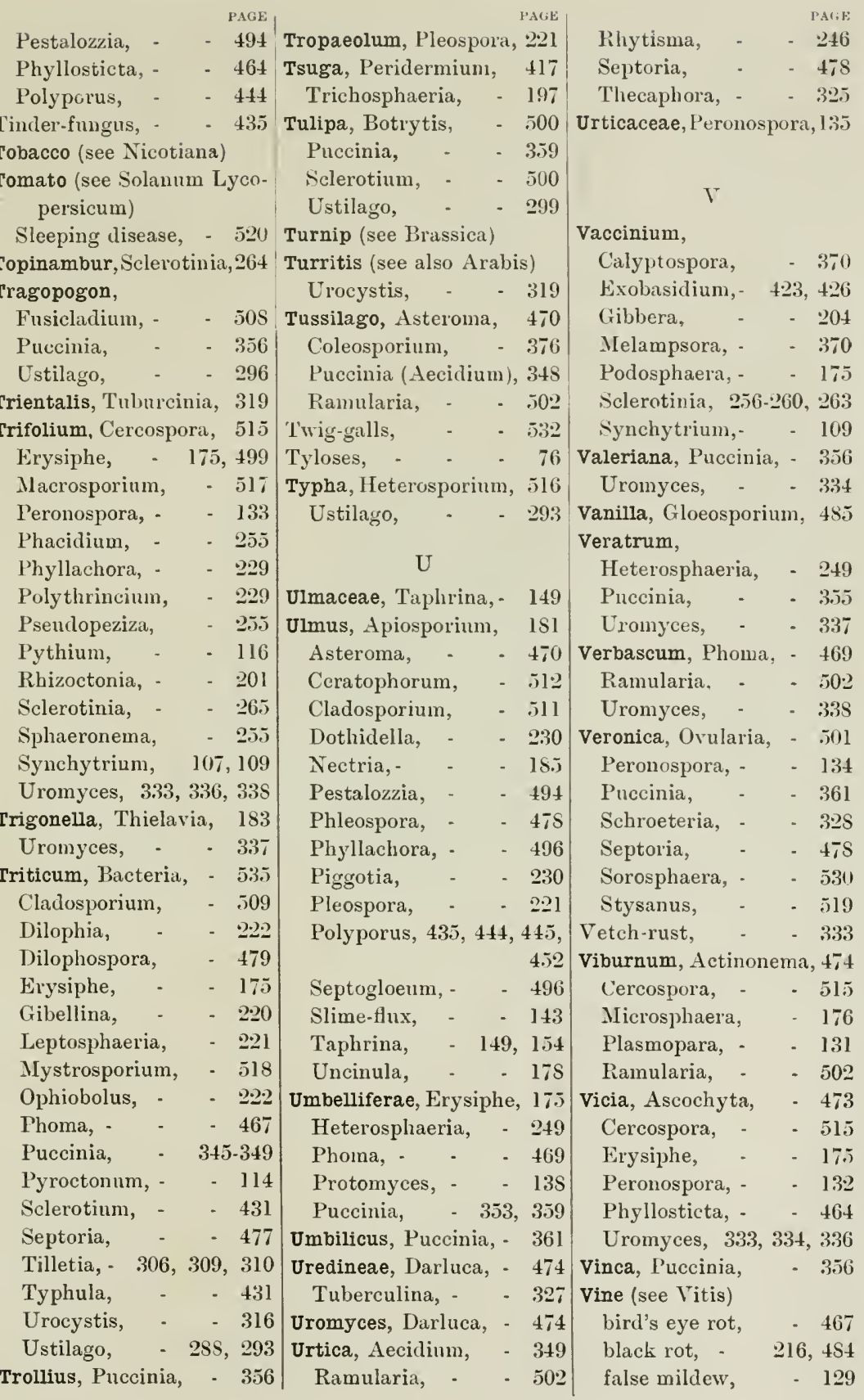




\begin{tabular}{|c|c|c|c|}
\hline & & & \\
\hline & 7 & - 216,467 & Wound-cork, \\
\hline & 202 & rodiophora, 528, 529 & duramen, \\
\hline & 81,84 & opara, - & -infection, \\
\hline & 71 & locornmis, & -parasites, $\bar{\pi}, 17,7$ \\
\hline rican $\mathrm{h}$ & yblrid, 8I & rotinia, - & 75, \\
\hline , - & - 524 & Septosporium, & (sce also Polypore \\
\hline $\mathrm{m}$ & - 410 & -467 & etc.) \\
\hline & - 515 & -215 & at, \\
\hline & - $4 \$ 5$ & -176 & Wounds \\
\hline & -500 & Uredo, - & \\
\hline a, - & 134 & & $\mathrm{x}$ \\
\hline & -464 & & \\
\hline $\begin{array}{l}\text { Plic } \\
\text { Syn }\end{array}$ & $\begin{array}{l}340,359 \\
112,113\end{array}$ & $\begin{array}{l}\text { Clieiranthus) } \\
\text { glans) }\end{array}$ & $\begin{array}{l}\text { Xanthoxylum, } \\
\text { Aecidium, }\end{array}$ \\
\hline Urc & $1,31,317$ & Wein & \\
\hline iol & -340 & Weyn & $\mathrm{Y}$ \\
\hline$l_{1}$ & & WTh & ceharomy \\
\hline $\begin{array}{l}\text { yta, } \\
\text { ium, }\end{array}$ & $\begin{array}{l}-\quad 473 \\
-\quad 428\end{array}$ & $\begin{array}{l}\text { Whea } \\
\text { Whit }\end{array}$ & Yet \\
\hline . & - 534 & e) & $\mathrm{Z}$ \\
\hline ra, : & $\begin{array}{r}180,267 \\
-\quad 513\end{array}$ & Witch & Zea, Bacteria, - \\
\hline & - 114 & Aecidium, $18,24,72,88$, & Helminthosporium, \\
\hline & 510 & & Puccinia, \\
\hline & $4 \mathrm{SS}$ & -418 & Pythium, \\
\hline & 471 & Exoasceae, $19,24,52,145$, & Tilletia, - \\
\hline & 202 & 158 , etc. & Uredo, - \\
\hline & 482,484 & -403 & Ustilago, $\quad 279,281,28$ \\
\hline & 216 & stroying fungi, & Zinnia, Sclerotinia, - 26 \\
\hline & $\therefore \quad 221$ & 62,72 & Zizania, Ustilago, - \\
\hline - & $\begin{array}{r}177,499 \\
-\quad 180\end{array}$ & so $\mathrm{Pc}$ & Cephaleuros, \\
\hline & $\pi$ & & \\
\hline
\end{tabular}




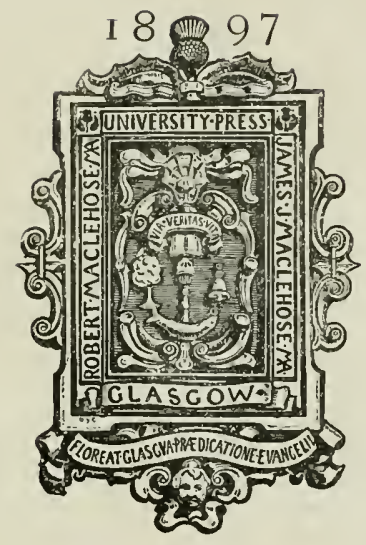




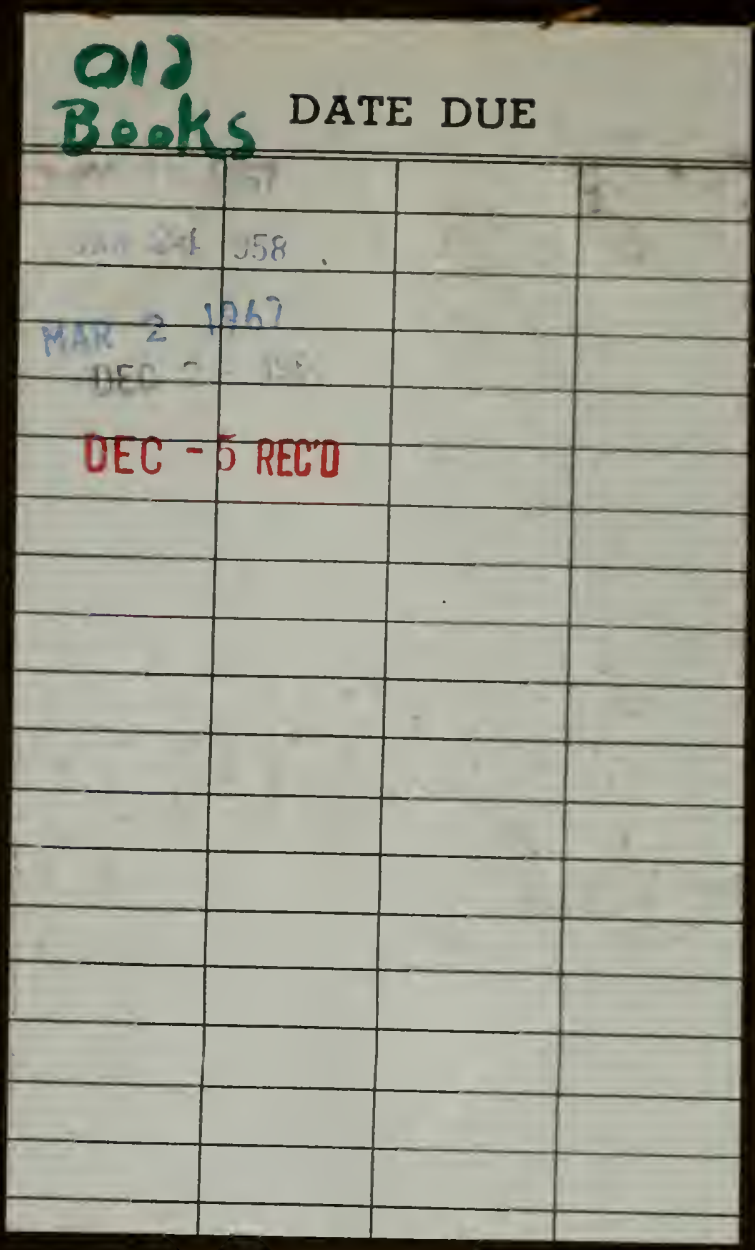


